\title{
Ökologisch verpflichtete Unternehmensführung und Rahmenbedingungen ihrer Implementierung in Südkorea
}

\author{
Dissertation \\ zur Erlangung des wirtschaftswissenschaftlichen \\ Doktorgrades des Fachbereiches Wirtschaftswissenschaften \\ der Georg-August-Universität zu Göttingen
}

vorgelegt von Dipl.-Kfm. Sang-Min Nam

aus Taejeon, Südkorea

Göttingen 2000 
Erster Gutachter: Prof. Dr. G. Schanz

Zweiter Gutachter: Prof. Dr. J. Bloech

Tag der mündlichen Prüfung: 05. 07. 2000 


\section{Inhaltsverzeichnis}

Abbildungsverzeichnis $-\mathrm{IV}$

Abkürzungsverzeichnis VI

Problemstellung, Zielsetzung und Aufbau der Arbeit 1

1. Einführung in die Umweltproblematik Südkoreas---1-- 7

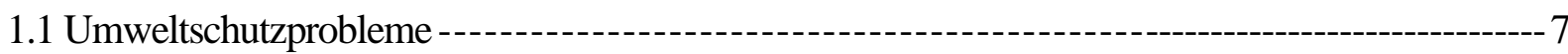

1.2 Aktuelle Situation der Umweltprobleme und ihre Ursachen -------- 10

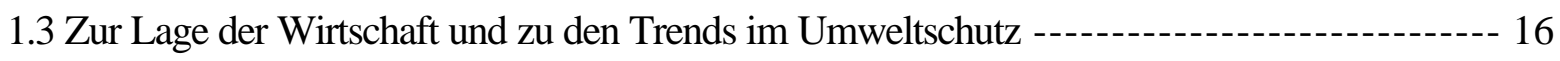

Teil I: Grundlagen einer ökologisch verpflichteten Unternehmensführung

2. Die Ökologieproblematik als Herausforderung für die Unternehmensführung 20

2.1 Die globale ökologische Krise und der gesellschaftlicher Wertewandel 21

2.2 Anforderungen und Auswirkungen auf die Unternehmen 30

2.3 Berücksichtigung der ökologischen Verpflichtung in betriebswirtschaftlichen Ansätzen ---

2.4 Ökologische Verpflichtung der Unternehmensführung 59

3. Unternehmen im Spannungsfeld zwischen Ökologie und Ökonomie 70

3.1 Begriffe und Funktionen derÖkologie 71

3.2 Unternehmen und ihre Umwelt --

3.3 Austauschbeziehungen zwischen Unternehmen und ökologischer Umwelt 92 
4.1 Grundlagen für die integrierte Konzeption

einer ökologisch verpflichteten Unternehmensführung

4.2 Ökologische Situationsanalyse als Ausgangspunkt für die Konzeption

einer ökologisch verpflichteten Unternehmensführung

4.3 Ökologisch verpflichtete Unternehmenspolitik

4.4 Integration ökologisch verpflichteten Wirtschaftens in die Unternehmensstrategien --- 152

4.5 Operative Umsetzung des Umweltschutzes in den funktionalen Bereichen 169

4.6 Umweltinformationssystem und Öko-Controlling

als Element ökologisch verpflichteter Unternehmensführung

4.7 Organisationsgestaltung im Dienst ökologisch verpflichteter Unternehmensführung -- 183

\section{Teil II: Rahmenbedingungen für die Implementierung einer ökologisch verpflichteten Unternehmensführung in Südkorea}

5. Gesellschaftliche Rahmenbedingungen

5.1 Die traditionelle Welt- und Naturanschauung in der koreanischen Gesellschaft

5.2 Westlicher Einfluß auf die koreanische Gesellschaft

5.3 Wertewandel in bezug auf die Umweltfrage in der koreanischen Gesellschaft

6. Politisch-rechtliche Rahmenbedingungen

6.1 Umweltpolitik und Umweltgesetzgebung in Südkorea 238

6.2 Internationale Umweltpolitik 254

7. Wirtschaftliche Rahmenbedingungen 277

7.1 Dynamik der wirtschaftlichen Entwicklung und Umweltprobleme

7.2 Wirtschaftspolitische Maßnahmen zur Förderung des betrieblichen Umweltschutzes -- 287 
8. Schlußbetrachtung: Möglichkeiten und Grenzen für die Implementierung einer ökologisch verpflichteten Unternehmensführung in Südkorea 301

8.1 Problemfelder für die Implementierung einer ökologisch verpflichteten Unternehmensführung in Südkorea

8.2 Möglichkeiten für die Implementierung einer ökologisch verpflichteten Unternehmensführung in Südkorea 316

Literaturverzeichnis 


\section{Abbildungsverzeichnis}

Abb. 1.1: Die struktuelle Entwicklung des sekundären Sektors in Südkorea Abb. 1.2: Die wichtigen Wirtschaftsindizes von Südkorea

Abb. 2.1: Die ökologische Krise als Konglomerat der Wahrnehmung von Einzelphänomenen Abb. 2.2: Betrachtungsebenen ökologischer Einflüsse auf das Unternehmen Abb. 2.3: Ökologierelevante Einflüsse auf das Unternehmen in sozioökonomischer Perspektive Abb. 2.4: Lebenszykluskonzept gesellschaftlicher Umweltschutzforderungen Abb. 2.5: Umwelteinfluß und Auswirkungen auf das Unternehmen Abb. 2.6: Dimensionen der ökologisch verpflichteten Unternehmensführung

Abb. 3.1: Der Leistungserstellungsprozeß in ökologischer und ökonomischer Perspektive Abb. 3.2: Unternehmensumwelt in dimensioneller und institutioneller Hinsicht Abb. 3.3: Wechselbeziehungen zwischen ökologischen und ökonomischen Systemen Abb. 3.4: Unterschiede zwischen ökologischer und ökonomischer Perspektive Abb. 3.5: Das Stakeholder-Management

Abb. 3.6: Das Spektrum ökologischer Anspruchsgruppen

Abb. 3.7: Beispiele möglicher wechselseitiger Interessen zwischen den Unternehmen und ihren wichtigen Anspruchsgruppen

Abb. 4.1: Integriertes Konzept einer ökologisch verpflichteten Unternehmensführung im Rahmen des St. Galler-Management-Modells

Abb. 4.2: Gesamtkonzeption einer ökologisch verpflichteten Unternehmensführung Abb. 4.3: Ökologische Situationsanalyse

Abb. 4.4: Chancen/Gefahren-Analyse

Abb. 4.5: Zielsysteme des Unternehmens

Abb. 4.6: Umweltschutz als Unternehmensziel

Abb. 4.7: Ökologiebezogenes strategisches Anpassungsverhalten

Abb. 4.8: Strategische Grundsatzentscheidungen

in der ökologisch verpflichteten Unternehmensführung

Abb. 4.9: Beispiele einer umweltschutzbezogenen Unternehmensstrategie

Abb. 4.10: Ökologieorientierte Wertschöpfungskette

Abb. 4.11: Klassifikation von Umweltinformationssystemen

Abb. 4.12: Umweltorientierte Anreizgestaltung

Abb. 4.13: Umweltschutz in einer Matrixorganisation 
Abb. 5.1: Staatliche Aufgaben für die Verbesserung der Umweltprobleme Abb. 5.2: Die relative Wichtigkeit der Umweltprobleme in Südkorea Abb. 5.3: Die persönliche Betroffenheit von Umweltverschmutzung Abb. 5.4: Die Anstrengungen der Unternehmen für Umweltschutz in der Bewertung durch die koreanische Bevölkerung

Abb. 6.1: Wichtige Umweltgesetze in Südkorea

Abb. 6.2: Übersicht über die Ziele der Umweltpolitik in Südkorea

Abb. 6.3: Institutionelle Organisation des Umweltschutzes in Südkorea Abb. 6.4: Akteure der globalen Umweltpolitik

Abb. 6.5: Elemente von Umweltmanagementsystemen

Abb. 6.6: Unterschiede zwischen Öko-Audit-Verordnung und ISO 14001

Abb. 7.1: Inhalte der Fünfjahrespläne (FJP) der Wirtschaftsentwicklung und der Umweltprobleme in Südkorea

Abb. 8.1: Gestaltungs- und Umsetzungsprobleme einer ökologisch verpflichteten Unternehmensführung in Südkorea

Abb. 8.2: Ökologische Nutzenpotentiale

Abb. 8.3: Mögliches Beispiel zur Formulierung einer ökologisch verpflichteten Unternehmensphilosophie für ein Unternehmen in Südkorea 


\section{Abkürzungsverzeichnis}

Abb.

ASEAN

Aufl.

BCSD

BFuP

BSP

BUIS

bzw.

ca.

d.h.

DBW

EG

EMAS

EU

et al.

etc.

f.

ff.

FAO

FCKW

FJP

GATT

GEF

ggf.

GTZ

Hrsg.

i.d.R.

IDRC

IFOAM

IIED

ILEIA

ILO

IMF
Abbildung

Association of South-East Asian Nations

Auflage

Business Council for Sustainable Development

Betriebswirtschaftliche Forschung und Praxis

Bruttosozialprodukte

Betriebliche Umweltinformationssysteme

beziehungsweise

circa

das heißt

Die Betriebswirtschaft

Europäische Gemeinschaft

Environment Management- and Eco-Audit-System

Europäische Union

et alii, und andere

et cetera, und so weiter

folgende Seite

folgende Seiten

Food and Agriculture Organisation

Fluor-Chlor-Kohlenwasserstoff

Fünfjahrespläne der Wirtschaftsentwicklung in Südkorea

General Agreement on Tariffs and Trade

Global Environmental Facility

gegebenenfalls

Gesellschaft für Technische Zusammenarbeit

Herausgeber

in der Regel

International Development Research Center

International Federation of Organic Agriculture Movements

International Institute for Environment and Development

Information Center Low External Input Agriculture

International Labour Organization

International Monetary Fund 
ISO

Jg.

Kap.

KEI

NAFTA

NGO

OECD

PAN

SIG

sog.

Sp.

TQEM

UEUS

UMS

UNCED

UNCTAD

UNCTC

UNEP

UNIDO

USM

usw.

UWF

Vgl.

WBCSD

WHO

WiSt.

WIR

WTO

WWF

z.B.

ZfB

zfo

zit.
International Organization for Standardization

Jahrgang

Kapitel

Korea Environment Institute

North American Free Trade Agreement

Nongovernmental Organization

Organization for Economic Cooperation and Development

Pesticide Action Network

Social Interest Group

sogenannte

Spalte

Total Quality Environmental Management

Umweltbezogene Entscheidungsunterstïtzungssysteme

Umweltmanagementsystem

United Nations Conference on Environment and Development

United Nations Conference on Trade and Development

United Nations Center on Transnational Corporations

United Nations Environment Program

United Nations Industrial Development Organization

Umweltbezogene Instrumente des Strategischen Managements

und so weiter

Umweltwirtschaftsforum

Vergleich

World Business Council for Sustainable Development

World Health Organization

Wirtschaftswissenschaftliches Studium

World Resources Institute

World Trade Organization

World Wide Fund for Nature

zum Beispiel

Zeitschrift für Betriebswirtschaft

Zeitschrift Führung + Organisation

zitiert 


\section{Problemstellung, Zielsetzung und Aufbau der Arbeit}

Seit der Industrialisierung in den frühen 60er Jahren hat die Wirtschaft zur Zunahme des Wohlstands und der Güterproduktion in Südkorea beigetragen. In diesem Sinne haben die Unternehmen in Südkorea als Orte der Wertschöpfung und damit Träger des Wohlstands die Aufgabe entsprechend der herkömmlichen Vorstellung von einer Industriegesellschaft hervorragend erfüllt. Aber eine Leistungsbeurteilung, die nur nach quantitativen Merkmalen, wie z.B. Wirtschaftswachstumsrate, Zunahme des Wohlstands, Güterproduktion etc. betrachtet wird, beleuchtet nur die positive Seite des Wirtschaftens. Nach eingehender Betrachtung ist feststellbar, daß der Prozeß des quantitativen Wirtschaftswachstums vor allem auf Kosten der natürlichen Umwelt bzw. der Gesundheit der Bürgern gegangen ist.

Das steigende Aktivitätsniveau der industriellen Produktion und das individuelle Streben nach einem höheren Lebensstandard waren in Südkorea in der Vergangenheit grundsätzlich mit Umweltproblemen, vor allem mit einem enormen Anstieg der Abfallmenge aus Produktion und Konsum, verbunden. Wirtschaftswachstum könnte ceteris paribus eine Zunahme der Umweltbelastung und damit Umweltprobleme mit sich bringen. In der bisherigen Wirtschaftspolitik Südkoreas steht immer das wirtschaftliche Wachstum im Vordergrund. Daher sind Konflikte zwischen den Zielen Wirtschaftswachstum und Umweltschutz denkbar, insbesondere dann, wenn das Ziel wirtschaftlichen Wachstums um jeden Preis, also unter Inkaufnahme von Umweltschäden, angestrebt wird. Die Ideologie des quantitativen Wachstums bestimmt jedoch weiterhin die Gesellschaft in Südkorea.

Die fortschreitende Zerstörung der natürlichen Lebens- und Wirtschaftsgrundlagen hat für das öffentliche Bewußtsein längst nicht mehr den Status einer zivilisatorischen Randbedingung. Seit dem ,ökologischen Schock“ wird im Gegenteil das Problem von Naturbeherrschung und Umweltschutz als eine der dringendsten Anforderungen an die koreanische Gesellschaft und Wirtschaft verstanden. Dabei stehen Unternehmen, insbesondere Industriebetriebe, als Hauptverursacher von Umweltschäden im Kreuzfeuer der Kritik. Ihnen wird vorgeworfen, die ökologische Dimension gänzlich unzureichend zu beachten.

Angesichts der Konsequenzen der Umweltprobleme, die unternehmerische Tätigkeiten stärkend in ihrer ökologischen, gesellschaftlichen und wettbewerbsstrategischen Dimension beeinflussen, ist die Notwendigkeit der Berücksichtigung von Umweltschutzforderungen bei unternehmerischen Entscheidungen auch in Südkorea kaum mehr in Frage zu stellen. Dabei lautet die zentrale 
These dieser Studie, daß auch heute noch in Südkorea dem Schutz der natürlichen Lebensgrundlagen in betriebswirtschaftlicher Hinsicht ein, angesichts des zunehmenden ökologischen Problemdrucks, unzureichender Stellenwert beigemessen wird. Hierbei soll die Frage gestellt werden, wieweit die Betriebswirtschaftslehre in Südkorea die Ökologieproblematik überhaupt aufgreift und der Praxis auf der Grundlage der diagnostizierten Defizite Hilfestellung anbietet. Dabei sei an dieser Stelle bereits die These vorweggenommen, daß es in der betriebswirtschaftlichen Forschung an umfassenden strategischen Ökologiekonzepten fehlt, die insbesondere der unternehmenspolitischen Umweltschutzproblematik Rechnung tragen.

Aus der diesbezüglichen Bestandsaufnahme, d.h. angesichts der Defizite in Wissenschaft und Praxis vor allem in der Betriebswirtschaftslehre in Südkorea, ergab sich die Zielsetzung der vorliegenden Arbeit, aufbauend auf der theoretischen Grundlage einer ökologisch verpflichteten Unternehmensführung die Rahmenbedingungen und Gestaltungsmöglichkeiten und -probleme sowie Ansatzpunkte zu einer ökologisch verpflichteten Unternehmensführung in Südkorea herauszuarbeiten. Dabei steht das Gesamtunternehmen im Mittelpunkt der Planungs- und Steuerungsaktivitäten. Auf diese Weise ist eine Ökologieorientierung bzw. -verpflichtung der Unternehmensfuihrung auf aktive und systematische Art möglich. Bereits an dieser Stelle sei betont, daß im Rahmen der vorliegenden Arbeit nicht die Entwicklung von Patentrezepten angestrebt werden soll, um der Vielschichtigkeit, Vernetzheit und Komplexität der Ökologieproblematik in der Praxis gerecht zu werden. Diese Arbeit versucht vielmehr, Bausteine für die ökologisch verpflichtete Unternehmensführung in Südkorea bereitzustellen, um möglichst komplexe bzw. umfangreiche Denkmuster zu erzeugen, die helfen, die konzeptionelle Gesamtsicht einer Ökologieverpflichtung bzw. -orientierung etwas problemadäquater zu formulieren und zu gestalten.

Aus dieser Problemstellung resultieren folgende Fragen:

1) Welche Beziehungen bestehen zwischen Unternehmen, ökologischer Umwelt und Unternehmensführung?

2) Welche Konsequenzen ergeben sich aus diesen Relationen für die ökologisch verpflichtete Unternehmensführung, und welche Probleme tauchen dabei auf?

3) Welche Rahmenbedingungen bestehen bezogen auf die spezifischen Verhältnisse in Südkorea für die ökologisch verpflichtete Unternehmensführung?

4) Welche Möglichkeiten und Grenzen bestehen für die ökologisch verpflichtete Unternehmensführung in Südkorea? 
In der Reihenfolge dieser Fragen ist das weitere Vorgehen wie folgt strukturiert:

Zunächst wird als Ausgangspunkt dieser Arbeit ein Überblick über die Umweltproblematik in Südkorea (Kap. 1) gegeben. Dies beinhaltet die Umweltschutzprobleme (Kap. 1.1), die aktuelle Situation der Umweltprobleme und ihre Ursachen (Kap. 1.2) und die aktuelle Lage der Wirtschaft und die Trends im betrieblichen Umweltschutz (Kap. 1.3).

In Teil I werden die Grundlagen einer ökologisch verpflichteten Unternehmensführung dargestellt. Dies beinhaltet die Ökologieproblematik als Herausforderung für die Unternehmensführung (Kap. 2), in der die häufig als ökologische Krise zitierte Ökologieproblematik erläutert wird, einschließlich der gesellschaftlichen Reaktion (Kap. 2.1) und den damit verbundenen Anforderungen und Auswirkungen für die Unternehmen (Kap. 2.2), Ansatzpunkte zur Behandlung der ökologisch verpflichteten Unternehmensführung besprochen werden (Kap. 2.3) und abschließend die Bedeutung der Ökologieverpflichtung der Unternehmensführung beleuchtet wird (Kap. 2.4). Danach werden die Beziehungen zwischen Unternehmen, ökologischer Umwelt und Management (Kap. 3) dargestellt, in der die ökologische Grundlagen (Kap. 3.1), die Unternehmen und ihre Umwelt (Kap. 3.2), die Zusammenhänge zwischen Unternehmen und ökologischer Umwelt (Kap. 3.3) und schließlich das Stakeholder-Konzept (Kap. 3.4) erläutert werden. Eine Darstellung des Stakeholder-Konzepts (Anspruchsgruppen-Konzept) scheint hier sinnvoll zu sein, da die Anforderungen und/oder die Notwendigkeit zur Verbesserung des betrieblichen Umweltschutzes nicht unmittelbar aus dem Bereich der ökologischen Umwelt erfolgen, d.h. ein Unternehmen wird durch selbstverursachte ökologische Schäden nicht direkt betroffen, sondern mittelbar durch Stakeholder, die ökologische Interessen vertreten. In diesem Sinne kann dieses Konzept als externer Zwang auf die Unternehmensführung dienen. Dabei soll das StakeholderKonzept auch als Grundlage für die integrierte Konzeption einer ökologisch verpflichteten Unternehmensführung in Südkorea im Kap. 4 dienen.

Im Kapitel 4 wird ein integriertes Konzept einer ökologisch verpflichteten Unternehmensführung herausgearbeitet. Bei einer solchen Konzeption handelt es sich um ein idealtypisches Modell, dessen Grundlagen hinterfragt werden können bzw. dessen Anwendungsmöglichkeiten eingeschränkt werden können. Für die Konzeption einer ökologisch verpflichteten Unternehmensführung in Südkorea wird hier von dem Phänomenen der zunehmenden Homogenisierung der internationalen Produktanforderung sowie des Marketings aufgrund einer weltweiten Angleichung der Käuferwünsche im Sinne der Globalisierung des Marktes ausgegangen. Eine solche Angleichung der Anforderungen der Konsumenten an die ökologiebezogene Produkteigenschaften 
würde ceteris paribus auch zu einer Angleichung der betrieblichen Problemlösungen in den verschiedenen Ländern, auch in Südkorea führen. Die konzeptionelle Ausführung, die in den deutschsprachigen Literaturen dargestellt wird, soll damit als Referenz dienen.

Anschließend an die Darstellung der Grundlagen für die integrierte Konzeption einer ökologisch verpflichteten Unternehmensführung (Kap. 4.1) wird zunächst die ökologische Situationsanalyse als Ausgangspunkt dargestellt (Kap. 4.2). Sie soll vor allem als Informationsgrundlage für die ntegrierte Konzeption einer ökologisch verpflichteten Unternehmensführung dienen, denn für die inhaltliche Ausgestaltung einer ökologisch verpflichteten Unternehmensführung bedarf es einer Ist-Zustandsanalyse der internen und externen Einflußfaktoren zur Ermittlung und Beurteilung der strategischen Ausgangslage.

Die folgenden konzeptionellen Ebenen einer ökologisch verpflichteten Unternehmensführung werden wie folgt konstruiert:

Die Ebene der ökologisch verpflichteten Unternehmenspolitik (Kap. 4.3) beschäftigt sich mit den generellen Zielen, den Prinzipien, den Normen und den Spielregeln des Unternehmens, die darauf ausgerichtet sind, die Lebens- und Entwicklungsfähigkeit des Unternehmens sicherzustellen. Anschließend werden die ökologisch verpflichtete Unternehmenskultur und -ziel als weitere normative Grundgerüste im Rahmen der ökologisch verpflichteten Unternehmenspolitik dargestellt.

Im Kap. 4.4 wird die Integration ökologisch verpflichteten Wirtschaftens in die Unternehmensstrategien behandelt. Die strategische Ebene umfaßt jene Führungsaufgaben, welche den Aufbau und die Pflege ökologisch hochwertiger Markterfolgspotentiale (Aufbau strategischer Ökologiepotentiale) zum Ziel haben. Diese sollen sicherstellen, daß das Unternehmen auch in Zukunft noch ökologisch effizient sein wird.

Kap. 4.5 beinhaltet die operative Umsetzung des Umweltschutzes in allen funktionalen Bereichen. Sie dient dazu, daß innerhalb einer verarbeiteten Umweltschutzstrategie die kurzfristige Erfolgsrealisierung sichergestellt werden soll. In der umfassenden Sichtweise der strategischen ökologisch verpflichteten Unternehmensführung stellt der Umweltschutz eine betriebliche Querschnittsfunktion dar, die sämtliche Unternehmensbereiche umfaßt. Im Rahmen einer ökologisch verpflichteten Unternehmensführung müssen somit sämtliche Bereiche der Wertschöpfungskette unter ökologischen Gesichtspunkte berücksichtigt werden, wobei die Erfassung der Interdepen- 
denzen der einzelnen Bereiche einen wesentlichen Faktor darstellt. Gegenstand der vorgenannten Steuerungsfelder sind die betrieblichen Grundfunktionen bzw. die primär leistungswirtschaftlichen Bereiche des Unternehmens.

Neben diesen Handlungsebenen sind für einen umfassenden Bezugsrahmen einer ökologisch verpflichteten Unternehmensführung noch weitere Managementbereiche zu berücksichtigen. Zur Wahrung des Verhaltensspielraumes bzw. der Handlungsautonomie des Managements ist es in einer dynamischen bzw. turbulenten Unternehmensumwelt erforderlich, die Umweltfaktoren zu analysieren und entscheidungsrelevante Informationen für sämtliche Managementbereiche bereitzustellen. Die Gestaltung eines effektiven und effizienten Umweltinformationssystems und Öko-Controllings (Kap. 4.6) stellt somit selbst eine wichtige Managementaufgabe im Rahmen einer ökologisch verpflichteten Unternehmensführung dar. Auf jeder Handlungsebene bedarf es nicht nur entsprechender Entscheidungen und Handlungen, sondern es bedarf auch eines angemessene Führungsinstrumentariums $\mathrm{zu}$ ihrer Unterstïtzung. Verlangt sind ökologische Führungssysteme in Gestalt von Informations-, Entscheidungs- und Controllingsystemen.

Die Berücksichtigung des Umweltschutzes im Zielsystem des Unternehmens und seine Einbeziehung in die strategische Ausrichtung ist eine (zwingend) notwendige, aber noch längst keine hinreichende Voraussetzung, um der ökologischen Herausforderung gewachsen zu sein. Vielmehr muß auch darüber nachgedacht werden, mit welchen Maßnahmen die Umsetzung in praktisches Handeln zu erreichen ist. Wenn dabei struktuelle Regelungen ins Spiel kommen, so deshalb, weil derartige Arrangements Mittel der Verhaltenssteuerung darstellen. Sie sind damit auch Mittel einer ökologisch relevanten Ausrichtung des Denkens und Tuns im Unternehmen. Eine weitere ökologisch relevante Managementaufgabe ist damit die Gestaltung der Organisation des Umweltschutzes (Kap. 4.7). Es geht dabei um die geplante horizontale und vertikale Implementation ökologisch verpflichteter Unternehmensstrategie in das arbeitsteilig strukturierte Organisationssystem des Unternehmens.

In Teil II werden die Rahmenbedingungen für die Implementierung einer ökologisch verpflichteten Unternehmensführung in Südkorea behandelt. Für die Analyse und Konzeption der ökologisch verpflichteten Unternehmensführung in Südkorea ist eine interdisziplinäre Betrachtung notwendig, da sich die gegenwärtige Problematik in Südkorea aus soziokulturellen und historischen Determinanten zusammensetzt. Die Kenntnisse und die Berücksichtigung des gesellschaftlichen Entwicklungsprozesses und der politisch-rechtlichen, sozialen und wirtschaftlichen Gegebenheiten in Südkorea sind deshalb Voraussetzung für die Konzipierung einer ökologisch ver- 
pflichteten Unternehmensführung. Es handelt sich dabei um die gesellschaftlichen (Kap. 5), politisch-rechtlichen (Kap. 6) und wirtschaftlichen Rahmenbedingungen (Kap. 7).

Bei der Untersuchung der gesellschaftlichen Rahmenbedingungen sollen vor allem die traditionelle Welt- und Naturanschauung in der koreanischen Gesellschaft (Kap. 5.1), der westliche Einfluß auf die koreanischen Gesellschaft (Kap. 5.2) und der Wertewandel im Bezug auf der Umweltfrage (Umweltbewußtsein) (Kap. 5.3) berücksichtigt werden.

Im Zuge jedes Wertewandels gerät auch der Staat in die Pflicht, die Rahmenbedingungen anzupassen. Bei den politisch-rechtlichen Rahmenbedingungen geht es um die Umweltpolitik und Umweltgesetzgebung in Südkorea (Kap. 6.1) sowie die internationale Umweltpolitik (Kap. 6.2), die vor allem durch die Globalisierung der Umweltproblematik und der Wirtschaft für die ökologisch verpflichtete Unternehmensführung wichtig ist.

Im Kapitel 7 werden die wirtschaftlichen Rahmenbedingungen dargestellt, die die wirtschaftliche Entwicklung und die damit verbundenen Umweltprobleme (Kap. 7.1) und die wirtschaftspolitischen Maßnahmen zur Förderung des betrieblichen Umweltschutzes (Kap. 7.2) beinhalten.

Abschließend faßt das Kapitel 8 als Schlußfolgerung die Möglichkeiten und Grenzen für die Gestaltung und Umsetzung einer ökologisch verpflichteten Unternehmensführung in Südkorea zusammen, und damit wird auch versucht, den Weg zum ökologisch verpflichteten Unternehmen bzw. zur ökologisch verpflichteten Unternehmensführung in Südkorea zu skizzieren. 


\section{Einführung in die Umweltproblematik Südkoreas}

\subsection{Umweltschutzprobleme}

Der Umweltschutz war und ist in Südkorea eine weitgehend vernachlässigte Problematik. Die mit der Industrialisierung, der Modernisierung sowie der Urbanisierung einhergehenden Umweltprobleme wurden nicht genug thematisiert. Dabei sind, entgegen einer verbreiteten Auffassung, die ökologischen Probleme in Südkorea wesentlich ernster als in anderen Industrienationen.

Bis in die frühen 70er Jahre herrschte eine weitgehende Übereinstimmung sowohl bei Entwicklungsexperten als auch bei den maßgebenden Politikern in Südkorea hinsichtlich des Verhältnisses zwischen Ökologie und Ökonomie, so daß der Umweltschutz, der als inkompatibel mit dem vorrangigen Ziel der ökonomischen Entwicklung galt, als eine weitgehend vernachlässigbare Größe angesehen wurde. ${ }^{1}$

Seither hat in Südkorea wie in vielen anderen Staaten, bedingt durch eine sich dramatisch verschlechternde Umweltsituation, ein grundlegender Umdenkungsprozeß in diesem Problembereich stattgefunden. Immer mehr setzt sich die Einsicht durch, daß der Umweltschutz einen integralen Bestandteil für eine nachhaltige, d.h. langfristig tragbare nationale und globale Entwicklung darstellt. ${ }^{2}$

So weist etwa die Weltbank darauf hin, daß der Schutz der Umwelt ein unverzichtbares Element für den Entwicklungsprozeß der Entwicklungsländer ${ }^{3}$ sei, denn ohne angemessenen Umwelt-

\footnotetext{
${ }^{1}$ Während der ersten UN-Umweltkonferenz 1972 in Stockholm vertrat die brasilianische Regierung die auch in vielen anderen Entwicklungsländern vorherrschende Position, daß die Verlagerung von Industrien mit hohem Schadstoffausstoß aus den Industrieländern in ihr Land wünschenswert sei und keine zusätzliche Belastung für die Umwelt darstelle. Vgl. Simonis, U. R. (1988), S. 101. Die gleiche Position vertrat Südkorea während des wirtschaftlichen Entwicklungsprozesses in den 70er Jahren: Die Industrialisierung sollte nicht durch frühzeitiges Einbeziehen von Umweltschutzmaßnahmen gestört werden. Begleitet wurde sie daher von einer öffentlichen Stellungnahme der südkoreanischen Regierung, daß der Umweltschutz vorerst ein Luxus der Industrieländer sei und ökologische Maßnahmen erst nach einer Anhebung des ökonomischen Entwicklungsniveaus in Angriff genommen werden könnten. Vgl. Kim, Z.-S. (1974).

${ }^{2}$ Vgl. Gladwin, Th. N. (1987), S. 4.

3 Als Entwicklungsländer werden nach Definition der Weltbank (1993: XII) solche Länder bezeichnet, die ein mittleres Bruttosozialprodukt (BSP) pro Kopf der Bevölkerung im Jahr 1991 von weniger als 7.911,- US\$ verzeichneten. Entwicklungsländer, die ein relativ hohes industrielles Niveau erreicht haben, werden auch als „Schwellenländer" bezeichnet. $\mathrm{Zu}$ diesen Ländern, die vom Gesichtspunkt der industriellen Entwicklung her an der Schwelle zu den Industrieländern stehen, gehören v.a. Länder der oberen Einkommenskategorie der Länder mit mittlerem Einkommen, das sind z.B. Südkorea und Taiwan. Im Gegensatz dazu werden Länder mit einem BSP pro Kopf der Bevölkerung von 7.911,- US\$ oder mehr für das Jahr 1991 als Länder mit hohem Einkommen bezeichnet. Diese Länder (mit Ausnahme der ölexportierenden Staaten, die man allgemein zu den Entwicklungsländern zählt) werden als Industrieländer bezeichnet. Vgl. Weltbank (1989, 1992 und 1993). Südkorea dürfte als Schwellenland eingestuft
} 
schutz wird die Entwicklung untergraben. Andererseits ist Entwicklung für die Umwelt erforderlich, denn ohne Entwicklung fehlen die Ressourcen für die notwendigen Investitionen, und der Schutz der Umwelt ist nicht gewährleistet. ${ }^{4}$ Dem Nutzen einer Entwicklung stehen immer durch Umweltschädigungen verursachte Kosten gegenüber. Aus ökonomischer Sicht ist eine Entwicklung nur dann sinnvoll, wenn die sozialen Kosten oder externen Effekte, vermittelt über die Energie- und Stoffkreisläufe des Systems natürlicher Ressourcen, die Nutzen (od. den Gewinn) nicht übersteigen. ${ }^{5}$

Das heutige Verständnis der Umweltzerstörung vor allem in Entwicklungsländern wurde grundlegend von den Forschungsarbeiten des Council on Environmental Quality (1986), der International Union for the Conservation of Nature (1981) und der OECD (1982) beeinflußt. Obwohl noch immer grundlegende Wissensdefizite über die Umweltzerstörung (vor allem in Entwicklungsländern) bestehen, ${ }^{6}$ kann heute von einer wesentlich besseren Kenntnis sowohl des Ausmaßes und der Ursachen als auch der Lösungsmöglichkeiten der Umweltproblematik ausgegangen werden als etwa noch zu Beginn der 70er Jahre. Trotz eines zunehmenden theoretischen Konsenses über die zentrale Bedeutung des Umweltschutzes für die zukünftige langfristige Entwicklung haben solche Einsichten allerdings oft noch wenig Einfluß auf das praktische politische Handeln. Gravierende existentielle Probleme in Südkorea und in vielen anderen Entwicklungsländern, die keine langfristige Problemsicht erlauben, sowie die direkte Einflußnahme mächtiger Interessengruppen, die kurzfristige, aus individueller Rationalität abgeleitete Ziele verfolgen und diese durch den Einsatz von Ressourcen auch durchsetzen können, verhindern bisher oft die Durchsetzung umweltverbessernder Maßnahmen.

$\mathrm{Zu}$ den größten Umweltproblemen der meisten Entwicklungsländern wie auch Südkoreas gehören u.a. die Wasser- und die Luftverschmutzung, insbesondere in städtischen Ballungsräumen, gefährliche Abfälle sowie Verschlechterung der Böden. Art und Ausmaß der Umweltverschmutzung in den einzelnen Ländern sind dabei abhängig vom jeweiligen Entwicklungsstand, der Wirtschaftsstruktur und der nationalen Umweltpolitik. Auch die ökologische Belastbarkeit der Umwelt spielt eine wesentliche Rolle. ${ }^{7}$

werden, da es in einigen Problematiken, vor allem der Umweltfrage, Gemeinsamkeiten mit anderen Schwellenländern aufweist.

${ }^{4}$ Vgl. Weltbank (1992), S. 2.

${ }^{5}$ Vgl. Altvater, E. (1987), S. 172ff.

${ }^{6}$ Vgl. Herkendell, J. (1992), S. 55.

${ }^{7}$ Vgl. Hartje, V. J. (1982), S. 14; Stier, P. (1988), S. 88; Borsdorf, A. (1989), $20 \mathrm{ff}$. 
Nach einer Analyse der Weltbank verstärken drei Faktoren die Umweltprobleme, die mit einer schnellen Industrialisierung von Entwicklungsländern verbunden sind. ${ }^{8}$ Erstens können die Emissionen bereits bestehender Industriebetriebe durch eine Ausweitung der Produktion so erhöht werden, daß sie von der Umwelt nicht mehr absorbiert werden können. Zweitens vergrößert sich durch die zunehmende Ausdehnung der Industriestädte die Anzahl der Menschen, die der Umweltverschmutzung ausgesetzt sind. Drittens verlagert sich die Industriestruktur weg von relativ gering umweltbelastenden Aktivitäten wie der Herstellung von Textilien, Holzprodukten und der Nahrungsmittelverarbeitung hin $\mathrm{zu}$ anderen Aktivitäten mit einem viel größeren umweltbelastenden Potential wie der Metallindustrie, der chemischen Industrie und der Papierherstellung.

Viele Entwicklungsländer haben ihre Ökonomien in Teilbereichen stark ausgebaut und auf den Export orientiert. Dies betrifft vor allem die Gewinnung mineralischer und landwirtschaftlicher Rohstoffe sowie die Nahrungsmittelindustrie. Aus diesem Grund sind sie besonders von den für den Bergbau und die Agroindustrie typischen Problemen betroffen (ausgewaschene Pestizide, Düngemittel, Erzschlämme, Staubemissionen).

Höherentwickelte Länder sind zusätzlich mit Umweltbelastungen konfrontiert, die bei der verschmutzungsintensiven Produktion von Grundstoffen auftreten. Dies betrifft etwa die chemische, Mineralöl-, Metall-, Leder-, Papier-, Zement- und Düngemittelindustrie. Insgesamt sind somit die Länder mit mittlerem Einkommen am stärksten von industriellen Umweltbelastungen betroffen, wobei meist gleichzeitig eine große räumliche Konzentration der auftretenden Belastungen vorliegt. In diese Ländergruppe, die sich einer rasant steigenden Umweltverschmutzung gegenübersieht, fallen insbesondere die lateinamerikanischen und asiatischen Schwellenländer inklusive Südkorea. Höhe bzw. Intensität der Belastungen übersteigen teilweise diejenigen in den Industrieländern bei weitem. Denn die Industrie ist nur an wenigen Orten angesiedelt - vor allem in den Haupt- und Küstenstädten - und Umweltschutzmaßnahmen wird oft nur ein geringer Stellenwert eingeräumt. ${ }^{9}$ Aufgrund dieser Problematik wird gerade den Schwellenländern eine besondere Bedeutung für die zukünftige globale Umweltsituation beigemessen. ${ }^{10}$

Von Entwicklungsexperten wird in diesem Zusammenhang die Forderung erhoben, daß die Entwicklungsländer im Industrialisierungsprozeß jene Fehler, die in den Industrieländern in der Vergangenheit begangen wurden, soweit wie möglich vermeiden müssen. ${ }^{11}$ Hier wird jedoch auf

\footnotetext{
${ }^{8}$ Vgl. Weltbank (1992), S. 155.

${ }^{9}$ Vgl. Glaeser, B. (1989), S. 199f.

${ }^{10}$ Vgl. Wilhelm, S. (1994), S. 124.

${ }^{11}$ Vgl. UNCTC (1985), S. 1.
} 
die Notwendigkeit der Zusammenarbeit mit den Industrieländern hingewiesen, um durch die Anwendung effizienter Lösungen die Umweltgefahren $\mathrm{zu}$ verringern. Viele Probleme könnten vermieden werden, wenn die Erfahrungen im Umweltschutz, welche in den Industrieländern bereits gemacht wurden, auf den Bereich der Entwicklungsländer übertragen würden: „Viele der Maßnahmen, die der Süden (Entwicklungsländer) ergreifen kann, um die industrielle Umweltverschmutzung ... einzuschränken, werden ... weithin von der Kooperation des Nordens (Industrieländer) beim Transfer von energiesparender und umweltverträglicher Technik abhängen. Ohne solche Zusammenarbeit wird es dem Süden sehr schwer fallen, bei dem notwendigen hohen Wirtschaftswachstum die industrielle Umweltverschmutzung zu verringern. ‘ ${ }^{12}$

\subsection{Aktuelle Situation der Umweltprobleme und ihre Ursachen}

In diesem Abschnitt wird versucht, konkrete Anhaltspunkte über Umweltprobleme und ihre Ursachen in Südkorea zu liefern. Erstere - die Umweltprobleme - können in drei Schwerpunkte hinsichtlich ihrer Entstehung eingeteilt werden: ${ }^{13}$

- Unzureichende sanitäre Situation,

- Erodierung der natürlichen Ressourcenbasis (Entwaldung, Bodenerosion),

- Moderne Umweltbelastung durch Industrie und Verstädterung.

Südkorea, das als sog. Schwellenland eingestuft wird, hat es vornehmlich mit der dritten Form der oben beschriebenen Umweltprobleme zu tun, die ebenso wie die Industrialisierung und Urbanisierung sehr schnell angewachsen sind. Die zum zweiten Problembereich gehörende Bodenerosion stellt ebenfalls ein nach wie vor ungelöstes Umweltproblem dar, weshalb Erosionskon-

\footnotetext{
12 Südkommission (1991), S. 206f. Viele der technischen Mittel, die zu einer Verbesserung der Umweltverträglichkeit der industriellen Produktion beitragen können, sind bereits verfügbar und ausgereift. Die meisten davon wurden in Industrieländern von Unternehmen als Reaktion bzw. als Vorgriff auf strenge gesetzliche Auflagen oder aufgrund ökonomischer Zielsetzungen entwickelt. Werden diese Techniken in Entwicklungsländern eingesetzt, so können sich im Vergleich zu Industrieländern zwei Vorteile ergeben. In vielen Fällen sind die Kosten von End-ofPipe-Technologien zur Beseitigung von bis zu 80\% der Emissionen einer Anlage relativ gering. Erst bei einer weiteren Reduzierung der Emis sionen steigen die marginalen Kosten stark an. Bestehen also in einer industriellen Produktionsanlage noch keine solchen Technologien, so kann mit vergleichsweise geringen Kosten eine relativ hohe schadstoffreduzierende Wirkung erzielt werden. Der zweite Vorteil kann sich dann ergeben, wenn beim Neubau von Produktionsanlagen im Zuge einer fortschreitenden Industrialisierung abfallarme integrierte Produktionsprozesse verwirklicht werden. Diese Produktionsprozesse können durch eine Reduktion der Inputfaktoren nicht nur die Emissionen wesentlich verringern, sondern auch zu einer Kostenreduzierung beitragen. Hier haben die Entwicklungsländer gegenüber den Industrieländern den Vorteil, daß sie in vielen Fällen nicht an bereits bestehende und in ökologischer Hinsicht technologisch überholte Produktionsanlagen gebunden sind, sondern daß beim Neuaufbau einer industriellen Struktur solche modernen umweltschonenden Produktionstechnologien verwirklicht werden könnten.

${ }^{13}$ Vgl. Hartje, V. J. (1982), S. 12ff.
} 
trollmaßnahmen unter den Hauptzielen des ersten und zweiten Zehnjahresplanes zur Wiederbewaldung des Landes zu finden sind. ${ }^{14}$

Die Auswirkungen der modernen Umweltbelastungen sind vielfältig: Verunreinigung der Umweltmedien (Boden, Wasser, Luft, Flora und Fauna), Lärm, Kontamination von Nahrungsmitteln, diffuse Verbreitung von Schwermetallen sowie Radioaktivität, Gefahrenpotential technischer Anlagen (Chemie, Verkehr, Industrieabfalldeponien und Kernkraftwerke), Zerstörung des Landschaftsbildes durch Bauten usw. All dies kommt heute in Südkorea vor. Insofern unterscheiden sich koreanische Umweltprobleme nicht von denen Deutschlands.

Die aufgelisteten Arten von Umweltbelastungen lassen sich in drei Wirkungsformen differenzieren: ${ }^{15}$

- Akute Umweltzerstörung,

- Schleichende Umweltzerstörung,

Aufbau eines Risikopotentials.

Akute Umweltzerstörungen sind solche, die an bestimmten Orten als eindeutig identifizierbare Erscheinungen auftreten: das „Umkippen“ eines Gewässers, Aussterben von Tier- und Pflanzenarten, Smog usw. Dies ist die sicherlich spektakulärste und augenscheinlichste Form der Umweltzerstörung. Schleichende Umweltzerstörung äußert sich zunächst in einer graduellen Verschlechterung der Umweltqualität (Anreicherung der Organismen mit Schwermetallen oder Anwachsen des $\mathrm{CO}_{2}$-Gehalts in der Atmosphäre), die früher oder später in akute Umweltzerstörung wie z.B. Waldsterben übergeht. Schließlich ist noch der Aufbau eines Risikopotentials zu nennen. Technische Anlagen bergen in der Regel Unfallgefahren in sich. Als Risiko bezeichnet man das Produkt der Schadenhöhe und der Wahrscheinlichkeit, daß der Unfall eintritt. Dafür sind Kernkraftwerke und bestimmte chemische Produktionstechnologien gute Beispiele, die sowohl lokale als auch überregionale Katastrophen auslösen können.

Die derzeitige Umweltpolitik in Südkorea beschäftigt sich in erster Linie mit der akuten Umweltzerstörung. Die anderen zwei Wirkungsformen spielen eine geringere Rolle. Das rechtzeitige Einbeziehen dieses vernachlässigten, jedoch mit hohen Gefahren beladenen Bereichs der Um-

\footnotetext{
${ }^{14}$ Vgl. näheres über Maßnahmen der Erosionskontrolle in Südkorea Woo, B.-M.(1982).

${ }^{15}$ Vgl. Bechmann, A. (1984), S. 120ff.
} 
weltpolitik ist notwendig, um die gefährliche Entwicklung Südkoreas in diese Richtung aufzuhalten.

Obwohl sich in Südkorea erst in den siebziger Jahren ein zunehmendes Umweltbewußtsein entwickelte, ist die Umweltverschmutzung in Südkorea kein neues Problem. Schon seit den frühen sechziger Jahren förderte man in Südkorea die Industrialisierung. Große Schwerindustriegebiete und Industriestädte entstanden aufgrund gezielter staatlicher Förderung und Planung zu Zeiten der Militärregierung. Insbesondere durch die Erstellung von Fünfjahresplänen (FJP) wurde die wirtschaftliche Entwicklung des Landes vorangetrieben. ${ }^{16}$

Mit diesem staatlich geförderten wirtschaftlichen Wachstum ist jedoch auch die Entstehung erheblicher Probleme verbunden: Rohstoffe müssen eingeführt und die daraus gefertigten Waren wieder ausgeführt werden, da Südkorea kaum Rohstoffe besitzt. Infolgedessen hat die exportorientierte Industrie Südkoreas weder eine solide wirtschaftliche und finanzielle Grundlage, noch besteht eine für die langfristige Entwicklung notwendige Infrastruktur. Darüber hinaus gehört Südkorea auch zu den am dichtesten bevölkerten Ländern der Welt. Jedoch sind nur ca. 20\% des Landes nutzbar, da der übrige Teil von unwirtlichen Gebirgen eingenommen wird. Infolge dieser ungünstigen geographischen Gegebenheiten wird eine verhältnismäßig begrenzte Fläche des Staatsgebietes von massiven Umweltschäden betroffen. Außer den Schädigungen durch Luftund Wasserverschmutzung sowie durch die Abfallwirtschaft treten Gefährdungen durch Pestizide und bauliche Maßnahmen auf.

Das Wirtschaftswachstum und die damit zusammenhängende Verstädterung haben die materielle Seite des Lebens in Südkorea verbessert. Damit sind aber auch die Zerstörung der Landschaft und die Auslösung von Gesundheitsschäden verbunden. Mittlerweile haben die Umweltschäden in Südkorea derart erschreckende Ausmaße angenommen, daß in naher Zukunft das tägliche Leben durch Umweltschäden beeinträchtigt werden könnte. Verursacht wurde diese Entwicklung durch eine Politik, die die wirtschaftliche Entwicklung über die Belange des Umweltschutzes stellte.

Zusammenfassend ist festzustellen, daß das erstaunliche wirtschaftliche Wachstum in Südkorea vor allem auf Kosten der Gesundheit der Bürger und des Zustandes der Natur ging. Die radikale Industrialisierung wurde bis in die achtziger Jahre fortgesetzt, ohne die Folgen für die Umwelt zu 
berücksichtigen. Erst allmählich setzte sich die Erkenntnis durch, daß man hinsichtlich des Verhältnisses zur Umwelt am Scheideweg stand. Denn es stellte sich heraus, daß die Umweltverschmutzung für das gesamte Land dramatische Folgen haben würde, wenn nicht binnen kürzester Zeit die negativen Auswirkungen der Industrialisierung und Urbanisierung - zumindest in ihren krassesten Ausformungen - beseitigt werden würden. Insbesondere ein Vorfall im Jahre 1991 sensibilisierte die Öffentlichkeit für die Belange der Umwelt. In diesem Jahr wurde bekannt, daß giftige Chemikalien unbehandelt in den Nakdong Fluß eingeleitet wurden. Bis zu diesem Zeitpunkt war Südkorea von Umweltkatastrophen größeren Ausmaßes, wie z.B. Tschernobyl in der Ukraine, verschont geblieben.

Wenn man die Umweltveränderungen in Südkorea in den letzten 40 Jahren betrachtet, erkennt man eine enorme Zunahme der Umweltgefährdung. Die Umweltsituation hat in vielen Bereichen die tolerablen Grenzwerte überschritten und einen bedrohlichen Zustand erreicht. Bisher ist von dem lang gehegten Wunsch nach wirtschaftlichem Wachstum noch nicht in Richtung Umweltschutz umgedacht worden. Es wurden auch noch keine wirkungsvollen Gegenmaßnahmen ergriffen, um die bedrohliche Entwicklung zu verhindern.

Im folgenden werden die (entwicklungsbedingten) Ursachen der Entstehung von Umweltproblemen in Südkorea anhand dreier Kategorien untersucht, und zwar die Wirtschaftsstruktur mit Schwerpunkt auf der Schwer- und Chemieindustrie, das Bevölkerungswachstum und die Verstädterung.

Wirtschaftliches Wachstum geht gewöhnlich mit einem Strukturwandel einher. Der Weg der Entwicklung und des notwendigen Strukturwandels in den Ländern der weltwirtschaftlichen Peripherie, die in ihrer ökonomischen Entwicklung zurückgeblieben sind, und deren Wirtschaftspolitik darauf gerichtet sind, den eingetretenen Rückstand möglichst schnell aufzuholen, ist in groben Zügen durch das Vorbild der Industrieländer vorgezeichnet. ${ }^{17}$

Die koreanische Wirtschaftsstruktur hat sich während der letzten 30 Jahre drastisch geändert. Der Industriesektor weitete sich besonders schnell aus. Die Anteil der einzelnen Sektoren an der gesamtwirtschaftlichen Wertschöpfung (BSP) verschob sich in Südkorea in schnellem Tempo vom primären Sektor (Land- und Forstwirtschaft) auf den sekundären (verarbeitende Industrie)

\footnotetext{
16 Übergeordnetes Ziel der FJP (der erste galt für die Jahre 1962-1966) war die nationale industrielle Entwicklung des Landes, wobei die koreanische Wirtschaftsstruktur grundlegend verändert wurde. Vgl. zu den FJP in Südkorea Kap. 5.2 dieser Arbeit.

${ }^{17}$ Vgl. Neumann, M. (1994), S. 125.
} 
und den tertiären Sektor (Dienstleistungen). ${ }^{18}$ Diese strukturelle Verschiebung ging einerseits mit der Veränderung der internen Produktivität der betreffenden Sektoren einher, andererseits hatte sie Auswirkung auf die staatliche Unterstützungspolitik, z.B. für die strategische Industrien und führte zum Wandel der Arbeitskräfte vom primären zum sekundären Sektor. Vor allem in den 70er und 80er Jahren traten neue Industrien im sekundären Sektor auf, die die Umwelt besonders stark belasteten.

Abb. 1.1 veranschaulicht die Entwicklung der industriellen Produktion im sekundären Sektor von einer arbeitsintensiven zu einer kapitalintensiven Herstellung.

\begin{tabular}{|l|l|}
\hline & \multicolumn{1}{|c|}{ Industrielle Produktionen } \\
\hline 50er Jahre & Textilherstellung, Zuckerherstellung und Mehlherstellung \\
\hline 60er Jahre & Chemiefaser, Konservenbüchsen, Zement, Düngemittel, Elektrizität und Mineralöl \\
\hline 70er Jahre & Eisen und Stahl, Petrochemie, Maschinen, Schiffe, Kraftwagen und Nichteisenmetalle \\
\hline Seit den 80er Jahren & Elektrotechnische Erzeugnisse, Computer, Halbleiter, Atomkraft und Gentechnologie \\
\hline
\end{tabular}

Abb. 1.1: Die struktuelle Entwicklung des sekundären Sektors in Südkorea

(Quelle: Industriebank Südkorea (1984), S. 17)

Seit dem Ausbau der Schwer- und Chemieindustriezentren verschlechterte sich die Umweltsituation drastisch. Eine besondere Rolle spielte dabei neben der sog. „Frei-Export-Zone“ die Ansiedlung der besonders umweltbelastenden Industrien aus Japan und den USA in Südkorea, die aufschlußreiche Beispiele für den Export von Umweltverschmutzung durch ausländische Unternehmen sind. ${ }^{19}$

Weitere Ursachen der Entstehung von Umweltproblemen in Südkorea sind das Bevölkerungswachstum und die Verstädterung. Die Gesamtbevölkerung Südkoreas betrug im Jahr 1970 etwa 32,2 Mill. und 1995 etwa 44,85 Mill. Mit einer Bevölkerungsdichte von 451 Einwohnern pro Quadratkilometer im Jahr 1995 gilt Südkorea als eines der dichtest besiedelten Länder der Welt. Da seit 1991 mehr als 73\% der Bevölkerung in den Städten leben (1970: 41\%), ist auch die Ver-

\footnotetext{
18 Im Jahr 1961war die sektorale Aufteilung des BSP im Primärsektor 39,70\%, Sekundärsektor 15,50\% und Tertiärsektor 45,40\%. Aber im fünften FJP (1983) veränderten sich die prozentualen Anteile wie folgt: Primärsektor $(13,70 \%)$, Sekundärsektor $(28,90 \%)$ und Tertiärsektor $(57,40 \%)$. Im Jahr 1996: Primärsektor $(6,40 \%)$, Sekundärsektor $(30,30 \%)$ und Tertiärsektor $(63,30 \%)$. Vgl. Industriebank Korea (1984), S. 15.

19 Krödgen weist nach einer empirischen Untersuchung darauf hin, daß Umweltschutz in der Bundesrepublik Deutschland nur in Ausnahmefällen ein Motiv für Produktionsverlegung ins Ausland ist. Hingegen gibt es in anderen Industrieländern deutlich Hinweise dafür, daß Verlegungen aus Gründen von Umweltschutzauflagen im eigenem Land vor sich gehen. Als Beispiel führt sie an, daß Japan umweltbelastende bzw. -verschmutzende Industrie bevorzugt nach Südkorea verlagert. Vgl. Krödgen, G. (1982), S. 17.
} 
teilung der Siedlungsfläche regional sehr ungleich: Im Jahr 1990 konzentrierten sich 48,2\% der Gesamtbevölkerung auf die sechs größten Städte Seoul, Busan, Daegu, Inchon, Kwangju und Daejeon. ${ }^{20}$

Aus der dargestellten Bevölkerungsentwicklung ergeben sich entsprechende Auswirkungen auf die Umwelt. Durch das Bevölkerungswachstum und die Zunahme der Produktion und des Konsums steigt die Menge der Abfallprodukte, deren ordnungsgemäße Entsorgung nicht in jedem Fall gegeben ist. Die umweltbelastenden produktionstechnischen Veränderungen und ein geändertes Konsumverhalten führen zu einer zusätzlichen negativen Beeinflussung der Umwelt.

Als Beispiele für diese Entwicklung seien das Trinkwasserversorgungs- und Abfallentsorgungsproblem, der saure Regen sowie die landwirtschaftliche Bodennutzung genannt. Diese Umweltprobleme haben sich zu schwer lösbaren gesellschaftlichen Problemen entwickelt:

Die vier größten Flüsse (Han, Nakdong, Keum und Youngsan) sind infolge der Einleitung von Abwasser stark verschmutzt und haben teilweise schon ein kritisches Niveau erreicht, in dem Flora und Fauna der Gewässer nicht mehr überlebensfähig sind. Diese Umweltsituation im Gewässerbereich begrenzt vor allem die Versorgung der Bewohner des Unterlaufes des Flusses mit qualitativ hochwertigem Trinkwasser. Weil in der Vergangenheit auch giftige Schadstoffe (z.B. Phenol und Mineralöl) in diese Gewässer eingeleitet wurden, hat dies zu großen Problemen geführt.

- Die Trinkwasserversorgung beruht in Südkorea auf Oberflächengewässern. Sie wird durch den Bau von Staudämmen gesichert. Da sich die großen wirtschaftlichen Zentren an den Uhterläufen der Flüsse befinden, werden die Anwohner des Oberlaufes des Flusses mit dem Ziel des Trinkwasserschutzes jeweils den Regelungen für Wasserschutzgebiete ausgesetzt. Zwischen den Anwohnern des Unterlaufes und Oberlaufes des Flusses ist somit die Konkurrenz um die Nutzung der Gewässer besonders stark ausgeprägt. Dies führt in Südkorea zu einem tiefgreifenden gesellschaftlichen Konflikt, der jedesmal, wenn die Verfügungsrechte für die Nutzung oberhalb des Staudammes (innerhalb der Wasserschutzgebiete) liegenden Vermögen einschränkt werden sollen, neu zutage tritt.

- Die Abfallmengen nehmen in Südkorea jährlich um rund $10 \% \mathrm{zu}^{21}$ wovon die entsorgungspflichtigen Gebietskörperschaften zur Zeit 90\% deponieren müssen. Wollen sie den Deponieraum ausweiten, so stoßen sie, wie überall auf der Welt, auf großen Widerstand der Bürger,

\footnotetext{
${ }^{20}$ Vgl. Umweltministerium Südkorea - Umweltjahrbuch (1996), S. 16ff.

${ }^{21}$ Vgl. Shin, H.-G. (1994), S. 117.
} 
die in der Umgebung der geplanten Deponie wohnen. Die Deponie beeinträchtigt nicht nur die Landwirtschaft, sondern geht auch mit Geruchsbelastungen einher. Der Wert der anliegenden Grundstücke sinkt. Mit der beginnenden Selbstverwaltung der lokalen Gebietskörperschaften bildet die Abfallentsorgung besonders in den Großstädten ein schwer zu lösendes gesellschaftliches Problem. Es entsteht sowohl ein Konflikt zwischen Gebietskörperschaften als auch zwischen Bürgern und Gebietskörperschaften.

Die Schadstoffemissionen in die Luft haben in Großstädten bereits die Grenzwerte (z.B. minimaler pH-Wert 4,2 für Seoul, 4,3 für Daegu und 4,9 für Busan) erreicht. ${ }^{22}$ Bei einem $\mathrm{pH}-$ Wert von 4,5 wird bekanntlich das Wachstum der Pflanzen behindert. Lebensgefährdende Bedrohungen für die Natur und auch für den Menschen haben also schon begonnen.

- Die Verbrauchsmenge von Pflanzenschutzmitteln (organische Fungizide, Insektizide und Herbizide) steigt weiter an, während der Verbrauch von Mineraldünger konstant auf einem hohen Niveau bleibt. ${ }^{23}$ Der hohe Einsatz der Dünge- und Pflanzenschutzmittel als ertragssteigernde Mittel führte zu gravierenden Änderungen des ländlichen Bodens. Viele Bodentiere verschwinden aus dem stark übersäuerten Boden, der viele langlebige, schwer abbaubare chlorierte Kohlenwasserstoffe sowie organische Phosphorverbindungen und eine hohe Konzentration an anorganischen Stoffen enthält. Die Bodenvergiftung beeinflußt Pflanzen und Wasser und bedroht die Gesundheit der Menschen. Diese Bodenbelastungen werden sich wahrscheinlich in Zukunft noch erhöhen.

Diese Entwicklungen in Südkorea haben dazu beigetragen, das Bewußtsein zu wecken, daß eine derartige Umweltverschmutzung, die die menschlichen Lebensgrundlagen bedroht, nicht fortbestehen kann. Die individuellen Wünsche und Hoffnungen zur Erhaltung der Lebensgrundlagen haben die Politiker dazu veranlaßt, Versuche zu unternehmen, diese Entwicklungen aufzuhalten oder gar umzukehren. Der gesellschaftliche Bewußtseinswandel erfordert eine Änderung des gesellschaftlichen Zielsystems und der diesbezüglichen Institutionen.

\subsection{Zur Lage der Wirtschaft und zu den Trends im betrieblichen Umweltschutz}

Im folgenden wird die aktuelle Lage der Wirtschaft kurz dargestellt. Die Ideologie des Wirtschaftswachstums nimmt in Südkorea eine vorrangige Stellung vor dem Umweltschutz bzw. der Umweltpolitik ein. Daher scheint diese Darstellung wichtig zu sein, um die aktuelle Situation der Umweltschutzprobleme überblicken zu können.

\footnotetext{
${ }^{22}$ Vgl. Die Cho-Sun-Zeitung (1994), S. 28.

${ }^{23}$ Vgl. Ministry of Agriculture, Forestry \& Fisheries (1993), S. 47ff.
} 
In der Realität stellt die ökonomische Krise, die sich in Südkorea in den letzten Jahren weiter verschärft hat, jedoch ein wesentliches Hindernis für erhöhte Umweltschutzanstrengungen von staatlicher Seite dar: „,... es ergibt sich derzeit das Dilemma, daß einerseits deutlicher denn je die Bedeutung einer langfristig vorsorgenden Umweltpolitik für Entwicklungsländer gesehen wird, nämlich in der Schaffung von Arbeitsplätzen, der Förderung moderner Technologie, der Verbesserung des Gesundheitspotentials und der Erhaltung natürlicher Ressourcen; daß aber andererseits kurzfristige Finanzierungsbeschränkungen derartige Überlegungen zunichte machen, ja kaum noch konventionelle Entwicklungsmaßnahmen zulassen. ${ }^{\text {(24 }}$

\begin{tabular}{|c|c|c|c|c|}
\hline & $\overline{1994}$ & 1995 & 1996 & 1997(4/4 Quartal) \\
\hline Wirtschaftswachstum (\%) & 8,6 & 8,9 & $\overline{7,1}$ & $5,5(3,9)$ \\
\hline $\begin{array}{l}\text { Wachstum der } \\
\text { industriellen Produktion (\%) }\end{array}$ & 10,9 & 12,0 & 7,3 & $6,9(5,5)$ \\
\hline $\begin{array}{l}\text { Teuerungsrate des } \\
\text { Verbraucherpreises (\%) }\end{array}$ & 6,2 & 4,5 & $\overline{4,9}$ & $4,5(5,1)$ \\
\hline Arbeitslosigkeit (\%) & 2,4 & 2,0 & 2,0 & $2,6(3,1)$ \\
\hline Leistungsbilanzsaldo (Md. \$) & $-4,53$ & $-8,95$ & $-23,72$ & $-8,6(3,3)$ \\
\hline
\end{tabular}

Abb. 1.2: Die wichtigen Wirtschaftsindizes von Südkorea (Quelle: National Statistical Office Republic Korea, 1998)

Im Jahr 1997 betrug das Wirtschaftswachstum in Südkorea 5,5\%. Um 6,9\% stieg die industrielle Produktion an. Die Entwicklungstendenz ist stabil. Der Verbraucherpreis stieg um 4,5\% und die Arbeitslosigkeit auf 2,6\%. Diese Entwicklung änderte sich im Zuge der „Asienkrise“. Im Dez. 1997 hat Südkorea insgesamt 58,35 Md. \$ internationale Finanzhilfe (einschließlich 21,0 Md. \$ von IMF) bekommen. Der Wirtschaftsindex vom 4. Quartal 1997 zeigt die Krisensituation der koreanischen Wirtschaft. Das Wirtschaftswachstum und der Anstieg der industriellen Produktion fielen im Vergleich zum vorherigen Jahre von 7,1\% und 7,3\% auf 3,9\% bzw. 5,5\%. Der Anstieg des Exportpreises durch die Abwertung der koreanischen Währung wirkte sich auf den Verbraucherpreis (5,5\%) aus. Die Arbeitslosigkeit stieg von 2,0\% auf 3,1\%. ${ }^{25}$ Die Arbeitslosigkeit, eine Folge der Wirtschaftskrise und der anschließenden Umstrukturierungen unter der Aufsicht des Internationalen Währungsfonds, ist nach wie vor alarmierend hoch. Dies alles beeinflußt die Umweltschutzmaßnahmen, insbesondere von der Seite des Staates und der Industrieunterneh-

\footnotetext{
${ }^{24}$ Glaeser, B. (1989), S. 22.

${ }^{25}$ Die Arbeitslosigkeit im Mai 1999 lag bei 6, 4\% (im Mai 1998 bei 6,9\% und im Dezember 1998 bei 7,9\%). Vgl. National Statistical Office Korea (1999).
} 
men. Der Jahresetat des staatlichen Haushalts für Umweltschutz im 1998 wurde jedoch um $13,8 \%$ gekürzt. $^{26}$

Gegenwärtig werden Unternehmen in Südkorea von drei Faktoren im Umweltschutz beeinflußt. ${ }^{27}$ Der erste Faktor ist die staatliche Gesetzgebung. Die Novellierung fast aller Gesetze wird schon jetzt spürbar. Dabei ist für die Unternehmen weniger die Erhaltung von Grenzwerten das eigentliche Problem, sondern der hohe bürokratische Aufwand, der nicht nur Ressourcen bindet, sondern - entscheidender - viel Zeit kostet. Und dieser Bürokratisierungsprozeß ist noch nicht abgeschlossen. Marktorientierte Instrumente scheinen derzeit nur eine geringe Chancen zu haben. Die Effizienzverluste und Innovationshemmnisse, die daraus entstehen, können hier nicht weiter verfolgt werden.

Dazu kommt zunehmend als zweiter Faktor die Sensibilität der Verbraucher im Umweltbereich. Produkt- bzw. Produktionsskandale sind hier nur die Spitze des Eisberges. Es gibt gute Gründe für die Annahme, daß jetzt die Phase beginnt, in der sich das allgemeine Umweltbewußtsein der Bürger auch in Verhaltensänderungen umsetzt. Damit wandelt sich der Umweltschutz vom reinen Kollektivgut (das der staatlichen Regelung bedarf) $\mathrm{zu}$ einem teilweise ,privatisierten“ Gut mit der Folge, daß in bestimmten Segmenten die Umweltfreundlichkeit eines Produktes als Zusatznutzen vermarktbar ist bzw. andererseits Produkte mit ökologischen Risiken auch zunehmend Marktrisiken bedeuten. Damit verbreitet sich der Bereich, in dem Unternehmen mit Umweltschutz konfrontiert sind.

Der dritte Faktor kann als Globalisierung der Umweltprobleme bezeichnet werden. Stichworte wie Treibhauseffekt oder Ozonzerstörung sind längst in das öffentliche Bewußtsein gedrungen. Beim Weltwirtschaftsgipfel 1989 in Paris nahm der Umweltschutz erstmals ein Drittel der Abschlußerklärung ein. Insbesondere war die 1992 in Rio durchgeführte UN-Konferenz für Umwelt und Entwicklung sowohl in der Unternehmenspolitik als auch in der Wissenschaft Anstoß dafür, die Globalität und Internationalität der ökologischen Krise anzuerkennen und daraus theoretische wie praktische Schlußfolgerungen $\mathrm{zu}$ ziehen. ${ }^{28}$ Zwar sind Erklärungen noch keine verbindliche

\footnotetext{
${ }^{26}$ Vgl. Umweltministerium Südkorea (1998), S. 9.

${ }^{27}$ Nach einer repräsentativen Untersuchung sind die Gründe für die Anstrengungen der Unternehmen zum Umweltschutzes in Südkorea aus folgenden Faktoren zurückzuführen: staatliche Umweltgesetzgebung und Umweltpolitik $(47,9 \%)$, Anstieg des Umweltbewußtsein von Konsumenten $(29,5 \%)$, Verbesserung des Unternehmensimages und Wettbewerbsfähigkeit (12,6\%) sowie internationale Umweltpolitik und umweltschutzbezogene Abkommen $(10,0 \%)$. Dieses Ergebnis entstand aus einer Befragung, die im Jahr 1997 durchgeführt wurde. Daraufhin wurde untersucht, welche Faktoren bzw. Gründe für Anstrengungen zum Umweltschutz und zur ökologisch verpflichteten Unternehmensführung in den Unternehmen sind. Vgl. KEI (1997), S. 75.

${ }^{28}$ Die dort erarbeitete Agenda 21 machte die Vorstellung einer nachhaltigen Entwicklung weltweit zu einem Leitziel der Umwelt- und Entwicklungspolitik. Es handelt sich um ein Pflichtenheft für eine zukunftsfähige Entwicklung im
} 
verbindliche Politik, es spricht aber einiges dafür, daß die ökologische Problematik weltweit an Bedeutung zunehmen wird. Auf der einen Seite wird diese für die Unternehmen Entlastung bringen, weil sich zumindest in den betroffenen Ländern die Umweltstandards einander annähern. Andererseits steigt damit aber auch die Eigendynamik eines ökologieverträglichen Strukturwandels, der in seinen Dimensionen - am deutlichsten zeichnet sich dies z.Zt. in der Chemieindustrie $\mathrm{ab}$ - über den rein technischen Umweltschutz mit seinen End-of-Pipe-Technologien ${ }^{29}$ weit hinausgeht. Für die Unternehmenspolitik wurde dies besonders deutlich an der Bildung eines $\mathrm{Bu}-$ siness Council for Sustainable Development. ${ }^{30}$ Dieser Unternehmerrat veröffentlichte im Vorfeld der UN-Konferenz einen Bericht, in dem es u.a. heißt: „Durch die Kooperation im Kontext einer nachhaltigen Entwicklung erhält die Unternehmensverantwortung neue zeitliche und räumliche Dimensionen. Die Unternehmen müssen die Auswirkungen ihrer Tätigkeit auf künftige Generationen und auf Menschen in anderen Teilen der Welt in Betracht ziehen. ${ }^{\text {‘3 }}$

Für die Unternehmensführung bestehen damit Gründe, den Umweltschutz künftig als eigene genuine Aufgabe zu betrachten. Die weitere Bürokratisierung im staatlichen Umweltschutz mit seinem Autonomieverlust für die Unternehmen kann nur gestoppt werden, wenn die Unternehmen vorausschauend die Umweltprobleme konstruktiv angehen. Ökologische Verträglichkeit oder Risikopotentiale werden marktrelevant und dies nicht nur national, so daß heute derjenige seine Wettbewerbsposition für die Zukunft sichert, der Umweltschutz zu einem Kriterium seiner Unternehmensstrategie macht. Dazu ist es notwendig, daß die Unternehmen die ökologische Dimension des Wirtschaftens in ihr Zielsystem integrieren. Denn an diesen Zielen orientiert sich die Entwicklung von Strategien und deren Umsetzung in den funktionalen Bereichen.

21. Jahrhundert. Die heute weitgehend akzeptierte Definition „Nachhaltige Entwicklung“ (Sustainable Development) bedeutet dabei eine ,...Entwicklung, die die Bedürfnisse der Gegenwart befriedigt, ohne zu riskieren, daß künftige Generationen ihre eigenen Bedürfnisse nicht befriedigen können“. Vgl. Hauff, V. (1987), S. 46.

${ }^{29}$ Im Rahmen der technologischen Entwicklungen im Umweltschutzbereich ist zwischen folgenden Basistechnologien zu unterscheiden: End-of-pipe-Technologien werden dem eigentlichen Produktions- oder Konsumtionsprozeß nachgeschaltet, ohne ihn technologisch zu verändern (Müllendorff, R. (1981), S. 256). Im Sinne einer additiven Technologie werden vorhandene Prozeß- und Produkttechnologien um eine Technologie ergänzt, deren Zweck die nachträgliche Minderung bereits entstandener Umweltbelastungen ist (z.B. Filtertechniken und Deponierungstechniken). Vgl. zu den Ansätze zur Klassifikation von Umweltschutztechnologien Strebel, H. (1990), S. 9.; Steger, U. (1988), S. 108ff.; Meffert, H./Kirchgeorg, M. (1998), S. 90ff.

30 „Sustainable Development“, d.h. in deutscher Sprache nachhaltige, dauerhafte, langfristig tragfähige Entwicklung steht seit 1992 dafür, daß Probleme von ökologischer Umwelt und Entwicklung (ökonomisch weniger entwickelter Länder) nur noch gemeinsam bearbeitet und gelöst werden können. Als Konzept geht es dabei um die Frage nach den Bedingungen der Möglichkeiten, die Wirtschafts-, Arbeits- und Lebensmodelle der entwickelten Länder so umzugestalten, daß deren Globalisierung auf dem ganzen Erdball möglich ist. Vgl. hierzu z.B. Harborth, H.-J. (1991); Feess, E. (1997), S. 31ff.; Faber, M./Jöst, F./Manstetten, R. (1997), S. 51ff.

${ }^{31}$ Schmidheiny, S. (1992), S. 129. 


\section{Teil I: Grundlagen einer ökologisch verpflichteten Unternehmensführung}

\section{Die Ökologieproblematik als Herausforderung für die Unternehmensführung}

Man pflegt heute zu sagen, daß der Zustand der ökologischen Umwelt mehr als besorgniserregend und unter vielerlei Aspekten katastrophenträchtig ist. Luft-, Wasser-, Bodenverschmutzung, Klimaveränderungen haben dabei zu einer wachsenden Umweltsensibilität für Gefährdungen von Menschen, Tieren und Pflanzen, d.h. dem gesamten Ökosystem in der breiten Öffentlichkeit geführt.

Aufgrund weltweiter ökologischer Probleme erhöhen sich sowohl die gesellschaftlichen Anforderungen als auch die industriespezifischen Herausforderungen an die Unternehmen, die insbesondere wegen ihrer auf eine Gewinnerzielung ausgerichteten Unternehmensaktivitäten die Umweltverschmutzung und den Rohstoffverbrauch erhöhen. Man beurteilt solche Unternehmen bzw. Unternehmensführung als Hauptverursacher für die Umweltverschmutzung. Ihnen wird vorgeworfen, die ökologische Dimensionen gänzlich zu vernachlässigen. Dabei stehen die ökologischen Probleme als Bestimmungsfaktoren der Unternehmenspolitik in der aktuellen Diskussion.

Das steigende Umweltbewußtsein der Bevölkerung führt einerseits in vielen Branchen zu einer Veränderung des Nachfrageverhaltens, welches ökologisch verträglichen Produkten auch eine Marktchance eröffnet. Dazu können Akzeptanz- und Vertrauensverluste in der Gesellschaft aufgrund nicht umweltgerechten Verhaltens den langfristigen Erfolg von Unternehmen gefährden. Von staatlicher Seite bringt die zunehmende, schwer überschaubare Flut gesetzlicher Regelungen und Auflagen im Umweltbereich andererseits eine Veränderung der wirtschaftlichen Rahmenbedingungen mit sich. Weiter setzt sich in vielen Unternehmen die Einsicht durch, daß eine Verminderung des Energie- und Ressourcenverbrauches, welche aus Umweltschutzgesichtspunkten wünschenswert ist, auch zu Kosteneinsparungen führen kann. Diese Entwicklungen führen insgesamt dazu, daß das ökologisch verantwortliche Verhalten von Unternehmen in vielen Fällen zu einem wichtigen Faktor für die Wettbewerbsfähigkeit wird und eine Herausforderung für die Unternehmensführung darstellt. Angesicht dieses sich entwickelnden Bewußtseins für die ökologische Umwelt überrascht es nicht, daß sich die Unternehmen nicht nur in den hochentwickelten Industrieländern, sondern auch in Südkorea zunehmend mit ökologischen Problemstellungen auseinandersetzen müssen. 
Im folgenden wird zunächst die häufig als ökologische Krise zitierte Ökologieproblematik einschließlich der gesellschaftlichen Reaktion erläutert. Aufbauend auf dieser Problematik werden die damit verbundenen Auswirkungen für das Unternehmen und Ansatzpunkte zur Behandlung der ökologisch verpflichteten Unternehmensführung dargestellt. Abschließend ist zu klären, was Ökologieverpflichtung der Unternehmensführung bedeutet. Dabei wird die häufig zu findende Verwendung von „ökologieorientierter Unternehmensführung“ vermieden, denn diese vermittelt einen falschen Eindruck vom Zweck des Wirtschaftens. Statt dessen wird der Begriff „ökologisch verpflichtete Unternehmensführung“" verwendet, in dem auch die ethische Dimension dessen mitschwingt, was zeitgemäßem Management heute auferlegt ist. ${ }^{1}$

\subsection{Die globale ökologische Krise und der gesellschaftliche Wertewandel}

Die Erschöpfung oder Übernutzung vieler natürlicher Ressourcen und die Belastung durch die Freisetzung schwer abbaubarer Schadstoffe durch den Menschen haben die tolerierbaren Grenzen, d.h. die Regenerierungsfunktion der natürlichen Umwelt, bereits längst überschritten. ${ }^{2}$ Dies stellt eine ernst zunehmende Bedrohung für die Menschheit dar, die ein tiefgreifendes Umdenken und Umsteuern unserer Kultur und Wirtschaftsweise notwendig macht. ${ }^{3}$

Die globalen Umweltprobleme werden damit häufig als die „ökologische Krise“ bezeichnet. ${ }^{4}$ Berichte wie „Die Grenzen des Wachstums“ des Club of Rome, das Wachstumsmodell der UNO oder „Global 2000“ haben das Bewußtsein der Öffentlichkeit geschärft und die zunehmende Bedeutung der ökologischen Problematik für die Gesellschaft unterstrichen.

Als der Club of Rome 1972 seinen Bericht über die „Grenzen des Wachstums“ veröffentlichte, führte dies zu einer ersten breiten internationalen Diskussion über das Phänomen einer ökologischen Krise. Sie hat darauf hingewiesen, daß die Ressourcen für eine weitere wirtschaftliche Expansion begrenzt sind. Mit diesem Bericht wurde der Gedanke eines unbegrenzten Wachstums und Fortschritts in Frage gestellt und die Frage nach dem Überleben der Menschheit ernsthaft aufgeworfen. ${ }^{5}$

\footnotetext{
${ }^{1}$ Ferner wird auch auf den Begriff „Umweltmanagement“ verzichtet, denn nicht die Umwelt, sondern das Unternehmen gilt es zu managen. Vgl. Schanz, G. (1999), Vorwort.

${ }^{2}$ Vgl. Meadows, D. et al. (1992), S. 9ff.

${ }^{3}$ Vgl. Weizsäcker, E. v. (1990), S. 7.

${ }^{4}$ Hierbei kann die Entwicklung zu einer zunehmenden Gefährdung der ökologischen Umwelt, die für die globale ökologische Krise verantwortlich gemacht werden soll, im allgemeinen auf drei Ursachenkategorien zurückgeführt werden: auf die entwicklungsbedingten, die sozio-ökonomischen und die wirtschaftssystembezogenen Ursachen. Vgl. hierzu ausführlich Wicke, L. (1991), S. 27ff.

${ }^{5}$ In einem am Massachusetts Institute of Technologie (MIT) angefertigten und 1972 veröffentlichten Bericht an den Club of Rome über die „Grenzen des Wachstums (Bericht zur Lage der Menschheit)“ wurden fünf weltweite, sich
} 
Insbesondere war die 1992 in Rio durchgeführte UN-Konferenz für Umwelt und Entwicklung sowohl in der Unternehmenspolitik als auch in der Wissenschaft Anstoß dafür, die Globalität und Internationalität der ökologischen Krise anzuerkennen und daraus theoretische wie praktische Schlußfolgerungen zu ziehen. Sie bestanden u.a. in der Bildung eines „World Business Council for Sustainable Development“ (WBCSD). ${ }^{6}$ Dieser Unternehmerrat veröffentlichte im Vorfeld der UN-Konferenz einen Bericht, in dem es u.a. heißt: „Durch die Kooperation im Kontext einer nachhaltigen Entwicklung erhält die Unternehmensverantwortung neue zeitliche und räumliche Dimensionen. Die Unternehmen müssen die Auswirkungen ihrer Tätigkeit auf künftige Generationen und auf Menschen in anderen Teilen der Welt in Betracht ziehen.“7

\begin{tabular}{|l|l|l|l|}
\hline Naturzerstörung & $\begin{array}{l}\text { Gesundheitliche } \\
\text { Belastungen }\end{array}$ & Katastrophen & $\begin{array}{l}\text { Langfristige Destabilisierung } \\
\text { der Lebensgrundlagen }\end{array}$ \\
\hline Reduzierung & $\begin{array}{l}\text { Immissions- } \\
\text { belastungen }\end{array}$ & $\begin{array}{l}\text { Technische } \\
\text { Katastrophen }\end{array}$ & $\begin{array}{l}\text { Verbrauch von } \\
\text { Ressourcen }\end{array}$ \\
\hline Reduzierung & Folgewirkungen & Menschlich & Zunahme der \\
naturbelas sener & der medialen & induzierte & Bevölkerung \\
Flächen & Belastungen & Naturkatastrophen & \\
\hline Zerstörung der & Belastung der & Sozial-ökologische & Abnahme der potentiellen \\
Umweltmedien & Nahrungsmittel & Kriegskatastrophen & Nahrungsmittelproduktion \\
\hline
\end{tabular}

Abb.2.1: Die ökologische Krise als Konglomerat der Wahrnehmung von Einzelphänomenen (Quelle: Hallay, H. (1996), S. 99)

gegenseitig beeinflussende Entwicklungstrends untersucht: die beschleunigte Industrialisierung, die weltweite Unterernährung, das rapide Bevölkerungswachstum, die Ausbeutung der Rohstoffreserven, die Zerstörung des Lebensraumes. Daraus wurden zentrale Aussagen und Ergebnisse herausgearbeitet: unter der Voraussetzung, daß sich diese Größen so weiterentwickeln wie seit dem Jahr 1900, treibt durch eine beschleunigte Zivilisationsdynamik, die ihren Ausdruck in Bevölkerungsexplosion, zunehmender Umweltzerstörung und Ressourcenerschöpfung findet, das planetarische System Erde einem zivilisatorischen und ökologischen Kollaps entgegen. Die Ursachen: Einzelne Größen sind durch ,positive Regelkreise“ miteinander verbunden, schaukeln sich gegenseitig auf, bewirken exponentielles Wachstum, das an natürliche Grenzen stößt. Beim sog. „Standard-Computer-Durchlauf“ tendiert das Weltmodell eindeutig dazu, in der ersten Hälfte des 21. Jahrhunderts die Wachstumsgrenzen zu überschreiten und dann zusammenzubrechen. Eine Schlüsselrolle spielen dabei die begrenzten Rohstoffvorräte. Die durch das industrielle Wachstum gespeiste Rohstoffnachfrage führt zu steigenden Preisen und schließlich zur Erschöpfung der Lagerstätten. Der Spielraum für weiteres Wirtschaftswachstum wird dadurch immer enger. Vgl. Meadows, D. et al. (1972), insb. S. $165 f f$.

${ }^{6}$ Der WBCSD ist ein Zusammenschluß von 120 internationalen Firmen, die sich in ihrem Handeln von den Prinzipien des ökonomischen Wachstums und der nachhaltigen Entwicklung leiten lassen. Die Mitglieder stammen aus 33 Ländern und aus über 20 größeren Industriezweigen. Der WBCSD nutzt ein aktives globales Netz aus neun nationalen und regionalen Business Councils und aus vier Partnerorganisationen. Der WBCSD befürwortet nachhaltige Entwicklung und unterstützt eine enge Zusammenarbeit von Wirtschaft, Staat und anderen Organisationen. Er tritt für hohe Standards beim Öko-Management ein. Schließlich engagiert sich der WBCSD auch bei einer Reihe von Feldversuchen in Entwicklungs- und Schwellenländern. Vgl. Fussler, C. (1999), S. VI.

${ }^{7}$ Schmidheiny, S. (1992); S. 129. 
Die heutige Diskussion der „ökologischen Krise“ kann als das Konglomerat der Wahrnehmung und Beschreibung unterschiedlichster Einzelphänomene dargestellt werden (vgl. Abb. 2.1). Die ökologische Krise ist damit unter zwei Gesichtswinkeln zu betrachten:

- $\quad$ Als Krise der Umwelt und

- Als gesellschaftliche Krise.

Die drohende Gefahr durch die Erwärmung des Weltklimas, Ozonloch und die gesamte terrestrische Öko-, Atmo-, Hydro- und Litosphäre, insbesondere aber die Biosphäre in ihnen, zeigen sich zunehmend im Stand der weltweiten Krise oder des Verfalls.

Es ist unumstritten, daß viele ökologische Probleme im Grunde globalen Charakter haben. Die wechselseitige Abhängigkeit der Nationen ist typisch für das gegenwärtige Zeitalter. Umweltprobleme und Wirkungsformen betrieblicher Handlungen haben sich im Lauf der Zeit geändert. Früher lokal oder regional beschränkte Umweltprobleme wurden zu großräumigen, z.T. globalen Problemen. Blieben vor- und frühindustrielle Schäden zumeist auf die Umgebung einer Fabrik oder einer Stadt beschränkt, so haben wir es heute mit flächendeckenden Umweltschäden zu tun oder mit global wirkenden Schädigungen. ${ }^{8}$ Zur Verdeutlichung dieser Problematik insbesondere in bezug auf die Globalität ökologischer Probleme sollen folgende Beispiele dienen, die natürlich von ihrer Auswahl her die Zusammenhänge nur annähernd widerspiegeln können: ${ }^{9}$

Das Klima: Die langsam aber stetig zunehmende Konzentration an $\mathrm{CO}_{2}$ in der Atmosphäre, die vor allem auf die Verbrennung fossiler Energien zurückzuführen ist, wird als Einflußfaktor allmählicher großräumiger Erwärmung, verbunden mit globalen klimatischen Veränderungen, diskutiert. Globale Auswirkungen auf den möglichen Nahrungsmittelanbau aufgrund steigender Temperaturen, geringerer Niederschläge und abnehmender Bodenfeuchtigkeit stellen sich dabei als besonders gravierende Folgen des komplexen Wirkungsnetzes dar. ${ }^{10}$

\footnotetext{
${ }^{8}$ In letzter Zeit haben sich die Ebenen des umweltpolitischen Handelns deutlich verändert. Umweltprobleme haben dabei lokale, regionale und globale Dimension. Betrachtet man diese Situation, so lassen sich die folgende Perioden und Merkmale beschreiben: (vgl. Schahausen, F. J. (1997), S. 275)

- Ende der 60er Jahre bis zum Beginn der 80er Jahre: Konzentration auf lokale, allenfalls regionale Umweltprobleme wie z.B. Gewässerverschmutzung, lokale Immissionsschäden, Waldschäden und Abfallproblem usw.

- Beginn der 80er Jahre bis zum Ende der 80er Jahre: Erkennen des grenzüberschreitenden Handlungsbedarfs (mu 1tinationale Umweltkonferenz 1984 in München/ECE-Abkommen über $\mathrm{SO}_{2}$-Minderung, Abfalltourismus usw.).

- Ende der 80er Jahre: Globale Umweltprobleme wie z.B. Abbau der Ozonschicht, Treibhauseffekt, Wälder und Artenvielfalt, Boden und Wasser, Wüstenproblematik und Verknüpfung der Umweltfragen mit Fragen der regionalen Entwicklung (Nord-Süd/Ost-West-Auseinandersetzung/Thema: Armut und Umwelt ).

${ }^{9}$ Vgl. Bick, H. /Hansmeyer, K. H./Olschowy, G./Schmoock, P. (1984, Bd. II), S. $410 \mathrm{ff}$.
} 
Bevölkerungs- und Ernährungsentwicklung: Die Wachstumsrate der Weltbevölkerung ging Anfang der 80er Jahre zurück. Weiterhin nahm aber die Gesamtbevölkerung zu, insbesondere in den Entwicklungsländern. Deren Anteil beträgt nahezu 75\% der Gesamtbevölkerung. Auch das globale Wachstum der Stadtbevölkerung liegt erheblich über der durchschnittlichen Wachstumsrate. Obwohl die Lebensmittelproduktion insgesamt in den Entwicklungsländern überdurchschnittlich anwuchs, stieg wegen des Bevölkerungswachstums die Pro-Kopf-Lebensmittelproduktion weit weniger. Der Gesamtbedarf liegt über der Produktivität, die die regionalen Ökosysteme erbringen können. Soweit tierische Erzeugnisse wesentlicher Bestandteil der Ernährung sind, ist die Anzahl der ernährbaren Menschen im Verhältnis geringer als bei einer pflanzlichen Ernährung (Prinzip der Energiekaskaden oder tropischen Ebenen). Sowohl die zunehmende Bevölkerungsdichte als auch die Verbesserung der Deckung des Nahrungsmittelbedarfs in diesen Regionen führen zu erheblichen Einwirkungen auf die betroffenen Ökosysteme. ${ }^{11}$

Genetischer Pool: Unter dem genetischen Pool versteht man den gesamten Genbestand einer Population. Seine Vielfalt ist ein wesentlicher Einflußfaktor für die Anpassungsfähigkeit einer Population an sich verändernde Umweltsituationen. Im Rahmen der Züchtung von Nutzpflanzen und -tieren versucht man durch gezielte Selektion von Pflanzen- und Tiergenen bestimmte Anpassungsmerkmale $\mathrm{zu}$ selektieren und $\mathrm{zu}$ manipulieren. Einerseits kann dadurch die Produktivität dieser Züchtungen unter optimalen Bedingungen wesentlich erhöht werden. Andererseits führt aber auch die bewußte Auslese nicht gewünschter genetischer Anlagen zu einer Abnahme des genetischen Pools. Die Wahrscheinlichkeit zunehmender Empfindlichkeit z.B. gegenüber Krankheitserregern oder klimatischen Veränderungen wächst. ${ }^{12}$

Aus der ökologischen Wissenschaft wächst die Erkenntnis, daß System und Umwelt eine Überlebenseinheit bilden: „Wir lernen durch bittere Erfahrungen, daß der Organismus, der seine Umwelt zerstört, sich selbst zerstört. “' ${ }^{\text {(13 }}$ Der Mensch zerstört, wenn er die Natur zerstört, seine eigene Existenzgrundlage. ${ }^{14}$ Hier herrscht allerdings weiterhin Skepsis vor. Den etablierten Mechanismen der sozialen und politischen Regulierung wird ihre Eignung zur Bewältigung der ökologischen Herausforderung abgesprochen. Statt dessen wird für die Zukunft gefordert, in einem kreativen und konstruktiven Dialog nach Wegen zur Bewältigung der Umweltkrise zu suchen und sich gemeinsam dieser Herausforderung zu stellen.

\footnotetext{
${ }^{10}$ Vgl. OECD (1983), S. 19.

11 Vgl. Global 2000 (1981), S. 145ff.; Bick, H./Hansmeyer, K. H./Olschowy, G./Schmoock, P. (1984, Bd. II), S. 428ff.; Meadows, D. et al. (1992), S. 72ff.

${ }^{12}$ Vgl. Fellenberg, G. (1985), S. 7f.

${ }^{13}$ Bateson, G. (1985), S. 620.

${ }^{14}$ Vgl. Spamann, R. (1986), S. 197f.
} 
Andererseits ist die ökologische Krise eine gesellschaftliche Krise in dem Sinne, daß die gesellschaftlichen Verhaltensmuster nicht adäquat erscheinen, um die gesellschaftlich wahrgenommene Bedrohung zu beseitigen. ${ }^{15}$ Denn die Gesellschaft ist nicht in der Lage, angemessen auf die wahrgenommenen Krisenphänomene $\mathrm{zu}$ reagieren, indem sie die Wirtschaftssubjekte dazu bringt, die ökologische Herausforderung so zu integrieren, daß eine sinnvolle Handhabung dieser Phänomene möglich erscheint. ${ }^{16}$ Die „ökologische Krise“ kann also als eine Krise des sozialen und ökonomischen Systems der Gesellschaft bezeichnet werden.

Luhmann weist in diesem Zusammenhang auf die gesellschaftliche Dimension des ökologischen Krisenbegriffs hin. Er benutzt hierfür den Begriff der Wahrnehmung einer „ökologischen Gefährdung“. ${ }^{17}$ Zur Identifizierung von Problemen ist deren Wahrnehmung, die durch die direkt Betroffenen oder durch Dritte erfolgt, die logische Voraussetzung. Für Luhmann umfaßt der Begriff der Wahrnehmung zunächst jede Kommunikation über Umwelt, die das Ziel hat, eine Änderung von Strukturen des Kommunikationssystems Gesellschaft zu veranlassen. ${ }^{18}$ Hierbei handelt es sich für Luhmann ausschließlich um ein gesellschaftsinternes Phänomen. Die scheinbar objektiv wahrnehmbaren Tatsachen der Veränderung der Welt spielen dabei nur dann eine Rolle, wenn sie sich in einem gesellschaftlichen Wahrnehmungsprozeß widerspiegeln. Ebenso ist die Krisenwahrnehmung ursächlich mit den Erklärungsmodellen verknüpft. ${ }^{19}$

Für die Frage nach den Ansprüchen, die an eine ökologisch verpflichtete Unternehmenspolitik gestellt werden, ist zunächst darzulegen, welche Phänomene in der Wahrnehmung der gesellschaftlichen Akteure die Grundlage der „ökologischen Krise“ bilden. Denn die Wahrnehmung einzelner Krisenphänomene reicht nicht, um die gesellschaftliche Wahrnehmung einer ökologischen Krise zu konstatieren. Einzelne der hier dargestellten Krisenaspekte sind durchaus nicht neu, d.h. die Wahrnehmung dieser Einzelaspekte ist zum Teil schon Jahrhunderte alt. Trotzdem kann bezüglich vorheriger Epochen nur bedingt von der gesellschaftlichen Wahrnehmung einer

\footnotetext{
${ }^{15}$ Damit kann erst dann von einer Krise gesprochen werden, wenn scheinbar aus der Sicht der Gesellschaftsmitglieder das Potential zur Reduktion der Krisenphänomen in der herrschenden Gesellschaftsordnung nicht vorhanden ist. Vgl. hierzu Hallay, H.(1996), S. 101.

${ }^{16}$ Vgl. Hallay, H. (1996), S. 98 ff. In diesem Sinne sieht Beck vor allem durch die Globalisierung der Umweltris iken die Gesellschaft auf dem Wege der Industriegesellschaft herkömmlicher Art (Schichtengesellschaft) zur „Ris ikogesellschaft“ (Gefahrengemeinschaft): Die Industriegesellschaft sei zur Risikogesellschaft mutiert, in der „organisierte Unverantwortlichkeit ... Alltäterschaft in Freispruch verwandelt ... und in der es der sozialen Struktur nach ... keine Entscheidung, keinen Entscheider, keinen Ort und keine Hindernis gibt, das Ab- und Zustimmung erlaubt. Nur extreme und extrem einseitige Beweislasten, die denjenigen aufgehalst werden, die Bedenken geltend machen." Im Zusammenhang damit wird es zu einer zunehmenden gesellschaftlich-politischen Einwirkung auf die Unternehmen und damit zu einer Politisierung der Wirtschaft kommen. Vgl. Beck, U. (1988), S. 11f.

${ }^{17}$ Vgl. Luhmann, N. (1986), S. 60ff.

${ }^{18}$ Vgl. Luhmann, N. (1986), S. 63.

${ }^{19}$ Vgl. Luhmann, N. (1986), S. 63.
} 
ökologischen Krise gesprochen werden. ${ }^{20}$ Eine gesellschaftliche Krisenwahrnehmung entsteht erst dann, wenn im Rahmen des gesellschaftlichen Wahrnehmungsprozesses verschiedene Aspekte zusammentreffen: Ökologische Schäden haben gewiß ihre eigene Realität. Aber erst durch den Rückbezug auf das Gesellschaftliche werden sie zu ökologischen Problemen und damit handlungsrelevant für den Menschen.

Die Grundlage der plötzlichen Wahrnehmung eines Bedrohungspotentials als Krise kann zum einen eine Veränderung der gesellschaftlichen Wert- und Normenvorstellungen in der Weise sein, daß den von diesen Phänomenen betroffenen Wertvorstellungen in der Gesellschaft eine zunehmende Bedeutung eingeräumt wird. Nur wenn man z.B. den von der Ausrottung bedrohten Tieren einen wie auch immer gearteten positiven Wert $^{21}$ beimißt, kann das Verschwinden einer Art als Problem angesehen werden. Gleiches gilt für den Gesundheitsschutz und die Katastrophenvorsorge. Nur wenn der langfristige Gesundheitsschutz gesellschaftliche Priorität hat, werden Phänomene, die eine langfristige Gesundheitsgefährdung mit sich bringen, als Bedrohung empfunden.

Wenn man also von der Wahrnehmung einer umfassenden ökologischen Krise reden will, ist deshalb außer der Wahrnehmung einzelner Kriseneffekte auch eine Wahrnehmung der ursächlichen Verknüpfungen dieser Aspekte notwendig. Basis für diese Verknüpfung ist sowohl die Wahrnehmung der Häufung und der Ausdehnung einzelner Krisenphänomene als auch die räumliche und/oder zeitliche Anhäufung unterschiedlicher Krisenphänomene.

Ein weiteres Phänomen ist die Häufung in der Wahrnehmung von Bedrohungspotentialen. Erst wenn regional oder global eine große Zahl von Tieren und Pflanzen vom Aussterben bedroht ist, erst wenn großflächig eine gesundheitsbedrohliche Luftverschmutzung wahrgenommen wird, kann von einer gesellschaftlich antizipierten Krise gesprochen werden.

Die ökologische Krise muß nicht nur als eine Krise der Umwelt verstanden werden, vielmehr ist sie eine gesellschaftliche Krise in dem Sinne, daß die gesellschaftlichen Verhaltensmuster nicht adäquat erscheinen, um die wahrgenommenen Bedrohungen zu beseitigen. Die ökologische Krise ist somit vor allem eine Krise der Lebensweise in einer Gesellschaft.

\footnotetext{
${ }^{20}$ Vgl. Trepl, L. (1987).

${ }^{21}$ Vgl. zur Wertediskussion Immler (1989); Trepl, L. (1988).
} 
Trotz weiterer kritischer globaler Studien, ${ }^{22}$ Maßnahmen, Gesetze und Initiativen hat sich die Umweltsituation weiter rapid verschlechtert. Fast täglich wird in den Medien über Umweltkatastrophen, über den aktuellen Stand der Schadstoffbelastung von Luft, Boden und Wasser, über Treibhauseffekt und Ozonlöcher berichtet. Inzwischen ist das, was im politischen und akademischen Raum als ökologische Krise identifiziert wird, offenkundig wesentlich komplexer geworden. Zudem muß noch berücksichtigt werden, daß die natürliche Umwelt infolge kombinierter und synergetischer Effekte bei Schadstoffeinträgen stärker in Anspruch genommen wird, als bislang angenommen wurde. Die Berichte bestimmen die heutige Lage der Menschheit als eine ökologische Krise, eine Krise des ganzen Lebenssystems, die in einer weltweiten Katastrophe endet, wenn nicht eine radikale und sofortige Umkehr im Denken und Handeln der Menschen gschieht. In diesem Zusammenhang unter Berücksichtigung der weiterhin extensiven Nutzung von nichtregenerierbaren Rohstoffen kann auf der Erde so schnell wohl keine Entwarnung gegeben werden. Es macht daher durchaus Sinn, von einer Umweltkrise zu sprechen.

Im folgenden soll nun geklärt werden, welche Reaktionen der Gesellschaft auf die immer schlechter werdende Umweltsituation zeigt. Die aktuell herrschenden Probleme und dadurch ausgelösten Phänomene unserer Gesellschaft lassen sich mit folgenden Stichworten skizzieren: fortschreitende Zerstörung der natürlichen Lebens- und Wirtschaftsgrundlagen, wirtschaftliche Stagnations- und Krisenerscheinungen, zunehmende Ökonomisierung aller Gesellschaftsbereiche, Konzentrationserscheinungen in der Wirtschaft und damit verbundene Einschränkungen des Wettbewerbs durch Machtmißbrauch, rasanter technischer Fortschritt und damit verbundene Nichtabsehbarkeit technologischer Nebenfolgen, Manipulation der Verbraucher, Mißbrauch von politischer Macht, Mißachtung der Grundrechte, Expertenabhängigkeit, Bildungs- und Traditionsverlust, neue Werthaltungen im sozialen Umfeld, bedeutende demographische Veränderungen, neue Informations- und Kommunikationssysteme etc.

Dies alles sind Faktoren, die sich in einem wachsenden Vertrauensverlust in Staat, Wirtschaft und ihre Institutionen, sowie in Zukunftspessimismus und einer Sinn- und Orientierungskrise niederschlagen und gesellschaftlichen Wertewandel auslösen können. Die Umweltkrise mit ihren einzelnen Symptomen stellt dabei einen wesentlichen Faktor für den gesellschaftlichen Wertewandel dar. Ökologische Auswirkungen wie befürchtete oder bereits eingetretene Gesundheitsschäden, das Aussterben von Tieren und Pflanzen, verschmutzte Gewässer und sichtbar werdendes Waldsterben haben in der Gesellschaft ein starkes Bewußtsein für Umweltgefahren geschaffen.

${ }^{22}$ Vgl. z.B. Global 2000 (1980); Meadows, D. et al. (1992). 
Das Interesse an einer intakten, sauberen Umwelt, an einem bedachteren Umgang mit ökologisch knappen Ressourcen sowie dem Erhalt der natürlichen Lebensgrundlagen und - daraus abgeleitet - die Herausbildung eines ausgeprägten Umweltbewußtseins i.S. eines sehr stabilen Wertekomplexes kann in Südkorea nachgewiesen werden. Nach einer repräsentativen Umfrage, die die Einstellungen der koreanischen Bevölkerung und Unternehmen in Bezug auf Umweltschutz untersuchen soll, haben 94,2 \% der Befragten die Umweltprobleme als mehr als besorgniserregend bezeichnet. Dies zeigt, daß im Jahr 1997 gegenüber Anfang der 80er bzw. der 90er Jahre die Situation der Umwelt deutlich schlechter eingeschätzt wird und die persönliche Betroffenheit durch Umweltverschmutzung zugenommen hat. Während das Umweltthema im Jahre 1982 eine untergeordnete Rolle spielte (mit 5,7\% an letzter Stelle), rückte es im Jahre 1997 mit 27,7\% an die 1. Stelle. ${ }^{23}$ Ein Ergebnis dieser Untersuchungen ist die Erkenntnis, daß die Bevölkerung für die Umweltproblematik in hohem Maße sensibilisiert ist. Wie groß dabei die persönliche Betroffenheit und Angst von Umweltverschmutzung aber auch wie tief die Unzufriedenheit der Bevölkerung mit dem Verhalten der Institutionen von Staat und Wirtschaft (Unternehmen) sind, offenbaren nicht nur diese Befragungen zum Umweltbewußtsein, sondern auch das Phänomen der Bürgerinitiativen.

Im Zuge dieser gesellschaftlichen Strömungen gelangen neben den sozialen und ökonomischen Wachstumsgrenzen vor allem ökologische Grenzen einer Wirtschaft in das Bewußtsein, die die natürliche Umwelt zerstört und die Reproduktionsgrundlagen gefährdet. Im Zentrum dieser Kritik stehen dabei die Unternehmen und die Industrie, die eine Schlüsselrolle im fortschreitenden Prozeß der ökologischen Zerstörung einnehmen.

Die Antwort auf die Frage, was dieser gesellschaftliche Wertewandel für die Unternehmensführung bedeutet, ist darin $\mathrm{zu}$ sehen, daß veränderte Konsumeinstellungen und ein erhöhter ökologischer Wissensstand auf der Verbraucherseite zu einem differenzierteren und durchaus kritischeren Verbraucherverhalten führen. ${ }^{24}$ Auch von der Mitarbeiterseite her werden in verstärktem Maße ökologische Erwartungen an das Unternehmen gerichtet. Die somit umrissenen ökologiebezogenen Push-Faktoren (z.B. Mitarbeiter, Konkurrenten) sowie die ökologiebezogenen PullFaktoren (z.B. Verbraucher, Handel) ${ }^{25}$ wirken damit in hohem Maße erfolgs-, überlebens- und entwicklungskritisch auf das Unternehmen ein. Als grundlegendes Werteziel ökologieorientierter Unternehmensführung resultiert hieraus die Forderung: Das Unternehmen soll einen Beitrag zum Erhalt und der Förderung einer intakten Umwelt leisten.

\footnotetext{
${ }^{23}$ Der gesellschaftliche Wertewandel in Bezug auf die Umweltfrage in Südkorea wird in Kap. 5.3 behandelt.

${ }^{24}$ Vgl. Meffert, H./Bruhn, M./Schubert, F./Walther, T. (1986), S. 141; Steger, U. (1990), S. 50.
} 
Vor dem Hintergrund des hohen Umweltbewußtseins ist auch das Phänomen der öffentlichen Exponiertheit von Unternehmen zu sehen, das im Hinblick auf ein ökologisch verpflichtetes Unternehmensverhalten relevant ist. Unter dem Begriff „öffentliche Exponiertheit“ eines Unternehmens ist die Tatsache $\mathrm{zu}$ verstehen, daß ,... Unternehmungen durch ihre Tätigkeit öffentliche Interessen berühren, aber auch umgekehrt durch Handlungen, die im Namen öffentlicher Interessen ausgeübt werden, selber betroffen werden“. ${ }^{26}$ Dies bedeutet, daß die Unternehmen in ihrem Handeln unter bestimmten Bedingungen Beeinflussungen und Beurteilungskriterien unterworfen werden, denen sonst nur öffentliche Organisationen ausgesetzt sind. Dies führt dazu, daß sich die Unternehmen einem wachsenden Druck der Öffentlichkeit ausgesetzt sehen, nicht nur ihre Tätigkeit und deren Resultate $\mathrm{zu}$ legitimieren, sondern diese entsprechend den gesellschaftlichen Anforderungen auch $\mathrm{zu}$ verändern und umfassend darüber Rechenschaft abzulegen. Insofern kann je nach der Stärke der öffentlichen Exponiertheit die privatautonome Entscheidungs- und Gestaltungsfreiheit der Unternehmen eingeschränkt werden. ${ }^{27}$

Die Stärke der öffentlichen Exponiertheit eines Unternehmens hängt von unterschiedlichen Faktoren $a b .^{28}$ Aber für die Wirkung dieser Faktoren ist das Vorhandensein einer „öffentlichen Sensibilität“ in der Bevölkerung notwendig. Diese öffentliche Sensibilität kommt in dem hohen Umweltbewußtsein zum Ausdruck, das auch in Südkorea mit der Zeit stark gewachsen ist. Aufgrund dieses hohen Umweltbewußtseins kann die Aufmerksamkeit der Gesellschaft auf bestimmte Wirtschaftsbereiche, Unternehmen, Produkte oder Produktionsverfahren gelenkt werden.

${ }^{25}$ Vgl. Meffert, H./Kirchgeorg, M. (1998), S. 262ff.

${ }^{26}$ Dyllick, T, (1992), S. 209.

${ }^{27}$ Vgl. Dyllick, T. (1992), S. 209ff.

${ }^{28}$ Diese Faktoren sind z.B. die industriespezifischen, die unternehmenspezifischen und die produktspezifischen Faktoren: (vgl. Kirchgeorg, M. (1992), S 93ff.)

- Industriespezifische Faktoren: Während die Absatzaktivitäten in der Konsumgüterindustrie auf die breite Öffentlichkeit ausgerichtet sind, konzentrieren sich die Marketingaktivitäten in der Investitionsgüterindustrie oft auf eine überschaubare Anzahl von Kunden. Daher ist die Konsumgüterindustrie i.d.R. einer stärkeren öffentlichen Exp oniertheit ausgesetzt als die Investitionsgüterindustrie, die lediglich bei Großprojekten (z.B. dem Bau eines Kernkraftwerkes) sehr stark exponiert ist.

- Unternehmensspezifische Faktoren: Hierbei spielt vor allem die Größe des Unternehmens eine Rolle. Große Unternehmen sind i.d.R. wesentlich stärker exponiert als kleine Betriebe, da sie aufgrund ihres Produktionsumfangs weitreichende Probleme verursachen können. Diese Probleme ziehen die öffentliche Aufmerksamkeit auf sich und begründen somit das hohe Exponierungspotential der großen Unternehmen.

- Produktspezifische Faktoren: Hierbei sind zwei Dimensionen zu unterscheiden. Zum einen kommt es darauf an, inwiefern die Produkte oder Dienstleistungen als Notwendigkeit (z.B. Nahrungsmittel) oder als Luxusgut (z.B. Parfüm) angesehen werden. Während bei lebensnotwendigen Gütern die Öffentlichkeit versuchen wird, Entscheidungen über Verfügbarkeit, Erschwinglichkeit und Sicherheit des Produktes zu beeinflussen, ist die Einflußnahme bei Luxusgütern eher gering, da die Kaufentscheidung dem Individuum selbst überlassen bleibt. Zum anderen spielen die negativen Auswirkungen der Produkte und/oder Produktionsprozesse auf die natüliche Umwelt eine große Rolle. Je größer diese negativen Effekte sind, desto höher ist der Grad der öffentlichen Exponiertheit der jeweiligen Unternehmen. 
Die öffentliche Exponiertheit von Unternehmen führt dazu, daß an die Unternehmen Anforderungen im Namen übergeordneter Interessen der Gesellschaft gestellt werden. Zu diesen Forderungen gehören aufgrund der großen Aktualität der Umweltprobleme und des hohen Umweltbewußtseins in der Bevölkerung der Schutz der natürlichen Umwelt. Auf diese umweltschutzorientierten Anforderungen und die daraus folgenden Auswirkungen auf die Unternehmen wird im folgenden eingegangen.

\subsection{Anforderungen und Auswirkungen auf die Unternehmen}

Die Umweltkrise und der mit ihr verbundene gesellschaftliche Wertewandel hat zwangsläufig tiefgreifende Konsequenzen für die gesamte Wirtschaft und die einzelnen Unternehmen. Insbesondere Industriebetriebe, die produktions- und produktbedingt zu den größten Schädigern des Ökosystems, d.h. als Hauptverursacher von Umweltschäden gezählt werden, sind gezwungen, die ökologische Herausforderung ihrer Zeit anzunehmen.

\begin{tabular}{|l|l|}
\hline Stofflich-energetische Ebene & Soziö̈konomische Ebene \\
\hline Abfallaufkommen & Gesellschaftliche Erwartungen \\
Bodenbelastungen & Werthaltungen \\
Wasserbelastungen & Politische Prioritäten \\
Lärmbelastungen & Rechtliche Auflagen \\
Energieverbrauch & Behördliche Vorschriften \\
Ressourcenverbrauch & Nachfrageverhalten \\
Auswirkungen auf Ökosysteme & Attraktivität als Arbeitgeber \\
$\ldots$ & $\ldots$ \\
$\Rightarrow$ Naturwissenschaftliche & $\Rightarrow$ Sozialwissenschaftliche \\
Zusammenhänge & Zusammenhänge \\
$\Rightarrow$, Sekundäre Umwelt“ & $\Rightarrow$,Primäre Umwelt“ \\
indirekte, vermittelte Wirkung & direkte, unvermittelte Wirkung \\
Ökologische Umwelt (i.e.S.) & Gesellschaft, Politik und Markt \\
& (Ökologische Umwelt i.w.S.) \\
\hline
\end{tabular}

Abb. 2.2: Betrachtungsebenen ökologischer Einflüsse auf das Unternehmen

(Quelle: Dyllick, T./Hummel, J. (1996), S. 6)

Betrachtet man zunächst die Herausforderungen, die durch den direkten Einfluß der ökologischen Probleme an die Unternehmensführung herangetragen werden können, so führt mittel- und langfristig die Verknappung von natürlichen Ressourcen $\mathrm{zu}$ einer notwendigen Neuorientierung 
ganzer Branchen oder sogar $\mathrm{zu}$ einer existenziellen Bedrohung der rohstofferzeugenden und verarbeitenden Industrie. Selbst bei ausreichender Verfügbarkeit von regenerierbaren Ressourcen erfordern bereits heute Qualitätsminderungen, wie z.B. die zunehmende Belastung von Nahrungsmitteln durch Schadstoffe (Blei, Cadmium, Nitrat u.a.m.), immer aufwendigere Methoden der Nahrungsmittelgewinnung und -kontrolle. Schneller als erwartet vollzieht sich der „Treibhauseffekt" durch den Anstieg der $\mathrm{CO}_{2}$-Konzentration in der Atmosphäre. Durch die Freisetzung von Chlorverbindungen wie Fluorchlorkohlenwasserstoff (FCKW) ist in den letzten 10 Jahren das „Ozonloch“ um ein Vielfaches gewachsen, mit noch nicht absehbaren Folgen auf das ökologische Gleichgewicht und das globale Klimasystem. Angesicht dieser Situation wird in Zukunft die Unternehmensführung ein existenzielles Interesse daran haben müssen, die Unternehmensaktivitäten auch unter dem Ziel einer ökologischen Effizienz zu gestalten. ${ }^{29}$

Die ökologisch relevanten Einflüsse auf die Unternehmen kommen aus unterschiedlichen Bereichen. Dabei werden Unternehmen nicht mit den eigentlichen ökologischen Problemen in verschiedenen Formen wie z.B. Luftverschmutzungen oder Bodenbelastungen konfrontiert, sondern sie werden vielmehr für diese eigentlich erst dann und nur in dem Masse relevant, wie sie durch gesellschaftliche Ansprüche, politische Regulierungen oder marktliche Veränderungen zu verhaltensrelevanten Ansprüchen transformiert worden sind. ${ }^{30}$

Eine wichtige Voraussetzung für die Identifizierung konkreter umweltschutzbezogener Anforderungen bildet die Kenntnis der jeweiligen Bezugsgruppen, von denen die Anforderungen ausgehen. Bei diesen Bezugsgruppen kann man zwischen unternehmensexternen und -internen Bezugsgruppen differenzieren. ${ }^{31}$ Zunächst sollen die umweltschutzbezogenen Anforderungen be-

\footnotetext{
${ }^{29}$ Im Gegensatz zu der ökonomis chen Perspektive, in der die ökonomische Effizienz als dominante Zielgröße im Vordergrund steht, ist es im Rahmen der ökologischen Perspektive die ökologische Effizienz. Analog zum Begriff der ökonomischen Effizienz wird hierunter eine Form der Leistungserstellung verstanden, die ihre Ziel unter Minimierung von Stoffdurchsatz und Umweltbelastung erreicht. Maßstab erfolgreichen Wirtschaftens ist hierbei nicht der möglichst effiziente Einsatz der Produktionsfaktoren Kapital und Arbeit, sondern der möglichst effiziente Einsatz der Ressourcen der Natur. Öko-Effizienz kann damit grob auf drei Arten interpretiert werden:

- Bei der ökonomischen Kosteneffizienz geht es um die kostengünstigste Erstellung einer bestimmten Leistung. Voraussetzung für eine kosteneffiziente Wirtschaftsweise ist, daß Ressourcen dort eingesetzt werden, wo sie den größten zusätzlichen Nutzen stiften (allokative Effizienz).

- Die ökologische Effizienz ist die Maßgröße für die verursachte Umweltbelastung pro erstellte Leistung.

- Die ökonomisch-ökologische Effizienz mißt die verursachte Umweltbelastung pro erwirtschaftete Geldeinheit. Umweltschutz wird nur dann langfristig erfolgreich betrieben, wenn er als ökonomisch tragbar erachtet wird. ÖkoEffizienz als Maßgröße für nachhaltiges Wirtschaften wird im Rahmen der vorliegenden Arbeit deshalb als ökonomisch-ökologische Effizienz verstanden und behandelt. Für eine detailliertere Diskussion des Konzepts der ÖkoEffizienz vgl. Schalteger, S./Sturm, A. (1994); Dyllick, T. (1992), S. $397 f$.

${ }^{30}$ Vgl. Dyllick, T. (1992), S. 402.

31 Achleitner unterscheidet je nach der Bedeutung der jeweiligen Stakeholder für die Unternehmen, die mit Hilfe der Kriterien Vertrautheits-, Abhängigkeits- und Einflußgrad beurteilt werden, zwischen „Bezugsgruppen“, „Interessengruppen“ und „Anspruchsgruppen.“ Vgl. Achleitner, P. M. (1985), S. 76f. Zur Abgrenzung dieser Gruppen und dem daraus abgeleiteten Stakeholderkonzept vgl. Kap. 3.4 dieser Arbeit und die dort angegebene Literatur.
} 
schrieben werden, die von unternehmensexternen Bezugsgruppen ausgehen können. Anschließend werden die unternehmensinternen Anforderungen dargestellt.

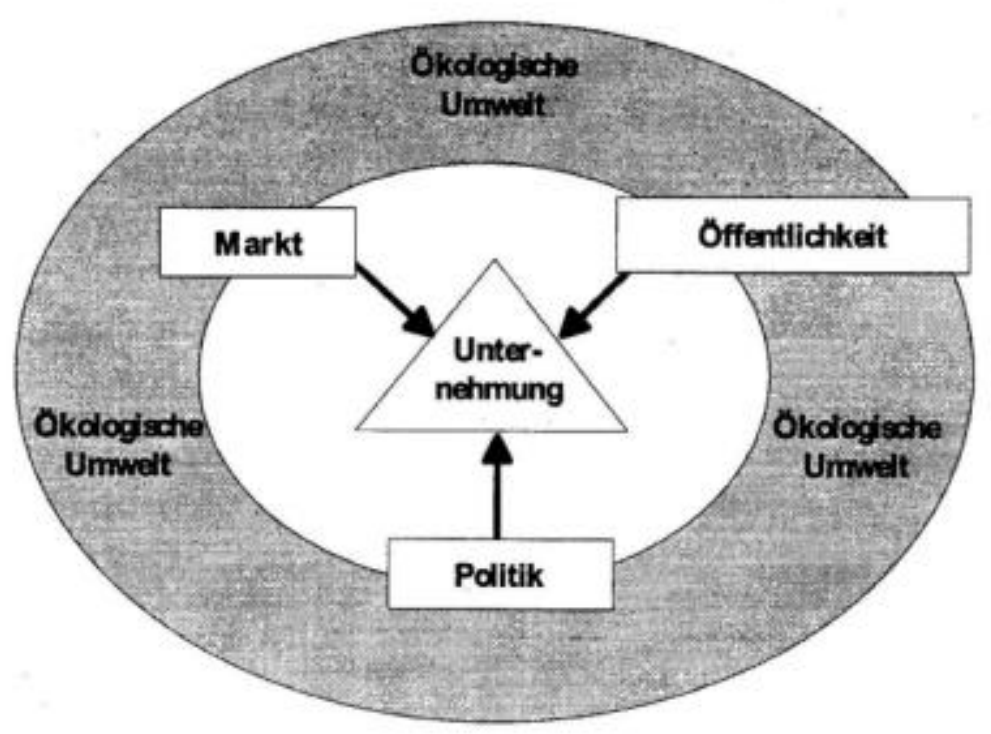

Abb. 2.3: Ökologierelevante Einflüsse auf das Unternehmen in sozioökonomischer Perspektive (Quelle: Dyllick, T./Hummel, J. (1996), S. 13)

Die unternehmensexternen umweltschutzbezogenen Anforderungen können von marktbezogenen, politischen und gesellschaftlichen Bezugsgruppen an die Unternehmen gestellt werden. Diese Klassifizierung der verschiedenen Bezugsgruppen ist auf unterschiedliche „Lenkungssysteme“ des Unternehmens zurückzuführen. ${ }^{32}$ Im einzelnen lassen sich die Lenkungssysteme „Markt“, „Politik“ und „Gesellschaft“ voneinander unterscheiden (vgl. Abb. 2.3). ${ }^{33}$ Diese drei externen Lenkungssysteme basieren auf unterschiedlichen Mechanismen, mit deren Hilfe die umweltschutzbezogenen Anforderungen an die Unternehmen herangetragen werden.

In den folgenden Ausführungen werden, ausgehend von einer Beschreibung der spezifischen Merkmale der drei Lenkungssysteme, die umweltschutzbezogenen Anforderungen abgeleitet, die von marktbezogenen, politischen und gesellschaftlichen Bezugsgruppen an die Unternehmen herangetragen werden können.

Die marktbezogenen Anforderungen werden im Rahmen des Lenkungssystems „Markt“ an das Unternehmen gestellt. Für das Unternehmen stellt der Markt ein externes Lenkungssystem dar,

\footnotetext{
${ }^{32}$ Unter einem Lenkungssystem wird ein System verstanden, das ein Unternehmen in seinem Handeln bewußt oder unbewußt in unterschiedlich starkem Maße beeinflußt. Vgl. Dyllick, T. (1992), S. 221.

${ }^{33}$ Vgl. Dyllick, T. (1990), S. 83.
} 
in dem durch die Kaufentscheidungen der Verbraucher bestimmt wird, was zu produzieren ist. Der Verbraucher ist somit als Souverän des marktwirtschaftlichen Lenkungssystems zu sehen. Das Erfolgskriterium des marktwirtschaftlichen Lenkungssystems ist die wirtschaftliche Effizienz. Wirtschaftlich effizientes Handeln bildet eine wichtige Voraussetzung für die langfristige Existenz und die erfolgreiche Behauptung der Unternehmen im Markt. Neben den Unternehmen gibt es im marktwirtschaftlichen Lenkungssystem noch eine ganze Reihe anderer Marktteilnehmer, die mit den Betrieben in Beziehung stehen. $\mathrm{Zu}$ diesen Marktteilnehmern gehören Kunden und Verbraucher, der Handel, Lieferanten, Konkurrenten, Kreditgeber und Versicherungen.

Im Hinblick auf die Umweltproblematik kann festgestellt werden, daß die Unternehmen innerhalb des marktwirtschaftlichen Lenkungssystems durch ökonomischen Druck dazu veranlaßt werden können, ihr Handeln nach ökologieorientierten Gesichtspunkten auszurichten. Dieser ökonomische Druck wird in verschiedenen Anforderungen der marktbezogenen Bezugsgruppen artikuliert, die u.a. auf das hohe Umweltbewußtsein zurückzuführen sind. Diese marktbezogenen Umweltschutzforderungen zeichnen sich dadurch aus, daß sie den Unternehmen u.U. neue Ertragschancen bieten können. ${ }^{34}$ Von den unterschiedlichen Bezugsgruppen der Unternehmen können folgende umweltschutzorientierte Anforderungen gestellt werden:

Oppositionelle Kritik am Unternehmensverhalten gibt es von Seiten der Konsumenten. Konsumenten (Kunden und Verbraucher) können als Souverän des marktwirtschaftlichen Lenkungssystems die Unternehmen durch ein ökologieorientiertes Kaufverhalten dazu bewegen, umweltverträgliche Produkte herzustellen. ${ }^{35}$ In Bezug auf den Umweltschutz und im Sinne der Wahrnehmung ihrer sozialen Verantwortung stellen Konsumenten dabei folgende Forderungen an die Unternehmen: ${ }^{36}$

- Die Produktion ungesunder oder schädlicher Stoffe/Produkte soll eingestellt werden.

- Die Unternehmen sollen über die Stoffbestandteile und ökologischen Nebenwirkungen ihrer Produkte selbst informieren.

- Die Produkte sollen umweltfreundlich verpackt werden.

- Es sollen energiesparende Gebrauchsgüter entwickelt werden.

- Umweltschädliche Rohstoffe sollen nicht verarbeitet werden.

\footnotetext{
${ }^{34}$ Während die marktbezogenen Forderungen „Ökologie-Pull-Wirkungen“ darstellen, können die umweltschutzorientierten Forderungen, die in dem politischen und gesellschaftlichen Lenkungssystem an die Unternehmen gestellt werden, als „Ökologie-Push-Wirkungen“ bezeichnet werden. Vgl. z.B. Kirchgeorg, M. (1990), S. 76; Zahn, E./Schmid, U. (1992), S. 52f.

${ }^{35}$ Vgl. Meuser, T. (1994), S. 54.

${ }^{36}$ Vgl. Meffert, H/Bruhn, M./Schubert, F./Walther, T. (1986), S. 143.
} 
Gesellschaftliche Kosten, die durch die Produktion entstehen, sollen die Industriebetriebe selbst übernehmen.

Die Unternehmen sind zur Anpassung an die veränderten Ansprüche der Kunden bzw. allgemein der Verbraucher bezüglich der Umweltverträglichkeit der Produkte gezwungen, da sonst die Gefahr von Umsatz- und Gewinnrückgängen besteht. ${ }^{37}$ Damit die Verbraucher die Umweltverträglichkeit der Produkte beurteilen können, müssen ihnen Informationen über die ökologischen Wirkungen der jeweiligen Produkte zur Verfügung gestellt werden. ${ }^{38}$ In diesem Zusammenhang ist jedoch anzumerken, daß bei den Verbrauchern häufig eine Diskrepanz zwischen umweltschutzorientierten Wertvorstellungen einerseits und umweltbewußtem Einkaufsverhalten andererseits zu beobachten ist. ${ }^{39}$

Neben den Konsumenten kann auch der Handel als Absatzmittler die Unternehmen dazu veranlassen, ihr Verhalten nach umweltschutzorientierten Kriterien auszurichten. Einerseits kann der Handel als „Mittler“ zwischen Verbraucher und Hersteller die kundenbezogenen Forderungen z.B. hinsichtlich der Belieferung mit umweltverträglichen Produkten an die Hersteller weiterleiten. ${ }^{40}$ Andererseits kann der Handel aber auch im Rahmen einer ökologischen Sortimentspolitik umweltschutzorientierte Forderungen an die Unternehmen stellen. Diese Forderungen beziehen sich u.a. auf Informationen über die Umweltverträglichkeit der bezogenen Produkte, die für die Umsetzung einer ökologischen Sortimentspolitik eine notwendige Voraussetzung darstellen. ${ }^{41}$

Außerdem können auch die Lieferanten u.U. umweltschutzorientierte Anforderungen gegenüber ihren Abnehmern erheben. So können die Lieferanten z.B. im Rahmen einer ökologisch verpflichteten Unternehmensführung umweltrelevante Informationen über die weitere Verarbeitung ihrer Vorprodukte und deren ökologische Wirkungen verlangen. Hierbei ist jedoch anzumerken, daß die Lieferanten nur dann ökologieorientierte Forderungen an ihre Abnehmer stellen können, wenn sie über eine vergleichsweise starke Machtposition verfügen. Somit hängt die Möglichkeit für Lieferanten, umweltschutzorientierte Anforderungen gegenüber ihren Abnehmern geltend zu machen, wesentlich von der Machtkonstellation in der Zulieferer-Abnehmer-Beziehung ab. ${ }^{42}$

\footnotetext{
${ }^{37}$ Vgl. Nitze, A. (1991), S. 94f.

${ }^{38}$ Vgl. Schulz, W. (1989), S. 52.

39 Vgl. z.B. Kirchgeorg, M. (1990), S. 77; Steinle, C./Lawa, D./Schollenberg, A. (1994), S. 433. Zu den möglichen Erklärungsansätzen für die Divergenz zwischen Wertvorstellungen und Verhalten vgl. Meffert, H./Kirchgeorg, M. (1998), S. 132ff.; Adelt, P./Müller, H./Zitzmann, A. (1991), S. 155ff.

${ }^{40}$ Vgl. Nork, M. E. (1992), S. 63.

${ }^{41}$ Vgl. Günther, E./Wagner, B. (1993), S. 164; Sieler, C. (1994), S. 2.

42 Vgl. Stölzle, W. (1993), S. 27. In der Literatur wird meist davon ausgegangen, daß die Abnehmer über eine relativ starke Machtposition verfügen und daher eher ökologieorientierte Anforderungen an ihre Lieferanten stellen. Vgl. etwa Günther, E. (1994), S. 55ff.
} 
Eine weitere marktliche Bezugsgruppe, die die Unternehmen dazu veranlassen kann, ihr Handeln nach ökologieorientierten Kriterien auszurichten, stellen die Konkurrenten dar. Insbesondere in einem qualitätsorientierten Wettbewerb ${ }^{43}$ können an die Unternehmen umweltschutzbezogene Anforderungen der Wettbewerber gestellt werden. So kann sich ein Unternehmen in einem qualitätsorientierten Wettbewerb dazu veranlaßt sehen, ebenfalls ökologische Kriterien bei der Produkt- und Verfahrensgestaltung zu berücksichtigen, da andernfalls die Gefahr besteht, daß Kunden zu Anbietern ökologieorientierter Produkte abwandern. Um dieser Gefahr vorzubeugen, versuchen die Unternehmen, ein umweltschutzorientiertes Image bei den Kunden aufzubauen oder zu bestätigen. Somit kommt es zu einem Imagewettbewerb im Umweltschutzbereich zwischen den Unternehmen.

Darüber hinaus können Kreditgeber (z.B. Banken) ökologieorientierte Anforderungen an die Unternehmen stellen. So ist festzustellen, daß Banken im Rahmen ihrer Kreditwürdigkeitsprüfung zunehmend umweltschutzorientierte Beurteilungskriterien verwenden. Dies kann zum einen auf eine ökologieorientierte Geschäftspolitik des Kreditgebers zurückzuführen sein, in deren Rahmen das Finanzierungsvolumen von der Realisierung bestimmter Umweltschutzmaßnahmen durch den Kunden abhängig gemacht werden kann. Zum anderen sind jedoch auch die ökonomischen Folgen zu berücksichtigen, die eine Nichtbeachtung ökologischer Tatbestände mit sich bringen. Werden z.B. von einem Unternehmen die Kosten für die Altlastenerfassung, -sanierung und die anschließende Überwachung zu gering eingeschätzt oder überhaupt nicht beachtet, kann dies u.U. zu einem Vergleich oder Konkurs führen, wobei die Bank zumindest einen Teil ihrer Forderungen abschreiben muß. ${ }^{44}$ Damit sind die Banken auf umweltschutzrelevante Informationen des Unternehmens angewiesen, um die Ökologieorientierung der Unternehmensführung und das damit verbundene Risikopotential abschätzen zu können. ${ }^{45}$

Schließlich erheben auch Versicherungen umweltschutzorientierte Anforderungen gegenüber den Unternehmen. Gegenstand dieser Anforderungen sind vor allem die kontinuierliche Spezifikation von Stoffen, Anlagen und Verfahren, die sich aus den neuen Regelungen des Umwelthaftungsrechts ergibt, sowie die Umsetzung der Ergebnisse von Sicherheitsberatungen zur Verringerung der Haftungsrisiken. ${ }^{46}$ Durch die kontinuierliche Spezifikation von Stoffen, Anlagen und

\footnotetext{
${ }^{43}$ Grundsätzlich kann man bei der Wettbewerbsintensität zwischen den Komponenten des Preis - und Qualitätswettbewerbs differenzieren. Während bei einem preisorientierten Wettbewerb der Spielraum für Umweltschutzmaßnahmen aufgrund der niedrigen Gewinnspannen relativ klein ist, läßt ein qualitätsorientierter Wettbewerb umfangreichere Umweltschutzinvestitionen zu. Vgl. etwa Kirchgeorg, M. (1990), S. 81; Nitze, A. (1991), S. 95; Nork, M. E. (1992), S. 59.

${ }^{44}$ Vgl. Stölzle, W. (1993), S. 30; Coenenberg, A. G./Baum, H.-G./Günther, E./Wittmann, R. (1994), S. 98.

${ }^{45}$ Vgl. Schulz, W. (1989), S. 54.

${ }^{46}$ Vgl. Stölzle, W. (1993), S. 38.
} 
Verfahren ist es den Versicherungen möglich, die Risikolage der Versicherungsnehmer einschätzen zu können. Um das Haftungsrisiko zu reduzieren, sind von den Unternehmen Empfehlungen von externen Experten im Rahmen von Sicherheitsberatungen zu beachten. ${ }^{47}$

Im politischen Lenkungssystem steht für die Unternehmen im Hinblick auf die Umweltschutzproblematik die Erfüllung der gesetzlichen Umweltschutzvorschriften im Vordergrund, aber auch eine Mitverantwortung für die Weiterentwicklung der politischen Rahmenbedingungen. Die Unternehmen sind dazu gezwungen, die bestehenden Umweltschutzgesetze einzuhalten, um politisch legitim $\mathrm{zu}$ handeln. Insofern stellt das Erfolgskriterium des politischen Lenkungssystems die politische Legitimität des Handelns dar. ${ }^{48}$

Im Rahmen dieses Lenkungssystems werden an die Unternehmen eine Vielzahl umweltschutzorientierter Forderungen gestellt. Die Träger dieser Forderungen sind staatliche Institutionen (z.B. die verschiedenen im Umweltschutzbereich tätigen Behörden). Gleichsam verbindlichen Charakter haben die Forderungen der staatlichen Umweltpolitik, da sie den gesamten betriebswirtschaftlichen Entscheidungs- und Handlungsspielraum direkt beeinflussen. Die Änderung der gesetzlichen Rahmenbedingungen und die Verschärfung von Vorschriften hat für die meisten Verursachergruppen national und auch international in den letzten Jahren als Triebfeder für den Umweltschutz gewirkt. So wurden z.B. Gesetze zur Schadensbegrenzung bei Emissionen in Luft, Wasser und Boden erlassen. Folge dieser gesetzlichen Vorgaben waren erhebliche Investitionen in den Umweltschutz, in erster Linie in sog. „End of the Pipe-Technologien“ im Bereich der Luftreinhaltung.

Die umweltschutzorientierten Anforderungen, die gegenüber den Unternehmen erhoben werden, sind auf umweltpolitische Maßnahmen zurückzuführen. Insofern werden im folgenden kurz die Grundzüge der Umweltpolitik skizziert, um darauf aufbauend die umweltschutzorientierten Anforderungen an die Unternehmen herausarbeiten zu können.

Unter dem Begriff „Umweltpolitik“ versteht man die ,... Gesamtheit aller Maßnahmen, die notwendig sind, um dem Menschen eine Umwelt zu sichern, wie er sie für seine Gesundheit und für ein menschenwürdiges Dasein braucht, um Boden, Luft und Wasser, Pflanzen- und Tierwelt vor nachteiligen Wirkungen menschlicher Eingriffe zu schützen und um Schäden und Nachteile aus

\footnotetext{
${ }^{47}$ Vgl. Wicke, L. (1993), S. 266.

${ }^{48}$ Vgl. Dyllick, T. (1992), S. 225.
} 
menschlichen Eingriffen zu beseitigen“. ${ }^{49}$ Die Umweltpolitik orientiert sich an den grundlegenden Prinzipien der Verursachung, der Kooperation und der Vorsorge.

Den Prinzipien staatlicher Umweltpolitik liegen dabei folgende Forderungen implizit zugrunde: ${ }^{.0}$

- Verursacherprinzip: Ökologische Kosten, die Unternehmen aufgrund der KollektivgutEigenschaft der natürlichen Umwelt verursachen, sollen von ihnen auch getragen werden. Dadurch soll eine Internalisierung von bisher nicht entgoltenen Umweltnutzungen in die private Wirtschaftsrechnung der Wirtschaftssubjekte erreicht werden. Dies hat zur Konsequenz, daß Unternehmen dazu gezwungen werden, ihre Einwirkung auf die natürliche Umwelt zu kontrollieren und gegebenenfalls zu unterbinden.

- Kooperationsprinzip: Bei Inkongruenz von Verursachern und Betroffenen ökologischer Schäden sollen die Unternehmen als Akteure mit der öffentlichen Hand als Stellvertreter Betroffener zur Verbesserung des Umweltschutzes zusammenarbeiten und somit auch Mitverantwortung für die erfolgreiche Bekämpfung der Umweltbelastung übernehmen. Das Kooperationsprinzip baut auf dem demokratischen Grundverständnis auf und versucht, durch eine möglichst weitgehende Beteiligung aller betroffenen Gruppen in der Bevölkerung die verantwortliche Mitgestaltung im Umweltbereich zu fördern.

- Vorsorgeprinzip: Soweit möglich, sollen Unternehmen ökologische Probleme von vornherein vermeiden. Somit müssen bei allen Entscheidungen auf den verschiedensten Gebieten ökologische Gesichtspunkte berücksichtigt werden, um Entwicklungen zu verhindern, die künftig zu Umweltbelastungen führen können.

Zur Durchsetzung dieser Forderungen stehen der staatlichen Umweltpolitik Instrumente zur Verfügung, die sich unterschiedlich auf die Unternehmen auswirken, wie z.B. gesellschaftliche Infrastrukturmaßnahmen (z.B. Anschlußzwang an öffentlichen Entsorgungseinrichtungen), Überzeugung durch eine öffentliche Kommunikationspolitik (Moral Suasion), Verbote und Auflagen, Subventionen, Umweltabgaben sowie Lizenzierung der Umwelt.

Bei den am Verursacherprinzip orientierten Instrumenten kann man zwischen ordnungsrechtlichen und marktorientierten Instrumenten unterscheiden. Während bei den ordnungsrechtlichen Instrumenten der Staat die Bedingungen für die Inanspruchnahme des (öffentlichen) Gutes Umwelt zwingend vorschreibt, knüpfen die marktorientierten Instrumente an der erwerbswirtschaft-

\footnotetext{
${ }^{49}$ Wicke, L. (1993), S. 703.

${ }^{50}$ Vgl. Töpfer, K. (1991), S. 30f.; Wicke, L. (1991), S. $128 f f$.
} 
lichen Orientierung der Unternehmen an. $\mathrm{Zu}$ den ordnungsrechtlichen Instrumenten gehören Auflagen, die das am weitesten verbreitete Instrument der Umweltpolitik in Deutschland und auch in Südkorea darstellen und in vielen Erscheinungsformen vorkommen. So können Auflagen beispielsweise bestimmte Emissionen nur bis zu einem festgesetzten Grenzwert erlauben oder sie sogar vollständig verbieten. ${ }^{51}$ Insofern stellen Auflagen u.a. umweltschutzorientierte Anforderungen an die Unternehmen bezüglich ihrer Emissionsabgabe. Im Gegensatz zu den Auflagen sind Ressourcensteuern, Umweltabgaben oder Umweltzertifikate den marktorientierten Instrumenten zuzuordnen. Bei diesen Instrumenten entstehen für die Unternehmen Anforderungen über den Marktpreis, der für die jeweiligen Steuern, Abgaben oder Zertifikate zu entrichten ist. ${ }^{52}$

Das Gemeinlastprinzip wird z.B. mit Hilfe von Subventionen oder Finanzhilfen für umweltschonende Produkte oder Verfahren umgesetzt. Die Finanzierung dieser Maßnahmen über (allgemeine) Steuererhöhungen stellt zumindest indirekt Anforderungen an die Unternehmen, sofern diese von den jeweiligen Steuerarten betroffen sind. ${ }^{53}$

Das Vorsorgeprinzip umfaßt Gebote zur Ressourcenschonung oder zur Abwehr von Umweltschädigungsgefahren. Je nachdem, auf welchen Bereich sich diese Gebote beziehen, können sie für die Unternehmen im Rahmen einer ökologisch verpflichteten Unternehmenspolitik u.U. umweltschutzorientierte Anforderungen darstellen. ${ }^{54}$

Das Kooperationsprinzip wird mit Hilfe von freiwilligen Vereinbarungen wie z.B. Selbstbeschränkungsabkommen zwischen Unternehmen und staatlichen Institutionen umgesetzt. Hierbei werden an die Unternehmen umweltschutzorientierte Anforderungen gestellt, die von den anderen Kooperationspartnern oder staatlichen Institutionen ausgehen. ${ }^{55}$

Die juristische Grundlage für den Einsatz der jeweiligen umweltpolitischen Instrumente stellt das Umweltrecht dar. Durch umweltrechtliche Regelungen werden konkrete umweltschutzorientierte Anforderungen an die Unternehmen gestellt. In den letzten Jahren sind die umweltschutzorientierten Anforderungen an die Unternehmen, die sich aus der Vielzahl umweltrechtlicher Regelungen ergeben, stark angestiegen. Insofern ist im Bereich des Umweltrechts eine zunehmende Verschärfung und eine hohe Änderungsgeschwindigkeit zu konstatieren. Anhand der bereits realisierten oder geplanten rechtlichen Regelungen wird deutlich, daß die Unternehmen in Zukunft

\footnotetext{
${ }^{51}$ Vgl. Wicke, L. (1993), S. 195ff.

${ }^{52}$ Vgl. Wicke, L. (1991), S. 382ff.

${ }^{53}$ Vgl. Stölzle, W. (1993), S. 15.

${ }^{54}$ Vgl. Wicke, L. (1993), S. 162.
} 
gefordert sind, eine größere ökologische Transparenz zuzulassen und die betrieblichen Umwelteinwirkungen abzubilden, d.h. an die Unternehmen werden erhöhte Anforderungen im Hinblick auf die Abbildung der betrieblichen Umwelteinwirkungen gestellt. ${ }^{56}$

Aus den vorangegangenen Ausführungen geht hervor, daß die Unternehmen neben den umweltschutzorientierten Anforderungen von marktbezogenen Interessengruppen auch einer Vielzahl von politisch-rechtlichen umweltschutzorientierten Anforderungen ausgesetzt sind. Die Unternehmensleitungen müssen jedoch bei ihren Entscheidungen nicht nur marktbezogene und politisch-rechtliche Aspekte beachten, sondern auch gesellschaftliche Anforderungen in ihre Entscheidungen einbeziehen, d.h. das unternehmerische Handeln muß nicht nur ökonomisch effizient und politisch legitim sein, sondern auch gesellschaftlichen Anforderungen gerecht werden. Ein notwendiges Maß an Übereinstimmung des Unternehmensverhaltens mit den nicht ökonomischen gesellschaftlichen Werthaltungen im Sinne eines Legitimitätsanspruchs ist aber langfristig zur Sicherung der Unternehmensexistenz unabdingbar. Insofern ist der Umweltschutz als gesellschaftlich vermittelter Anspruch und als Element der gesellschaftsbezogenen Legitimität im Rahmen der Unternehmensführung zu berücksichtigen. Die Gesellschaft hat sich dabei in den letzten Jahren zu einer treibenden Kraft im Umweltschutzbereich entwickelt. ${ }^{57}$ Auf diese gesellschaftlichen Anforderungen wird im folgenden näher eingegangen.

Im Rahmen des gesellschaftlichen Lenkungssystems werden an die Unternehmen umweltschutzorientierte Anforderungen von gesellschaftlichen Bezugsgruppen gestellt. Die Wirkung dieser Forderungen beruht im wesentlichen auf der (potentiellen) Mobilisierung von öffentlichem Druck. Dieser öffentliche Druck kann unterschiedliche Formen annehmen. Beispielsweise kann öffentlicher Druck auf die Unternehmen ausgeübt werden durch Informationskampagnen, Protestaktionen oder gezielte Boykottaufrufe gegen umweltschädigende Produkte. ${ }^{58}$ Wird ein solcher öffentlicher Druck gegen bestimmte Unternehmen aufgebaut, so kann dies eine Viel-

\footnotetext{
${ }^{55}$ Vgl. Stölzle, W. (1993), S. 15.

${ }^{56}$ Vgl. Zahn, E./Steimle, V. (1993), S. 227; Feess, E./Hohmann, H. (1994), S. 95.

57 Im Rahmen der ökologischen Herausforderung des Unternehmens kann die Gesellschaft in dreifacher Hinsicht aufgegliedert werden (vgl. Pfriem, R. (1995), S. 41):

- Als direkt Betroffene unternehmenspolitischer Maßnahmen. Das können Anwohner sein, die unter den Schadstoffemissionen einer nahen Industrieanlage leiden, ebenso wie Hausbesitzer, die wegen eines Ansiedlungsvorhabens zum Verkauf gedrängt werden;

- Als Menschen, die sich aufgrund persönlichen Engagements, möglicherweise sogar hauptberuflich, in Verbänden oder Initiativen des Umweltschutzes engagieren. Diese verschiedenartigen Gruppen bzw. Institutionen stellen in einer durch Verbände mitgeprägten repräsentativen Demokratie eine wichtige ökologische Lobby dar;

- Als kritische Öffentlichkeit. Weil ökologische Schäden auch in dem Sinne global sind, daß Nichtkäufer von den ökologischen Gefahren eines Produktes oder einer infrastrukturellen Veränderung ebenso betroffen sein können wie Käufer, hat sich längst eine vielfältige und facettenreiche kritische Öffentlichkeit im ökologischen Handlungsfeld herausgebildet, die über die verschiedenen Informations- und Kommunikationsmedien in ihrer Wirkung verstärkt wird.
} 
zahl negativer Wirkungen (z.B. Image- und Glaubwürdigkeitsverluste oder Verlust des „Goodwill“ in der Öffentlichkeit) zur Folge haben. ${ }^{59}$ Insofern geht von der Mobilisierung von öffentlichem Druck eine bedeutende Lenkungswirkung auf die Unternehmen aus. ${ }^{60}$

Um zu verhindern, daß ein solcher öffentlicher Druck gegen ein bestimmtes Unternehmen aufgebaut wird, muß das Management bei allen Entscheidungen auch die möglichen gesellschaftlichen Auswirkungen bei der Entscheidungsfindung berücksichtigen. ${ }^{61}$ Durch die Berücksichtigung der gesellschaftlichen Auswirkungen bei den unternehmerischen Entscheidungen kann die Akzeptanz und Legitimität des Unternehmens bei den relevanten gesellschaftlichen Bezugsgruppen gesichert werden. Dies ist notwendig, da sonst die langfristige wirtschaftliche Existenz des Unternehmens gefährdet wird. Insofern stellt die Akzeptanz des Unternehmens und seiner Tätigkeit das Erfolgskriterium des gesellschaftlichen Lenkungssystems dar. ${ }^{62}$

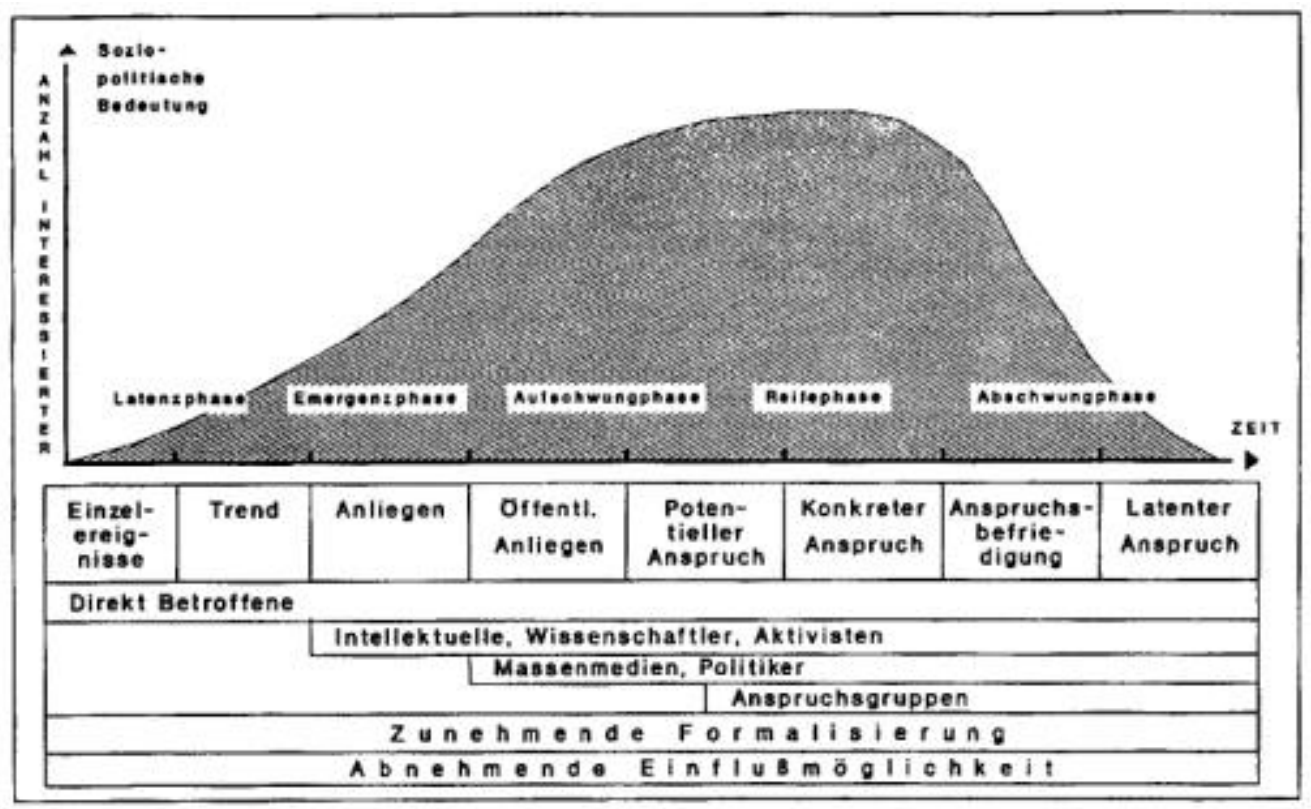

Abb. 2.4: Lebenszykluskonzept gesellschaftlicher Umweltschutzforderungen (Quelle: Achleitner, P. M. (1985), S.94)

Für die umweltschutzorientierten Anforderungen, die im Rahmen des gesellschaftlichen Lenkungssystems gegenüber den Unternehmen erhoben werden, läßt sich ein Lebenszykluskonzept aufstellen, das in der folgenden Abbildung dargestellt ist. Abb. 2.4 zeigt, wie einzelne Ereignisse

\footnotetext{
${ }^{58}$ Vgl. Schmid, U. (1992), S. 171.

${ }^{59}$ Vgl. Gege, M. (1994), S. 213.

${ }^{60}$ Vgl. Dyllick, T. (1990), S. 20f.

${ }^{61}$ Vgl. z.B. Nork, M. E. (1992), S. 107; Gege, M. (1994), S. 213.

${ }^{62}$ Vgl. Schmid, U. (1992), S. 175; Dyllick, T. (1992), S. 403; Dyllick, T./Beiz, F. (1995), S. 58.
} 
durch bestimmte Personen wie direkt Betroffene (z.B. Anwohner am Produktionsstandort), Wissenschaftler (z.B. in Umweltschutz- oder Verbraucherorganisationen), Journalisten oder Politiker mit Hilfe der Medien zu einem öffentlichen Anliegen und gesellschaftlich relevanten Umweltthema gemacht werden. Diese öffentlichen Anliegen werden dann durch etablierte Organisationen wie z.B. politische Parteien vertreten und in umweltrechtliche Regelungen umgesetzt. ${ }^{63}$ Insofern können umweltschutzorientierte Anforderungen bestimmter gesellschaftlicher Bezugsgruppen als Ursache für eine Politisierung von Umweltschutzproblemen und den daraus folgenden umweltrechtlichen Regelungen angesehen werden. ${ }^{64}$

Der zunehmende gesellschaftliche Druck manifestiert sich in der Forderung, daß neben dem Staat hauptsächlich die Unternehmen Maßnahmen und Instrumente zur Beseitigung und Verhinderung gegenwärtiger und zukünftiger Umweltbeeinträchtigungen entwickeln oder vielmehr realisieren sollen. Darüber hinaus wird jedoch auch eine ethisch-moralische Verantwortung der Unternehmen gefordert, daß betriebliche Entscheidungen und deren Konsequenzen nicht nur auf der Basis ökonomischer, sondern auch nach ökologischen Kriterien getroffen und bewertet werden sollen.

Die in der Gesellschaft artikulierten Umweltschutzforderungen üben auch einen Einfluß auf die Veränderung des Wettbewerbsumfeldes aus. ${ }^{65}$ Dementsprechend müssen sich Unternehmen zunehmend auch mit dem Umweltschutz als wettbewerbsstrategischem Problem auseinandersetzen. Angesicht der wettbewerbsstrategischen Dimension des Umweltschutzes beinhaltet ökologisch verpflichtetes Management auch die Wahrung der ökonomischen Effizienz zur Absicherung bestehender und Erschließung neuer Gewinn- und Profilierungspotentiale. Die Unternehmen sind gefordert, einen eigenständigen Beitrag zur Lösung der aufgezeigten Problemfelder des Umweltschutzes zu leisten. Dies erfordert einen Bewußtseinswandel in der Unternehmensführung, um den Umweltschutz nicht allein als Wachstumsbegrenzung, sondern vielmehr als Wachstumsvoraussetzung zu begreifen.

\footnotetext{
${ }^{63}$ Vgl. Achleitner, P. M. (1985), S. 95; Meffert, H./Kirchgeorg, M. (1998), S. 97ff. Dyllick unterscheidet in dem Lebenszykluskonzept gesellschaftlicher Anliegen fünf verschiedene Entwicklungsphasen. Diese Entwicklungsphasen bezeichnet er als Latenzphase, Emergenzphase, Aufschwungphase, Reifephase und Abschwungphase. Werden die Unternehmen von öffentlichen Umweltschutzanliegen betroffen, so ist es für deren Reaktionsstrategien wichtig, die jeweilige Phase zu bestimmen, in der sich die öffentliche Diskussion befindet. Je weiter fortgeschritten die öffentliche Diskussion ist, desto mehr nimmt der Verhaltensspielraum der Unternehmen ab. Vgl. Dyllick, T. (1990), S. $241 \mathrm{ff}$.

${ }^{64}$ Vgl. Dyllick, T. (1990), S. 60; Kirchgeorg, M. (1990), S. 68.

${ }^{65}$ Der gesamtgesells chaftliche Druck ist keineswegs konstant, sondern in einem permanenten Wandel begriffen und für jedes Unternehmen unterschiedlich. Seine Entwicklung und damit die potentiellen Risiken hängen ab von: dem faktischen Wissen über die von dem Unternehmen verurs achten oder beeinflußbaren ökologischen Probleme, dem zeitlichen Handlungshorizont des Unternehmens und der Öffentlichkeit, dem Grad der Betroffenheit und der aktuel-
} 
Neben diesen unternehmensexternen Forderungen werden gegenüber den Unternehmen aber auch umweltschutzorientierte Anforderungen von unternehmensinternen Bezugsgruppen erhoben, wie z.B. dem Management, den Mitarbeitern, den Umweltschutzbeauftragten sowie den Anteilseignern. ${ }^{66}$ Die umweltschutzorientierten Forderungen des Managements sind auf die veränderten Einstellungen und Werthaltungen hinsichtlich der Bedeutung des Umweltschutzes zurückzuführen, die insbesondere bei den Führungskräften festzustellen sind. Dieser Wertewandel deutet auf eine stärkere Wahrnehmung ökologischer Verantwortung durch das gesamte Management oder einzelner Manager hin. Ökologische Verantwortung eines Managers zeigt sich in seinem Bemühen, die umweltrelevanten Folgen seines Handelns zu erkennen und Umweltschutzziele im Rahmen seiner Handlungsspielräume zu fördern und zu verfolgen, um so die Belastungen der natürlichen Umwelt durch wirtschaftliche Aktivitäten des Unternehmens nachhaltig $\mathrm{zu}$ reduzieren. ${ }^{67} \mathrm{Um}$ ein derartiges ökologisch verantwortliches Unternehmerhandeln realisieren zu können, bedarf das Management umweltrelevanter Informationen über die Umwelteinwirkungen, die im Zusammenhang mit der betrieblichen Leistungserstellung und -verwertung auftreten. Diese umweltrelevanten Informationen bilden eine wesentliche Voraussetzung für den Einbezug ökologischer Aspekte in die unternehmerischen Entscheidungen. ${ }^{68}$

Die umweltschutzorientierten Anforderungen der Mitarbeiter beziehen sich zum einen auf Aspekte des Arbeitsschutzes und zum anderen auf das umweltbezogene Unternehmensimage. Bezüglich der Arbeitsschutzaspekte ist festzustellen, daß die Mitarbeiter ein Interesse daran haben, über die Umwelteinwirkungen in ihrem Tätigkeitsbereich informiert zu werden. Im Hinblick auf das umweltbezogene Unternehmensimage ist anzumerken, daß die Mitarbeiter bestrebt sind, in einem Unternehmen tätig $\mathrm{zu}$ sein, das ein positives Umweltimage genießt. ${ }^{69}$ Ein derartiges Unternehmensimage trägt dazu bei, daß die gesellschaftliche Wertschätzung der Beschäftigten gefördert wird. ${ }^{70}$ Insofern sind die Mitarbeiter daran interessiert, frühzeitig und ausführlich über Umweltschutzaktivitäten ihres Unternehmens informiert zu werden. ${ }^{71}$

len Motivation der Öffentlichkeit (insb. der Medien) sowie dem Organisationsgrad der Öffentlichkeit und der Sanktionswahrscheinlichkeit einer Nichtberücksichtigung der ökologischen Problematik durch das Unternehmen.

${ }^{66}$ Hierbei ist anzumerken, daß die Bezugsgruppen der Mitarbeiter, Umweltschutzbeauftragten und Anteilseigner mit Abgrenzungsproblemen verbunden sind. So können diese Personengruppen auch umweltschutzorientierte Anforderungen äußern, die den Forderungen unternehmensexterner Bezugsgruppen sehr ähnlich sind. Insofern nehmen die Gruppen eine Zwischenstellung zwischen unternehmensexternen und -internen Bezugsgruppen ein. Im folgenden wird jedoch davon ausgegangen, daß der Interessenschwerpunkt dieser Gruppen im unternehmensinternen Bereich liegt. Dementsprechend werden sie hier den unternehmensinternen Bezugsgruppen zugeordnet.

${ }^{67}$ Vgl. Pfriem, R. (1989), S. 122f. Nach Günther und Wagner gehen die Impulse für eine ökologisch verantwortliche Unternehmensführung häufig vom jüngeren Middle-Management aus. Vgl. Günther, E./Wagner, B. (1993), S. 157.

${ }^{68}$ Vgl. Zahn, E./Steimle, V. (1993), S. 228; Schmid, U. (1992), S. 178.

${ }^{69}$ Dies gilt auch für potentielle Mitarbeiter des Unternehmens. Vgl. Bartscher, T./Fleischer, H. (1991), S. 443.

${ }^{70}$ Vgl. Stölzle, W. (1993), S. 39. 
Eine weitere unternehmensinterne Bezugsgruppe, die umweltschutzorientierte Forderungen an die Unternehmen stellen kann, sind die Umweltschutzbeauftragten. Die Aufgaben der Umweltschutzbeauftragten umfassen Kontroll-, Beratungs- und Informationsfunktionen. Im Rahmen der Kontrollfunktion sind die Umweltschutzbeauftragten dazu verpflichtet, im Zuge der Einhaltung behördlicher Auflagen und Gesetze Anlagen zu überwachen, Mängel zu beheben und Maßnahmen zu deren Beseitigung zu treffen. Die Beratungs- und Informationsfunktion umfaßt die Beteiligung bei der Entwicklung und Einführung umweltverträglicher Verfahren und Produkte, die Information der Unternehmensleitung über die Umwelteinwirkung des Unternehmens sowie die Stellungnahme vor Investitionsentscheidungen. Um diese Aufgaben in befriedigender Weise lösen zu können, müssen die Umweltschutzbeauftragten auf eine Vielzahl umweltrelevanter Informationen zurückgreifen können. ${ }^{72}$

Schließlich können auch die Anteilseigner wie z.B. Aktionäre umweltschutzorientierte Anforderungen an die Unternehmen stellen. Bei den ökologieorientierten Anforderungen der Anteilseigner kann man zwischen den Forderungen derzeitiger und potentieller Anleger unterscheiden. So können derzeitige Anteilseigner eine umweltschutzorientierte Ausrichtung der Unternehmenspolitik verlangen, damit sich das jeweilige Unternehmen durch umweltverträgliche Produkte Wettbewerbsvorteile verschafft, die die zukünftige Ertragskraft des Unternehmens sichern. ${ }^{73}$ Bezüglich der umweltschutzorientierten Anforderungen potentieller Anteilseigner ist festzustellen, daß es immer mehr Anleger gibt, die ihre Anlageentscheidungen so tätigen, daß die natürliche Umwelt nicht belastet und wenn möglich die Umweltqualität sogar verbessert wird. $^{74}$ Die zunehmende Anzahl der Anleger, die bei ihren Anlageentscheidungen auch umweltschutzorientierte Kriterien berücksichtigen, wird an den Zuwachsraten deutlich, die ethisch-ökologisch orientierte Geldanlagen zu verzeichnen haben. Um derartige umweltschutzorientierte Anlageentscheidungen zu realisieren, benötigen die Anleger umweltrelevante Informationen, mit deren Hilfe sie das ökologische Risikopotential des Unternehmens einschätzen können. ${ }^{75}$

Den möglichen Herausforderungen und Gefahren für die Unternehmensführung, die eine Nichtberücksichtigung der Ökologieproblematik beinhalten könnten, stehen aber Chancen gegenüber, die aktive ökologiebewußte Unternehmenskonzepte für das Unternehmen bieten. $\mathrm{Zu}$ einer Gewinnverbesserung könnten mögliche Marktchancen beitragen. Marktchancen bieten sich z.B

\footnotetext{
${ }^{71}$ Vgl. Günther, E./Wagner, B. (1993), S. 163.

$72 \mathrm{Zu}$ den Aufgaben der Umweltschutzbeauftragten vgl. z.B. Bundesumweltministerium/Umweltbundesamt (1995), S. 52ff.; Günther, E. (1994), S. 102.

${ }^{73}$ Vgl. Schulz, W. (1989), S. 54; Stölzle, W. (1993), S. 41.

${ }^{74}$ Vgl. Coenenberg, A. G./Baum, H.-G./Günther, E./Wittmann, R. (1994), S. 98.

${ }^{75}$ Vgl. Günther, E. (1994), S. 61.
} 
zunächst durch eine Verbesserung des Unternehmensimages sowie durch Innovationen im Technologiebereich. $^{76}$ Mit material- und energiesparenden Investitionen im eigenen Unternehmen lassen sich erhebliche Kostenminderungen vor allem bei Energie-, Wasser-, Rohstoff- und Abfallkosten realisieren. Als weitere Chancen lassen sich eine Motivationssteigerung bei den Mitgliedern des Unternehmens auf allen Unternehmensstufen und damit Produktivitätssteigerungen feststellen. Abb. 2.5 veranschaulicht die in diesem Abschnitt dargestellten Zusammenhänge.

\begin{tabular}{|l|c|}
\hline Wertewandel in der Gesellschaft & $\begin{array}{c}\text { Erkenntnisse über Gefährdungen der } \\
\text { ökologischen Lebensgrundlagen }\end{array}$ \\
\hline
\end{tabular}

höhere Priorität für den Umweltschutz vermittelt durch

$\Downarrow$

\begin{tabular}{|l|l|l|l|l|l|l|}
\hline \multicolumn{7}{|c|}{ Staatliche Regelungen } \\
\hline $\begin{array}{l}\text { Straf- } \\
\text { recht }\end{array}$ & Kostenwirksame & Höhere & Produkt- & Neue & Wettbewerbs- & Neue \\
& Auflagen für & technische & und & Märkte & vorteile & gesellschaftliche \\
& umweltbelastende & Standards & Umwelthaftung & & & Legitimität für \\
& Produktionen & & & & & Markwirtschaft \\
\hline
\end{tabular}

beeinflussen die Handlungsspielräume der Unternehmen

$\Downarrow$

\begin{tabular}{|l|l|l|l|l|}
\hline Stillegung bzw. & Rückgang der & Substitutionskonkurrenz & Zwang zur & Zwang zur \\
Unterbrechen des & Nachfrage & $\begin{array}{l}\text { der umweltfreundlichen } \\
\text { Produkte }\end{array}$ & $\begin{array}{l}\text { technologischen } \\
\text { Innovation }\end{array}$ & Produktinnovation \\
\hline
\end{tabular}

Abb. 2.5: Umwelteinfluß und Auswirkungen auf das Unternehmen

(Quelle: Steger, U. (1990), S. 50)

\subsection{Berücksichtigung der ökologischen Verpflichtung in betriebswirtschaftlichen Ansätzen}

Aufgrund wachsender gesellschaftlicher, vor allem ökologischer, Probleme, die heute im Vordergrund der politischen und gesellschaftlichen Aufmerksamkeit stehen und damit ein bedeutendes Druckpotential auf das gesellschaftliche Subsystem „Unternehmen“ bzw. auf die unternehmerische Tätigkeit darstellen, ist die klassische, rein ökonomische Managementlehre an ihre Grenzen gestoßen. Deshalb werden in der Literatur Konzeptionen diskutiert, die die Ausdehnung des Objektbereichs der Managementlehre um die soziale Dimension vorschlagen. In der Konzep-

\footnotetext{
${ }^{76}$ Vgl. Meffert, H./Benkenstein, M./Schubert, F. (1987), S. 34; Terhart, K. (1986), S. 402; Pfriem, R. (1986), S. 99f;
} 
tion einer gesellschaftsbezogenen Managementlehre werden bei der Erarbeitung der relevanten Unternehmensumwelt neben dem Markt explizit die politisch-rechtlichen Rahmenbedingungen durch das Lenkungssystem Politik sowie ethische Ansprüche durch das Lenkungssystem der Moral thematisiert. ${ }^{77}$ Auf diesem Umweltverständnis wird die Konzeption der ökologisch bewußten Unternehmensführung weiter entwickelt. Im Rahmen der ökologisch bewußten Unternehmensführung wird die Umweltkonzeption, neben der klassischen Betrachtung der Unternehmen als sozio-ökonomische Subsysteme, zusätzlich als ökologisches bzw. stofflich-energetisches Subsystem einbezogen. ${ }^{78}$ Ökologisch verpflichtete Unternehmensführung ist dabei eine junge Disziplin in der Betriebswirtschaftslehre, die ihren Standort erst finden muß. Fest steht indes, daß Umweltschutz für die Betriebswirtschaftslehre keine Modeerscheinung, sondern eine wichtige Zukunftsaufgabe wird.

Zur Lösung dieser Aufgabe hat die Betriebswirtschaftslehre auf vielfältige Weise mittels Modifikationen und Erweiterungen bestehender Konzepte der Funktionslehren und Wissenschaftsprogramme eigenständige Aufklärungs-, Erklärungs- und Gestaltungsbeiträge geliefert. Ohne Zweifel hat die Beschäftigung mit der Ökologie in der Betriebswirtschaftslehre zu stärker funktionsübergreifenden und prozeßorientierten Denkansätzen geführt. Trotz aller Fortschritte ist jedoch eine geschlossene und einheitliche Integration der ökologisch verpflichteten Unternehmensführung in die betriebswirtschaftliche Forschung und Lehre bisher nicht erreicht worden. Neue Formen der interdisziplinären Vernetzung sind daher notwendig.

Nach Meffert/Kirchgeorg werden die verschiedenen betriebswirtschaftlichen Ansätze zur ökologisch verpflichteten Unternehmensführung entsprechend ihrer Forschungsgebiete wie folgt systematisiert: $^{79}$

- Umwelt als Produktionsfaktor

- Umweltschutz als betriebswirtschaftliches $\mathrm{Ziel}^{80}$

Stitzel, M.(1976), S. 85.

${ }^{77}$ Vgl. Dylick, T. (1989), S. $127 \mathrm{ff}$.

${ }^{78}$ In den Literatur werden die unterschiedlichen, sich zum Teil aber überschneidenden Ansätze der betriebswirtschaftlichen Auseinandersetzungen mit dem Umweltschutz behandelt, wie z.B. die themenbezogenen, systemischen und institutionellen Umweltkonzepte. Vgl. Sauter-Sachs, S. (1992), S. 189.; Brockhaus, M. (1996), S. 17ff.

${ }^{79}$ Vgl. die folgende Ausführung Meffert, H. (1996), S. 5ff.; Meffert, H./Kirchgeorg, M. (1998), S. 37 ff. Die Konzepte der ökologisch verpflichteten Betriebswirtschaftslehre werden auch z.B. nach Steinle/Lawa/ Schollenberg in theoretisch-geschlossene, realökonomisch-sozialkritische, normativ-strategische sowie empirisch-analytische Ansätze unterteilt (vgl. Steinle, C./Lawa, D./Schollenberg, A. (1993), S. 7ff.).

${ }^{80}$ Der Ansatz „Umweltschutz als betriebswirtschaftliches Ziel” beschäftigt sich mit dem Stellenwert von Umweltschutzzielen im Zielsystem bzw. den Beziehungen zwischen ökologischen und ökonomischen Zielen eines Unternehmens. (vgl. zu näheren Ausführungen von Sihler, H. (1987), S. 11ff.; Meffert, H./Kirchgeorg, M. (1989), S. 5ff.) Generell werden Unternehmensziele als Vorstellung über den zukünftigen Zustand der Unternehmen, der als erstre- 
- Umweltschutz als ethischer Anspruch

- Umweltschutz als gesellschaftlicher Anspruch ${ }^{81}$

- Umweltschutz als Wettbewerbsfaktor ${ }^{82}$

- Systemtheoretischer Ansatz des Umweltschutzes

- Entscheidungsorientierter Ansatz des Umweltschutzes

- Sozial-ökologischer Ansatz im Umweltschutz.

- Integrierter Ansatz einer ökologisch verpflichteten Unternehmensführung ${ }^{83}$

Im folgenden werden diese Ansätze in der betrieblichen Funktionslehre und den Wissenschaftsprogrammen skizziert und diskutiert. Zunächst sollen die betriebswirtschaftliche Ansätze zur ökologisch verpflichteten Unternehmensführung in bezug auf die betrieblichen Funktionsbereiche dargestellt werden.

Produktion: Erste umweltbezogene Ansätze finden sich in der betriebswirtschaftlichen Produktionstheorie. Bei den Überlegungen zum Umweltschutz wird die natürliche Umwelt im Rahmen des klassischen Produktionsfaktorsystems ${ }^{84}$ in ihrer Versorgungsfunktion durch die Bereitstel-

benswert angesehen wird, als die eigentliche Bestimmungsgröße des Unternehmensverhaltens gekennzeichnet. (vgl. Heinen, E. (1976), S. 45; Meffert, H./Kirchgeorg, M. (1998), S. 44ff.; Schanz, G. (1999), S. 6ff.).

${ }^{81}$ Die Relevanz gesellschaftlicher Ansprüche für das umweltbewußte Verhalten von Unternehmen wird in Ansätzen zur gesellschaftsbezogenen Unternehmenspolitik thematisiert. (vgl. zu näheren Ausführungen Stitzel, M. (1987), S. 377ff.; Dyllick, T. (1989), insb. S. 86ff.) Es ergänzt sich mit dem Konzept der Berücksichtigung des Umweltschutzes als ethischer Anspruch. Ein solcher Ansatz ist das Stakeholder-Konzept. Damit wird der Einfluß verschiedener Anspruchsgruppen auf den unternehmensbezogenen Entscheidungsprozeß untersucht. Stakeholder sind Gruppen oder Personen, ohne deren Unterstützung eine Organisation nicht existieren könnte. Demnach können die von Unternehmen ursprünglich angestrebten Ziele durch verstärkte Umweltschutzforderungen von marktbezogenen (Kunden, Handel) und gesellschaftlichen Anspruchsgruppen (Bürgerinitiativen, Verbraucherverbände, Gewerkschaften, staatliche Instanzen) beeinträchtigt werden. Die Unternehmen werden somit veranlaßt, die verursachten externen Kosten bzw. Umweltbelastungen und die mit einem erhöhten Umweltbewußtsein veränderten Ansprüche der Gesellschaft zu internalisieren und umweltgerecht oder umweltverträglich zu handeln, um mögliche Sanktionen der Anspruchsgruppen zu vermeiden.

82 Der wettbewerbstheoretische Ansatz analysiert den Einfluß des Umweltschutzverhaltens von Unternehmen auf deren Wettbewerbsfähigkeit bzw. Wettbewerbsintensität. (vgl. zu näheren Ausführungen Kirchgeorg, M. (1990), S. 200ff.; Meffert, H. (1991), S.11ff.; Zahn, E./Schmid, U. (1992), S. 39ff.) Umweltschutz wird zunehmend zu einem zentralen Wettbewerbsfaktor aufgrund eines veränderten Nachfrageverhaltens, umweltpolitischer Maßnahmen des Staates und des Innovationsverhaltens einzelner Unternehmen.

${ }^{83}$ Weiterführende Ansatzpunkte für einen tragfähigen integrativen Bezugsrahmen des Umweltmanagements werden in Konzepten des strategischen und integrierten Managements gesehen, wie sie von Kirsch und Vertretern der St. Galler Schule unter Einbeziehung entscheidungs- und systemtheoretischer Betrachtungsweisen entwickelt wurden. Hierbei erfolgt die Integration des Umweltschutzes auf der normativen, strategischen und operativen Ebene. Neben dieser prozeßorientierten Betrachtungsweise zeichnet sich der Ansatz insbesondere durch die Synthese instrumenteller und wertorientierter Betrachtungsweisen aus, auf deren Grundlage auch die Entwicklungs- und Fortschrittsfähigkeit eines integrativen Managementansatzes aufbauen. Der auf der normativen Ebene zu formulierenden Management-Philosophie bzw. Unternehmenskultur wird als integrierende Kraft ein besonderer Stellenwert zugewiesen. Vgl. Meffert, H./Kirchgeorg, M. (1998), S. 70ff.

${ }^{84}$ Gutenberg entwickelte ein Produktionsfaktorsystem, das zwischen menschlicher Arbeit, Betriebsmitteln und Werkstoffen unterscheidet. Ausgehend von einer derartigen Unterteilung lassen sich Elementarfaktoren und dispositive Faktoren sowie Potential- und Verbrauchsfaktoren unterscheiden. Aber in diese Einteilung können einige bei der Produktion einzusetzenden Faktoren wie z.B. Dienstleistungen (Versicherungs- und Speditionsleistungen), Immaterialgüterrechte (Patente, Lizenzen) sowie freie (natürliche Ressourcen wie Licht oder Luft) und öffentliche Gii- 
lung natürlicher Ressourcen als Inputfaktor bei Vorliegen von Marktpreisen und Knappheit für die Produktionsprozesse betrachtet. Dabei ist die natürliche Umwelt auch als produktiver Faktor zu berücksichtigen. ${ }^{85}$ Aber bei dieser Betrachtungsweise werden angesichts des Marktversagens bei Umweltgütern outputbezogene Wirkungen, d.h. die Einbeziehung „externer Effekte“ der Produktion, im System der Produktionsfaktoren vernachlässigt, ${ }^{86}$ weil Leistungserstellungsprozesse jeglicher Art sowohl unerwünschte Kuppelprodukte als auch erwünschte Konsum- und Investitionsgüter bereitstellen, die ebenfalls die Trägerfunktion der Umwelt in Anspruch nehmen. In der Vergangenheit waren viele Umweltgüter nicht knapp, wodurch eine Verwendungsbeschränkung entfielt und für die Nutzer keine Kosten entstanden. Die natürliche Umwelt wird damit im klassischen Faktorsystem als Kollektivgut oder freies Gut betrachtet, das keine Person von der Nutzung ausschließen kann. Durch die Überbeanspruchung wurde sie knapp behandelt.

Ansätze zur Berïcksichtigung der Umweltnutzung im Rahmen der Produktionstheorie werden neben der zu maximierenden Zielfunktion (Gewinn, Deckungsbeitrag) und den üblichen Nebenbedingungen (Kapazitätsrestriktion, Absatzrestriktion und Nichtnegativitätsbedingungen) als ökologieorientierte Restriktionen einbezogen, wie z.B. Ressourcenrestriktionen, Abfall- und Schadstoffrestriktionen und andere Technologierestriktionen, die die verschiedenen, im Produktionsprozeß alternativ oder neu einzusetzenden Umweltschutztechnologien durch Prozeßkombinationen mit den ursprünglichen Produktionstechnologien berücksichtigen. ${ }^{87}$ Die Nutzung der natürlichen Umwelt wird hierbei als mengenmäßige Restriktion aufgefaßt, wobei die Höhe der Restriktionen aus gesetzlich fixierten Grenzwerten abzuleiten ist. Damit unterstellt dieser Ansatz ein eher reaktives Umweltschutzverhalten, d.h. Unternehmen reagieren hierbei erst, wenn eine Knappheit des Produktionsfaktors Umwelt entsteht. Bei betriebswirtschaftlichen Überlegungen zum Umweltschutz werden auch die marktbezogenen Chancen nicht berücksichtigt. Darüber hinaus wird die Ausrichtung der Optimierungsansätze an ökonomischen Zielgrößen wie Gewinn oder Deckungsbeitrag zu eng gefaßt, um den Legitimitäts- und Imagezielen im Markt und in der Gesellschaft Rechnung zu tragen. ${ }^{88}$

\footnotetext{
ter (staatliche Leistungen) nur schwer eingeordnet werden. Vgl. Gutenberg, E. (1983), S. 3ff.; Strebel, H. (1980), S. $38 f$.

${ }^{85}$ Vgl. zu näheren Ausführungen Steven, M. (1991), S. 509ff.; Strebel, H. (1980), S. 38ff.

86 Als Aufnahmemedium für Kondukte wird die ökologische Umwelt weitgehend kostenfrei in Anspruch genommen. Deren begrenzte Aufnahme- und Absorptionsfähigkeit für den unerwünschten Output wirkt sich aber wiederum auf den Preis der ökologischen Umwelt als Inputfaktor aus, indem z.B. Wasser aufbereitet werden muß, um einen gewünschten Reinheits grad zu erlangen. Vgl. Schmidtchen, D. (1980), S. 339.

${ }^{87}$ Vgl. Meffert, H./Kirchgeorg, M. (1998), S. 42.

${ }^{88}$ Vgl. Meffert, H./Kirchgeorg, M. (1998), S. 44.
} 
Eine wesentliche Weiterführung produktionstheoretischer Analysen brachte die Auseinandersetzung mit dem Recyclinggedanken. ${ }^{89}$ Die Ansätze eines inner- und überbetrieblichen Recycling in seinen Ausprägungsformen, Wieder- und Weiterverwendung oder Wieder- und Weiterverwertung fanden Eingang in die Diskussion über die Gestaltung des Kreislaufwirtschaftsgesetzes. Darüber hinaus kam es im Zuge der Recycling-Diskussion zu einer ökologieorientierten Erweiterung der (traditionellen) Güterklassifikation. Emissionen werden als „Produktionsfaktoren“ aufgefaßt. So wird in neueren theoretischen Grundlagen einer umweltorientierten Produktionswirtschaft auf der Inputseite zwischen Gut-, Bei- und Übelfaktoren ${ }^{90}$ und auf der Outputseite zwischen Produkten und erwünschten oder unerwünschten Nebenprodukten ${ }^{91}$ unterschieden. Daraus folgt in Erweiterung des traditionellen Wirtschaftlichkeitsprinzips die Zielsetzung, den erwünschten Input und Output zu maximieren und den unerwünschten Input und Output zu minimieren. ${ }^{92}$

Die aktuelle umweltbezogene Diskussion in der Produktionstheorie und -planung ist im wesentlichen durch die Berücksichtigung ökologieorientierter Aspekte bei der Wahl der Produktionstechnologie, ${ }^{93}$ bei der Verfeinerung linearer Aktivitätsanalysen ${ }^{94}$ und bei der Entwicklung integrierter Systeme zur Produktions- und Recyclingplanung ${ }^{95}$ geprägt.

In produktionsnahen betrieblichen Funktionen sind ebenfalls bemerkenswerte Anstrengungen zur Einbeziehung von Belangen des Umweltschutzes festzustellen. Im Bereich der Materialwirtschaft $^{96}$ stehen dabei neben einer umweltfreundlichen Materialbeschaffung die Steigerung der Materialeffizienz und die Verwirklichung von Kreislaufstrategien im Vordergrund. Daneben wird besonders die Notwendigkeit einer rückstands- und verwertungsorientierten Forschung und Entwicklung betont. ${ }^{97}$ Schließlich sind im Bereich Logistik vielfältige Ansatzpunkte für Umweltentlastungen im Transportwesen ${ }^{98}$ und der Entsorgungslogistik ${ }^{99}$ aufgezeigt worden.

Rechnungs- und Informationswesen: Als Ausgangspunkt einer umweltbezogenen Unternehmensrechnungslegung sind Sozialbilanzen zu suchen, die die Einbeziehung sozialer Kosten in

\footnotetext{
${ }^{89}$ Vgl. Berg, C. C. (1979); Strebel, H. (1980).

${ }^{90}$ Vgl. Dyckhoff, H. (1991), S. $275 \mathrm{ff}$.

${ }^{91}$ Vgl. Dinkelbach, W. (1996), Sp. 1338ff.

${ }^{92}$ Vgl. Dyckhoff, H. (1991), S. $275 \mathrm{ff}$.

${ }^{93}$ Vgl. Kistner, K.-P. (1989), S. 30ff.

${ }^{94}$ Vgl. Kistner, K.-P./Steven, M. (1993), S. 106ff.

${ }^{95}$ Vgl. Rautenstrauch, C. (1993), S. 87ff.

${ }^{96}$ Vgl. Stahlmann, V. (1988).

${ }^{97}$ Vgl. Strebel, H. (1988), S. $97 \mathrm{ff}$.

${ }^{98}$ Vgl. Dyckhoff, H./Soukal, R. (1996), S. 43ff.

${ }^{99}$ Vgl. Wildemann, H. (1996), S. 58ff.
} 
das betriebliche Rechnungswesen versuchen. ${ }^{100}$ Regelmäßiger Bestandteil dieser auf freiwilliger Basis erstellten und veröffentlichten Bilanzen bildete die quantitative oder auch nur verbale Beschreibung externer Umwelteffekte. Allerdings beschränken vielfältige Kritikpunkte (wie z.B. Unschärfen bei der Ermittlung der auszuweisenden Werte, eine fehlende Normierung, keine externe Prüfungs- und Sanktionierungsmöglichkeit) den Einsatz von Umwelt- und Sozialbilanzen als externes Rechnungslegungsinstrument.

Statt dessen wird die Verwendung von Umweltkennziffern in Form eines mehrdimensional angelegten Indikatorensystems vorgeschlagen. Allerdings liefern auch Umweltkennziffern bei Verlagerungen von Umweltbelastungen zwischen einzelnen Medien keine gültigen Bewertungs- und Entscheidungsmaßstäbe. Zur Behebung dieses Defizits hat Müller-Wenk einen vielbeachteten Entwurf einer ökologischen Buchhaltung vorgelegt. ${ }^{101}$ Sein Buchhaltungssystem mißt in einem ersten Schritt die betrieblichen Umwelteinwirkungen in einem kontenartigen Erfassungssystem. Über die Einführung von Äquivalenzkoeffizienten werden die jeweiligen Umwelteinwirkungen dann zu einer Maßzahl der Gesamteinwirkung eines Unternehmens zusammengefaßt. Trotz eines stringenten logischen Aufbaus hat die ökologische Buchhaltung in der betrieblichen Praxis lediglich eine geringe Verbreitung erfahren. Neben einer ausgeprägten Komplexität der Datenerhebung sind die bei der Bemessung der Äquivalenzkoeffizienten auftretenden Probleme (knappheitsorientierte Bewertung, Mehrdimensionalität ökologisch relevanter Dimensionen) als Haupthindernis bei der Umsetzung zu bezeichnen.

Eine andere Vorstellung zur Monetarisierung von Umwelteinwirkungen liegt dem Vermeidungskosten-Ansatz zugrunde. In diese Richtung zielen z.B. die Vorschläge, Vorsorge-, Recycling-, Entsorgungs- und Sicherheitsmaßnahmen in Form von kompensierten Umweltschutzkosten und umweltschutzorientierten Opportunitätskosten in Investitions- und Erlös-Kostenrechnungen explizit einzubeziehen. ${ }^{102}$ Darüber hinaus wird empfohlen, für alle nicht internalisierten Kosten im Rahmen einer ökologieorientierten Kostenrechnung Kostenpotentialanalysen durchzufahren, um mögliche Schwachstellen $\mathrm{zu}$ identifizieren und fehlende oder $\mathrm{zu}$ teure Umweltschutzmaßnahmen aufzudecken. Die damit verbundenen Meß-, Aggregations- und Bewertungsprobleme bleiben indes weitgehend offen.

Auch wenn die betriebswirtschaftlichen Bemühungen um eine umfassende Bewertung aller von einem Unternehmen ausgehenden realen Umweltbelastungen bisher nicht einer konsensfähigen

\footnotetext{
${ }^{100}$ Vgl. z. B. Dierkes, M. (1974).

${ }^{101}$ Vgl. Müller-Wenk, R. (1978).
} 
Lösung zugeführt werden konnten, so hat es doch im Bereich des Öko-Controlling eine beachtliche Entwicklung von Ansätzen gegeben, die geeignet sind, eine proaktive ökologisch verpflichtete Unternehmensführung $\mathrm{zu}$ unterstützen. Hervorzuheben sind der Bereich überwiegend stofflich orientierter Öko-Bilanzen mit ihren vielfältigen Unterformen, das Technology Assessment, ${ }^{103}$ die Produktlinienanalyse und schließlich das Öko-Audit. Hierbei spielt auch die Umweltinformatik, die sich seit Mitte der 80er Jahre mit der Entwicklung EDV-gestützter Umweltinformationssysteme in Betrieben auseinandersetzt, eine ganz wichtige Rolle. ${ }^{104}$

Marketing: Auch im Marketing sind Bestrebungen für eine Berücksichtigung ökologieorientierter Anforderungen $\mathrm{zu}$ finden. Dem kommerziellen, am Wachstum ausgerichteten Marketing werden verschiedene negative Folgen auf die ökologische Umwelt angelastet wie z.B. Ausbeutung der Rohstoffressourcen insbesondere infolge von Obsoleszenzstrategien, zu wenig Berücksichtigung der eigentlichen Bedürfnisse und Wünsche der Verbraucher (z.B. Angebot umweltsowie gesundheitsgefährdender Produkte), Hang zur Verschwendung (z.B. durch Werbeanreize, Produktdifferenzierung, Verkürzung der Lebensdauer der Produkte). Diese Folgen werden dabei als Hauptverursacher der konsumbedingten Umweltprobleme angesehen. ${ }^{105}$ Aber andererseits können umweltverträglichere Problemlösungen vielfach nur durch marketingpolitische Maßnahmen am Markt erfolgreich durchgesetzt werden. Dabei wird Marketing vielfach als diejenige

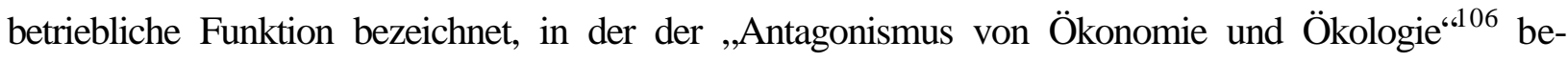
sonders offenkundig ist.

Im Zuge der weiteren Entwicklung wurden im Marketing vor allem die folgenden Aspekte der ökologisch verpflichteten Unternehmensführung aufgegriffen: ${ }^{107}$

Analyse und Erklärung des umweltbewußten Konsumentenverhaltens unter besonderer Berücksichtigung der Divergenzen zwischen Umweltbewußtsein und -verhalten.

Ausbau und Erweiterung der klassischen Marketinginstrumente um ökologische Aspekte (Produktgestaltung im Wertschöpfungskreislauf, Verpackungsproblematik, Öko-Label, Retrodistributionssysteme).

\footnotetext{
${ }^{102}$ Vgl. Frese, E./Kloock, J. (1989), S. 1ff.

${ }^{103}$ Vgl. Dierkes, M. (1974).

${ }^{104}$ Vgl. Arndt, H.-K./Günther, O. (1996), S. 11ff.

${ }^{105}$ Vgl. Meffert, H./Bruhn, M./Schubert, F./Walther, T. (1986); Raffée, H./Wiedmann, K.-P. (1985).

${ }^{106}$ Vgl. Seidel, E./Strebel, H. (1991).

${ }^{107}$ Vgl. Hansen, U. (1992); Meffert, H. (1991).

${ }^{107}$ Vgl. Meffert, H. (1991).
} 
- Die Rolle des Handels als „ökologischer Gatekeeper“, die veränderte Funktionsverteilung in Absatzkanälen im Rahmen der Retrodistribution und Kooperation und Konflikte in integrierten Entsorgungs- und Recyclingsystemen (z.B. Duales System).

- Grundtypen und Erfolgsvoraussetzungen umweltorientierter Wettbewerbsstrategien.

Ausdehnung des Marketing auf gesellschaftliche Anspruchsgruppen und Lösung von Umweltproblemen durch soziales Marketing.

Vielfach wurde mit Hinweis auf den Kollektivgutcharakter und den Risikoaspekt von Umweltprodukten im Zusammenhang mit dem Einsatz von absatzpolitischen Instrumenten (z.B. Werbung) die Kritik einer unreflektierten und verkürzten Übertragung herkömmlicher Marketinggedanken laut. Erkenntnisfortschritte brachten hier institutionenökonomische Betrachtungen, z.B. bei den Problemen der Überwindung von lnformationsasymmetrien zwischen Anbietern und Nachfragern beim Verkauf von Produkten mit umweltorientierten Leistungsmerkmalen, ${ }^{108}$ die angesichts des Vertrauensgutcharakters ökologischer Produkteigenschaften auf besondere Formen der Leistungsbegründung (z.B. Signaling, Labeling) zur Förderung von umweltorientierten Markttransaktionen hinweisen und durch Differenzierung individueller und kollektiver Nutzenvorstellungen wesentlich zur Standortbestimmung des Öko-Marketing beigetragen haben.

Bei der Erweiterung des kommerziellen Marketing bzw. der absatzorientierten Unternehmenspolitik um ökologische Entscheidungsfaktoren ist nach Seidel/Menn im allgemeinen zu berücksichtigen: $^{109}$

- Integration des Umweltschutzgedankens in alle Teilbereiche des betrieblichen MarketingMix (Leitideen einer modernen Marketing-Philosophie).

- Verlagerung der Sicht von der Bedürfnisweckung - als zentralem Aspekt konventionellen Marketings - zur relativen Begrenzheit von Rohstoffen, Umweltgütern etc.

- Wendung der Verstärkungs- und Beeinflussungspotentiale der Marketinginstrumente und techniken hin zur Forcierung angemessenen Umweltverhaltens (im Unternehmen und über das Unternehmen hinaus).

Abkehr von Marketingstrategien der geplanten Obsoleszenz von Produkten, der Scheininnovationen, der verschleiernden Werbebotschaften, der unangemessenen Produktdarreichung (z.B. Mogelpackungen).

- Verzicht auf weitere Forcierung von „Wegwerfmentalität“ und „Anspruchsinflationierung“.

\footnotetext{
${ }^{108}$ Vgl. Kaas, K. P. (1992).

${ }^{109}$ Vgl. Seidel, E./Menn, H. (1988), S. 132.
} 
Einbindung eines gesellschafts-ökologischen Marketings in das Konzept strategischer Unternehmensführung.

Kritik an „,(Selbst)Zerstörungsexporten“ in andere Länder, insbesondere der dritten Welt (z.B. Pestizide).

Organisation, Personal und Führung: Die Beiträge der Organisationsforschung zur Berücksichtigung von aufbau- und ablauforganisatorischen Anforderungen des Umweltschutzes befassen sich zunächst mit Fragen der Institutionalisierung von gesetzlich vorgeschriebenen Betriebsbeauftragten. ${ }^{110}$ Danach stoßen die organisatorischen Implikationen eines funktionsübergreifend und proaktiv angelegten Konzeptes der ökologisch verpflichteten Unternehmensführung in zunehmenderem Maße auf Interesse. Mit der Forderung „Umweltschutz ist Chefsache“ wird nicht nur der Stellenwert der ökologisch verpflichteten Unternehmensführung als Führungskonzept betont, sondern es werden auch - unter Rückgriff auf bekannte Organisationskonzepte Fragen nach adäquaten Organisationsmodellen der hierarchischen Einbindung von umweltverantwortlichen Macht- und Fachpromotoren laut. Dementsprechend konzentrieren sich die Forschungsarbeiten weitgehend auf verschiedene aufbauorganisatorische Aspekte bis hin zu Analysen geeigneter Formen der interorganisationalen Zusammenarbeit mit Behörden oder Systempartnern in Form von Kooperationen und Netzwerkarrangements. Die besondere Bedeutung einer dauerhaften aufbau- und ablauforganisatorischen Integration des Umweltschutzes ist mit der Einfuihrung des EG-Öko-Audits auch in seiner Praxisrelevanz unterstrichen worden.

Wenngleich die Bedeutung der Mitarbeitermotivation zum umweltorientierten Verhalten und die Schaffung unternehmenskultureller Voraussetzungen im Zusammenhang mit organisatorischen Fragen des Umweltschutzes zunehmend betont werden, steht die wissenschaftliche Durchdringung dieser Problemstellungen noch am Anfang. Vergleichsweise selten sind Arbeiten, die auf der Grundlage von Fallstudienanalysen arbeitspolitische Aspekte unternehmerischer Ökologiesierungspfade herausarbeiten. ${ }^{111}$ Frese und Kloock betonen, daß ,... in der Konzipierung eines Anreizsystems zur umweltbewußten Motivation der operativen Einheiten ohne Zweifel eine große Schwierigkeit bei der organisationalen Implementierung des Umweltschutzes liegt “. ${ }^{112}$ Traditionelle Koordinations- und Anreizsysteme, wie z.B. Profit-Center, vermögen eine Förderung des umweltorientierten Mitarbeiterverhaltens nicht zu leisten. Vielmehr muß sich in den Anreizmechanismen die Mehrdimensionalität des Zielbezuges der ökologisch verpflichteten Unternehmensführung niederschlagen. So bleibt denn vielfach der Verweis auf die Entwicklung ,öko-

\footnotetext{
${ }^{110}$ Vgl. Frese, E./Kloock, J. (1989).

${ }^{111}$ Vgl. Hildebrandt, E. (1995).
} 
logiebewußter Unternehmenskulturen“ im Sinne von ,shared values“, die - in Leitsätzen der Unternehmensführung verankert - umweltbewußtes Verhalten in Unternehmen fördern und ausrichten sollen. Ein am Leitbild des „Sustainable Development“ orientiertes Umweltmanagement wird auf dieser Umsetzungsstufe jedoch nicht verharren können. Statt dessen verlangen die Kernelemente des „Sustainable Development“ das Kreislauf-, Verantwortungs- und Kooperationsprinzip, eine weitergehende Implementierung innerhalb der Unternehmensstrukturen, systeme und -strategien.

Die Einbeziehung ökologischer Erfordernisse in die Funktionenlehren verdeutlicht insbesondere die „Allgegenwärtigkeit“ umweltschutzbezogener Problemfelder und somit die Notwendigkeit, ökologisch verpflichtete Unternehmensführung als funktionsübergreifendes Konzept zu begreifen. Fragt man im weiteren nach der programmatischen und theoretischen Verankerung der Integrationsbemühungen ökologischer Erfordernisse in der Betriebswirtschaftslehre, so haben sich bestehende Wissenschaftsprogramme in unterschiedlicher Weise der Umweltschutzthematik geöffnet. Je nach „Reichweite“ ihres paradigmatischen Fundaments sind mehr oder weniger starke Modifizierungen oder Erweiterungen der jeweiligen Theoriegebäude $\mathrm{zu}$ beobachten. Ohne Anspruch auf Vollständigkeit sind hier in erster Linie systemorientierte, entscheidungsorientierte und umweltethische Ansätze zu nennen. Diese betriebswirtschaftlichen Ansätze zur ökologisch verpflichteten Unternehmensführung in bezug auf betriebswirtschaftliche Wissenschaftsprogramme werden im folgenden dargestellt.

Systemorientierte Ansätze: Systemtheoretische Konzeptionen befassen sich mit den „Umwelten" des Systems Unternehmen ${ }^{113}$ und dabei entwickelten sich in der Betriebswirtschaftslehre eigenständige Bestrebungen, über systemtheoretische Betrachtungen differenzierte Einblicke in die Unternehmens-Umwelt-Beziehungen $\mathrm{zu}$ erlangen. ${ }^{114}$ In den systemtheoretischen Betrachtungen wird die Umwelt eines Unternehmens von unterschiedlichen Komponenten zusammengestellt und werden Umweltmodelle zur Strukturierung und Abgrenzung von Teilumwelten in verschiedenen Ansätzen diskutiert. Hierbei bildet neben poltisch-rechtlichen, gesellschaftlichen, ökonomischen und technischen Umweltsphären die natürliche bzw. ökologische Umwelt ein weiteres Subsystem. Mit Zunahme der Umweltprobleme wurden die Austauschbeziehungen zwischen Unternehmen und der natürlichen Umwelt in diesen Ansätze verstärkt berücksichtigt. Da die natürliche Umwelt sich nicht selbst artikulieren kann, werden die ökologischen Probleme der natür-

\footnotetext{
${ }^{112}$ Frese, E./Kloock, J. (1989).

${ }^{113}$ Vgl. z.B. Nüßgens, K. H. (1974), S. 111ff.

${ }^{114}$ Vgl. Meffert, H./Kirchgeorg, M. (1998), S. 60ff.
} 
lichen Umwelt in ihren gesellschaftlichen Problemdimensionen und damit im Rahmen des Anspruchsgruppen-Konzepts in ihren Implikationen für die Unternehmensführung untersucht. ${ }^{115}$

Die Erkenntnisfortschritte systemtheoretischer Überlegungen zur Integration des Umweltschutzes lassen sich dabei im wesentlichen an drei Punkten festmachen:

Die Interpretation von Unternehmen als offene zielgerichtete Systeme haben einen konzeptionellen Bezugsrahmen zur Berücksichtigung der direkten Wechselwirkung zwischen ökonomischen und ökologischen Systemen sowie der über gesellschaftliche und politischrechtliche Teilumwelten an die Unternehmen herangetragenen Umweltschutzforderungen geliefert. Eine tiefergehende Analyse der Austauschbeziehungen ist insbesondere unter Einbeziehung verhaltenstheoretischer (z.B. Stakeholderansatz, Koalitionsmodelle) und naturwissenschaftlicher Ansätze erfolgt.

Systemtheoretische Betrachtungen haben auch die Übertragung thermodynamischer Gesetzmäßigkeiten in die Sphäre betriebswirtschaftlicher Entscheidungen gefördert. GeorgescuRoegen hat auf die Zusammenhänge zwischen Produktion und Entropie hingewiesen ${ }^{116}$ und verdeutlicht, daß Produktions-, Konsum- oder Recyclingprozesse als irreversible stoffliche und energetische Umwandlungsprozesse zu begreifen sind. Obwohl die Anwendungsvoraussetzungen und Operationalisierung des Konstruktes „Entropie“ für betriebswirtschaftliche Überlegungen bis heute einer kontroversen Diskussion unterliegen, ist entsprechendes Gedankengut in vielfältiger Weise in die Methoden und Sichtweisen der ökologisch verpflichteten Unternehmensfuihrung eingeflossen. Nicht zuletzt findet die energetische und stoffliche Gegenüberstellung von Input- und Outputfaktoren in Ansätzen der Öko-Bilanzierung mit Bezug auf thermodynamische Gesetzmäßigkeiten ihre Begründung. Darüber hinaus betonen entropische Betrachtungen die Unabdingbarkeit einer holistischen Analyse der Umwelteinwirkungen von Produktions-, Konsum-, Recycling- und Entsorgungsprozessen in einem vernetzten ökologischen Gesamtsystem.

- Die systemtheoretischen Betrachtungen haben auch die Öffnung der Betriebswirtschaftslehre für Erkenntnisse und Analogieschlüsse anderer Disziplinen gefördert. Hervorzuheben sind in diesem Zusammenhang die in den 70er Jahren insbesondere von der St. Galler Schule entwickelten biokybernetischen Systemansätze. Erkenntnisse und Gesetzmäßigkeiten der Ökosystemforschung werden hierbei auf betriebswirtschaftliche Fragestellungen projiziert, um neuartige Entscheidungshilfen für die strategische Unternehmensführung zu liefern. Auch bei der

\footnotetext{
$\overline{115}$ Vgl. z.B. Janisch, M. (1993); Dyllick, T. (1989); Wiesner, J. (1983).

${ }^{116}$ Vgl. Georgescu-Roegen, N. (1971).
} 
wissenschaftlichen Durchdringung von Ansätzen des „Sustainable Development“ liefern systemtheoretische Betrachtungen des Modells einer Kreislaufwirtschaft wertvolle Anregungen.

Der besondere Erkenntniswert systemtheoretischer Ansätze für die ökologisch verpflichtete Unternehmensführung ist in ihrer Strukturierungs- und Beschreibungsfunktion komplexer Beziehungsgeflechte zwischen ökologischen und ökonomischen Systemen begründet. Im Sinne einer Meta-Theorie haben sie eine interdisziplinäre Ausrichtung und die Einbeziehung naturwissenschaftlicher Erkenntnisse in betriebswirtschaftliche Überlegungen gefördert. Ihr Beitrag zur prozessualen und konzeptionellen Ausgestaltung einer ökologisch verpflichteten Unternehmensführung ist allerdings bisher als begrenzt einzustufen.

Entscheidungsorientierte Ansätze: Entscheidungsorientierte Ansätze erfassen Aussagen über rationale Wahlhandlungen des verantwortlichen Managements. ${ }^{117}$ Sie können den Problemen des Umweltschutzes im Rahmen der Ziel- oder Mittelentscheidungen Rechnung tragen. ${ }^{118}$ Umweltschutzüberlegungen können dabei zu einer Anpassung oder Erweiterung des Zielsystems des Unternehmens und damit der entsprechenden strategischen und operativen Planung führen. Entscheidungsorientierte Ansätze haben - ausgehend vom Paradigma der Bewertung von Alternativen - insbesondere zur systematischen Einbeziehung des Umweltschutzes bei Ziel- und Mittelentscheidungen einen wichtigen Beitrag geleistet und damit den Stellenwert der ökologisch verpflichteten Unternehmensführung als Führungsaufgabe verdeutlicht. Durch die Betonung der Abhängigkeit betriebswirtschaftlicher Ziel- und Mittelentscheidungen von alternativen Umweltzuständen sind aufgrund veränderter umweltgesetzlicher Restriktionen, Forderungen gesellschaftlicher Anspruchsgruppen und eines zunehmenden umweltbezogenen Konsumenten- und Wettbewerbsverhaltens die Erweiterungsmöglichkeiten unternehmensbezogener Zielsysteme und Anpassungserfordernisse in allen Phasen des unternehmerischen Entscheidungsprozesses in den Mittelpunkt entscheidungsorientierter Analysen des Umweltschutzes gestellt worden.

Die damit veränderten Zielpräferenzen des Unternehmens bilden neue Bewertungsmaßstäbe für die Lösung möglicher Konflikte zwischen ökonomischen und ökologischen Zielen heraus. Aus-

\footnotetext{
117 Vgl. zu näheren Ausführungen Meffert, H./Kirchgeorg, M. (1998), S. 66ff.; Terhart, K. (1986); Rückle, D./Terhart, K. (1986), S. 393ff.; Stitzel, M. (1987), S, 673ff.; Rückle, D. (1992), S. 57ff.

118 Die Entscheidungsprobleme sind mit den Begriffen Ziele, Alternativen bzw. Aktionen, Umweltzustände und Konsequenzen bzw. Entscheidungsresultate zu beschreiben. Damit kann der Begriff „Umweltzustand” formal nur so interpretiert werden, daß die Variablen der verschiedenen Umweltsphären wie z.B. Natur, Rechtsordnung, Gesellschaft und Wettbewerbsverhalten nicht kontrolliert werden können.
} 
gangspunkt dieses Prozeßmodells bildet die Situationsanalyse, in der unternehmensinterne und -externe Rahmenbedingungen zu erfassen sind. ${ }^{119}$

Neben der Analyse des Stellenwerts des Umweltschutzes im Zielsystem der Unternehmen widmen sich die Arbeiten insbesondere der Identifikation und Erklärung komplementärer und konfliktärer Beziehungen zwischen ökonomischen und ökologischen Zielkategorien. Hierdurch ist der Blick für umweltschutzinduzierte Zielkonflikte und mögliche Ansatzpunkte ihrer Überwindung im Rahmen der strategischen und operativen Planung geschärft worden. Im Rahmen der Mittelentscheidungen haben entscheidungsorientierte Sichtweisen insbesondere zur Ausdifferenzierung von strategischen Ansätzen in ökologisch verpflichteter Unternehmensführung beigetragen, die von der Modifikation strategischer Planungsinstrumente über die Adaption wettbewerbs- und gesellschaftsbezogener Strategieansätze bis hin zur Ausgestaltung von Risikostrategien reicht. ${ }^{120}$ Die primär funktionsübergreifend angelegten Strategieansätze haben eine integrierte Ausrichtung und Durchsetzung von Umweltschutzmaßnahmen gefördert.

Somit ist dem entscheidungsorientierten Ansatz eine integrative Wirkung bei der umweltorientierten Ausrichtung von Unternehmensentscheidungen zuzusprechen. Allerdings wird die systematische Entscheidungsfindung durch Zielsetzungs-, Bewertungs-, Wirkungs- und Lösungsdefekte erschwert, für deren Lösung interdisziplinären Bezügen zu wenig Beachtung geschenkt wird. Offen bleiben weiterhin Lösungsansätze inhaltlicher Probleme des Umweltschutzes, Werturteilsprobleme bei der Entschärfung von Zielkonflikten sowie Rückkopplungsmechanismen in dynamischen Systemen.

Der entscheidungsorientierte Ansatz zeigt ein breites Spektrum von Möglichkeiten auf, wie der Umweltschutz systematisch in den Planungsprozeß des Unternehmens integriert werden kann. Dabei können im ökologisch verpflichteten Entscheidungsprozeß einige Schwierigkeiten in Bezug auf inhaltliche Probleme des Umweltschutzes (z.B. Umwelt als Produktions- und Wettbewerbsfaktor) und Werturteils- und Anspruchsprobleme bei der Zielbildung sowie Rück-

\footnotetext{
${ }^{119}$ In der ökologieorientierten Situationsanalyse wird versucht, die Beziehungen und Wechselwirkungen in der ökologischen, ökonomischen, gesellschaftlichen, technologischen und politisch-rechtlichen sowie marktbezogenen Umwelt zu analysieren und die ökologischen Chancen und Risiken (externe Faktoren) für das Unternehmen darzustellen. Darüber hinaus sind die Stärken und Schwächen des internen Bedingungsrahmens (interne Faktoren) zur Bestimmung der strategischen Ausgangsposition zu ermitteln. Die Situationsanalyse bildet als Ausgangspunkt die notwendige Voraussetzung für die weitere ökologiegerechte Festlegung der Unternehmensphilosophie und -grundsätze sowie die Formulierung und Einbeziehung von ökologieorientierten Unternehmenszielen in das Ziels ystem des Unternehmens. Daraus sind entsprechende Strategien zur Begegnung der ökologischen Herausforderungen abzuleiten. Schließlich erfordert die Umsetzung eines erfolgreichen integrierten Umweltmanagements den Einsatz entsprechender Umweltschutzmaßnahmen in allen Unternehmensfunktionen. Vgl. z. B. Sauer, B. (1993) sowie Kap. 4.2 dieser Arbeit.
} 
koplungsmechanismen in dynamischen Systemen entstehen. ${ }^{121}$ Entscheidungsorientierte Ansätze werden daher dem Komplexitätsdruck der umweltverpflichteten Unternehmensführung und der besonderen Dynamik ökologischer Herausforderungen nicht gerecht.

Umweltethische Ansätze: Ethische Fragestellungen beschäftigen sich mit der „Suche nach dem rechten Handeln", sofern Unternehmen einen Handlungsspielraum haben. ${ }^{122}$ Umweltethik bildet hierbei ein Korrektiv zur ökonomischen Rationalität, das im Sinne einer Öko-Rationalität als Synthese eines ökonomisch rationalen und ökologischen Handelns realisiert werden soll. ${ }^{123}$

Die Beantwortung der Sinnfrage ökologisch verpflichteten Unternehmensverhaltens steht im Mittelpunkt unternehmensethischer Betrachtungen. Werturteilsfragen werden von Vertretern sog. konstruktivistischer Ansätze explizit in die betriebswirtschaftliche Forschung einbezogen. Dabei wird der Wert der natürlichen Umwelt aus einer anthropozentrischen, biozentrischen und holistischen Perspektive beleuchtet. ${ }^{124}$ Es wird das Retinitätsprinzip als Schlüsselprinzip einer Umweltethik aufgegriffen, das die Einsicht der Gesamtvernetzung des Menschen mit der ,ihn tragenden Natur“ zum Prinzip umweltorientierten Handelns erhebt. Orientiert am Retinitätsprinzip kann dem Konzept des „Sustainable Development“ in seiner statischen (Gegenwartsverantwortung) wie auch dynamischen Betrachtung (Zukunftsverantwortung) zur Förderung der Einsicht in die Gesamtvernetzung von Ökonomie und Ökologie ein besonderer Stellenwert beigemessen werden. ${ }^{125}$ Ulrich merkt allerdings an: „Mit dem einfachen Postulat der Übernahme sozialer und ökologischer Verantwortung durch die Unternehmensleitung ist es nicht getan. Solange nämlich die Anreize des Marktes selbst noch Ausdruck 'organisierter Unverantwortlichkeit' sind, besteht eine Dilemmasituation für den Unternehmer zwischen Ethik und Erfolg“،. ${ }^{26}$

Ulrich sieht in der Leitidee einer integrativen Unternehmensethik einen Lösungsansatz. Die Entscheidungsträger werden aufgefordert, die Schnittmenge zwischen unternehmensethischem Handeln und ökonomischem Erfolg zu maximieren und gleichzeitig eine ordnungspolitische Mitverantwortung zu übernehmen, um im Sinne eines öffentlichen Diskurses den Ausbau einer umwelt-

\footnotetext{
${ }^{120}$ Vgl. Kreikebaum, H. (1993); Dyllick, T. (1989); Steger, U. (1988); Meffert, H./Kirchgeorg, M. (1998), S. 66ff.

${ }^{121}$ Vgl. Meffert, H./Kirchgeorg, M. (1998), S. 68.

122 Vgl. zu näheren Ausführungen z.B. Seifert, E./Pfriem, R. (1989); Seidel, E. (1989), S. 161ff.; Stitzel, M. (1990), S. 101ff.; Steinmann, H./Löhr, A. (1992), S. 183ff.; Dichtl, E. (1991), S. 269.

${ }^{123}$ Vgl. Thielemann, U. (1990), S. 59.

124 Aus der Sicht einer anthropozentrischen Umweltethik wird der Wert der Umwelt aus ihrer Nutzenstiftung für den Menschen heraus definiert. Darüber hinaus fordert die biozentrische Umweltethik die Verantwortung für den Schutz aller Lebewesen und Pflanzen, die leidensfähig sind. Hingegen verzichtet die holistische Umweltethik auf eine Wertdifferenzierung zwischen unterschiedlichen Naturelementen nach der Verhaltensnorm ,jeder nimmt auf alles Rücksicht“. Vgl. hierzu Stitzel, M. (1991), S. 101ff.

${ }^{125}$ Vgl. zum Retinitätsprinzip der Umweltethik SRU (1994); Meffert, H./Kirchgeorg, M. (1998), S. $51 f$.
} 
sowie sozialverträglichen Rahmenordnung für die Marktwirtschaft voranzutreiben. Letzteres erfordere den Aufbau von dialogischen Verständigungspotentialen mit allen Stakeholdern. Ereignisse um die Brent Spar oder aktuell um die wieder auflebende Diskussion der Atommüllentsorgung unterstreichen den zukunftsweisenden Charakter von „dialogischen Verständigungsprozessen“. 127

Eine bewußte Abkehr der praktisch-normativen Sicht entscheidungsorientierter Ansätze wird auch von Vertretern einer sozial-ökologischen Betriebswirtschaftslehre beschritten. ${ }^{128}$ Ökologieorientiertes Unternehmensverhalten wird als alternatives Leitprinzip zum wirtschaftlichen Denken und Handeln von Unternehmen verstanden. So fordert Freimann „eine neue Bescheidenheit im interdisziplinären Diskurs“, dem in erster Linie eine Aufklärungs- und in zweiter Linie eine Gestaltungsfunktion zugesprochen wird. ${ }^{129}$ Vertreter dieses Ansatzes wählen einen am Mengengerüst ökonomischer Aktivitäten orientierten realökonomischen Zugang, um betriebswirtschaftliche Fragestellungen im Kontext der ökologischen Problemstellungen von Grund auf zu hinterfragen. Dabei wird der Entwicklung von Methoden zur Erfassung und Analyse der komplexen ökologischen Wirkungsdimensionen ökonomischen Handelns ein besonderer Stellenwert eingeräumt. Allerdings stellen sich ungelöste Fragen bei der Synthese des aus realökonomischen Erkenntnissen abgeleiteten Mengengerüstes mit der Wertkomponente, um zwischen einem Mehr an Umweltqualität und einem Mehr an Gütern abzuwägen. Wenn Vertreter der realökonomischen Ansätze darauf verweisen, die Prägungen und Deformationen der Realökonomie durch monetäre Orientierungen und Kalküle zu entdecken, stellt sich unweigerlich ein Entscheidungsdilemma. ${ }^{130}$

Mit dem Bekenntnis der Betriebswirtschaftslehre, verantwortungsethische Grundsätze als Korrektiv gegenüber der ökonomischen Rationalität zuzulassen, stellt sich die Frage nach dem vermeintlichen Postulat der Wertfreiheit. Allerdings scheint der funktions- und unternehmensübergreifende Charakter einer ökologisch verpflichteten Unternehmensführung für die Entscheidungsträger weit mehr Einsicht in und Verantwortung für eine dauerhafte „Gesamtvernetzung“ zu erfordern.

Die oben vorgestellten Ansätze zeigen ein breites Spektrum von Möglichkeiten auf, wie der Umweltschutz systematisch in die Planung von Unternehmen integriert werden kann. Trotz dieser Möglichkeiten können die betriebswirtschaftlichen Überlegungen zum Umweltschutz - iso-

\footnotetext{
${ }^{126}$ Ulrich, P. (1991).

${ }^{127}$ Vgl. zu den dialogethische Konzepte im Umweltbereich z.B. Steinmann, H./Löhr, A. (1991); Hansen, U. (1995).

${ }^{128}$ Vgl. zum sozial-ökologischen Ansatz im Umweltschutz Meffert, H./Kirchgeorg, M. (1998), S. 68ff.

${ }^{129}$ Vgl. Freimann, J. (1991), S. $73 \mathrm{ff}$.
} 
liert betrachtet - in kleinster Weise ein vollständiges Bild der Wechselbeziehungen zwischen Ökologie und Ökonomie im Sinne einer integrierten ökologisch verpflichteten Unternehmensführung liefern. Unternehmen müssen also die Wirkung ihres Handelns auf die natürliche Umwelt in seiner Vielschichtigkeit berücksichtigen. In den Begründungsansätzen z.B. „Umwelt als Produktionsfaktor“ und „relativ-entscheidungsorientierter Ansatz des Umweltschutzes“ wird der Umweltschutz als Restriktion unternehmerischen Handelns betrachtet und damit auf einzelne betriebliche Funktionen beschränkt. Dagegen wird in den integrativen und funktionsübergreifenden Ansätzen der Umweltschutz als unternehmensbezogene Chance angesehen. Die verschiedenen Betrachtungsweisen sollten sich daher ergänzen. Die betriebswirtschaftlichen Überlegungen, die z.B. sowohl eine Systemorientierung als auch eine Entscheidungsorientierung über alle Zielhorizonte der ökologisch verpflichteten Unternehmensführung umfassen, werden als integrierte Konzeptionen bezeichnet. ${ }^{131}$

\section{4 Ökologische Verpflichtung der Unternehmensführung}

Angesichts der vielerlei katastrophenträchtigen Konsequenzen der Umweltprobleme in ihren ökologischen, gesellschaftlichen und wettbewerbsstrategischen Dimensionen liegen die Herausforderungen der Unternehmensführung in einer offensiven, marktorientierten Auseinandersetzung mit den Umweltproblemen. Aufgrund der unterschiedlichen Erkenntnisziele und deskriptiven oder normativen Bezugnahme der einzelnen betriebswirtschaftlichen Ansätze ist aber festzuhalten, daß im Rahmen der ökologisch verpflichteten Betriebswirtschaftslehre, trotz der in letzter Zeit zunehmend unternommenen Versuche einer Integration und Zusammenfassung, eine Vielzahl von Begriffen verwendet wird. Es werden vor allem die Begriffe ,betriebliche Umweltökonomie“, „ökologisch orientierte Unternehmenspolitik“, „ökologieorientierte Unternehmensführung“, „betriebswirtschaftliche Umweltpolitik“ oder „strategisches Ökologiemanagement“, „,marktorientiertes Umweltmanagement“ etc. gebraucht, ohne damit allerdings einen einheitlichen Vorstellungsinhalt zu verbinden. ${ }^{132}$ Statt der oben erwähnten Begriffe wird in dieser Arbeit der Begriff „ökologisch verpflichtete Unternehmensführung“ verwendet, um damit erkenntlich zu machen, daß das Geschehen in Unternehmen in Bezug auf Umweltschutz nicht als Können oder Müssen sondern vielmehr als Sollen betrachtet wird. Dieses ethische Verhalten zum Um-

\footnotetext{
${ }^{130}$ Vgl. Freimann, J. (1991), S. 73ff.

${ }^{131}$ Vgl. Meffert, H./Kirchgeorg, M. (1998), S. 70ff.

${ }^{132}$ In der vorliegenden Arbeit werden die Begriffe wie z.B. Umweltmanagement etc. mit einer ökologisch verpflichteten Unternehmensführung als Synonym behandelt, denn insbesondere das Umweltprogramme gemäß der EMASVerordnung und ISO 14001, d.h. der UMS-Normsysteme beschäftigen sich mit dem Begriff von „Umweltmanagement".
} 
weltschutz setzt die Antizipation der Konsequenzen unternehmerischer Aktivitäten für alle Gesellschaftsgruppen und zukünftige Generationen voraus. ${ }^{133}$

Um die Bedeutung der Ökologieverpflichtung bzw. -orientierung der Unternehmensfuihrung besser überblicken zu können, soll aber hier vorher die Kreislaufwirtschaft, die mit der ökologisch verpflichteten Unternehmensführung in enger Verbindung stehen soll, kurz dargestellt werden.

Die von Menschen gemachte und betriebene Wirtschaft (Ökonosphäre) steht mit einer natürlichen Umwelt (Ökosphäre) in Wechselbeziehungen. Die Wirtschaft bezieht aus der Umwelt Ressourcen in Form primärer Materie und Energie, wandelt diese durch Produktion in ökonomisch höherwertige Produkte um und gibt diese nach Ge- oder Verbrauch in Form von Rest- oder Abfallstoffen wieder an die Umwelt ab. Durch die Prozesse der Wirtschaft werden außerdem Giftstoffe und Abwärme erzeugt und in die Umwelt transferiert. In diesem Modell der Durchflußwirtschaft wird die Umwelt gleichzeitig als unerschöpfliches Reservoir (Quelle) von Materie und Energie einerseits und als unbegrenzter Abfalldeponieraum (Senke) oder Schadstoffabsorptionsmechanismus andererseits betrachtet.

Rationales wirtschaftliches Handeln beschränkt sich auf die in der Ökonosphäre geschaffenen „knappen“ Güter. Dagegen sind die Ökosphäre „,freie“ Güter und als solche lediglich „Gegenstand der Aneignung und des Verbrauchs“. Das Ziel einer Verbesserung des materiellen Wohlstandes manifestiert sich in der Durchflußwirtschaft mithin in einer Vergrößerung des Flusses von Stoffen aus der Ökosphäre in die Ökonosphäre und wieder in die Ökosphäre. Ökonomisch rationales Handeln verführt hier zu einem wettbewerbsmäßigen Raubbau an der Natur.

$\mathrm{Da}$ eine derartige Wirtschaftsweise in eine ökologische aber damit auch in eine ökonomische Katastrophe führen muß, ist evident. Die inzwischen entstandenen Umweltprobleme in Gestalt von Müllbergen, Wasser- und Luftverschmutzungen, Bodenverunreinigungen und -erosionen, Ozonlöchern usw. machen deutlich, daß eine als Einbahnstraße durch die Umwelt angelegte Wirtschaft in einer Sackgasse enden muß. In einer solchen Ökonomie gewinnen Bemühungen um Stoffkreisläufe im Sinne der Wiederverwertung und Wiederverwendung knapper Ressourcen an Bedeutung.

Im Gegensatz zu einer Durchflußwirtschaft werden in einer Kreislaufwirtschaft die Ressourcen als endlich und deshalb knapp betrachtet. Eine Kreislaufwirtschaft, in der Stoffströme zirkulie-

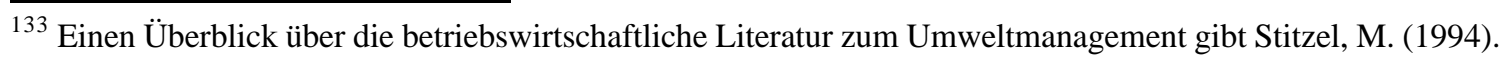


ren, entspricht offenbar den natürlichen Gegebenheiten des Ökosystems, die es nicht zulassen, daß Materie in nennenswertem Umfang von außen bezogen und Abfallstoffe nach außen gebracht werden können. In dieser Kreislaufwirtschaft wird der Mensch eher als Teil eines zirkularen denn eines linearen ökologischen Systems gesehen.

Die Natur ist, abgesehen von der Energiezufuhr durch die Sonne, auf Eigenversorgung angewiesen. Sie muß sich aus ihren eigenen Reststoffen versorgen. Im natürlichen Ökosystem sind Rohstoffe und Abfälle ein und dieselbe Materie. Dieses Phänomen entspricht dem „Ersten Hauptsatz der Thermodynamik (Energieerhaltungssatz)“, demzufolge Energie weder geschaffen noch vernichtet, sondern lediglich umgewandelt wird. In einem von der Umwelt isolierten d.h. geschlossenen System geht die Summe aus Energie und Materie mithin nicht verloren sondern bleibt konstant. Allerdings vermindert sich mit jedem mechanischen, thermischen, chemischen und biologischen Vorgang die Menge oder die Zustandsform der nutzbaren Materie und der arbeitsfähigen Energie. Diese Konsequenz folgt aus dem ,Zweiten Hauptsatz der Thermodynamik“ dem sogenannten „Entropiegesetz“. ${ }^{134}$ Dem Entropiegesetz entsprechend findet im Wirtschaftsprozeß eine kontinuierliche Umwandlung von nutzbarer Materie und Energie (im Zustand niedriger Entropie) in weniger nutzbare Materie und Energie (im Zustand hoher Entropie), also in nicht verwertbare Reststoffe, statt, d.h. Entropie und Ordnung sind negativ korreliert und es besteht eine konstante Tendenz zur Unordnung. Betrachtet man Entropie gleichzeitig als ein Maß für die Nutzbarkeit und Verfügbarkeit von Materie und Energie, dann sind die Unvermeidbarkeit der Erschöpfung nicht-regenerierbarer Ressourcen und die Existenz von Grenzen des quantitativen Wachstums eine logische Folge. ${ }^{135}$

Aufgrund der Tatsache, daß das entropische Problem unlösbar und das Naturgeschehen unumkehrbar ist, ${ }^{136}$ kann man feststellen, daß jede Form des Wirtschaftens langfristig gesehen einmal ein Ende haben muß. Aber dennoch impliziert die Idee der Kreislaufwirtschaft anders als die Durchflußwirtschaft entsprechend der ökonomischen Vernunft den sparsamen Umgang mit den natürlichen Reichtïmern und damit die Schonung der menschlichen Lebensgrundlagen. Sie orientiert sich an Vorbildern geschlossener Stoffkreisläufe in der Natur und trägt dem Umstand der Verknappung von nicht regenerierbaren Energieformen und von Entsorgungsmöglichkeiten und

\footnotetext{
${ }^{134}$ Die Entropie steht für den Grad der Unordnung eines Systems. Ein Zustand hoher Entropie kann nur unter Zuführung von Energie auf eine Stufe niedrigerer Entropie überführt werden. Vgl. Strebel, H. (1990), S. 705; Weiland, R. (1992), S. 458ff.. Das Gesetz der Entropie wurde von Angrist und Hepler für den Energiebereich entwickelt. Georgescu-Roegen übertrug es auf die Materie. Vgl. Georgescu-Roegen, N. (1971) und (1974), S. 17-28.

${ }^{135}$ Vgl. Meadows, D. et al. (1972 und 1992); Zahn, E./Dogan, D. (1996), S. 51.

${ }^{136}$ Die Grenzen der Kreislaufwirtschaft sind theoretisch durch den zweiten Hauptsatz der Thermodynamik (Zunahme der Entropie) und praktisch durch den hohen ökonomischen und ökologischen Aufwand gesteckt, der erforderlich ist, um weit verteilte Güter in den Kreislauf zurückzuführen. Vgl. Zahn, E./Dogan, D. (1996), S. 50ff.
} 
der Belastbarkeit der Umwelt Rechnung. Die Kreislaufwirtschaft kann als System interpretiert werden, das sich durch Nutzungsdauerverlängerungsstrategie, wie z.B. Wiederverwendung, Reparatur, Grunderneuerung von Produkten und Wieder- und Weiterverwertung von Ausgangsstoffen, und Materialrecyclingsstrategie selbst versorgt.

Wird in einer Durchflußwirtschaft der fortlaufende Vorgang der Konversion von wertvollen Stoffen in wertlosen Abfall beschleunigt, gilt es diesen in einer modernen Kreislaufwirtschaft zu verlangsamen. Zur Verwirklichung dieser Kreislaufwirtschaft sind deshalb umweltverträgliche Maßnahmen erforderlich, die eine Zunahme der Entropie und damit den Raubbau an den natïrlichen Ressourcen verringern. Hierzu zählen einerseits der sparsame Umgang mit knappen Rohstoffen und andererseits die Verringerung der Umweltbelastung durch Recycling und Entsorgung. ${ }^{137}$

Die Verwirklichung der Ideen der Kreislaufwirtschaft kann in der Realität natürlich nur annähernd umgesetzt werden. Das Konzept der Kreislaufwirtschaft muß daher durch andere Konzepte und Instrumente ergänzt werden. Es läßt sich erkennen, daß es gleichermaßen Potentiale und Hindernisse gibt. Diese können sich in technischen Möglichkeiten sowie in ökonomischen, sozialen und politischen Rahmenbedingungen manifestieren. ${ }^{138}$

Es wäre denkbar, daß der Weg in eine Kreislaufwirtschaft stufenweise umgesetzt werden kann. Dieser Weg beginnt zunächst bei der Beseitigung grober Umweltschädigungen durch Abfälle und führt weiter über die Reduktion von Abfällen und Emissionen durch Separierung von Abfallstoffen, die interne und externe Wiederverwertung durch Materialrecycling sowie Prozeßänderungen zur effizienten Materialnutzung bis zu Produkt- und Materialänderungen.

Die unternehmerischen Aktivitäten, an deren Anpassungs- und Innovationsfähigkeit in Zeiten turbulenter Umweltentwicklung hohe Anforderungen gestellt werden, können sich in einer Kreislaufwirtschaft z.B. aufgrund bereits fixierter Rahmenbedingungen und etablierter Stoffkreisläufe, als reaktions- und innovationshemmend erweisen. Aber auch solche Zielkonflikte

\footnotetext{
${ }^{137}$ Hierbei spielen auch die Innovationen zur Erschließung neuer Quellen niedriger Entropie und zur effektiven Nutzung bestehender Quellen hoher Entropie eine wichtige Rolle. Zu solchen zeitgewinnenden Innovationen zählen insbesondere Fortschritte auf dem Gebiet der abfallvermeidenden und abfallverwertenden Stoffwirtschaft, z.B. in Gestalt von recyclingfähigen Werkstoffen, Verbundteilen und Bauteilen, recyclingfähiger Produktkonstruktion, angepaßter Produktions- sowie geeigneter Demontage- und Ve rwertungstechnologien.

${ }_{138}$ Recycling ist zwar ein wirksames, aber letztlich doch begrenztes Instrument, um den unumkehrbaren Prozeß der Entropieerhöhung zu verhindern. Alle Rückhol-, Wiederaufbereitungs- und Wiederverwertungsmöglichkeiten geraten trotz aller technischen Fortschritte früher oder später an einen kritischen Punkt, von dem ab es kostengünstiger wird, die Schadstoffe in der nicht mehr nutzbaren Unordnung zu belassen, anstatt sie wieder in eine alte Ordnung zurückzuführen. Das Wirtschaften in Kreisläufen ist deshalb auch ökologisch problematisch.
} 
müssen erkannt und gelöst werden. Im Zuge der Kreislaufwirtschaft werden tiefgreifende Veränderungen in den Strukturen industrieller Wertschöpfungssysteme stattfinden. Neue Produktions- und Distributionsstrukturen sowie neue Markt- und Wettbewerbsstrukturen werden sich herausbilden. In den Unternehmen werden sich Wertschöpfungsaktivitäten und ihr Zusammenspiel mit der Ökologie, aber auch das Denken wandeln. Daraus ergeben sich für das einzelne Unternehmen, aber auch für die ganze Volkswirtschaft durchaus günstige Perspektiven. Beispielsweise bietet sich den Unternehmen die Chance, den Umweltschutz, insbesondere die Umweltschutztechniken zu einem wichtigen Wettbewerbsfaktor zu machen.

Auf der Ebene der Unternehmen müssen die Chancen des Wandels in Richtung Kreislaufwirtschaft erkannt und durch klare strategische Konzeptionen genutzt werden. Die Voraussetzung dafür ist nicht zuletzt die Ausbreitung eines ganzheitlichen, prozeßorientierten Denkens auf allen Ebenen des Unternehmens und eine intensive Kooperation der Partner in den nach mehr Dezentralisierung tendierenden industriellen Wertschöpfungssystemen. Auch der Staat ist aufgerufen, durch eine weitsichtige Umwelt-, Technologie- und Wirtschaftspolitik Voraussetzungen und Anreize für eine sich weitgehend selbstorganisierende Evolution auf dem Weg zu einem nachhaltigen Wirtschaften zu schaffen.

„Die natürliche Umwelt, wenn sie intakt ist, schafft den Rahmen bzw. die Arena, innerhalb dessen das Unternehmen das erreichen soll und will, deswegen sie gegründet wurde: wirtschaftlich erfolgreich zu sein. Das ökologisch geführte Unternehmen ist demnach nicht weniger ökonomisch als das klassische Unternehmen ... sie muß sich vermehrt Zielkonkurrenzen stellen, sie muß versuchen, Ökonomie und Ökologie zu vereinbaren.“139 Die ökologisch verpflichtete Unternehmensführung stellt somit den Versuch dar, eine gleichzeitige Erreichung sowohl der ökonomischen als auch ökologischen Zielsetzungen des Unternehmens zu ermöglichen.

Im folgenden sollen einige Definitionen vom Begriff ,ökologisch verpflichteter Unternehmensführung“ dargestellt werden, um die Bedeutung der Ökologieverpflichtung der Unternehmensführung und daraus den Begriff der ökologisch verpflichteten Unternehmensführung im Rahmen der vorliegenden Arbeit formulieren zu können.

Seidel/Menn definieren ökologisch orientierte und verpflichte Unternehmenspolitik als ,... Inbegriff all jener Maximen (Unternehmensgrundsätze, Meta-Ziele, Verfahrensregeln etc.) ..., die das (Gesamt-)Verfahren des Unternehmens gegenüber Interessenten und Betroffenen einschließlich

${ }^{139}$ Stitzel, M./Wank, L. (1990), S. 110. 
der natürlichen Umwelt regeln. Als Verkörperung der Gesamtheit übergeordneter Rahmenentscheide (Normen), die die ökologisch relevanten Verhaltensfelder für das Unternehmen festlegen, markiert die Unternehmenspolitik - für Wissenschaft und Praxis - zugleich Weg und Ziel der betriebswirtschaftlichen Entwurfsarbeit zu angestrebten Verhaltensänderungen.“ ‘140

Wicke definiert beispielsweise offensives, gewinnorientiertes Umweltmanagement als den Versuch, ,... in allen betrieblichen Bereichen und Funktionen die Umweltschutzanforderungen, die vom Staat oder vom Markt ausgehen, in die betrieblichen Abläufe offensiv zu integrieren. Zielsetzung ist es in diesem Zusammenhang nicht nur, diese Anforderungen nur zu erfüllen, sondern sie geradezu als betriebswirtschaftliches Instrument $\mathrm{zu}$ benutzen, um möglichst alle denkbaren Vorteile eines umweltbewußten Verhaltens für den Betrieb zu erhalten. Mit einem offensiven Umweltschutzkonzept wird also versucht, sowohl die betriebliche Ziele, z.B. das der langfristigen Gewinnmaximierung, als auch die Umweltverbesserungsziele gemeinsam zu erreichen.“' ${ }^{141}$

Meffert/Kirchgeorg leiten folgende Definition für ein marktorientiertes Umweltmanagement ab: „Das Umweltmanagement berïcksichtigt bei der Planung, Durchsetzung und Kontrolle der Unternehmensaktivitäten in allen Bereichen Umweltschutzziele zur Verminderung und Vermeidung der Umweltbelastungen und langfristigen Sicherung der Unternehmensziele. ${ }^{\text {142 }}$

Da die Fülle der Konzeptionen und Ansätze in dieser noch jungen Teildisziplin mit einer entsprechenden Vielfalt und Uneinheitlichkeit der Begrifflichkeiten einhergeht, wird in der Literatur mit dem in dieser Arbeit verwandten Begriff ,ökologisch verpflichtete Unternehmensführung“ kein einheitlicher Vorstellungsinhalt verbunden. ${ }^{143}$ Es zeichnet sich aber hier eine zunehmende Einigkeit über die konstitutiven Elemente einer solchen Managementkonzeption ab. Dabei wird die veränderte Aufgabenstellung der strategischen Unternehmensführung im Unterschied zu Management im herkömmlichen Sinne vor allem am mehrdimensionalen Zielbezug (hinsichtlich einer ökologieorientierten, gesellschafts- und marktorientierten Ausrichtung des Umweltmanagements), dem funktions- und unternehmensübergreifenden Charakter sowie der proaktiven Verhaltensausrichtung und dem Prozeß kontinuierlicher Verbesserung festgemacht. ${ }^{144}$ Sie sollen im folgenden dargestellt werden.

\footnotetext{
${ }^{140}$ Vgl. Seidel, E./Menn, H. (1988), S. 79.

${ }^{141}$ Vgl. Wicke, L. (1988), S. 21.

142 Vgl. Meffert, H./Kirchgeorg, M. (1998), S. 23.

${ }^{143}$ Vgl. Meffert, H./Kirchgeorg, M. (1998), S. 16.

${ }^{144}$ Vgl. Dyllick, T. (1995), S. 179ff.; Meffert, H./Kirchgeorg, M. (1998), S. $18 f f$.
} 
Der mehrdimensionale Zielbezug der ökologisch verpflichteten Unternehmensführung bedeutet, daß darunter ein systematisch geplanter, ökologisch intendierter und kontrollierter Prozeß zu verstehen ist, welcher auf einer Analyse der unternehmensinternen und -externen Rahmenbedingungen aufbaut. Hierbei erweist sich die Verknüpfung verschiedener Ziele und die Festlegung konkreter Normen zur Bestimmung des notwendigen Ausmaßes an „Ökologieverpflichtung“ als ein besonderes Problem. ${ }^{145} \mathrm{Da}$ das zentrale Verhaltensziel die Vermeidung oder Verminderung von Umweltbelastungen ist, erschöpft sich eine ökologisch verpflichtete Unternehmensführung nicht in zu diesem Zweck ergriffenen Einzelmaßnahmen.

Die Erweiterung der betriebswirtschaftlichen Zielkonzeption um ökologische Zielgrößen wird als Voraussetzung dafür angesehen, um bei der Planung, Durchsetzung und Kontrolle ökonomischer Tätigkeiten eine Vermeidung und Verminderung von Umweltbelastungen sicherzustellen. Es besteht Einigkeit darüber, daß diese Zielsetzungen nicht dem Anspruch einer vollständigen Reduzierung von Umweltbeeinträchtigungen durch Unternehmen gerecht werden können, weil jede ökonomische Tätigkeit in Form von Produktion oder Konsum mit einer Beeinträchtigung der ökologischen Umwelt einhergeht. Ökologisch verpflichtete Unternehmensführung kann deshalb nur auf eine relative Verbesserung der Umweltqualität abzielen. In diesem Zusammenhang stellt sich unweigerlich die schwierige Frage, welches zulässige Ausmaß an Umweltbeeinträchtigungen aus ökologischer und gesellschaftlicher Sicht erstrebenswert und aus ökonomischer Sicht bei Sicherung der Wettbewerbsfähigkeit von Unternehmen noch vertretbar erscheint. Unter diesem Kalkül muß sich die ökologisch verpflichtete Unternehmensführung in besonderer Weise mit schlecht strukturierten Problemen auseinandersetzen, die sich durch Wirkungs-, Bewertungsund Zielsetzungsdefekte auszeichnen. Vielfach lassen sich die Wirkungsmechanismen zwischen unternehmensbedingten Emissionen und möglichen Umweltbeeinträchtigungen selbst im interdisziplinären Dialog nicht eindeutig klären. Darüber hinaus erschweren ökologische als auch ökonomische Bewertungsdefekte die Entscheidungsprozesse, weil Umweltqualitätsziele nicht eindeutig zu quantifizieren sind und die Märkte die wahren Knappheitspreise für den Verbrauch von ökologischen Ressourcen nicht widerspiegeln. Schließlich bedingen Zielkonflikte zwischen Ökonomie und Ökologie vielfach ein Entscheidungsdilemma, das letztlich nur durch Werturteile der einzelnen Entscheidungsträger zu lösen ist.

Die „Allgegenwärtigkeit von Umweltproblemen“ betont das Erfordernis, ökologisch verpflichtete Unternehmensführung aus einer funktions- und unternehmensübergreifenden Sicht und damit als Führungsfunktion im Sinne von „Umweltschutz ist Chefsache“ zu begreifen. Der Quer-

$\overline{145}$ Vgl. Stitzel, M. (1987), S. 375ff.; Strebel, H. (1980). 
schnittscharakter der ökologisch verpflichteten Unternehmensführung verweist auf die potentielle Betroffenheit aller betriebswirtschaftlichen Teildisziplinen und bestärkt die Notwendigkeit, dem Umweltschutz in seinen Bezügen zur Allgemeinen Betriebswirtschaftslehre eine besondere Aufmerksamkeit $\mathrm{zu}$ schenken. Gleichzeitig gewinnen die interdisziplinären Bezüge zu den rechts-, naturwissenschaftlichen und technischen Disziplinen einen neuen Stellenwert. Die Verankerung der ökologisch verpflichteten Unternehmensführung in der betriebswirtschaftlichen Forschung und Lehre stellt somit eine Gratwanderung zwischen notwendiger Generalisierung und hinreichender Spezialisierung mit interdisziplinären Bezügen dar.

Die funktionsübergreifende Ausrichtung der ökologisch verpflichteten Unternehmensführung bedeutet, daß ökologiebezogene Anpassungsmaßnahmen in sämtlichen funktionalen Bereichen wie Beschaffung, Produktion, Absatz sowie in den Bereichen Forschung und Entwicklung, Lagerung und Logistik, Finanzierung, Planung, Information, Organisation und Führung erforderlich sind. ${ }^{146}$ Eine isolierte Betrachtung einzelner Problembereiche ist damit langfristig nicht nur ökologisch sondern auch ökonomisch als wenig effizient anzusehen. Es sind die Interdependenzen zwischen den einzelnen Funktionsbereichen zu berücksichtigen.

Je mehr die unternehmerischen Entscheidungsprozesse fortschreiten, desto weiter reichen die ökologischen Probleme und die damit verbundenen Maßnahmen aus der Sicht des Unternehmens über deren Grenzen, Verantwortlichkeiten und Handlungsmöglichkeiten hinaus. ${ }^{147}$ Gerade die Orientierung an Produkten, Funktionen oder Bedürfnissen macht ganzheitliche Lösungen auf der Basis von unternehmensübergreifenden Kooperationen notwendig, um die Herausforderungen im gesamten ökologischen Wirkungsbereich des Unternehmens aufzugreifen und einer effizienten Lösung zuzuführen. Eine solche Kooperation betrifft insbesondere Lieferanten und Geschäftskunden sowie Mitbewerber der Branche, aber auch Behörden, Verbände und gesellschaftliche Gruppen (Umweltschutzgruppen, Verbraucherverbände etc.). Die Kooperationsstrategie, der im Rahmen des konventionellen strategischen Managements lediglich in einer späten Phase des Konzepts eines idealtypischen Verlaufs der Unternehmensentwicklung Bedeutung zukommt, wird damit zum tragenden Element einer dynamischen ökologisch verpflichteten Unternehmensführung. ${ }^{148}$

Nicht zuletzt der Vorwurf der Naturvergessenheit ökonomischer Theorien hat gerade im letzten Jahrzehnt dazu geführt, die Proaktivität des Umweltmanagements, d.h. die proaktive Verhal-

\footnotetext{
${ }^{146}$ Vgl. Senn, J. F. (1986); Strebel, H. (1990); Winter, G. (1990 und 1998),

${ }^{147}$ Vgl. Dyllick, T. (1995), S. 181.
} 
tensausrichtung der ökologisch verpflichteten Unternehmensführung als wichtiges Wesensmerkmal herauszuarbeiten. Hierin erhebt sich der Anspruch, im Rahmen der strategischen Unternehmensplanung Umweltschutzprobleme in ihrer ökologischen, gesellschaftlichen und ökonomischen Dimension mit geeigneten Instrumenten $\mathrm{zu}$ antizipieren, um Problemlösungen $\mathrm{zu}$ entwickeln, bevor sie durch verschärfte umweltgesetzliche Regelungen und kritische Anspruchsgruppen an die Unternehmen herangetragen werden.

Im Rahmen einer offensiven ökologisch verantwortlichen Unternehmensführung wird eine proaktive Begegnung potentieller Umweltprobleme gefordert. Gegenüber einem reaktiven Umweltschutzverhalten wird durch die proaktive Verhaltensausrichtung der ökologisch verpflichteten Unternehmensführung eine konsequente Wahrnehmung von Marktchancen und eine Bewältigung der wettbewerbsbezogenen Herausforderungen im Umweltschutz möglich. Hieraus erhebt sich der Anspruch an die Unternehmensführung, im Rahmen der strategischen Unternehmensplanung gesellschaftliche Umweltschutzansprüche im Entscheidungsprozeß zu antizipieren und die ökologischen Folgen der Unternehmensaktivitäten zu erfassen, um Problemlösungen zu entwickeln, bevor sie zum Gegenstand einer öffentlichen Umweltschutzdiskussion werden. Ökologisch verpflichtete Unternehmensführung, die sich lediglich an reaktiven bzw. defensiven d.h. zeitlich begrenzten gesellschaftlichen Anforderungen oder den verfügbaren Technologien oder den gesetzlichen Auflagen orientiert, beschränkt meist den Handlungsspielraum und -zeitraum für innovative Problemlösungen. Für die einzelne Unternehmen können sich aus einem reaktiven Umweltschutzverhalten langfristig Folgen ergeben, die sich auf die Kosten- und/oder Ertragssituation negativ auswirken. $\mathrm{Zu}$ berücksichtigen sind auch steigende Kosten der Risikoabsicherung. Die Zunahme der Umweltschutzgesetze und Verordnungen, sowie verschärfte gesellschaftliche Umweltschutzansprüche führen zu immer höheren Risiken eines Reagierens auf Umweltschäden.

Die Forderung nach einer proaktiven Verhaltensausrichtung in der ökologisch verpflichteten Unternehmensführung weist der Betriebswirtschaftslehre selbst als angewandte Wissenschaft die besondere Verantwortung zu, ihre Beratungs- und Gestaltungsfunktion im Dialog mit der Wirtschaft und Politik frühzeitig wahrzunehmen, bevor Unternehmen letztlich über den institutionellen Rahmen möglicherweise zu ökonomisch als auch ökologisch ineffizienten Verhaltensanpassungen gezwungen werden. Ökologisch verpflichtete Unternehmensführung bewegt sich somit im Spannungsfeld zwischen ökonomischer und ökologischer Effizienz und gesellschaftlicher Legitimität. Kein Unternehmen kann sich den aus diesem Spannungsfeld erwachsenden Zu-

\footnotetext{
${ }^{148}$ Vgl. Bleicher, K. (1992), 346ff.
} 
kunftsaufgaben - wie etwa den Erfordernissen der Kreislaufwirtschaft - entziehen, wenn es langfristig die Existenz am Markt sichern will.

Der Begriff ökologisch verpflichteter Unternehmensführung zielt auf die ökologische Verantwortung der Wirtschaften (bzw. der unternehmerischen Tätigkeit) im allgemeinen und des einzelnen Unternehmens im besonderen. Statt der häufig zu findenden Rede von „ökologieorientierter Unternehmensführung“, die einen falschen Eindruck vom Zweck des Wirtschaftens vermittelt werden kann, und auch vom „Umweltmanagement“, denn nicht die Umwelt, sondern das Unternehmen gilt es zu managen, wird in dieser Arbeit der Begriff ,ökologisch verpflichtete Unternehmensführung" verwendet. In diesem Begriff schwingt auch die ethische Dimension dessen mit, was zeitgemäßem Management heute auferlegt ist. ${ }^{149}$

\begin{tabular}{l} 
Ökologische Dimensionen der Unternehmensführung \\
\hline Ökologiebezogene Dimension: \\
- Ressourcenknappheit und -erschöpfung und Verschlechterung der Ressourcenqualität: fossile Ressourcen \\
und Energiequellen. \\
- Minimierung von Stoffdurchsatz und Umweltbelastungen. \\
- Umweltverschmutzung: Abfall, Luft, Wasser, Boden \\
- Zerstörung ökologischer Systeme und Kreisläufe \\
Gesellschaftsbezogene Dimension: \\
- Sicherung von Akzeptanz und Legitimität bei den relevanten gesellschaftlichen Anspruchsgruppen. \\
Politikbezogene Dimension: \\
- Erfüllung gesetzlicher Umweltschutzvorschriften und Mitverantwortung für die Weiterentwicklung der \\
politischen Rahmenbedingungen. \\
\hline Marktbezogene bzw. wettbewerbsstrategische Dimension: \\
- Veränderungen von Markteintritts- und -austrittsbarrieren und Machtstrukturen in Beschaffungsmärkten. \\
- Ökologieorientierter Substitutionswettbewerb. \\
- Kosteneffiziente Anpassung an ökologische Anforderungen und Auflagen, aber auch Aufbau ökologischer \\
Innovationspotentiale.
\end{tabular}

Abb. 2.6: Dimensionen der ökologisch verpflichteten Unternehmensführung ${ }^{150}$

Unternehmen werden nur sehr selten direkt mit den eigentlichen ökologischen Folgen der von ihnen verursachten ökologischen Probleme z.B. in Gestalt der übermäßigen Belastungen von

\footnotetext{
${ }^{149}$ Vgl. Schanz, G. (1999), Vorwort. Hierbei wird nach Thielemann hervorgehoben: „Das Ökologische kommt ohne Ethik nicht auf den Weg - auch nicht in die Unternehmung, ... es sei denn, man hofft auf die metaphysische Kraft eines Systemgeistes, der die betriebswirtschaftlichen Sachzwänge schon richtig anordnen wird." Thielemann, U. (1990), S. 59.

${ }^{150}$ Vgl. Dyllick, T. (1992), S. 403; Kirchgeorg, M. (1990), S. 96ff.; Meffert, H./Kirchgeorg, M. (1998), S. $12 \mathrm{ff}$.
} 
Gewässern oder Böden konfrontiert. Umweltbelastungen werden für Unternehmen in der Regel erst dann relevant, wenn diese in unmittelbar spürbare gesellschaftliche Ansprüche, politische Regulierungen oder marktliche Veränderungen münden. Unternehmen stehen sich im ökologischen Zusammenhang, d.h. in einer unmittelbar relevanten inneren, sozio-ökonomisch bestimmten „Primärumwelt“ gegenüber, die aus den externen Lenkungssystemen Gesellschaft, Politik und Markt sowie den darin eingeschlossenen Stakeholders bestehen. Diese Primärumwelt ist eingebettet in die mittelbar relevante äußere „Sekundärumwelt“, die ökologische Umwelt. Hieraus lassen sich ein mehrdimensionaler Bedingungsrahmen der ökologisch verpflichteten Unternehmensführung ableiten, bestehend aus einer ökologischen, gesellschaftlichen, politischen und marktlichen Dimensionen (vgl. Abb. 2.6).

Ökologieverpflichtung oder -orientierung der Unternehmensführung kann demnach als der Versuch dargestellt werden, die Unternehmen so zu führen, daß ein möglichst großer Teil der realisierten oder zu realisierenden Handlungen der Schnittmenge ökonomisch- und ökologischrationaler Handlungen zugeordnet werden kann. ${ }^{151}$ Die Ökologieverpflichtung oder -orientierung der Unternehmensführung muß sich dazu auf alle Bereiche der Unternehmen erstrecken, da sich alle unternehmerischen Bereiche unmittelbar oder mittelbar auf die Umwelt auswirken. Die ganzheitliche Ausrichtung bedeutet aber, daß die Ökologieverpflichtung oder -orientierung der Unternehmensführung nicht auf ökologieorientierte Einzelaktivitäten abzielt, sondern aufeinander abgestimmte, ökologieorientierte Aktivitäten anstrebt. ${ }^{152}$ Ökologisch verpflichtete Unternehmensführung aus einer dynamischen Perspektive kann auch als ein kontinuierlicher Lernprozeß im Sinne einer ökologischen Unternehmensentwicklung verstanden werden. ${ }^{153}$

In dieser Arbeit wird ökologisch verpflichtete Unternehmensführung definiert als das Bemühen eines Unternehmens, bei der Planung, Durchsetzung und Kontrolle der Unternehmensaktivitäten in allen Bereichen, innerhalb der betriebswirtschaftlichen Rahmenbedingungen von Existenzund Rentabilitätssicherung, aktive betriebliche Umweltpolitik über die gesetzlichen Vorschriften und Auflagen, sowie über den Bereich kurzfristiger Renditesicherung hinaus zu betreiben, d.h. die Verantwortung und Verpflichtung für die ökologischen Bedingungen und Folgen des eigenen Tuns möglichst ernstzunehmen.

\footnotetext{
${ }^{151} \mathrm{Vgl}$. Zu ökonomisch-rationalen und ökologisch-rationalen Alternativen Klink, G. O. (1996), S. 8ff.

152 Vgl. z.B. Stitzel, M. (1991); Kirschten, U./Stitzel, M. (1995), S. 331f.

${ }^{153}$ Vgl. Brockhaus, M. (1996), S. 28ff.
} 


\section{Unternehmen im Spannungsfeld zwischen Ökologie und Ökonomie}

Die Untersuchung der Beziehungen zwischen der ökologischen Umwelt und dem Unternehmen ist lange Zeit überhaupt kein Gegenstand in der betriebswirtschaftlichen Forschung gewesen. ${ }^{1}$ In letzter Zeit wird jedoch innerhalb der Betriebswirtschaftslehre zunehmend anerkannt, daß eine an der Realität orientierte Betrachtungsweise der Unternehmensführung und damit die Rolle des Unternehmens in der heutigen Gesellschaft und Wirtschaft eine weitergehende Unternehmensumwelt-Betrachtung erfordert. Hier steht die Frage nach der sog. Umweltverpflichtung oder orientierung im Vordergrund. Dabei stehen die umwelt- und unternehmensbezogenen Entwicklungen im Mittelpunkt der Entscheidungen der Unternehmensführung. ${ }^{2}$

Da es Aufgabe eines Unternehmens ist, über den Einsatz von knappen Produktionsfaktoren für die Herstellung der Produkte $\mathrm{zu}$ entscheiden und schließlich die hergestellten Produkte oder Dienstleistungen zu verkaufen, ist diese Entscheidung hinsichtlich ökologischer Güter bzw. des Umweltbewußtseins zu untersuchen. Die teilweise recht tiefgreifenden Veränderungen in der unternehmerischen Umwelt verlangen ein vermehrtes und systematisches Umweltmanagement als zentrale Aufgabe der Unternehmensleitungen. Dazu sind die erforderlichen Voraussetzungen zu schaffen.

Der Begriff „Ökologie“ wird mit einer unüberschaubaren Vielzahl von Bedeutungsinhalten belegt. Eine umfassende Behandlung des Ökologiebegriffs und seiner Entstehungsgeschichte scheint im Rahmen vorliegender Arbeit überflüssig zu sein. ${ }^{3}$ Aber wegen seiner zentralen Bedeutung für das vorliegende Thema und zur späteren Grundlegung der Konzeption einer „ökologisch verpflichteten Unternehmensführung“ werden in diesem Kapitel als Ausgangspunkt der Analyse zunächst die grundlegenden Bedeutungsinhalte von Ökologie dargestellt.

Um die Grundlage einer fundierten Erfassung der Ökologieverantwortung bei der Unternehmensführung zu schaffen, sollen hier weiter die Eigenschaften und Dimensionen von Unternehmen und ihrer Umwelt dargestellt werden, da die Unternehmen und die Beziehung Unternehmen/Umwelt im Mittelpunkt ökologieorientierter betriebswirtschaftlicher Überlegung (auch vorliegender Arbeit) stehen. Dabei entscheidend ist, daß Unternehmen mit ihrer Umwelt, insbeson-

\footnotetext{
${ }^{1}$ Vgl. Dyllick, T. (1992), S. 392; Schreyögg, G. (1993), Sp. 4231; Frese, E. (1992), Sp. 2433.

${ }^{2}$ Zur ökologischen Öffnung der Betriebswirtschaftslehre vgl. z.B. Dyllick, T. (1992), S. 392ff.

${ }^{3}$ Nicht die endgültige Lösung von Umweltproblemen, sondern schon der Versuch, Ursachen und Auswirkungen der Umweltbelastungen verstehen zu wollen, ist kompliziert und erfordert die Zusammenarbeit verschiedener Fachdisziplinen. Deshalb kann eine Auseinandersetzung mit ökonomischen Aspekten von Umweltproblemen nur erfolgreich sein, wenn ein Mindestwissen über ökologische Grundlagen und Zusammenhänge gegeben ist.
} 
dere hier mit ihrer ökologischen Umwelt in engen Austauschbeziehungen stehen. Diese Austauschbeziehungen und Interdependenzen sollen diskutiert werden. Schließlich soll das Stakeholder-Konzept dargestellt werden. Dies scheint wichtig, weil die ökologisch verpflichtete Unternehmensführung sich nicht mit auftretenden ökologischen Problemen, sondern vielmehr mit den Problemen, die aus den Ansprüchen der umweltrelevanten Anspruchsgruppen entstehen können, auseinandersetzen sollte.

\subsection{Begriffe und Funktionen der Ökologie}

Der Begriff „Ökologie“ trat erst Ende der 60er Jahre mit einer generellen Bewußtseinsbildung in Fragen der Umweltverschmutzung, Bevölkerungsexplosion und Ressourcenverknappung ins Licht der breiten Öffentlichkeit. Ökologie beschäftigt sich dabei als Teildisziplin der Biologie mit den lebenden Organismen in ihren Wechselbeziehungen und -wirkungen. Mit der zunehmenden Bedeutung der Ökologie ist dabei auch das Bedeutungsspektrum des Begriffs der Ökologie gewachsen. Somit steht Ökologie neben ihrer Aufgabe als Wissenschaft für die Erfassung der Phänomene der realen Lebenswelt für eine spezifische Geisteshaltung. ${ }^{4}$ Darüber hinaus hat sich die Ökologie zu einem Hauptthema von Politikern, Medien und Wirtschaftlern entwickelt. ${ }^{5}$

Die Ökologie wird als Wissenschaft von den wechselseitigen Beziehungen zwischen Organismen (Mikroorganismen, Pflanzen, Tieren und Menschen) und ihrer Umwelt bezeichnet. Umwelt umfaßt dabei alle Komponenten der Außenwelt, die direkt oder indirekt auf die Organismen einwirken. Sie können sowohl unbelebter (abiotischer) Natur wie Temperatur, Feuchtigkeit, Salzgehalt, Wind etc. als auch belebter (biotischer) Natur wie Nahrungsangebot und -bedarf von Organismen sein. ${ }^{6}$

Zentrale Begriffe der Ökologie sind das Ökosystem, das ökologische Gleichgewicht und die Umwelt. Das Wirkungsgefüge von Populationen und deren abiotischer Umwelt wird als Ökosystem bezeichnet. ${ }^{7}$ Ein Ökosystem umfaßt dabei die Gesamtheit einer Lebensgemeinschaft, die in Wechselwirkung mit ihrer Umwelt steht und in diese integriert sind. Innerhalb eines Ökosystems

\footnotetext{
${ }^{4}$ „Die Ökologie hat heute für politische Bewegungen auf Weltanschauungsebene einen ähnlich, leitenden Charakter wie früher z.B. die Evolutionsbiologie für sozialdarwinistische und rassistische Strömungen, und sie hat als Wissenschaft für viele andere Wissenschaften eine Art diffusen Vorbildcharakter - ähnlich dem, der der Physik einige Jahrhunderte hindurch zukam“. Trepl, L. (1987), S. 12 und 226.

${ }^{5}$ Diese Entwicklung begründet Vester mit ,,dem plötzlichen Bewußtwerden der Tatsache, daß der Mensch auch nur ein Glied der Natur ist und mit seiner jahrhundertelangen Entwicklung unter dem Aspekte des technischen Fortschritts nun selber an die Grenzen seines Wachstums gelangt ist.“ Vester, F. (1984), S. 415.

${ }^{6}$ Vgl. Osche, G. (1981), S. 11f.; Odum, E. P./Reichholf, J. (1980), S. 11.

${ }^{7}$ Vgl. Osche, G. (1981), S. 84.
} 
lassen sich drei biotische Komponenten unterscheiden: Produzenten, Konsumenten und Destruenten. ${ }^{8}$

Produzenten sind vor allem Pflanzen. Produzenten allein besitzen die Fähigkeit, die körpereigenen, organischen Substanzen aus anorganischen Stoffen (Kohlenstoff, Stickstoff, Wasser etc.) und der mittels der Photosynthese nutzbaren Sonnenenergie aufzubauen. Neben den körpereigenen organischen Substanzen fällt innerhalb dieses Umwandlungsprozesses der für Konsumenten wichtige Sauerstoff an. ${ }^{9}$

Die Lebensgrundlage der Konsumenten ist die Produktion der Produzenten. Konsumenten ernähren sich direkt von Produzenten als Pflanzenfresser bzw. pflanzenfressende Tiere (Herbivore, Konsumenten 1. Ordnung) oder indirekt als Fleischfresser durch das Fressen von Herbivoren (primäre Karnivore, Konsumenten 2. Ordnung) oder von primären Karnivoren (sekundäre Karnivore, Konsumenten 3. Ordnung). ${ }^{10}$ Die Konsumenten liefern ihrerseits für die Produktion der Produzenten das wichtige $\mathrm{CO}_{2}$.

Destruenten sind Mikroorganismen, die tote Organismen und Exkremente wieder in anorganische (mineralische) Stoffe zersetzen. Damit sind diese wieder für Produzenten verfügbar. Somit ist in einem Bio-Ökosystem als Wirkungsgefüge von Populationen und deren abiotischer Umwelt mit Produzenten, Konsumenten und Destruenten der ökologische Stoffkreislauf geschlossen.

Angetrieben durch Zufluß an Sonnenenergie vollzieht sich im Rahmen von Stoffkreisläufen ein ständiger Aufbau, Umbau und Abbau von chemischen Verbindungen und Stoffen. Auf dieses Öko-System hat der Mensch gestaltend und mit Hilfe entwickelter Technologien eingewirkt und so ein Techno-Ökosystem ${ }^{11}$ geschaffen. Im Gegensatz zum natürlichen Kreislaufsystem vollziehen sich die Prozesse unserer Versorgung mit Gütern und Dienstleistungen in einer Durchfluß-

\footnotetext{
${ }^{8}$ Vgl. Osche, G. (1981), S. 30f.

${ }^{9}$ Vgl. Bick, H. /Hansmeyer, K. H./Olschowy, G./Schmoock, P. (1984), S. 19; Osche, G. (1981), S. $74 f$.

${ }^{10}$ Vgl. Fellenberg, G. (1985), S. 7.

${ }^{11}$ Kausalverflechtungen von Wirtschaft mit ihrer Umwelt sind von unterschiedlicher Art. Sie unterscheiden sich schon aufgrund der unterschiedlichen Umwelten, die Einzelwirtschaften umgeben. Versteht man unter Umwelt alles, was eine Einzelwirtschaft umgibt, auf sie einwirken und sie selbst beeinflussen kann, so wird i.d.R. zwischen einem natürlichen Ökosystem und in einem künstlichen Ökosystem unterschieden. Für diese Dualität können auch die Begriffe eines Bio-Ökosystems und eines Techno-Ökosystems (vgl. Strebel, H. (1990), S. 699: Haber, W. (1991), S. 42ff.) verwendet werden. Vgl. hierzu auch die Begriffsvielfalt von Ökosystem-Ansätzen, z.B. von Ökosphäre und Ökonosphäre und von der zyklischen Ökologie und der nicht-zyklischen Ökonomie Zahn, E./Schmid, U./Seebach, A. (1996), S. 66; Zahn, E./Dogan, D. (1996), S. 48ff.
} 
wirtschaft. Die ökologische Umwelt dient dabei als Lieferant von Material und Energie und als Aufnahmemedium für unerwünschten Output, d.h. Kondukte ${ }^{12}$ der betrieblichen Produktion.

Der Mensch und das von ihm errichtete ökonomische System (Ökonosphäre) können im Ökosystem als Teil der globalen ökologischen Kreisläufe betrachtet werden. Jedes Lebewesen befindet sich in einem individuellen Durchflußsystem. Es bedarf einer ständigen Zufuhr von Energie und Materie und gibt ständig Stoffe und Energie, die für seinen Organismus selbst nicht mehr brauchbar sind, nach außen ab. Andere Lebewesen jedoch können die ausgeschiedenen Stoffe nutzen. Für sie stellen letztere eine Zufuhr an Stoffen und Energie dar, die transformiert werden und somit in eine neue, andersartige Emission münden, um Lebensprozesse aufrecht zu erhalten. Der Kreislauf zwischen Produzenten, Konsumenten und Destruenten ist notwendig für die stoffliche und energetische Existenz eines natürlichen Ökosystems. ${ }^{13}$ Prinzipiell sind deshalb auch Menschen und das von ihnen aufgebaute ökonomische System Teil des permanenten stofflichen Recycling. Ökonomische Systeme sind offen und benötigen zum Erhalt ihrer Strukturen Stoffe und Energie, die der Umwelt entnommen und später in scheinbar nicht mehr brauchbarer Form an die Umwelt wieder abgegeben werden.

In einem Ökosystem ist die Lebensgemeinschaft aus zahlreichen Populationen aufgebaut. Diese beeinflussen sich gegenseitig und für jede liegt eine bestimmte Kapazität vor. In seinen wesentlichen Komponenten (Energieflüsse, Stoffumsätze und Populationsdichte) reguliert sich das Ökosystem selbst. Aufgrund von systemimmanenten Ausgleichsmechanismen werden Schwankungen dieser Bestandsgrößen so variiert, daß sich das Gesamtsystem in einem Gleichgewichtszustand befindet. ${ }^{14}$ Aus dem Zusammenspiel aller Faktoren ergibt sich das „ökologische Gleichgewicht", also das Schwanken des Arten- und Individuenbestandes um einen Mittelwert, der von der Gesamtkapazität des Ökosystems bestimmt ist. Es handelt sich um ein „dynamisches Gleichgewicht“" (d.h. Fließgleichgewicht). Das ökologische Gleichgewicht umschließt ein von den Organismen getragenes Gleichgewicht des Stoffhaushaltes und des Energieumsatzes. ${ }^{15}$

Grundlegend für das ökologische Gleichgewicht sind schließlich die Wechselbeziehungen zur Umwelt. Unter „Umwelt“ in ökologischen Sinne wird die Gesamtheit aller direkt oder indirekt

\footnotetext{
12 Statt „Produkte” wird hier der Begriff „Kondukte” gewählt, wobei Produkte erwünschten Output darstellen, Kondukte hingegen zusammen mit (lat. cum = mit) diesen entstehen, ohne erwünscht zu sein. Sie umfassen sowohl feste Substanzen (Rückstände) als auch flüssige und gasförmige. Kondukte stellen zugleich Materie und freiwerdende oder gespeicherte Energie dar, die ineinander überführt werden können. Vgl. z.B. auch Bei- und Übelprodukte Dyckhoff, H. (1991), S. 291.

${ }^{13}$ Vgl. Stephan, G./Ahlheim, M. (1996), S. 18ff.; Odum, E. (1991), S. 50

${ }^{14}$ Vgl. Vester, F. (1984), S. 416.

${ }^{15}$ Vgl. Bick, H. /Hansmeyer, K. H./Olschowy, G./Schmoock, P. (1984), S. 23.
} 
auf Organismen einwirkenden Komponenten der Außenwelt, d.h. als das gesamte Wirkungsgefüge zwischen Natur und Lebewesen verstanden. ${ }^{16}$ Umwelt in weitestem Sinne ist alles, was den Menschen in seinen physischen, emotionalen, technischen, ökonomischen und sozialen Bedingungen und Interaktionen seiner Existenz berührt. ${ }^{17}$ Für die vorliegende Aufgabenstellung ist es jedoch sinnvoll, nur die ökologische Umwelt, und zwar unter ökonomischen Gesichtspunkten abzugrenzen. $\mathrm{Zu}$ dieser ökologischen Umwelt gehören die klassischen Umweltmedien wie Wasser, Luft und Bodenbeschaffenheit, aber auch die Landschaft oder die Vielfalt von Pflanzen und Tieren.

In der vorliegenden Arbeit wird das Unternehmen als System gesehen. Wird die Umwelt aus der Sicht des einzelnen Unternehmens definiert, dann bezeichnet die Umwelt im Kontext sozialer Systeme (Unternehmen) analog die Summe aller zum System gehörenden Elemente des Umsystems. ${ }^{18}$ Das gesamte Umsystem eines Unternehmens besteht aus verschiedenen Umwelten. Die (ökologische) Umwelt als Gesamtheit der den menschlichen Lebensraum umfassenden Gegebenheiten liefert dem ökonomischen System öffentliche Konsumgüter wie Wasser, Luft und Energiereserven, stellt den Raum zur Verfügung, in dem sich ökonomische Aktivitäten abspielen können, und nimmt die Abfallstoffe aus dem Konsum und der Produktion auf.

Die ökologische Umwelt ist dabei Ausgangspunkt der Schwierigkeiten für das Unternehmen bzw. die Unternehmensführung, denn die Auswirkungen des Unternehmensverhaltens auf diesen Umweltbereich stellen den Ursprung des Spannungsfeldes dar. ${ }^{19}$ Durch das Spannungsfeld selbst und seine vielgestaltigen Folgen werden aber fast alle Bereiche des Unternehmens betroffen. Die ganze Weite des Spannungsfeldes in seiner Bedeutung für das Unternehmen macht deren spezifische Ökologie-Problematik aus. ${ }^{20}$ In diesem Zusammenhang wird in Theorie und Praxis weitgehend nicht von Ökologie, sondern lediglich von Umwelt gesprochen. ${ }^{21}$ Für die vorliegende Arbeit ist es jedoch sinnvoll, den Begriff Ökologie stets bezogen auf die Ökologie-Problematik des Unternehmens zu verwenden und den Begriff der Umwelt auf die gesamte Umwelt des Unternehmen zu beziehen. ${ }^{22}$

\footnotetext{
${ }^{16}$ Die einwirkenden Umweltkräfte werden als Umweltfaktoren (ökologische Faktoren) bezeichnet. Dabei stehen sie in Wechselbeziehungen, d.h. sie beeinflussen sich gegenseitig. Vgl. Bick, H./Hansmeyer, K. H./Olschowy, G./Schmoock, P. (1984), S. 17.

${ }^{17}$ Vgl. Bick, H. /Hansmeyer, K. H./Olschowy, G./Schmoock, P. (1984), S. 25.

${ }^{18}$ Vgl. Therhart, K. (1986), S. 401.

${ }^{19}$ Vgl. de Haas, J. P. (1989), S. 8.

${ }^{20}$ Vgl. de Haas, J. P. (1989), S. 37ff.

${ }^{21}$ Vgl. Pfriem, R. (1986), S. 247.

22 In fast allen betriebswirtschaftlichen Arbeiten werden Ökologie und Umwelt weitgehend synonym verwendet.
} 
Nach der umfassenden Definition des Umweltbegriffs können drei Hauptfunktionen der ökologischen Umwelt für den Menschen bzw. die Wirtschaft hervorgehoben werden: die Produktionsbzw. Versorgungsfunktion, die Träger- und Regelungsfunktion. ${ }^{23}$

Im Ökosystem liefert die ökologische Umwelt natürliche Ressourcen wie Wasser, Boden, Luft und Energiereserven zur Befriedigung der Elementarbedürfnisse der Menschen sowie für Produktions- und Konsumprozesse, und darüber hinaus übernimmt die ökologische Umwelt durch die Aufnahme von produzierten Erzeugnissen sowie Schad- und Abfallstoffen eine Trägerfunktion. Die Regelungsfunktion schließlich dient der notwendigen Aufrechterhaltung des ökologischen Gleichgewichts und der Steuerung der Vorgänge des Naturhaushalts. ${ }^{24}$

Mit der zunehmenden Bedeutung der Ökologie bringt schließlich der Begriff neben seiner Bedeutung als Wissenschaft und als Lebenswelt eine diffuse Geisteshaltung zum Ausdruck. Zum einen zeigt sich die Bedeutung der Ökologie als Weltanschauung und Lebensgefühl einer ganzen Bewegung. ${ }^{25}$ Zum anderen bezeichnet Ökologie einen im wesentlichen ganzheitlichen Denkansatz in der Forschung. ${ }^{26}$ Bei ihm geht es darum, die als zusammengehörig zu begreifenden Gesamtheiten von Strukturen, Funktionen und ihre Interdependenzen in konsequent ganzheitlicher Betrachtung zu erfassen. Ein derartiges Forschungskonzept geht dabei von der Prämisse aus, daß es keinen beziehungslosen Forschungsgegenstand gibt, sondern dieser immer Teil einer Ganzheit darstellt, die sich aus Ganzheiten konstituiert und wiederum Element einer übergeordneten Ganzheit ist. $^{27}$

\subsection{Unternehmen und ihre Umwelt}

Dieser Abschnitt zur Darstellung der Unternehmen und ihrer Umwelt wurde an die Systemtheorie mit ihrer ganzheitlichen Betrachtungsweise angelehnt. Eine ganzheitliche Denkweise berücksichtigt explizit die zumeist interdependenten Beziehungen zwischen System und Umgebung. ${ }^{28}$ Dabei kann unter einem System ,eine geordnete Gesamtheit von Elementen, zwischen denen irgendwelche Beziehungen bestehen oder hergestellt werden können“29 bzw. „ein dynamische

\footnotetext{
${ }^{23}$ Vgl. Siebert, H. (1976), S. 2; Frey, B. S. (1985), S. 15; Der Rat der Sachverständigen für Umweltfragen (1987), S. 40f.; Kirchgeorg, M. (1990), S. 3f.

${ }^{24}$ Vgl. Freimann, J. (1990), S. 12.

${ }^{25}$ Vgl. Trepl, L. (1987), S. 12.

${ }^{26}$ Vgl. Vgl. de Haas, J. P. (1989), S. 9.

27 Vgl. z.B. Haber, W. (1980), S. 76; Fraser-Darling, F. (1986), S. 15f.; Passmore, J. (1986), S. 208ff.; Bateson, G. (1985), S. 15f. sowie $515 \mathrm{ff}$.

${ }^{28}$ Vgl. Kratky, K. W. (1989), S. 18.

${ }^{29}$ Ulrich, H. (1968), S. 105.
} 
Ganzes, das als solches bestimmte Eigenschaften und Verhaltensweise besitzt ${ }^{\star 30}$ verstanden werden. Das System „besteht aus Teilen, die so miteinander verknüpft sind, daß kein Teil unabhängig ist von andern Teilen und das Verhalten des Ganzen beeinflußt wird vom Zusammenwirken aller Teile. ${ }^{31}$

Das Unternehmen: Nach Ulrich wird das Unternehmen als ein ,produktives soziales System“ betrachtet. $^{32}$ Hierbei ist wichtig, daß das Unternehmen als System betrachtet wird. Durch diese Sichtweise ist es möglich und sinnvoll, auch die Umwelt, mit der das Unternehmen in Wechselwirkungen steht, als System zu verstehen. Dieses „Umsystem“ wiederum beinhaltet das Unternehmen als Teilsystem. Das Unternehmen als Ganzes läßt sich als ein solches System bezeichnen, daß sich aus verschieden Subsystemen zusammensetzt. ${ }^{33}$ Da ein System in seiner allgemeinen Form eine geordnete Gesamtheit von Elementen darstellt, zwischen denen irgendwelche Beziehungen bestehen oder hergestellt werden können, ${ }^{34}$ muß das System „Unternehmen” durch bestimmte Systemeigenschaften präzisiert werden.

Das Unternehmen bildet den Mittelpunkt der betriebswirtschaftlichen Betrachtungen. Am Anfang einer unternehmensphilosophischen Positionsbestimmung steht deshalb die Frage nach dem Unternehmensmodell, von dem die Unternehmensleitung ihr Rollen- und Selbstverständnis ableitet. $^{35}$ Aufgrund gesellschaftlicher und kultureller Veränderungen hat sich in den vergangenen Jahrzehnten ein Wandel des Unternehmensmodells ergeben. ${ }^{36}$

Die Unternehmensidentität (Corporate Identity) kann den gesellschaftlichen Herausforderungen der Zeit nur dann entsprechen, wenn sie auf der Grundlage einer gedanklichen Klärung der wünschbaren gesellschaftlichen Rolle des Unternehmens beruht. Ausgehend von der Betrachtung des Unternehmens als System sollen im folgenden die einzelnen Eigenschaften von Unternehmen dargestellt werden. Das Unternehmen kann demzufolge als ein offenes, komplexes, dynamisches, zweck- und zielorientiertes, marktgerichtetes und marktabhängiges, teilweise autonomes, strukturiertes, kommunikatives, produktives, soziales System definiert werden, ${ }^{37}$ das wiederum in einer komplexen und dynamischen, gesellschaftlichen Umwelt eingebettet ist.

\footnotetext{
${ }^{30}$ Ulrich, H./Probst, G. (1991), S. 30.

${ }^{31}$ Ulrich, H./Probst, G. (1991), S. 30.

${ }^{32}$ Vgl. Ulrich, P. (1977).

${ }^{33}$ Vgl. Schwaninger, M. (1989), S. 184.

${ }^{34}$ Vgl. Ulrich, P./Fluri, E. (1992), S. 31.

${ }^{35}$ Vgl. Ulrich, P./Fluri, E. (1992), S. 58.

${ }^{36}$ Vgl. Ulrich, P./Fluri, E. (1992), S. 58f.

${ }^{37}$ Vgl. Ulrich, H. (1970), S. 153ff.; Krulis -Randa, J. (1990), S. 17.
} 
Eine Definition des Begriffes Unternehmen und die Bestimmung der grundlegenden und wesensbestimmenden Merkmale ist nicht allgemeingültig und eindeutig abzugrenzen. Es ist kein Unternehmensmodell denkbar, das allgemein akzeptiert würde, da jeder Definition und Wesensbestimmung des Unternehmens bestimmte sozialphilosophische und ordnungspolitische Vorstellungen zugrunde liegen. ${ }^{38}$

Um die Spannweite entsprechender Unternehmensmodelle $\mathrm{zu}$ verdeutlichen, erweist es sich für die vorliegende Arbeit als sinnvoll, zwei recht weit auseinanderliegende Modelle stichwortartig $\mathrm{zu}$ charakterisieren. Hierbei spielen die verschiedene Vorstellungen von Unternehmen im Bereich des Spannungsfeldes Ökologie-Ökonomie eine entscheidende Rolle. Es gilt, Unternehmen als private Erwerbseinheit eines oder mehrerer Eigentümer-Unternehmer und als quasiöffentliche Institution zu unterscheiden. ${ }^{39}$

Im klassischen Grundmodell eines Eigentümer-Unternehmens wird das Unternehmen als private Erwerbseinheit eines oder mehrerer Eigentümer-Unternehmer betrachtet. Das Unternehmen ist deren privatwirtschaftliches Instrument zur Verfolgung individueller Ziele. Dieses Modell baut auf den Vorstellung des klassischen Liberalismus (Paläoliberalismus) auf. ${ }^{40}$ Nach diesem Modell erscheint das bedingungslose Streben nach Gewinnmaximierung nicht nur als legitimes Recht, sondern geradezu als moralische Pflicht des Unternehmens im Interesse des Gemeinwohls. Doch diese harmonistischen Prämissen sind in einer Welt voller negativer externer Effekte privaten Wirtschaftens ziemlich weltfremd geworden und entsprechen größtenteils nicht der heutigen Realität. ${ }^{41}$

Zur Bewältigung aktueller Probleme sowohl aus gesamtwirtschaftlicher Sicht als auch aus Sicht des Unternehmens erscheint ein anderes Grundmodell sinnvoller. Im neuen Grundmodell wird das Unternehmen als quasi-öffentliche Institution angesehen. Dieses moderne sozialwissenschaftliche Modell, das der heutigen Realität besser gerecht wird, versucht das Unternehmen aus seinem Verhältnis zur gesamten gesellschaftlichen Umwelt und nicht allein aus seinen Eigen-

${ }^{38}$ Vgl. Ulrich, P./Fluri, E. (1992), S. 58ff. insb. S. 61.

${ }^{39}$ Vgl. Ulrich, P. (1970); Ulrich, P./Fluri, E. (1992), S. 58ff.

${ }^{40}$ Das Modell geht im wesentlichen von folgenden sozialpolitischen Vorstellungen aus, die auf einem klassischen Liberalismus aufbauen (vgl. Ulrich P./Fluri, E. (1992), S. 59):

- Gesellschaftlicher Status des Unternehmens als privater Zweckverband von Kapitaleigentümern.

- Es herrscht freie marktwirtschaftliche Konkurrenz, in der jeder die Chancen hat, berechtigt durch eigene Leistung, Kapitaleigentümer und Unternehmer zu sein.

- Zwischen der Verfolgung der individuellen Ziele und den Zielen der Volkswirtschaft (Gesamtgesellschaft) besteht Harmonie.

- Die Freiheit des Staatsbürgers wird garantiert und verkörpert Gewerbefreiheit, Vertragsfreiheit und das Recht auf Privateigentum. 
tumsverhältnissen heraus zu verstehen. Das Unternehmen wird als multifunktionale und dementsprechend pluralistisch legitimierte Wertschöpfungseinheit gesehen, die sozioökonomische Funktionen für verschiedene Anspruchsgruppen, wie Arbeitnehmer, Kapitalgeber, Kunden, Staat und Öffentlichkeit, erfüllt. ${ }^{42}$ Seine Grundfunktion ist zunächst die Schaffung ökonomischer Werte durch die Erstellung entgeltlicher Leistungen (Produkte oder Dienstleistungen) für Abnehmer. Die geschaffenen Geldwerte, die dem Unternehmen verbleiben (Wertschöpfung), dienen der Erfüllung weiterer Funktionen, wie Einkommenserzielung für die beschäftigten Mitarbeiter, Kapitalverzinsung (Entschädigung von Eigen- und Fremdkapitalgebern), Steueraufkommen für den Staat zur Finanzierung der Staatsaufgaben und soziale und u.U. kulturelle Funktionen (Ausbildung, Forschung und Entwicklung, Sozialleistungen usw.). Je umfangreicher der Funktionskata$\log$ wird, um so mehr ist das Unternehmen nicht mehr Privatangelegenheit der Eigentümer, sondern berührt vor allem als Großunternehmen elementare Interessen der Gesellschaft. Faktisch sind die großen Unternehmen längst $\mathrm{zu}$ quasi-öffentlichen Institutionen geworden. ${ }^{43} \mathrm{Ihr}$ Eigentum ist zwar privat, aber ihre Wirkungszusammenhänge sind - wie die sog. „externen Effekte“, die die gesellschaftlichen Kosten und Nutzen privaten Handelns belegen - öffentlich relevant. Dementsprechend stehen vor allem große Unternehmen zunehmend mitten im Brennpunkt aktueller gesellschaftlicher Wert- und Interessenkonflikte; ihre Aktivitäten unterliegen einer wachsenden öffentlichen Exponiertheit. ${ }^{44}$

Welches nun allerdings die grundlegenden, wesensbestimmenden Merkmale eines Unternehmens sind, wird im betriebswirtschaftlichen Schrifttum recht unterschiedlich gesehen. Es bestehen also verschiedene Vorstellungen darüber, was ein Unternehmen sein soll, d.h. welches seine gesellschaftliche Funktion (Aufgabe) und Legitimation (Rechtfertigung) ist. Der Unternehmensbegriff bedarf daher einer Definition, wobei zunächst seine Abgrenzung vom Begriff „Betrieb” von Bedeutung ist. Demnach ist Betrieb ein gemeinsamer Oberbegriff für das Unternehmen (Betriebe der Fremdbedarfsdeckung) und für den Haushalt (Betriebe der Eigenbedarfsdeckung). ${ }^{45}$ Die Unternehmen ihrerseits unterteilen sich in private und öffentliche Unternehmen. ${ }^{46}$ Substantiell werden Unternehmen, zumeist im Hinblick auf eine zu betrachtende Fragestellung, recht

\footnotetext{
${ }^{41}$ Vgl. Ulrich P./Fluri, E. (1992), S. 59.

${ }^{42}$ Vgl. Ulrich P./Fluri, E. (1992), S. 60ff.

${ }^{43}$ Vgl. Ulrich, P. (1977); Ulrich, P./Fluri, E. (1992), S. 60.

${ }^{44}$ Vgl. Dyllick, T. (1989), S. 15ff.

${ }^{45}$ Ein wichtiges Merkmal für die Unterteilung der Klasse der Betriebe in Unterklassen ist die Art ihrer Bedarfsdeckung, wobei Fremdbedarfsdeckung und Eigenbedarfsdeckung unterschieden werden können. Vgl. Schweitzer, M. (1990), S. 20ff.

${ }^{46}$ Anteilseigner privater Unternehmen sind Privatpersonen oder private Gesellschaften, die betont privatwirtschaftliche Ziele verfolgen, wie Gewinnsteigerung, Umsatzsteigerung, Imageverbesserung, Mindestrentabilität oder Erhöhung des Marktanteils. Anteilseigner öffentlicher Unternehmen ist dagegen ganz oder überwiegend die öffentliche
} 
unvollständig und unterschiedlich mit Hilfe von Adjektiven beschrieben. Demnach ist das Unternehmen beispielsweise eine "technische, soziale, wirtschaftliche und umweltbezogene Einheit mit der Aufgabe der Fremdbedarfsdeckung, mit selbständigen Entscheidungen und eigenen Risiken“ ${ }^{4}{ }^{47}$

Nach dem Verständnis, das dieser Arbeit zugrunde liegt, lassen sich Unternehmen anhand der Eigenschaften charakterisieren. ${ }^{48}$ Danach bestehen zwischen den einzelnen Merkmalen interdependente Beziehungen, die mehr oder weniger starken Einfluß auf deren konkretes inhaltliches Erscheinungsbild besitzen. Im folgenden werden die einzelnen Merkmale und Einflüsse partiell vor allem in Verbindung mit dem Merkmal der Offenheit dargestellt. ${ }^{49}$

Unternehmen sind keine natürlichen Konstrukte, sondern künstliche und dadurch unvollkommene von Menschen bewußt geschaffene Systeme, die die Elemente „Mensch“ und „Sachmittel“ in einer zielgerichteten Anordnung kombiniert und in Beziehung zueinander setzen. ${ }^{50}$ Ihre Tätigkeit beruht auf menschlicher Arbeit geistiger und körperlicher Art, unterstützt von immer zahlreicheren und leistungsfähigeren Maschinen und Anlagen. In diesem Sinne stellen Unternehmen proaktive, sozio-technische Systeme dar. ${ }^{51}$ Eine wesentliche Voraussetzung der Existenzfähigkeit und der zielorientierten Handlungsmöglichkeit eines Unternehmens stellen die System- bzw. Unternehmensstrukturen dar. Unter Struktur wird allgemein die Ordnung eines Systems verstanden, wobei darunter sowohl die explizite, formale Ordnung als auch die implizite Anordnung der Beziehungen zwischen den Systemelementen zu zählen sind. ${ }^{52}$ Das Unternehmen ist das Ergebnis eines bewußten Gestaltungsprozesses. Die Struktur des Unternehmens wird meist als Organisation bezeichnet. Das Gefüge ist nicht nur das Ergebnis bewußter Gestaltungsmaßnahmen, d.h. formale Organisationsstruktur, sondern hat sich auch ungewollt gebildet, d.h. informale Informationsstruktur. Die Beziehung ist relativ dauerhaft. ${ }^{53}$ Dabei weist

Hand. Öffentliche Unternehmen orientieren sich i.d.R. an gemeinwirtschaftlichen Zielen, wie Kostendeckung, Verlustreduktion oder Verlustminderung. Vgl. Schweitzer, M. (1990), S. $26 \mathrm{ff}$.

47 Schweitzer, M. (1990), S. 21. „Die Unternehmung als Aktions-, Interessen- und Vertragszentrum charakterisieren wir nunmehr als ein sozio-technisches System, in dem Güter (Sachziele) zur Fremdbedarfsdeckung erstellt werden, um maximale diskontierte Überschüsse/Kapitalwerte bzw. hilfsweise maximale kalkulatorische Gewinne (Wertziele) zu erwirtschaften - unter Beachtung von Zielen aus dem Humanbereich (Sozialziele) sowie sonstigen Anforderungen aus dem System und aus dem Umsystem (Rahmenbedingungen)”. Hahn, D. (1996), S. 16.

${ }^{48}$ Der Kern dieser Merkmale entspricht den Eigenschaften, die Unternehmen bei „Zürcher Ansatz zur Führungslehre" zugeordnet werden. Der gleichartige Ansatz findet sich u.a. aber auch zur St. Galler Schule. Vgl. Rühli, E. (1984), S. 347f.; Ulrich, H. (1970), S. 13ff.

${ }^{49}$ Vgl. Ulrich, P./Fluri, E. (1992), S. 30ff. Das Verhältnis zwischen sozialem System Unternehmen und Umwelt wird vor allem durch die Eigenschaften der Offenheit sozialer Systeme interpretiert. Da die Offenheit eines Unternehmens eine Umweltverbundenheit zum Ausdruck bringt, die nicht nur auf Marktbeziehungen beschränkt bleibt, stellt dies einen wichtigen Ansatzpunkt für die ökologisch verpflichtete Unternehmensführung als auch für das Verständnis der Merkmale von Unternehmen dar.

${ }^{50}$ Vgl. Ulrich, H./Krieg, W. (1974), S. 17; Ulrich, H. (1968), S. 42 und 102; Grochla, E. (1970), S. 1ff.

${ }^{51}$ Vgl. Ulrich, H./Krieg, W. (1974), S. 17.

${ }^{52}$ Vgl. Ulrich, H. (1970), S. 212; Schwaninger, M. (1989), S. 184. 
tionsstruktur. Die Beziehung ist relativ dauerhaft. ${ }^{53}$ Dabei weist die Unternehmensorganisation keinen Wert an sich auf, sondern sie dient lediglich der rationelleren, im Sinne von besseren, standardisierten Zielerreichung des Unternehmens unter sich ständig verändernden Einflüssen. ${ }^{54}$

Ein weiteres Merkmal von Unternehmen ist ihre Vernetztheit bzw. Komplexität. ${ }^{55}$ Alle Unternehmen können als mehr oder weniger stark vernetzt gelten. Für die Unternehmen beruht diese Komplexität wesentlichen aus dem Umstand, daß sie aus einer Vielzahl von Systemelementen (Subsystemen und Mitgliedern) bestehen, die in vielfältig geknüpften, interdependenten Beziehungen zwischen diesen Elementen zueinander stehen. Von entscheidender Bedeutung ist dabei, daß die Komplexität des Unternehmens nicht etwa nur eine zu duldende Eigenschaft ist, ein unvermeidbares Übel gewissermaßen, sondern daß die Komplexität für die Prosperität eines Unternehmens notwendig ist. Ihre Anpassungsfähigkeit, Flexibilität, Lern- und Entwicklungsfähigkeit steht in ursächlichem Zusammenhang mit der Komplexität, die sie aufweist. ${ }^{56}$

Die Vielschichtigkeit und auch die Verschiedenartigkeit der Beziehung zur Gestaltung des organisationalen Entscheidungssystems läßt keine genauen Aussagen über das Zusammenwirken der Unternehmensteile zu. Das Verhalten der Organisationen und dadurch auch das Verhalten des Unternehmens sind nicht sicher und vollständig bestimmbar. Über die Beziehungen lassen sich keine eindeutigen Aussagen treffen. Es sind höchstens Wahrscheinlichkeitsaussagen möglich, weshalb Unternehmen auch das Merkmal probabilistisch, d.h. nur teilweise determiniert bzw. stochastisch, zuzuordnen ist. ${ }^{57}$

Ein weiteres Merkmal des Unternehmens ist die Offenheit. ${ }^{58}$ Dies heißt zum einem, daß das Unternehmen nicht unter dem Siegel falsch verstandener Wissenschaftlichkeit gedanklich von seiner Umwelt und anderer darin vorkommender Systeme isoliert werden darf. Unternehmen leben in Wechselbeziehungen mit einer sich laufend verändernden Umwelt, an die sich die Unternehmen anpassen müssen. Die Offenheit ergibt sich, wenn die Intensität der Beziehungen des Unternehmens zur Umgebung, zum Umsystem, untersucht wird, bzw. wenn es die Beziehungen nach außen, d.h. zu seiner Umwelt, unterhält. ${ }^{59}$ Danach lassen sich isolierte, abgeschlossene und offene Systeme unterscheiden. ${ }^{60}$ Unter offenen Systemen versteht man „Systeme, die im Ener-

\footnotetext{
${ }^{53}$ Vgl. Hopfenbeck, W. (1998), S. 53.

${ }^{54}$ Vgl. Ulrich, H. (1970), S. 212.

${ }^{55}$ Vgl. Fischer, H./Kriese, R. (1991), S. 908; Sauter-Sachs, S. (1992), S. 190.

${ }^{56}$ Vgl. Malik, F. (1979), S. 29.

${ }^{57}$ Vgl. Sauter-Sachs, S. (1992), S. 190.

${ }^{58}$ Vgl. Ulrich, P./Fluri, E. (1992), S. 30ff.

${ }^{59}$ Vgl. Ulrich, H. (1968), S. 112; Ulrich, H./Probst, G. (1988), S. 50.

${ }^{60}$ Vgl. Bertalanffy, L. v./Beier, W./Laue, R. (1977), S. $29 f$.
} 
gie- und Materialaustausch mit ihrer Umgebung stehen und deren Verhalten von der Umwelt beeinflußt wird. ${ }^{61}$ Dabei zu berücksichtigen sind, daß die Beziehungen beliebiger Intensität zur Umwelt und den mit ihnen einhergehenden Interaktionen von essentieller Bedeutung für die Überlebensfähigkeit und den Fortbestand des betrachteten Systems Unternehmen sind. Unternehmen sind Teile eines dichten und für ihre Existenz überaus wichtigen Netzwerks von Austauschbeziehungen und -prozessen materieller und immaterieller, wirtschaftlicher, juristischer und gesellschaftlicher Art. Sie sind auch ein Teil einer Volks- und Weltwirtschaft und bewegen sich in einer oder mehreren Wirtschaftsordnungen. Unternehmen sollen deshalb als offene Systeme in einer marktwirtschaftlichen Wirtschaftsordnung verstanden werden. Bei der ökologisch verpflichteten Unternehmensführung ist dies von großer Bedeutung, weil das Verhältnis zwischen sozialem System und (ökologischer) Umwelt vor allem durch die Eigenschaft der Offenheit sozialer Systeme interpretiert wird.

Unternehmen sind zugleich auch (lebendige) soziale Systeme. Sie bestehen aus Individuen und Menschengruppen, die sich teilweise zu sozialen Subsystemen zusammenschließen. ${ }^{62}$ Auch kommt es zwischen diesen Teilen und dem Unternehmen $\mathrm{zu}$ wechselseitigen Verhaltensbeeinflussungen. Alle Veränderungsprozesse auf externe und interne Einflüsse sind auch Lernprozesse. Im weiteren Sinne werden Unternehmen als gesellschaftliche Institutionen, d.h. als Bestandteil der Gesellschaft und ihrer Umwelt betrachtet, die bei ihren Entscheidungen stets die Interessen und Werte der Gesellschaft bzw. einzelner Gesellschaftsgruppen einbeziehen und dementsprechend auch verschiedene sozio-ökonomische Funktionen erfüllen müssen. ${ }^{63}$ Zwischen den Ansprüchen der verschiedenen Bezugsgruppen des Unternehmens bestehen teilweise Zielkonflikte. Unternehmenspolitik ist die Politik des Unternehmens im Umgang mit Interessenkonflikten nach außen und innen. ${ }^{64}$ Sie bewegen sich in einem übergeordneten sozialen System, von dem sie zumindest teilweise abhängig sind, und tragen als dessen Teil eine gewisse soziale Verantwortung. ${ }^{65}$

Unternehmen sind nicht nur Bestandteil der Gesellschaft und ihrer Umwelt, sie bilden selbst eine Gesellschaft, die sie sich aus Individuen und Gruppen mit unterschiedlichen Ansprüchen zusammensetzt. ${ }^{66}$ Deshalb sind Unternehmen als autonom zu kennzeichnen, obwohl ihnen und ihrer Umgebung Abhängigkeiten bestehen. „Autonomie liegt vor, wenn die Beziehungen und In-

\footnotetext{
${ }^{61}$ Bertalanffy, L. v./Beier, W./Laue, R. (1977) S. 30.

${ }^{62}$ Vgl. Sauter-Sachs, S. (1992), S. 190; Fischer, H./Kriese, R. (1991), S. 908.

${ }^{63}$ Vgl. Hill, W. (1991), S. 14; Ulrich, P./Fluri, E. (1992), S. 61.

${ }^{64}$ Vgl. Ulrich, P./Fluri, E. (1992), S. 61.

${ }^{65}$ Vgl. Ulrich, P. (1977), S. 212ff.

${ }^{66}$ Vgl. Hunziker, R. (1980), S. 7.
} 
teraktionen, die das System als Einheit definieren, nur das System selbst involieren und keine anderen Systeme.67 Demnach bedeutet Autonomie völlige Verhaltensfreiheit, Selbstgestaltung, -lenkung und -entwicklung eines Systems. ${ }^{68}$ Unternehmen entwickeln also eigenständig interne Regelwerke, an denen sie das Verhalten nach innen und außen ausrichten. Unternehmen erlangen so individuelle Identität ${ }^{69}$ und besitzen stets die Freiheit, auf die Rahmenbedingungen Einfluß zu nehmen oder ihre unternehmerische Tätigkeit einzustellen. Diese totale Autonomie in Bezug auf das Unternehmen muß allerdings auf eine relative modifiziert werden, da die Autonomie des Unternehmens von seinen Beziehungen zur Umwelt begrenzt wird. Das Unternehmen strebt zum einem nach der Erfüllung der von der Umwelt an es herangetragenen Zwecke und ist somit direkt von seiner Umwelt abhängig, zum anderen aber beeinflußt das Unternehmen seinerseits die Umwelt durch sein Handeln. ${ }^{70}$ Das Unternehmen kann somit nur teilweise als autonom gelten. $^{71}$

Vom Prinzip her sind Unternehmen auf Dauer angelegte Systeme. ${ }^{72}$ Das heißt aber nicht, daß sie bis in alle Ewigkeit Bestand haben müssen, denn bekanntlich ist nichts von Dauer. Entscheidend ist, daß bei ihrer Gründung i.d.R. nicht von vornherein ein bestimmter, in nicht allzu weiter Ferne liegender Zeitpunkt der Unternehmensauflösung fixiert wird, so daß die Unternehmensleitung bei ihren Entscheidungen von einer Fortführung der Unternehmenstätigkeit ausgeht. Der Wille, dauerhaft $\mathrm{zu}$ existieren, bedingt die Offenheit von Unternehmen, denn nur offene Systeme sind über längere Zeit lebensfähig. ${ }^{73}$

Betrachtet man das Unternehmensverhalten über längere Zeit, so ergibt sich ein weiteres Unternehmensmerkmal. Unternehmen werden als dynamisches System angesehen. Dynamische Systeme liegen dann vor, wenn die Systeme ihre Struktur im Zeitablauf verändern können, d.h. innerhalb des Unternehmens selbst und mit der Umwelt laufen ständig Prozesse ab. Die Berücksichtigung der Dynamik des Unternehmens bedeutet den ausdrücklichen Einbezug der Tatsache, daß sie einem ständigen Wandel ausgesetzt ist, den sie teilweise selbst verursacht, der vor allem aber aus der Umwelt auf das Unternehmen einwirkt. Das System Unternehmen muß sich laufend

\footnotetext{
${ }^{67}$ Probst, G. (1987), S. 82.

${ }^{68}$ Vgl. Probst, G. (1987), S. 82.

${ }^{69}$ Vgl. Sauter-Sachs, S. (1992), S. 190.

${ }^{70}$ Vgl. Ulrich, H. (1987), S. 13.

${ }^{71}$ Selbstverständlich bewegen sich diese Regeln, und damit auch die Aktivitäten des Unternehmens, innerhalb bestimmter Grenzen, die durch die im Umsystem bestehenden verständlichen Rahmenbedingungen fixiert sind. Vgl. Ulrich, H./Probst, G. (1987), S. 56; Sauter-Sachs, S. (1992), S. 190.

${ }^{72}$ Vgl. Kropfberger, D. (1986), S. 180.

${ }^{73}$ Vgl. Vester, F. (1988), S. 29.
} 
neuen Rahmenbedingungen anpassen. Das Unternehmen ist damit zu permanenten Entwicklungen herausfordert oder gezwungen.

Unternehmen werden als lebendige Organismen angesehen, für die besondere Gesetzmäßigkeiten gelten, nämlich die der Evolution. Wenn sie überleben wollen, müssen sie in der Lage sein, sich den laufend verändernden Rahmenbedingungen anzupassen. Diese Anpassung sollte möglichst aktiv, d.h. ohne Anstoß von außen, erfolgen und nicht ausschließlich aus reaktiven Maßnahmen bestehen. Unternehmen sollten als lernende Systeme vielmehr in der Lage sein, Veränderungen zu antizipieren und neu entwickelte Regeln auf diese Störereignisse anzuwenden. ${ }^{74}$

Unternehmen stellen keine Zufallsprodukte, sondern bewußt geplante Strukturen dar. Sie verfolgen einen vorgegebenen Zweck, nämlich die Ausübung bestimmter Funktionen in der Umwelt, und sie können wie jedes System nur aus ihrem Zweck heraus verstanden werden. Unternehmen haben bestimmte originäre Funktionen in der Gesellschaft zu erfüllen wie z.B. zur Fremdbedarfsdeckung, d.h. Versorgung mit bestimmten Produkten. ${ }^{75}$ Grundsätzlich besteht der Zweck eines Unternehmens jedoch in der Befriedigung verschiedener Ansprïche interner und externer Anspruchsgruppen. ${ }^{76} \mathrm{Um}$ dies zu erreichen, fixiert das Unternehmen, unter Berücksichtigung der engagierten Anspruchsgruppen, ein Zielsystem, an dem es anschließend sein Verhalten ausrichtet. Dabei ist das Zielsystem im Zeitablauf veränderlich. Stellen die Unternehmen veränderte Bedingungen fest, kommt es meist zu Anpassungen des Zielsystems. Unternehmen sind damit also zielsuchend und zielgerichtet.

Unternehmen sind produktiv, unabhängig von Größe und Art erfüllen sie in der modernen Gesellschaft produktive Funktionen. Sie erbringen durch Erzeugen und Verteilen von Sachgütern sowie durch Anbieten und Ausüben von Diensten vielfältige Leistungen, die der Befriedigung menschlicher Bedürfnisse dienen. ${ }^{77}$ Dies ergibt sich aus der Tätigkeit, die Unternehmen zum Zwecke der Zielerreichung und damit zur Befriedigung der Ansprüche der Stakeholder ausführen. Sie nutzen u.a. ihre Fähigkeiten zur Selbstregulation und Selbstorganisation und erstellen Leistungen für Dritte.

\footnotetext{
${ }^{74}$ Vgl. Biethahn, J./Mucksch, H./Ruf, W. (1990), S. 35.

${ }^{75}$ Vgl. Schweitzer, M. (1990), S. $21 \mathrm{ff}$.

76 Vgl. Hill, W. (1991), S. 10; Ulrich, P./Fluri, E. (1992), S. 77ff. Anstelle des Begriffes Anspruchsgruppen wird häufig der Begriff Stakeholder verwendet. Siehe dazu ausführlich Kap. 3.4.

77 Vgl. Ulrich, H./Krieg, W. (1974), S. 17. Nach der Körperlichkeit der erzeugten Leistungen werden dabei Sachund Dienstleistungen unterschieden. Vgl. Schweitzer, M. (1990), S. 28.
} 
Im Rahmen der ökologisch verpflichteten Unternehmensführung wird das Unternehmen als ein ökonomisch-ökologische System aufgefaßt. Was aber bedeutet es, das Unternehmen als ökologisches Subsystem aufzufassen?

Als ökologisches Subsystem wird das Unternehmen nicht als Teil des Wirtschaftskreislaufs gesehen, sondern als Teil des natürlichen Stoffkreislaufs. Im Vordergrund stehen somit Stoff- und Energieflüsse, nicht die für die ökonomische Perspektive zentralen Geldflüsse. ${ }^{78}$ In ökonomischer Sichtweise bezieht das Unternehmen Arbeit, Kapital, Boden und Know-how als zentrale Produktionsfaktoren auf der Inputseite und transformiert diese in Produkte als dem erwünschten Output der unternehmerischen Wertschöpfungsprozesse. Abbildungsmedium dieser Input- und Outputflüsse ist monetäre Größen (Geldeinheiten).

Input

Transformationsproze $\beta$

Output

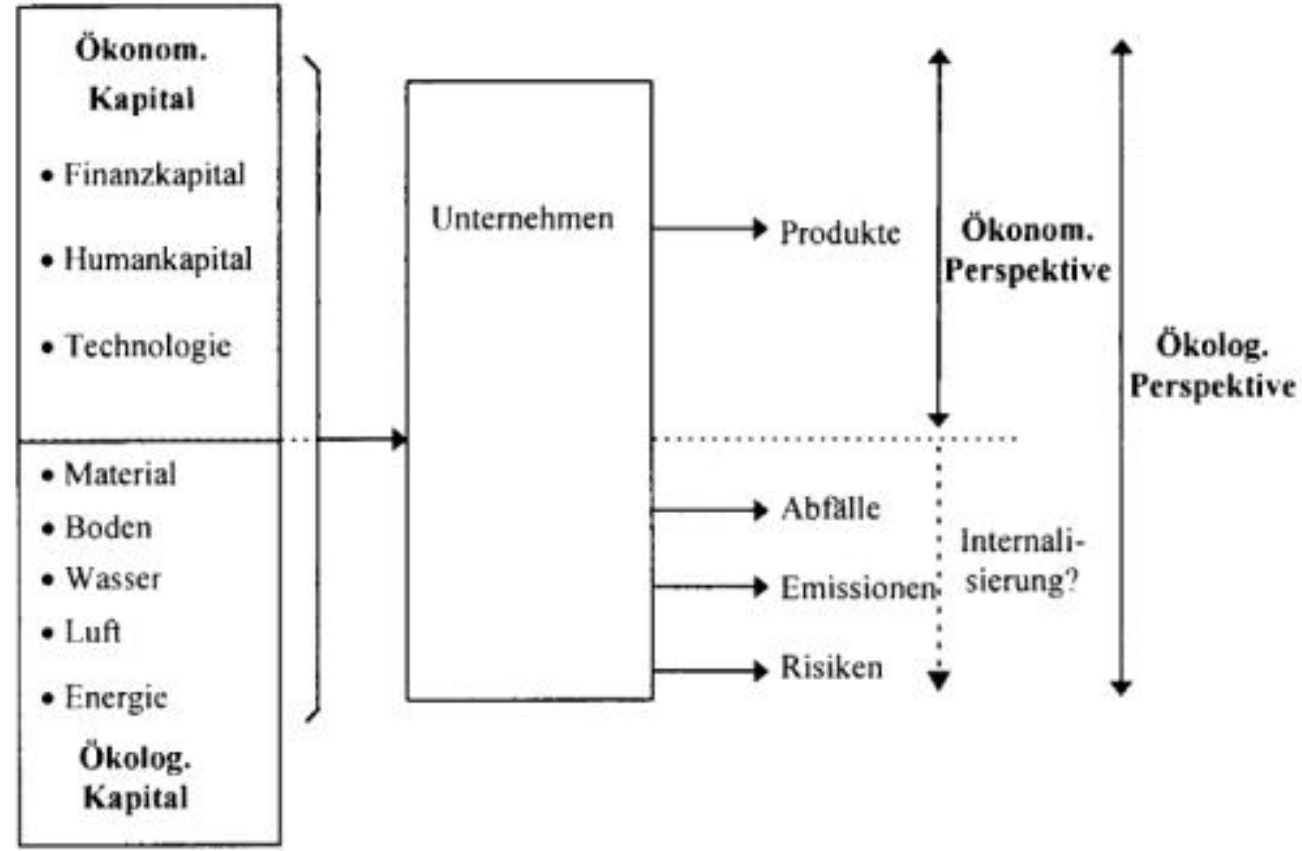

Abb. 3.1: Der Leistungserstellungsprozesse in ökologischer und ökonomischer Perspektive (Quelle: Seisreiner, R. (1997), S. 39)

In ökologischer Sichtweise sind es ganz andere Elemente, die von Bedeutung sind. Hier sind es natürliche Ressourcen auf der Inputseite sowie Emissionen, Abfälle und Risiken als dem nichterwünschten Output der Schadschöpfungsprozesse, die neben den Produkten auf der Outputseite eine Rolle spielen. Abbildungsmedien sind hier physikalische Größen (Schadstoffeinheiten). Die

\footnotetext{
${ }^{78} \mathrm{Zu}$ den Kriterien der ökonomischen und ökologischen Perspektive vgl. Kap. 3.3 dieser Arbeit.
} 
unternehmerischen Produkte werden als gemeinsamer Output der Wert- und Schadschöpfungsprozesse gesehen. Der Leistungserstellungsprozeß wird folglich nicht mehr über die Kombination der traditionellen Produktionsfaktoren bzw. ökonomischen Kapitalfaktoren definiert, sondern über alle Ressourcen, die ein Unternehmen in Anspruch nimmt ${ }^{79}$ (vgl. Abb. 3.1).

Entsprechend dieser veränderten Sichtweise des Unternehmens stehen in ökologischer Perspektive auch andere Ziele im Vordergrund, die sich auf die Bereiche Ressourcenschutz, Emissionsschutz, Abfallvermeidung und -verminderung, Risikovermeidung und -verminderung sowie auf die Entwicklung umweltverträglicher Produkte beziehen. Der Umweltschutz als Unternehmensziel erhält hierdurch eine inhaltlich klare und operationale Bedeutung zugewiesen.

Die Unternehmensumwelt: Ein Kernpunkt dieses Abschnitts ist die Betrachtung von Unternehmen als System. Durch diese Sichtweise ist es möglich, auch die Umwelt, mit der das Unternehmen in Wechselwirkungen steht, als System zu verstehen. Dieses Umsystem wiederum beinhaltet das Unternehmen als Teilsystem. Die weiteren Teilsysteme bzw. Umwelten, die für eine ökologisch verpflichtete Unternehmensführung eine entscheidende Rolle spielen und das Unternehmen durch Anforderungen beeinflussen, werden als Umsystem des Unternehmens im folgenden dargestellt, wobei jedoch eine eindeutige Abgrenzung der einzelnen Umweltkategorien weder möglich noch beabsichtigt ist. Ebenso können bei jeder Umweltkategorie nur einige ausgewählte Aspekte Berücksichtigung finden.

Die Betrachtung der Unternehmens-Umwelt war und ist auf einige Teilbereiche der relevanten betrieblichen Umwelt, vor allem die ökonomische und technische Dimension beschränkt. Mit dem systemtheoretischen Ansatz wird die Erweiterung der Umweltaspekte unternommen. Damit werden die soziale bzw. gesellschaftliche Umwelt und die Betrachtung des Unternehmens als offenes soziotechnisches bzw. produktives soziales System, unter dessen Bedingungen ein Überleben im umfassenderen gesellschaftlichen Supersystem möglich ist, zu einem wichtigen Gegenstand der Analyse. Wesentliche Berücksichtigung finden hier die Austauschprozesse des Systems Unternehmen mit dem Supersystem Gesellschaft. ${ }^{80}$

\footnotetext{
${ }^{79}$ Dyllick, T./Hummel, J. (1996), S. 7; Seisreiner, R. (1997), S. 37ff.

${ }^{80}$ Aus dieser Sichtweise ergibt sich die Forderung nach der Berücksichtigung der Umwelt in dreifacher Hinsicht (vgl. Staehle, C. (1991), S. 581f.; Dyllick, T. (1982), S. 167ff.; Ulrich, H. (1970), S. 135):

- sie bietet die Möglichkeit, Produkte und Dienstleistungen abzusetzen,

- sie stellt Anforderungen und Ansprüche an das Unternehmen,

- sie setzt die rechtlichen Rahmenbedingungen.
} 
Die Erweiterung der Umweltaspekte durch die ökologische Umwelt stellt die weitere Ausdehnung des Betrachtungshorizontes der Umwelt innerhalb der Betriebswirtschaftslehre dar. Die Gründe für die Erweiterung der Umweltperspektive auf ökologische Umwelt im Rahmen der Betriebswirtschaftslehre sind auf die Erfordernisse zurückzuführen, die sich aufgrund der zunehmenden krisenhaften Tendenzen im ökologischen System und den daraus folgenden negativen Rückkopplungen für Unternehmen ergeben haben. Auslöser war dabei eine Änderung des gesellschaftlichen Wertsystems ${ }^{81}$ hin zur verstärkten Forderung nach dem Schutz der Umwelt, der in zunehmenden Maße auch der Tätigkeit von Unternehmen als wesentliches Element des ökonomischen Systems bedarf. ${ }^{82}$

Die Abgrenzung des fokalen Systems „Unternehmen“ gegenüber seiner Umwelt erfolgt über dessen Eigenschaften. Jedes Unternehmen ist jedoch in eine spezifische Umwelt einbezogen, wobei vielfältige gegenseitige Austausch- und Einwirkungsprozesse stattfinden. Ein Unternehmen kann nur überleben, wenn es sich immer wieder von neuem mit den sich ständig ändernden Umweltbedingungen befaßt, diese in Beziehung setzt $\mathrm{zu}$ den eigenen Gegebenheiten, Mitteln und Möglichkeiten und daraus die Grundlagen seines gegenwärtigen und zukünftigen Verhaltens ableitet. $^{83}$ Damit wird neben der Komplexität und Dynamik des ganzen Beziehungsgefüges ${ }^{84}$ auch die Notwendigkeit klar, dieses zu erkennen und $\mathrm{zu}$ analysieren. Wesentlich erscheint, daß man diese Komplexität nicht durch Abstraktionen zu eliminieren sucht, sondern mit ihr umzugehen lernt.

Die Umwelten des Unternehmens stellen ein vielschichtiges System dar, die unter verschiedenen Gesichtspunkten eingeteilt werden können. Der Begriff „Umwelt“ kann somit in unterschiedlicher Weise verwendet und in einem weiteren oder engeren Sinne definiert werden. Im weiteren Sinne wird unter Umwelt die Gesamtheit der existenzbestimmenden Faktoren, also der Faktoren definiert, ${ }^{85}$ die die physischen, psychischen, technischen, ökonomischen und sozialen Bedingungen und Beziehungen des Menschen bestimmen. Dieser weite Umweltbegriff enthält in sich die Teilbegriffe wie soziologische Umwelt, räumliche Umwelt sowie biologische bzw. ökologische

\footnotetext{
81 Die Forderung aus dem gesellschaftlichen Wertewandel sowohl an Unternehmen als auch an die betriebswirtschaftliche Forschung ist nach Rohn wie folgt zu formulieren: „Jedes Unternehmen steht dreifach im System seiner Umwelt; sozial, technisch, ökonomisch. Es wird höchste Zeit, daß es auch seiner ökologischen Umwelt die erforderliche Aufmerksamkeit schenkt und sich in das ,Gesamtsystem Natur" ebenso einpaßt wie in die Supersysteme Gesellschaft und Wirtschaft." Zit. nach Schreiner, M. (1988), S. 8.

${ }^{82}$ Vgl. Frese, E. (1992), Sp. 2433.

${ }^{83}$ Vgl. Ulrich, H./Krieg, W. (1974), S. 18.

${ }^{84}$ Unter der Komplexität der Umwelt verbirgt sich die große Anzahl der relevanten Elemente des Umfeldes eines Unternehmens, ihre Verschiedenartigkeit sowie das Ausmaß der Beziehungen zwischen den einzelnen Elementen. Die Dynamik hingegen zielt auf die Veränderung der einzelnen Elemente im Hinblick auf ihren Inhalt und ihre Bedeutung sowie die Veränderung der Beziehungen zwischen den Elementen im Zeitablauf ab.
} 
Umwelt. Die ökologische Umwelt umfaßt den ,Zustand der Umwelt für Tier, Mensch und Pflanzen und die Bedingungen für ihr gemeinsames Zusammenleben““ ${ }^{86}$

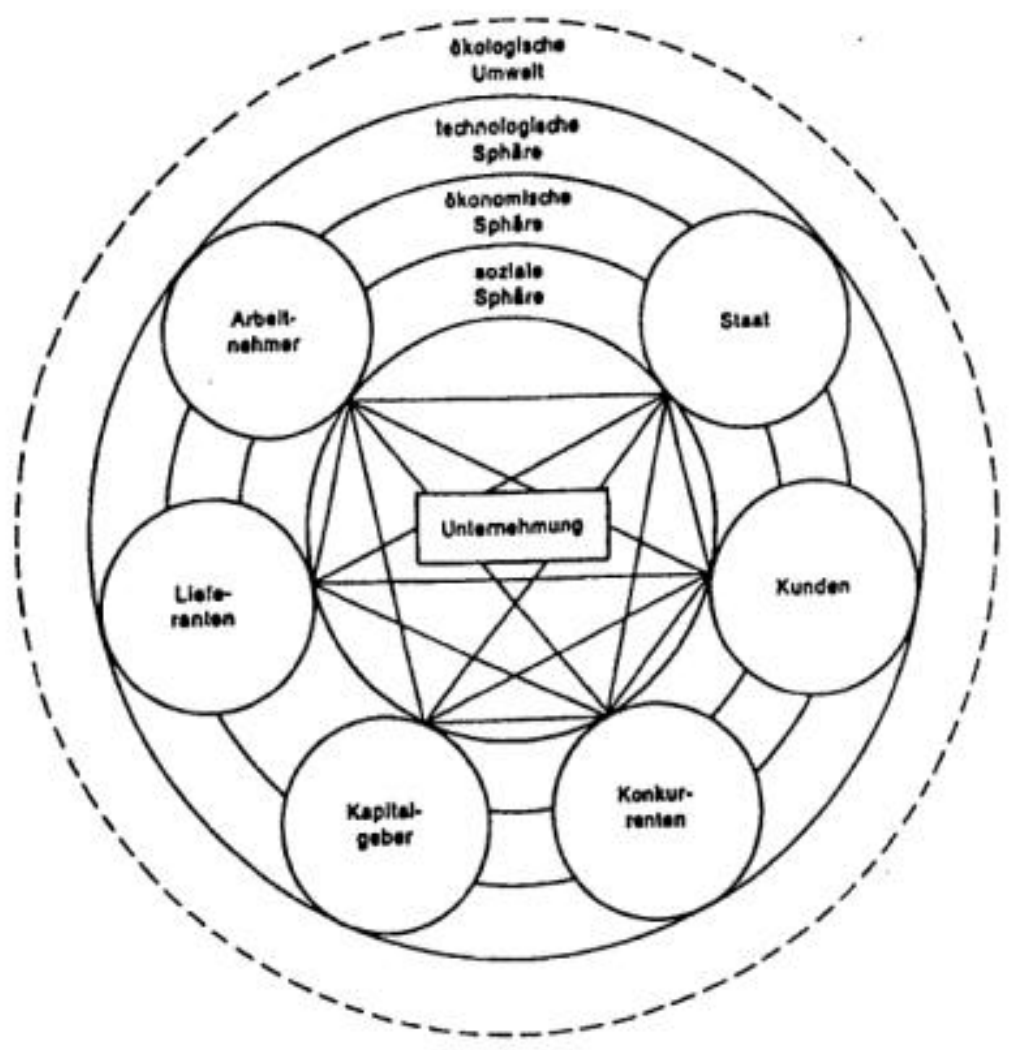

Abb. 3.2: Unternehmensumwelt in dimensioneller und institutioneller Hinsicht (Quelle: Ulrich, H. (1990), S. 67)

Nach der allgemeinen Definition der Umwelt lassen sich bei der Unternehmensumwelt drei Umweltsphären unterscheiden, die übergreifende Sachverhalte darstellen, sich aber ihrerseits auf die ökologische Umwelt, den Gesamthaushalt der Natur, beziehen, nämlich: ${ }^{87}$

- Eine technologische Umweltsphäre,

- Eine ökonomische Umweltsphäre (Wirtschaftssystem),

- Eine soziale Umweltsphäre (Gesellschaftssystem) und

- $\quad$ Eine ökologische Umwelt (Ökosystem).

\footnotetext{
${ }^{85}$ Vgl. Wicke, L. (1991), S. 5.

${ }^{86}$ Vgl. Wicke, L. (1991), S. 5 f.

87 Vgl. Ulrich, H./Krieg, W. (1974), S. 19f.; Sauter-Sachs, S. (1992), S. 192ff.; Jahnes, S./Tammler, U. (1997), S. 5ff. Zur Abgrenzung bzw. Einordnung der Umwelt von Unternehmen in globaler Umwelt (Makroumwelt), die makroökonomische, sozio-kulturelle, politisch-rechtliche, technologische und natürliche Umwelt umfaßt, und in aufgabespezifischer Umwelt (Mikroumwelt), die Absatzmärkte (Wettbewerber, Distributionsorgane und unterstützende Dienstleister und Endabnehmer) und Beschaffungsmärkte (Kapital, Arbeit und Betriebsmittel und Materialien) umfaßt. Vgl. hierzu Sander, M. (1998), S. 42ff.).
} 
Die technologische Umweltsphäre umfaßt die Wirkungsbereiche der Naturwissenschaften und der Technik im weitesten Sinne. ${ }^{88}$ Sie bildet die materielle Basis des Wirtschaftens. Für das Lhternehmen sind vor allem technologische und technische Informationen über Produktion und Produkte von Bedeutung, aber auch soziale Technologien wie z.B. soziale Neuerung, politische Programme oder Gesetze (Schnittstelle zur politisch-rechtlichen Umwelt). Hinzu kommt die wachsende Bedeutung von ,thought technologies“, wie z.B. Software oder ManagementTechnologie. Letztere umfaßt die Instrumente der Unternehmensführung und Organisation und somit Ansätze, Denkweisen, Modelle, Methoden und Hilfsmittel, z.B. für die Innovations- und Technologieplanung. ${ }^{89}$ Gerade die erfolgreiche technische Innovation ist an die Kombination von Produkt- und/oder Produktionstechnologie mit Management-Technologie gebunden. Gegenstand einer Betrachtung der technologischen Umwelt kann der Stand der Entwicklung und zukünftiges Potential von Technologie und Technik sein, z.B. konkret bezogen auf Forschungsund Entwicklungstätigkeiten.

Die technologische Umwelt ist in letzter Zeit von einer besonders ausgeprägten Dynamik gekennzeichnet. Damit weist dieser Umweltsektor aus Unternehmenssicht aufgrund der geringen Vorhersehbarkeit von Entwicklungen ein besonders hohes Risiko- (aber auch Chancen-)potential auf. Die rechtzeitige Antizipation und Nutzbarmachung von Entwicklungen spielen hier eine große Rolle. $\mathrm{Zu}$ spätes Erkennen technologisch bedingter Risiken kann für verschiedene Industriezweige $\mathrm{zu}$ ernsthaften Bedrohungen und für viele Unternehmen zum Ausschneiden aus dem Markt führen (z.B. die Hersteller mechanischer Schreibmaschinen). Die besondere Dynamik im Bereich der technologischen Umwelt ist u.a. auf die verkürzten Innovationszeiten zurückzuführen, welche wiederum selbst technologiebedingt sind. Moderne Computertechnologien (z.B. CAD, CAM) ermöglichen z.B. die Konstruktion komplexer Produkte am Bildschirm, ohne daß physische Modelle in aufwendiger Handarbeit gebaut werden müssen. Einher mit dieser Entwicklung auf der Angebotsseite gehen verkürzte Produktlebenszyklen auf der Nachfrageseite, welches sich direkt auf die Mikroumwelt, d.h. auf die Absatz- und Beschaffungsmärkte des Lhternehmens auswirken. ${ }^{90}$

Die ökonomische Umweltsphäre erfaßt die volkswirtschaftlichen Zusammenhänge insgesamt. Das Wirtschaftssystem kann als gesellschaftliche Teilsystem verstanden werden, das zur Minderung der Knappheit durch Beschaffung, Bereitstellung und Verteilung von ökonomischen Gütern

\footnotetext{
${ }^{88}$ Technologie bezeichnet eine übergreifende - Wirtschaft, Gesellschaft und Technik verklammernde - Wissenschaft. Technik beinhaltet den künstlichen Gegenstand, Handlungszusammenhänge und Einrichtungen, in denen Gegenstände entstehen und verwendet werden. Vgl. hierzu Jahnes, S./Tammler, U. (1997), S. 14.

${ }^{89}$ Vgl. Hübner, H./Jahnes, S. (1992), S. 37.
} 
und Leistungen dient. Die ökonomische Umwelt beinhaltet hierbei die für das Unternehmen relevanten Wirtschaftssubjekte, z.B. Lieferanten, Kunden und Wettbewerber, aber auch wirtschaftspolitische Rahmenbedingungen und volkswirtschaftliche Gesamtgrößen (z.B. das Bruttosozialprodukt). Von Bedeutung sind weiterhin die zusammengefaßten Handlungen der Wirtschaftssubjekte am Markt, differenziert nach Absatz- und Beschaffungsmarkt und spezifiziert z.B. nach den Kriterien Marktraum (Stichwort: Globalisierung des Wettbewerbs), Marktstruktur oder Preis. Struktur und Funktionsweise der Wirtschaft, Wachstum und Konjunktur, außenwirtschaftliche Verflechtungen und langfristige Entwicklungsperspektiven werden hier in ihren Auswirkungen auf das Unternehmensgeschehen untersucht.

Die soziale Umweltsphäre bezieht sich auf die Gesellschaft schlechthin, einschließlich ihrer kulturellen, rechtlichen und politischen Aspekte. Die Gesellschaft wird als das jeweils umfassendste System menschlichen Zusammenlebens definiert. „Nach Parsons (Theorie des Handlungssystem) wird Gesellschaft als Kollektivität (d.h. soziales System mit gemeinschaftlicher Wertorientierung und Handlungsfähigkeit) definiert, die alle erhaltungsnotwendigen Funktionen in sich erfüllt. Bestimmend für die sozialen Beziehungen ist das Hineinwachsen des Einzelnen durch die von der Kultur angebotenen Orientierungen und Handlungsnormen. ${ }^{91}$ Der Mensch als Individuum und als soziales Wesen mit seinen Werten, Normen, Einstellungen und Verhaltensweisen steht hier im Mittelpunkt.

Die drei Umweltsphären sind nun aber ihrerseits in die ökologische Umwelt, den Gesamthaushalt der Natur, einbezogen. Das umfassendste, für das Unternehmen relevante Umweltsystem ist das Ökosystem, der natürliche Lebensraum. Das Ökosystem ist originär ein Produkt natürlicher Evolution, während die Gesellschaft, die Wirtschaft oder das Unternehmen, als soziale Systeme Konstrukte der Menschen sind, die durch deren Zielsetzungen, Strukturen und Kulturen ausgeprägt werden. Diese Systeme haben sich im Lauf der Zeit als Subsysteme des Ökosystems gebildet und teilweise das Gleichgewicht der Lebensbedingungen desselben merklich gestört. Das Ökosystem hat als oberstes Ziel das Überleben. Die damit verbundenen Probleme der Bevölkerungsentwicklung, der Nahrungsmittel- und Industriegüterproduktion, des Abbaus natürlicher Ressourcen sowie der Umweltverschmutzung rufen immer dringender nach Lösungen, die für die Gesamtwirtschaft wie für das einzelne Unternehmen $\mathrm{zu}$ grundlegend veränderten Bedingungskonstellationen technologischer, ökonomischer und sozialer Art führen können.

\footnotetext{
${ }^{90}$ Vgl. Sander, M. (1998), S. 52ff.

${ }^{91}$ Vgl. Parsons, T. (1960). Zit. nach Sauter-Sachs, S. (1992), S. 192.
} 
Wichtig für die nachfolgende Ausführung ist, daß die technologische Umweltsphäre die materielle Basis des Wirtschaftens bildet und das Unternehmen ein Subsystem der Wirtschaft, die Wirtschaft ein Subsystem der Gesellschaft und die Gesellschaft ein Subsystem des Ökosystems ist, daß damit diese Systeme miteinander verzahnt sind und daß demzufolge deren Beziehungen beachtet werden müssen. Dadurch entstehen Überlappungsbereiche, die auch die Multifunktionalität der Mitglieder der einzelnen Systeme verdeutlichen.

Neben der oben erwähnten dimensionellen Gliederung der Unternehmensumwelt wird die Unternehmensumwelt in institutioneller Hinsicht $^{92}$ in einzelnen Interessengruppen, etwa Kunden, Lieferanten, Kapitalgeber, Arbeitnehmer, Staat sowie Konkurrenten gegliedert, die mit einem Unternehmen in jeweils unterschiedlicher Weise interagieren. Ein betriebswirtschaftlicher Ansatz, der solche Wechselbeziehungen des Unternehmens mit seinem Umfeld in einem theoretischen Modell zu erfassen versucht, ist das Konzept der Stakeholder. ${ }^{93}$ Für die ökologisch verpflichtete Unternehmensführung stellt der Stakeholder-Ansatz insofern ein wichtiges Konzept dar, als externe Zwänge auf Unternehmen zur Verbesserung des Umweltschutzes nicht unmittelbar aus dem Bereich der ökologischen Umwelt erfolgen, sondern mittelbar durch Anspruchsgruppen, die ökologische Interessen vertreten.

Nach der institutionellen Betrachtungsweise ist die Umwelt eines Unternehmens dadurch gekennzeichnet, daß sie aus einer Vielzahl verschiedener sozialer Systeme und Gruppierungen besteht und sie in interne und externe Anspruchsgruppen eingeordnet werden kann. In dieser Darstellung wird eine Gewichtung der Umwelt in primäre (Unternehmen und Wirtschaftssystem) und sekundäre Verpflichtungen (Gesellschafts- und Ökosystem) zum Ausdruck gebracht. Das Unternehmen verfügt über vier Hauptkategorien von Anspruchsgruppen: ${ }^{94}$

- Interne Anspruchsgruppen (Eigentümer, Management, Mitarbeiter),

- Wirtschaftliche Anspruchsgruppen (Kunden, Lieferanten, Konkurrenten, Kapitalgeber, potentielle Arbeitnehmer),

- Gesellschaftliche Anspruchsgruppen (staatliche und nichtstaatliche Institutionen verschiedener Art wie z.B. Staat, Medien, Interessengruppen usw.),

- Anwaltsgruppen des Ökosystems (Wissenschaft, Interessenverbände, Staat usw.). Diese Gruppen sind insofern von spezieller Ausprägung, als es sich nicht um Anspruchsgruppen im engeren Sinne handelt. Sie sind Anwälte der natürlichen Umwelt, die mit den übrigen Stake-

\footnotetext{
92 Vgl. Ulrich, H. (1978), S. 67.

${ }^{93}$ Vgl. Kap. 3.4 dieser Arbeit und dort angegebene Literatur.
} 
holders im Sinne des Ökosystems verhandeln. Anwaltsgruppe dieser Art sind Organisationen für Naturschutz, Umweltschutz, Heimatschutz und ähnliches.

Alle diese Gruppen sind für das Unternehmen situativ in unterschiedlicher Weise von Relevanz. Hierbei ist die Beziehung stets wechselseitig, d.h. die Stakeholders hegen Ansprüche gegenüber dem Unternehmen und/aber das Unternehmen erhebt auch Ansprüche an diese Gruppen. Damit hat nicht nur das Unternehmen eine Verantwortung gegenüber der Gesellschaft, sondern die Gesellschaft (Stakeholder) hat auch eine Verantwortung gegenüber dem Unternehmen.

Für eine ökologisch verpflichtete Unternehmensführung ist nun entscheidend, ob die interaktiven Beziehungen mit den jeweiligen Anspruchsgruppen über marktliche oder nichtmarktliche Prozesse ablaufen. Danach kann man zwischen Ökologie-Pull- und Ökologie-Push-Effekten unterscheiden. Ökologie-Pull-Effekte kennzeichnen dabei verstärkte Forderungen relevanter Nachfrager und des Handels nach umweltgerechten Problemlösungen, wobei hier ein direkter marktlicher Anreiz auf das Unternehmen bezüglich vermehrter Umweltschutzbemühungen ausgeübt wird. Gegenüber diesen nachfrageinduzierten Einflüssen kennzeichnen Ökologie-Push-Effekte nicht-marktliche Einflüsse, die einen Internalisierungsdruck zur Implementierung umweltgerechter Produkt- und Prozeßtechnologien bewirken. Solche Einflüsse sind insbesondere umweltpolitische Eingriffe des Staates oder Pionierleistungen von Wettbewerbern. ${ }^{95}$

Die für die Unternehmensführung relevante Umwelt kann als zunehmend komplex und dynamisch bezeichnet werden. ${ }^{96}$ Die aus der Ökologieproblematik hervorgegangenen neuen Anforderungen an Unternehmen haben zu einer Steigerung der Komplexität sowie der Dynamik der Unternehmensumwelt geführt. So sorgt z.B. die zunehmende Entwicklung integrierter Umweltschutztechnologien und die Substitution für umweltschädigende Einsatzstoffe für einen Innovationsschub und somit für eine steigende Umweltdynamik im technologischen Umfeld.

Die größte Herausforderung für die Unternehmensführung dürfte sich allerdings aus zunehmenden Turbulenzen in der gesellschaftlichen Umwelt ergeben. Die Zunahme der Umweltschädigungen im Zeitablauf, die gesellschaftliche Wahrnehmung dieser Verschlechterung, die Verän-

\footnotetext{
${ }^{94}$ Vgl. Sauter-Sachs, S. (1992), S. 193 sowie Kap. 3.4 dieser Arbeit.

${ }^{95}$ Vgl. Meffert, H./Kirchgeorg, M. (1998), S. 150f.

96 Der Begriff Umweltkomplexität kann als Ausmaß an Vielgestaltigkeit sowie Unübersichtlichkeit des betrieblichen Umfeldes bezeichnet werden. Je größer die Anzahl der Umweltelemente und je verschiedenartiger diese sind, desto größer ist das Ausmaß an Umweltkomplexität. Die Umweltdynamik kennzeichnet die Veränderung des Umfeldes im Zeitablauf. Ein stabile Umwelt zeichnet sich durch eine weitgehende Konstanz und Vorhersagbarkeit der Umweltelemente sowie deren Beziehungen zueinander aus. Vgl. Heinen, E. (1985), S. 63ff.; Rüdenauer, M. R. A. (1991), S. 39ff.
} 
derung des gesellschaftlichen Wertesystems und die Auswirkungen dieses Wertewandels auf das politische sowie ökonomische System haben etwa zu einer Veränderung des Käuferverhaltens geführt, die viele Unternehmen zu spät erkannt haben, anderen jedoch neue Marktchancen eröffnet hat. Im Bereich der Umweltpolitik haben diese Tendenzen zu einer Flut von neuen Gesetzen und Auflagen geführt, die bis zum Verbot von Produkten und der Stillegung der Produktion wie z.B. FCKW, Asbest etc. reichen. ${ }^{97}$

\subsection{Austauschbeziehungen zwischen Unternehmen und ökologischer Umwelt}

Die Bestimmung des Stellenwertes der Ökologieproblematik für die unternehmenspolitischen Entscheidungen verlangt eine verstärkt interdisziplinäre Sicht, in der Wechselwirkungen zwischen ökonomischen und ökologischen Systemen analysiert werden. Mit der Zunahme der Umweltprobleme und der dadurch entstandenen Sensibilisierung in der Öffentlichkeit, die die Unternehmen als Hauptverursacher der Umweltprobleme verantwortlich gemacht hat, werden insbesondere in neuen systemtheoretischen Betrachtungen die Austauschbeziehungen zwischen Unternehmen und der natürlichen Umwelt (bzw. ökonomischem und ökologischem System) verstärkt untersucht. ${ }^{98}$

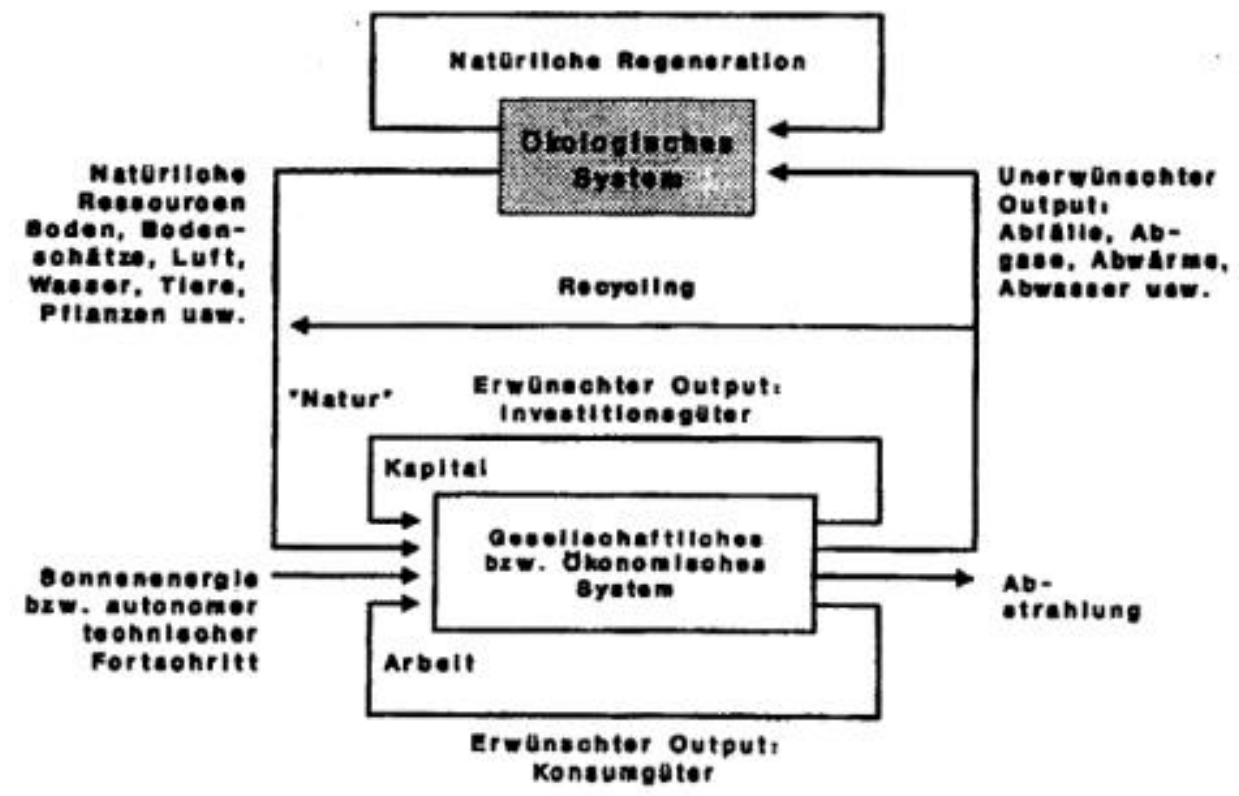

Abb. 3.3: Wechselbeziehungen zwischen ökologischen und ökonomischen Systemen

(Quelle: Meffert, H./Kirchgeorg, M. (1993), S. 48)

\footnotetext{
${ }^{97}$ Für das einzelne Unternehmen resultiert aus dieser Betrachtungsweise die Notwendigkeit eines bewußten Stakeholder-Managements. Daher wird im Abschnitt 3.4 das Stakeholder-Konzept ausführlich behandelt.
} 
Abb. 3.3 zeigt die Beziehungen zwischen ökologischen und ökonomischen Systemen. Dabei wird das ökologische und das sozio-ökonomische System im Rahmen der ökologischen Ökonomie, deren Forschungsgegenstand die Schnittstelle zwischen ökonomischem und ökologischem System ist, als separates jedoch interdependentes System betrachtet. ${ }^{99}$

Menschliches Wirtschaften vollzieht sich seither in zwei Kreisläufen: zu dem ,natürlichen Regelkreis“ (Ökologie) hat sich der „künstlich geschaffene Wirtschafts- und Produktionskreislauf“ (Ökonomie) gesellt. ${ }^{100}$

\begin{tabular}{|l|l|}
\hline \multicolumn{1}{|c|}{ Ökologie } & \multicolumn{1}{|c|}{ Ökonomie } \\
\hline Zirkularität & Linearität \\
\hline Materie- und Energiekreislauf & Materie-, Energie- und Gelddurchfluß \\
\hline Selbstregulation und Gleichgewicht & (Fremd-) Steuerung und (exponent.) Wachstum \\
\hline Niedrige Entropie & Hohe Entropie \\
\hline Ökologische Knappheit & Ökonomische Knappheit \\
\hline Entstehen und Vergehen (Reversibilität) & Anwachsen und Belasten (Irreversibilität) \\
\hline Ökologische Effizienz & Ökonomische Knappheit \\
\hline Vielfalt und Vernetzheit & Einfachheit und Isoliertheit \\
\hline Schadschöpfungsprozeß & Wertschöpfungsprozeß \\
\hline Bedarfsproduktion & Verbrauchsproduktion \\
\hline Gemeinschaftsprinzip & Individualprinzip \\
\hline
\end{tabular}

Abb. 3.4: Unterschiede zwischen ökologischer und ökonomischer Perspektive ${ }^{101}$

Das Wort Ökologie ist etymologisch auf den griechischen Wortstamm „oikos“, der Haus oder Haushalt bedeutet, zurückzuführen. „logos“ kann mit Untersuchung, Wissenschaft oder Lehre übersetzt werden. Die Herleitung ergibt somit die Definition der Ökologie als Lehre vom Haushalt oder Untersuchung des Hauses. ${ }^{102}$ Der Begriffsbestandteil „,nomos“ von Ökonomie ist eine von „,nemein“ mit der Bedeutung Zuteilen, Zuweisen oder Verwalten abgeleitete Ergänzung und heißt soviel wie Verwaltung, Regelung oder Ordnung. Aus dieser Sicht umschreibt Ökonomie etwa die Verwaltung des Hauses. ${ }^{103}$

\footnotetext{
${ }^{98}$ Schon Anfang der 70er Jahre wird der ökologischen Umwelt als Unternehmensumwelt besondere Bedeutung beigemessen. Vgl. Ulrich, H./Krieg, W. (1974); Nüßgens, K. H. (1974), S. $111 \mathrm{ff.}$

${ }_{99}$ Vgl. z.B. Stephan, G./Ahlheim, M. (1996), S. $15 \mathrm{ff}$.

${ }^{100}$ Vgl. Kuba, R. (1986), S. 329ff.

${ }^{101}$ Vgl. Schmid, U. (1992), S. 163ff.; Zahn, E. et al. (1996), S. 66; Dyllick, T. (1992), S. 395.

${ }^{102}$ Vgl. Odum, E. P. (1980), S. XXII; Haas, J.-P. (1989), S. 5; Krulis-Randa, J. S. (1989), S. 45.

${ }^{103}$ Vgl. Odum, E. P. (1980), S. XXIII; Immler, H. (1989), S. 47.
} 
Ein Vergleich der Begriffe belegt die Ähnlichkeit der umschriebenen Sachverhalte. Trotzdem gibt es über das Verhältnis beider Gebiete unterschiedliche Ansichten, die unvereinbar scheinen. Tatsächlich beruhen ökologische und ökonomische Systeme in ihrer gegenwärtigen Form auf unterschiedlichen Rationalitäten und Lenkungsprinzipien wie die Gegenüberstellung in Abb. 3.4 illustriert. $^{104}$

Im Gegensatz zur ökonomischen Perspektive, bei der Geldflüsse Beachtung finden, stehen im Rahmen der ökologischen Perspektive Stoff- und Energieflüsse im Vordergrund. Sie bilden die Grundlage der ökologischen Betrachtungsweise. ${ }^{105}$ Diese finden ihren Niederschlag auf der Ebene von Geldflüssen, d.h. dies ist darauf zurückzuführen, daß die monetären Leistungsziele die Stoff- und Energieflüsse der ökologischen Perspektive nur unvollständig oder verzerrt und damit falsch abbilden, denn eine vollständige monetäre Bewertung dieser Ströme setzt eine Internalisierung aller (positiven und negativen) externen Effekte des verursachenden Unternehmens voraus. Deshalb sind sie als eigenständiger Bereich durch entsprechende Informationen und Führungsinstrumente unmittelbar zu erfassen und zu lenken. ${ }^{106}$

Die ökologischen Probleme in unserer Gesellschaft entstehen auf der Ebene der Stoff- und Energieflüsse. Quellen natürlicher Ressourcen versiegen, die Aufnahmefähigkeit natürlicher Kreisläufe wird überfordert, und die Reproduktionsfähigkeit natürlicher Systeme wird beeinträchtigt. Stoff- und Energieflüsse stoßen somit an natürliche Grenzen, die jenseits menschlicher Verfigungsgewalt liegen. Demgegenüber sind die Geldflüsse prinzipiell grenzenlos und kennen diese natürlichen Begrenzungen nicht, ja sie sind ihnen eigentlich völlig wesensfremd. Entsprechend ist die Betrachtungsebene in ökologischer Perspektive primär die der Stoff- und Energieflüsse und nicht die der Geldflüsse.

Die ökonomische Perspektive konzentriert sich auf die direkten, unternehmerischen Wertschöpfungsprozesse und klammert deren (negative und positive) externe Effekte weitgehend aus. Die Schaffung und Verteilung der Wertschöpfung steht im Vordergrund dieser Perspektive. Implizit konstituieren sich dadurch die monetären Leistungsziele wie Gewinn, Rentabilität und Liquidität, die unabdingbare Zielsetzungen für das Überleben des Unternehmens darstellen. Die ökonomische Perspektive ist damit eine vornehmlich erfolgs- und zweckorientierte Sichtweise. Dagegen betrachtet die ökologische Perspektive die unternehmensübergreifende Schadschöpfungsprozesse und schließt die externen Effekte mit ein.

\footnotetext{
${ }^{104}$ Vgl. Schmid, U. (1992), S. 163ff.; Dyllick, T. (1992), S. $395 \mathrm{ff}$.

${ }^{105}$ Vgl. Dyllick, T. (1992), S. 395.
} 
„Schadschöpfung“ wird definiert als „die Summe aller durch betriebliche Leistungsprozesse direkt oder indirekt (durch Beschaffung, Transport, Konsum, Recycling und Entsorgung) verursachten und nach ihrer relativen ökologischen Schädlichkeit gewichteten Stoff- und Energieflüsse in die Ökospäre“. Ökologische Schäden werden zunächst einmal durch Produktions- und Betriebsprozesse verursacht. Hierbei handelt es sich um eine „direkte“ Schadschöpfung, die in den unmittelbaren Verantwortungsbereich des Unternehmens fällt. Daneben treten ökologische Schäden aber auch auf vorgelagerten oder nachgelagerten Produktstufen auf, bei der Rohstoffund Energiegewinnung oder bei Transporten, aber auch im Zuge von Verteilung, Konsum oder Entsorgung. Hierbei handelt es sich um ,indirekte“ Schadschöpfung, für die das betreffende Unternehmen als Nachfrager und als Hersteller mitverantwortlich, aber nicht allein verantwortlich ist. Hieraus ergibt sich das Bild einer „Schadschöpfungskette“ als Summe der EinzelSchadschöpfungen auf jeder Stufe des ökologischen Produktlebenszykluses. ${ }^{107}$

Steht im Rahmen der ökonomischen Perspektive die Bewältigung der ökonomischen Knappheit im Vordergrund, so betrachtet die ökologische Perspektive die „ökologische Knappheit“. Die ökologische Knappheit bezieht sich darauf, daß in einem gegebenen räumlichen Bereich und in einem gegebenen Zeitraum die einzelnen Elemente der natürlichen Umwelt nur in beschränktem Maß belastet werden dürfen, wenn man verhindern will, daß eine nicht hinnehmbare Zustandsverschlechterung des betreffenden Umweltgutes eintritt. ${ }^{108}$

Knappheit ergibt sich in ökonomischer und ökologischer Hinsicht aus dem Zusammentreffen von Angebot und Nachfrage. Dennoch stehen völlig unterschiedliche Objektbereiche im Mittelpunkt, die anderen Gesetz- und Regelmäßigkeiten gehorchen. Bezieht sich ökonomische Knappheit auf das ökonomische Kapital in Gestalt materieller und finanzieller, teilweise auch technologischer und humaner Produktionsmittel, so bezieht sich ökologische Knappheit auf das ökologische Kapital in Gestalt von natürlichen Ressourcen (Wasser, Boden, Erdöl, Fischbestände etc.), der Rezeptionsfähigkeit der Aufnahmemedien Boden, Wasser und Luft für Zivilisationsrückstände, aber auch der generellen Widerstands- und Regenerationsfähigkeit natürlicher Systeme und Kreisläufe. Und stehen die Eigentümer der ökonomischen Produktionsmittel als Verhandlungspartner zur Verfügung, und sind diese zumeist in Märkte eingebunden, die die Berechnung eines Marktpreises erlauben, so sind im Falle der Natur sowohl der Eigentümer als auch der Marktpreis problematisch. Komplexität der Schadstoffe und Inkongruenz der Bewertungsdimensionen lassen die Entwicklung eines allgemeingültigen Bewertungsansatzes unmöglich er-

\footnotetext{
${ }^{106}$ Vgl. Dyllick, T./Hummel. J. (1996), S. 3.

${ }^{107}$ Schalteger, S./Sturm, A. (1994), S. 31
} 
scheinen. Dieses wissenschaftliche Erkenntnisproblem der Ökologie wird durch ein politisches Bewertungsproblem erweitert. Bewertungen der ökologischen Knappheit bzw. Umweltbelastungen finden deshalb i.d.R. im Rahmen gesellschaftlicher und politischer Normierungsprozesse statt. $^{109}$

Um die Wechselbeziehungen zwischen ökologischen und ökonomischen Systemen besser verstehen zu können, wird hier die ökonomische Bedeutung der ökologischen Umwelt weiter behandelt.

Durch Produktion, Konsum und Entsorgung hervorgerufene Umweltbelastungen und schädigungen werden in der neoklassischen Theorie als Folge negativer externer Effekt ökologischer Art erklärt. ${ }^{110}$ Im Rahmen der Umweltökonomie wird versucht, solche Transaktionen der Wirtschaftssubjekte in ihre Theorien und Modelle $\mathrm{zu}$ integrieren, die zu Umweltbeeinträchtigungen führen und bislang weder über den Markt vermittelt werden noch Bestandteil einzelwirtschaftlicher Kalküle sind. Daraus wird festgestellt, daß eine Knappheit an Umwelt(gütern) besteht, die es explizit zu berücksichtigen gilt. In marktwirtschaftlichen Systemen wird diese Knappheit vernachlässigt, weil die natürliche Umwelt darin allzu häufig den Charakter eines „freien Gutes“ oder „öffentlichen Gutes“ annimmt, für das sich ein Markt und damit der Preis nicht bilden kann, da kein Einkommen hiermit erzielt werden kann. ${ }^{111}$ Demzufolge gibt das Preissystem als zentraler marktlicher Lenkungsmechnismus die tatsächliche ökologische Knappheit nicht richtig wieder. Seite Lenkungsfunktion für eine ressourceneffiziente und umweltgerechte Steuerung des Wirtschaftsgeschehens ist deshalb beschränkt. Dies hat zur Folge, daß der Umweltverbrauch bei einzelwirtschaftlichen Entscheidungen nicht oder nur unzulänglich thematisiert wird. Übersteigt dann der Umweltverbrauch die Assimilationsfähigkeit der Natur, so befinden sich Ökonomie und Ökologie im Ungleichgewicht. Da die Existenz externer Effekte gleichermaßen umweltbeeinträchtigend und volkswirtschaftlich effizienzmindernd wirkt, ist deren Beseitigung in Gestalt einer Internalisierung erforderlich.

In diesem Sinne steht trotz der unterschiedlichen Perspektiven von Ökologie und Ökonomie die Aufgabe der „ökologisch verpflichteten Unternehmensführung“ für einen Managementansatz, der externe Effekte systematisch in unternehmerische Entscheidungen und betriebliche Abläufe

\footnotetext{
108 Vgl. Braunschweig, A./Müller-Wenk, R. (1993), S. 45.

${ }^{109}$ Vgl. Dyllick, T. (1992), S. 399.

${ }^{110}$ Externe Effekte ergeben sich dadurch, daß bei bestimmten Gütern oder wirtschaftlichen Handlungen die Kosten (negative externe Effekte) oder Nutzen (positive externe Effekte) streuen, also nicht nur ihren Verursacher allein treffen. Die einzelwirtschaftlichen und gesamtwirtschaftlichen Kosten und Nutzen weichen aufgrund externer Effekte voneinander ab. Vgl. Frey, B. S. (1985), S. 42ff.; Weimann, J. (1991), S. $15 f f$.
} 
$\mathrm{zu}$ integrieren sucht, dabei aber zugleich strategische Wettbewerbsvorteile durch Umweltschutz aufzeigt, ganzheitliche Instrumente zur ökologiebezogenen Informationsbeschaffung einsetzt sowie Umweltkompetenz gesamthaft im Unternehmen verankert und glaubhaft nach außen befördert.

Die Charakterisierung des Unternehmens als offenes System erfolgt - in Abgrenzung zum geschlossenen System - anhand der Existenz fortwährender Austauschprozesse, die das Unternehmen mit der Umwelt verbinden. ${ }^{112}$ Diese Sichtweise stellt eine Erweiterung dar, weil nicht mehr nur die einseitige Abhängigkeit des Unternehmens von der Umwelt betrachtet wird, sondern eben der wechselseitige Charakter der Beziehungen herausgestellt wird. Eine Besonderheit der hier eingenommenen Sichtweise besteht auch darin, sämtliche denkbaren Beziehungen zwischen Unternehmen und Umwelt als Austausch bzw. Transformation von Ressourcen zu interpretieren. Analog zum theoretischen Referenzmodell eines offenen energetischen Input-Output-Systems, dessen Energierückfluß aus der Outputabgabe das ganze System reaktiviert, wandeln Unternehmen als sozio-technische Systeme den Output in erneuten Input um. ${ }^{113}$ Die Systemumwelt fungiert in diesem Umwandlungsprozeß als Transformator von Unternehmensoutputs in neuerliche Unternehmensinputs.

Unternehmen, hier insbesondere Industriebetriebe, sind auf vielfältige Weise mit der natïrlichen Umwelt verbunden. Wirtschaftliche Tätigkeit bedeutet insbesondere, daß Materie und Energie von einer Zustandsform in eine andere umgewandelt werden. Betrachtet man den Wertschöpfungsprozeß eines Industriebetriebs, so entstehen für den Produktionsprozeß zwei Formen der Interaktion zwischen dem ökonomischen System einerseits und dem ökologischen System andererseits. Erstens müssen Rohstoffe und Energie von der natürlichen bzw. ökologischen Umwelt entnommen werden, um Produktion und Konsum überhaupt durchführen zu können. Zweitens entstehen beim Wirtschaften nicht nur erwünschte und nutzbringende Güter, sondern auch Schadstoffe und Abfallprodukte, die sowohl bei der Produktion als auch beim Konsum anfallen und aus dem ökonomischen System entfernt werden müssen, um dessen Funktionsfähigkeit langfristig zu erhalten. Also steht die ökologische Umwelt für das ökonomische System als Lieferant von Material und Energie und als Aufnahmemedium für unerwünschten Output der betrieblichen Produktion.

\footnotetext{
${ }^{111}$ Vgl. Frey, B. S. (1985), S. 48 ff.; Wicke, L. et al. (1991), S. 41 ff.

${ }^{112}$ Vgl. Grochla, E. (1970), S. 1ff.

${ }^{113}$ Vgl. Katz, D./Kahn, R. L. (1966), S. 16f.; Eulgem, S. (1993), S. 45.
} 
Die übermäßige Beanspruchung der natürlichen Lebensgrundlagen des Menschen ist insbesondere im Zeitalter der Industriegesellschaft immer problematischer geworden. So werden auf der $\mathbf{h}$ putseite natürliche Ressourcen immer knapper. Auf der Outputseite zeigt sich dagegen die begrenzte Aufnahmekapazität der ökologischen Umwelt in zunehmender Umweltverschmutzung und nicht zuletzt in den damit einhergehenden Gesundheitsschäden der Menschen. ${ }^{114}$ Aus systemtheoretischer Sicht sind damit die bislang konstanten Austauschbeziehungen zwischen System und Umwelt destabilisiert worden, ein zuvor vergleichsweise irrelevantes Umweltsegment ist $\mathrm{zu}$ einem turbulenten Umsystem geworden, das Gefahr läuft, das ökologische Fließgleichgewicht und damit die Existenz des gesamten Systems zu gefährden.

Im folgenden sollen die ökologischen Folgen der ökonomischen Aktivitäten, die insbesondere im Zusammenhang mit den Austauschbeziehungen zwischen Unternehmen und der ökologischen Umwelt auftreten können, untersucht werden. ${ }^{115}$

Eine ökologische Beurteilung ökonomischen Handelns hängt davon ab, die Austauschbeziehungen zwischen Unternehmen und Umwelt zu erfassen. Diese Austauschbeziehungen sind hinsichtlich ihrer Wirkungen zu systematisieren, um diese Wirkungen beurteilen zu können. ${ }^{116}$ Die Erfassung, Zuordnung und Bewertung der Austauschbeziehungen ist zunächst eine Frage der Grenzziehung zwischen Unternehmen und Umwelt. Betrachtet man das Unternehmen als ein soziales System mit einer räumlichen, zeitlichen und personenbezogenen Struktur, ist eine mehrfache Differenzbildung zwischen dem System und seiner Umwelt möglich. ${ }^{117}$

Im folgenden werden zunächst die unmittelbaren Einflüsse anhand dreier Perspektiven möglicher Umwelteinwirkungen bei der Unternehmensführung dargestellt: ${ }^{118}$

- Die Beeinflussung der nicht-biologischen Natur durch mediale Stoff- und Energieaustauschbeziehungen,

- Die Beeinflussung der anthropogenen Natur und

- Die Beeinflussung der öko-sozialen Umwelt.

\footnotetext{
${ }^{114}$ Vgl. Senn, F. J. (1986), S. 2ff.

115 Vgl. dazu ausführlich Freimann, J. (1989).

116 Dies entspricht der Systematik, wie sie allgemein bei der Erstellung von Ökobilanzen angewendet wird (Erfassung der Austauschbeziehungen, Erfassung der Wirkungen, Bewertung der Wirkungen). Vgl. UBA (Hrsg.) (1992); Wagner, G. R. (1992); Hofstetter, P. (1991).

${ }^{117}$ Vgl. dazu die Ausführungen im Kapitel 3.2 dieser Arbeit

${ }^{118}$ Vgl. zur folgenden Ausführung Hallay, H. (1996), S. 83ff.
} 
Die direkteste ökologische Folgewirkung besteht in den stofflichen und energetischen Austauschbeziehungen mit der medialen Umwelt des Unternehmens. Überall dort, wo Unternehmen zur Erbringung ihrer Leistung Austauschbeziehungen in Form der Entnahme, Nutzung, Umwandlung und Rückgabe von Ressourcen und Energien haben, entstehen zwangsläufig Wirkungen auf die das Unternehmen umgebende Umwelt. Die ökologische Bewertung des produktionsbezogenen Verhaltens von Unternehmen ist deshalb grundsätzlich an diese Stoff- und Energieaustauschbeziehungen geknüpft. Aber auch mit Blick auf die Produkte und deren ökologischen Produktlebenszyklus ist die direkteste Beeinflussung die über Stoff- und Energieaustauschbeziehungen. Die Beeinflussung der ökologischen Folgen der Produktherstellung, Nutzung und Entsorgung liegen weitestgehend in den Händen des Unternehmens, das für das Design, die Funktionalitätsbestimmung etc. verantwortlich ist. In diesem Sinne ist die Bewertung ökologischen Verhaltens auch von der ökologischen Bewertung der Produkte und damit von den mit diesen Produkten zusammenhängenden Stoff- und Energieaustauschbeziehungen abhängig.

Zwangsläufig ruft jeder menschliche Eingriff zur Erstellung von Gütern, die eine Nutzung von Ressourcen darstellt, eine Veränderung der Umwelt und damit auch ökologisch zu berücksichtigende Wirkungen hervor. Jede ökonomische Tätigkeit, die in Form von Produktion oder Konsum die Bedürfnisse der Menschen befriedigen soll, geht daher prinzipiell mit einer Beeinträchtigung der ökologischen Umwelt einher. Insofern kann „ökologisches Wirtschaften“ nicht wie in der öffentlichen Diskussion oftmals dargestellt dem Anspruch einer vollständigen Vermeidung von Umweltbeeinträchtigungen durch Unternehmen gerecht werden. Ökologisches Wirtschaften bzw. ökologisch verpflichtete Unternehmensführung kann deshalb nur auf eine relative Verbesserung der Umweltqualität abzielen.

In diesem Zusammenhang stellt sich unweigerlich die schwierige Frage, welches zulässige Aus$\mathrm{maß}$ an Umweltbeeinträchtigungen aus ökologischer und gesellschaftlicher Sicht erstrebenswert und aus ökonomischer Sicht bei Sicherung der Wettbewerbsfähigkeit von Unternehmen noch vertretbar erscheint. Unter diesem Kalkül muß sich die ökologisch verpflichtete Unternehmensführung in besonderer Weise mit schlecht strukturierten Problemen auseinandersetzen, die sich durch Wirkungs-, Bewertungs- und Zielsetzungsdefekte auszeichnen. Eine ökologische Bewertung der von einem Unternehmen hervorgebrachten Umweltwirkungen bedeutet dann, die Quantität und Qualität dieser Austauschbeziehungen zu hinterfragen. Bei der Bewertung der Schädigungswirkungen einer Emission kann die Human- und Biotoxikologie durchaus wertvolle Hilfe leisten. Die Forschung darüber, wann eine bestimmte Immission von Stoffen eine Schädigung pflanzlicher, tierischer oder humaner Systeme zur Folge hat, gibt Anhaltspunkte für die Gefähr- 
lichkeit von Emissionen. Hier entsteht aber die Schwierigkeit, daß solche wissenschaftlichen Erkenntnisse sich jeweils nur auf die Immission von Stoffen beziehen, die hieraus zu folgernde Bewertung von Emissionen aber vielfachen Problemen unterliegt. So lassen sich die Wirkungsmechanismen zwischen unternehmensbedingten Emissionen und möglichen Umweltbeeinträchtigungen häufig selbst im interdisziplinären Dialog nicht eindeutig klären. Darüber hinaus erschweren sowohl ökologische als auch ökonomische Bewertungsdefekte die Entscheidungsprozesse, weil Umweltqualitätsziele nicht eindeutig zu quantifizieren sind und die Märkte die wahren Knappheitspreise für den Verbrauch von ökologischen Ressourcen nicht widerspiegeln. Schließlich bedingen Zielkonflikte zwischen Ökonomie und Ökologie vielfach ein Entscheidungsdilemma, das letztlich nur durch Werturteile der einzelnen Entscheidungsträger zu lösen ist.

Die aufgeführten Argumente sollen nicht dem Beweis dienen, daß die Betrachtung der Stoff- und Energieaustauschbeziehungen eines Unternehmens ohne Bedeutung für die Frage der ökologischen Beurteilung unternehmerischen Handelns ist. Sie zeigen vielmehr die zwangsläufigen Einschränkungen der zu erwartenden Ergebnisse von Vorhaben, allein mit Hilfe einer scheinbar wissenschaftlichen Betrachtung der ökotoxischen Folgewirkungen von Stoff- und Energieaustauschbeziehungen normative Antworten auf die Frage nach dem richtigen bzw. sinnvollen ökologischen Verhalten zu entwickeln, wie sie z.B. in der quantitativen Öko-Bilanz-Forschung und den damit einhergehenden Normierungsbemühungen ${ }^{119} \mathrm{zu}$ finden sind.

Auf der zweiten Wirkungsebene hat menschliches Wirtschaften zwangsläufig Auswirkungen auf die ihn umgebende Landschaft. Landschaft meint in diesem Zusammenhang die zu einem bestimmten Zeitpunkt, in einem bestimmten Gebiet vorfindbare anthropogene Umwelt der Menschen inklusive Tiere und Pflanzen.

Durch ihre Stoff- und Energieaustauschbeziehungen, durch die Nutzung und Manipulation von Fauna und Flora zu ihrer Leistungserstellung, durch ihre materielle Anwesenheit nehmen Unternehmen Einfluß auf die anthropogene Natur, die sie umgibt. Hinzu kommen die diesbezüglichen kulturell prägenden Wirkungen ihrer Produkte und Dienstleistungen.

In dem Maße, wie der Mensch im Laufe seiner Entwicklungsgeschichte seßhaft wurde, Werkzeuge und Technologien entwickelte, nahm das Maß der Natureinwirkungen zu. Heute können 
wir davon ausgehen, daß ein Großteil der Erde im ursprünglichen Sinne nicht natürliche, sondern von Menschenhand geprägte bzw. mitgeprägte Landschaften sind. Die von Menschen wahrgenommene anthropogene Natur ist jedoch keine statische Größe, vielmehr unterliegt diese selbst einem evolutiven Wandlungsprozeß. Natürlich aus der Sicht der Menschen ist eine Landschaft dann, wenn sie ihrem räumlichen und zeitlichen Empfinden nach zumindest nicht direkten prägenden menschlichen Veränderungseinflüssen ausgesetzt ist.

Die Rolle des Menschen im Verständnis der Natur ist damit zwiespältiger Art. Einerseits ist Natur im Empfinden genau der Teil der den Menschen umgebenden Umwelt, der nicht von ihm beeinflußt erscheint. Andererseits ist die Naturwahrnehmung an das menschliche Dasein gekoppelt. Insofern sind der menschliche Eingriff und seine Folgen durchaus auch in der Wahrnehmung der Natur durch den Menschen Bestandteil eben dieser Natur. Der Schutz der Natur ist in diesem Sinne also nicht Schutz einer menschlich unberührten Landschaft, sondern in weiten Gebieten der Schutz von Landschaften, die von den gegenwärtig lebenden Menschen als naturnahe Heimat $^{120}$ verstanden werden. In diesem Sinne kann man also nicht von einer Zerstörung oder Erhaltung der „einen Natur ${ }^{\text {‘1 } 21}$ sprechen. Ebenso ist ein Zurück zu eben dieser einen Natur nicht möglich. ${ }^{122}$

Die „Wissenschaft von den Zusammenhängen der biologischen Systeme“،123 kann deshalb zwar die Folgen menschlicher Eingriffe in ein Öko-System beschreiben und gewichten. „Die Ökologie beschreibt aber gar nicht das, was sein soll, sondern das, was vor sich geht. Sie beschreibt, in welcher Weise alle Lebewesen mit ihrer belebten und unbelebten Umwelt in vielfältigen und verschlungenen Zusammenhängen verbunden und auf diese Zusammenhänge angewiesen sind“. ${ }^{124}$ Ohne eine vom Menschen vorzunehmende Beschreibung dessen, was zeitlich und räumlich naturnahe Heimat für ihn bedeutet, ist allerdings eine Beurteilung, ob ein Eingriff der Naturerhaltung oder -zerstörung dient, nicht möglich. ${ }^{125}$

${ }^{119}$ Die hier dargestellte Ansicht findet sich auch in der Diskussion um die Anwendbarkeit von quantitativen ÖkoBilanzen und deren Interpretation. Vgl. stellvertretend Pfriem, R. (1993); Hallay, H. (1992); Wagner, B. (1992). Gne gegenteilige Argumentation findet sich bei Ahbe, St., et al. (1990); Braunschweig, A. (1992).

${ }^{120}$ Vgl. zum Begriff der Heimat im hier verwendeten Sinn: Trepl, L. (1983), in Anlehnung an den Begriff der Heimat, den Bloch in seinem Werk „Das Prinzip Hoffnung“ verwendet hat. Vgl. Bloch, E. (1979), S. 810ff.

${ }^{121}$ Dies gilt insbesondere für unsere Kulturlandschaften. Inwieweit Landschaften wie der tropische Regenwald als naturbelassen angesehen werden können, kann jedoch ebenfalls kritisch hinterfragt werden. Vgl. hierzu Altvater, E. (Hrsg.) (1994).

${ }^{122}$ Daß Natur sich im Rahmen unserer Kulturlandschaften auf den Begriff der zeitlich und räumlich erlebten Heimat bezieht, wird deutlich, wenn etwa im Zeichen des Naturschutzes landwirtschaftlich genutzte Streuwiesen weiter gemäht werden sollen, um hierdurch entstehende ökologische Nischen für bestimmte vom Aussterben bedrohte Pflanzen und Tiere zu erhalten.

${ }_{123}^{123}$ Trepl, L. (1983), S. 39ff.

${ }^{124}$ Dahl, J. (1982), S. 74.

${ }^{125}$ Vgl. zu diesem Gedanken vor allem die Aufsätze von Dahl, L. (1982); Sachs, W. (1991/92). 
Neben der Wahrnehmung der direkten Auswirkungen auf die Umweltmedien und die anthropogene Natur spielen bei der Wahrnehmung der ökologischen Krise die öko-sozialen Folgen ökonomischer Aktivitäten eine besondere Rolle. Öko-soziale Folgen entstehen dann, wenn in der Wahrnehmung der Menschen das nicht adäquate ökologische Verhalten dazu führt, daß über die Einwirkungen auf die Umweltmedien und die anthropogene Natur nachteilige Folgen für die Gesundheit und Lebensqualität der Menschen entstehen.

Prinzipiell lassen sich hierbei verschiedene Dimensionen der Folgewirkungen herausstellen:

- Gesundheitliche Folgen als Problem der Veränderung der Umweltmedien ${ }^{126}$

- Langfristige Zerstörung der Lebensgrundlagen

- Belastung mit Katastrophenrisiken ${ }^{127}$

Die Umweltmedien (Luft, Wasser und Boden) dienen nicht nur der anthropogenen Natur als Lebensgrundlage, ebenso sind sie für die Menschen lebenswichtig. Der Eintrag von Schadstoffen in diese Umweltmedien hat damit nicht nur Folgen für die Natur, sondern auch direkte und indirekte sowie kumulierende Folgen für die menschliche Gesundheit. Direkte Folgen für den Menschen durch eine Veränderung der Umweltmedien entstehen dann, wenn die Emission eines bestimmten Schadstoffes zu Veränderungen der Immissionsumgebung führt. Indirekte Folgewirkungen entstehen, wenn die Emissionsbelastungen der anthropogenen Natur zu Veränderungen von Pflanzen und Tieren führen, die wiederum als Nahrungsmittel vom Menschen verwendet werden. Insbesondere schwermetallhaltige Verbindungen und halogenierte Kohlenwasserstoffverbindungen sind durch die natürlichen Assimilationsketten nur sehr schwer abbaubar und gelangen über die Nahrungskette zum Menschen. Ebenso kommt es zu solchen indirekten Folgen, wenn durch die Stoff- und Energieaustauschbeziehungen ökonomischer Aktivitäten Stoffe in einer Art und Menge freigesetzt werden, die in der Folge in den Umweltmedien durch Veränderungsprozesse erst eine humantoxische Wirkung entfalten.

Neben den bereits dargestellten Schwierigkeiten der Zuordnung einer bestimmten Emission zu einer konkreten Belastung kommt durch diese indirekten Folgen noch das Problem hinzu, daß sich eine Einzelbetrachtung der Toxizität aufgrund der kumulierenden Wirkungen von Schadstoffen verbietet. Kumulierende Wirkungen ergeben sich in der gemeinsamen Schadwirkung verschiedener Stoffe oder auch in der Summenbelastung mit einem Schadstoff. Gerade aber indi-

${ }^{126}$ So etwa die Studien des Club of Rome, Global 2000 oder des World Watch Institutes. Vgl. Meadows, D. C. et al. (1972 und 1992). 
rekte Umwelteinwirkungen lassen sich nur sehr schwierig kausal auf bestimmte Verursacher zurückführen. Problematisch ist hierbei nicht nur die Verknüpfung zwischen Emissionen und Immissionen, sondern auch der zeitliche Horizont der Belastungssituation. So können Schadwirkungen in langfristiger Folge erst nach Jahren oder Jahrzehnten auftreten.

Neben den bisher dargestellten Problemen der Einwirkung auf die Umweltmedien und die anthropogene Natur stellt die langfristige Zerstörung der Lebensgrundlagen in der heutigen Krisenwahrnehmung sicherlich die größte Problematik dar. Im Rahmen der Diskussion um die nachhaltige Entwicklungsfähigkeit (sustainable development) geht es insbesondere darum, langfristig eine gerechte Verteilung $\mathrm{zu}$ verwirklichen. Dies bedeutet zunächst, allen den gleichen $\mathrm{Zu}-$ gang zu den für die Überlebensfähigkeit notwendigen Ressourcen zu ermöglichen.

„Sustainability“ als Bewertungsmaßstab betrieblicher Aktivitäten im Rahmen von „Sustainable Development“ muß hierbei zwei Aspekte berücksichtigen. Zum einen geht es um die intragenerative Verteilungsgerechtigkeit, d.h. die Nutzung der stofflichen Ressourcen, die Belastung der Umweltmedien ebenso wie die Beeinflussung der anthropogenen Natur müssen so gestaltet werden, daß die Überlebensfähigkeit der derzeit lebenden Menschen erreicht werden kann. Andererseits gilt es, die intergenerative Verteilungsgerechtigkeit nicht aus den Augen zu verlieren, d.h. die Überlebensfähigkeit auf der Erde muß auch für die zukünftigen Generationen gesichert werden. $^{128}$

Für die Unternehmenspraxis ergibt sich allerdings aus dem normativen Anspruch der Verteilungsgerechtigkeit zunächst kein eindeutiger Bewertungsmaßstab ökologischen Handelns. Es läßt sich nur erkennen, daß die Umsetzung dieses Gedankens weitreichende Folgen haben könnte. In welcher Art und Weise für ein konkretes Unternehmen sich diese Ansprüche entwickeln, bleibt im Konzept der nachhaltigen Entwicklung weitestgehend offen.

Auch hier stellt sich die Problematik der gesellschaftlichen Wahrnehmung und der Bereitschaft zur Umsetzung dieser Ansprüche. Während bei den bisher aufgezeigten Phänomenen der ökologischen Beeinflussung durch unternehmerisches Handeln die Wahrnehmung der Probleme und die konkrete Umsetzung in Ansprüche an die Unternehmen eine Frage der derzeitigen Gesellschaft ist, kommt bei der Frage von sustainability das Problem der gesellschaftlichen Umsetzung von intra- und intergenerativen Ansprüchen hinzu. Inwieweit jemals die Ansprüche an die Über-

${ }^{127}$ Vgl. Schmidheiny, S. (1992).

${ }^{128}$ Schmidheiny, S. (1992), S. 34. 
lebensfähigkeit, die andere Kulturen haben, innerhalb unserer Gesellschaft in einen gesellschaftlich manifestierten und mit Umsetzungsmacht ausgestatteten Anspruch übergehen, bleibt abzuwarten. Gleiches gilt für die gesellschaftliche Umsetzung der intergenerativen Verteilungsgerechtigkeit. Die Ansprüche zukünftiger Generationen können lediglich von „Statthaltern“ oder „Anwälten“ formuliert werden.

Ein weiteres Krisenphänomen in der sozial-ökologischen Dimension ist die Wahrnehmung der zunehmenden Häufigkeit und Schwere von Katastrophen ${ }^{129}$ mit Auswirkungen auf die anthropogene Natur und die Menschen gleichermaßen. Katastrophenphänomene können dabei in allen bisher genannten Wirkungsdimensionen auftreten, d.h. sie können einen direkten Einfluß auf die Umweltmedien, die Zerstörung der Natur oder die Zerstörung der Lebensgrundlagen zur Folge haben.

Grundsätzlich lassen sich drei Katastrophenphänomene unterscheiden: Sozial-ökologische Katastrophen können einerseits durch Störfälle menschlicher Aktivitäten entstehen, die direkte Folgen für die Umweltmedien und über diese dann für Natur und Menschen haben. Die Erfahrungen mit den Risiken der Atomenergiegewinnung oder bestimmter chemischer Prozesse zeigen die globalen Folgewirkungen solcher Katastrophen. Andererseits können menschliche Eingriffe in die anthropogene Natur Veränderungen eben dieser hervorbringen, die ungewollte und risikoreiche Rückkoppelungen mit den menschlichen Aktivitäten hervorbringen. Ein Beispiel hierfür ist die Beeinflussung von Flußläufen zum Schutz vor Hochwasser. Nicht vorhergesehene Zusammenhänge zwischen natürlichen Vorgängen und menschlichen Aktivitäten führen zu einer Rückkoppelung in der Art, daß die bisher betriebenen Schutzmaßnahmen zur Verstärkung der Phänomene beitragen, vor denen sie schützen sollten. In der Folge entstehen katastrophale Wirkungen, die nicht nur die Menschen, sondern auch die anthropogene Natur gefährden. Ähnliche Folgewirkungen entstehen zum Beispiel durch die Ausrottung von insektenfressenden Tieren durch Pflanzenschutzmittel, in deren Folge es zu einer Vermehrung von Pflanzenschädlingen kommt. Die dritte und vielleicht folgenschwerste Art von öko-sozial induzierten Katastrophen entsteht in der Form von gesellschaftlichen Auswirkungen der Zerstörung der menschlichen Lebensgrundlagen.

\footnotetext{
${ }^{129}$ Katastrophen zeichnen sich gegenüber anderen Schädigungsursachen dadurch aus, daß das Eintreten einer Schädigung nur mit einer bestimmten Probabilität vorherzusehen ist. Katastrophenwirkungen sind nicht in einer kausalen Kette mit den sie erzeugenden Ursachen verknüpft. Vielmehr entstehen sie unter dem Einfluß der Wahrscheinlichkeit des Eintretens bestimmter kausaler Zusammenhänge.
} 
Die unabsehbaren Folgen der Verteilungsungerechtigkeit in der Welt und die damit einhergehende Naturzerstörung können $\mathrm{zu}$ öko-sozialen Katastrophen von ungeahntem Ausmaß führen. Eine Art solcher ökosozialer Katastrophen ist durch das Entstehen eines Teufelskreises von Naturzerstörung und sozialem Elend geprägt. Dabei führt soziales Elend zu verstärkter Naturzerstörung und diese wiederum zu verstärktem sozialen Elend. ${ }^{130}$ Ein weiteres Problem sind zunehmende Spannungen um die Nutzung von Boden- oder Naturschätzen. Die sozialen Folgen können von Konflikten zwischen unterschiedlichen Gesellschaftsformen in einer Region bis hin zu kriegerischen Auseinandersetzungen zwischen Nationen reichen.

Einzelwirtschaftlich betrachtet bedeutet ökologisch sinnvolles Handeln in diesem Zusammenhang die Vermeidung der dargestellten Katastrophen. Doch auch hierbei besteht zunächst das Problem der individuellen Zuordnung einzelner Aktivitäten.

Katastrophen entstehen ja gerade ungewollt, weil bestimmte Ursachen in einer nichtvorhersehbaren Kausalität zusammentreffen. Dies führt zu dem Problem der Einschätzung der Probabilität möglicher Folgewirkungen. Hierbei taucht im Zusammenhang von öko-sozialen Risiken das Problem der dynamischen Vernetztheit der Zusammenhänge einzelner Veränderungsparameter auf. In der Einschätzung der Folgen individuellen Handelns entsteht damit ein komplexes Problem mit allen Folgen für die gesellschaftliche Bewertung des individuellen Handelns.

\subsection{Das Stakeholder-Konzept}

Die ökologiebezogenen Ansprüche, die vor allem aus dem zunehmenden Umweltbewußtsein der Bevölkerung resultieren, stellen ein relativ junges gesellschaftliches Phänomen dar. Diese Entwicklungen sind Teil eines viele gesellschaftliche Bereiche betreffenden, sich zunehmend beschleunigenden Wertewandels. Die ökologisch relevanten Einflüsse auf die Unternehmen kommen aus sehr unterschiedlichen Bereichen. Dabei werden Unternehmen nicht mit den eigentlichen ökologischen Problemen wie z.B. in Form von Luftverschmutzungen oder Bodenbelastungen konfrontiert, sondern sie werden für diese eigentlich erst dann und nur in dem Maße relevant, wie sie durch gesellschaftliche Ansprüche, rechtlich-politische Regulierung oder marktliche Veränderungen $\mathrm{zu}$ verhaltensrelevanten Ansprüchen transformiert worden sind. Dabei spielen die umweltrelevanten Anspruchsgruppen für eine ökologisch verpflichtete Unternehmensfüh-

${ }^{130}$ Vgl. Postel, S. (1994), S. 11ff. 
rung eine entscheidende Rolle. ${ }^{131}$ Für das einzelne Unternehmen resultiert aus dieser Betrachtungsweise die Notwendigkeit eines bewußten Stakeholder-Managements.

Die ökologischen und gesellschaftlichen Entwicklungstendenzen im allgemeinen sowie der technologische Fortschritt, der wirtschaftliche Strukturwandel und die Veränderungen der menschlichen Arbeits- und Verbrauchsgewohnheiten im besonderen erfordern ständige Anpassungen der Unternehmen und des arbeitsteiligen Unternehmensgeschehens. Die Realisierbarkeit bzw. der Erfolg einer ökologisch verpflichteten Unternehmensführung hängt nicht zuletzt davon ab, inwieweit die Anspruchsgruppen die ökologische Umorientierung akzeptieren und diese, soweit sie Einfluß haben, auch fordern. Eine solche Auseinandersetzung mit gesellschaftlichen Anspruchsgruppen ist besonders in umweltproblematischen Bereichen oder Branchen unerläßlich, da die Anspruchsgruppen ihre Forderungen nicht an bestimmte Personen oder Funktionen im Unternehmen richten, sondern an das Unternehmen als Ganzheit. ${ }^{132}$

Für die ökologisch verpflichtete Unternehmensführung stellt der Stakeholder-Ansatz ein wichtiges Konzept dar, ${ }^{133}$ denn die ökologischen Anforderungen an Unternehmen zur Verbesserung des Umweltschutzes erfolgen nicht unmittelbar aus dem Bereich der ökologischen Umwelt, d.h. ein Unternehmen wird durch selbstverursachte ökologische Schäden nicht direkt betroffen, sondern mittelbar durch Stakeholder, die ökologische Interessen vertreten. Daher wird im folgenden näher auf das Stakeholder-Konzept eingegangen, das die Beziehungen des Unternehmens mit ihrem Umfeld bzw. Anspruchsgruppen in einem theoretischen Modell zu erfassen versucht.

Stakeholder werden allgemein als irgendwelche Individuen oder Gruppen gekennzeichnet, welche die Handlungen, Entscheidungen, Politik oder Ziele einer Organisation beeinflussen können oder durch diese betroffen sind. ${ }^{134}$ Stakeholder zeichnen sich dadurch aus, daß sie unterschiedli-

\footnotetext{
131 Als gutes Beispiel hierzu ist der Fall „Brent Spar“ zu nennen. 1995 mußte der Shell-Konzern aufgrund erheblichen öffentlichen Drucks - insbesondere seitens von Kunden und Politikern - die geplante Versenkung der Ölplattform „Brent Spar“ im Meer aufgeben. Durch den wochenlangen Boykott konnten unternehmensexterne Anspruchsgruppen Einfluß auf die Unternehmenspolitik eines Konzerns nehmen. Dies bedeutete für Shell zugleich erhebliche Umsatz-, Image- und Ergebniseinbußen. Diese Einflußnahmen auf die Unternehmensführung spiegelt das wachsende Interesse der Öffentlichkeit einerseits an einer Einflußnahme auf die Unternehmenspolitik, andererseits an Informationen, die über die herkömmliche ökonomische Rechenschaftspflicht hinausgehen, wider. Vgl. z.B. Ulrich, P. (1996), S. 27ff.; Osterloh, M./Tiemann, R. (1995), S. 321ff.

132 Vgl. Steger, U. (1991), S. 122.

${ }^{133}$ In Anlehnung an den ursprünglichen Begriff des „Share-holder“ entwickelte zunächst Freeman das Konzept des „Stake-holder“, dessen Ansprüche und deren Integration in das Unternehmenskonzept die Legitimation des Unternehmens bestimmen. Zur theoretischen Fundierung des Stakeholder-Konzeptes vgl. Freeman, R. E. (1984).

134 „Als Anspruchsgruppe gilt jede Person, Personengruppe oder Institution, welche die Unternehmensziele selbst, ihre Erreichung und damit die Bedingungen, unter denen die Unternehmung handelt, beeinflussen kann oder durch die Unternehmensziele selbst, ihre Erreichung und damit die Bedingungen, unter denen die Unternehmung handelt, beeinflußt wird.“ (Schaltegger, S./Sturm, A. (1990), S. 288) Der Begriff „Anspruchsgruppe“ wird im folgenden mit dem allgemeinen anglo-amerikanischen Begriff „Stakeholder“ gleichgesetzt, welcher sich auch im deutschsprachi-
} 
che Interessen an einem Unternehmen haben oder durch diese verfolgen. Neben der Dimension „Interesse an Unternehmen“ ist die Macht, über welche die Anspruchsgruppen verfügen, eine entscheidende Einflußgröße. Darunter wird die Fähigkeit der Anspruchsgruppen verstanden, durch den Einsatz von Ressourcen ein bestimmtes Ergebnis zu bewirken. Danach handelt es sich bei wichtigen Anspruchsgruppen um staatliche Institutionen/politische Parteien, Arbeitskräfte, Kunden, Konkurrenten, gesellschaftliche Gruppierungen, Kapitalgeber und Lieferanten. ${ }^{135}$ Der Stakeholderansatz entspricht der institutionellen Erfassung von Unternehmen und Umwelt. ${ }^{136}$

Ein Stakeholder-Konzept setzt sich aus mehreren Schritten zusammen (vgl. Abb. 3.5): ${ }^{137}$

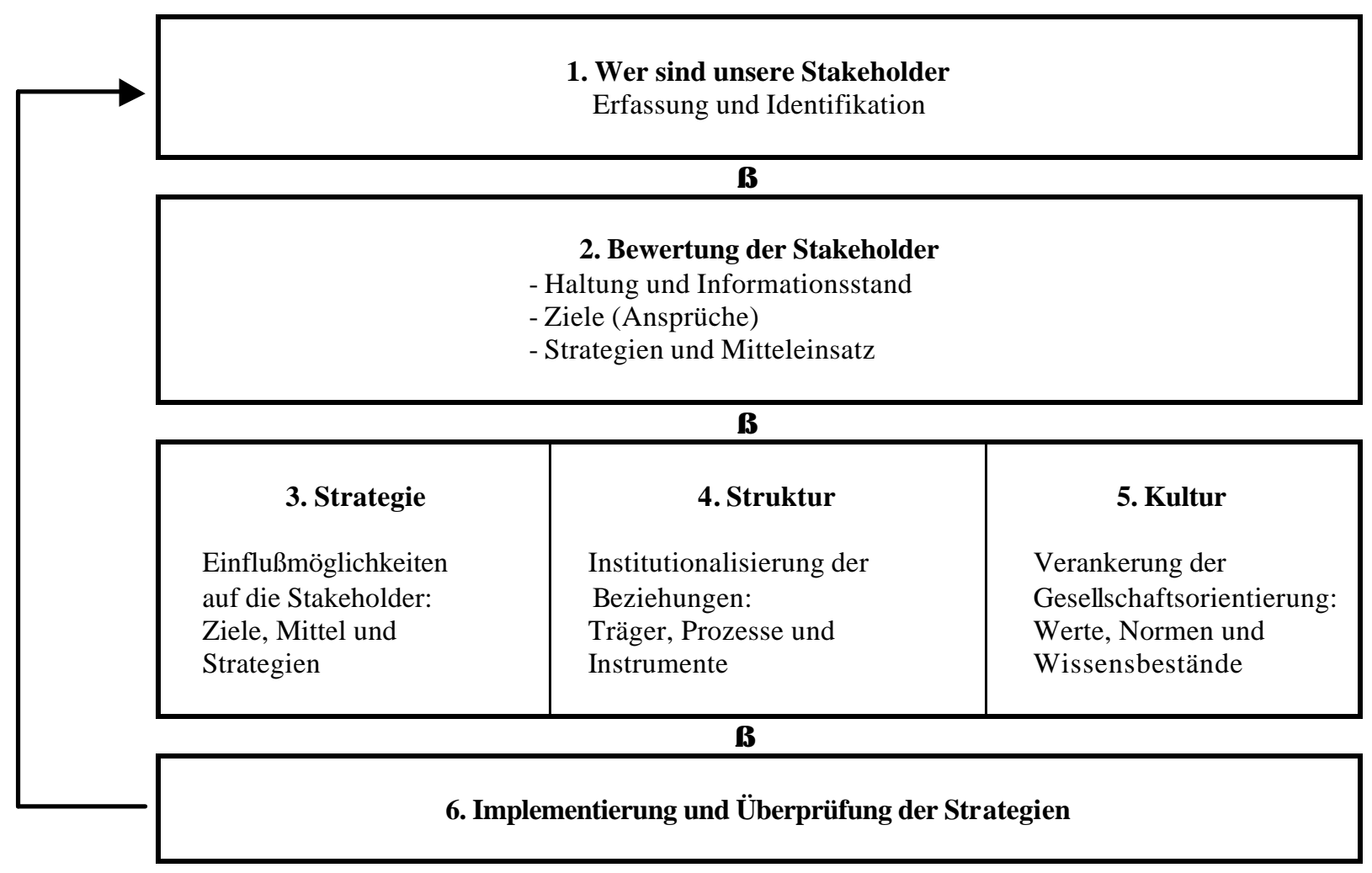

Abb. 3.5: Das Stakeholder-Management (Quelle: Sauter-Sachs, S. (1992), S. 195)

Im ersten Schritt des Stakeholder-Konzepts werden die relevanten Anspruchsgruppen erfaßt. Abb. 3.6 veranschaulicht die umweltrelevanten Anspruchsgruppen.

gen Raum zunehmend als Oberbegriff für sämtliche mit einem Unternehmen in Beziehung stehende Gruppen durchgesetzt hat. Der Begriff „Stakeholder“ wurde 1963 vom Stanford Research Institute (jetzt SRI International, Inc.) entwickelt. „Stakeholders are those groups without whose support the organisation would cease to exist.“ (Freeman, R. E. (1984), S. 31). Vgl. hierzu Ulrich, P./Fluri, E. (1992), S. 77; Achleitner, P. M. (1985), S. 76.

${ }^{135}$ Vgl. Ulrich, P./Fluri, E. (1992), S. 79; Scaltegger, S./Sturm, A. (1990), S. $19 \mathrm{ff}$.

${ }^{136}$ Vgl. Sauter-Sachs, S. (1992), S. 187.

${ }^{137}$ Vgl. Sauter-Sachs, S. (1992), S. 194; Janisch, M. (1993), S. 386ff.; Seisreiner, R. (1997), S. $113 f f$. 


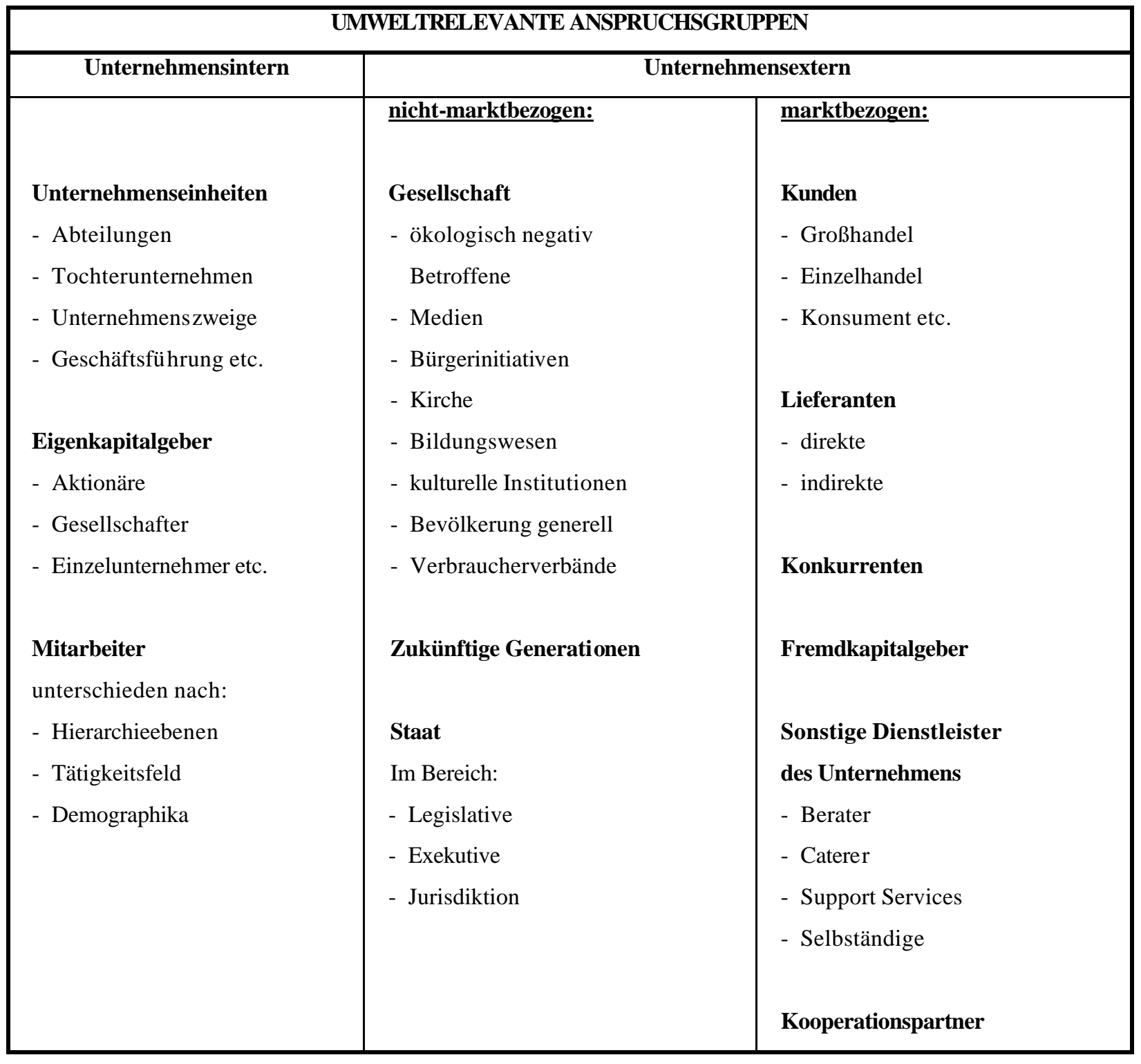

Abb. 3.6: Das Spektrum ökologischer Anspruchsgruppen

(Quelle: Meffert, H./Kirchgeorg, M. (1998), S. 95)

Das Unternehmen wird von der dauerhaften Aufrechterhaltung seiner Beziehungen zu seinen relevanten Umweltgruppen getragen, in Abhängigkeit der Art und Ausprägungen der Macht der sozialen Gruppen gegenüber dem Unternehmen sowie dem Willen, diese Macht auch auszuüben.

„Die Aufgabe der Unternehmensführung, als Träger der direkten Verantwortung, besteht deshalb darin, durch gegenwärtige Lenkung und Gestaltung die Entwicklung des Unternehmens im Spannungsfeld von Dynamik und Komplexität so zu beeinflussen, daß das Unternehmen als gesellschaftlich wertschöpfende Institution, welche infolge der dauernd wechselnden Forderungen und Beiträge von Anspruchsgruppen massiven Autonomitätsbedrohungen ausgesetzt ist, nicht nur lenkbar, sondern langfristig sinnvoll überlebensfähig bleibt““ ${ }^{138}$

${ }^{138}$ Janisch, M. (1993), S. 119. 
Es lassen sich somit folgende Gruppen unterscheiden und charakterisieren: Bezugsgruppen, Interessengruppen und strategische Anspruchsgruppen/Stakeholder: ${ }^{139}$

- $\mathrm{Zu}$ den Bezugsgruppen gehören alle sozialen Gruppen, welche zum Unternehmen irgendeinen tatsächlichen oder potentiellen, direkten oder indirekten Bezug aufweisen. (z.B. Kirchenorganisation, Universitäten, UN-Organisationen wie WHO, FAO etc.)

- $\mathrm{Zu}$ den Interessengruppen gehören jene sozialen Gruppen, welche eine tatsächliche direkte oder indirekte Beziehung zum Unternehmen aufweisen und deshalb unmittelbar Interessen an dem Unternehmen und ihren Verhaltensweisen bekunden. (z.B. Gewerkschaften)

- $\mathrm{Zu}$ den strategischen Anspruchsgruppen bzw. Stakeholder zählen diejenigen Umweltgruppen, die ihre Interessen in Form von konkreten Erwartungen und Ansprüchen an das Unternehmen formulieren und entweder selbst oder durch Interessenvertreter auf die Unternehmensziele, deren Erreichung, die unternehmerische Tätigkeit und auf ihr Verhalten Einfluß nehmen können sowie selbst von den Unternehmenszielen, deren Erreichung, der Tätigkeit und dem Verhalten des Unternehmens beeinflußt werden.

In der instrumentellen Ausgestaltung dieses Ansatzes durch Janisch wird grundsätzlich zwischen legitimen Ansprüchen der von unternehmerischen Aktivitäten Betroffenen und den für das Unternehmen relevanten Anspruchsgruppen unterschieden. Für das Unternehmen von besonderer Bedeutung sind nämlich die strategischen Anspruchsgruppen, d.h. jene gesellschaftlichen Gruppen, die mittel- und langfristig Einfluß auf die Legitimationsbasis ausüben können.

$\mathrm{Zu}$ den strategischen Anspruchsgruppen zählen in diesem Konzept dementsprechend die Bezugsgruppen, die:

- „,...über eine effektiv wirkende, erfolgreiche Macht verfügen, wobei die Machtgrundlage der strategischen Anspruchsgruppen sich auf die Beschaffungs-, Absatz- und Unterstiutzungsabhängigkeit des Unternehmens gegenüber ihren Anspruchsgruppen bezieht und

- auch über den Willen zur Machtausübung verfügen, so daß die strategischen Anspruchsgruppen mit Hilfe ihrer Sanktionsmöglichkeiten das Verhalten des Unternehmens in ihrem Interesse zu beeinflussen vermögen, indem sie dem Unternehmen mit ihrer Leistungs- und Befähigungsverweigerung drohen“. ${ }^{140}$

\footnotetext{
${ }^{139}$ Vgl. Achleitner, P. (1985), S. 76; Janisch, M. (1993), S. $126 \mathrm{ff}$.

${ }^{140}$ Vgl. Janisch, M. (1993), S. 128.
} 
Der Kontakt zu und die Kommunikation mit den Anspruchsgruppen kann sowohl direkt als auch indirekt erfolgen. Direkte Kommunikation kommt dort zustande, wo zwischen dem Unternehmen und der spezifischen Anspruchsgruppe entsprechende Kontaktmöglichkeiten gegeben sind. Indirekte Kommunikation ergibt sich dort, wo die Anspruchsgruppen mit Hilfe ihrer Machtstellung politische und gesellschaftliche Prozesse beeinflussen und damit über solche Dritte mit ihren Anforderungen an das Unternehmen herantreten. Entsprechend ist es die Aufgabe der Unternehmensführung, die direkten und indirekten Ansprüche zu identifizieren und in den unternehmerischen Zielprozeß zu integrieren.

Nach der Erfassung und Identifikation der relevanten Anspruchsgruppen werden sie hinsichtlich ihrer Haltung gegenüber dem Unternehmen, dem Informationsstand sowie der Ziele, Strategien und Mittel, über die sie verfügen, analysiert. Die Marktforschung erfährt damit eine Erweiterung zur Gesellschaftsforschung.

Zur Durchsetzung ihrer Anliegen nutzen die Anspruchsgruppen dabei eine oder mehrere der folgenden Strategien: ${ }^{141}$

- Mobilisierung des öffentlichen Drucks (z.B. Sensibilisierung der anderen Stakeholdergruppen auf das Fehlverhalten eines Unternehmens, insbesondere über Massenmedien),

- Mobilisierung des politischen Drucks ( z.B. Ausübung von Druck auf den Staat, sich eines bestimmten Themas anzunehmen),

- Mobilisierung der Marktkräfte (z.B. Aufruf zum Konsumboykott der Produkte eines Unternehmens),

- Aktivierung der Gesellschafter von Unternehmen (z.B. Nicht-Kauf der Aktien eines Unternehmens oder durch minimalen Anteilerwerb zur Nutzungsmöglichkeit des Forums Hauptversammlung),

- Direkte Verhandlungen mit den Unternehmen.

Die Auswirkung dieser Strategien für betroffene Unternehmen können von Verlust des Ansehens über Umsatzeinbußen bis hin zu einer Belastung der Arbeitsmoral der Mitarbeiter reichen. Die langfristige Überlebenssicherung eines Unternehmens hängt somit nicht mehr nur von Steuerungsmechanismen des Wettbewerbs und staatlichen Regulierungen, sondern zusätzlich vom Druck der Anspruchsgruppen ab. ${ }^{142}$ Dies verursacht einen Begründungs- und Legitimitätszwang

\footnotetext{
${ }^{141}$ Vgl. Dyllick, T. (1989), S. 56ff.

${ }^{142}$ Vgl. Wiedmann, K.-P. (1989), S. 232.
} 
für unternehmerische Handlungen bei den betroffenen Unternehmen gegenüber der Öffentlichkeit. $^{143}$

Nach der Analyse und Prognose des Verhaltens der Stakeholder stehen Unternehmen vor der Aufgabe, mit diesen Erkenntnissen eigene Strategien für den Umgang mit den jeweiligen Anspruchsgruppen $\mathrm{zu}$ entwickeln (Societal Strategy). ${ }^{144}$ Diese kann stark auf einzelne „Social Issues“ ausgerichtet sein (Issue Management). ${ }^{145}$ Ziel dieser Strategien ist einerseits, das Verhalten der jeweilige Stakeholdertypen vorhersehbarer und somit kontrollierbar zu machen, um auf mögliche Aktionen und Beeinflussungen besser vorbereitet $\mathrm{zu}$ sein. Andererseits ist es durch die Erhöhung der Kooperationsbereitschaft möglich, die Gefahr einer Einflußnahme durch die Stakeholder zu vermeiden. Die Zuordnung der Strategie zu den einzelnen Stakeholdertypen ist nicht als streng anzusehen. Es kann in bestimmten Fällen besser sein, gegenüber einer Gruppe eine andere Strategie einzusetzen (z.B. Verwendung einer Einbeziehungsstrategie gegenüber zukünftigen Nachbarn). Die Menschen, aus denen Anspruchsgruppen bestehen, sind oder fühlen sich zumindest von den Handlungen der Unternehmen tangiert. ${ }^{146}$ Häufig versuchen sie deshalb unmittelbar, das Unternehmensverhalten in ihrem Sinne zu beeinflussen und/oder Bedingungen zu schaffen, die diese bei der Gestaltung der betrieblichen Aktivitäten zu beachten haben. ${ }^{147}$ Stakeholder stellen auf ihren Wertesystemen basierende Ansprüche an Unternehmen.

Bei den Strategien der Unternehmen empfiehlt es sich, aufgrund der verschiedenen Beeinflussungspotentiale für jede relevante Anspruchsgruppe verschiedene Strategien zu verwenden: ${ }^{148}$

- Die Einbeziehungsstrategie (Involve): Sie richtet sich an die supportiven Stakeholder, die sich durch ein Höchstmaß an Kooperationsbereitschaft auszeichnen und über ein geringes Beeinflussungspotential verfügen wie z.B. Mitarbeiter, Gewerkschaften oder Lieferanten. Dabei versuchen die Unternehmen, diese Stakeholdern durch Teilnahme an Unternehmensentscheidungen zu größtmöglicher Kooperationsbereitschaft zu ermutigen wie z.B. durch erweiterte Einbeziehung der Mitarbeiter in Fragen der Arbeitsplatzsicherheit oder des Umweltschutzes am Arbeitsplatz.

- Die Beobachtungsstrategie (Monitor): Sie zielt auf die marginalen Stakeholder ab, die weder ein besonderes Beeinflussungspotential noch eine große Kooperationsbereitschaft besitzen

\footnotetext{
${ }^{143}$ Vgl. Dyllick, T. (1989), S. XIX.

${ }^{144}$ Zu den Einzelheiten von „Societal Strategy“ vgl. z.B. Rühli, E./Krulis -Randa, J. S. (1990).

${ }^{145} \mathrm{Zu}$ den Einzelheiten von „Issue-Management“ vgl. Seisreiner, R. (1997), S. 104ff.

${ }^{146}$ Vgl. Schaltegger, S./Sturm, A. (1994), S. 9.

${ }^{147}$ Vgl. Kubicek, H./Thom, N. (1976), Sp. 3980.

${ }^{148}$ Vgl. Savage, G. T./Nix, T. W./Whitehead, C. J./Blair, J. D. (1991), S. $61 \mathrm{ff}$.
} 
z.B. Wettbewerber/Branchenmitglieder, Nachbarn oder Wissenschaft/ Schulen. Durch das geringe Beeinflussungspotential und die hohe Kooperationsbereitschaft ist es einem Unternehmen möglich, das Verhalten dieser Gruppe unter Verwendung von minimalem Aufwand $\mathrm{zu}$ beobachten. In die weitere Analyse werden diese dann nur einbezogen, wenn ein besonderes Thema zu einer Änderung in ihrem Verhalten führt (z.B. ist die Berücksichtigung der Interessen der Nachbarschaft hinsichtlich geschäftspolitischer Entscheidungen weit weniger wichtig als bei ökologischen Themen).

- Die Verteidigungsstrategie (Defend): Diese soll die Abhängigkeit des Unternehmens vom Verhalten der nonsupportiven Stakeholder, die durch ein hohes Beeinflussungspotential und geringe Kooperationsbereitschaft die größte Gefahrenquelle für ein Unternehmen darstellen wie z.B. Medien, Staat oder Special Interest Group bzw. Social Interest Group (SIG), durch Reduzierung der Basis für eine Auseinandersetzung vermindern (z.B. durch das Vorwegnehmen gesetzlicher Entwicklungen oder Publizierung und Lösung ökologischer Probleme vor der Aufdeckung durch Medien oder SIG).

- Die Zusammenarbeitsstrategie (Collaborate): Mit dieser Strategie wird versucht, die ohnehin hohe Kooperationsbereitschaft der über ein hohes Beeinflussungspotential verfügenden „,mixed blessing“ Stakeholder, die zwar über ein hohes Beeinflussungspotential verfügen, dem Unternehmen aber i.d.R. kooperativ gegenüberstehen wie z.B. Anteilseigner/Investoren, Management, Kunden, Banken oder Versicherungen, durch gemeinsames Erarbeiten von Problemlösungen $\mathrm{zu}$ stabilisieren oder $\mathrm{zu}$ erhöhen (z.B. Einbeziehung der Banken in wichtige umweltrelevante Entscheidungen).

„Das Hauptziel der Unternehmung resultiert somit aus einer ganz bestimmten Legitimation bzw. Daseinsberechtigung, welche im Rahmen des strategischen Anspruchsgruppen-Managements als möglichst optimale Nutzengenerierung für sämtliche Anspruchsgruppen umschrieben wird.“، ${ }^{\text {149 }}$

Als Hilfe kann hierbei ein anspruchsgruppenorientiertes Ziel- und Meßsystem das Management unterstützen. „Indem die Unternehmung ihre gesamten Aktivitäten und Verhaltensweisen auf die optimale Nutzengenerierung und -steigerung ihrer Anspruchsgruppen ausrichtet, sichert sie sich weitgehend im Prozeß dieser Zielerreichung ab. “150

In dieser Sichtweise wird die Erfüllung ökologischer Ansprüche dann zu einem Ziel im Unternehmen, wenn sich jeweils Gruppen mit ökologischen Anforderungen an das Unternehmen fin-

\footnotetext{
149 Janisch, M. (1993), S. 145.

150 Janisch, M. (1993), S. 145.
} 
den, die die oben genannten Kriterien als Anspruchsgruppe erfüllen. Die ökologische Herausforderung wird in dieser Sichtweise damit zu einer Herausforderung der Einbeziehung der Ansprüche von Gruppen, die als Anspruchsgruppen identifiziert worden sind. Die grundsätzliche Komplexität, die bei Vielfältigkeit der ökologischen Herausforderung zwangsläufig aufkommt, wird auf eine rein soziale Aspekte berücksichtigende Fragestellung reduziert.

Die aus den Anforderungen der Anspruchsgruppen generierten ökologischen Unternehmensziele können sich je nach Situation konfliktorisch oder komparativ zu anderen Unternehmensunterzielen verhalten. Deshalb ist es die Aufgabe der Unternehmensführung, eine Zielharmonisierung zu erreichen, bei der grundsätzlich davon ausgegangen wird, daß eine Berücksichtigung ökologischer Aspekte, im Sinne der Anspruchsgruppen, die Legitimität des Unternehmens und damit den Erfolg zwangsläufig erhöht. Damit gelingt eine Integration ökologischer Ansprüche in das Zielsystem der Unternehmen, die den tendenziellen Konflikt zwischen ökonomischen und ökologischen Ansprüchen zumindest formal entschärfen kann. Zwar können auch im Anspruchsgruppenmodell Konflikte im Zielsystem auftreten, doch sind diese als immanente Konflikte anzusehen, ähnlich anderen betriebswirtschaftlichen Zielkonflikten wie etwa zwischen den Cashflow-Zielen und denen der strategischen Entwicklung des Unternehmens.

Die gesellschaftliche Funktion und die gesellschaftliche Verantwortung des Unternehmens müssen aber auch bei der Strukturgestaltung berücksichtigt werden. Dies geschieht sowohl in der Aufbauorganisation, wo die zur Wahrnehmung geeigneten Träger bestimmt werden, als auch in der Ablauforganisation, wo die Interaktionen festgelegt werden. Dazu bedarf es geeigneter Instrumente. Wesentlich ist aber auch, daß die Umweltorientierung in der Unternehmenskultur verankert ist.

Schließlich erfolgt bei dem Stakeholder-Konzept dann die Umsetzung und die Kontrolle. Wie der gesamte Erfassungsprozeß und die Strategieformulierung interaktiv ist, so ist es auch die Kontrolle: Der Markt kontrolliert das Unternehmen durch den Wettbewerb; das Unternehmen den Markt z.B. durch die Lieferantenwahl. Von der Gesellschaft werden die Handlungen der Lnternehmen durch ihre Organe und Gruppierungen (Wirtschaftspresse, Konsumentenforum usw.) überwacht; das Unternehmen überwacht die Gesellschaft auf ihre Effizienz hin (z.B. Konkurrenzierung öffentlicher Unternehmen, Lobbying usw.).

Alle Anspruchsgruppen sind situativ in unterschiedlicher Weise von Relevanz. Hierbei ist die Beziehung stets wechselseitig. Zweifellos stellen aber nicht nur die Stakeholder Ansprüche an 
das Verhalten der Unternehmen. Mit einer analogen Argumentation entwickeln auch Unternehmen Erwartungshaltungen gegenüber ihren Anspruchsgruppen. Abb. 3.7 zeigt einige Beispiele möglicher wechselseitiger Interessen zwischen den Unternehmen und ihren wichtigsten Anspruchsgruppen. Die Unternehmen besitzen eine Verantwortung gegenüber den Anspruchsgruppen, aber die Anspruchsgruppen tragen auch eine Verantwortung gegenüber den Unternehmen. ${ }^{151}$

\begin{tabular}{|c|c|c|}
\hline $\begin{array}{c}\text { Anspruchsgruppen } \\
\text { (Stakeholder) }\end{array}$ & $\begin{array}{c}\text { Interessen der } \\
\text { Anspruchsgruppen }\end{array}$ & $\begin{array}{l}\text { Interessen der } \\
\text { Unternehmen }\end{array}$ \\
\hline $\begin{array}{l}\text { Staatliche Institutionen/ } \\
\text { politische Parteien } \\
\text { (nationale und } \\
\text { internationale) } \\
\text { - Judikative } \\
\text { - Exekutive } \\
\text { - Legislative }\end{array}$ & $\begin{array}{l}\text { - Einkommen } \\
\text { - Sicherung von Arbeitsplätzen } \\
\text { - Schutz der Umwelt } \\
\text { - Beiträge zur wirtschaftlichen } \\
\text { Entwicklung } \\
\text { - Wahrnehmung sozialer } \\
\text { Verantwortung } \\
\text { - Einhaltung von Rechtsvorschriften } \\
\text { und gesellschaftlichen Normen } \\
\text { - Teilnahme an der politischen } \\
\text { Willensbildung }\end{array}$ & $\begin{array}{l}\text { - Gestaltung fairer und stabiler } \\
\text { Rahmenbedingungen } \\
\text { - Schaffung einer Infrastruktur } \\
\text { - Förderungsmaßnahmen } \\
\text { - angemessene Gesetzgebung } \\
\text { - Stärkung der internationalen } \\
\text { Wettbewerbsfähigkeit } \\
\text { - gerechte Abwägung und Berücksich- } \\
\text { tigung der Unternehmensinteressen } \\
\text { - Belohnung besonderer Leistungen } \\
\text { (z.B. im Umweltschutz) }\end{array}$ \\
\hline $\begin{array}{l}\text { Arbeitskräfte } \\
\text { - Management } \\
\text { - Mitarbeiter }\end{array}$ & $\begin{array}{l}\text { - angemessene Einkommen } \\
\text { - zwischenmenschliche Kontakte } \\
\text { - soziale Sicherheit } \\
\text { - Entfaltung eigener Ideen und Fähigkeit } \\
\text { - Status, Anerkennung, Prestige } \\
\text { - Entscheidungsautonomie } \\
\text { - körperliche Unversehrtheit } \\
\text { - Identifikationsmöglichkeit mit dem Un- } \\
\text { ternehmen und seiner Produkte } \\
\text { - Vertrauen }\end{array}$ & $\begin{array}{l}\text { - Loyalität gegenüber } \\
\text { dem Unternehmen } \\
\text { - Adäquate quantitative und } \\
\text { qualitative Arbeitsleistung } \\
\text { - Bereitschaft zur Fortbildung } \\
\text { - Wahrung des Betriebsfriedens } \\
\text { - Akzeptanz betrieblicher Strukturen } \\
\text { - Verschwiegenheit } \\
\text { - aktive Beteiligung an } \\
\text { Problemlösungen } \\
\text { - Einhaltung gesetzlicher und } \\
\text { betrieblicher Bestimmungen }\end{array}$ \\
\hline $\begin{array}{l}\text { Kunden } \\
\text { z.B. } \\
\text { - Öffentliche Haushalte } \\
\text { - Private Haushalte } \\
\text { - Industrieunternehmen } \\
\text { - Handelsbetriebe }\end{array}$ & $\begin{array}{l}\text { - quantitativ/qualitativ } \\
\text { befriedigende Marktleistung } \\
\text { - sichere, zuverlässige und } \\
\text { umweltfreundliche Produkte } \\
\text { - gute Preis/Leistungsverhältnisse } \\
\text { - faires Geschäftsgebaren } \\
\text { - ständige Lieferbereitschaft }\end{array}$ & $\begin{array}{l}\text { - Belohnung besonderer Leistungen } \\
\text { - Markentreue } \\
\text { - Einhaltung vertraglicher } \\
\text { Vereinbarungen und Fairneß } \\
\text { - Akzeptanz auskömmlicher Preise } \\
\text { - Verantwortungsbewußter Umgang } \\
\text { mit den Produkten }\end{array}$ \\
\hline
\end{tabular}

${ }^{151}$ Vgl. Sauter-Sachs, S. (1992), S. 194. 


\begin{tabular}{|c|c|c|}
\hline & - bedarfsgerechte Innovationen & \\
\hline $\begin{array}{l}\text { Konkurrenten } \\
\text { - auf Absatzmarkt } \\
\text { - auf Beschaffungsmarkt }\end{array}$ & $\begin{array}{l}\text { - faires Wettbewerbsverhalten } \\
\text { - Kooperationsbereitschaft auf } \\
\text { branchenpolitischer Ebene } \\
\text { - solidarisches Verhalten in Krisensitua- } \\
\text { tion }\end{array}$ & $\begin{array}{l}\text { - faires Wettbewerbsverhalten } \\
\text { - Kooperationsbereitschaft auf } \\
\text { branchenpolitischer Ebene } \\
\text { - solidarisches Verhalten in } \\
\text { Krisensituation }\end{array}$ \\
\hline $\begin{array}{l}\text { Gesellschaftliche Gruppen } \\
\text { z.B. } \\
\text { - Gewerkschaften } \\
\text { - Arbeitgeberverbände } \\
\text { - Verbraucherorganis ation } \\
\text { - Bürgerinitiativen } \\
\text { - Kirchen } \\
\text { - Medien }\end{array}$ & $\begin{array}{l}\text { - Informationsbereitstellung } \\
\text { - Einkommen } \\
\text { - Erhaltung einer lebenswerten Umwelt } \\
\text { - Schutz sozialer Standards } \\
\text { - Kooperationsbereitschaft } \\
\text { - Berücksichtigung der eigenen } \\
\text { Interessen } \\
\text { - Beachtung von Gesetzen und } \\
\text { gesellschaftlichen Normen } \\
\text { - Risikominimierung } \\
\text { - Kontrollmöglichkeiten }\end{array}$ & $\begin{array}{l}\text { - vorurteilsfreie Prüfung und } \\
\text { Darstellung der Handlungen } \\
\text { des Unternehmens } \\
\text { - Kooperationsbereitschaft bei } \\
\text { gemeinsamen Problemen } \\
\text { - am Leistungsvermögen des Unter- } \\
\text { nehmens ausgerichtete Forderungen } \\
\text { - Vertretung von } \\
\text { ternehmensinteressen } \\
\text { - Beteiligung an Unternehmensent- } \\
\text { scheidungen }\end{array}$ \\
\hline $\begin{array}{l}\text { Kapitalgeber } \\
\text { z.B. } \\
\text { - Banken } \\
\text { - Versicherungen } \\
\text { - Aktionäre }\end{array}$ & $\begin{array}{l}\text { - befriedigende Verzinsung des } \\
\text { eingesetzten Kapitals } \\
\text { - Informationsbereitstellung } \\
\text { - Vermögenszuwachs } \\
\text { - Green Investments } \\
\text { - Macht, Einfluß, Prestige } \\
\text { - pünktliche Zins- und } \\
\text { Tilgungszahlungen } \\
\text { - Sicherheit der Kapitalanlage } \\
\text { - ethisch einwandfreier Einsatz der } \\
\text { Produktionsfaktoren }\end{array}$ & $\begin{array}{l}\text { - dauerhafte Überlassung des Kapitals } \\
\text { - Unterstützung in Krisensituationen } \\
\text { - maßvolle Ausschüttung von } \\
\text { Gewinnen } \\
\text { - Risikokapital } \\
\text { - wohldosierte Einflußnahme } \\
\text { auf Entscheidungen } \\
\text { - günstige Kredite }\end{array}$ \\
\hline $\begin{array}{l}\text { Lieferanten } \\
\text { z.B. } \\
\text { - Produzenten von } \\
\text { Werkstoffen } \\
\text { - Produzenten von } \\
\text { Betriebsmitteln } \\
\text { - Händler }\end{array}$ & $\begin{array}{l}\text { - regelmäßige Auftragseingänge } \\
\text { - dauerhafte Liefermöglichkeiten } \\
\text { - günstige Lieferkonditionen } \\
\text { - vertrauensvolle Kunden- } \\
\text { Lieferantenbeziehungen } \\
\text { - Zahlungsfähigkeit der Kunden } \\
\text { - Gemeinsame Forschungs- und } \\
\text { Entwicklungsanstrengungen }\end{array}$ & $\begin{array}{l}\text { - hohe Lieferbereitschaft und } \\
\text { Lieferzuverlässigkeit } \\
\text { - dauerhafte Lieferbeziehungen } \\
\text { - angemessenes Preis - } \\
\text { Leistungsverhältnis } \\
\text { - unternehmensspezifische } \\
\text { Produktentwicklungen } \\
\text { - umweltgerechte Erzeugnisse }\end{array}$ \\
\hline
\end{tabular}

Abb. 3.7: Beispiele möglicher wechselseitiger Interessen zwischen den Unternehmen und ihren wichtigsten Anspruchsgruppen (Quelle: Schulz, K. (1996), S. 77) 
Die wechselseitigen Ansprüche von Unternehmen und Anspruchsgruppen können grundsätzlich auf direktem Wege und/oder auf indirektem Wege, unter Zwischenschaltung einer oder mehrerer anderer Anspruchsgruppen, offeriert werden. ${ }^{152}$ Aufgrund gesellschaftlicher und kultureller und insbesondere ökologischer Veränderungen hat sich in den vergangenen Jahrzehnten ein Wandel des Unternehmensmodells ergeben. ${ }^{153}$ Die daraus erfolgsstrategisch erwachsende gesellschaftliche Verantwortung der Unternehmen gegenüber verschiedenen, auch untereinander heterogenen Anspruchsgruppen kann angemessen nicht als monologische, sondern nur als dialogische Verantwortung hergestellt werden. ${ }^{154}$

Nach Schaltegger/Sturm lassen sich aus dem Stakeholder-Konzept vier zentrale Erfolgskriterien für die ökologisch verpflichtete Unternehmensführung ableiten, und zwar Legitimität, Legalität, Effektivität, sowie Effizienz. Ein Unternehmen kann nur dann erfolgreich sein, wenn es durch sozioökonomisch-rationales, d.h. legitimes, legales, effektives sowie effizientes Handeln, seinen Zweck im Rahmen der gesellschaftlichen Umwelt erfüllt: ${ }^{155}$

Legitimität stellt die an der Gesamtheit aller anspruchsgruppenspezifischen Werthaltungen gemessene, moralische und ethische Anerkennungswürdigkeit der Handlungen von Programmen und Ordnungen eines Unternehmens dar. ${ }^{156}$ Legitimität bezieht sich somit auf die moralische bzw. ethische Dimension der Unternehmensziele. Die Handlungen des Managements müssen den Werthaltungen seiner Anspruchsgruppen genügen, d.h. sie müssen als legitim akzeptiert werden. ${ }^{157}$

- Legalität betrifft die gesetzlichen Rahmenbedingungen, d.h. die Einhaltung der überwiegend kodifizierten und verpflichtenden gesamtgesellschaftlichen Normen. Weiter fallen darunter vertragliche Vereinbarungen, die einen verpflichtenden Charakter aufweisen. Diese Rahmenbedingungen stellen zwingende Restriktionen bei der Verfolgung unternehmerischer Ziele dar. Insbesondere das umweltrelevante Recht nimmt im Rahmen der ökologisch verpflichteten Unternehmensführung eine Sonderstellung ein, weil die Befolgung der gesetzlichen Regelungen aufgrund der staatlichen Hoheitsgewalt erzwungen werden kann. ${ }^{158}$

- Effektivität bezieht sich auf das Ausmaß des Zielerreichungsgrades bzw. das Ausmaß an Nutzenstiftung unternehmerischer Leistung für die jeweilige Anspruchsgruppe. Von Bedeutung ist hierbei, daß die unternehmerischen Leistungen zunehmend nicht nur anhand wirt-

\footnotetext{
${ }^{152}$ Vgl. Janisch, M. (1993), S. 132ff.

${ }^{153}$ Vgl. Ulrich, H. (1977); Ulrich, P./Fluri, E. (1992), S. $58 f$

${ }^{154}$ Vgl. Steinmann, H./Löhr, A. (1992); Ulrich, P. (1986).

155 Vgl. Schaltegger, S./Sturm, A. (1994), S. 198 und (1993), S. $184 \mathrm{ff}$.

${ }^{156}$ Vgl. Schaltegger, S./Sturm, A. (1993), S. 201.

${ }^{157}$ Vgl. Barmann, J. P. (1992), S. $416 \mathrm{ff}$.
} 
schaftlicher, sondern auch bezüglich ökologischer Nutzen bewertet werden. Die betriebliche Leistung wird somit nicht nur bezüglich der Hauptnutzen, sondern auch der Nebennutzen oder Zusatznutzen beurteilt.

Effizienz ist das klassische betriebswirtschaftliche Erfolgskriterium. Es bezieht sich auf das Verhältnis von Output zu Input. Dabei wird gefragt, mit welchem Aufwand ein bestimmtes Ziel erreicht wird. Eine Handlung ist dann ökonomisch rational, wenn ein bestmögliches Verhältnis zwischen Input und Output erreicht werden kann. Durch die Zunahme und den gsteigerten Stellenwert ökologischer Ansprüche vieler Stakeholder haben sich die Erfolgskriterien inhaltlich geändert, was insbesondere die Erweiterung des Kriteriums der Effizienz um die ökologische Dimension betrifft. ${ }^{159}$ Die ökologische Effizienz stellt das zentrale Erfolgskriterium einer ökologisch verpflichteten Unternehmensführung dar. Sie stellt das Verhältnis von Wertschöpfung zu Schadschöpfung dar. ${ }^{160}$

So scheint zunächst eine betriebswirtschaftliche Konzeption gefunden $\mathrm{zu}$ sein, die die Basis für die Herausbildung einer ökologischen Unternehmenspolitik darstellen kann. Allerdings zeigt das Stakeholder-Konzept bei einer genaueren Betrachtung der möglichen Einbeziehung ökologischer Ansprüche deutliche Lücken. ${ }^{161}$

So kann die Natur nicht als eine Anspruchsgruppe definiert werden. Damit ist nur eine indirekte Beziehung zwischen ökologischen Problemen und deren Aufnahme durch Anspruchsgruppen gegeben. Als Mitglieder von ökologischen Anspruchsgruppen können somit nur die von ökologischen Folgen betroffenen Menschen gesehen werden. Damit sind aber zumindest zwei Probleme verbunden.

Einerseits entsteht das Problem der Zeitverschiebung bei ökologischen Folgen. Z.B. etwa bei der FCKW-Diskussion ist festzustellen, daß zwischen der menschlichen Betroffenheit etwa durch das Ozonloch und der diesem Problem zugrundeliegenden menschlichen Einwirkung Jahrzehnte vergehen können. Beim Auftreten vielfacher ökologischer Problemfelder kommt es damit aber zwangsläufig zu einer Verschiebung zugunsten aktueller Probleme, weil diese eine stärkere Betroffenheit erzeugen. Andererseits ist die Betroffenheit von der spezifischen Wahrnehmung

\footnotetext{
${ }^{158}$ Vgl. Dyllick, T. (1989), S. 84; Macharzina, K, (1993), S. 20.

159 Die Zielsetzung der Öko-Effizienz auf Unternehmensebene hat weitreichende Folgen, so daß die Unternehmen als öko-effizient bezeichnet werden, „die auf dem Weg zu langfristig tragbarem Wachstum Fortschritte machen, indem sie ihre Arbeitsmethoden verbessern, problematische Materialien substituieren, saubere Technologien und Produkte einführen und sich um die effizientere Verwendung und Wiederverwendung von Ressourcen bemühen.“ Schmidheiny, S. (1992), S. 38, Fußnote.

${ }^{160}$ Vgl. Dyllick, T. (1992), S. 397f.

${ }^{161}$ Vgl. Hallay, H. (1996), S. $72 f$.
} 
durch die Betroffenen und deren spezifischen Interessen abhängig. Unterschiedliche ökologische Probleme erzeugen dabei durchaus unterschiedliche Wahrnehmungen und Interessenkonstellationen.

Damit sind die ökologischen Anforderungen an ein Unternehmen durchaus nicht als homogene Größe zu betrachten. Das bedeutet, daß die verschiedenen „ökologischen Stakeholder“ durchaus unterschiedliche oder sogar völlig entgegengesetzte Vorstellungen und Ansprüche aussprechen können. Dies führt dazu, daß eine ökologische Unternehmenspolitik, die sich an den jeweils aktuellen Stakeholdern mit der derzeit größten Macht orientiert, sich der Gefahr weitgehender Beliebigkeit aussetzt. Die Frage ist, ob dies wirklich grundsätzlich der Herausbildung einer ökologischen Unternehmenspolitik und einer langfristigen Stabilisierung des Unternehmens dient.

In diesem Sinne stellt zwar das Stakeholder-Konzept eine Erweiterung der Sichtweise einer ökologischen Unternehmenspolitik dar, ${ }^{162}$ jedoch unterliegt dieses Modell, durch die einseitige Reduzierung der ökologischen Herausforderung der Unternehmen auf die Einbeziehung eines gesellschaftlichen Diskurses, einer wesentlichen Verkürzung. Ebenso fehlt dem Anspruchsgruppen-Modell als Bestandteil eines normativen Managements die operative und in Grenzen auch die strategische Umsetzungskomponente. Da aber das Anspruchsgruppen-Konzept auf einem anderen Unternehmensmodell beruht, stellt sich die Frage, inwieweit dieses Konzept mit den Konzepten der operativen und strategischen Einbeziehung ökologischer Faktoren kompatibel ist.

Das Stakeholder-Konzept wird zwar nicht auf jeden Einzelfall anwendbar sein, stellt aber eine sinnvolle Ausgangsposition zur Vereinfachung der Beobachtung bzw. Analyse von Stakeholdern dar und ermöglicht Unternehmen, über ein bloßes Reagieren auf die Anforderungen ihrer Stakeholder hinaus, z.B. durch ein Vorwegnehmen anstehender Entwicklungen, proaktive Aktionsmöglichkeiten zu ergreifen.

162 Insbesondere das hier zugrundeliegende Unternehmensmodell und die hieraus abgeleiteten Folgen für die Zielintegration ökologischer Aspekte stellen eine wesentliche Komponente einer ökologischen Unternehmenspolitik dar. Vgl. Kap. 4.3 dieser Arbeit. 


\section{Integrierte Konzeption einer ökologisch verpflichteten Unternehmensführung}

Angesichts der Konsequenzen der Umweltprobleme, die unternehmerische Tätigkeiten stärkend in ihrer ökologischen, gesellschaftlichen und wettbewerbsstrategischen Dimension beeinflussen, ist die Notwendigkeit der Berücksichtigung von Umweltschutzforderungen bei unternehmerischen Entscheidungen auch in Südkorea kaum mehr in Frage zu stellen. Dabei lautet die zentrale Anliegen folgender Ausführung, daß auch heute noch in Südkorea dem Schutz der natürlichen Lebensgrundlagen in betriebswirtschaftlicher Hinsicht ein unzureichender Stellenwert beigemessen wird. Deshalb soll hier die Frage gestellt werden, wieweit die Betriebswirtschaftslehre in Südkorea die Ökologieproblematik überhaupt aufgreift und der Praxis auf der Grundlage der dagnostizierten Defizite Hilfestellung anbietet. Dabei sei an dieser Stelle bereits die These vorweggenommen, daß es in der betriebswirtschaftlichen Forschung an umfassenden strategischen Ökologiekonzepten in Südkorea fehlt, die insbesondere der unternehmenspolitischen Umweltschutzproblematik Rechnung tragen.

Auf einer diesbezüglichen Bestandsaufnahme wurde die Zielsetzung der folgenden Ausführung angesetzt, die Gestaltungsmöglichkeiten einer ökologisch verpflichteten Unternehmensführung in Südkorea herauszuarbeiten, welche das Gesamtunternehmen in der Mittelpunkt der Planungsund Steuerungsaktivitäten stellen und eine Ökologieverpflichtung der Unternehmensführung in aktiver und systematischer Weise ermöglichen. Die konzeptionelle Ausführung, die in den deutschsprachigen Literaturen dargestellt wird, soll dabei als Referenz dienen.

In diesem Zusammenhang ist die Frage zu erklären, ob die vorwiegend für den deutschsprachigen Raum entwickelten Konzepte einer ökologisch verpflichteten Unternehmensführung auf Südkorea übertragen werden können. Für eine solche Übertragbarkeit wird vom Phänomen der zunehmenden Homogenisierung der internationalen Produktanforderungen sowie des Marketings aufgrund einer weltweiten Angleichung der Käuferwünsche im Sinne der Globalisierung des Marktes ausgegangen. Eine solche Angleichung der Anforderungen der Konsumenten an die ökologiebezogenen Produkteigenschaften würde ceteris paribus auch $\mathrm{zu}$ einer Angleichung der betrieblichen Problemlösungen in den verschiedenen Ländern, also auch in Südkorea führen. ${ }^{1}$

\footnotetext{
${ }^{1}$ Internationale Untersuchungen des länderspezifischen Einsatzes von Instrumenten der Umweltpolitik sowie über die jeweiligen Handlungsbedingungen zeigen, daß weltweit eine Angleichung in den „Politikstilen“ und in der Wahl der Instrumente der Umweltpolitik konstatiert werden kann, so daß eine globale Politikkonvergenz und ein hohes internationales Diffusionstempo umweltpolitischer Konzepte zu beobachten sind und damit auch in der ökologisch verpflichteten Unternehmensführung von international einheitlichen umweltpolitischen Restriktionen auszugehen ist (vgl. Jähnicke, M./Weidner, H. (1997), S. 15 ff.). Auf der anderen Seite kann die gegenteilige Auffassung vertreten werden, daß in Südkorea aufgrund des divergenten Umfeldes (z.B. demographische und kulturelle Heterogenität, Einkommensverteilung usw.) andersartige Strategien notwendig sind als z.B. in Deutschland. Gleichzeitig konstatie-
} 
Dabei sei bereits an dieser Stelle betont, daß im Rahmen der folgenden Ausführung nicht die Entwicklung von Patentrezepten in Südkorea angestrebt werden soll, der Vielschichtigkeit, Vernetzheit und Komplexität der Ökologieproblematik und der speziellen Gegebenheiten Südkoreas in der Praxis gerecht zu werden, sondern es soll versucht werden, viele Bausteine für die ökologisch verpflichtete Unternehmensführung in Südkorea bereitzustellen, um möglichst komplexe und umfangreiche Denkmuster $\mathrm{zu}$ erzeugen, die helfen, die konzeptionelle Gesamtsicht einer Ökologieverpflichtung bei der Unternehmensführung problemadäquat zu formulieren und zu gestalten. Bei der Konzeption einer ökologisch verpflichteten Unternehmensführung in Südkorea handelt es sich dabei um ein idealtypisches Modell, dessen Grundlagen hinterfragt und dessen Anwendungsmöglichkeiten eingeschränkt werden können.

\subsection{Grundlagen für die Konzeption einer ökologisch verpflichteten Untemehmensführung}

Die Umweltproblematik ist keine kurzlebige Modeerscheinung, die sich die Gesellschaft bzw. die Unternehmen nur leisten können, wenn die Konjunktur dies zuläßt. Sicherlich bestehen in der Auseinandersetzung mit dem Themenkomplex diesbezügliche Überlagerungen, aber in einer Gesellschaft, die die Notwendigkeit des „Haushaltens“ mit den natürlichen Ressourcen erkannt hat, läßt sich diese Sensibilisierung nur schwer wieder reduzieren. ${ }^{2}$

Die Forderung nach einem ökologischen Engagement von Unternehmen wird im Rahmen der ökologisch verpflichteten Betriebswirtschaftslehre mit einer Reihe von Argumenten begründet. ${ }^{3}$ Im allgemeinen sprechen drei Argumente dafür, deren Wirksamkeit im Zeitablauf als starke und stabiler Trend aufgefaßt werden kann, Forderungen der Unternehmensumwelt durch die Umsetzung einer ökologisch verpflichteten Unternehmensführung in die betrieblichen Prozesse zu integrieren: ${ }^{4}$

ren die Untersuchungen ein weitgehendes Fehlen sowohl theoretischer als auch empirischer Forschungsarbeiten zu Fragen der Unternehmensstrategie bzw. vor allem der Konzepte einer ökologisch verpflichteten Unternehmensführung in Südkorea. Insbesondere ist das ökologieintendierte Konsumentenverhalten in Südkorea noch größtenteils unerforscht, wobei signifikante kulturelle Differenzen zu erwarten sind. Diese These bleibt in dieser Arbeit jedoch unberücksichtigt, denn sie versucht, nicht Lösungsansätze zur ökologisch verpflichteten Unternehmensführung zu liefern, die neben den allgemeinen (theoretischen) Grundlagen alle speziellen Gegebenheiten Südkoreas umfassen müssen, sondern eine möglichst breite Grundlagen für die Berücksichtigung der ökologischen Verpflichtung in der Unternehmensführung in Südkorea bereitzustellen.

${ }^{2}$ Vgl. Ulrich, P. (1991), S 2f.

3 Vgl. z.B. Achleitner, P.-M. (1985), S. 155; Plaschka, G./Frank, H./Rössl, D. (1989), S. 126; Ulrich, P./Fluri, E. (1992), S. 33; Günther, E. (1994), S. 17; Nitze, A. (1991), S. 97; Kirchgeorg, M. (1990), S. 87f. Die im folgenden dargestellten Begründungssätze bzw. Argumente für ein ökologisches Engagement der Unternehmen, die in deutschsprachigen Publikationen häufig begründet sind, dürften auch in Südkorea gelten.

${ }^{4}$ Vgl. Steinle, C. (1995), S. 914ff.; Thielemann, U. (1990), S. 3ff.; Marcharzina, K. (1993), S. 28.; Pfriem, R. (1989); Hopfenbeck, W. (1993), S. 963. 
- Der externe Zwang durch den gesellschaftlichen Wertwandel, d.h. das Umweltbewußtsein der Bürger und Mitarbeiter als aktives Kritik- und Forderungspotential in bezug auf einen wirksamen Umweltschutz. Dieser Zwang wirkt einerseits durch ein geändertes Konsumentenverhalten direkt auf den Märkten, was eine ökologisch orientierte Produktpolitik erforderlich macht. Andererseits ergeben sich nichtmarktliche Wirkungen durch die öffentliche Meinung, welche es ratsam erscheinen läßt, ein ökologisches Firmenimage aufzubauen und das Vertrauen in die Problemlösungskraft von Unternehmen wieder herzustellen.

- Die Ressourcenknappheit und begrenzte Emissionsaufnahmekapazität der natürlichen Umwelt. Auf der betrieblichen Inputseite wirkt sich ein verminderter Energie- und Ressourcenverbrauch zugleich umweltschonend und kostensparend aus. Auf der betrieblichen Outputseite lassen sich durch eine Verringerung der Emissionen und Abfälle Entsorgungsgebühren und somit Kosten einsparen.

- Eine dezidierte Umweltgesetzgebung mit der Folge einer Veränderung oder Verschärfung der unternehmerischen Handlungs- und Haftungssituation.

Neben diesen betriebswirtschaftlichen werden auch ethische Begründungsansätze einer ökologischen Unternehmenspolitik genannt. $\mathrm{Zu}$ diesen gehören Argumente, die auf berechenbaren Kalkülen basieren und gesellschaftspolitische und ideele Faktoren berücksichtigen und dem Bereich der Unternehmensverantwortung bzw. der Unternehmensethik zuzurechnen sind. Der Bereich der Unternehmensethik umfaßt dabei „,... alle durch dialogische Verständigung mit den Betroffenen begründeten bzw. begründbaren materiellen und prozessualen Normen, die von einem Unternehmen zum Zwecke der Selbstbindung verbindlich im Kraft gesetzt werden, um die konfliktrelevanten Auswirkungen des Gewinnprinzips bei der Steuerung der konkreten Unternehmensaktivitäten zu begrenzen“.5 Die Unternehmensethik wird in diesen Begründungsansätzen als situatives Korrektiv angesehen, wenn bei der ausschließlichen Verfolgung des Gewinnstrebens ethisch bedenkliche ökologische Auswirkungen auftreten würden.

Durch zögerliche Reaktionen der Unternehmen auf die aktuellen umweltrelevanten Herausforderungen, oder durch gezielte Falschinformationen kann es in einer aufgeklärten Öffentlichkeit zu einem nur schwer wiedergutzumachenden Imageverlust für die betreffenden Unternehmen kommen. Dies wird sich langfristig negativ für die Absatzchancen und somit auf den ökonomischen Erfolg auswirken. Weiterhin vergeben sich Unternehmen mit einem negativen UmweltImage ein wichtiges Akquisitionspotential für qualifizierte Mitarbeiter und erschweren dem vorhandenen Mitarbeiterstamm das Verständnis für die Unternehmenspolitik, was sich negativ auf

\footnotetext{
${ }^{5}$ Vgl. Steinmann, H./Löhr, A. (1989), S. 10.
} 
die Arbeitsmotivation niederschlägt. Zusammenfassend läßt sich festhalten, daß neben ethischen Gründen vor allem der positive Beitrag zur Erhöhung der Wettbewerbsfähigkeit für die Ökologieorientierung eines Unternehmens spricht.

Allerdings besteht eine Zurückhaltung vieler Unternehmen bei der freiwilligen Ausrichtung des Unternehmensverhaltens an den ökologischen Erfordernissen. Die Versäumnisse der Unternehmen zum Umweltschutz können hauptsächlich auf drei Gründe zurückgeführt werden. Erstens werden vielfältige Konflikte zwischen ökologischen und ökonomischen Zielen gesehen, die durch die Internalisierung der ökologischen Kosten, z.B. in Form von Investitionen und Betriebskosten für umweltgerechte Prozeßtechnologien, entstehen. Zweitens werden die fehlenden staatlichen Anreize zur innovativen Begegnung von Umweltschutzproblemen und drittens mangelndes Wissen zur Lösung betrieblicher Umweltschutzprobleme als Gründe einer zögernden Umweltorientierung des Unternehmens angeführt. ${ }^{6}$

Betrachtet man im Rahmen der ökologisch verpflichteten Betriebswirtschaftslehre die im Kap 2.3 behandelten Ansätze, so läßt sich feststellen, daß bislang noch keine geschlossene, umfassende Konzeption vorliegt. ${ }^{7}$ Es liegen vielmehr eine große Anzahl von isolierten Bausteinen zu einzelnen betrieblichen Funktionen bzw. Bereichen vor, die den Anforderungen einer ganzheitlichen Ökologieverpflichtung noch nicht genügen. ${ }^{8}$ Uneinigkeit besteht insbesondere bezüglich der Frage, in welcher Form die Auseinandersetzung mit ökologischen Fragestellungen von Seiten der Betriebswirtschaftslehre geführt werden soll.

Nach Stitzel/Wank können ökologische Aspekte auf drei Arten in das Konzept einer strategischen Unternehmensführung integriert werden: ${ }^{9}$ Der erste, umfassende Ansatz besteht darin, - im Sinne einer Maximum-Strategie der Einbeziehung der Ökologie - eine eigenständigen ökologische Betriebswirtschaft als Teil-Disziplin der Wissenschaft „Ökologie“ zu konzipieren. In diesem Ansatz werden die betriebswirtschaftliche Überlegungen zum Umweltschutz auf den Werten bzw. Zielsystemen der Entscheidungsträger innerhalb des Unternehmens und den Anspruchsgruppen außerhalb des Unternehmens berücksichtigt. Hierbei wird die Unternehmensführung gleichzeitig durch ein Höchstmaß an Ökologieverpflichtung und langfristiger betriebswirtschaftlicher Rationalität ausgerichtet. Diese Konzepte werden mit dem Verweis auf die soziale und ethische Verantwortung der Unternehmensführung, d.h. Ökologie als Paradigma begründet.

\footnotetext{
${ }^{6}$ Vgl. Meffert, H./Bruhn, M./Schubert, F./Walther, T. (1986).

${ }^{7}$ Vgl. Stitzel, M./Wank, L. (1990), S. 106.

${ }^{8}$ Vgl. Steinle, C./Lawa, D./Schollenberg, A. (1993), S. 9.

${ }^{9}$ Vgl. Stitzel, M./Wank, L. (1990), S. $105 f f$.
} 
Die zweite Möglichkeit besteht in einer Integration ökologischer Aspekte in das klassischen Instrumentarium der strategischen Unternehmensführung. Dieser als „Minimum-Strategie“ verfolgte Ansatz vermittelt Unternehmen Entscheidungshilfen und Verfahrensregeln, um sicherzustellen, daß Aspekte zum Umweltschutz bei betrieblichen Entscheidungen als Chancen oder Risiken erkannt und in Planungskonzepte einbezogen werden z.B. durch umweltschutzorientierte Produktionsverfahren und Recycling-Maßnahmen oder Profilierung durch Marketingkonzepte.

Die dritte Möglichkeit besteht darin, betriebswirtschaftliche Aussagesysteme um ökologische Aspekte bzw. durch ökologische Fragestellungen zu ergänzen oder zu modifizieren, ohne die Aussagesysteme in ihrer Grundstruktur zu verändern. Ökologische Rahmenbedingungen werden dabei als eines von mehreren relevanten Umweltsegmenten explizit bei den konstitutiven, institutionellen sowie funktionellen Unternehmensentscheidungen berïcksichtigt und Instrumente der strategischen Unternehmensführung um ökologische Aspekte ergänzt. Diesem Ansatz, bei dem kein Paradigmenwechsel innerhalb der Betriebswirtschaftslehre notwendig ist, dürfen die meisten der im Rahmen der Betriebswirtschaftslehre entwickelten Konzepte zuzurechnen sein.

Eine Konzeption ökologisch verpflichteter Unternehmensführung bedarf nicht nur eines Ordnungsgerüsts auf der Ausführungsebene, das einer Klärung der sachlich relevanten Zusammenhänge dient, sie benötigt darüber hinaus auch gewisse Vorstellungen über die Führungsebene, darüber also, wie diese Zusammenhänge durch die Führung zu beeinflussen sind. Aufgrund der Komplexität und praktischen Bedeutung ökologischer Herausforderungen für die Unternehmensführung bedarf es einer integrierten Gesamtkonzeption, die Führungsentscheide auf unterschiedlichen Handlungsebenen erfordert.

Ohne eine Darstellung bestehender Theorien und Ansätze der Unternehmensführung zu führen, ist festzuhalten: ${ }^{10}$ Der Bedarf an Führung ist im Handeln der Organisationsmitglieder begründet, welche eine Koordination der angestrebten Ziele verlangt. Im Unternehmen bezieht sich diese Koordination nicht nur auf Personen, sondern zusätzlich auf im Wertschöpfungsprozeß eingesetzte Sachmittel und auch auf immaterielle Güter, wie z.B. Information, Werte etc. Geht man weiter zu den drei Grundfunktionen der Unternehmensführung bzw. des Managements, nämlich:

- Gestaltung (des institutionellen Rahmens, der es ermöglicht, eine handlungsfähige Ganzheit über ihre Zweckerfüllung überlebens- und entwicklungsfähig zu erhalten),

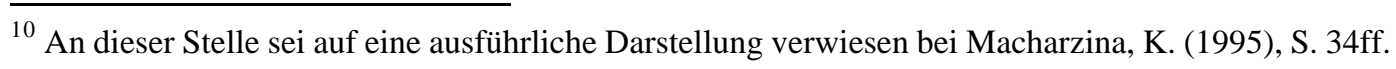


- Lenkung (Bestimmung von Zielen; Festlegen, Auslösen und Kontrollieren zielgerichteter Aktivitäten des Systems und seine Elemente) und

- Entwicklung (als Ergebnis von Gestaltungs- und Lenkungsprozessen bzw. als eigenständig Evolution begründet im Erlernen von Wissen, Können und Einstellungen),

so bietet sich für die Erarbeitung eines integrierten Konzeptes ökologisch verpflichteter Unternehmensführung das „St. Galler-Management-Modell“ (Konzept des integrierten Managements) als Ansatzpunkt für einen tragfähigen Bezugsrahmen an (vgl. Abb. 41).



Abb. 4.1: Integriertes Konzept einer ökologisch verpflichteten Unternehmensführung im Rahmen des St. Galler-Management-Modells (Quelle: Dyllick, T./Hummel, J. (1996), S. 17) 
Dieser Ansatz integriert unter Einbeziehung einer entscheidungs- und systemorientierten Betrachtungsweise verschiedene Betrachtungsebenen und Dimensionen, zwischen denen vielfältige Vor- und Rückkopplungsprozesse ablaufen, und in denen Bausteine einer theoretischen Konzeption für eine ökologisch verpflichtete Unternehmensführung entwickelt werden. ${ }^{11}$

Im ökologischen Zusammenhang sind gegenüber den herkömmlichen Konzepten vier Handlungsebenen $\mathrm{zu}$ unterscheiden, wobei auf jeder Ebene eine andere Zielsetzung im Vordergrund steht. Danach werden die Managementaufgaben, die eine ökologisch verantwortungsbewußte Unternehmensführung mit sich bringt, auf verschiedenen Handlungsebenen des Management zugeordnet, und zwar der ordnungspolitischen, der unternehmenspolitischen, der strategischen und der operativen Ebene. ${ }^{12}$

Die Ebene der Unternehmenspolitik beschäftigt sich mit den generellen Zielen des Unternehmens, mit Prinzipien, Normen und Spielregeln, die darauf ausgerichtet sind, die Lebens- und Entwicklungsfähigkeit des Unternehmens sicherzustellen. ${ }^{13}$ Auf unternehmenpolitischer Ebene steht die Sicherung von Akzeptanz und Glaubwürdigkeit bei den relevanten Anspruchsgruppen des Unternehmens im Vordergrund. Somit umfaßt die Ebene des normativen Managements den Aufbau jener unternehmerischen Erfolgsvoraussetzungen, die nicht unmittelbar auf dem Markt, sondern in gutem Verhältnis zu allen Bezugsgruppen des Unternehmens liegen.

Als wichtiger Faktor der ökologiebezogenen Steuerung des Unternehmens wird zunehmend die Unternehmenskultur angesehen. ${ }^{14}$ Eine ökologieorientierte Unternehmenskultur ist eine wesent-

11 Vgl. Ulrich, H. (1984); Bleicher, K. (1996), S. 70ff.; Dyllick, T./Hummel, J. (1996), S. 13ff.; Meffert, H./Kirchgeorg, M. (1998), S. 72 ff. Die Synthese und wesentliche Merkmale der Konzepte des strategischen und integrierten Managements lauten kurz zusammengefaßt (vgl. hierzu Kirsch, W./Maaßen, H. (1989); Kirsch, W./ Roventa, P. (Hrsg.) (1983); Kirsch, W./Trux, W. (1981); Bleicher, K. (1996); Ulrich, H. (1984); Dyllick, T. (1988)):

- Langfristige, strategische Ausrichtung unter Markt- und Wettbewerbsaspekten, verbunden mit dem Versuch, antizipative Entwicklungen zu erfassen, d.h. sich an Chancen zu orientieren.

- Prozeßorientierte und vernetzt ganzheitliche Betrachtungsweise, wobei die Analyse von Zusammenhängen und Wechselbeziehungen im Vordergrund steht.

- Grundlage sind lernfähige bzw. evolutionäre Konzepte, die die Unternehmensentwicklung als dynamischen Prozeß begreifen.

- Innovative Sicherstellung der relativen Verbesserung der Umweltverträglichkeit unter einer ökologischen und gesellschaftlichen Verantwortung bzw. Führungsphilosophie, d.h. konsequente Orientierung an den Bedürfnissen der Austauschpartner.

- Bezugnahme auf interdisziplinäre Erkenntnisse.

${ }^{12}$ Vgl. z.B. Ulrich, P. (1991), S. 13ff.; Bleicher, K. (1996), S. 70ff.; Stähler, C. (1991), S. 62ff.

${ }^{13}$ Lebens- und Entwicklungsfähigkeit sind Erscheinungen, die ein Unternehmen als Ganzes betreffen. Die Entwicklungsfähigkeit umschließt dabei eine qualifizierte Veränderung in Richtung eines positiven, sinnvollen Wandels. Für den Ökologiebereich bedeutet dies die Konkretisierung unternehmerischer Visionen, die Gestaltung von Unternehmensverfassung und Kultur sowie im Rahmen der Legitimität die Nutzenstiftung für Bezugsgruppen. Vgl. Bleicher, K. (1996), S. $73 \mathrm{f}$.

14 Vgl. Hammerl, B. M. (1994); Meffert, H./Kirchgeorg, M. (1998), S. 420ff.; Hopfenbeck, W. (1991), S. 128ff. und (1998), S. 597ff.; Schanz, G. (1994), S. 207ff. und (1999), S. $27 \mathrm{ff.}$ 
liche Motivationsgrundlage für das umweltbewußte Verhalten der Mitarbeiter. Außerdem bietet sie einen Orientierungsrahmen in Entscheidungsprozessen und dient dem Denken in funktionsübergreifenden Zusammenhängen. In diesem Sinne stellt die Förderung einer ökologisch bewußten Unternehmenskultur eine wesentliche Aufgabe im Rahmen einer ökologisch verpflichteten Unternehmensführung dar.

Zur Konkretisierung der Unternehmenskultur in Form wünschenswerter Zustände dienen Unternehmensziele. In der Sichtweise der entscheidungsorientierten Betriebswirtschaftslehre erfüllen Ziele im Rahmen eines Unternehmens die Funktion, die Tätigkeiten und Prozesse in einer gewissen Weise zu steuern. ${ }^{15}$ Damit sind die Unternehmensziele die eigentlichen Bestimmungsgrößen des Unternehmensverhaltens, die durch die Formulierung zielentsprechender Unternehmensstrategien und deren Umsetzung in konkrete Maßnahmen in einem Entscheidungs- oder Problemlösungsprozeß anzustreben sind.

Die strategische Ebene umfaßt jene Führungsaufgaben, welche den Aufbau und die Pflege ökologisch hochwertiger Markterfolgspotentiale (Aufbau strategischer Ökologiepotentiale) zum Ziel haben. Diese Marktpotentiale stellen sicher, daß das Unternehmen auch in Zukunft noch ökologisch effizient sein wird. Solche strategischen Ökologiepotentiale finden sich zum einen in der Verminderung ökologischer Risikopotentiale, zum anderen im Aufbau ökologischer Erfolgs- und Nutzenpotentiale. ${ }^{16}$ Die Basis dafür bilden die auf der unternehmenspolitischen Ebene hergestellten Verständigungs- und Glaubwürdigkeitspotentiale. Auf deren Basis wird es möglich, „,.. die postulierten strategischen Innovationen in der Produkt/Markt-Konzeption des Unternehmens und bezüglich ihrer Produktionsverfahren längerfristig und stufenweise $\mathrm{zu}$ planen und zielstrebig zu verwirklichen.“" ${ }^{17}$

Zur operativen Ebene zählen die Managementaufgaben, die mit der kurzfristigen Erfolgsrealisierung innerhalb einer gegebenen Geschäftsstrategie zusammenhängen. Auf dieser Ebene wird der Umweltschutz als Kostenfaktor bzw. als Faktor der Kostensenkung relevant. Dabei zielt die Leitidee der ökologischen Rationalisierung darauf $\mathrm{ab}$, ,... anlog $\mathrm{zu}$ den bisherigen Rationalisierungsanstrengungen in bezug auf die Effizienz des Faktors ,Arbeit‘ nunmehr auch die Effizienz des Einsatzes natürlicher Ressourcen systematisch und stetig zu steigern, auf der Inputseite (Energie- und Stoffeinsatz) ebenso wie auf der Outputseite (Wiederverwendung von Abfall, Emis-

\footnotetext{
${ }^{15}$ Vgl. Kreikebaum, H. (1989), S. 46ff.; Heinen, E. (1985), S. $26 \mathrm{ff}$.

${ }^{16}$ Vgl. Dyllick, T. (1991); Bundesumweltministerium/Umweltbundesamt (1995), S. $10 \mathrm{ff}$.

${ }^{17}$ Vgl. Ulrich, P. (1991), S. 16.
} 
sionsminderung)““ ${ }^{18}$ Auf operativer Ebene steht dabei als Zielsetzung die Sicherung einer möglichst umwelt- und ressourcenschonenden Leistungserstellung und -verwertung im Vordergrund.

Darüber hinaus ist im ökologischen Kontext die ordnungspolitische Ebene von besonderer Bedeutung. Sie umfaßt die Verantwortung einer ökologieorientierten Unternehmensführung für die ökologische Weiterentwicklung der Rahmenbedingungen der Marktwirtschaft. ${ }^{19}$ Die politischen Bemühungen hin zu einer öko-sozialen Marktwirtschaft, welche den Spielraum für ein ökologisch verträgliches Handeln erweitert, sollten nach Möglichkeit unterstützt werden. Dies steht im Gegensatz zur weitverbreiteten reaktiven Widerstandshaltung von Unternehmen und Unternehmensverbänden gegenüber umweltpolitischen Innovationen. Es kann kaum bestritten werden, daß zwischen dem ökologisch verpflichteten Management auf Unternehmensebene und dem wirtschaftlichen Ordnungsrahmen auf nationaler und internationaler Ebene ein enger Zusammenhang besteht. ${ }^{20}$ So wie ein ökologisch falsch gesetzter Ordnungsrahmen Unternehmen bisher dazu verleitet hat, Erfolg auf Kosten der Natur zu suchen, so sind die heutigen politischen Bemühungen dadurch gekennzeichnet, die soziale Marktwirtschaft zur öko-sozialen Marktwirtschaft weiterzuentwickeln. Es gilt, daß ein ökologisch richtig gesetzter Rahmen den Spielraum erweitert, innerhalb dessen die Unternehmen sowohl ökonomisch ,erträglich“ als auch ökologisch „verträglich“ handeln können. ${ }^{21}$ Eine ökologisch verpflichtete Unternehmensführung, die diesen Namen verdient, umfaßt deshalb auch eine entsprechende Mitverantwortung für die ökologische Weiterentwicklung der Rahmenbedingungen der Marktwirtschaft.

Neben diesen Handlungsebenen sind für einen umfassenden Bezugsrahmen einer ökologisch verpflichteten Unternehmensführung noch weitere Managementbereiche $\mathrm{zu}$ berücksichtigen. Die Berücksichtigung des Umweltschutzes im Zielsystem des Unternehmens und seine Einbeziehung in die strategische Ausrichtung ist eine (zwingend) notwendige, aber noch längst keine hinreichende Voraussetzung, um der ökologischen Herausforderung gerecht zu werden. Vielmehr muß auch darüber nachgedacht werden, mit welchen Maßnahmen die Umsetzung in praktisches Handeln $\mathrm{zu}$ erreichen ist. Wenn dabei struktuelle Regelungen ins Spiel kommen, so deshalb, weil derartige Arrangements Mittel der Verhaltenssteuerung darstellen. ${ }^{22}$ Sie sind damit auch Mittel einer ökologisch relevanten Ausrichtung des Denkens und Tuns im Unternehmen. Eine weitere ökologisch relevante Managementaufgabe ist damit die Gestaltung der Organisation des Umweltschutzes. Es geht dabei um die geplante horizontale und vertikale Implementation ökolo-

\footnotetext{
${ }^{18}$ Vgl. Ulrich, P. (1991), S. 17.

${ }^{19}$ Vgl. Dyllick, T. (1992), S. 406.

${ }^{20}$ Vgl. Dyllick, T. (1992), S. 198ff.

${ }^{21}$ Vgl. Ulrich, P. (1991), S. 9 ff.
} 
gisch verpflichteter Unternehmensführung in das arbeitsteilig strukturierte Organisationssystem des Unternehmens. ${ }^{23}$

Zur Wahrung des Verhaltensspielraumes des Managements ist es in einer dynamischen und turbulenten Unternehmensumwelt erforderlich, die Umweltfaktoren $\mathrm{zu}$ analysieren und entscheidungsrelevante Informationen für sämtliche Managementbereiche bereitzustellen. Die Gestaltung eines effektiven Umweltinformationssystem stellt somit eine wichtige Managementaufgabe im Rahmen einer ökologisch verpflichteten Unternehmensführung dar. Auf jeder Handlungsebene bedarf es nicht nur entsprechender Entscheide und Handlungen, sondern es bedarf auch eines angemessene Führungsinstrumentariums zu ihrer Unterstützung. Verlangt sind mit anderen Worten ökologische Führungssysteme, in Gestalt von Informations-, Entscheidungs- und Controllingssystemen. Hier liegt mittlerweile auch ein reichhaltiges Instrumentarium vor, das normative, strategische und operative Elemente aufweist. ${ }^{24}$

Im folgenden sollen die einzelnen Bereiche dieses integrierenden Bezugsrahmens ausführlich dargestellt werden, die einzelne Ansätze trotz aller Unterschiede zu einer geschlossenen Konzeption mit wechselseitiger Verknüpfbarkeit verbinden.

Bevor auf die integrierte Gesamtkonzeption einer ökologisch verpflichteten Unternehmensführung eingegangen wird, soll zunächst als Ausgangspunkt die ökologische Situationsanalyse dargestellt werden. Sie soll vor allem als Informationsgrundlage für die integrierte Konzeption einer ökologisch verpflichteten Unternehmensführung dienen, denn für die inhaltliche Ausgestaltung einer ökologisch verpflichteten Unternehmensführung bedarf es einer Ist-Zustandsanalyse der internen und externen Einflußfaktoren zur Ermittlung und Beurteilung der strategischen Ausgangslage. Das Ergebnis zeigt dem Unternehmen den notwendigen Handlungsbedarf und mögliche Verbesserungspotentiale. Für die Ermittlung entsprechender Informationen bieten sich an: ${ }^{25}$ Analyse und Prognose der Unternehmensumwelt (Ermittlung von Chancen und Risiken) sowie Unternehmensanalyse (Ermittlung von Stärken und Schwächen).

\footnotetext{
$\begin{gathered}\text { Ökologische Situationsanalyse } \\ \Rightarrow \text { Identifikation strategischer Schlüsselfaktoren und Bestimmung der ökologischen Strategieposition }\end{gathered}$
$\begin{array}{ll}\text { Ökologische Chancen und Risiken in der Umwelt (externe Faktoren) } \\ \text { Ökologische Stärken und Schwächen im Unternehmen (interne Faktoren) }\end{array}$
${ }^{22} \mathrm{Vgl.} \mathrm{Schanz,} \mathrm{G.} \mathrm{(1994),} \mathrm{S.} \mathrm{68ff.}$
${ }^{24} \mathrm{Vgl.} \mathrm{Meffert,} \mathrm{H./Kirchgeorg,} \mathrm{M.} \mathrm{(1998),} \mathrm{S.} \mathrm{397ff.}$
${ }^{25}$ gl. Dyllick, T. (1992), S. 407ff.
Hopl. Ulrich, H. (1987), S. 51ff.; Hinterhuber, H. H. (1992), S. 73ff.; Meffert, H./Kirchgeorg, M. (1998), S. 81ff.;
} 


\begin{tabular}{|c|}
\hline $\begin{array}{l}\text { Ökologisch verpflichtete Unternehmenspolitik } \\
\Rightarrow \text { Aufbau von dialogischen Verständigungs- und Glaubwürdigkeitspotentialen bei } \\
\text { allen Stakeholdern des Unternehmens in bezug auf die Ökologieproblematik }\end{array}$ \\
\hline $\begin{array}{l}\text { - Umweltschutzbezogene Werte (Vision/Philosophie, Unternehmensethik) } \\
\text { - Ökologisch verpflichtete Unternehmenskultur } \\
\text { - Ökologisch verpflichtete Unternehmensziele }\end{array}$ \\
\hline
\end{tabular}

$\rightarrow$\begin{tabular}{ll|}
\hline \multicolumn{1}{c|}{ Ökologisch verpflichtete Unternehmensstrategie } \\
$\Rightarrow$ Aufbau ökologischer strategischer Nutzen- und Markterfolgspotentiale \\
$\qquad \begin{array}{l}\text { Ökologiebezogene Basis strategien } \\
\text { Ökologiebezogene Unternehmensstrategien (Kreislauf-, Wettbewerbs-, Internationalisierungs- und } \\
\text { Risikostrategien) }\end{array}$ \\
$\Downarrow \downarrow$
\end{tabular}

$\rightarrow$\begin{tabular}{l} 
Operative Umsetzung des Umweltschutzes in den funktionellen Bereichen \\
$\Rightarrow$ Ökologische Rationalisierung (Senkung von ökologischen und betriebswirtschaftlichen Kosten) \\
\hline $\begin{array}{l}\text { Unternehmensführung, Forschung und (Produkt)Entwicklung, Beschaffung (Materialbeschaffung), } \\
\text { Produktion, Marketing/Vertrieb (Verkauf)/Kundendienst, Organisation, Logistik, Controlling, Finanzen, } \\
\text { Recycling/Entsorgung, Personal }\end{array}$ \\
$\qquad \Downarrow$
\end{tabular}

\begin{tabular}{|c|}
\hline Durchsetzung und Kontrolle ökologisch verpflichteten Wirtschaftens im Unternehmen \\
\hline $\begin{array}{l}\text { - Umweltinformationssystem und Öko-Controlling } \\
\text { - Umweltschutzorganisation }\end{array}$ \\
\hline
\end{tabular}

Abb. 4.2: Gesamtkonzeption einer ökologisch verpflichteten Unternehmensführung

(Quelle: eigene Darstellung)

\section{2 Ökologische Situationsanalyse als Ausgangspunkt}

Für die Gestaltung einer ökologisch verpflichteten Unternehmensführung bedarf es zunächst individuell $\mathrm{zu}$ erarbeitender Checklisten, um die unternehmensspezifischen Schlüsselprobleme zu identifizieren und nach Lösungswegen $\mathrm{zu}$ suchen. Hilfestellung bietet hier das Konzept der strategischen Unternehmensführung mit einem Instrumentarium zur Bestimmung der strategischen Ausgangslage. Analog zum Strategieinstrumentarium sind insbesondere die Frühaufklärungssysteme um ein ökologieorientiertes Indikatorensystem zu erweitern. ${ }^{26}$

Die Analyse bezieht sich auf zwei Felder. Über eine Umweltanalyse zur Ermittlung von Chancen und Risiken, eine Unternehmensanalyse zur Ermittlung von Stärken und Schwächen können die notwendigen Informationsgrundlagen für eine Situationsanalyse geschaffen werden. Die klassische Umwelt- und Unternehmensanalyse ${ }^{27}$ in ihrer Ausprägung als Checkliste bzw. Fragenkata$\log$ ist um einen ökologieorientierten Kriterienkatalog zu ergänzen. Die zwei Elemente der Situationsanalyse sollten im Zeitablauf nicht linear abgearbeitet werden, vielmehr sind ihre vernetzten

\footnotetext{
${ }^{26}$ Vgl. Krystek, U./Behrendt, J. (1991), S. 17ff.

${ }^{27}$ Vgl. z. B. Hinterhuber, H. H. (1992), S. 76ff. und 83ff.
} 
und bedingenden Zusammenhänge zu berücksichtigen, insbesondere bezogen auf den Zusammenhang von Stärken und Chancen bzw. Schwächen und Risiken.

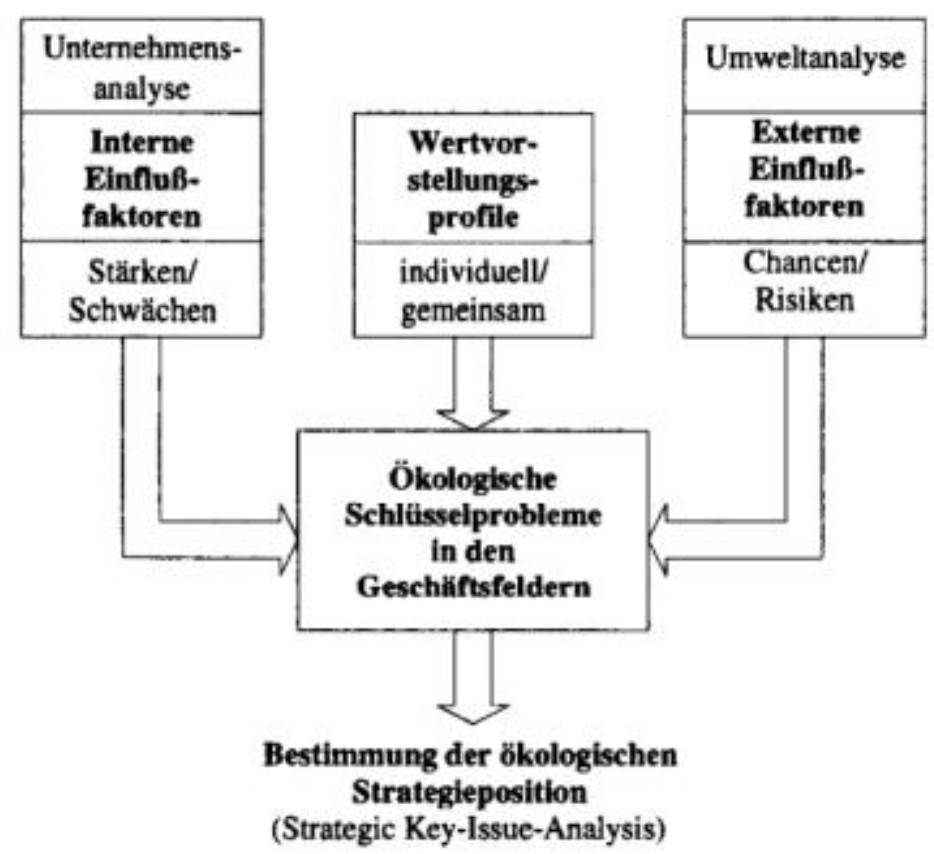

Abb. 4.3: Ökologische Situationsanalyse (Quelle: Hopfenbeck, W. (1998), S. 778)

Mit den Ergebnissen einer ökologischen Situationsanalyse sollen ökologische Schlüsselprobleme in den Geschäftsfeldern identifiziert bzw. festgelegt werden, wieweit das Unternehmen in der Lage ist, mit seinem Stärken-Schwächen-Profil den Chancen und Risiken der neuen ökologischen Dimension bzw. Herausforderung entgegenzutreten. Auf der Basis dieser ökologischen Situationsanalyse können eine entsprechende ökologisch verpflichtete Unternehmenspolitik, die Bildung und Formulierung von Umweltzielen und die daraus abzuleitenden Strategien erarbeitet werden. $^{28}$

Umweltanalyse (Ermittlung von Chancen und Risiken): Für das Unternehmen als offenes, mit der Umwelt und anderen Wirtschaftssubjekten (Konkurrenten, Lieferanten, Kunden, Kapitalgebern, Staat oder Arbeitnehmern) in Austauschbeziehungen stehendes System ist das laufende Erkennen der Umfeld- bzw. Umweltentwicklung und das rechtzeitige Einstellen darauf (überlebens-) notwendig. Diese Entwicklungen müssen deshalb systematisch in den Planungs- und Steuerungsprozeß einbezogen werden, um auf Dauer erfolgreich zu bestehen. Das Instrumentari-

\footnotetext{
${ }^{28}$ In diesem Stadium sind die zu beschaffenden und zu verarbeitenden Daten relativ grober „Natur“. Das heißt, daß es sich bei den für die Umwelt- und Unternehmensanalyse notwendigen Informationen oft um „weiche“ Daten handelt, also um Daten, die mit Unsicherheiten behaftet sind und die es subjektiv zu interpretieren und zu bewerten gilt, und nicht um objektive, „harte Fakten“. An dieser Stelle sei zudem auf Besonderheiten von Informationen die öko-
} 
um der Umweltanalyse (wie auch die Unternehmensanalyse) ist unternehmensspezifisch zu erarbeiten. Ein allgemeingültiges, strukturiertes System der Informationsgewinnung, verarbeitung und -bewertung existiert nicht.

Bei der Durchführung der Umweltanalyse sind z.B. folgende Kriterien oder Indikatoren zu beachten und eventuell unternehmensspezifisch zu ergänzen: ${ }^{29}$

\section{Ökologische Umwelt:}

- Zerstörung ökologischer Systeme (global, kontinental, national, regional, lokal)

- Beeinträchtigung der Grundfunktionen der ökologischen Umwelt (Versorgungs-, Träger-, Regenerierungsfunktion)

- Art, Intensität und Ausmaß von Umweltbelastungen auf unbelebte Natur (Boden, Wasser, Luft) und belebte Natur (Mensch, Flora, Fauna)

- Ressourcensituation: Geologische Situation (Fundstätten und Konzentrationen), Ressourcenreichweite (in Jahren), Ressourcenverfügbarkeit und -knappheit (qualitative Aspekte, z.B. Aufwand der Rohstoffgewinnung), Ressourcenabhängigkeit (auf internationalen und nationalen Märkten)

- Energiesituation: Energieintensität und -potential (z.B. Heizwert), Regenerative oder nichtregenerative Energieressourcen, Umweltbelastungsgrad der Energieerzeugung und des Energieverbrauchs

- Langfristige Trends in der naturwissenschaftlichen Grundlagenforschung

\section{Ökonomische Umwelt:}

- Umfang und Struktur (Art/Höhe) von Umweltschutzinvestitionen

- Marktqualität hinsichtlich umweltverträglicher Produkte: Schrumpfungs- und Sättigungserscheinungen, Markteintrittsbarrieren, Wettbewerbsdruck, Nachfrageentwicklung nach umweltverträglichen Produkten und Verfahren in allgemeinen Trends, Abnehmerpotential und -volumen. Umweltbewußtsein und -handeln marktbezogener unternehmensexterner Anspruchsgruppen, Beschaffungs- und Kaufverhalten von Kunden (Industrie, Groß- und Einzelhandel, Konsument etc.), Angebotsverhalten von direkten und indirekten Lieferanten, Konkurrenzverhalten auf den Absatz- und Beschaffungsmärkten, Fremdkapitalgeber, sonstige Dienstleister des Unternehmens (Berater, Subunternehmer), Kooperationspartner

logische Umwelt betreffend hingewiesen: hohe Dynamik und Unsicherheit, interdisziplinäre Erkenntnisse, schwierige bzw. unmögliche Quantifizierbarkeit. Vgl. Stahlmann, V. (1993), S. 101f. 


\section{Technologische Umwelt:}

- Umweltschutztechnologie (Entwicklung, Stand, Komplexität)

- Wirkungsbereiche von Umweltschutztechnologien (Schadstoffe/Emissionen, Boden, Wasser/Abwasser, Luft, Abfall, Recycling)

- Neue Entwicklungen/Trends bei Rohstoffen, Werkstoffen, Energieträgern

- Umweltschutzwirkungen der Technologie direkt oder indirekt (End-of-pipe-Technologie, integrierte Technologie, Recyclingtechnologie, Substitutionstechnologie, Umweltinformationstechnologie, Meß- und Regeltechnik)

- Wirkungsgrad der Umweltschutztechnologie

- Produkt- und/oder Prozeßtechnologie/-innovation

- Kosten der Umweltschutztechnologie (Entwicklungs-, Anschaffungs-, Betriebs-, Lern- und Umstellungskosten)

- Trends in Wissenschaft und Forschung

\section{Rechtlich-politische Umwelt:}

- Globale politische Entwicklungstendenzen (Ost-West, Nord-Süd, Marktstellung der Rohstoffproduzenten, Gefahr lokaler oder internationaler Konflikte)

- Umweltpolitische Rahmenbedingungen (Finanz- und Wirtschaftspolitik, Technologie- und Innovationspolitik)

- Verhalten staatlicher Organe: Parteipolitische Entwicklungen und Positionen, Behörden (z.B. informelle Einflußnahme über Appelle und Bereitstellung von Umweltinformationen, Umweltzeichenvergabe), Umweltgesetzgebung, Umwelthaftung, Gesetze in den Bereichen Luft, Lärm, Gewässer, Abfall, Produkte etc.

\section{Sozio-kulturelle Umwelt:}

- Bevölkerungsentwicklung in relevanten Ländern

- Änderung grundlegender Wertstrukturen

- Informationsstand in der Bevölkerung hinsichtlich ökologischer Fragestellungen

- Umweltbewußtsein und -handeln nicht-markbezogener unternehmensextener Anspruchsgruppen: Gesellschaft (ökologisch negativ Betroffene, Medien, Bürgerinitiativen, Kirche,

${ }^{29}$ Vgl. Hopfenbeck, W. (1998), S. 779ff.; Meffert, H./Kirchgeorg, M. (1998), S. 81ff. 
Bildungswesen, kulturelle Institutionen, Bevölkerung generell, Verbraucherverbände, Umweltverbäde), zukünftige Generation, Staat (Bereiche Legislative, Exekutive, Jurisdiktion)

Zusätzlich zur groben Umweltanalyse ist die Analyse der ökonomischen Umwelt über eine Branchenanalyse (Analyse, Bewertung und Prognose der Gesamtbranche und von Teilbranchen) und Konkurrenzanalyse (Analyse, Bewertung und Prognose der Aktivitäten der Wettbewerber) durchzuführen. ${ }^{30}$ Folgende Bereiche bezogen auf ökologische Aspekte sind hierbei zu analysieren und zu prognostizieren: ${ }^{31}$

- Strategien, die die Konkurrenten mit welchem Erfolg verfolgen

- Ökologische Wertvorstellungen und Zielsetzungen der Konkurrenten

- Mögliche zukünftige Strategien der Konkurrenten und daraus resultierende Chancen und Risiken für das Unternehmen

- Prämissen, auf denen die voraussichtlichen Strategien der Konkurrenten beruhen

- Stärken und Chancen der Konkurrenten

- Schwächen und Risiken der/für die Konkurrenten als Ansatzpunkte eigener Offensivstrategien.

Diese Analyse muß Aussagen vermitteln über die Wahrscheinlichkeit und das Ausmaß der Reaktion auf die ökologische Marketingkonzeption sowie über die Fähigkeiten des Unternehmens, sich gegenüber den Wettbewerbskräften abzuschirmen und Reaktionen der Konkurrenten wirksam zu begegnen.

Unternehmensanalyse (Ermittlung von Stärken und Schwächen): Ausgehend von der Ermittlung externer Einflußgrößen (Chancen/Risiken-Analyse) sind im Rahmen einer Unternehmensanalyse Stärken und Schwächen zur Begegnung der ökologischen Herausforderungen zu ermitteln. Zweck der Unternehmensanalyse ist es herauszufinden, was das Unternehmen aufgrund spezifischer Stärken und Schwächen im Hinblick auf qualifizierte Konkurrenten tun kann.

Folgende Aufgaben können durch die gewonnenen Informationen der Unternehmensanalyse erfüllt werden: ${ }^{32}$

\footnotetext{
${ }^{30}$ Vgl. Hinterhuber, H. H. (1992), S. 80ff. und 138ff.; Macharzina, K. (1995), S. $251 \mathrm{ff.}$

${ }^{31}$ Vgl. Hopfenbeck, W. (1998), S. 781.
} 
- Erkennen von eigenen Stärken, die über den Weg bestehender und/oder neuer Strategien aufzubauen oder auszunutzen sind

- Erkennen von eigenen Schwächen, die über den Weg bestehender und/oder neuer Strategien zu vermeiden, zu umgehen oder zumindest zu minimieren sind

- Erkennen strategischer ökologischer Schlüsselprobleme

- Erkennen der Synergiepotentiale, die von neuen Strategien auszunützen sind

- Erkennen der eigenen Mittel

- Beurteilung der heutigen Situation hinsichtlich der rentabilitätsbestimmenden Faktoren

In Abhängigkeit der spezifischen Unternehmenssituation lassen sich als interne Schlüsselfaktoren insbesondere folgende Faktoren hervorheben: ${ }^{33}$

- Die Aufgeschlossenheit und Flexibilität der Unternehmensleitung gegenüber ökologischen Problemen,

- Die Höhe der zur Verfügung stehenden finanziellen Mittel für umweltschutzbezogene Investitions- und Betriebskosten (z.B. zur Diversifizierung im Umweltschutzmarkt, zur Entwicklung umweltfreundlicher Produkte, zur Einrichtung von Recyclingcentern etc.),

- Die Charakteristik und Nähe des Leistungsprogramms der Unternehmen zu Umweltschutzmärkten (Nutzung von Synergien),

- Das technische Know-how des Unternehmens,

- Das Vorhandensein von Instrumenten ökologisch verpflichteter Unternehmenspolitik als Planungshilfe (ökologische Buchhaltung, Stoff- und Energiebilanzen, Umweltverträglichkeitsprüfungen, Technologiefolgenabschätzungen, Produktlinienanalyse/Checklisten zur Entwicklung umweltfreundlicher Produkte und Verfahren, Ökobilanzen, MarketingAssessment),

- Die Exponiertheit oder Erscheinung des Unternehmens in der Öffentlichkeit.

\footnotetext{
${ }^{32}$ Vgl. Hopfenbeck, W. (1998), S. 779.
}

${ }^{33}$ Vgl. Hopfenbeck, W. (1998), S. 779. 
Im Anschluß an die Umweltanalyse, in der über Kriterien und Indikatoren die bestehende Situation und mögliche Entwicklungen erarbeitet wurden, sind diese Ergebnisse mit den unternehmensspezifischen Gegebenheiten (Stärken und Schwächen) zu verknüpfen. Aus dieser Verknüpfung sind Entwicklungsmöglichkeiten (Chancen) und Bedrohungen (Risiken) abzuleiten (vgl. Abb. 4.4).

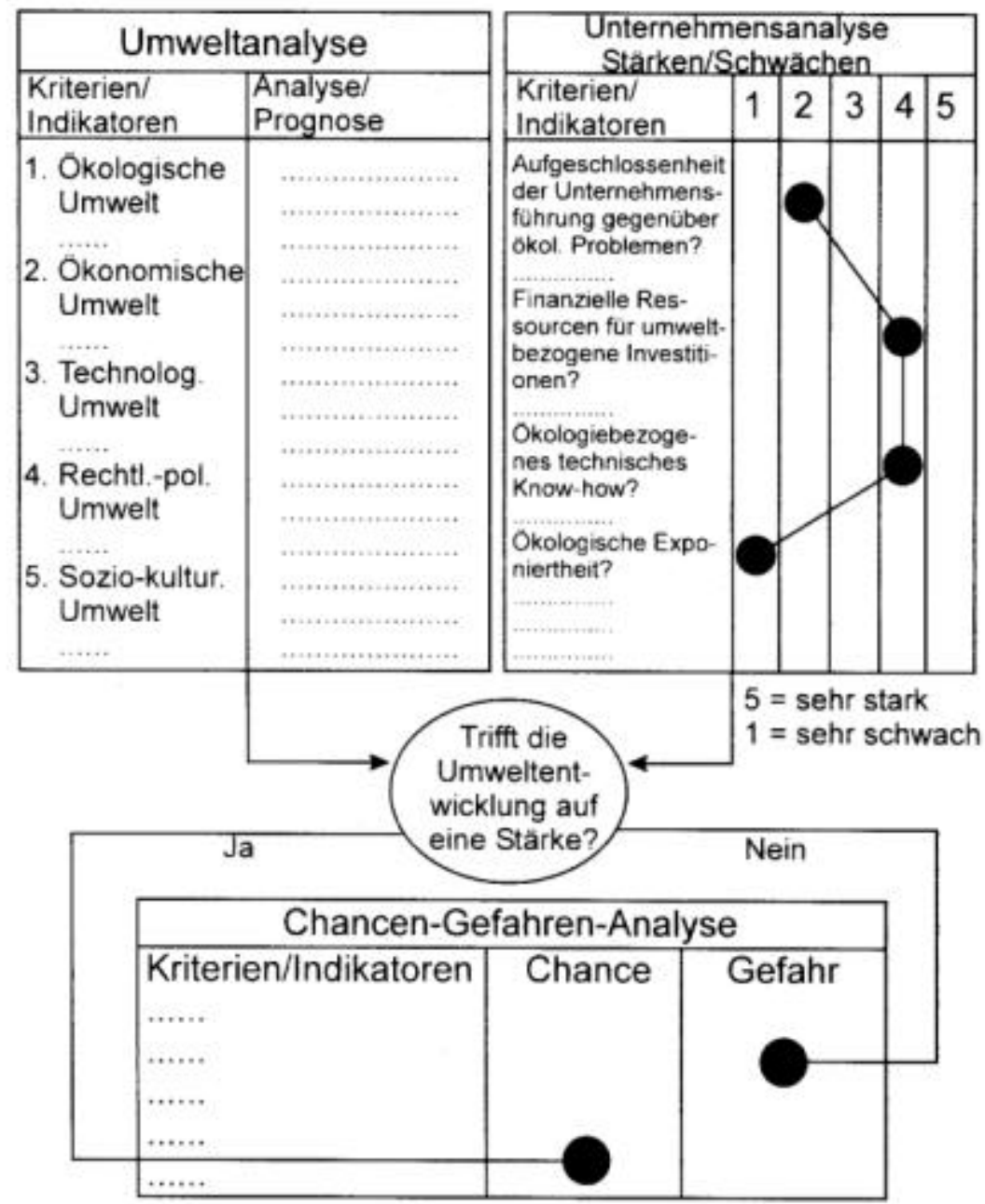

Abb. 4.4: Chancen/Gefahren-Analyse (Quelle: Macharzina, K. (1995), S. 256)

Die beide Analysen ermöglichen die Bestimmung der ökologischen Strategieposition eines Unternehmens und eine konsequente Ausrichtung der Strategie auf die Lösung der Schlüsselprobleme sowie eine Bestimmung und Bewertung der „kritischen“ Faktoren in der strategischen Ökobilanz (z.B. mangelnde Übertragbarkeit von vorhandenem technologischen Know-how auf Umweltschutzmärkte, fehlende Sensibilität der Führungskräfte, negative Ausstrahlungseffekte eines Ökoproduktes auf das Restsortiment u.ä.). ${ }^{34}$

\footnotetext{
$\overline{{ }^{34} \text { Vgl. Hopfenbeck, W. (1998), S. } 782 .}$
} 


\section{3 Ökologisch verpflichtete Unternehmenspolitik}

Die ökologisch verpflichtete Unternehmenspolitik kann als Inbegriff all jener Maximen, d.h. die Gesamtheit der übergeordneten Rahmenentscheide (Unternehmensgrundsätze, Meta-Ziele, Verfahrensregeln etc.) aufgefaßt werden, welche die ökologisch relevanten Verhaltensfelder des Unternehmens gegenüber Interessenten und Betroffenen einschließlich der natürlichen Umwelt festlegen. ${ }^{35}$ Es handelt sich dabei um Grundsatzentscheidungen der obersten Führungsebene, welche die generelle Richtung der beabsichtigen Unternehmensentwicklung festlegen. In der Unternehmenspolitik manifestiert sich damit die Verpflichtung zum Umweltschutz als Grundsatzentscheidung der oberste Führungsspitze. Sie stellt deshalb den Ausgangspunkt und die wesentlich notwendige - allerdings nicht hinreichende - Bedingung für die Implementierung einer ökologisch verpflichteten Unternehmensführung dar. ${ }^{36}$ Der ökologisch-unternehmenspolitische Rahmen stellt daher in diesem integrierenden Gesamtkonzept den übergeordneten Bereich dar, der die nachgelagerten Ebenen (Strategien und operative Bereiche, Organisation und Information/Controlling) wesentlich beeinflußt.

Die Ebene der Unternehmenspolitik bzw. des normativen Managements umfaßt den Aufbau jener unternehmerischen Erfolgsvoraussetzungen, die nicht unmittelbar auf dem Markt, sondern im guten Verhältnis zu allen Bezugsgruppen des Unternehmens liegen wie z.B. Öffentlichkeit, Mitarbeiter, Kapitalgeber, Kunden, Lieferanten, Behörden und Bürgerinitiativen usw. ${ }^{37}$ Im Rahmen einer ökologisch verpflichteten Unternehmenspolitik ist dabei von besonderer Bedeutung, daß nicht nur die Umweltschutzbewegung, sondern auch traditionelle Anspruchsgruppen in verstärktem Maße ökologiebezogene Forderungen an Unternehmen herantragen. Die ökologisch verpflichtete Unternehmenspolitik hat dabei eine unternehmensinterne sowie -externe (gesellschaftliche) Bedeutung. ${ }^{38}$

Die externe Bedeutung des unternehmenspolitischen Rahmens zeigt sich in seinem maßgeblichen Einfluß auf die sozio-politischen Umweltbeziehungen. Unter diesen Umweltbeziehungen können alle nicht primär marktgerichteten Außenbeziehungen verstanden werden. Sie beruhen statt dessen auf Konflikten, Verhandlungen oder Kooperation außerhalb der Marktgesetze und haben einen gesellschaftsbezogenen sozialen bzw. politischen Charakter. ${ }^{39}$

\footnotetext{
${ }^{35}$ Vgl. Kirsch, W./Trux, W. (1983), S. 53ff.; Seidel, E./Menn, H. (1988), S. 79.

${ }^{36}$ Vgl. Dyllick, T./Hummel, J. (1996), S. 19.

${ }^{37}$ Vgl. Ulrich, P. (1991), S. 14.

${ }^{38}$ Vgl. Dyllick, T./Hummel, J. (1996), S. 19f.
} 
Die Umweltbeziehungen müssen durch eine ökologisch verpflichtete Unternehmensführung in einer angemessenen Weise gehandhabt werden, da bei einer andauernden Nichterfüllung der Ansprüche der Stakeholder das Überleben des Unternehmens gefährdet werden kann. Ihre externe Funktion ist also die Dokumentation ökologischer Verantwortung. Sie bezweckt somit eine Image- und Vertrauensbildung bei wichtigen Anspruchsgruppen des Unternehmens. In diesem Zusammenhang liefert das Stakeholder-Konzept die unternehmerischen Erfolgsvoraussetzungen.

Die unternehmensinterne Bedeutung der Unternehmenspolitik ergibt sich aus der Vermittlung einer Grundorientierung (Rahmenbedingungen und Leitplanken) für das ökologisch relevante Entscheiden und Handeln der Mitglieder des Unternehmens. Damit schafft sie Orientierung und vermittelt Verhaltenssicherheit. Der unternehmenspolitische Rahmen steckt dabei den Entwicklungspfad für die Zukunft des Unternehmens ab. ${ }^{40}$ Die Formulierung und Durchsetzung ökologisch verpflichteter unternehmenspolitischer Grundsätze zielt auf die bewußte Änderung von Wertvorstellungen und damit des Verhaltens in und von Unternehmen ab. Damit die Unternehmenspolitik verhaltenswirksam wird, müssen die ökologischen Verhaltensregeln einen Verbindlichkeitscharakter, d.h. die Gestalt relativ konkreter Zielvorlagen, annehmen. ${ }^{41}$

Als Verkörperung der Gesamtheit übergeordneter, ökologieorientierter Rahmenentscheide bezeichnet die ökologisch verpflichtete Unternehmenspolitik zugleich Weg und Ziel betriebswirtschaftlicher Entwurfsarbeit zu angestrebten Verhaltensänderungen. ${ }^{42}$

Als auslösendes Moment für die Integration neuer Werte in die Unternehmenspolitik kann auf einer Metaebene die unternehmerische Vision herangezogen werden. Diese muß offiziell bekannt sein und ist dann einerseits „nahe genug“ hinsichtlich einer möglichen Realisierung, andererseits „fern genug“, um das Unternehmen „für eine neue Wirklichkeit“ (z.B. die Übernahme einer Schrittmacherrolle in bezug auf Umweltschutzaspekte in der relevanten Branche) zu motivieren. $^{43}$ Die Vision ist somit als Leitstern für die Unternehmensentwicklung, an dem sich ein Unternehmen auch bei permanentem Wandel orientieren $\mathrm{kann},{ }^{44}$ und sie ist gleichzeitig Ausgangspunkt und Ausdruck der Unternehmensziele. ${ }^{45}$ Die visionären Grundwerte des Unternehmens manifestieren sich in der Unternehmensphilosophie und werden durch diese „erhellt“. ${ }^{46}$

\footnotetext{
${ }^{39} \mathrm{Vgl}$. Achleitner, P. A. (1985), S. 13f.

${ }^{40}$ Vgl. Bleicher, K. (1996), S. 111.

${ }^{41}$ Vgl. Seidel, E./Menn, H. (1991), S. 80.

${ }^{42}$ Vgl. Seidel, E./Menn, H. (1988), S. 79.

${ }^{43}$ Vgl. Hinterhuber, H. H. (1992), S. $41 f$.

${ }^{44}$ Vgl. Bleicher, K. (1996), S. 84.

${ }^{45}$ Vgl. Rühli, E. (1990), S. $115 f$.

${ }^{46}$ Vgl. Bleicher, K. (1992), S. 64.
} 
Die Unternehmensphilosophie prägt damit die ökologisch verpflichtete Ausrichtung des Unternehmens, indem sie auf das Verhalten der Mitarbeiter ausstrahlt und folglich zur Grundlage und Handlungsmaxime einer ökologisch verpflichteten Unternehmenspolitik wird. ${ }^{47}$

Ausgangspunkte einer ökologiebezogenen Unternehmenspolitik können Wert-, Ressourcen-, Emissions- und Risiken-/Haftungsziele sein, die auf Umweltbewußtsein, Ressourcenknappheit und Emissionsaufnahmekapazität und Umweltgesetzgebung und Haftungssituation zurückzuführen sind. In ihnen zeigt sich die unternehmerische Verantwortung gegenüber der natürlichen Umwelt. Die dahinterstehenden Wertpositionen, die insgesamt den ökologiebezogenen Bereich der Unternehmensphilosophie verdeutlichen, können in folgenden Leitmaximen zusammengefaßt werden: ${ }^{48}$

- Im Sinne einer Fortentwicklung der Grundaufgabe versteht sich das Unternehmen auch als ökologischer Problemlöser (,Von der Produkt- zur Funktionsorientierung“),

- Nutzung natürlicher Ressourcen unter dem Primat von Sparsamkeit und ökologischem Gleichgewicht,

- Gezielter Einsatz des im Unternehmen vorhandenen Informations- und Innovationspotentials zur Vermeidung und Verminderung von Umweltverschmutzung,

- Aktive Schaffung und Weiterentwicklung eines Umweltbewußtseins bei Unternehmensmitgliedern und Marktpartnern.

Ein zentrales Instrument zur Umsetzung entsprechender ökologiezentrierter Werte in tatsächliches Handeln des Unternehmens und ihrer Mitglieder nach „,innen“ und „außen“ stellt ein entsprechendes Umweltschutzleitbild dar, das als ökologiespezifizierter Teil des grundlegenden Leitbildes anzusehen ist. In ihm finden sich: ${ }^{49}$

- Die Basispositionen ökologiezentrierten Unternehmensverhaltens im Sinne der ökologischen Unternehmensphilosophie bzw. -kultur,

- Leitvorstellungen zur Bedeutung von Umweltschutzzielen - vor anderen Zielen des Unternehmens,

- Grundsätze, die Beziehungen zu Anspruchsgruppen im ökologischen Feld regeln und die Aussagen für die einzelnen Funktionsbereiche treffen.

\footnotetext{
${ }^{47}$ Vgl. Steinle, C. (1994), S. 299.

${ }^{48}$ Vgl. Ospelt, F. (1977), S. 37f.
} 
Als ein Elemente des normativen Managements steckt die ökologische Unternehmensethik mit den normativen Rahmen für das unternehmerische Handeln ab. In einer ökologischen Unternehmensethik kommt zum Ausdruck, wie das Unternehmen seiner Mitverantwortung für alle von ihm verursachten Umweltbelastungen gerecht wird. Sie beeinflußt im wesentlichen das Zielsystem des Unternehmens und führt ggf. zu einer Selbstbeschränkung beim Einsatz von Mitteln und Instrumenten, wenn diese aus ökologischen Aspekte fragwürdig sind. ${ }^{50}$ Die ökologische Unternehmensethik nimmt insofern die Funktion eines ,situativen Korrektivs“ "wahr. ${ }^{51}$

Die Begründung ethisch motivierten Handelns resultiert allerdings nicht nur aus der Berücksichtigung rein unternehmensinterner Kriterien. Vielmehr umfaßt die ökologische Unternehmensethik die dialogische Verständigung mit den vom unternehmerischen Handeln Betroffenen und deshalb die Einbeziehung der Interessen der Anspruchsgruppen. ${ }^{52}$ Eine sog. Dialogethik dient durch die Initiierung individueller Reflexionsprozesse der Erzielung eines hohen Beteiligungsempfindens bei den Mitarbeitern aller Ebenen, der Möglichkeit der Erstellung konsensfähiger und handlungsleitender Unternehmensleitbilder sowie der Beeinflussung der Unternehmenskultur im Sinne von Lernfähigkeit sowie sozialer und ökologischer Orientierung. ${ }^{53}$

Durch die Verankerung ökologischer Werte in der Unternehmenskultur wird die Herausbildung eines grundlegenden ökologischen Selbstverständnisses im Unternehmen ermöglichen und auf seiten der Mitarbeiter der Grundstein für ein ökologisch verpflichtetes Verhalten gelegt. Die Integration ökologischer Aspekte in die tägliche Aufgabenerledigung als Handlungsmaxime unterstützt die eigendynamische Entwicklung und Bewußtseinwerdung ökologischer Werte auf Mitarbeiterseite in einem selbstverstärkenden Prozeß. Dabei kommt nicht nur die Akzeptanz für die Relevanz der Umweltschutzproblematik zum Tragen, sondern auch die Notwendigkeit des eigenen zu leistenden Problemlösungsbeitrags. Eine auf diese Weise evolvierende ökologisch verpflichtete Unternehmenskultur kann somit als „,... Schlüsselgröße im Rahmen des betrieblichen Wandels und als Quelle strategischer Stoßkraft ${ }^{54}$ bezeichnet werden und dabei entsprechend auf die ökologisch verpflichtete Unternehmenspolitik und weiter die Grundstrategie des Unternehmens einwirken. ${ }^{55}$

\footnotetext{
${ }^{49}$ Vgl. Senn, J. F. (1986), S. 302ff.

${ }^{50}$ Vgl. Steinmann, H./Löhr, A. (1989), S. 10.

${ }^{51}$ Vgl. Steinmann, H./Oppenrieder, B. (1985), S. 173.

${ }^{52}$ Vgl. Steinmann, H./Löhr, A. (1989), S. 238.

53 Vgl. Zabel, H.-U. (1994), S. 67. Die Dialogethik geht in ihrer ursprünglichen Form auf Habermas zurück, vgl. Habermas, J. (1983), S, 127ff.

${ }^{54}$ Meffert, H. (1988), S. 152.

${ }^{55}$ Vgl. Steinle, C. (1994), S. 299.
} 
Bei der Einführung ökologischer Aspekte in die Unternehmensführung ist die existente Unternehmenskultur als Ausgangsbedingung zu berücksichtigen. Deshalb ist es keineswegs ausreichend, die ökologische Verantwortung in den Unternehmensgrundsätzen zu dokumentieren und in das Zielsystem einzustellen und dann auf Verhaltensänderungen der Mitarbeiter zu hoffen. Vielmehr sind durch ein kulturbewußtes, symbolisches Management von der Unternehmensleitung ,Zeichen zu setzen“, mit denen in stetiger Weise eine strategiekonforme Grundorientierung vorgelebt wird und zudem im Sinne einer Dialogethik und einem konsensorientierten Management dialogische Willensbildung initiiert und praktiziert wird.

Im folgenden werden die ökologisch verpflichtete Unternehmenskultur und Unternehmensziele als weitere normative Grundgerüste im Rahmen der ökologisch verpflichteten Unternehmenspolitik dargestellt.

Ökologisch verpflichtete Unternehmenskultur: Unternehmen werden in der jüngeren organisationstheoretischen Literatur nicht nur als Systeme betrachtet, die typisch ökonomische Ziele verfolgen, sondern auch als Kulturgemeinschaften interpretiert. Obwohl diese Sichtweise keineswegs völlig neu ist, trägt sie zu einem tieferen Verständnis des Funktionierens dieser komplexen Gebilde bei. ${ }^{56}$ Die Bedeutung der Unternehmenskultur wird als wesentlicher strategischer Erfolgsfaktor angesehen und auch zunehmend im Rahmen der ökologisch verpflichteten Betriebswirtschaftslehre anerkannt. ${ }^{57} \mathrm{Im}$ Sinne eines integrierten Umweltmanagements sollte sich auch die Unternehmenskultur dem Umweltschutz verpflichten.

Die Unternehmenskultur umfaßt „,...die Gesamtheit der in der Unternehmung vorherrschenden Wertvorstellungen, Traditionen, Überlieferungen, Mythen, Normen und Denkhaltungen, die den Mitarbeitern auf allen Verantwortungsebenen Sinn und Richtlinien für ihr Verhalten vermitteln. ${ }^{68}$ Die Kultur prägt implizit das Verhalten aller Mitarbeiter im Unternehmen, indem sie vergangenheitbezogene Werte und Normen in die Zukunft transportiert und den Mitarbeitern hierdurch das von ihnen erwartete Verhalten aufzeigt. Die vermittelten Werte und Normen hel-

\footnotetext{
${ }^{56}$ Vgl. Schanz, G. (1999), S. 27.

57 Vgl. Hopfenbeck, W. (1990), S. 128ff.; Meffert, H./Kirchgeorg, M. (1998), S. 420ff. Hnsichtlich der Begriffe „Unternehmenskultur“, „Unternehmensphilosophie“ und „Unternehmensidentität“ herrscht in der betriebswirtschaftlichen Literatur Uneinigkeit. Nach Raffèe/Wiedmann soll Unternehmensphilosophie als Sinn- und Wertebene des Unternehmens bezeichnet werden. Hierzu gehören grundlegende Überzeugungen, Paradigmen bzw. Weltbilder, Visionen, Werthaltungen und Normen. Die Unternehmenskultur ist die Objekt- und Verhaltensebene. Sie stellt die Konkretisierung der Unternehmensphilosophie in Artefakten und Verhaltensroutinen, in Organisationsstrukturen, Mythen und Legenden dar. Die Unternehmensidentität ist die Interaktions- und Entwicklungsperspektive. Sie ist die Persönlichkeit eines Unternehmens und hebt das „Besondere” im Vergleich zu anderen Unternehmen hervor, das „Beständige“ in der Zeit. Vgl. Raffèe, H./Wiedmann, K.-P. (1993), S. 47.

${ }_{58}$ Hinterhuber, H. H. (1992), S. 248. Zu Einzelheiten der Unternehmenskultur vgl. Schanz, G. (1994), S. $270 f f$.
} 
fen darüber hinaus den Entscheidungsträgern, Informationen, Politik, Strukturen, Systeme und Träger auszuwählen und beeinflussen damit die Unternehmensentwicklung. Die spezifische Kultur eines Unternehmens verleiht ihr somit eine eigene, unverwechselbare Systemidentität, nach innen und nach außen. Unternehmenskultur kann auch dazu beitragen, daß die Arbeit im Unternehmen von Loyalität, Engagement und Identifikation getragen ist. ${ }^{59}$ Nach Macharzina kann von Unternehmenskultur eine „Einengung des Interpretations- und Handlungsspielraums bei Problemlösungen erzeugt werden. Unternehmenskulturen erfüllen nämlich die in gemeinsam geteilten Philosophien, Zielsystemen, Symbolstrukturen, Mythen und Traditionen gespeicherten Handlungsnormen aktivierende, koordinierende und legitimierende Funktionen. ${ }^{\star 60}$

Die Unternehmenskultur stellt somit neben der formalen Organisationsstruktur sowie der persönlichen Anweisung ein weiteres Steuerungsinstrument innerhalb des Unternehmens dar. Es handelt sich dabei um einen nicht-strukturellen Koordinationsmechanismus, der auf einer normativen Steuerung, d.h. auf einer inneren Verpflichtung der Organisationsmitglieder auf gemeinsame Normen, basiert. ${ }^{61}$ Führungsentscheidungen, die nicht im Einklang mit der Unternehmenskultur stehen, sind kaum umzusetzen. Daraus ergibt sich die besondere Bedeutung der Unternehmenskultur. $^{62}$ Weiter kann die Unternehmenskultur bei dynamischen Umweltentwicklungen und zunehmender Unternehmensumwelt-Interdependenz den übrigen Koordinationsmechanismen - Organisationsstruktur bzw. Standardisierung und Formalisierung von Entscheidungen - überlegen sein. $^{63}$

Eine umweltbewußte Unternehmenskultur soll ökologieorientierte Strömungen aus dem sozioökonomischen Umfeld des Unternehmens aufnehmen und eine wesentliche Motivationsgrundlage für das zielkonforme Verhalten der Mitarbeiter sowie einen Orientierungsrahmen bei Entscheidungen schaffen. Diese werden im Unternehmen verankert und institutionalisiert. ${ }^{64}$ Schließt man sich der Auffassung an, daß von einer prinzipiellen Gestaltbarkeit der Unternehmenskultur auszugehen ist, dann liegt der Gedanke nahe, die ökologische Verantwortung des Unternehmens nicht nur auf der strategischen und strukturellen, sondern auch auf der kulturellen Ebene zu verankern. Ein entsprechender Versuch läuft auf ökologisch verpflichtetes Kulturmanagement ${ }^{65}$ hinaus und beinhaltet im Kern das aktive Pflegen und Weiterentwickeln ökologiebezogener Werte und Normen. Konkretisieren jißt sich diese Idee durch Bezug auf die von Schein entwickelte

\footnotetext{
${ }^{59}$ Vgl. Becker, J. (1993), S. 33.

${ }^{60}$ Macharzina, K. (1993), S. 91.

${ }^{61}$ Vgl. Schreyögg, G. (1990), S. 196; Meffert, H./Kirchgeorg, M. (1998), S. 424.

${ }^{62}$ Vgl. Hinterhuber, H. H. (1992), S. $247 \mathrm{ff}$.

${ }^{63}$ Vgl. Macharzina, K. (1993), S. 196.

${ }^{64}$ Vgl. Hammerl, B. M. (1994), S. 89; Seidel, E. (1989), S. 266.
} 
Modellvorstellung, wonach sich Unternehmenskultur in folgenden drei Ebenen als Elemente einer ökologisch verpflichteten Unternehmensführung niederschlägt: ${ }^{66}$

- Grundannahmen (anthroposophisches Menschenbild, Umweltschutz als verantwortungsethisches Anliegen),

- Wertvorstellungen (Einbeziehung des Umweltschutzes in die Unternehmensgrundsätze, internalisierte Öko-Werte bei den Mitarbeitern auf verschiedenen Unternehmensebenen z.B. Einstellungen gegenüber Natur und Erhaltung von Ressourcen),

- Artefakte und Kreationen (baubiologische Architektur der Gebäude und Arbeitsplätze, neue Formen der Öffentlichkeitsarbeit und des Dialogs mit Umweltorganisationen, Anreizsysteme für umweltbewußtes Verhalten im Unternehmen, betriebliches Vorschlagswesen für umweltfreundliche Problemlösungen, Aufstellung von Recyclingbehälter für Mitarbeiter u.a.m.).

Grundannahmen stellen die kulturelle Kernsubstanz dar und werden als selbstverständlich angenommen. Sie konkretisieren sich in Wertvorstellungen, in denen insbesondere zum Ausdruck kommt, welchen Prioritäten das Handeln und Verhalten der Organisationsmitglieder folgen soll. Ihren Niederschlag können sie vor allem in Unternehmens- und Führungsgrundsätzen finden. Die verhaltensprägenden Wirkungen von Werthaltungen werden bei der Planung, Koordination und Kontrolle ökologieorientierter Strategien und Maßnahmen erkennbar. Dabei ist es wichtig, die für eine erfolgsprägende Wirkung entscheidenden Beurteilungskriterien $\mathrm{zu}$ kennen. ${ }^{67}$ Artefakte und Kreationen schließlich sind jene Ausprägungen der Unternehmenskultur, die sich für den Beobachter in spezifischen Umgangsformen, Sprachregelungen, Gebräuchen bis hin zur Gebäudearchitektur äußern. Die kulturtragenden Komponenten der Artefakte-Ebene spielen somit eine doppelte Rolle. Sie bieten einerseits Ansatzpunkte für eine unmittelbare Kennzeichnung ökologieorientierter Ausprägung der Unternehmenskultur im Sinne einer Identifikation. Andererseits zeigen sie die Ausprägungen dieser Artefakte, wohin sich richtiges umweltbewußtes Verhalten im Unternehmen niederschlägt. Hierdurch kommt die Signal- oder Vorbildfunktion der Artefakte zum Ausdruck.

Die Verankerung der ökologischen Dimension des Wirtschaftens in Unternehmen kann auf allen drei genannten Kulturebenen erfolgen. Diese Verankerung kann durch kulturelle Artefakte und Kreationen, die deutlich sichtbare Teile der Unternehmenskultur sind und damit Symbolcharak-

\footnotetext{
${ }^{65}$ Vgl. etwa Seidel, E. (1989), S. 77.

66 Vgl. Schein, E. H. (1985), S. 9ff.; Schanz, G. (1999), S. 29f.; Hopfenbeck, W. (1998), S. 773f.; Meffert, H./Kirchgeorg, M. (1998), S. 422f.; Dyllick, T./Hummel, J. (1996), S. 32f.

${ }^{67}$ Vgl. Heinen, E. et al. (1987), S. 26ff.
} 
ter haben, wie eine umwelt- und energiebewußte Gebäude- und Arbeitsplätzekonzeption oder durch eine ebenfalls umweltbewußte innere Funktionsorganisation oder durch menschliche Handlungen erreicht werden.

Die Ausprägung der Unternehmen (Unternehmenskultur) und dabei die Gegenstände der Bildung von Unternehmenskultur wie Symbole, Zeremonien, Rituale insbesondere Mythenbildung und Erzählung, die die Unternehmenskultur vermitteln, sind häufig herausragende Persönlichkeiten der Unternehmensgründer und auch die mit ihnen verbundenen Führungskräfte. Daher kommt in seiner Rolle als Vorbildfunktion dem Kreis der Führungskräfte für die Verankerung der Ökologieverantwortung der Unternehmensführung große Bedeutung zu. Umweltschutz wird in diesem Sinne als „Chefsache“ angesehen. Deshalb müssen in diese Vorreiterrolle auf allen betrieblichen Hierarchieebenen Lernprozesse angestoßen und von subjektiven Erfolgserlebnissen sowie der Möglichkeit, Erfahrung zu sammeln, begleitet werden. Als Auslöser kann ein aktives Engagement der Geschäftsführung wie z.B. Formulierung der eigenen Wertvorstellungen in ökologisch erweiterten Leitbildern gesehen werden. ${ }^{68}$ Ökologiebezogene Wertvorstellungen finden ihren Niederschlag naheliegenderweise in den Unternehmens- und Führungsgrundsätzen. Wenn in organisationsweit verbindlichen Grundsätzen ein expliziter Bezug zur ökologischen Verantwortung des Unternehmens hergestellt wird, so dürfte dies die Implementierung der verschiedenen sonstigen umweltschutzbezogenen Maßnahmen wesentlich erleichtern.

Wird Umweltschutz dort als verantwortungsethisches Anliegen herausgestellt, dann kann möglicherweise sogar einer Verankerung auf der Ebene der Grundannahmen gelingen. Der behutsame Umgang mit der Natur würde damit als selbstverständlich-unbewußte Verhaltensrichtschnur wirksam. Dies dürfte eine besonders gute Voraussetzung für eine Berücksichtigung des Umweltschutzziels im Rahmen der Unternehmensführung sein. ${ }^{69}$

Die Unternehmenskultur soll im Rahmen einer ökologisch verpflichteten Unternehmensführung mit ihren koordinierenden, integrierenden und motivierenden Wirkungen zu einer Effizienz- und Effektivitätssteigerung beitragen. Im Gegensatz zum strukturellen Koordinationsmechanismus der formalen Organisation fungiert die Unternehmenskultur als nicht-struktureller Koordinationsmechanismus. In diesem Zusammenhang sind Maßnahmen angesprochen, die sich positiv auf das engagierte Mitdenken und Handeln der Mitarbeiter auswirken. Bei entsprechender Ausrichtung der Mitarbeiter auf die markt- und umweltorientierten Unternehmensziele sichert eine star-

\footnotetext{
${ }^{68}$ Vgl. Hopfenbeck, W. (1990), S. 128.

${ }^{69}$ Vgl. Schanz, G. (1999), S. 30.
} 
ke Unternehmenskultur einen gemeinsamen Grundkonsens. Hierdurch entsteht eine Motivationsgrundlage für zielkonformes Verhalten der Mitarbeiter. Ferner dienen die internalisierten Werte den Organisationsmitgliedern bei der Entscheidungsfindung als Orientierungsquelle. Darüber hinaus ist davon auszugehen, daß die zur Verfügung stehenden Entscheidungsalternativen von vornherein auf diejenigen beschränkt werden, die mit den kulturellen Normen und Werten vereinbar sind. Die Integrationsfunktion der Unternehmenskultur ist schließlich für eine funktionsübergreifende, ökologisch verpflichtete Unternehmensführung deshalb von besonderer Bedeutung, weil gemeinsame Werte und Normen den Zusammenhalt und das funktionsübergreifende Denken in einzelnen Teilbereichen fördern. In diesem Sinne erfüllt eine funktionale bzw. strategieadäquate Unternehmenskultur effizienz- und effektivitätsteigernde Funktionen. In diesem Zusammenhang spielt die integrierende Funktion der Unternehmenskultur über gemeinsame Werte und Normen bei der funktionsübergreifenden Umsetzung von Umweltschutzzielen eine wichtige Rolle.

Ökologisch verpflichtete Unternehmensziele: Zur Konkretisierung der Unternehmenskultur in Form wünschenswerter Zustände dienen Unternehmensziele. In der Sichtweise der entscheidungsorientierten Betriebswirtschaftslehre erfillen Ziele im Rahmen eines Unternehmens die Funktion, die Tätigkeiten und Prozesse zu steuern. ${ }^{70}$ Damit sind die Unternehmensziele die eigentlichen Bestimmungsgrößen des Unternehmensverhaltens, die durch die Formulierung zielentsprechender Unternehmensstrategien und deren Umsetzung in konkrete Maßnahmen in einem Entscheidungs- oder Problemlösungsprozeß anzustreben sind.

Zur Bewältigung der Umweltprobleme in ihren ökologischen, gesellschaftlichen und wettbewerbsstrategischen Dimensionen stellt die Integration von Umweltschutzzielen in das Zielsystem des Unternehmens die notwendige Voraussetzung dar, um die Unternehmensaktivitäten den veränderten Rahmenbedingungen anzupassen und um bei der Planung, Durchführung und Kontrolle ökonomischer Tätigkeiten eine Vermeidung und Verminderung von Umweltbelastungen sicherzustellen. $^{71}$ Damit bringt der Zielbezug ökologisch verpflichteter Unternehmensführung zum Ausdruck, daß neben den ergriffenen Einzelmaßnahmen aufbauend auf einer Analyse der unternehmensexternen und -internen Rahmenbedingungen ein systematisch geplantes, ökologisch intendiertes und kontrolliertes Umweltschutzverhalten impliziert. ${ }^{72}$ Dies dokumentiert die Relevanz und den Stellenwert der Thematik für das gesamte Unternehmen und gereicht so für alle Mitarbeiter zur Handlungsmaxime. Dementsprechend sind umweltschutzbezogene Aufgaben,

\footnotetext{
${ }^{70}$ Vgl. Kreikebaum, H. (1989), S. 46ff.; Heinen, E. (1985), S. $26 \mathrm{ff}$.

${ }^{71}$ Vgl. Kirchgeorg, M. (1990), S. 103.
} 
Kompetenzen und Verantwortungen im Unternehmen $\mathrm{zu}$ formulieren, aufzubauen und $\mathrm{zu}$ verteilen.

Während in vielen früheren betriebswirtschaftlichen Modellen von einer Dominanz des Gewinnziels ausgegangen wurde, so konnten die Zielsysteme neben dem Gewinnziel als weitere ökonomische Zielkategorien wie Umsatz oder Marktanteil auch nicht-ökonomische Zielsetzungen wie Unabhängigkeit oder „Soziale Verantwortung“ identifiziert werden. ${ }^{73}$ Diese Ziele stehen hierarchisch auf verschiedenen Ebenen und bilden in ihr Gesamtheit ein Zielsystem (vgl. Abb. 4.5).

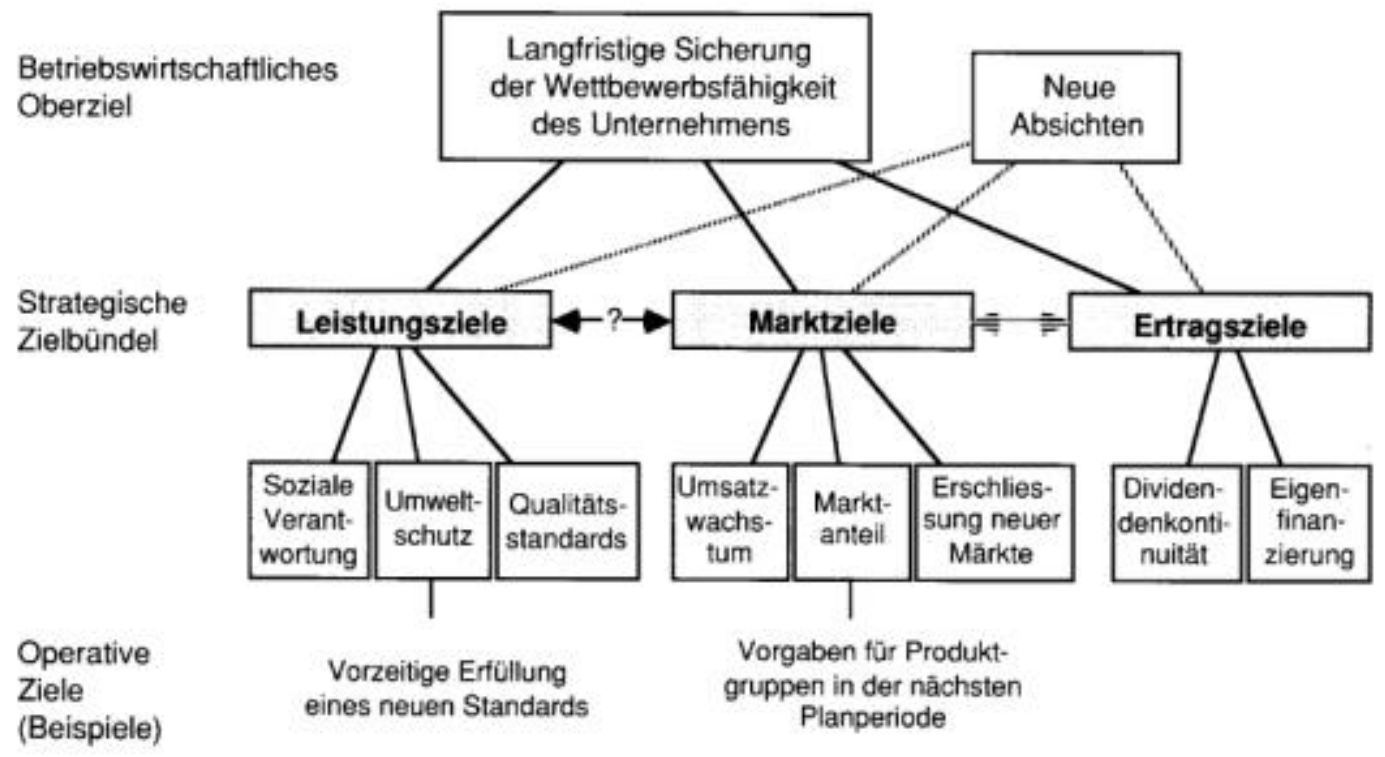

Abb. 4.5: Zielsysteme des Unternehmens (Quelle: Steger, U. (1993), S. 190)

Wenn von einem Zielsystem gesprochen wird, dann bedeutet dies, daß Unternehmen nicht nur ein einziges (übergeordnetes) Ziel verfolgen. Auch wenn der Erzielung eines angemessenen Gewinns herausragende Bedeutung zukommt, spielt in der Praxis der Unternehmensführung insbesondere das Umsatz- oder das Marktanteilstreben eine große Rolle. Ferner steht gelegentlich der Zwang zur Kostenreduzierung so stark im Vordergrund, daß man von einem eigenständigen Ziel sprechen darf. Verschiedentlich wird in der Literatur sogar die Aufrechterhaltung des finanziellen Gleichgewichts als Zielgröße interpretiert, wenngleich es vermutlich vorzuziehen ist, in diesem Fall von einer Nebenbedingung zu sprechen.

Unabhängig von ihren Inhalten können den verschiedenen Unternehmenszielen bestimmte Funktionen zugeschrieben werden. Die am einfachsten erkennbare Funktion besteht darin, das Verhal-

\footnotetext{
${ }^{72}$ Vgl. Meffert, H./Kirchgeorg, M. (1998), S. 22.

${ }^{73}$ Vgl. Meffert, H./Kirchgeorg, M. (1998), S. 45.
} 
ten und Handeln der Unternehmensmitglieder in bestimmter Weise zu kanalisieren. Dies ist die Steuerungs- oder Orientierungsfunktion von Unternehmenszielen. Konkret - und das heißt: vermittelt über diverse Ziel-Mittel-Verkettungen, deren Existenz die Beziehung zum Ausgangsziel gelegentlich zu einer schwer erkennbaren Angelegenheit machen kann - bedeutet dies z.B., daß ein Produktmanager im laufenden Geschäftsjahr einen bestimmten Umsatz erzielen soll, eine Arbeitsgruppe im operativen Kern für einen zusammenhängenden Aufgabenvollzug verantwortlich ist. Der Bezug zu den eher allgemein gehaltenen Unternehmenszielen muß dabei in der Regel durch geeignete Anreizsysteme hergestellt werden.

Unternehmensziele haben zweitens eine Koordinationsfunktion in dem Sinn, daß sie dafür sorgen, die auf den verschiedenen hierarchischen Ebenen und in den unterschiedlichen Bereichen des Unternehmens (Beschaffung, Forschung und Entwicklung, Produktion usw.) zu treffenden Entscheidungen aufeinander abzustimmen. Daß dies den Einsatz begleitender Maßnahmen erforderlich macht, dürfte selbstverständlich sein.

Schließlich ist drittens auf die Legitimationsfunktion von Unternehmenszielen aufmerksam zu machen. Sie gewinnt z.B. dann Bedeutung, wenn es das eigene Handeln (z.B. gegenüber dem Vorgesetzten) zu rechtfertigen gilt oder wenn unpopuläre Maßnahmen ergriffen werden (müssen).

Im Anschluß an diese einleitende Charakterisierung scheint es plausibel, eine Zielhierarchie zu unterstellen (vgl. Abb. 4.5). Oberstes Ziel ist - gerade im Hinblick auf die Risiken in einer turbulenten Umwelt - das Existenzsicherungsziel; das langfristige Überleben der Organisation also, das sich definiert als die langfristige Sicherung der Wettbewerbsfähigkeit des Unternehmens. Bei sich veränderndem Umfeld ist hierfür auch die Fähigkeit zur Weiterentwicklung eine wichtige Voraussetzung. Die nachfolgende Ebene bilden Bündel von strategischen Zielen, die als langfristige Vorgaben das Oberziel konkretisieren. Sie lassen sich in drei Gruppen untergliedern: ${ }^{74}$

- Leistungsziele sind solche Ziele, deren Erfüllung von Dritten, der Gesellschaft, der Politik, den Abnehmern usw. erwartet wird. Ihre Nicht-Beachtung würde langfristig das Existenzsicherungsziel gefährden, weil bei dauerhafter und intolerabler Verletzung von Interessen Dritter die Handlungsautonomie der Unternehmen eingeschränkt wird. Die Erreichung dieser Ziele dient also der Sicherung der Legitimation der Unternehmensautonomie, die deshalb von

\footnotetext{
${ }^{74}$ Vgl. Steger, U. (1993), S. 189; Fritz, W. et al. (1985), S. $381 f$.
} 
der Gesellschaft gewährt wird, weil damit gesamtgesellschaftliche Aufgaben und Ziele besser und effizienter erfüllt werden als mit anderen Steuerungsmechanismen.

- Marktziele sind Unternehmensziele im engeren Sinne. Sie umfassen langfristige Umsatzziele (z.B. um geplante Investitionen oder Forschungsanstrengungen zu nutzen), Ziele der Marktstellung (z.B. Branchenführer) oder Marktanteilsziele, die erfahrungsgemäß in engem Zusammenhang stehen mit .

- Ertragszielen, die der Finanzierung eines stabilen Wachstums, der Befriedigung von Aktionärsansprüchen usw. dienen. Die Erreichung von Markt- und Ertragszielen ist dabei positiv korreliert, während der Zusammenhang mit den Leistungszielen weniger eindeutig bestimmt ist.

Diese strategischen Zielbündel werden abschließend auf operative Ziele heruntergebrochen. Zeitlich steht ein solches komplettes Zielsystem nicht am Anfang, sondern am Ende des Panungsprozesses. Denn erst, wenn nach einer Markt- und Konkurrenzanalyse die Strategien - auch im Hinblick auf die verfügbaren Ressourcen - festgelegt sind, können die Ziele konkret bestimmt werden. Am Anfang des Planungsprozesses stehen die strategischen „Absichten“, d.h. die normativen Leitbilder, die sich im weiteren Planungsverlauf - mit mehreren Rückkopplungen - zu klar formulierten Zielen entwickeln, denn: „Um zu wissen, was man will, muß man wissen, was man kann. ${ }^{\text {75 }}$

Umweltschutzziele lassen sich grundsätzlich in input- und outputbezogene Ziele unterscheiden. Inputbezogene Ziele betreffen Ressourcenschonung und -erhaltung (Ressourcenziel). Outputbezogene Ziele betreffen unerwünschten Output und beziehen sich auf Frage der Umwelt als Aufnahmemedium (Emissionsziel). ${ }^{76}$ Hinzu kommt die Verminderung potentieller Gefahren und die Verhinderung von Störfällen (Risikoziel). Da die Zielbildung im Unternehmen aufgrund der ständigen Veränderung unternehmensexterner und -interner Gegebenheiten ein permanenter Prozeß ist, sind auch Ziele dieser drei Zielbereiche nicht für immer festgeschrieben. Insbesondere hinsichtlich des Zielmaßstabs und -ausmaßes sind Umweltschutzziele gesellschaftlichen Bedingungen (Umweltschutzgesetzgebung/Grenzwerte, Stand der Technik oder gesteigertes Umweltbewußtsein und entsprechendes Kaufverhalten von Konsumenten) und ökologischen Erkenntnissen (Entdecken von neuen Ursache-Wirkung-Zusammenhängen, Langzeitwirkungen) im Sinne einer kontinuierlichen Verbesserung anzupassen. Die Zielkategorien ökologisch verpflichteter Unternehmensführung zeigt Abb. 4.6.

\footnotetext{
${ }^{75}$ Steger, U. (1993), S. 191.

${ }^{76}$ Vgl. Schreiner, M. (1988), S. 33.
} 


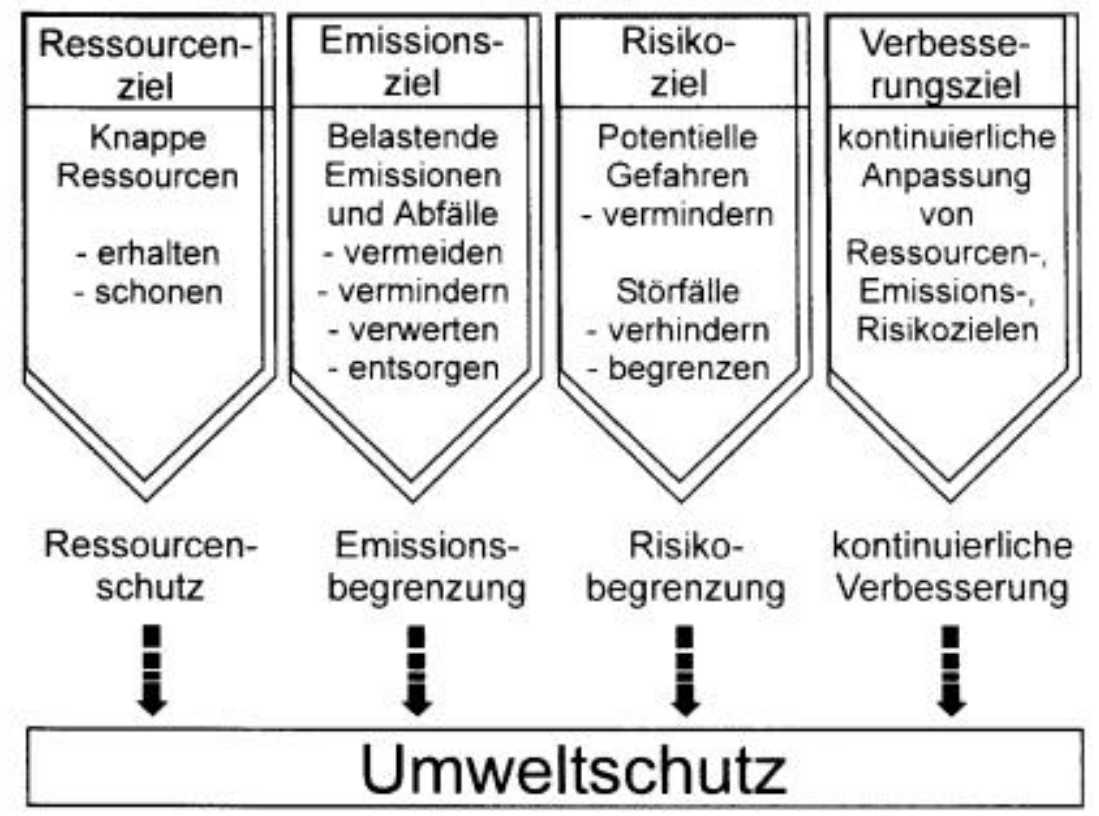

Abb. 4.6: Umweltschutz als Unternehmensziel (Quelle: Jahnes, S. (1997), S. 72)

Wichtig für die ökologisch verpflichtete Unternehmensführung ist nun die Frage, wo Umweltschutz in diesem Zielsystem zu plazieren ist und ob bzw. welche Zielkonflikte sich daraus ergeben können. ${ }^{77}$ Wie aus Abb. 4.5 ersichtlich, läßt sich das erwähnte Umweltschutzziel (einschließlich seiner Unterziele) innerhalb dieser Systematik als Bestandteil des Leistungsziels interpretieren. Die Begründung hierfür ist im wesentlichen, daß Umweltschutz für ein Unternehmen zunächst kein ,Ziel an sich“ sein kann, da jede Erstellung von Gütern oder Dienstleistungen zwangsläufig mit einer Belastung der Umwelt einhergeht. Grundlegende Motivation ist daher die Aufrechterhaltung des „Fließgleichgewichtes“, mit dem das Unternehmen versucht, Konflikte zwischen sich und seinem weiteren Umfeld abzubauen, um so seine Handlungsfähigkeit und Autonomie zu wahren. Dort, wo durch das Verbraucherverhalten Umweltschutz zu einem Marktfaktor geworden ist, kann er auch Teil der Marktziele werden. Nur wenn die Einschätzung zur Steuerungs- und Selektionsfunktion von normativen Vorgaben der Unternehmenskultur und der Leitbilder richtig ist, wird das Unternehmen dieses Marktpotential frühzeitig ausschöpfen, selbst wenn es über eine eigenständige Umweltschutz-Zielsetzung verfügt. Da aber Ziele sich nicht wissenschaftlich begründen lassen, können Unternehmen zugegebenermaßen ihr Umweltschutzziel als normative Setzung auch an anderer Stelle im Zielsystem positionieren.

\footnotetext{
${ }^{77}$ Dabei liegt es nahe, von einem Umweltschutzziel zu sprechen, das sich seinerseits in verschiedene Unterziele wie z.B. ein Ressourcenziel, ein Emissionsziel und ein Risikoziel unterscheiden kann. Vgl. zu Einzelheiten Jasch, C./Kleindorfer, S. (1991), S. 44.
} 
Wenn nun das Umweltschutzziel mit den oben erwähnten Funktionen von Unternehmenszielen in Verbindung gebracht wird, dann erfüllen Umweltschutzziele die Funktionen Koordination (verhindern, daß Umweltschutz lediglich in einzelnen Funktionsbereichen als Insellösung Berücksichtigung findet), Steuerung und Orientierung (Berücksichtigung ökologischer Effizienzanforderung als Bewertungskriterium bei Unternehmensentscheidungen, sämtliche Mitarbeiter des Unternehmens für die Notwendigkeit des Umweltschutzes $\mathrm{zu}$ sensibilisieren und ihr Verhalten und Handeln - ggf. unterstützt durch Vorgabe situationsspezifisch angemessener Anreize - entsprechend $\mathrm{zu}$ kanalisieren) und Kontrolle (Umweltschutzziele als Frühwarninstrumentarium zur Vermeidung von rechtlichen und gesellschaftlichen Legitimationsproblemen). Weiterhin erfüllen Umweltschutzziele eine sachlich-rationale und sozio-emotionale Funktion: Zum einen sind sie gegenüber unternehmensspezifischen Anspruchsgruppen $\mathrm{zu}$ kommunizieren, um die Legitimität von Umweltschutzaktivitäten des Unternehmens zu sichern. Andererseits soll das Bekenntnis von Führungskräften zum Umweltschutz eine Vorbild- und Identifikationsfunktion hinsichtlich eines umweltbewußten Klimas erzeugen. ${ }^{78}$

Wichtig erscheint auch die Frage, in welcher Beziehung das Umweltschutzziel $\mathrm{zu}$ den anderen Zielsetzungen des Unternehmens steht. Generell konnte die betriebswirtschaftliche Forschung einiges dazu beitragen, die Beziehungen zwischen verschiedenen Zielen zu klären. Ziele können sich neutral zueinander verhalten, d.h. die Erreichung eines Zieles beeinflußt weder positiv noch negativ die Erreichung eines anderen. Dies dürfte jedoch eher der Ausnahmefall sein. Meist sind Zielbeziehungen komplementär (die Erreichung eines Zieles fördert oder bedingt die Erreichung eines anderen) oder konträr (eine Zielerreichung be- oder verhindert eine andere). So ist heute relativ unbestritten, daß zwischen hohem Marktanteil und hoher Rendite zumindest eine positive Korrelation besteht. Umgekehrt existiert oft ein Zielkonflikt zwischen der Bereinigung der Produktpalette als einem Kostensenkungsziel und dem Ziel der Marktabdeckung durch ein differenziertes Produktangebot.

Bei einer Integration ökologischer Zielsetzungen in das Zielsystem eines Unternehmens werden folgende Formen von Interdependenzen mit ökonomischen Zielen unterschieden: ${ }^{79}$

- Der Umweltschutz steht in konfliktärer Beziehung zu den ökonomischen Unternehmenszielen und stellt eine von außen vorgegebene Restriktion des Gewinnzieles dar.

\footnotetext{
${ }^{78}$ Vgl. Schanz, G. (1999), S. 6ff.; Meffert, H./Kirchgeorg, M. (1998), S. 186ff.

${ }^{79}$ Vgl. Meffert, H./Kirchgeorg, M. (1998), S. 48.
} 
- Es besteht eine komplementäre Beziehung bzw. eine Mittel-Zweck-Beziehung zwischen Umweltschutzzielen und der Gewinnerzielung.

- Der Umweltschutz folgt aus der sozialen Verantwortung der Unternehmensführung und stellt ein autonomes Ziel dar. Die Integration als gleichrangiges Unternehmensziel neben den ökonomischen Zielsetzungen erfolgt unabhängig von externen Umweltschutzforderungen und unter freiwilliger Gewinnreduzierung.

Unternehmen, die den Umweltschutz in konfliktärer Beziehung zu den ökonomischen Zielen sehen, versuchen, nur die gesetzlichen umweltschutzrelevanten Minimalerfordernisse zu erfüllen. Diese werden als Nebenbedingung und Restriktion der Gewinnerzielung angesehen. Die aus einer solchen Grundhaltung resultierende Behandlung ökologierelevanter Problemstellungen kann als defensives Umweltschutzmanagement bezeichnet werden: „Aus Gründen der Vermeidung von zusätzlichen Belastungen durch Umweltschutzanforderungen, aber auch aus Unkenntnis der Chancen, die sich den Betrieben bieten, und nicht zuletzt wegen zu geringer Anreize für umweltfreundliche Betriebsweisen und Produkte, die von der Umweltpolitik ausgehen, betreiben die allermeisten Betriebe noch immer ein eher defensives Umweltschutzmanagement. Dies führt zu unnötig hohen Umweltbelastungen durch die Betriebe und ist zumeist (zumindest mittel- und langfristig) wegen ausgelassener Chancen auch betriebswirtschaftlich ineffizient. ${ }^{\text {(80 }}$

Die Sichtweise, in der eine komplementäre Beziehung zwischen Umweltschutz- und Gewinnziel besteht, liegt den Konzepten der ökologieorientiert-strategischen Unternehmensführung zugrunde. Die Umweltorientierung wird als ein Mittel zur (langfristigen) Sicherung oder Erhöhung des Unternehmensgewinnes angesehen. Der Umweltschutz wird „... als Chance wahrgenommen, um durch umweltgerechte Prozeß- und Produktinnovationen eine Kopplung zwischen Kosten- und Ertragszielen mit einer verbesserten Umweltqualität zu erreichen ... . ‘81

Umweltschutzziele stellen drittens eigenständige Zielsetzungen dar. Entsprechend dieser Sichtweise sollen durch den Bezug auf moralische Grundsätze oder ethische Prinzipien in betrieblichen Entscheidungssituationen die negativen Auswirkungen auf die ökologische Umwelt, die aus den marktwirtschaftlichen Systemzwängen folgen, gemildert werden. Umstritten ist allerdings, wie groß der Freiraum für ethisch-orientiertes Handeln in einer marktwirtschaftlichen Ordnung ist. Für Ulrich sind die Sachzwänge der Marktkonkurrenz, selbst bei nicht besonders vernünftigen Rahmenbedingungen, nie total. Es gibt demnach immer verschiedene Wege, die zu unter-

\footnotetext{
${ }^{80}$ Wicke, L. (1988), S. 11.

${ }^{81}$ Meffert, H./Kirchgeorg, M. (1998), S. 48.
} 
nehmerischem Erfolg führen, wobei erhebliche Unterschiede in der Qualität des jeweiligen ethischen Unterbaus bestehen können. ${ }^{82}$ Nach den empirischen Zielforschungen läßt sich aber feststellen, daß der Umweltschutz nicht als autonomes Formalziel des Unternehmens anzusehen ist, er ist vielmehr in einer Mittel-Zweck-Beziehung zu den ökonomischen Zielsetzungen. ${ }^{83}$ Die Integration des Umweltschutzes erfolgt also aufgrund veränderter Kundenanforderungen oder Wettbewerbsbedingungen zur Wahrnehmung von potentiellen Chancen. ${ }^{84}$ Die besondere Herausforderung für eine ökologisch verpflichtete Unternehmensführung liegt somit in der Handhabung möglicher ökologisch-ökonomischer Zielkonflikte.

Die Beziehungen der ökologischen Ziele zu den ökonomischen nehmen daher einen breiten Raum in den Forschungsarbeiten ein. ${ }^{85}$ Im Rahmen der strategisch orientierten Betriebswirtschaftslehre werden die ökologieorientierten Zielsetzungen nicht isoliert von den ökonomischen Zielbezügen des Unternehmens gesehen, da die für die Zielerreichung einzusetzenden Mittel Auswirkungen auf diese Zielsetzungen haben. In diesem Zusammenhang wird u.a. darauf hingewiesen, daß in einem marktwirtschaftlichen System die ökologischen Zielsetzungen nicht den Stellenwert von Oberzielen im Zielsystem eines Unternehmens einnehmen können, sondern , ...daß kein Unternehmen betrieben wird, nur um ... umweltfreundlich zu sein“. ${ }^{86}$

Schwieriger sind die Beziehungen zwischen Leistungszielen einerseits sowie Markt- und Ertragszielen andererseits. Hier sind generelle Aussagen kaum zu treffen, weil dies von den unterschiedlichen Ausgangsbedingungen und der jeweils eingeschlagenen Strategie abhängt. Entscheidend ist: Konflikte zwischen den „klassischen“ betriebswirtschaftlichen Markt- und Ertragszielen und den Leistungszielen - hier insbesondere dem Umweltschutz - sind nicht ,gegeben“ oder „natürlich“, sondern (zumindest in Grenzen) ein Ergebnis der Unternehmensstrategie, ihrer Voraussetzungen und ihrer Implementierung. Darum kommt der Strategieformulierung entscheidende Bedeutung zu. Diese „Strategieabhängigkeit“ der Zielbeziehungen bedeutet die Abhängigkeit von einer Reihe von Ausgangsbedingungen, die nur situativ entschieden werden können. Keinesfalls werden Strategien voluntaristisch gewählt, nur um Ziele zu harmonisieren. Aber die im strategischen Planungsprozeß notwendige iterative Annäherung und dann simultane Entscheidung von Zielen und Strategien hat genau ihre Ursache. Sie gilt gleichermaßen für die komplementäre Integration der Umweltzielsetzung wie für die Harmonisierung anderer Ziele. ${ }^{87}$

\footnotetext{
${ }^{82}$ Vgl. Ulrich, P. (1991), S. 13.

${ }^{83}$ Vgl. zu den empirischen Zielforschungen z.B. Steger, U. (1993), S. $193 \mathrm{ff}$.

${ }^{84}$ Vgl. Meffert, H./Kirchgeorg, M. (1998), S. 48.

${ }^{85}$ Vgl. Meffert, H./Kirchgeorg, M. (1989), S. $5 f f$.

${ }^{86}$ Strebel, H. (1980), S. 48.

${ }^{87}$ Vgl. Steger, U. (1993), S. $192 \mathrm{f}$.
} 
Die Erweiterung der betriebswirtschaftlichen Zielkonzeption um ökologische Zielgrößen wird als Voraussetzung dafür angesehen, um bei der Planung, Durchsetzung und Kontrolle ökonomischer Tätigkeiten eine Vermeidung und Verminderung von Umweltbelastungen sicherzustellen. Es besteht Einigkeit darüber, daß diese Zielsetzungen nicht dem Anspruch einer vollständigen Reduzierung von Umweltbeeinträchtigungen durch Unternehmen gerecht werden können, weil jede ökonomische Tätigkeit in Form von Produktion oder Konsum mit einer Beeinträchtigung der ökologischen Umwelt einhergeht. Ökologisch verpflichtete Unternehmensführung kann deshalb nur auf eine relative Verbesserung der Umweltqualität abzielen. In diesem Zusammenhang stellt sich unweigerlich die schwierige Frage, welches zulässige Ausmaß an Umweltbeeinträchtigungen aus ökologischer und gesellschaftlicher Sicht erstrebenswert und aus ökonomischer Sicht bei Sicherung der Wettbewerbsfähigkeit von Unternehmen noch vertretbar erscheint. Unter diesem Kalkül muß sich die ökologisch verpflichtete Unternehmensführung in besonderer Weise mit schlecht strukturierten Problemen auseinandersetzen, die sich durch Wirkungs-, Bewertungsund Zielsetzungsdefekte auszeichnen. Vielfach lassen sich die Wirkungsmechanismen zwischen unternehmensbedingten Emissionen und möglichen Umweltbeeinträchtigungen selbst im interdisziplinären Dialog nicht eindeutig klären. Darüber hinaus erschweren sowohl ökologische als auch ökonomische Bewertungsdefekte die Entscheidungsprozesse, weil Umweltqualitätsziele nicht eindeutig zu quantifizieren sind und die Märkte die wahren Knappheitspreise für den Verbrauch von ökologischen Ressourcen nicht widerspiegeln. Schließlich bedingen Zielkonflikte zwischen Ökonomie und Ökologie vielfach ein Entscheidungsdilemma, das letztlich nur durch Werturteile der einzelnen Entscheidungsträger zu lösen ist. ${ }^{88}$

\subsection{Integration ökologisch verpflichteten Wirtschaftens in die Unternehmensstrategien}

Im Mittelpunkt der strategischen Aktivitäten des Unternehmens steht die Konkretisierung der ökologisch verpflichteten Unternehmenspolitik durch Umweltstrategien. Die Umweltschutzstrategien dienen somit der längerfristigen und stufenweise geplanten Entwicklung von Handlungsleitlinien zur Erreichung der im ökologieorientierten Zielsystem festgelegten Position. Sie haben damit den Aufbau ökologisch möglichst effizienter Markterfolgspotentiale zum Ziel. Diese ökologische Grundhaltung bildet den Handlungsrahmen für die Art (Objektdimension), den Umfang (Intensitätsdimension) und das Timing (Zeitdimension) der operativen Umsetzung ökologieorientierter Unternehmensaktivitäten. ${ }^{89}$ Zielsetzung ist es dabei, sowohl die angestrebten Umweltverbesserungsziele zu erreichen als auch die Wettbewerbsfähigkeit des Unternehmens zu erhö-

\footnotetext{
${ }^{88}$ Vgl. Meffert, H. (1996), S. 2.

${ }^{89}$ Vgl. Kirchgeorg, M. (1990), S. 15.
} 
hen. Für die ökologisch verpflichtete Unternehmensführung besteht die Herausforderung darin, durch eine marktorientierte Ausrichtung im Gegensatz zu einer ausschließlich innenorientierten Umweltschutzstrategie die Marktchancen, welche sich durch Ökologie-Pull-Effekte ergeben können, konsequent wahrzunehmen und damit die Wettbewerbsfähigkeit eines Unternehmens zu erhöhen. Eine Umweltschutzstrategie bildet damit das Bindeglied zwischen den konkreten Umweltschutzzielen und den einzelnen Maßnahmen in den operativen Bereichen. Sie umfaßt strukturierende Maßnahmenbündel, innerhalb derer die konkreten Umweltschutzmaßnahmen in den einzelnen Unternehmensfunktionen als operativer Planungsprozeß vollzogen werden. ${ }^{90}$

\begin{tabular}{|c|c|}
\hline \multicolumn{2}{|c|}{ Strategische Anpassungsalternativen } \\
\hline Defensives Verhalten & Offensives Verhalten \\
\hline Konflikthandhabung & Konflikthandhabung \\
\hline - $\quad$ Reaktiv bzw. passiv & - $\quad$ Proaktiv bzw. aktiv \\
\hline - $\quad$ Statisch & - Dynamisch \\
\hline - Abwartend & - Vorausschauend \\
\hline - Beschränkend & - $\quad$ Beeinflussend \\
\hline - Kompensierend & - Vermeidend \\
\hline - Anpassend & - Innovativ \\
\hline - $\quad$ Isoliert & - Integriert \\
\hline - $\quad$ Individuell & - Kooperativ \\
\hline - Unternehmensbezogen & - Anspruchsgruppenbezogen \\
\hline - Sachzwänge & - $\quad$ Eigenständige Konzeption \\
\hline Wettbewerbswirkung & Wettbewerbswirkung \\
\hline - Hinnahme & - $\quad$ Gestaltung \\
\hline - $\quad$ Gegenwartsorientierung & - Zukunftsorientierung \\
\hline - $\quad$ Krisenmanagement & - Chancenmanagement \\
\hline
\end{tabular}

Abb. 4.7: Ökologiebezogenes strategisches Anpassungsverhalten

(Quelle: Zahn, E./Schmid, U. (1992), S. 58)

Im Rahmen der ökologisch verpflichteten Betriebswirtschaftslehre wurden eine Anzahl von Strategietypologien entwickelt, die eine Klassifizierung möglicher Strategien zum Umweltschutz vornehmen und teilweise aus empirischen Studien abgeleitet wurden. ${ }^{91}$ Auf die Einflußnahme der Ökologie kann stellvertretend die häufig in der Literatur vorgenommene Differenzierung zwischen einer passiven (bzw. defensiven) und einer aktiven (bzw. offensiven) Umweltschutz-

\footnotetext{
${ }^{90}$ Vgl. Meffert, H./Kirchgeorg, M. (1998), S. 195.

${ }^{91}$ Eine ausführliche Strategietypologie im Überblick findet sich z.B. bei Meffert, H./Kirchgeorg, M. (1998), S. 197; Macharzina, K. (1995), S. 855ff.; Steger, U. (1993), S. 210ff.; Zahn, E./Schmid, U. (1992), S. 57ff.
} 
strategie betrachtet werden, wobei diese beiden Verhaltensweisen je nach individueller Situation des Unternehmens $\mathrm{zu}$ differenzieren sind (vgl. Abb. 4.7). Die passive Umweltschutzstrategie wird dadurch gekennzeichnet, daß das Unternehmen erst Umweltschutzmaßnahmen ergreift, wenn gesetzgeberische Aktivitäten es erfordern. Bei der Verfolgung der aktiven Strategie werden Umweltprobleme im vornhinein in die Planungsüberlegungen einbezogen. ${ }^{92}$ Eine offensive Umweltstrategie ist wegen der Chancen $\mathrm{zu}$ Kostensenkungen, Vermeidung von Entsorgungsproblemen, Umsatzsteigerung, Imageverbesserungen u.a. einer defensiven vorzuziehen. ${ }^{93}$

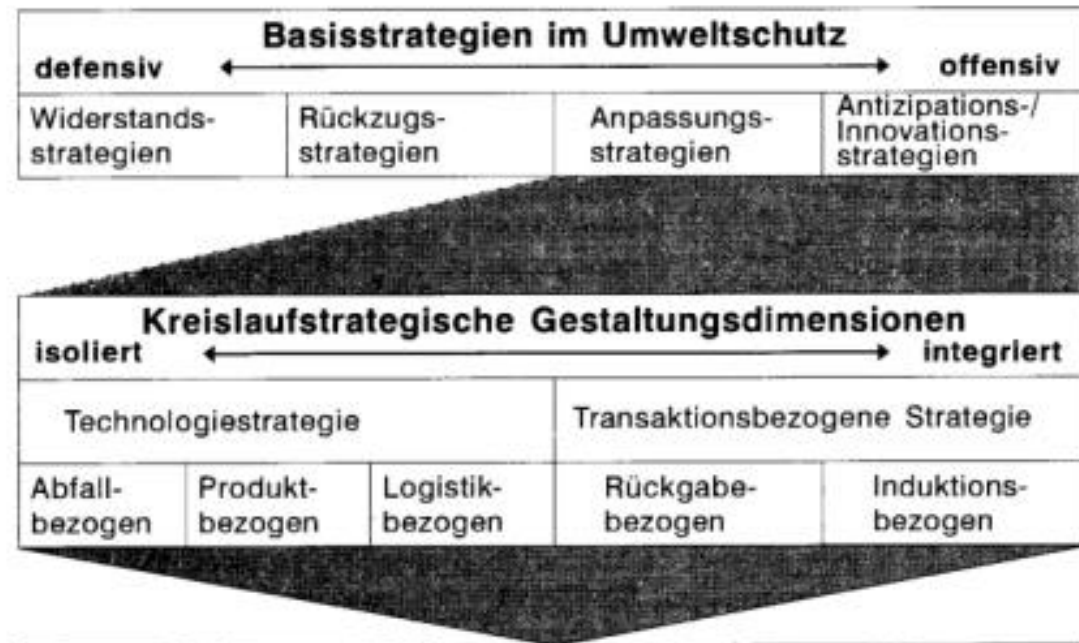

\begin{tabular}{|c|c|}
\hline \multicolumn{2}{|c|}{ Wettbewerbsstrategische Gestaltungsdimensionen } \\
\hline Qualitätsführerschaft & Kostenführerschaft \\
\hline Nischen-/Gesamtmarktorientierung \\
\hline \multicolumn{2}{|c|}{ Internationale Gestaltungsdimensionen } \\
\hline \multicolumn{2}{|c|}{ Differenzierung } \\
\hline Standardisierung & produkt- und prozeßbezogen \\
\hline
\end{tabular}

\begin{tabular}{|l|l|l|l|}
\hline \multicolumn{4}{|c|}{ Risikostrategische Gestaltungsdimensionen } \\
\hline Vermeidung & Verminderung & Überwälzung & "Selbst-tragen" \\
\hline \multicolumn{3}{|c|}{ Risikodialog } \\
\hline
\end{tabular}

Abb. 4.8: Strategische Grundsatzentscheidungen in der ökologisch verpflichteten

Unternehmensführung (Quelle: Meffert, H./Kirchgeorg, M. (1998), S. 196)

${ }^{92}$ Vgl. Meffert, H./Bruhn, M./Schubert, F./Walther, T. (1986), S. 148. 
Die strategischen Anpassungsalternativen des defensiven und offensiven Umweltschutzverhaltens mit den jeweiligen Ausprägungen der Konkurrenzhandhabung und Wettbewerbswirkung lassen sich nach Meffert/Kirchgeorg weiter in Basisstrategien (Widerstand, Passivität, Rückzug, Anpassung und Innovation) unterscheiden. (vgl. Abb. 4.8). ${ }^{94}$ Diese Basisstrategien des Umweltschutzes lassen sich auf der Grundlage folgender strategischer Grunddimensionen ableiten: ${ }^{95}$

- Ökologieorientierte Anpassungsintensität (Unterscheidung in aktives bzw. offensives und passives bzw. defensives Verhalten mit den jeweiligen Ausprägungen),

- Verhaltensbezugsebene der Umweltstrategien (Strategieobjekt; extern: Markt/Wettbewerber, Gesellschaft und intern: Unternehmen/innengerichtet),

- Zeitpunkt der Strategieentwicklung und Maßnahmenrealisierung (Zeitbezug proaktiv: Reaktion auf erste ,schwache Signale“ im Vorfeld konkreter Umweltschutzforderungen und somit Ausnutzung eines Zeitvorteils, das in Image- und Ertragsvorteile gegenüber reaktiven Wettbewerbern umgesetzt werden kann; Zeitbezug reaktiv: Umweltschutzerfordernisse werden erst durch eine Betroffenheitssituation, z.B. Umweltschutzgesetze, berücksichtigt),

- Art der Strategieentwicklung (integriert: Ausrichtung der Umweltschutzstrategie auf alle Unternehmensfunktionen und -bereiche; isoliert: Berücksichtigung nur partieller Aspekte des Umweltschutzes, z.B. im Produktionsbereich),

- Form der Durchsetzung der Strategie (kooperativ: Kooperation mit anderen Unternehmen der Branchen, mit Zulieferern oder Abnehmern, Verhaltensabstimmungen in Form von Branchenabkommen hinsichtlich der Umweltschutzmaßnahmen; individuell: alleinige Entwicklung und Durchsetzung von Umweltschutzstrategien).

Die Basisstrategien sind jeweils durch folgende Merkmale gekennzeichnet: ${ }^{96}$

- Widerstandsstrategie: Sie ist im Hinblick auf die ökologieorientierte Anpassungsintensität gekennzeichnet durch ein passives Verhalten, was die ökologieorientierte Anpassungsintensität betrifft, während gesellschafts- und marktbezogenen Umweltschutzforderungen aktiv mit einer Konfrontation begegnet wird (z.B. als Reaktion auf die Umweltschutzanforderungen von Bürgerinitiativen). Im Vordergrund steht dabei aber nicht zwangsläufig ein rein passives Verhalten, sondern die Anwendung des Risiko-Managements. Allgemein ist RisikoManagement darauf gerichtet, Störpotentiale, die eine Realisierung von Absichten, Erwar-

\footnotetext{
${ }^{93}$ Vgl. z.B. Hopfenbeck, W. (1994); Zahn, E./Schmid, U. (1992), S. 57ff.

${ }^{94}$ Vgl. Meffert, H./Kirchgeorg, M. (1998), S. 195ff.

95 Vgl. Meffert, H./Kirchgeorg, M. (1998), S. 198ff.
} 
tungen und Plänen des Unternehmens aufgrund von Störprozessen verhindern, besser zu erkennen, zu beurteilen und durch die Berücksichtigung in der Organisation und bei allen Führungsaufgaben und -entscheidungen abzubauen. ${ }^{97}$ Grundsätzlich wirken Widerstandsstrategien der Erreichung ökologischer Zielsetzungen im Sinne der Vermeidung und Verminderung von Umweltbelastungen entgegen. Langfristig kann die Verfolgung dieser Strategie die gesellschaftliche Legitimität des Unternehmens gefährden. Zudem kann die Vernachlässigung marktbezogener Chancen langfristig zur Beeinträchtigung der Wettbewerbsposition führen. Diese Strategie ist demnach dann sinnvoll, wenn Unternehmen gar nicht oder nur in geringem Maße von ökologischen Problemstellungen betroffen sind und bei großen eigenen Umweltrisiken geringe Marktchancen durch den Umweltschutz bestehen.

- Passivität: Passivitätsstrategie ist durch „Nicht-Verhalten“ und Ignoranz von Umweltproblemen gekennzeichnet. Bezogen auf die gesellschaftliche Legitimität wird sich das passive Verhalten im Gegensatz zur aktiven Widerstandsstrategie weniger stark auswirken, da das Unternehmen sich gegenüber externen Anspruchsgruppen nicht explizit gegen eine Integration ökologischer Forderungen ausspricht.

- Rückzugsstrategie: Beim Verfolgen einer Rückzugsstrategie versucht das Unternehmen, sich artikulierten Umweltschutzanforderungen $\mathrm{zu}$ entziehen, weil keine adäquaten Anpassungsmöglichkeiten zur Lösung bestehender Umweltprobleme gesehen werden. Bezogen auf die Verhaltensbezugsebene kann sich der Rückzug als betriebsbezogene Strategie, z.B. auf die Verlagerung von Teilen umweltbelastender Unternehmensfunktionen wie Produktion oder Entsorgung ins Ausland beziehen. Dadurch entzieht sich das Unternehmen der nationalen Umweltgesetzgebung und kann evtl. auch international wettbewerbsbezogene Kostennachteile durch die Vermeidung gesetzlich bedingter Umweltschutzinvestitionen ausgleichen. Es geschieht jedoch keine Vermeidung oder Verminderung von Umweltbelastungen, sondern diese werden lediglich regional verlagert, die Legitimität im Inland jedoch gesichert. Demgegenüber besteht für das Unternehmen aufgrund einer zunehmend internationalen Vernetzung von Umweltschutzverbänden, wie z.B. Greenpeace, wiederum die Gefahr entsprechender Kritik. Der komplette Rückzug aus einem Geschäftsfeld, d.h. das nicht mehr Weiterproduzieren eines Produktes oder einer Produktgruppe, hat die vollständige Vermeidung von durch Produktion, Nutzung und Entsorgung bedingten Umweltbelastungen zur Folge, jedoch werden marktbezogene Chancen des Umweltschutzes den Wettbewerbern überlassen.

\footnotetext{
96 Vgl. Meffert, H./Kirchgeorg, M. (1998), S. 202ff.; Zahn, E./Schmid, U. (1992), S. 59f.; Steger, U. (1993), S. $203 \mathrm{ff}$.

${ }^{97}$ Die Anwendung von risikopolitisch orientierten Unternehmensstrategien kann weitgehende Initiativen voraussetzen, während das rein passives oder defensives Verhalten als ein initiativloses Befolgen staatlicher Anforderungen wie z.B. Auflagen zu verstehen ist. Die risikoorientierten Strategien sind vorrangig auf die langfristige Existenzs i-
} 
- Anpassungsstrategie: Die Anpassung betrifft die gesetzlich bedingte Berücksichtigung von Erfordernissen des Umweltschutzes, wobei diesen Anforderungen lediglich entsprochen wird, ohne marktbezogene Chancen des Umweltschutzes innovativ zu nutzen. Die aus den externen Sachzwängen resultierenden Anpassungen, d.h. Umweltschutzmaßnahmen werden isoliert für speziell aktuelle Umweltprobleme in einzelnen Unternehmensbereichen entwickelt und durchgeführt. Die Anpassungsstrategie kann von einzelnen Unternehmen und/oder von einer ganzen Branche verfolgt werden.

- Antizipations- und Innovationsstrategie: Hierbei identifiziert das Unternehmen unabhängig von gesellschaftlichen oder marktbezogenen Umweltschutzforderungen ökologische Problemfelder und begegnet ihnen mit einer integrierten, auf alle Unternehmensbereiche ausgerichteten Strategie innovativ. Diese Strategie ist dann zweckmäßig, wenn sich bei eigenen großen Umweltrisiken gleichzeitig große Marktchancen durch Umweltschutz oder umweltfreundliche Produkte ergeben oder durch umweltfreundlichere Produktionsverfahren die Umweltbelastungen reduziert werden können. Die Antizipationsstrategie ist also in besonderem Maße geeignet, ökologieorientierte Wettbewerbsvorteile zu erreichen, denn das Unternehmen begegnet in seinen spezifischen Stärken den Umweltproblemen innovativ und aus einer integrierten Gesamtsicht. Antizipationsstrategien zeichnen sich dadurch aus, daß der strategische Handlungsspielraum genutzt wird, um systembezogene bzw. integrierte Umweltschutzinnovationen $\mathrm{zu}$ entwickeln, die abgestimmte Verhaltensweisen in unterschiedlichen Unternehmensfunktionen auf der Basis differenzierter ökologieorientierter Informationsgrundlagen umfassen und dadurch von Konkurrenten nicht so schnell kopiert werden können.

Im Zusammenhang mit der Kennzeichnung des Merkmals der integrierten Strategieentwicklung wird hervorgehoben, daß durch eine Orientierung am Kreislaufprinzip unternehmensbezogene Verhaltensschwerpunkte für eine funktions- und unternehmensübergreifende Entwicklung von Umweltschutzstrategien identifiziert werden können. Beim Übergang von der sog. Durchflußwirtschaft zu einer Kreislaufwirtschaft sind zusätzliche güter- oder stoffbezogene Transformations- und Transaktionsphasen in die Betrachtungen einzubeziehen, deren Ausgestaltung im Rahmen der Konkretisierung einer umweltorientierten Basisstrategie zu berücksichtigen ist. ${ }^{98}$

Kreislaufstrategische Gestaltungsdimensionen beziehen sich dabei auf die stofflichen Transformationsphasen und die Transaktionsphasen eines künstlich zu gestaltenden Stoffkreislaufes. Sie unterscheiden sich in technologischen Optionen zur Gestaltung kreislaufspezifischer Strategien 
und in strategischen Optionen zur Gestaltung von rückgabe- und induktionsorientierten Transaktionen: ${ }^{99}$

Bei der Betrachtung der zentralen stofflichen Transformationsphasen bei der Herstellung, Verwendung, physischen Rückführung von Abfällen sowie ihrer Aufarbeitung und Aufbereitung in der Reduktionsphase erfordert die Gestaltung von Stoffkreisläufen eine Neuausrichtung und Erweiterung der Technologiestrategie von Unternehmen. Als sog. kreislaufspezifische Technologien können jene Problemlösungen verstanden werden, die im weitesten Sinne durch die Transformation von stofflichen Eigenschaften in qualitativer, quantitativer, zeitlicher und räumlicher Hinsicht einen Beitrag zur Erreichung kreislaufwirtschaftlicher Ziele leisten (Ressourcenschonung und Abfallverringerung). Entsprechende technologische Ansatzpunkte zur Gestaltung von produktbezogenen Stoffkreisläufen ergeben sich in der Herstellungs-, Kollektions- und Reduktionsphase eines Kreislaufzykluses.

Die Gestaltung der Reduktionsphase erfordert den Einsatz von abfallbezogenen Technologien d.h. Recycling- bzw. Reduktionstechnologie. Sie stellen darauf ab, Produkte mit ihrer spezifischen Abfallcharakteristik nach der Nutzungsphase einer Verwendung oder Verwertung zuzuführen. Je nachdem, ob durch den Einsatz von Reduktionstechnologien der Erhalt oder die Zerstörung der in einem Altprodukt möglicherweise noch vorhandenen Wertschöpfung aus dem erstmaligen Erstellungsprozeß bewirkt werden, sind zwischen komponentenbezogenen und stoffbezogenen bzw. energetischen Basistechnologien zu unterscheiden. Während Technologien der komponentenbezogenen Reduktion durch Zerlegung eines Altproduktes die physische und stoffliche Gestalt von Komponenten bzw. Bauteilen unverändert lassen, wird bei der Anwendung materialer und stofflicher Reduktionstechnologien die physische Gestalt von Komponenten aufgelöst und eine stoffliche Trennung bzw. Umwandlung durch mechanische, chemische, biologische oder thermische Verwertungsverfahren vorgenommen. Während beim komponentenbezogenen Recycling ein hohes Maß an Wertschöpfung, die zur Komponentenerstellung im Erstellungsprozeß aufgewendet wurde, erhalten bleiben, wird beim Material- und stofflichen Recycling die in der Kombinationsleistung begründete Wertschöpfung eines Produktes vernichtet.

Wird hingegen zu Beginn eines Produktlebenszyklusses in der Herstellungsphase bereits bei der Forschung und Entwicklung durch veränderte Produkttechnologien oder auch Produktionstechnologien durch eine kreislaufgerechte Konstruktion die zukünftige Abfallcharakteristik eines

\footnotetext{
${ }^{98} \mathrm{Vgl.} \mathrm{zu}$ den Bedeutungsinhalten der Kreislaufwirtschaft Kap. 1.4 und dort angegebenen Literaturen.

${ }^{99}$ Vgl. Meffert, H./Kirchgeorg, M. (1998), S. $208 f f$.
} 
Produktes beeinflußt, können diese Problemlösungen als integrierte Umweltschutztechnologien bezeichnet werden. Während die abfall- und produktbezogenen Technologien auf die quantitative und qualitative Dimension des Abfalls einwirken, ist durch die Einbeziehung logistischer Technologien die Schließung eines Stoffkreislaufs in räumlicher und zeitlicher Hinsicht, d.h. die Rückführung der Altprodukte von den Produktverwendern bis zum Ort zur Ausführung des Reduktionsprozesses, zu erzielen. Somit stellen die logistischen Technologien eine weitere Dimension zur Spezifizierung der Technologiestrategien dar. Grundsätzlich kann zwischen zwei zentralen Gestaltungsdimensionen, den Bring- und Holsystemen unterschieden werden. Bei sog. Bringsystemen werden Rückgabeorte definiert, zu denen die Altprodukte durch die jeweiligen Letztverwender transportiert werden müssen. Bei Holsystemen werden die Altprodukte direkt durch den Letztbesitzer abgeholt und an einem von ihm bestimmten Ort gebracht.

Die Auswahl adäquater Technologien zur Gestaltung eines Stoffkreislaufes kann nur auf der Grundlage ganzheitlicher, d.h. auf den gesamten Kreislaufzyklus aufgerichteten Ökobilanzen erfolgen, um sicherzustellen, daß tatsächlich ein ökologischer Nettoeffekt zur Ressourcenschonung und Abfallverringerung gewährleistet werden kann.

Neben den technologischen Grundsatzentscheidungen sind im Rahmen einer kreislauforientierten Ausrichtung der umweltorientierten Basisstrategie auch die in einem Stoffkreislauf neu zu gestaltenden Transaktionsphasen zur Kollektion und Induktion von Abfällen zu berücksichtigen. ${ }^{100}$ Ein möglichst hoher Geschlossenheitsgrad eines Stoffkreislaufes, z.B. für Altprodukte, wird nur dann erreicht, wenn sichergestellt werden kann, daß die Altprodukte vom Verwender wieder in ein entsprechend bereitgestelltes Recyclingsystem zurückgegeben werden und die aus den Recycling- bzw. Reduktionsprozessen resultierenden Sekundärkomponenten bzw. -stoffe auch wieder in den Wirtschaftsprozeß eingeführt werden können. Eine wichtige Phase zur Erschließung eines Kreislaufzyklusses stellt die Kollektionsphase dar, in der die Rückgabetransaktionen der produktbezogenen Abfälle stattfinden. Neben der Entscheidung über die einzusetzenden logistischen Technologien sind die zentralen Bedingungen der Rückgabetransaktionen festzulegen, worunter im Rahmen der strategischen Ausrichtung die Grundsatzentscheidung zu treffen ist, ob die Hersteller die Altprodukterückgabe primär kosten- oder prämienbezogen oder kostenneutral ausgestalten. ${ }^{101}$

\footnotetext{
${ }^{100}$ Vgl. Kirchgeorg, M. (1998).

${ }^{101}$ Vgl. Meffert, H./Kirchgeorg, M. (1998), S. $212 f$.
} 
Während Hersteller über die Gestaltung der Kontrahierungsformen für die Rückgabetransaktion das Rückgabeverhalten der Produktverwender beeinflussen können, sind die marktstrategischen Optionen zur Gestaltung der induktionsorientierten Transaktionen auf den erneuerten Einsatz von Sekundärkomponenten bzw. -stoffen ausgerichtet. ${ }^{102}$ Für die Systematisierung von induktionsbezogenen Strategieoptionen stellt sich aus der Herstellersicht grundsätzlich die Frage, welche Art von Sekundärmaterialien (Komponenten, stoffliche Fraktionen) und in welcher Form (direkt, indirekt), auf welchen Märkten (bestehende, neue) abgesetzt werden können.

Die oben skizzierten technologie- bzw. transformations- sowie transaktionsorientierten Optionen zur Gestaltung von Stoffkreisläufen für Produkte können in ihrer Verknüpfung zur Konzeptionalisierung von kreislaufspezifischen Basisstrategien herangezogen werden. Eine offensive und integrierte Gestaltung von Stoffkreisläufen zeichnet sich dadurch aus, daß produktverantwortliche Hersteller kreislaufspezifische Maßnahmen auf alle Phasen eines Kreislaufzyklusses ausrichten. Demgegenüber impliziert eine defensive Basisstrategie die isolierte Konzentration auf wenige Teilprobleme und ein end-of-pipe-orientiertes Anpassungsverhalten. Hersteller versuchen im Rahmen dieser strategischen Grundausrichtung in ihrer bestehenden Wertkette, grundlegende Veränderungen aufgrund der Berücksichtigung kreislaufspezifischer Anforderungen zu vermeiden, und versuchen der erweiterten Produktverantwortung dadurch gerecht $\mathrm{zu}$ werden, daß sie sich nur auf die Schaffung der notwendigen Voraussetzungen der Kollektion der Altprodukte konzentrieren und dabei i.d.R. auf Systempartner auslagern.

Zieht man das Merkmal der isolierten und integrierten Gestaltungsschwerpunkte und die technologie- und transaktionsorientierten Gestaltungsdimensionen zur Ableitung kreislaufspezifischer Strategien heran, können die folgenden kreislaufspezifischen Basisstrategien unterschieden werden: ${ }^{103}$

- Abfallfokussierte Anpassungsstrategie: Bei der Verfolgung dieser Strategie konzentrieren sich die Unternehmen auf eine isolierte Anpassung der Abfalltechnologien an die bestehende Produktcharakteristik und ergreifen die notwendigen Maßnahmen zur Sicherung der Kollektion von Altprodukten.

\footnotetext{
${ }^{102}$ Die Problemstellungen des erneuerten Einsatzes von Sekundärmaterialien zum Recycling werden danach abgegrenzt, in welchen Produktionsprozeß sie wieder eingeführt werden. In diesem Zusammenhang werden zwischen Wieder- und Weitereinsatz von Sekundärmaterialien unterscheiden. Bei Wiedereinsatzstrategien wird die aus dem Reduktionsprozeß kommenden Sekundärmaterialien in jeden Produktionsprozeß zurückgeführt, in den sie auch in einem ersten Kreislaufzyklus für die Neuerstellung eines Produktes einbezogen wurden. Hingegen findet der Begriff des Weitereinsatzes Anwendung, wenn Sekundärmaterialien i.d.R. in anderen Produktionsprozessen bzw. in anderen Unternehmen zum Einsatz gelangen. Vgl. Meffert, H./Kirchgeorg, M. (1998), S. 213.

${ }^{103}$ Vgl. Meffert, H./Kirchgeorg, M. (1998), S. 219ff.
} 
- Abfallfokussierte Kreislaufprofilierung läßt sich dadurch charakterisieren, daß Hersteller die Einbeziehung von Sekundärmaterialien in die eigene Produktion vornehmen und/oder eine gewerbliche Herausstellung einer Recyclinggarantie beim Absatz der Neuprodukte anstreben, wenngleich Vorinvestitionen in einer kreislaufgerechten Produktgestaltung nicht erfolgen und Anpassungserfordernisse in bestehenden Unternehmensfunktionen nur selektiv (z.B. veränderte Werbung im Marketing) gesehen werden.

- Produktintegrierte Kreislaufanpassung: Bei dieser strategischen Ausrichtung konzentrieren sich die Hersteller überwiegend auf die vom (Kreislaufwirtschafts-) Gesetz geforderte Kollektion zur Rückführung von Altprodukten, während sie hingegen bei der technologischen Ausrichtung neben den notwendigen technologischen Gestaltungsoptionen für die Reduktionsprozesse auch Anpassungen der Produktkonstruktion vornehmen. Maßnahmen zur Erschließung von Induktionsmöglichkeiten und zur wettbewerbsstrategischen Profilierung stehen bei dieser Basisstrategie jedoch nicht im Vordergrund.

- Produktintegrierte Kreislaufprofilierung: Diese Basisstrategie kann durch eine integrierte Technologiestrategie und aktive Erschließung von Induktionsmöglichkeiten für Sekundärmaterialien gekennzeichnet werden.

Neben dem Verfolgen der angeführten Basisstrategien gilt es, zusätzlich die wettbewerbsstrategische Ausrichtung des Unternehmens am Markt zu berücksichtigen. Grundlegende Zielsetzung bei der Berücksichtigung von Wettbewerbsstrategien ist die Entwicklung und Kultivierung einer unternehmensspezifischen Kompetenz, durch die gegenüber der Konkurrenz Wettbewerbsvorteile aufgebaut und abgesichert werden sollen. ${ }^{104}$ Diese Zielsetzung kann erreicht werden durch das Verfolgen der Strategien der Kosten- oder Qualitätsführerschaft unter Berücksichtigung der Aspekte Marktraum (Nischen-/Gesamtmarktorientierung) und Zeit (Timingstrategie). ${ }^{105}$

Unter Verfolgung einer proaktiven Innovationsstrategie ergeben sich für Wettbewerbsstrategien verschiedene Verhaltensmöglichkeiten. Das Unternehmen kann sich durch Schaffung qualitativer Produktvorteile über die zusätzliche Produktion von umweltfreundlichen Produkten bei ökologisch sensibilisierten Zielgruppen profilieren und gegenüber dem Wettbewerb differenzieren. Diese Qualitätsführerschaftsstrategie soll den differenzierten Abnehmerbedürfnissen besser gerecht werden. Im Rahmen der Qualitätführerschaft kommt der Produktentwicklung eine herausragende Bedeutung zu, denn durch sie werden alle Produkteigenschaften, z.B. die Produktnutzung oder die Entsorgbarkeit von Produkten, festgelegt. Umweltschutzbelange bieten als zusätz-

${ }^{104}$ Vgl. Meffert, H./Kirchgeorg, M. (1998), S. 221ff. 
liche Qualitätsdimension erweiterte Differenzierungspotentiale zur Erlangung von Wettbewerbsvorteilen. Von entscheidender Bedeutung für die Verfolgung der Qualitätsführerschaftsstrategie im Hinblick auf eine innovative Basisstrategie ist die Innovationsfähigkeit des Unternehmens, d.h. die Leistungsfähigkeit bezogen auf das Hervorbringen von (umweltverträglichen) Neuerungen. Die Innovationsfähigkeit wird wesentlich bestimmt durch die im Unternehmen vorhandenen Innovationspotentiale, z.B. technisches Innovationspotential, und das unternehmensspezifische Innovationsklima als Gesamtheit interner Rahmenbedingungen bzw. organisatorischer Voraussetzungen für die Hervorbringung von Neuerungen.

Bei der ökologieorientierten Kosten- oder Preisführerschaft wird durch produktivitätssteigernde Verfahrensinnovation sowie Standardisierung versucht, die Stïckkosten der ökologieorientierten (Neu-)Produkte unter das Niveau der wichtigsten Wettbewerber zu senken und durch relativ niedrige Preise Wettbewerbsvorteile zu erzielen. Als ökonomische „Effizienzstrategie“ weist die Kostenführerschaft auch eine ökologische Effizient auf. So können über Erfahrungskurveneffekte Ausschlußquoten verringert werden, was zu Rohstoff- und/oder Energieeinsparungen führen kann. Über Recyclingverfahren können Produktionsabfälle minimiert und somit Entsorgungskosten gespart werden. Auch gibt es viele Bereiche, in denen umweltschädigende und teure Rohstoffe durch umweltverträgliche und billigere Rohstoffe oder Recyclingmaterialien ersetzt werden können.

Die Strategie der Qualitätsführerschaft zielt auf eine möglichst breite Marktabdeckung ab und setzt eine günstige Marktposition und hohe Marktmacht des Unternehmens voraus. Sind diese Voraussetzungen nicht gegeben, erscheint eine qualitätsorientierte Nischenstrategie mit Spezialisierung auf bestimmte Marktsegmente sinnvoll.

Gerade auf der strategischen Ebene wird dem Zeitfaktor in der betriebswirtschaftlichen Forschung eine wesentliche Rolle eingeräumt. Die grundlegende Entscheidung der Timingstrategie betrifft die Frage, ob eine umweltorientierte Profilierung zeitlich vor oder nach den Hauptwettbewerbern geschehen soll (Pionier- oder Folgerstrategie). Danach ist eine weitere Typisierung der umweltbezogenen Basisstrategie nach dem Zeitbezug in reaktives und proaktives Verhalten möglich. Bei reaktivem Verhalten werden Umweltschutzmaßnahmen erst in einer aktuellen Betroffenheitssituation ergriffen. Proaktives Verhalten zeichnet sich hingegen dadurch aus, daß gesellschaftliche Umweltschutzansprüche bereits im unternehmerischen Planungs- und Entschei-

105 Vgl. zur wettbewerbsstrategischen Ausrichtung des Unternehmens: Porte, M. (1984); Macharzina, K. (1995), S. 855ff.; Meffert, H./Kirchgeorg, M. (1998), S. $222 \mathrm{ff.}$ 
dungsprozeß antizipiert und Problemlösungen für ökologische Folgen der Unternehmensaktivitäten entwickelt werden. Durch diese Strategie können Unternehmen einen Zeitvorsprung in Form von Image- und Ertragsvorteilen erlangen, sofern es ihnen gelingt, sich durch innovative Lösungen in der Öffentlichkeit und auf dem Markt als umweltbewußtes Unternehmen zu profilieren. ${ }^{106}$ Eine positive Verbindung von ökologischen und ökonomischen Zielsetzungen, insbesondere die langfristige Aufrechterhaltung der Wettbewerbsfähigkeit im Rahmen der Unternehmenstätigkeit, läßt sich nur dann erzielen, wenn ein genügend großer zeitlicher Spielraum für die Implementierung von Umweltschutzstrategien zur Verfügung steht, d.h. wenn Entwicklungen der Unternehmensumwelt durch ein proaktives bzw. offensives Umweltschutzmanagement frühzeitig antizipiert werden. $^{107}$

Angesicht der Globalisierung der Umweltprobleme und der Wirtschaft sehen sich die international tätige Unternehmen vielfach unterschiedlichen sozio-kulturellen, politisch-rechtlichen und ökonomischen Umfeldeinflüssen in einzelnen Ländern ausgesetzt und verursachen durch ihre Unternehmenstätigkeit grenzüberschreitende Einwirkungen auf die natürlichen Umwelt. Somit kommt den Unternehmen eine Rolle als Mitverursacher von ökologischen Problemen in verschiedenen Ländern zu, und sie sehen sich länderspezifischen Umweltschutzforderungen ggf. in unterschiedlichem Umfang ausgesetzt. Damit erlangen international divergierende Umweltschutzansprüche und Standortbedingungen bei der strategischen Ausrichtung der ökologisch verpflichteten Unternehmensführung eine besondere Relevanz.

Brodel analysierte, welche Verbundeffekte bei multinationalen Unternehmen für die standardisierte oder differenzierte Ausrichtung einer internationalen Umweltschutzstrategie eine Rolle spielen. ${ }^{108}$ Dabei wurden unterschiedlichen Internalisierungsniveaus von externen Kosten besondere Berücksichtigung geschenkt. In diesem Zusammenhang wurde zwischen einer internationalen Internalisierung und Externalisierung von Umweltkosten unterschieden. Eine internationale ökologische Internalisierung liegt bei einem multinationalen Unternehmen dann vor, wenn im Gesamtunternehmensverbund im Vergleich zu einem nationalen Unternehmen ein verbessertes Umweltschutzniveau realisiert ist. Demgegenüber wird als internationale ökologische Externalisierung das Herunterfahren der betrieblichen Umweltschutzstandards gegenüber national tätigen Unternehmen bezeichnet.

\footnotetext{
${ }^{106}$ Vgl. Meffert, H./Kirchgeorg, M. (1998), S. 231f.

${ }^{107}$ Vgl. Macharzina, K. (1993), S. 787; Meffert, H./Kirchgeorg, M. (1998), S. 231f.; Wicke, L. (1988), S. $30 \mathrm{ff}$.

${ }^{108}$ Vgl. Brodel, D. (1996).
} 
Als relevante Einflußgrößen, die eine internationale ökologische Internalisierung oder Externalisierung fördern, können folgende Faktoren hervorgehoben werden: ${ }^{109}$

- Durch den länderübergreifenden Einsatz von Unternehmens-Know-how im Umweltschutz lassen sich über die Nutzung internationaler Erfahrungskurveneffekte Wettbewerbsvorteile erzielen, d.h. entsprechende Effekte fördern eine internationale Internalisierung.

- Die Ausnutzung von Kostendegressionseffekten erfordert i.d.R. eine internationale Produktwie auch Prozeßstandardisierung. Dementsprechend erweist es sich tendenziell als vorteilhaft, wenn die Produkte nach Maßgabe der strengsten nationalen Umweltschutznormen standardisiert hergestellt werden.

- Die internationale Harmonisierung der Umweltschutzgesetze sowie mögliche Angleichungen der Marktbedürfnisse hinsichtlich der Umweltverträglichkeit von Produkten und der Herstellungs- und Entsorgungsprozesse (Global-Village-Effekt) fördern weiterhin die internationale ökologische Internalisierung.

- Internationale Transferbarrieren zum Umweltschutz (z.B. Einfuhrverbote für Produkte mit bestimmten Substanzen, Rücknahmepflichten für Altprodukte etc.) führen tendenziell zu einer Angleichung der Umweltschutsstandards international tätiger Unternehmen.

- Die Ausnutzung internationaler Faktorunterschiede kann bei multinationalen Unternehmen zur Ausschöpfung umweltschutzbezogener Arbitrage-Effekte führen, die tendenziell mit einer internationalen Externalisierung von Umweltschutzkosten einhergehen. Sofern die Ressourcen in bestimmten Ländern z.B. durch nicht umweltverträgliche Gewinnungsmethoden oder durch nicht nachhaltige Nutzung international zu Dumpingpreisen angeboten werden, können multinationale Unternehmen diese Ressourcen durch länderübergreifende Logistikprozesse weltweit für alle Produktionsstandorte verfügbar machen.

- Bei der Anhebung von Umweltschutzstandards in bestimmten Ländern können multinationale Unternehmen durch eine nationale Rückzugsstrategie und Standortverlagerung in jene Länder ausweichen, in denen geringere Umweltschutzanforderungen an die Wirtschaft gestellt werden, damit die $\mathrm{zu}$ internalisierenden Umweltkosten geringer ausfallen (Entwicklungsstand-Portfolio-Effekte).

- Koordinations- und Komplexitätsbarrieren werden als Gründe für einen eher geringen Standardisierungsgrad internationaler Umweltschutzstrategien angeführt.

Je nach Kontextbedingungen und den hieraus resultierenden Externalisierungs- und Internalisierungsvorteilen werden nach Brodel internationale Basisstrategien im Umweltschutz unterschie-

${ }^{109}$ Vgl. Brodel, D. (1996), S. 405f. 
den, die multinationale Unternehmen verfolgen können. Die Merkmale der einzelnen Internationalisierungsstrategien im Umweltschutz sind folgende: ${ }^{110}$

- Als multinationale Umweltschutzstrategie werden jene Verhaltensweisen eingestuft, bei denen sich Unternehmen mit ihren jeweiligen Tochtergesellschaften an den lokalen Umweltschutzanforderungen der einzelnen Länder orientierten. Dementsprechend wird keine länderübergreifende Standardisierung bei der umweltorientierten Ausrichtung der Wertaktivitäten vorgenommen.

- Bei einer globalen Kostenminimierungsstrategie stehen bei umweltschutzrelevanten Entscheidungen ökonomische Ziele im Vordergrund, so daß durch die multinationale Unternehmenstätigkeit Möglichkeiten ausgenutzt werden, einer Internalisierung von Umweltschutzkosten auszuweichen. Jene Länder werden im Rahmen einer globalen Kostenminimierungsstrategie für Produktionsstandorte bevorzugt, in denen geringe Umweltstandards bestehen und/oder sogar noch staatliche Anreize geschaffen werden, Industrieansiedlungen unabhängig ihrer Umweltbelastungen zu fördern.

- Global-proaktive Umweltschutzstrategien kennzeichnen jene Ausrichtung des Unternehmensverhaltens, bei der eine internationale Standardisierung der Wertschöpfungsaktivitäten im Hinblick auf die Berücksichtigung von Umweltschutzerfordernissen antizipativ nach Maßgabe der international strengsten Standards erfolgt. Für die Ableitung der Umweltschutzstandards bilden die vom Unternehmen autonom festgelegten Umweltschutzgrundsätze und -ziele eine weltweite Orientierung. Sowohl verantwortungsethische Argumente als auch die Verpflichtung der Industrienationen zur Umsetzung des Leitbildes einer nachhaltigen Entwicklung stellen die Verfolgung einer global-proaktiven Umweltschutzstrategie in den Mittelpunkt der ökologisch verpflichteten Unternehmensführung international tätiger Unternehmen.

- Die selektive Umweltschutzstrategie ist sowohl durch die Realisierung von Vorteilen der internationalen ökologischen Internalisierung als auch der Externalisierung gekennzeichnet. Durch ein entsprechendes duales Vorgehen können Unternehmen versuchen, einerseits die Chancen hoher Umweltschutzstandards in einigen Produktprogrammen und andererseits auch die ökonomischen Vorteile geringer länderspezifischer Umweltschutzanforderungen zu nutzen.

Ökologieorientierte Basisstrategien sind neben ihrer wettbewerbssrategischen auch in ihrer risikostrategischen Dimension zu konkretisieren. Die Wahl einer bestimmten Basis- und Wettbe-

${ }^{110}$ Vgl. Brodel, D. (1996), S. 408ff. 
werbsstrategie bedingt Risiken in geringerem oder höherem Ausmaß und erfordert entsprechende Formen der Risikoabsicherung. Im Rahmen einer spezifischen Risikoanalyse sind die aus den ökologischen Problemstellungen resultierenden gesellschaftsbezogenen, technologiebezogenen und politisch-rechtlichen Verlustgefahren zu berücksichtigen, denn sie bestimmen die Erfolgsposition eines Unternehmens. ${ }^{111}$

Im Rahmen des Umwelt- und Risikomanagements stehen unterschiedliche Optionen der Risikobewältigung zur Auswahl. Grundsätzlich ist durch die geeignete Auswahl von Risikostrategien, die vielfach nicht isoliert, sondern kombiniert eingesetzt werden, ein für das Unternehmen optimales Sicherheitsniveau zu realisieren. Grundsätzlich lassen sich die strategischen Optionen im Risikomanagement in ursachen- und wirkungsorientierte Strategien differenzieren. Die Merkmale der einzelnen Risikostrategien sind folgende: ${ }^{12}$

- Risikovermeidung: Die Strategie der Risikovermeidung ist ursachenorientiert, da sie auf die Beseitigung der eigentlichen Ursachen des Risikos abzielt. Dies kann durch Rückzugsstrategie erfolgen, z.B. über den Verzicht des Angebotes umweltgefährdender Produkte, Verfahren und Stoffe. Eine vollständige Risikovermeidung ist jedoch nicht möglich, denn Produktion und Konsum ist immer mit mehr oder weniger belastenden Umweltwirkungen verbunden. Hierzu kommt, daß das Unternehmen nur beschränkt Einfluß auf globale Risiken nehmen kann. Hier sind globale Vermeidungsstrategien gefragt, wie sie über Branchen- oder internationale Abkommen erreicht werden können.

- Risikominderung: Risikominderungsstrategien können ursachenorientiert (Schadensverhütung und Verringerung der Eintrittswahrscheinlichkeit eines Schadens) und wirkungsorientiert (Herabsetzung der Folgen eines möglichen Schadens) ausgerichtet sein. Die ursachenorientierte Strategie kann über die Erhöhung betriebsinterner Standards, Substitution von umweltgefährdenden Einsatzstoffen sowie durch Kommunikations-, Aufklärungs- und Schulungsmaßnahmen bei Mitarbeitern und Produktnutzen konkretisiert werden. Maßnahmen einer wirkungsorientierten Strategie bei umweltgefährdenden Technologien können einerseits durch konstruktionsbedingte Schadensbegrenzungsmaßnahmen, wie z.B. durch Re- dundanzen (mehrfache Kontrollinstrumente, Abdichtungen usw.) und Diversifizität von Sicherheitsmaßnahmen oder räumliche Trennung von Anlagen, andererseits durch produktbezogene Maßnahmen beim Auftreten von umweltgefährdenden Stoffen in bereits angebotenen Pro-

${ }_{111}$ Vgl. Steger, U./Antes, R. (1991), S. 13ff.; Wagner, G. R. (1997), S. 50ff.; Meffert, H./Kirchgeorg, M. (1998), S. $239 \mathrm{ff}$.

${ }^{112}$ Vgl. Meffert, H./Kirchgeorg, M. (1998), S. 249ff. 
dukten z.B. durch eine Rückrufaktion, einen Umwelttelefon-Service oder präventive Kundendienstpolitik u.a.m. zur Reduzierung von markbezogenen Risiken beitragen.

- Risikoüberwälzung: Bei der Verfolgung einer Risikoüberwälzungsstrategie werden die Ursachen des Risikos nicht beseitigt, sondern vielmehr die Schadensfolgen auf andere übertragen. Beispielsweise können Risiken aus der Lagerung umweltgefährdender Stoffen auf den Lieferanten übertragen werden, indem die Lagerung bis zum Weiterverarbeitungsprozeß beim Lieferanten erfolgt. In den meisten Fällen werden Versicherungen, die individuell auftretende Risiken in regelmäßig anfallende Prämien umsetzen, zur Risikoüberwälzung herangezogen.

- Selbsttragen des Risikos: Unternehmen können freiwillig oder unfreiwillig (nicht versicherbare Schadensfälle) Risiken selber tragen. Sofern das von der Versicherung angebotene Sicherheitsniveau insbesondere bei der Kumulation vieler kleiner Schäden mit höheren Kosten verbunden ist als ein erwarteter Schadensaufwand, ist eine freiwillige Beteiligung (Selbsttragen) vorteilhaft. Wenn das Risiko selbst getragen werden soll, kann zwischen einer aktiven und einer passiven Strategie unterschieden werden. Bei einer aktiven Sicherungsstrategie können eigene finanzielle Reserven für Schadensfälle aufgebaut werden. Im Rahmen einer passiven Strategie ohne Bildung finanzieller Reserven werden Schäden vom Unternehmen bewußt unvorbereitet selber getragen.

- Risiko-Dialog: Mit der Strategie des Risiko-Dialogs wird versucht, aus Sicht des Unternehmens auf Risiken hinzuweisen und mit betroffenen internen und externen Anspruchsgruppen $\mathrm{zu}$ auf breitem Konsens beruhenden ,partnerschaftlichen Risikoentscheidungen“ zu kommen. Darüber hinaus kann der Risiko-Dialog auch unter dem Ziel eines ,public learning“ durchgeführt werden, um für Störfälle den einzelnen Betroffenen entsprechende Verhaltensregeln zu vermitteln. Somit kann die Kommunikation über Risiken und Risikoursachen neuer Technologien oder innovativer Problemlösungen im Umweltschutz zur Objektivierung der Risikodiskussion in der Öffentlichkeit und Verringerung von Legitimitäts- und Akzeptanzrisiken unternehmensbezogener Maßnahmen beitragen. Es ist festzuhalten, daß zur Vorbereitung eines Dialogs eine systematische Erfassung von Risikoursachen und Risikoausmaß die Generierung alternativer Formen der Risikobewältigung und die Auswahl objektivierter Bewertungsansätze (z.B. Vergleich verschiedener Technologie- und Produktalternativen anhand objektivierter Umweltbilanzen) eine wichtige Voraussetzung darstellen.

Rückkoppelnd zur offensiven Verhaltensrichtung und der Innovationsstrategie erscheinen nur die Strategie der Risikovermeidung und -minderung im Sinne von Risikovorsorge für eine ökologisch verpflichtete Unternehmensführung geeignet. 
Derartige in der Literatur zu findende inhaltliche Beschreibungen sowie die Charakterisierung zeigen deutlich, daß das Begriffspaar offensives/defensives Verhalten einer verdichteten Betrachtung entstammt. ${ }^{113}$ Ohne explizit darauf hinzuweisen, erstrecken sich die Definitionen über mehrere unterschiedliche Klassifikationskriterien, wobei der Schwerpunkt auf dem Aktivitätsniveau des Verhaltens liegt. Die oben dargestellte, aber auch andere im Schrifttum benannte Handlungsalternativen manifestieren sich bei genauer Betrachtung deshalb größtenteils als Konglomerate der isoliert dargestellten grundlegenden Verhaltenstypen bzw. Umweltschutzstrategien.

Die Unternehmensumwelt erweist sich als komplex und dynamisch. ${ }^{114}$ Dabei zeigt sich ein auf veränderte Rahmenbedingungen zurückzuführendes Verhalten im Rahmen der Umweltschutzstrategien in der Regel vielschichtiger als eine Kombination mehrerer Grundtypen. Diese können ,aufeinander folgen, sich gegenseitig ablösen oder auch ergänzen und überlagern““ ${ }^{115}$

Abb. 4.9 veranschaulicht das grobe Beispiel einer umweltschutzbezogenen Unternehmensstrategie. Praktisch alle Bereiche des Unternehmens sind von ökologisch induzierten Aspekten betroffen. ${ }^{116}$ Danach können die umweltschutzbezogenen Unternehmensstrategien aus einem System unterschiedlicher Teilstrategien zusammengesetzt werden, deren Inhalt an der jeweiligen Situation auszurichten ist. ${ }^{117}$

\begin{tabular}{|l|l|}
\hline \multicolumn{1}{|c|}{ Teilstrategie } & \multicolumn{1}{c|}{ Ausprägungen } \\
\hline Organis ationsstrategie & $\begin{array}{l}\text { Institutionalisierung des Umweltschutzes auf hoher Ebene; klare } \\
\text { Kompetenzabgrenzung; umfangreiches innerbetriebliches Informationswesen }\end{array}$ \\
\hline Personalstrategie & $\begin{array}{l}\text { Gesundheit fördern; Umweltbewußtsein fördern; Umweltschutz-Image als Personalatt- } \\
\text { raktion; Aus- und Weiterbildung gemäß neuer Berufsbilder; Vorschlagswesen verbes- } \\
\text { sern }\end{array}$ \\
\hline Finanzstrategie & $\begin{array}{l}\text { Langfristige Finanzplanung in Abstimmung mit Umweltschutzinvestition; Subventio- } \\
\text { nen an andere erschweren; steuerliche Erleichterungen und spezielle Finanzierungsquel- } \\
\text { len nutzen }\end{array}$ \\
\hline Marketingstrategie & $\begin{array}{l}\text { Forcierung neuer, umweltunschädlicher Produkte; Zukunftsmarkterforschung - neue } \\
\text { Verbrauchergewohnheiten; Kundenaufklärung über umweltfreundliche Produkte; Wer- } \\
\text { bung für Umweltschutzmaßnahmen des Unternehmens (Image); Hochpreispolitik }\end{array}$ \\
\hline PR-Strategie & $\begin{array}{l}\text { Kooperation mit den Interessenvertretungen und öffentlichen Stellen - Mitwirkung an } \\
\text { Umweltschutzmaßnahmen; Aufklärung von Bevölkerung und Nachbarschaft; Ve r- } \\
\text { ständnis für Handlungen des Unternehmens wecken; Erklärung der Maßnahmen und ih- }\end{array}$ \\
\hline
\end{tabular}

$\overline{113}$ Vgl. Kirchgeorg, M. (1990), S. 50.

${ }^{114} \mathrm{Vgl}$. Kap. 3.2 in dieser Arbeit.

115 Krüger, W. (1974), S. 68.

${ }^{116}$ Vgl. Brauchlin, E. (1972), S. 170.

${ }^{117}$ Vgl. Hinterhuber, H. H. (1992), S. 3ff.; Hofmann, M. (1972), S. $99 \mathrm{ff}$. 


\begin{tabular}{|l|l|}
\hline & rer Wirkungen \\
\hline Standortstrategie & $\begin{array}{l}\text { Verlegung alter, sorgfältige Prüfung neuer Standorte; Anstimmung mit langfristigen } \\
\text { Raumordnungskonzepten; Belastungswege-Analyse; Meidung von Inversionsklima und } \\
\text { stadtnahen, fremdenverkehrgünstigen Gebieten; Industriesiedlungen mit Grüngürtel; } \\
\text { Transportwege überprüfen }\end{array}$ \\
\hline E \& F - & $\begin{array}{l}\text { Verwendungs- und Verwertungsforschung für Abfall (Recycling); Verlustquellenfor- } \\
\text { schung; optimale Stoffverwertung; Forschungskooperationen; Hilfe für Klein- und Mit- } \\
\text { telbetriebe; neue, umweltunschädliche Produkte und Verfahren entwickeln; Abstim- } \\
\text { mung mit der Marktforschung }\end{array}$ \\
\hline Kontrollstrategie & $\begin{array}{l}\text { Laufende, freiwillige Kontrolle der eigenen Emissionen; umweltschutzbezogenes } \\
\text { Rechnungswesen; betriebliche Umweltrechnungslegung; allgemeine Emissionskontrol- } \\
\text { le }\end{array}$ \\
\hline Produktionsstrategie & $\begin{array}{l}\text { Optimale Abfallverwertung; Selbstverwertung und Marktverwertung der Abfallstoffe } \\
\text { ermöglichen; umweltfreundliche Lagerungs- und Transportpolitik; Produktion umwelt- } \\
\text { freundlicher Produkte mit längerer Lebensdauer; Einsatz umweltfreundlicher Verfahren }\end{array}$ \\
\hline
\end{tabular}

Abb. 4.9: Beispiele einer umweltschutzbezogenen Unternehmensstrategie

(Quelle: Schulz, K. (1996), S. 37)

\subsection{Operative Umsetzung des Umweltschutzes in den funktionalen Bereichen}

Die operative Umsetzung des Umweltschutzes in allen funktionalen Bereichen dient dazu, innerhalb einer verarbeiteten Umweltschutzstrategie die kurzfristige Erfolgsrealisierung sicherzustellen. In der umfassenden Sichtweise der strategischen ökologisch verpflichteten Unternehmensführung stellt der Umweltschutz eine betriebliche Querschnittsfunktion dar, die sämtliche Unternehmensbereiche umfaßt. ${ }^{118}$

Unternehmen können die sich langfristig im Umweltschutz bietenden Chancen nur dann nutzen, „wenn sie systematisch in allen Unternehmensfunktionen ökologische Problembereiche identifizieren und mögliche Umweltschutzmaßnahmen auf ihr Ansatzpunkte zur Verbesserung der Wertschöpfung bzw. Gewinnspanne hin analysieren“.119 Im Rahmen einer ökologisch verpflichteten Unternehmensführung müssen somit sämtliche Bereiche der Wertschöpfungskette unter ökologischen Gesichtspunkten berücksichtigt werden, wobei die Erfassung der Interdependenzen der einzelnen Bereiche einen wesentlichen Faktor darstellt. ${ }^{120}$

\footnotetext{
${ }^{118}$ Vgl. Wicke, L. (1988), S. 23ff.; Meffert, H./Kirchgeorg, M. (1998), S. 20.; Macharzina, K. (1993), S. $790 f f$.

${ }^{119}$ Meffert, H./Kirchgeorg, M. (1998), S. 151f.

${ }^{120}$ Vgl. Macharzina, K. (1993), 791. Zum Konzept der Wertschöpfungskette vgl. z.B. Porter, M. E. (1985), S. 33ff.
} 


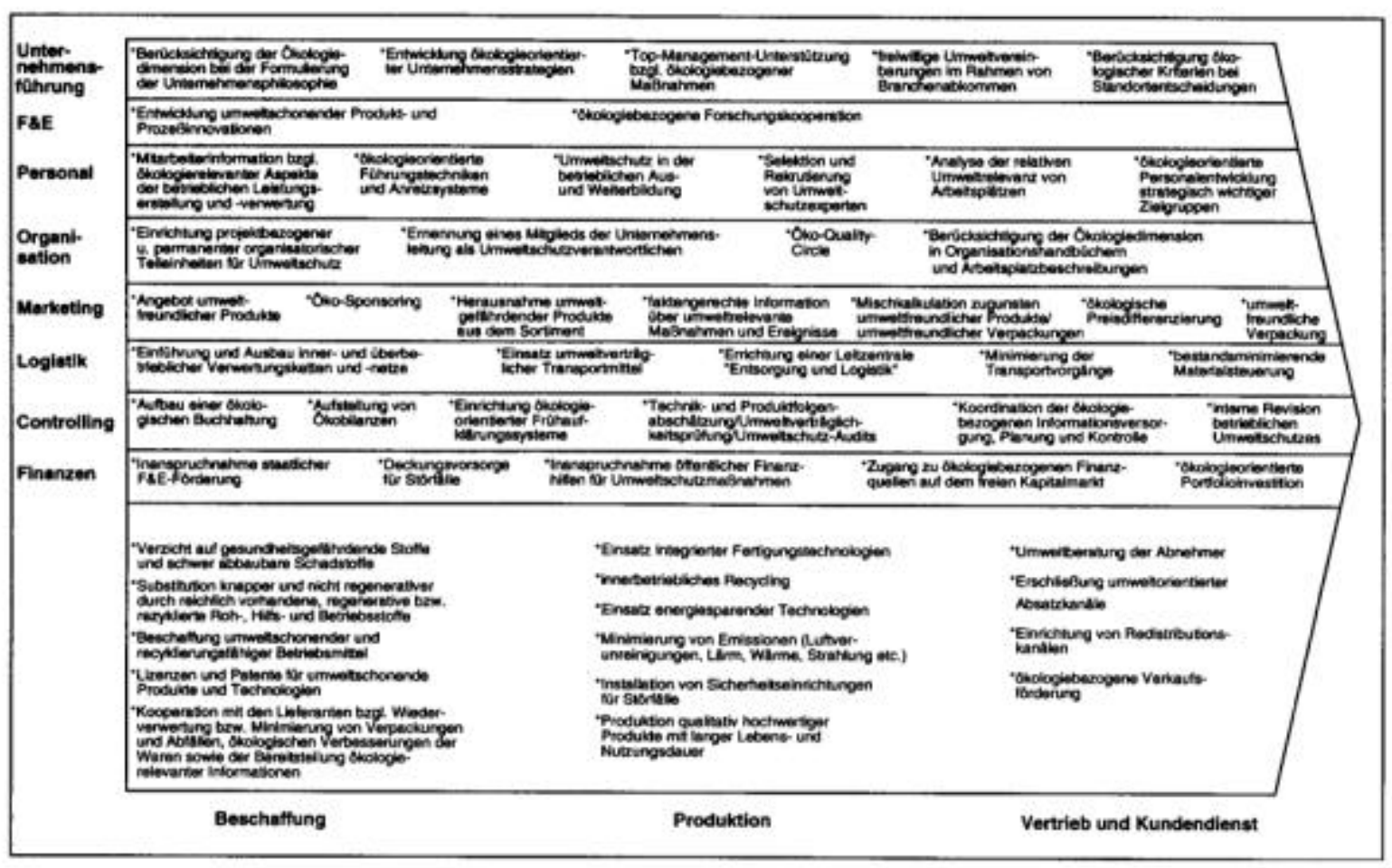

Abb. 4.10: Ökologieorientierte Wertschöpfungskette (Quelle: Macharzina, K. (1993), S. 791)

Gegenstand der vorher genannten Steuerungsfelder sind die betrieblichen Grundfunktionen oder die primär leistungswirtschaftlichen Bereiche des Unternehmens. In ihnen zeigen sich spezifisch ökologische Problemfelder, die in vorgenannten Steuerungsbereichen noch nicht erfaßt wurden. Werden die funktionalen Ansatzbereiche für ökologiebezogenes Unternehmenshandeln eingekreist und mit ökologischen Zielkriterien versehen, dann kann die nachfolgende Übersicht erstellt werden: ${ }^{121}$

\section{Unternehmensführung:}

- Berücksichtigung der Ökologiedimensionen bei der Formulierung der Unternehmensphilosophie,

- Entwicklung ökologieorientierter Unternehmensstrategie,

- Top-Management-Unterstützung bzgl. ökologiebezogener Maßnahmen,

- Freiwillige Umweltvereinbarungen im Rahmen von Branchenabkommen,

- Berücksichtigung ökologischer Kriterien bei Standortentscheidungen.

\section{Forschung und (Produkt)Entwicklung:}


- Entwicklung umweltschonender Produkt- und Prozeßinnovation,

- Ökologiebezogene Forschungskooperation,

- Produktmerkmale (langlebig, wartungsfreundlich, reparaturfähig, recyclierbar, ressourcenund energiesparend),

- Produktbestandteile (nicht toxisch, neben- und spätwirkungsfrei),

- Produktverwendung (risikofrei, abfall-, emissionsarm),

- Produktentsorgung (Rückgabe möglich, abbaubar, entsorgungssicher, Wieder/Weiterverwendung mitgeplant).

\section{Beschaffung (Materialbeschaffung):}

- Eigenschaften (regenerierbar, recycliert, haltbar, sicher, nicht toxisch, abbaubar),

- Information (Inhaltstoffe/Herstellverfahren bekannt),

- Verzicht auf gesundheitsgefährdende Stoffe und schwer abbaubare Schadstoffe,

- Substitution knapper und nicht regenerativer durch reichlich vorhandene, regenerative bzw. rezyklierte Roh-, Hilfs- und Betriebsstoffe,

- Beschaffung umweltschonender und recyclingsfähiger Betriebsmittel,

- Lizenzen und Patente für umweltschonende Produkte und Technologien,

- Kooperation mit den Lieferanten bzgl. Wiederverwertung oder Minimierung von Verpackungen und Abfällen, ökologischen Verbesserungen der Waren sowie der Bereitstellung ökologierelevanter Informationen.

\section{Produktion:}

- Einsatz integrierter Fertigungstechnologien (energie-/rohstoffsparend),

- Innerbetriebliches Recycling,

- Minimierung von Emissionen (Luftverunreinigung, Lärm, Wärme, Strahlung etc.),

- Installation von Sicherheitseinrichtungen für Störfälle,

- Produktion qualitativ hochwertiger Produkte mit langer Lebens- und Nutzungsdauer,

- Risiken (risikoarm bezüglich Arbeit, Umwelt, Gesundheit),

- Bauten/Anlagen (energiesparend, lärmgeschützt, bedienungssicher, umweltfreundliche Baustoffe).

121 Vgl. hierzu die „Checklisten“ von Dyllick, T. (1990), S. 29ff.; Winter, G. (1990), S. 142ff.; Macharzina, K. (1993), S. 791. 


\section{Organisation:}

- Einrichtung projektbezogener und permanenter organisatorischer Teileinheiten für Umweltschutz,

- Ernennung eines Mitglieds der Unternehmensleitung als Umweltschutzverantwortlichen,

- Öko-Quality-Circle,

- Berücksichtigung der Ökologiedimensionen in Organisationshandbüchern und

- Arbeitsplatzbeschreibungen.

\section{Marketing/Vertrieb(Verkauf)/Kundendienst:}

- Angebot umweltfreundlicher Produkte,

- Öko-Sponsoring,

- Herausnahme umweltgefährdender Produkte aus dem Sortiment,

- Faktengerechte Information über umweltrelevante Maßnahmen und Ereignisse,

- Mischkalkulation zugunsten umweltfreundlicher Produkte und Verpackungen,

- Ökologische Preisdifferenzierung,

- Umweltfreundliche Verpackung,

- Umweltberatung der Abnehmer,

- Erschließung umweltorientierter Absatzkanäle,

- Einrichtung von Redistributionskanälen,

- Ökologiebezogene Verkaufsförderung,

- Marketing-Mix (Ersatz/Ergänzung durch umweltfreundliche Produkte/Bestandteile, differenzierte Preisgestaltung, Förderung umweltfreundlicher Produkte),

- Verpackung (wenig aufwendig, wiederverwendbar, regenerierbare Materialien, abbaubar),

- Werbung/Absatzkanal (ökologischen Nutzen bewußt machen, umweltfreundlichen Konsum fördern, Position bezüglich Ökologie verdeutlichen; Retrodistributionsfähigkeit herstellen).

\section{Logistik:}

- Einführung und Ausbau inner- und überbetrieblicher Verwertungsketten und -netze,

- Einsatz umweltfreundlicher Transportmittel,

- Errichtung einer Leitzentrale „Entsorgung und Logistik“,

- Minimierung der Transportvorgänge, 
- Bestandsminimierende Materialsteuerung,

- Strukturen (Distanzen zwischen Produktion, Lager und Konsum durch Standortpolitik verringern),

- Transporte (Routen optimieren, umweltfreundliche Transportmittel verwenden und voll auslasten, Risiken vermeiden),

- $\quad$ Lagerung (Bestände riskanter Stoffe minimieren, Lagerbestände kontrollieren, Risiken absichern).

\section{Controlling:}

- Aufbau einer ökologischen Buchhaltung,

- Aufstellung von Ökobilanzen,

- Einrichtung ökologieorientierter Frühaufklärungssysteme,

- Technik- und Produktfolgenabschätzung, Umweltverträglichkeitsprüfung, Öko-Audits,

- Koordination der ökologiebezogenen Informationsversorgung, Planung und Kontrolle,

- Interne Revision des betrieblichen Umweltschutzes.

\section{Finanzen:}

- Inanspruchnahme staatlicher F\&E-Förderung,

- Deckungsvorsorge für Störfälle,

- Inanspruchnahme öffentlicher Finanzhilfen für Umweltschutzmaßnahmen,

- Zugang zu ökologiebezogenen Finanzquellen auf dem freien Kapitalmarkt,

- Ökologieorientierte Portfolioinvestition.

\section{Recycling/Entsorgung:}

- Innerbetrieblich (Rückstände sammeln, rückgewinnen, wiederverwenden),

- Überbetrieblich (Rückstände anderer Wiederverwertung zuführen oder selber aufbauen),

- Entsorgung (kontrollierte Entsorgung, seriöse Entsorgungspartner, Entsorgungskooperation),

- Bedeutungssignal (Ökologie als Zielfeld, hinter dem die Unternehmensleitung steht).

\section{Personal:}


- Mitarbeiterinformation bzgl. ökologierelevanter Aspekte der betrieblichen Leistungserstellung und - verwertung,

- Ökologieorientierte Führungstechniken und Anreizsysteme,

- Umweltschutz in der betrieblichen Aus- und Weiterbildung (Integration der Ökologieverpflichtung in das interne Weiterbildungs- und Seminarprogramm, Förderung ökologischer Weiterbildungswünsche),

- Bedeutungssignal (Ökologie als Zielfeld, hinter dem die Unternehmensleitung steht),

- Selektion und Rekrutierung von Umweltschutzexperten,

- Analyse der relativen Umweltschutzrelevanz von Arbeitsplätzen,

- Ökologieorientierte Personalentwicklung strategisch wichtiger Zielgruppen.

\subsection{Umweltinformationssystem und Öko-Controlling}

\section{als Element ökologisch verpflichteter Unternehmensführung}

Gemeinsames, zielgerichtetes ökologisches Handeln im Rahmen einer ökologisch verpflichteten Unternehmensführung wird erst durch den Informationsaustausch möglich, der zwischen Unternehmen und ihrer Umwelt aber auch innerhalb der verschiedenen Stellen stattfinden muß. Dies bedeutet, daß es zur erfolgreichen Umsetzung und Beibehaltung einer ökologisch verpflichteten Unternehmensführung der Schaffung eines leistungsfähigen Umweltinformationssystems bedarf, das sowohl den internen als auch externen Bereich der ökologischen Nutzungspotentiale ${ }^{122}$ abdeckt. Ökologisch verpflichtete Unternehmensführung läßt sich somit als (ökologiebezogener) Informationsbearbeitungsprozeß beschreiben. Aufgrund der zunehmenden Komplexität und Dynamik der Unternehmensumwelt bildet die Analyse der Umweltfaktoren einen wesentlichen Bereich der ökologisch verpflichteten Unternehmensführung. Diese Umweltanalyse soll es dem Management ermöglichen, die externen Umweltbedingungen, welches das Unternehmen beeinflussen, zu erfassen und in einer entsprechenden Weise zu handhaben. Die Bereitstellung entscheidungsrelevanter Informationen dient dabei der Sensibilisierung/Anregung, Problemanalyse, Alternativenbewertung sowie Kontrolle und Steuerung im Rahmen der ökologisch verpflichteten Unternehmensführung. ${ }^{123}$ Nach Schulz wird das betriebliche Umweltinformationssystem folgendermaßen definiert: Ein betriebliches Umweltinformationssystem ist „ein betriebswirtschaftliches Instrument für vorausschauendes, langfristiges, strategisches, vorbeugendes und innovatives Handeln ..., das ökologische Chancen und Risiken aufdecken kann. ... Ein betriebliches Umwelt-

\footnotetext{
${ }^{122} \mathrm{Vgl}$. Bundesumweltministerium/Umweltbundesamt (1995), S. $10 \mathrm{ff}$.

${ }^{123}$ Vgl. Meffert, H./Kirchgeorg, M. (1998), S. 81.
} 
informationssystem dient nicht nur der Dokumentation im weitesten Sinne, sondern auch der Planung, Überwachung und Steuerung. ‘ ${ }^{124}$

Umweltinformationssysteme dienen der funktions- und unternehmensübergreifenden Informationsgewinnung mit Methoden und Instrumenten, die auf die Abbildung und Bewertung der von Unternehmen ausgehenden ökologischen Wirkungen gerichtet sind. ${ }^{125}$ Ein solches Informationssystem stellt die Grundlage für ein effektives und effizientes umweltschutzorientiertes Management sowohl in ökonomischer als auch in ökologischer Perspektive dar. Die umweltschutzbezogenen Informationsbedürfnisse in Unternehmen sind vielfältiger Natur. Sie reichen von der Kontrolle und der Einhaltung gesetzlicher Grenzwerte über die Aufdeckung ökologischer Mißstände im Unternehmen bis zur Identifikation von Marktchancen durch Umweltinnovationen.

Zur weiteren Präzisierung des Begriffes „Umweltschutzinformationssystem“ wird eine Abgrenzung hinsichtlich verschiedener Aufgaben und Ziele durchgeführt. Danach lassen sich Umweltinformationssysteme in drei Klassen einteilen: ${ }^{126}$

- Betriebliche Umweltinformationssysteme (BUIS) zur Kontrolle und Erfüllung gesetzlicher Vorgaben sowie zur Beurteilung der Umweltverträglichkeit von Produkten und Produktionsbzw. Wertschöpfungsprozessen.

- Umweltbezogene Instrumente des Strategischen Managements (USM) zur Identifikation umweltinduzierter Marktchancen und -risiken.

- Umweltbezogene Entscheidungsunterstützungssysteme (UEUS) zur Früherkennung und Antizipation ökologieinduzierter Strukturkrisen, hauptsächlich basierend auf computergestützten Simulationen. Diese Simulationsmodelle dienen dem Verständnis der dynamischen Wechselwirkungen von Unternehmensentscheidungen, Umweltzuständen und Reaktionen im sozio-ökonomisch-ökologischen Umfeld.

Die (aktuellen sowie prognostizierten) ökologierelevanten Daten der Unternehmensumwelt bilden die Grundlagen für Entscheidungen auf der unternehmenspolitischen, strategischen sowie operativen Ebene im Rahmen der ökologisch verpflichteten Unternehmensführung. Ein Umweltinformationssystem hat somit die Aufgabe, die entlang des gesamten Wertschöpfungsprozesses umweltrelevanten Informationen zu erheben, aufzubereiten und zu bewerten und damit für sämt-

\footnotetext{
${ }^{124}$ Schulz, W. (1991), S. 225.

${ }^{125}$ Der Vollständigkeit halber sei ergänzt, daß einzelne Bestandteile und Instrumente von Umweltinformationssystemen in der einschlägigen Literatur auch unter dem Stichwort „Öko-Controlling“ aufgeführt und diskutiert werden. Vgl. Wagner, G.-R. (1993), S. 207ff.
} 
liche Managementbereiche bereitzustellen. Somit wird insbesondere auf die entscheidungsunterstützende Funktion von Umweltinformationssystemen für die ökologisch verpflichtete Unternehmensführung Wert gelegt.

Darüber hinaus müssen im Rahmen der ökologisch verpflichteten Unternehmensführung Instrumente entwickelt werden, die Wirkungsbeziehungen zwischen natürlicher Umwelt, Gesellschaft und den wirtschaftlichen Rahmenbedingungen darzustellen vermögen. ${ }^{127}$ Erst mit solchen umweltbezogenen Strategieunterstützungsssystemen kann eine gezielte Transformation von Informationen in Aktionen unter der Berücksichtigung langfristiger Entscheidungshorizonte gelingen. $^{128}$

Alle betrieblichen Umweltinformationssysteme sind aber auch durch eine interne und externe Funktion gekennzeichnet, die sich an unterschiedliche Anspruchsgruppen wendet. Die interne Funktion von betrieblichen Informationssystemen bezieht sich auf Unternehmensführung, Abteilungen, Umweltschutzbeauftragte und Mitarbeiter. In der externen Funktion wenden sich betriebliche Umweltinformationssysteme an Kunden, Verbraucher, Lieferanten, Investoren, Versicherungen, Behörden und die Öffentlichkeit.

Die Entwicklung umweltbezogener Informationssysteme wird nicht losgelöst von den schon bestehenden Einrichtungen und Regularien der Informationsbeschaffung und -bereitstellung geschehen. Die konkrete Ausgestaltung der Umweltinformationssysteme richtet sich dabei nach den bereits im Betrieb vorhandenen allgemeinen Informationssystemen aus. Das vorhandene Konzept des betrieblichen Informationswesens stellt den Rahmen für die Einbindung umweltorientierter Informationssysteme zur Verfügung, wobei allerdings in einem wechselseitigen Prozeß Modifikationen des Informationsmanagements sowie der ursprünglichen Konzeption des Umweltinformationssystems unumgänglich erscheinen.

\footnotetext{
${ }^{126}$ Vgl. Zahn, E./Schmid, U./Seebach, A. (1996), S. 82.

${ }^{127}$ Einen umfassenden Überblick über verschiedene umweltorientierte Informations- und Planungsinstrumente unter der Sammelbezeichnung „Instrumente einer sozial-ökologischen Folgenabschätzung” im Betrieb hat Freimann herausgearbeitet und systematisiert und einer vergleichenden Analyse unterzogen. Sie erfüllen im Planungs- und Entscheidungsprozeß unterschiedliche Funktionen im Rahmen der Anregungs-, Analyse-, Bewertungs- und Kontrollphase. Er unterscheidet nach dem Kriterium der Anwendergruppenorientierung insgesamt 17 verschiedenen Verfahrensansätze, die in drei Gruppen zusammengefaßt werden können, und zwar die managementorientierten Verfahren, die Ansätze mit pluralistischer Ausrichtung und die arbeitsorientierten Instrumente. Vgl. Freimann, J. (1989), S. 166ff.; Wicke, L./Haasis, H.-D./Schafhausen, F./Schulz, W. (1992), S. 542f.

${ }^{128}$ Vgl. Zahn, E./Steimle, V. (1993), S. 229.
} 
Als Umweltinformationssystem wird neben der Informationsgewinnung und -strukturierung auch die Übertragung und Speicherung betrieblicher Umweltdaten betrachtet. ${ }^{129} \mathrm{Im}$ weiteren Sinne werden zu den betrieblichen Umweltinformationssystemen alle Methoden und Instrumente (betriebliche Umweltinformationssysteme wie z.B. Ökobilanzen und ökologische Buchhaltung, umweltbezogene Instrumente des strategischen Managements wie z.B. Ökologie-Portfolio und Produktlinienanalyse, umweltbezogene Entscheidungsunterstützungssysteme wie z.B. Wirkungsanalyse und Öko-Controlling) gezählt, die auf die Abbildung und Bewertung der von einem Unternehmen ausgehenden ökologischen Wirkungen gerichtet sind.

Umweltbezogene Instrumente des strategischen Management dienen der Identifikation von umweltinduzierten Marktchancen und -risiken. Schließlich bezeichnen umweltbezogene Entscheidungsunterstïtzungssysteme computerbasierte Simulationsmodelle, die zum Verständnis der dynamischen Wechselwirkungen von Unternehmensentscheidungen, Umweltzustand und den Reaktionen im sozio-ökonomischen Umfeld beitragen sollen. ${ }^{130}$ Die unterschiedlichen Ebenen informationsverarbeitender Prozesse im Unternehmen müssen und dürfen nicht unverbunden nebeneinander stehen, sondern sind zu einem integrierten System zu verknüpfen.

Umweltbezogene Strategieunterstützungssysteme integrieren Methoden des Öko-Controlling, ökologieorientierte Instrumente des strategischen Managements und computergestützte Entscheidungsunterstiutzungssysteme miteinander. Auf der Basis von Daten aus dem betrieblichen Informationssystem kann die modulare Verknüpfung betriebsinterner Wertschöpfungsaktivitäten mit externen Kontextfaktoren zu einem Wertschöpfungsring einen Bezugsrahmen für die Simulation ökologiegerichteter Entscheidungsbestände schaffen.

Die Einrichtung und Pflege von Schnittstellen zwischen den oben beschriebenen Subsystemen erlaubt die Generierung und Transformation von Informationen für spezifische Problemstellungen, sowohl auf der operativen Steuerungsebene als auch für das strategische Management. ${ }^{131}$

Angesicht der Datenvielfalt umweltrelevanter Informationen ist eine EDV-mäßige Erfassung und Auswertung unerläßlich. Dadurch besteht auch die Möglichkeit, Informationen überbetrieblicher Datenbanken oder überbetrieblicher Umweltinformationssysteme zu integrieren.

\footnotetext{
129 Vgl. Wicke, L./Haasis, H.-D./Schafhausen, F./Schulz, W. (1992), S. 492; Corsten, H./Götzelmann, F. (1993), S. 23.

${ }^{130}$ Vgl. Zahn, E./Steimle, V. (1993), S. 234.

${ }^{131}$ Vgl. Zahn, E./Steimle, V. (1993), S. $245 f$.
} 
Abb. 4.11 illustriert diesen Zusammenhang hin $\mathrm{zu}$ integrierten umweltbezogenen Strategieunterstützungssystemen, die eine Einordnung nach dem Grand ihrer Möglichkeit zur Entscheidungsunterstützung des Managements darstellt.

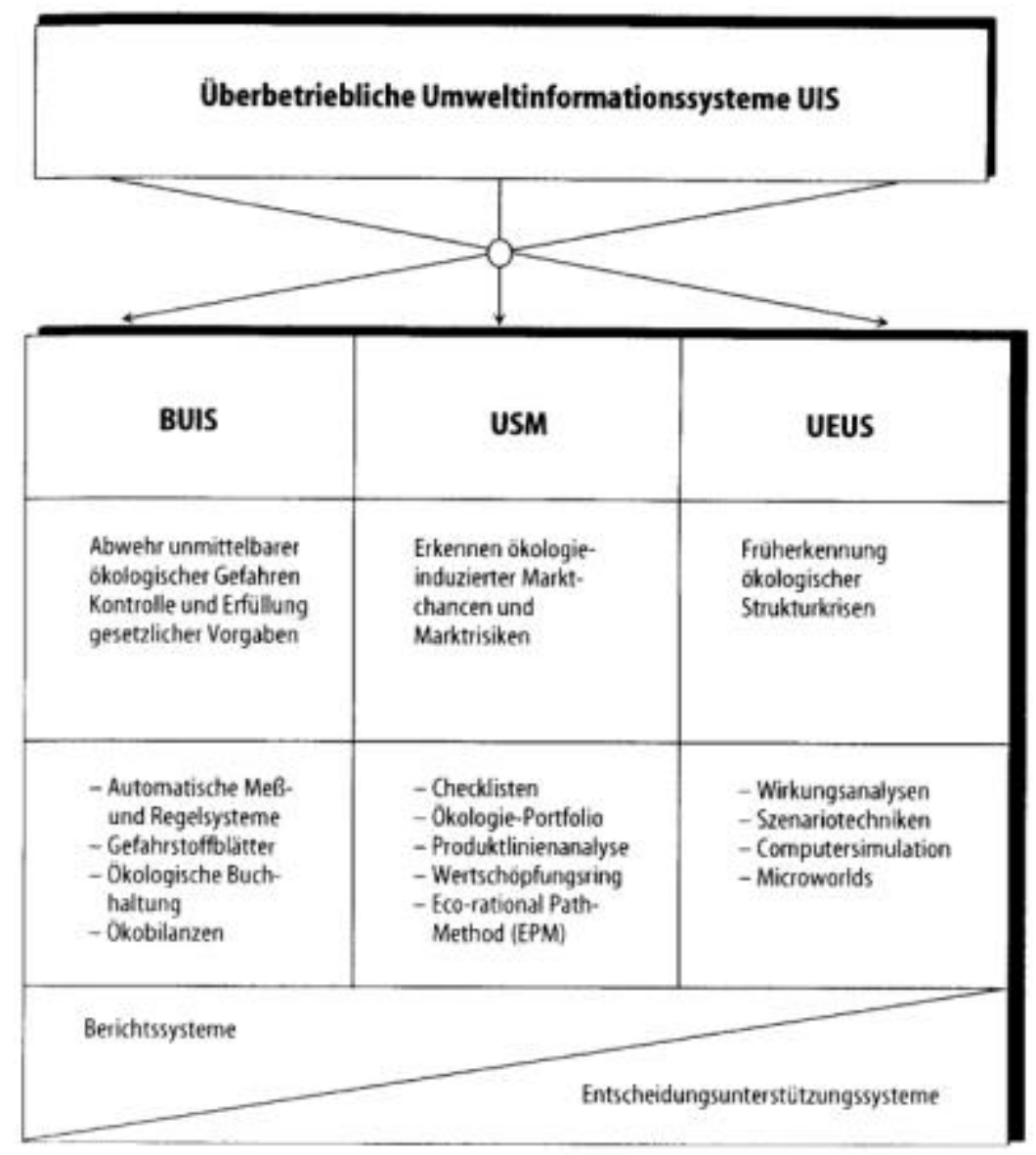

Abb. 4.11: Klassifikation von Umweltinformationssystemen

(Quelle: Zahn, E./Schmid, U./Seebach, A. (1996), S. 83)

Bei der Entwicklung und Durchführung eines betrieblichen Umweltinformationssystems sollten folgende (idealtypische) Anforderungskriterien eingehalten werden: ${ }^{132}$

- Vollständigkeit, d.h. es müssen alle bedeutsamen betrieblichen Umweltwirkungen ermittelt werden.

- Überprüfbarkeit bzw. Nachvollziehbarkeit, d.h. es müssen eindeutige Begriffsabgrenzungen sowie klare Vorstellungen über die Erfassungs- und Bewertungsmethodik vorhanden sein.

- Vergleichbarkeit, d.h. es muß ein einheitlicher Bewertungsmaßstab existieren, mit dem z.B. Produkte miteinander verglichen werden können. 
- Wirtschaftlichkeit, d.h. der Arbeitsaufwand für die Erstellung und Anwendung des Umweltinformationssystems muß für Unternehmen ökonomisch tragbar sein.

Zur Erfüllung dieser Anforderungen und weiterer zur Entwicklung und Durchführung eines betrieblichen Umweltinformationssystems werden gerade in ökologischen Bereichen eine Reihe theoretischer und praktischer Probleme, wie z.B. die Abgrenzungs-, Erfassungs- und Bewertungsprobleme aufgeworfen. Die Abschätzungen der ökologischen Folgen und Wirkungszusammenhänge und der zukünftigen Entwicklungen einer vielschichtigen Umwelt stellen eine ausgesprochen schlechtstrukturierte Problemstellung dar. Dieser Sachverhalt führt dazu, daß auf diesem Gebiet nur ansatzweise Möglichkeiten aufgezeigt werden können. Fronek/Uecker schlagen dafür mehrere Lösungsansätze und die Konzepte vor. Es lassen sich drei Grundtypen von Umweltinformationssystemen unterscheiden: ${ }^{133}$

- Sozio-ökonomische Konzepte: In diesem Konzept wird versucht, über die gesellschaftlichen Folgewirkungen der Umweltbeziehungen betrieblicher Aktivitäten in monetärer Größe zu berichten.

- Technische Konzepte: Hier wird versucht, Daten über die Belastungsbereiche (z.B. Luft- und Gewässerverschmutzung), deren Ursachen und Ausmaße (gemessen in physikalischen Einheiten) zu ermitteln und auszuweisen.

- Betriebswirtschaftlich-finanzwirtschaftliche Konzepte: Hier wird versucht, neben einer Beschreibung der Umweltprobleme Zusammenhänge und deren Lösungen durch Indikatoren wie Investitionsausgaben für den Umweltschutz oder durch verbale Berichterstattung aufzuzeigen.

Aus der Sicht betrieblicher Umweltinformationssysteme sind insbesondere die Sozialbilanz, die ökologische Buchhaltung, die Stoff- und Energiebilanz sowie die Produktfolgeabschätzung von Bedeutung. Außerdem werden noch weitere Varianten einer ökologischen Berichterstattung wie z.B. Umweltkennziffern und Umwelteinzelindikatoren diskutiert, die sachgerecht angewandt eine sinnvolle Ergänzung ökologischen Rechnens bieten. ${ }^{134}$

\footnotetext{
${ }^{133}$ Vgl. Schulz, E./Schulz, W. (1991), S. 588.

134 Nähere Erläuterungen zu den weiteren betrieblichen umweltorientierten Planungs- und Informationssystemen bzw. Instrumenten und Methoden finden sich bei Tischler, K. (1996), S. 289; Schreiner, M. (1993), S. 271ff.; Zahn, E./Steimle, V. (1993), S. 233ff.; Meffert, H./Kirchgeorg, M. (1998), S. $145 f f$.
} 
Im folgenden wird das Öko-Controlling weiter dargestellt, da die Schaffung eines Umweltinformationssystems eine der zentralen Grundlagen eines Öko-Controlling darstellt. ${ }^{135}$ Dabei geht es neben der Sammlung, Verarbeitung und Aufbereitung von umweltrelevanten Informationen auch um deren Bewertung und die direkte Entscheidungsunterstützung der Verantwortlichen im Unternehmen. Das System des Öko-Controlling ist dabei nicht als Einzelinstrument zu sehen, sondern als integrativer Bestandteil der gesamten Umweltinformationssysteme des Unternehmens.

Unter Öko-Controlling wird die Unterstützung des Management bei Planung, Steuerung und Kontrolle aller umweltrelevanten Entscheidungen eines Unternehmens verstanden. ÖkoControlling wird zumeist als ein Instrument zur Analyse, Planung, Steuerung und Kontrolle aller umweltrelevanten Aktivitäten des Unternehmens definiert. ${ }^{136}$ In eine umfassende Sichtweise werden auch Systeme der Früherkennung, der aktiven Steuerung und der Selbstregulierung mit langfristigen Perspektiven einbezogen. ${ }^{137}$

Die Zielsetzungen des Öko-Controlling lassen sich generell wie folgt festlegen: ${ }^{138}$

- Verbesserung der inner- und außerbetrieblichen Koordinationsfähigkeit unter ökologischen Aspekten,

- Verbesserung der Reaktionsfähigkeit auf umweltrelevante Störungen und Ineffizienzen der Stoff- und Energieflüsse,

- Förderung der Mitarbeitermotivation für ökologisch verpflichtetes Verhalten,

- Verbesserung der Anpassungsfähigkeit an durch Umweltaspekte bedingte Änderungen im Unternehmensumfeld.

Die Erfüllung dieser Ziele einer proaktiven Ausrichtung des Umweltmanagements ist ohne ein Instrumentarium für ein Öko-Controlling nicht erfüllbar. Informationen über alle umweltrelevanten Vorgänge und Aktivitäten im Unternehmen sind unerläßliche Voraussetzungen für jeden Umweltschutz. Nach Hallay/Pfriem übernimmt das Öko-Controllingsystem die Funktion der In-

\footnotetext{
${ }_{135}$ Vgl. Hallay, H./Pfriem, R. (1992), S. 34ff.

136 Zum Begriff Öko-Controlling im Diskussions- und Anwendungsfeld umweltbezogener unternehmerischer Planungs- und/oder Rechnungssysteme besteht Uneinigkeit. Er wird zum einen als Sammelbegriff für Ansätze wie ökologische Buchhaltung, Ökobilanzen, Stoff- und Energiebilanzen, Stoffstromrechnungen oder Produktlinienanalysen verwandt, ferner auch als Oberbegriff für diesen und Kategorien wie Umweltverträglichkeitsprüfung oder Technologiefolgeabschätzung sowie mitunter fast synonym zum Begriff und Inhalt betrieblicher Umweltinformationssysteme. Hierzu vgl. Günther, E./Wagner, B. (1993), S. 147ff.; Seidel, E./Behrens, S. (1992), S. 144; Pfriem, R./Hallay, H. (1992), S. 295ff.; Lange, C./Witt, M. (1992), S. 73ff.; Wagner, G.-R. (1993), S. 207f.; Bundesumweltministerium/Umweltbundesamt (1995), S. 523; Meffert, H./Kirchgeorg, M. (1998), S. $402 f$.

${ }^{137}$ Vgl. Tischler, K. (1996), S. 368ff.; Stahmann, V. (1994), S. $233 \mathrm{ff}$.

${ }^{138}$ Vgl. Hopfenbeck, W. (1998), S. 991.
} 
formationsbeschaffung, die Bereitstellung von Analyse- und Verarbeitungsverfahren und die Unterstützung der Planung und Steuerung der betrieblichen Abläufe. ${ }^{139}$

Im folgenden werden die Funktionen des Öko-Controlling kurz dargestellt. Danach lassen sich systembildende und systeminterne Funktionen des Öko-Controlling unterscheiden. ${ }^{140}$

Im Rahmen der systembildenden Funktionen wird versucht, ein aufbau- und ablauforganisatorisches Basissystem für das Umweltmanagement zu schaffen. ${ }^{141} \mathrm{Im}$ Mittelpunkt steht hierbei die Entwicklung und Anwendung umweltorientierter Planungs- und Kontrollinstrumente (z.B. ÖkoBilanz). Die systeminterne Funktion umfaßt die Informations-, Koordinations- und Kontrollbzw. Steuerungsaufgaben des Öko-Controlling. Dabei können die Informations- und Koordinationsfunktion als wesentliche Voraussetzungen zur Wahrnehmung der Steuerungsfunktion angesehen werden. ${ }^{142}$

Aufgrund der vielfältigen Informations- und Bewertungsprobleme bei der Bewältigung der unternehmensbezogenen Umweltschutzprobleme wird die Bereitstellung der entscheidungsrelevanten Informationen durch das Öko-Controlling als wesentliche Funktion dargestellt. Dafür übernimmt das betriebliche Umweltinformationssystem eine wichtige Unterstützungsfunktion des Öko-Controlling. Aus dem funktions- und unternehmensübergreifenden Charakter der ökologisch verpflichteten Unternehmensführung kommt der Koordinationsfunktion des ÖkoControlling die wohl größte Bedeutung zu. Ein regelmäßiger Informationsfluß und eine funktionsübergreifende Koordination durch Öko-Controlling führen bei der Lösung von unternehmensbezogenen Umweltschutzproblemen in den primären Funktionsbereichen Beschaffung, Logistik, Produktion und Absatz zu effizienteren Konzepten. Angesicht einer zunehmenden Verschärfung der Umweltgesetzgebung und gesellschaftlicher Ansprüche, der Intensivierung behördlicher Kontrollen im Bereich des betrieblichen Umweltschutzes oder der Notwendigkeit kooperativer Lösungen in vertikalen Systemen, wie z.B. Einführung eines dualen Abfallsystems, stellt neben dieser funktionsübergreifenden Koordination die unternehmensübergreifende Koordinationsfunktion, d.h. die Gestaltung der überbetrieblichen Koordination, ein weiteres Aufgabenfeld des Öko-Controlling dar. Dabei muß ein Öko-Controlling Informations- und Koordinati-

\footnotetext{
${ }_{139}$ Vgl. Hallay, H./Pfriem, R. (1992), S. 33ff.

140 Vgl. Bundesumweltministerium/Umweltbundesamt (1995), S. 24ff.; Meffert, H./Kirchgeorg, M. (1998), S. 411ff.; Kirschten, U. (1997), S. 129ff.; Güldenberg, S. (1997), S. 169ff.

141 Eine Darstellung der möglichen Organisation des Öko-Controlling findet sich bei Pfriem, R./Hallay, H. (1992), S. 309.

${ }^{142}$ Vgl. Bleis, C. (1995), S. 89.
} 
onserfordernisse erkennen und durch ein Schnittstellenmanagement ein angestimmtes Verhalten sicherstellen. $^{143}$

Die Informations- und Koordinationsfunktion bildet eine wichtige Voraussetzung für die Steuerungsfunktion eines Öko-Controlling. Im Rahmen der Planungsfunktion wird versucht, Sollvorgaben für die unternehmensbezogenen Umweltschutzmaßnahmen zu entwickeln. Darüber hinaus wird die Erreichung dieser Sollvorgaben durch gegenwarts- und zukunftsbezogene Soll-IstVergleiche innerhalb der Kontrollfunktion überwacht. Zur Wahrung des Verhaltensspielraumes bzw. der Handlungsautonomie des Managements und zur Sicherung der Wettbewerbsfähigkeit ist erforderlich, gesellschaftliche und technologische Entwicklungen im Umweltschutzbereich zu antizipieren. $^{144}$ Durch eine feed-forward-orientierte Analyse sind die Abweichungen zu antizipieren und mögliche Einflußfaktoren der Abweichungen zu identifizieren, um Anpassungsmaßnahmen zu ergreifen bevor Abweichungen auftreten. Somit hat ein Öko-Controlling eine Frühwarnfunktion, d.h. es müssen externe Entwicklungen, welche in Zukunft einen Einfluß auf das Unternehmen haben können, prognostiziert werden.

Bei der Ausübung der Kontrollfunktion sind zwei Bereiche eines Öko-Controlling, und zwar Umweltmanagement-Kontrolle und Umweltmanagement-Audit, zu unterscheiden. Im Sinne einer primär operativ ausgerichteten Kontrolle sind alle Unternehmensaktivitäten zu überprüfen. Aufgrund der Dynamik der Entwicklung praktikabler Planungsverfahren im Umweltschutz kommt jedoch einem Umweltmanagement-Audit ein wichtiger Stellenwert zu. Hierbei werden die gesamten Systeme, Planungsmethoden, Ziele, Strategien und Organisationskonzepte des Umweltmanagements überprüft, um Schwachstellen zu ermitteln und $\mathrm{zu}$ beheben. Es wird angestrebt, ein effizientes und koordiniertes Umweltmanagement in der strategischen und operativen Ausrichtung sicherzustellen.

Mit dem Aufbau eines Öko-Controlling wird gleichzeitig gewährleistet, die Anforderungen der EG-Öko-Audit-Verordnung zu erfüllen. Damit stellt das Öko-Controlling einen aktiven betriebswirtschaftlichen Erfolgsfaktor dar. ${ }^{145}$ Gegenstand des Öko-Audits sind betriebliche Umweltpolitik, -programme und -managementsysteme. Das Umweltmanagementsystem muß dabei folgende Aspekte berücksichtigen: ${ }^{146}$

\footnotetext{
${ }^{143}$ Vgl. Meffert, H./Kirchgeorg, M. (1998), S. 413f.

${ }^{144}$ Vgl. Oertli-Cajycob, P. (1990), S. 114.

${ }^{145}$ Vgl. Bundesumweltministerium/Umweltbundesamt (1995), S. 25.
} 
- Umweltpolitik, -ziele und -programme,

- Organisation und Personal,

- Auswirkungen auf die Umwelt,

- Aufbau- und Ablaufkontrolle,

- Umweltmanagement-Dokumentation,

- Umweltbetriebsprüfung.

Die organisatorische Einbindung des Öko-Controlling in das Unternehmen kann aufgrund der Komplexität des Unterfangens nur als ein evolutorischer Unternehmensentwicklungsprozeß vonstatten gehen. ${ }^{147}$ Hierzu bedarf es zur Einführung der Schaffung eines interdisziplinär besetzten betrieblichen Projektausschußes. In der zweiten Phase eines auf Dauer ausgelegten ÖkoControlling muß dessen personelle Struktur dem betriebswirtschaftlichen Promotorenmodell entsprechen. Damit ist ein Öko-Controlling dauerhaft fest in die bestehende Organisation des klassischen Controllings als Querschnittsaufgabe zu integrieren. ${ }^{148}$

\subsection{Organisationsgestaltung im Dienst ökologisch verpflichteter Unternehmensführung}

Umweltschutz beeinflußt als Aufgabe der Unternehmensführung alle Phasen des Entscheidungsprozesses im Unternehmen und bestimmt auch die strategische Erfolgsposition des Unternehmens im Markt und in der Gesellschaft nachhaltig mit. Über ein objektbezogenes und häufig sogar rein fertigungstechnisch reduziertes Verständnis betrieblichen Umweltschutzes hinaus schließt dies struktuelle und individuelle Perspektiven mit ein. Der Erfolg betrieblicher Umweltschutzstrategien und -maßnahmen und schließlich die Durchsetzung einer ökologisch verpflichteten Unternehmensführung verlangen die Schaffung der organisatorischen Voraussetzungen zur Bewältigung der Umweltschutzaufgaben. Somit stellt die Gestaltung der Unternehmensorganisation nach Umweltschutzgesichtspunkten einen wesentlichen Bereich einer ökologisch verpflichteten Unternehmensführung dar.

Die Institutionalisierung der unternehmerischen Umweltschutzaufgaben kann aus folgenden Gründen zweckmäßig sein: ${ }^{149}$

\footnotetext{
${ }^{146} \mathrm{Zu}$ den Einzelheiten des Gegenstandes des Öko-Audit-Systems und des Umweltmanagementsystems vgl. z.B. Bundesumweltministerium/Umweltbundesamt (1995), S. 565ff.

${ }^{147}$ Vgl. Pfriem, R./Hallay, H. (1992), S. 308.

148 Vgl. Pfriem, R./Hallay, H. (1992), S. 309; Meffert, H./Kirchgeorg, M. (1998), S. 415.

${ }^{149}$ Vgl. Wicke, L. et al. (1992), S. 40; Schulz, W. (1988 und 1990); Meffert, H./Kirchgeorg, M. (1998), S. 398.
} 
- Kompexitätsreduktion: Der Umweltschutzaufgabe braucht ein gewisses Maß an „Professionalität", die nur durch eine Umweltschutzorganisation sicherzustellen ist, um die naturwissenschaftlich, technisch und ökonomisch komplexen Probleme systematisch lösen zu können. ${ }^{150}$

- Kontroll- und Steuerungsfunktion: Professionalisierung und Spezialisierung schaffen für ein proaktives Umweltschutzmanagement eine notwendige Voraussetzung. Darüber hinaus erleichtert eine offiziell eingerichtete Organisationseinheit „Umweltschutz“ den aufsichtfuihrenden Behörden die Kommunikations- und Überwachungsfunktion.

- Entlastungs- und Koordinationsfunktion: Eine „Umweltschutz-Stelle” kann die in allen Bereichen des Unternehmens anfallenden Umweltschutzaufgaben umfassend koordinieren.

- Innovationsfunktion: Der Erfolg eines auf Innovationen ausgerichteten Umweltschutzmanagements wird von der Form der Verankerung des Umweltschutzes in der Unternehmensorganisation erheblich mitbestimmt.

Ökologisch verpflichtete Unternehmensführung muß in arbeitsteilig strukturierten Systemen in vertikaler und horizontaler Richtung implementiert werden. Die willendurchsetzenden Prozesse sind dabei meist mit einer Vielzahl von Anpassungsproblemen verbunden. Die Gestaltung einer Organisation unter Umweltaspekten kann nicht losgelöst von der schon bestehenden Unternehmensorganisation geschehen, sondern muß in ihr verankert werden. Bei der Forderung nach einem integrierten Umweltmanagement wird eine Durchdringung aller Unternehmensfunktionen und Hierarchiestufen gefordert, da die Allgegenwärtigkeit umweltschutzbezogener Problemstellungen von jedem Mitarbeiter ein ökologisch verpflichtetes Handeln erfordert. Die „ökologische Verantwortung von Unternehmen verweist nicht nur auf Umweltschutz in gegebenen Strukturen, sondern insbesondere auch auf Umweltschutz durch Transformation der Strukturen“. ${ }^{151}$ Der Weg zu einer ökologisch verpflichteten Unternehmensführung kann damit als ein dynamischer Prozeß der Entwicklung des Unternehmens dargestellt werden. In diesem Sinne stellt sich die Entwicklung $\mathrm{zu}$ einer ökologisch verpflichteten Unternehmensführung als Spezialfall organisationalen Wandels dar. Dieser Sachverhalt verweist auf die Notwendigkeit einer sorgfältigen Planung. Allgemein wird darunter die Absicht verstanden, bei sich verändernden Rahmenbedingungen oder Strategiemodifikationen die Funktionsweise einer Gesamtorganisation oder wesentlicher Teile davon mit dem Ziel der Effizienzverbesserung zu ändern. ${ }^{152}$ Dies erfordert insbesondere geeignete Maßnahmen der Organisationsentwicklung, um die Ziele und Strategien des integrierten Umweltmanagements möglichst leistungswirksam realisieren zu können.

\footnotetext{
${ }^{150}$ Vgl. Senn, J. F. (1986), S. 309.

${ }^{151}$ Kuhn, T. (1993), S. 110.
} 
Die Organisationsentwicklung zielt dabei als anwendungsbezogener Ansatz der verhaltenswissenschaftlichen Organisationsforschung auf eine planmäßige, mittel- bis langfristig wirksame Veränderung der Verhaltensmuster, Einstellungen und Fähigkeiten von Organisationsmitgliedern, Organisations- und Kommunikationsstrukturen sowie struktureller Regelungen im weitesten Sinne (Anreizsystem, Berichtssystem) ab. ${ }^{153}$

Bei der Organisationsentwicklung können Instrumente einer analogen Unterscheidung vorgenommen werden: Einerseits kann eine Integration der Umweltorientierung in bestehende Führungsinstrumente erfolgen (z.B. in Leitbilder, Budgets, Pläne, Organigramme, Stellenbeschreibungen), andererseits können neue umweltorientierte Instrumente eingesetzt werden (z.B. Umweltaudits, Ökobilanzen, umweltorientierte Portfolios). Umweltorientierung verlangt von einem Unternehmen die Entwicklung einer internen Systemstruktur, die den umweltorientierten Zielen ständig gerecht wird. Die Evolution von Organisationen, mit den damit verbundenen umweltorientierten Lern- und Entwicklungsprozessen, rückt in den Mittelpunkt der Betrachtung. Organisationaler Wandel läuft im Wechselspiel zwischen System und Organisationsmitgliedern als organisationaler Lernprozeß ab und kann somit nicht ausschließlich durch die Organisationsstrukturen (strukturaler Ansatz) gestaltet werden.

Die Personalführung (personaler Ansatz) erhält im Rahmen des organisationalen Lernens bzw. der organisationalen Bildung eine entscheidende Bedeutung. „Umweltschutzorganisation ist zum Großteil Umweltschutz-Organisationsentwicklung.“154 Damit stehen Organisation und Personalfunktion auch bei umweltorientierten Aktivitäten in einem engen Verhältnis: „Die durch den Umweltschutzgedanken bedingten Veränderungen bei den organisatorischen Abläufen ... erfordern statt isolierter Maßnahmen ein dynamisches, permanentes, integriertes und handlungsorientiertes Konzept zur Organisations- und Personalentwicklung. “ ${ }^{155}$

Personalfunktion kann sich sowohl auf interne Mitglieder des Unternehmens als auch auf externer Teilnehmer beziehen. ${ }^{156}$ Die Personalfunktion im Innenverhältnis wird mit Personalfuihrung gleichgesetzt. Ziel ist der Aufbau unternehmensspezifischer Erfolgsfaktoren, z.B. ,corperate identity ${ }^{\star 157}$ Ein Ziel der Personalfunktion im Außenverhältnis ist dagegen ein positives „,corperate

\footnotetext{
${ }^{152}$ Vgl. Staehle, W. H. (1980), S. 526.

153 Vgl. Staehle, W. H. (1980), S. 527. Zur Organisationsentwicklung im Dienst ökologisch verpflichteten Wirtschaftens vgl. Schanz, G. (1999), S. 33ff.

${ }^{154}$ Vgl. Seidel, E. (1990), S. 221.

${ }^{155}$ Hopfenbeck, W./ Willig, M. (1995), S. 198.

${ }^{156}$ Vgl. Bleicher, K. (1979), S. 10f. Zum Begriff der Personalfunktion und dessen vielseitigen Aspekten vgl. Wagner, D. (1994), S. 11ff.

${ }^{157}$ Zu einer umweltorientierten Personalführung vgl. Antes, R. (1991), S. 148ff.; Hopfenbeck, A./Willig, M. (1995).
} 
image“. Im Rahmen der Personalführung können umweltverantwortliche Einstellungen und Verhaltensweisen der Mitarbeiter hauptsächlich durch zwei Ansatzpunkte gefördert werden: ${ }^{158}$ Motivation (materielle und/oder immaterielle Anreizsysteme) ${ }^{159}$ und Qualifikation (,Managements-

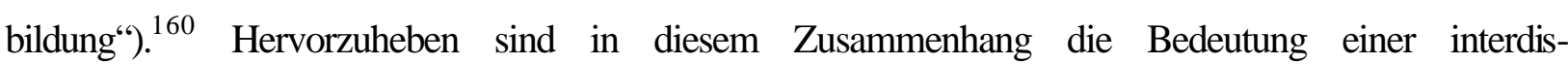
ziplinären Aus- und Weiterbildung zur Vermeidung von Kommunikationsbarrieren. Für eine ökologisch verpflichtete Unternehmensführung reicht diese interne, traditionale Sichtweise jedoch nicht aus, da sie sich fast ausschließlich auf die direkte Schadschöpfung des Unternehmens bezieht. Die beiden Ansatzpunkte Motivation und Qualifikation können gleichfalls auf die Personalfunktion im Außenverhältnis zur Reduzierung der indirekten Schadschöpfung übertragen werden. ${ }^{161}$

Organisation als Element einer ökologisch verpflichteten Unternehmensführung umfaßt sowohl die aufbau- als auch die ablauforganisatorische Bildung eines Aufgabenkomplexes „Umweltschutz“, seine Übertragung auf eine Personengruppe wie z.B. Umweltschutzbeauftragte, die Regelung der Kommunikationsbeziehungen und die raum-zeitliche Strukturierung der Arbeitsgänge. $^{162}$

Grundsätzlich zeigt sich bei der Durchsetzung einer Umweltschutzstrategie das klassische Strategie-Struktur-Dilema, ${ }^{163}$ denn bereits für die Initiierung, Planung und Durchsetzung einer offensiven Umweltschutzstrategie sind entsprechende organisatorische Voraussetzungen erforderlich. Insofern steht die Unternehmensführung bei der Institutionalisierung von Umweltschutzaufgaben im Spannungsfeld zwischen funktional-additiven und integrierten organisatorischen Lösungen.

Für die organisatorische Integration des Umweltschutzes spricht, daß Umweltschutz eine Querschnittsaufgabe ist, die alle Funktionsbereiche und Hierarchiestufen des Unternehmens umfaßt,

\footnotetext{
158 Vgl. Hopfenbeck, W. (1998), S. 890ff.; Kirschten, U./Stitzel, M. (1995), S. 314; Bungard, W. (1995), S. $45 \mathrm{ff}$.

${ }^{159}$ Vgl. Seidel, E. (1990), S. 338f.

160 „Managementbildung“ geht über Aus- und Weiterbildung hinaus und wird definiert als ,die Disposition zur reflexiven Auseinandersetzung mit sich und seinem Arbeitshandeln. Diese reflexive Auseinandersetzung muß zusätzlich in Handlungen münden, die auf den gewonnenen Erkenntnissen beruhen“. Nolte, H. (1996), S. 42.

${ }^{161}$ Es sind vertikale Anreizsysteme sowie Bildungsmaßnahmen denkbar, die Lieferanten sowie Entsorger als Teilnehmer einbeziehen. In diesem Zusammenhang ist interorganisationales Lernen bzw. interorganisationale Bildung im Rahmen von Unternehmenskooperationen von besonderer Wichtigkeit, d.h. erst durch eine Erweiterung der Personalführung zur unternehmensübergreifenden Personalfunktion wird im Rahmen der ökologisch verpflichteten Unternehmensführung eine Querschnittsaktivität generiert, die die gesamte Wertschöpfungskette umfaßt. Vgl. zum interorganisationalen Lernen Prange, C./Probst, G./Rüling, C.-C. (1996), S. 10ff.; Müller-Stewens, G./Osterloh, M. (1996), S. 18ff.; Senge, P./Scharmer, C. O. (1996), S. 32ff.

${ }^{162}$ Vgl. Senn, J. F. (1986), S. 269ff.; Wicke, L. et al. (1992), S. 40.

${ }^{163}$ Meffert, H./Kirchgeorg, M. (1993), S. 397.
} 
da die Allgegenwärtigkeit umweltschutzbezogener Problemstellungen von jedem Mitarbeiter ein ökologisch verantwortliches Handeln erfordert. ${ }^{164}$

Andererseits wird aber hervorgehoben, daß eine Tendenz zur Zentralisation umweltbezogener Planungen und Entscheidungen auf den höheren Hierarchie-Ebenen besteht. Als Argumente für die funktional-additive Organisation des Umweltschutzes wird angeführt, daß Umweltschutzaufgaben und komplexe Umweltschutzentscheidungen nur begrenzt teilbar sind und auch spezifisches Know-how und Professionalität erfordern. Die Konzentration der umweltschutzbezogenen Aufgaben in einem betrieblichen Teilbereich z.B. „Zentralbereich Umweltschutz“ erleichtert durch die Verkürzung der Entscheidungs- und Kommunikationswege die Abstimmung interdependenter Aufgaben. Die Berücksichtigung relevanter oder die Vermeidung störender Interdependenzen erfordert eine entsprechende Koordination der in allen Bereichen anfallenden Umweltschutzaufgaben.

Die Gestaltung der unternehmensspezifischen Organisationsstruktur soll sich dabei an folgenden vier Kriterien orientieren, weil es sich bei realistischer Betrachtung der oben dargestellten funktional-additiven und integrierten organisatorischen Lösungen nicht um Alternativen, sondern um Extrempositionen zwischen einem Kontinuum handelt: ${ }^{165}$

- An den gesetzlichen Erfordernissen, die zum Teil eine funktionsspezifische, additive Organisation vorschreiben, z.B. Umweltschutzbeauftragte,

- An der generellen Organisationsstruktur, z.B. Einpassung in eine Stab-Linien-Organisation oder in eine Matrix-Organisation,

- An der Exponierung des Unternehmens im Umweltschutz, die z.B. nicht nur arbeitsintensive Behördenkontakte, sondern auch Spezialaufgaben in der Öffentlichkeitsarbeit erforderlich machen,

- An dem Entwicklungsstand des Umweltschutzes, z.B. wird man in frühen Phasen mehr funktional-additive Stellen mit den Aufgaben vertrauen müssen, die Diffusion des Umweltschutzes in die einzelnen Funktionsbereiche des Unternehmens voranzutreiben, so daß schrittweise der Integrationsgrad des Umweltschutzes steigt.

\footnotetext{
164 Vgl. Steger, U. (1993), S. 344; Meffert, H./Kirchgeorg, M. (1998), S. 397.

165 Oft wird es sich dabei als zweckmäßig erweisen, die Primärorganisation durch eine Sekundärorganisation zu ergänzen. Wenn z.B. eine Umweltschutzabteilung als Stabfunktion existiert, kann diese durch einen „Unternehmensausschuß Umweltschutz“ in dem alle Bereiche hochrangig vertreten sind, und durch Projektgruppen ergänzt werden. Der Stab erfüllt dann Sekretariatsaufgaben wie z.B. Vorbereitung der Sitzungen, Protokolle etc., die funktions-
} 
Insofern muß sich die ökologisch verpflichtete Unternehmensführung mit der effektiven Gestaltung der Aufbau- und Ablauforganisation des Umweltschutzes auseinandersetzen. Im Rahmen der Aufbauorganisation als Träger, welche die umweltorientierten Aufgaben übernehmen, wird versucht, dauerhafte Beziehungen des Umweltschutzes $\mathrm{zu}$ anderen Organisationseinheiten im Unternehmen festzulegen. Mit den Aufgaben, Kompetenzen und Verantwortlichkeiten, die sich aus der Umweltorientierung ergeben, können in den Unternehmen insbesondere folgende Träger betraut werden: ${ }^{166}$ Geschäftsleitung, Stabsstellen/Zentralbereiche, nicht permanente Organe, Umwelt-Center und externe Beratung. Wird Organisation als Querschnittaufgabe verstanden, geht die größte umweltorientierte Wirkung von einer - integrativen, nicht additiven - Kombination mehrerer Organisationsformen, wie „Vorstandsressort“, „Projektgruppen“ und „Umweltbeauftragter (mit Kompetenzen)“ aus. Bei der Ablauforganisation als Prozeß für die Umweltbeziehungen des Unternehmens steht die Regelung der Prozeßstrukturen im Vordergrund. Dabei sind zwei Grundtypen aus dem Gesichtswinkel der Umweltorientierung zu unterscheiden.

Bei den Prozessen im engeren Sinne lassen sich drei wesentliche Kategorien unterscheiden: Kommunikationsmanagement, Stakeholder-Management, Issue-Management. Prozesse beziehen sich im weiteren Sinne auf eine Erweiterung bestehender Verfahrensabläufe um umweltorientierte Aspekte (z.B. Investitionsentscheidungen). Dabei dienen diese Prozesse speziell der ablaufmäßigen Verankerung der Außenbeziehungen. Das Unternehmen muß ein Kommunikationssystem aufbauen, welches garantiert, daß die wesentlichen Umwelt-Informationen erfaßt werden und in geeigneter Form den Planungs- und Entscheidungsträgern zufließen. Dabei sollen Umweltinformationssysteme eingesetzt werden. Somit entstehen interaktive Kommunikationsprozesse. Weitere wesentliche Prozesse bedingen die Beziehungen des Unternehmens zu den Stakeholder-Gruppen und ihren Ansprüchen (Information, Verhandlungen usw.). Unter IssueManagement sind die Identifikation der Themenbereiche, Analyse der Themenbereiche und Entwicklung einer Haltung (Strategie) bezüglich dieser Themenbereiche $\mathrm{zu}$ verstehen. Neben den aufbau- und ablauforganisatorischen Maßnahmen sind im Rahmen der Organisation des Umweltschutzes Koordinations- und Motivationsmaßnahmen durchzuführen. ${ }^{167}$ Die Koordinati-

spezifische Umsetzung der Beschlüsse obliegt den verantwortlichen Führungskräften, bei wichtigen Angelegenheiten ist eine Vorlage für die Geschäftsführung zur Beschlußfassung zu erarbeiten. Vgl. Steger, U. (1993), S. $344 f$.

${ }^{166}$ Vgl. Sauter-Sachs, S. (1992), S.195f.; Schreiner, M. (1996), S. 317ff.; Hopfenbeck, W. (1998), S. 875ff.

167 Vgl. Frese, E. (1992), S. 2438ff. Neben diesen Maßnahmen sind auch die Ausbildungssysteme zu berücksichtigen. Die Implementierung des Umweltschutzes in eine Organisation stellt hohe Anforderungen an das ökologische Fachwissen der Mitarbeiter. Dieses geht über die rein ökonomischen Aspekte hinaus und bezieht naturwissenschaftlich-technisches Wissen sowie Kenntnisse im Umweltrecht mit ein. Treten Differenzen zwischen der erforderlichen und der tatsächlich vorliegenden ökologierelevanten Qualifikation auf, müssen geeignete Maßnahmen der Personalentwicklung durchgeführt werden. Diese Maßnahmen sollen die Mitarbeiter dazu befähigen, mit den komplexen Problemen umzugehen, die durch die Verknüpfung von betriebswirtschaftlichen und ökologischen Problemen entstehen. Auch die Kommunikationsfähigkeit sowie die Bereitschaft zur interdisziplinären Zusammenarbeit stellen ein 
on bezieht sich auf die Eingliederung der Teilfunktion Umweltschutz in die Gesamtorganisation sowie die Beziehungen $\mathrm{zu}$ den anderen betrieblichen Teilfunktionen. Motivationsmaßnahmen umfassen die Konzipierung eines Anreizsystems zur umweltbewußten Verhaltenssteuerung der Aufgabenträger.

\begin{tabular}{|c|c|c|}
\hline \multicolumn{3}{|c|}{ UMWELTORIENTIERTE ANREIZGESTALTUNG IN DER UNTERNEHMUNG } \\
\hline $\begin{array}{l}\text { Materielle } \\
\text { Anreize }\end{array}$ & $\begin{array}{l}\text { - Spezifische Ausgestaltung des Bonussystems, so daß ökologische } \\
\text { Minderzielerreichung nicht durch ökonomische Übererfüllung } \\
\text { kompensiert werden kann. } \\
\text { - Verknüpfung von Beförderung/Karriereplanung und Gehaltsfin- } \\
\text { dung/ Leistungsbeurteilung mit der (Über-) Erfüllung ökologiebe- } \\
\text { zogener Ziele. } \\
\text { - Betriebliches Vorschlagswesen (Anbindung an Ecology Circles), in } \\
\text { Verbindung mit einem höheren Prämiensatz für umweltverbessem- } \\
\text { de Mitarbeitervorschläge }\end{array}$ & $\begin{array}{l}\text { Ansprache } \\
\text { materieller } \\
\text { Bedürfnisse }\end{array}$ \\
\hline $\begin{array}{l}\text { Immaterielle } \\
\text { Anreize }\end{array}$ & $\begin{array}{l}\text { - Information über toxische Stoffe, Sicherheit am Arbeitsplatz } \\
\text { - Ökologiebezogene Kennzahlensysteme, die „Feedback“ Informati- } \\
\text { onen liefern }\end{array}$ & $\begin{array}{l}\text { Ansprache } \\
\text { von Sicherheits- } \\
\text { bedürfnissen }\end{array}$ \\
\hline $\begin{array}{l}\text { Immaterielle } \\
\text { Anreize }\end{array}$ & $\begin{array}{l}\text { - Lernstatt, „Ecology Circles“, Umweltprojektteams usw. } \\
\text { - Solidaritätsfördernde Umwelt(lehr)veranstaltungen, -seminare, } \\
\text {-bildungsausflüge mit Umweltbezug } \\
\text { - Vorgesetzte fungieren als „Umweltschutz-Vorbild““ }\end{array}$ & $\begin{array}{l}\text { Ansprache } \\
\text { von sozialen } \\
\text { Kontaktbedürfnissen }\end{array}$ \\
\hline $\begin{array}{l}\text { Immaterielle } \\
\text { Anreize }\end{array}$ & $\begin{array}{l}\text { - Aufstiegsrelevanz umweltorientierten Verhaltens deutlich machen } \\
\text { - Auszeichnung von besonders umweltorientierten Mitarbeitern bei } \\
\text { Betriebs- bzw. Erfinderfesten, Lob durch den Vorgesetzten; Über- } \\
\text { tragung besonderer Aufgaben an umweltbewußte Mitarbeiter } \\
\text { - Frühzeitige Einbeziehung, Nutzung der Fachkompetenz, Informati- } \\
\text { on der Mitarbeiter hinsichtlich Umweltschutzmaßnahmen } \\
\text { - Eigenkontrollen }\end{array}$ & $\begin{array}{l}\text { Ansprache } \\
\text { von } \\
\text { Anerkennungs- } \\
\text { bedürfnissen }\end{array}$ \\
\hline $\begin{array}{l}\text { Immaterielle } \\
\text { Anreize }\end{array}$ & $\begin{array}{l}\text { - Herausfordernde, kreativitätsfördernde, ökologiebezogene Aufga- } \\
\text { beninhalte (,Job Enlargement/Enrichment“), } \\
\text { - Identitätsstiftende Tätigkeiten, durch die privat gelebtes Umwelt- } \\
\text { bewußtsein auch in der Unternehmung realisiert werden kann } \\
\text { - Partizipation bei der Fixierung von Umweltzielen } \\
\text { - Anregen zu ökologiebezogenen Innovationen } \\
\text { - Umweltbezogene Aus- und Weiterbildung (Personalentwicklung) }\end{array}$ & $\begin{array}{l}\text { Ansprache } \\
\text { von } \\
\text { Selbstverwirklichungs- } \\
\text { bedürfnissen }\end{array}$ \\
\hline
\end{tabular}

Abb. 4.12: Umweltorientierte Anreizgestaltung (Quelle: Steinle, C. (1995), S. 920.)

neues Element des ökologischen Lernens dar. Vgl. Meffert, H./Kirchgeorg, M. (1998), S. 399; Kreikebaum, H. (1993), S. 87. 
Die Motivation der Aufgabenträger zu umweltbewußtem Verhalten, die eine Grundvoraussetzung für die Implementierung des Umweltschutzes darstellt und darüber hinaus die notwendigen Änderungen im traditionellen Entscheidungs- und Arbeitsablauf wirkungsvoll unterstützt, ${ }^{168}$ erfordert die Gestaltung eines geeigneten Anreizsystems (vgl. Abb. 4.12). ${ }^{169}$

Dabei sind planorientierte Anreizsysteme im Umweltschutzbereich marktorientierten Lösungen überlegen. ${ }^{170}$ Die Kontrolle der Einhaltung unternehmensinterner und gesetzlicher Vorgaben, die Einführung eines entsprechenden Prämiensystems sowie die Beteiligung der Aufgabenträger an der Planformulierung (Partizipation) bilden den Kern eines solchen Anreizkonzeptes. ${ }^{171}$ In Analogie zum betrieblichen Vorschlagswesen bietet sich weiterhin die Einrichtung eines Umweltvorschlagswesens an, um den Mitarbeitern die Gelegenheit zu geben, aktiv beim betrieblichen Umweltschutz mitzuwirken. ${ }^{172}$

Bei Überlegungen von Alternativen zur Gestaltung der Umweltschutzorganisation im Unternehmen sind im Einzelfall die bestehenden Organisationsstrukturen zu berücksichtigen, d.h. die organisatorische Eingliederung umweltbezogener Aufgaben kann durch Aufgabenerweiterung aller Stellen im Unternehmen im Rahmen bestehender Organisationsstrukturen erfolgen.

Im Rahmen der Überlegungen von Alternativen zur Gestaltung der Umweltschutzorganisation im Unternehmen lassen sich die zentralen organisatorischen Eingliederungsmöglichkeiten des Umweltschutzes in folgende alternative Organisationsstrukturen unterscheiden: ${ }^{173}$

- Das organisationale Skelette bzw. die Makrostruktur,

- Die organisationalen Positionen bzw. die Mikrostruktur sowie

- Die organisationalen Querverbindungen bzw. die Lateralstruktur

Im Rahmen der Makrostruktur wird der Hintergrund bzw. die (strukturelle) Grundlage für alle weiteren Gestaltungsaktivitäten abgegeben. Im Rahmen der makrostrukturellen Grundformen läßt sich zwischen funktionalen, divisionalen und - wenngleich nur eingeschränkt - Matrixorganisationen unterscheiden.

\footnotetext{
${ }^{168}$ Wicke, L. (1988), S. 24ff.

${ }^{169}$ Vgl. Seidel, E. (11991), S. 171ff.

${ }^{170}$ Vgl. Frese, E. (1992), S. $2447 f f$.

${ }^{171}$ Vgl. Bartscher, T. R./Fleischer, H. (1991), 443.

${ }^{172}$ Vgl. Winter, G. (1988); S. 28; Hopfenbeck, W. (1991), S. 400.
} 
In der funktionalen Organisation im Umweltschutz wird neben den bestehenden Unternehmensfunktionen die Funktion Umweltschutz evtl. aufgeteilt nach einzelnen Teilfunktionen wie Abfallwirtschaft, Energie, Gewässerschutz oder Emissionsschutz. Damit vervollkommnet die funktionale Organisation durch die Bündlung von Spezialwissen und Erfahrung in den einzelnen Teilbereichen die mit der Stab-Linien-Organisation angestrebte Professionalsierung und Spezialisierung bei der Bewältigung der Umweltschutzaufgaben im Unternehmen.

Da Umweltschutzprobleme sowohl eine Daueraufgabe, (es handelt sich meistens nicht um abgrenzbare Einzelprobleme mit zeitlich begrenzter Dauer) als auch eine Querschnittsfunktion, die in alle traditionellen Unternehmensfunktionen hineinlangt, darstellen, kann die Matrixorganisation dieser Aufgabe offensichtlich am besten gerecht werden (vgl. Abb. 4.13). ${ }^{174}$

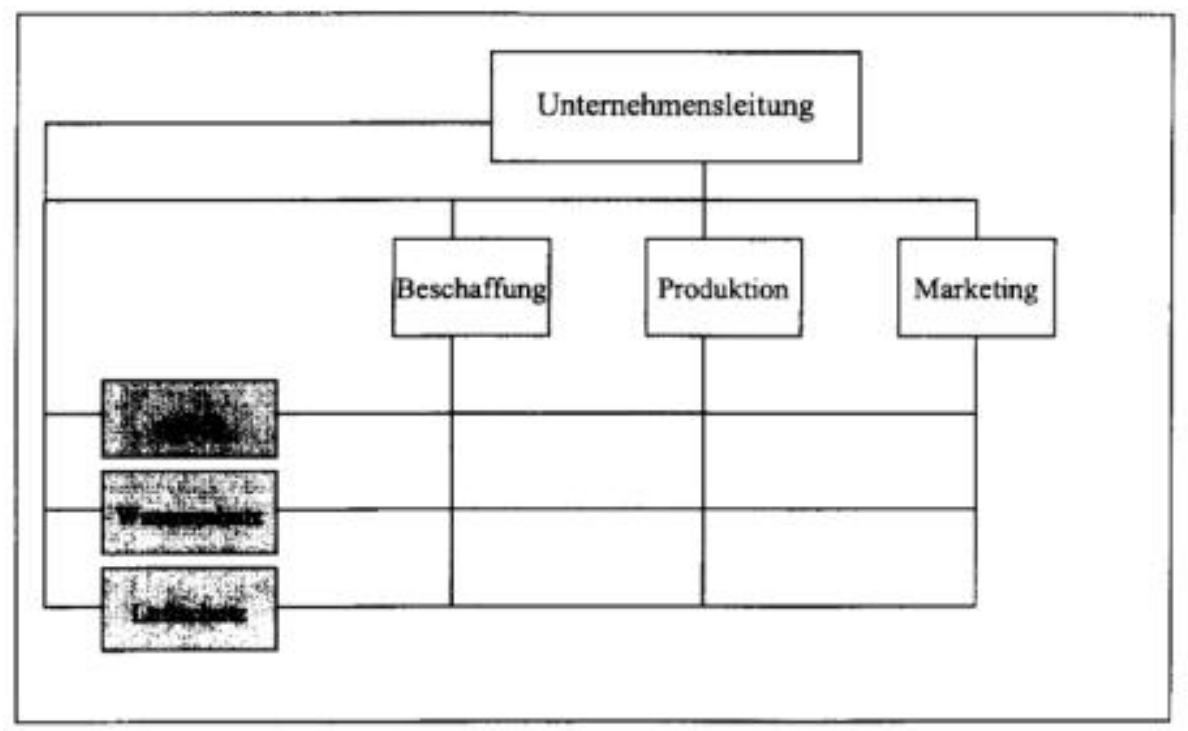

Abb. 4.13: Umweltschutz in einer Matrixorganisation (Quelle: Schanz, G. (1999), S. 22)

Die Matrixorganisation versucht, die Vorteile der funktionalen Organisation mit einer verbesserten Zusammenarbeit der einzelnen Funktionsbereiche zu verbinden. Bei der Matrixorganisation des Umweltschutzes erfolgt auch eine Spezialisierung mit einer funktionsübergreifenden $\mathrm{Ab}$ stimmung (Selbstabstimmung) der einzelnen Teilbereiche. Dabei steht diese Funktion in direktem Kommunikationskontakt mit den anderen Funktionsbereichen und steht diesen ihrerseits gleichberechtigt gegenüber. So wird eine notwendige Teamarbeit in allen Bereichen sichergestellt. Allerdings besteht aufgrund des höheren Abstimmungsbedarfs die Gefahr eines Zeitverlus-

\footnotetext{
${ }^{173} \mathrm{Zu}$ den alternativen Organisationsstrukturen und der folgenden Ausführung vgl. Schanz, G. (1994), S. 107ff. und (1999), S. 16ff.

${ }^{174}$ Vgl. Pfnür, A. (1995), S. 87; Meffert, H./Kirchgeorg, M. (1998), S. 404; Schanz, G. (1999), S. 22.
} 
tes, bis eine Gesamtentscheidung zustande kommt. Weiterhin darf die Störanfälligkeit eines solchen Systems bei unzureichender Kompetenz- und Verantwortungsabgrenzung nicht übersehen werden. Die Zusammenarbeit zwischen den Teilfunktionen läßt sich auch im Rahmen des betrieblichen Ausschußwesens regeln. Ausschüsse stellen ein variables Instrument der funktionsübergreifenden Zusammenarbeit dar und können kontinuierlich bzw. diskontinuierlich zur Abstimmung von Einzel- bzw. Sonderaufgaben eingesetzt werden.

Die divisionale Organisation folgt einer Orientierung am Objektprinzip. Objekte können dabei Sparten, Produkte, Geschäftsbereich oder Divisionen sein. Zur strukturellen Integration ökologisch verpflichteten Wirtschaftens in divisionale Organisationen ist es denkbar, einerseits den Umweltschutz jeder einzelnen Division zuzuordnen, was auf eine konsequent dezentrale Lösung hinausläuft.

Auf der anderen Seite besteht die Möglichkeit, daß neben den einzelnen Divisionen ein Zentralbereich „Umweltschutz“ etabliert wird. Dieser läßt sich dann weiter nach verschiedenen Umweltschutzaufgaben aufgliedern, welche ihrerseits als „Fachreferate“ geführt werden. Die Einrichtung eines derartigen Zentralbereichs zielt darauf $a b$, daß man den Umweltschutzaufgaben nur durch Bündelung von Expertenwissen der verschiedenen Gebiete (naheliegenderweise Technik und Recht, ggf. aber auch Medizin und Psychologie usw.) gerecht werden kann, weil sie mitunter wegen ihrer komplexen, mehrere Fachgebiete betreffenden Fragestellungen hohe Anforderungen mit sich bringen.

Da diese struktuellen Integrationsmöglichkeiten des Umweltschutzes in der unternehmerischen Praxis allerdings vergleichsweise selten anzutreffen sein werden, empfiehlt sich hier vielmehr eine organisatorisch-strukturelle Einliederung, die Elemente beider Alternativen übernimmt. Der Umweltschutz kann dabei zum einen als eigenständiger Zentralbereich, zum anderen in Form von Beauftragten in den einzelnen Divisionen, Geschäftsbereichen oder Sparten und den verschiedenen Betrieben oder Werken aufbauorganisatorisch mehrstufig verankert werden. ${ }^{175}$

Neben der oben dargestellten strukturellen Verankerung der Umweltschutzaufgaben können weitere Eingliederungsmöglichkeiten nach dem Einlinienprinzip, in Form von Einlinienorganisation oder Stabstellen in die Organisation eingebunden werden. ${ }^{176}$

\footnotetext{
175 Vgl. Schanz, G. (1999), S. 20.

${ }^{176}$ Vgl. Meffert, H./Kirchgeorg, M. (1998), S. 400ff.; Schreiner, M. (1993), S. 317ff.
} 
Die Einlinienorganisation basiert auf dem Grundsatz der Einheit von Leitung und Auftragsempfang. Die Linie fungiert als Dienstweg, über den der Entscheidungs- und Informationsfluß zu erfolgen hat. Für die ökologisch verpflichtete Unternehmensführung ist bei dieser Organisationsstruktur von Bedeutung, daß trotz der Delegation von Entscheidungs- und Anordnungskompetenzen und trotz der Aufgabenteilung bei der Durchsetzung eines Umweltschutzkonzeptes die Einheitlichkeit gewährleistet werden kann. Aber die mit dem Einliniensystem vorwiegend realisierte funktionale Unternehmensorganisation birgt die Gefahr in sich, daß alle Aufgaben und Informationen erst ihren „Dienstweg“ über die verschiedenen Hierarchieebenen gehen müssen und daß sich dabei neben zeitlichen Verzögerungen auch Problemreduzierungen und Verluste von Informationen ergeben und daß die straffe Einbindung fast sämtlicher Kommunikationsbeziehungen in vertikale Dienstwege einen hohen Koordinations- und Informationsaufwand erfordert. Die Lösungsansätze hierzu bietet die funktionale Organisation. Zudem sind die Linienstellen häufig mit Routinetätigkeiten überlastet, so daß für kreative und innovative Prozesse meist die Kapazität fehlt. Zu Lösung dieser Problematik bietet sich die Einrichtung von Stabsstellen an.

Eine Stab-Linien-Organisation im Umweltschutz versucht, die Nachteile der mangelnden Spezialisierung und die Überlastung der leitenden Instanzen durch die Einrichtung von Stabsstellen zu kompensieren. Den Umweltschutz-Stabsstellen werden die leitenden Funktionen in der Organisation zugeordnet. Sie übernehmen Aufgaben der Entscheidungsvorbereitung, Kontrolle und der allgemeinen fachlichen Beratung. Da die Aufgaben der Stabsstellen auf Informations- und Koordinationsaktivitäten ohne Weisungsbefugnisse beschränkt bleiben, nehmen die Mitarbeiter die Funktion von Fachpromotoren für den Umweltschutz wahr. Die Umweltschutzstellen können ihrerseits untereinander als Liniensysteme mit Leitungskompetenz ausgestattet sein.

Wenn es um die konkrete, d.h. tägliche, sich in kleinen Schritten vollziehende, Umsetzung des Umweltschutzes im Unternehmen geht, dann spielen die einzelnen Mitglieder des Unternehmens an ihren jeweiligen Arbeitsplätzen die entscheidende Rolle, ob und in welchem Ausmaß ein Unternehmen seiner ökologischen Verantwortung gerecht $\mathrm{zu}$ werden vermag. ${ }^{177}$ Beim mikrostrukturellen Gestalten des ökologisch verpflichteten Wirtschaftens handelt es sich vor allem um die „Verhaltensformalisierung“. ${ }^{178}$ Verhaltensformalisierung zielt einerseits darauf ab, die Handlungsspielräume von Positionsinhabern zu beschränken, weil Organisationen aus leicht nachvollziehbaren Gründen nicht an deren gesamtem Verhaltensrepertoire interessiert sind, andererseits

\footnotetext{
${ }^{177}$ Vgl. Schanz, G. (1999), S. 25ff.

${ }^{178}$ Vgl. Schanz, G. (1999), S. $25 f$.
} 
aber bestrebt sind, jene Aktivitäten abzufordern oder zu verstärken, die dem Erreichen der organisationalen Ziele dienlich sind. ${ }^{179}$

Im Rahmen der ökologisch verpflichteten Unternehmensführung soll durch Einsatz geeigneter Formalisierungsmechanismen erreicht werden, daß Verhaltensweisen reduziert werden, deren Konsequenzen sich als nicht umweltverträglich darstellen, und daß Verhaltensweisen verstärkt werden, deren Folgen umweltschonend sind. ${ }^{180}$ Beide lassen sich im Prinzip mit Hilfe von Stellenbeschreibungen (Arbeitsplatzbeschreibungen) bewirken. Unabhängig von der Person des Positionsinhabers konkretisieren sie insbesondere die Ziele der Stelle, die Aufgaben und Kompetenzen des Stelleninhabers, die Beurteilungskriterien sowie die Beziehungen $\mathrm{zu}$ anderen (ranghöheren, rangniedrigeren und gleichrangigen) Stellen. Die Stellenbeschreibungen können auch in den Dienst ökologisch verpflichteten Wirtschaftens gestellt werden. Dafür ist es notwendig, eine dazu passende Ergänzung durch personalwirtschaftliche Instrumente (z.B. Anreiz- und Karrieresysteme) zu schaffen. ${ }^{181}$

Die Stellenbeschreibungen können insbesondere dahingehend wirken, daß: ${ }^{182}$

- Das allgemeine Umweltschutzziel verbindlichen Eingang in die Zielsetzung der Stelle findet,

- Die Anforderungen an die fachliche Qualifikation potentieller Stelleninhaber „umweltbezogen“ erweitert werden und

- Klar zum Ausdruck gebracht wird, daß ökologisch beachtetes Handeln in die Beurteilung des Stelleninhabers einfließt.

Der Stellenwert lateralstruktureller Institutionalisierung des Umweltschutzes ergibt sich daraus, daß die Wirksamkeit der verschiedenen Umweltschutzaktivitäten des Unternehmens entscheidend von einer stimmigen Koordination abhängt. Im Rahmen der Gestaltung der Lateralstruktur gewinnen die organisationalen Verbindungseinrichtungen und Planungs- und Kontrollsysteme Bedeutung. Die organisationalen Verbindungseinrichtungen zielen darauf $a b$, die erforderliche wechselseitige Abstimmung zwischen hierarchisch unverbundenen Positionen oder Subeinheiten zu ermöglichen (Schnittstellenmanagement). Darüber hinaus werden durch die Planungs- und Kontrollsysteme Querverbindungen geschaffen. ${ }^{183}$ Koordinations-, Planungs- und Kontrollfunktionen des Umweltschutzes können mit Hilfe von Umweltschutzbeauftragten sowie Umweltaus-

\footnotetext{
${ }^{179}$ Vgl. Schanz, G. (1994), S. 170ff.

${ }^{180}$ Vgl. Schanz, G. (1999), S. 26.

181 Vgl. Seidel, E. (1991); Steinle, C. (1995).

182 Vgl. Schanz, G. (1999), S. 27.
} 
schüssen und speziellen Projektgruppen in Organisationen eingegliedert werden. Im Rahmen der Lateralstruktur wird zunächst die von der gesetzlich bestimmte Institution „Umweltschutzbeauftragte" im Unternehmen dargestellt, weil dieser Tätigkeitsbereich eines Unternehmens unter die entsprechenden Regelungen der einzelnen Gesetze fällt. ${ }^{184}$ Der Umweltschutzbeauftragte soll im Unternehmen folgende Aufgaben ausüben: ${ }^{185}$

- Überwachung der Einhaltung von Gesetzen, Verordnungen und behördlichen Anordnungen,

- Mitwirkung bei der Forschung, Entwicklung und Einführung umweltgerechter Produktionsverfahren und Produkte,

- Information der Unternehmensführung über Umweltrisiken,

- Aufklärung und Motivation der Mitarbeiter,

- Stellungnahmen zu Investitionsobjekten,

- Kontaktpflege zu Behörden und zur Öffentlichkeit in Umweltfragen.

Der Umweltschutzbeauftragte stellt somit in seinen vom Gesetzgeber fixierten Aufgabenbereichen einen Fachpromotor für den betrieblichen Umweltschutz dar, ohne weitere Weisungsbefugnisse. Darüber hinaus wird vom Umweltschutzbeauftragten im Rahmen einer offensiven Umweltschutzstrategie ein weiteres Aktionsfeld gefordert. So werden ihm noch weitere nicht gesetzlich geregelte Aufgaben im Umweltschutz oder verwandte Gebiete, z.B. Arbeitssicherheit mit dem Umweltschutz, zugeordnet.

Der Umweltausschuß wird als eine kompetente „Informationssammelstelle“ charakterisiert, die Fakten, Einschätzungen und Analysen der Betriebs- und Geschäftsleitung in entscheidungsfähiger Form zur Kenntnis bringt. ${ }^{186}$ Umweltausschüsse als Informations- und Beratungsgremien zielen darauf $\mathrm{ab}$, die umweltschutzbezogenen Aufgaben der verschiedenen Stellen innerhalb des Unternehmens aufeinander abzustimmen. ${ }^{187}$ Zur konkreten personellen Zusammensetzung derartiger Gremien gehören neben den Führungskräften der verschiedenen Unternehmensbereiche und

\footnotetext{
${ }^{183}$ Vgl. Schanz, G. (1999), S. 23 und (1994), S. 182ff.

${ }^{184}$ Wegen der länderspezifischen Gesetzgebung für den Umweltschutz sollen hier nur die Allgemeinheiten, d.h. allgemeingültige Definition und Aufgaben von Umweltschutzbeauftragten vorgestellt werden. Für die organisatorische Auslegung des Umweltschutzes im Betrieb existieren minimale gesetzliche Standards. So sind Unternehmen unter bestimmten Voraussetzungen verpflichtet, Betriebsbeauftragte für Immissionsschutz, für Gewässerschutz oder für Abfall einzusetzen. Reichweite und Grenzen der Effizienz dieses Instruments sind aber sehr beschränkt, da die Betriebsbeauftragten nur eine recht bescheidene Rolle bei der ökologischen Organisationsentwicklung übernehmen dürfen. Darüber hinaus stellen die meisten Unternehmen in Südkorea diesen sog. Umweltschutzbeauftragter nur dafür ein, den staatlichen Kontrollen entgegenkommen zu können. Vgl. hierzu ausführlich Umweltministerium Südkorea (1998).

${ }^{185}$ Vgl. Steger, U. (1993), S. 346; Schanz, G. (1999), S. 24.

${ }^{186}$ Vgl. Sietz, M./Sondermann, W. D. (1990), S. 96ff.

${ }^{187}$ Vgl. Middelhof, H. (1994), S. 391.
} 
dem Umweltschutzbeauftragten auch nach Möglichkeit ein Mitglied des obersten Leitungsorgans. Da es sich bei der Koordination der verschiedenen umweltschutzbezogenen Aktivitäten um eine sich fortlaufend stellende Aufgabe handelt, empfiehlt sich die dauerhafte Einrichtung von Umweltausschüssen. ${ }^{188}$ Die Umweltausschüsse werden sich primär mit übergreifenden Themen beschäftigen, wobei Mitglieder dieses Gremiums den Umweltbeauftragten partiell unterstïtzen sollten. $^{189}$

Weitere organisatorische Lösungsmöglichkeiten im Umweltschutz bestehen im Projektmanagement. Gerade in der Übergangsphase zur Schaffung einer festen organisatorischen Einrichtung „Umweltschutz“ scheint das Projektmanagement als temporäre Organisation besonders geeignet zu sein. Auch können gewisse funktionsübergreifende und interdisziplinäre Teilaufgaben, wie z.B. Erstellung von Öko-Bilanzen oder Planung neuer Umwelttechnologien und Produkte u.a.m. abgewickelt werden, obwohl der Umweltschutz im Unternehmen nicht als ein zeitlich begrenztes Projekt betrachtet werden darf. ${ }^{190}$

\footnotetext{
${ }^{188}$ Vgl. Schanz, G. (1999), S. 24.

${ }^{189}$ Vgl. Hopfenbeck, W. (1998), S. 880.

${ }^{190}$ Vgl. Schreiner, M. (1993), S. 321; Schanz, G. (1999), S. 25.
} 


\section{Teil II: Rahmenbedingungen}

\section{für eine ökologisch verpflichtete Unternehmensführung in Südkorea}

Die Naturzerstörung und die sie verursachende Fortschrittsideologie sind nicht alleine typisch abendländische Phänomene. Die sog. Dritte Welt, die den Imperialismus und den Kolonialismus schmerzlich erlebt hat, hält das Machtergreifen durch die Kriegsmachtverstärkung und das wirtschaftliche Wachstum für den einzigen Weg zum Überleben. Ihre Kulturen waren aber keineswegs primitiv oder gar unentwickelt, sondern hochkomplizierte Gleichgewichtssysteme im Verhältnis der Menschen zur Natur und zueinander. Aber heutzutage halten die Entwicklungsländer ihre Wertsysteme und Traditionen für lästig und für einen Stolperdraht. In ihnen wurden die Werte von Harmonie und Gleichgewicht durch die neuen Ziele Wachstum, Expansion, Entwicklung und Naturbeherrschung ersetzt. Oft setzte sich das Gefühl durch, daß die Logik der Macht und der Wirtschaft über die heutige moderne Gesellschaft herrscht, in der Gerechtigkeit und Rechtschaffenheit erst mit deren Machtergreifen garantiert werden. Das Ergebnis dieser Entwicklung, die in den meisten Entwicklungsländern in den letzten Jahrzehnten stattfand, sind vor allem die Naturzerstörung und die damit verbundenen ökologischen Probleme. Diese Probleme sind wesentlich ernster als diejenigen in den Industrienationen. Dies betrifft auch Südkorea.

Angesichts der Konsequenzen der Umweltprobleme, die unternehmerische Tätigkeiten stärkend in ihrer ökologischen, gesellschaftlichen und wettbewerbsstrategischen Dimension beeinflussen, ist die Notwendigkeit der Berücksichtigung von Umweltschutzforderungen bei unternehmerischen Entscheidungen auch in Südkorea kaum mehr in Frage zu stellen. Für die Analyse und Konzeption der ökologisch verpflichteten Unternehmensführung in Südkorea ist eine interdisziplinäre Betrachtung notwendig, da die gegenwärtige Problematik in Südkorea soziokulturelle und historische Determinanten berücksichtigen muß. Deshalb sollen in diesen Teil die gesellschaftliche, politisch-rechtliche und wirtschaftliche Rahmenbedingungen für die ökologisch verpflichtete Unternehmensführung in Südkorea besprochen werden.

\section{Gesellschaftliche Rahmenbedingungen}

Dieses Kapitel beschäftigt sich mit der analytischen Untersuchung der traditionellen Denk- und Verhaltensstrukturen der Koreaner in bezug auf Umweltfragen. Dabei soll die zentrale Frage diskutiert werden, welche spezifischen gesellschaftlichen Strukturen die Denktradition charakterisieren, insbesondere in bezug auf Umweltfrage (Naturanschauung) Südkoreas. Die traditionelle Denk- und Verhaltensformen in Südkorea haben sich hauptsächlich durch die konfuzianische 
Soziallehre herausgebildet bzw. ausgeprägt. Daher scheint die Untersuchung der koreanischen Gesellschaft nicht sinnvoll, ohne die konfuzianisch geprägten Weltanschauungen miteinzubeziehen. Darüber hinaus wird die traditionelle Sichtweise der Natur bzw. Umwelt durch buddhistische $^{1}$ und taoistische Vorstellungen geprägt. ${ }^{2}$ In diesem Abschnitt soll hauptsächlich der Taoismus behandelt werden, dessen naturphilosophische Denkrichtung in Südkorea stark vertreten war bzw. ist. Danach soll der westliche Einfluß auf koreanischen Gesellschaft behandelt werden, denn die heutige koreanische (Industrie) Gesellschaft beruht nicht nur unmittelbar auf ihrer eigenen soziokulturellen Figuration, sondern wird auch von der westlichen Kultur stark beeinflußt. Schließlich soll der Wertewandel in bezug auf die Umweltfrage in der koreanischen Gesellschaft (Umweltbewußtsein) dargestellt werden.

\subsection{Die traditionelle Welt- und Naturanschauung in der koreanischen Gesellschaft}

\footnotetext{
${ }^{1}$ Die Grundidee des Buddhismus besteht darin, über die Welt der Gegensätze hinauszugelangen. Das Ziel ist die Wirklichkeit, die als aus intellektuellen Konstruktionen und emotionalen Verzerrungen zusammengesetzt gesehen wird, zu überwinden und die geistige Welt der Unterschiedslosigkeit zu erkennen. Nur mit dieser Art des Denkens können die Dinge in einer vielschichtigen oder ganzheitlichen Weise gesehen werden. Alle Unvereinbarkeiten kommen dann zur Harmonie. Im Buddhismus dominiert die Vorstellung vom zyklischen Verlauf und der Interdependenz allen Lebens. Die Natur ist Wohnsitz von Geistern und Mächten und ihr ist deshalb mit Respekt und Verehrung zu begegnen. Das erste der zehn buddhistischen Gebote ist das Verbot der Vernichtung von Tieren und Pflanzen, eine Ableitung aus dem Prinzip der Barmherzigkeit, das von altersher den Ausdruck der durch den Buddhis mus vermittelten Liebe zum Leben darstellt. So ist der Umweltschutz als Schutz der gesamten Fauna und Flora einschließlich der Menschen bereits seit jeher in dieser philosophischen Tradition verankert. Auf weitere Ausführung über den Buddhismus wird in dieser Arbeit verzichtet. Zu verweisen sind hierauf u.a. Chang, G. C. C. (1989), S. 8f.; Suzuki, D. T. (1982); Lee, S.-N. (1985), S. 31.

${ }^{2}$ In dieser Arbeit werden Konfuzianismus, Buddhismus und Taoismus nicht als Religion, sondern als Philosophie betrachtet. Im allgemein wird z.B. der Taoismus zwischen dem philosophischen und religiöse Taoismus unterschieden. Mit dem ersten ist die Philosophie gemeint, die mit dem Namen des Laotse und Chuangtse eng verbunden ist, mit dem zweiten das System, in dem Magie und Schamanismus aus Nordostasien mit dem philosophischen Taoismus verschränkt sind. Der religiöse Taoismus eignete sich die philosophisch-taoistischen Texte einschließlich des Tao Te King und des Chuangtse an. Er akzeptierte Teile der Yin-Yang Schule, der konfuzianischen Ethik und viele buddhistische Rituale und Lehren. Und er strebte nach einem langen Leben und der Unsterblichkeit. Die Legende, daß Laotse außergewöhnlich lange lebte, entstand, als die Figur des Laotse vollkommen in den religiösen Taoismus absorbiert wurde. Im religiöse Taoismus war die Figur des Laotse nicht nur ein Gott, der vom Uranfang her existierte, sondern auch gleichzeitig der ideale Mensch, der sich in einen Unsterblichen verwandelt hat. Hier kann man erkennen, daß er sich weit von der Philosophie von Laotse und Chuangtse selbst entfernt hatte. In dieser Arbeit meint daher Taoismus u.a. den philosophischen Taoismus, der von Laotse und Chuangtse vertreten wurde und die Betrachtung des Taoismus beschränkt sich auf zwei Texte von Laotse und Chuangtse, nämlich Tao Te King und Chuangtse. Vgl. über den religiöse Taoismus z.B. Needham, J. (1969); Blofeld, J. (1986); Kaltemark, M. (1981).
} 
Der Konfuzianismus als Soziallehre: Die Weltanschauung bestimmt das Wertesystem der Cesellschaft und damit die gesellschaftliche Zielfunktion. Welche Ziele mit welcher Priorität angestrebt werden, um die Wohlfahrt zu maximieren, ob und in welchem Maße dies mit materiellen Zielen einhergeht und wessen Wohlfahrt zu maximieren ist, variiert jeweils in Abhängigkeit von der Weltanschauung der Gesellschaft. Die Weltanschauung der Koreaner war bzw. ist hauptsächlich durch den Konfuzianismus geprägt. Die Betrachtung des konfuzianischen Gesellschaftssystems ist daher für das Verstehen des heutigen Südkoreas notwendig.

Der Konfuzianismus war bzw. ist nur eine der vielen Richtungen der chinesischen Philosophie oder Denktradition, wenngleich auch eine der wichtigsten und er teilt mit den anderen Schulen (Taoismus, Buddhismus etc.) gewisse Gemeinsamkeiten, die auch dem gesamten koreanischen Denken eigen sind.

Das allgemeine Grundmotiv von Konfuzianismus ist das Streben nach Harmonie, nach der Mitte zwischen den Extremen. Das führt zur Idee vom Einklang des Menschen mit dem Kosmos. Ein deutliches Charakteristikum der konfuzianischen Philosophie und überhaupt des konfuzianischen Denkens ist das Ausgerichtetsein auf diese Welt, auf das Diesseits. In der Mitte des Denkens steht der Mensch. Dabei wird der Mensch aber nie allein als isoliertes Wesen und für sich gesehen, sondern stets im Zusammenhang mit der ihn umgebenden Natur und dem Mitmenschen. Die Philosophie wird so zur Sozialphilosophie und die Beschäftigung mit ihr führt letztlich zur Ethik und ihrer Einwirkung auf die Politik und das staatliche Leben der Menschen. Als Herrschaftsprinzip beeinflußte die konfuzianische Lehre in Südkorea die gesellschaftliche Erziehung und zielte auf eine einheitliche Denkart des Volkes. Durch diesen Prozeß wurde die konfuzianische Grundhaltung auf alle sozialen Bereiche, bis hin zum bürgerlichen Alltagsleben, verbreitet, um zur Basis der Weltanschauung zu werden.

Dabei wurde die konfuzianische Lehre in erster Linie als politisches Prinzip verstanden, um das paternalistische und autoritäre Familiensystem zu etablieren. Mit Hilfe dieser Systemetablierung wurde zunächst beabsichtigt, die zentralisierte königliche Herrschaftsmacht zu stärken. Dazu diente das Grundprinzip der konfuzianischen Lehre, die Vervollkommnung der Tugenden von Ehrfurcht und Kindesliebe, als Herrschaftsmittel mit absolutem Wert. Die Wertorientierung nach dem konfuzianischen Sozialprinzip setzte sich somit in der politisch herrschenden Schicht durch.

Was nun wichtig ist, sind die soziokulturellen Auswirkungen des Konfuzianismus auf die koreanische Gesellschaftsstruktur. Der Konfuzianismus dient als soziokulturelle Basis in fast allen ge- 
sellschaftlichen Handlungsbereichen. Dies gilt für die kleinste soziale Einheit wie die Familienstruktur und den persönlichen Umgang bis zu den höfischen Gesellschaften und Staatsorganen.

Die traditionelle Gesellschaftsstruktur Südkoreas weist darauf hin, daß die konfuzianische Lebensanschauung als elementare Prinzip nach wie vor Ethik und Moral des koreanischen Volks bestimmt. $^{3}$ Selbst der zunehmende Einfluß des Christentums in Südkorea vermindert nicht die Bedeutung der konfuzianischen Ethik für das Familienleben. ${ }^{4}$

Um die spezifische gesellschaftliche Konfiguration des traditionellen Südkoreas zu charakterisieren, können zwei Grundideen der konfuzianischen Soziallehre herangezogen werden. Es ist das patrimoniale Gesellschaftsprinzip und ein utopisches Gesellschaftskonzept.

Das patrimortiale Gesellschaftsprinzip: Der Kernpunkt der konfuzianischen Soziallehre ist ein patrimonial ausgerichtetes Ordnungsprinzip. Patrimoniale Herrschaften können primär als ökonomische Verbände gekennzeichnet werden, in denen der Familienvater die absolute Herrschaft über die anderen Mitglieder hat, im Gegenzug aber ihre Versorgung und Entwicklung gewährleistet. $^{5}$ Dieser wesentliche Charakter des Patrimonialismus läßt sich im traditionellen koreanischen Familiensystem deutlich erkennen, das durch das konfuzianische Verhaltensprinzip (Ehrfurcht, Kinderliebe) bestimmt wird. Der Staat wiederum ist eine erweiterte Form des patrimonialen Familiensystems. Aus diesem Grund kann die konfuzianische Verhaltensethik als eine „Familienethik“ bezeichnet werden. Dies soll im weiteren auch bedeuten, daß Südkorea als eine „familienorientierte“ oder „familistische“ Gesellschaft zu verstehen ist, während die westliche Kultur als ,ich-orientiert" gelten kann.

Ein utopisches Gesellschaftskonzept: Das zentrale Denken des Konfuzianismus ist der Edelmut, der gerade dem Humanismus den höchsten Wert einräumt. Der Edelmut bedeutet hier konkret die „Menschenliebe“, die den Mitmenschen anerkennt und ihn menschlich behandelt. Die Verwirklichung des Edelmutes ist das erste und letzte Ziel des Konfuzianismus, das durch das Vertrauen in die Menschen erreicht werden soll. Da der Edelmut von Ethik und Moral, die die Bindungskräfte der gesamten Menschheit und zugleich der Gesellschaft darstellen, ausgeht, entwickelte sich zuerst die Moralphilosophie. Auf dieser Basis baute dann das weitere Gesellschaftsdenken, nämlich das grundlegende Erziehungskonzept und die politische Philosophie, auf. Dem-

\footnotetext{
${ }^{3}$ Vgl. Hickmann, E. (1959), S. 188ff.; Vos, F. (1977), S. 173.

${ }^{4}$ Vgl. Lee, M.-T. (1974), S. 184.
} 
zufolge verkörpert das konfuzianische Denken das Prinzip der Tugendherrschaft und der Sittenherrschaft einer Gesellschaft. Dies ist die höchste Form des konfuzianischen Gesellschaftsprinzips. Der Konfuzianismus erwartet, daß durch eine geordnete Menschenbeziehung ein gesellschaftlich harmonisches Bild entsteht.

Die Konfuzianer legen großen Wert auf die menschlichen Normen, Moral und Institutionen und halten an der Befreiung des Menschen von den ihn bedrängenden Naturmächten durch die Entwicklung der Zivilisation fest. ${ }^{6}$ Auch in der koreanischen Gesellschaft spielt die Moral eine besondere Rolle. Die in der koreanischen Gesellschaft vorherrschenden moralischen Vorstellungen wurden vom Konfuzianismus geprägt. So sieht die konfuzianistische Lehre die Wiederherstellung der gesellschaftlichen Ordnung als Wiederherstellung der Moral an. Im Gegensatz dazu hat das Wort „Interesse“ in der europäischen Philosophie eine erhebliche Bedeutung. Dieser Unterschied beruht auf dem anderen Menschenbild in der koreanischen gegenüber der europäischen Philosophie. Im Konfuzianismus wurde der Mensch in einer Gesellschaft von Menschen als Mitmensch geboren, während in der europäischen Philosophie der Mensch von einem Gott als Individuum geschaffen wurde. ${ }^{7}$ Das Wort „Interesse“ setzt immer die Existenz ,anderer“ Menschen oder „,anderer“ Gruppen voraus. Somit kann das Wort „Interesse“ nur durch die Unterscheidung zwischen ,ich“ oder „wir“ und ,andere“ seine wahre Bedeutung gewinnen. Nur durch diese Unterscheidung kann das Wort „Individuum“ entstehen und existieren.

In diesem Zusammenhang kann man sagen, daß das Wort „Interesse“ immer eng mit dem Wort „Individuum“ verbunden ist, gleichgültig, ob ,ich“ oder „wir“ als Individuum verstanden wird. Die Unterscheidung zwischen ,ich“ respektive ,ich als kollektiver Begriff“ und „andere“ produziert eine klare Trennung zwischen „Subjekt“ und „Objekt“. Ein Objekt existiert nur für ein Subjekt und daher ist das Subjekt immer bereit, das Objekt auszunutzen, um seine Interessen durchzusetzen. Ein typisches Beispiel dafür ist die Sichtweise der Umweltprobleme in den westlichen Gesellschaft. Der Mensch als Subjekt, nutzt seine Umwelt als Objekt aus, um seine eigenen Interessen zu befriedigen. Daher konnte der Mensch in der westlichen Gesellschaft seine Umwelt beherrschen.

\footnotetext{
5 Patrimonialismus ist nach Weber eine Form der traditionellen Herrschaft; die Herrschaftsgewalt wird primär innerhalb einer nach Erbschaft geregelten familiären Organisation von einem bestimmten Herrn ausgeübt. Vgl. Weber, M. (1980), S. 133.

${ }^{6}$ Im Vergleich zum Konfuzianismus betonen die Taoisten die Befreiung des Menschen von menschlichen und künstlichen Normen und von der materiellen Zivilisation, die die originäre harmonische Eigennatur fesseln, die Einheit und die Harmonie mit der Natur verhindern und zerstören. Sie haben Ehrfurcht vor dem Leben und lieben die Kultur der weiblichen Weichheit mehr als die der männlichen, patriarchalischen Macht. Vgl. Roetz, H. (1984), S. 253; Sellmann, J. D. (1987), S. 375.

${ }^{7}$ Vgl. Peter, W. S. (1968), S. 220.
} 
„Moral“ ist anders beschaffen als „Interesse“. Obwohl „Moral“ auch ein Begriff ist, der durch die Beziehungen zwischen Menschen verstanden werden muß, bedeutet die Existenz anderer Menschen keine Unterscheidung zwischen ,ich“ und „,andere“, sondern eher eine Identifizierung des ,ich“ mit dem ,anderen“. Dabei entsteht keine Trennung zwischen „Subjekt“ und „Objekt“. Das gilt auch für die Beziehung zwischen der Natur und dem Menschen. Die nicht vorhandene Trennung zwischen „Subjekt“ und „Objekt“ - hier der Natur und dem Menschen - ermöglicht die konfuzianischen Vorstellungen der Weit. ${ }^{8}$

Als ein besonderer ökologischer Ansatz läßt sich die auf Yin-Yang und Hua-Yeng-Philosophie ${ }^{9}$ beruhende Feng-Shui-Theorie bezeichnen, die in Südkorea stark vertreten war bzw. ist und für die Naturanschauung der Ostasiaten repräsentativ ist. Allerdings wurden diese Einsichten durch westliche Einflüsse stark überlagert und bisher in der praktischen Umweltpolitik nicht beachtet. ${ }^{10}$

Die Lehre von Yin und Yang war eine Richtung naturphilosophischer Denker. Die Begriffe Yin und Yang bezeichnen zwei kosmische Grundprinzipien, mit denen man die Welt und die Erscheinungen des Kosmos zu erklären versuchte. Yin steht dabei für das dunkle Prinzip, das passiven und weiblichen Charakter hat, und Yang für das helle Prinzip, das aktiven und männlichen Charakter hat. Mit diesen beiden wurde ein grundlegender Dualismus in der Natur gesehen. Das Dualismus von Yin und Yang charakterisiert nicht die grundlegenden Materialien, aus den das Kosmos gebildet wurde, sondern die Eigenschaft oder den Zustand der Natur. Ungleich der „westlichen“ (ursprünglich persischen) Idee eines kämpferischen Dualismus zweier Prinzipien wie z.B. Gut und Böse, ist hier der Dualismus ein ständige Austauschen und Hin- und Herschwingen zwischen den beiden Kräften oder Zuständen. Der Gegensatz hindert nicht die Integration, sondern schafft sie erst. Je größer die eine Kraft wird, um so schneller schlägt sie in die andere um, wie die Sonne, die, wenn sie mittags am höchsten steht, in diesem Moment beginnt, in die Nacht abzusinken. Graphisch wird dies durch das Zeichen des in sich verschlungenen Kreises bekannt, der diese Hin- und Herschwingen der Kräfte andeutet. Durch diese harmoni-

\footnotetext{
${ }^{8}$ Vgl. Peter, W. S. (1968), S. 72.

${ }^{9}$ Die Yin-Yang und Hua-Yeng-Philosophie bestand ursprünglich aus zwei eigenständigen Theorien, die jedoch untrennbar miteinander verbunden sind. Deswegen wird die Yin-Yang-Hua-Yeng-Philosophie als zusammengesetzte Philosophie bezeichnet. Zu den beiden Wurzeln ist die Yin-Yang-Philosophie eine duatistische Theorie, d. h. ihr liegen gegensätzliche Phänomene zugrunde. Yin und Yang sind die archetypischen Pole alles Seienden. Sie stehen nicht nur für hell und dunkel, männlich und weiblich, oben und unten, sondern werden auch mit Himmel und Erde assoziiert. Die Hua-Yeng-Philosophie markiert den Gpfelpunkt buddhistischen Denkens, soweit es im ostasiatischen Raum in den letzten zweitausend Jahren entwickelt wurde. Ihr Zentralthema ist die Einheit und der innere Zusammenhang aller Dinge und Ereignisse. Diese Einheit ist die Es senz der östlichen Weltanschauung. Vgl. Lee, Y.H./Yoon, K.-B. (1986), S. 542.

${ }^{10}$ Vgl. Lee, Y.-H. (1992), S. 47.
} 
sche Interaktion der beide Kräfte werden alle Dinge im Kosmos als geschaffen gedacht, und im Alternieren von Tag und Nacht und den konstanten sich ineinander verändernden Jahreszeiten ist das Wirken dieses Prinzips deutlich zu erkennen. Die Yin-Yang Theorie erklärt die vier Jahreszeiten so, daß Yang im Frühling sprießt und im Sommer den Gipfel (Höhepunkt) erreicht. Im Herbst entsteht Yin und gelangt im Winter an seinem Höhepunkt. Was aber zu dieser saisonalen Änderung führt, ist nicht das Yin-Yang Prinzip, sondern der Himmel (Natur oder Umwelt). Die Yin-Yang Theorie der Naturphilosophie stellt die sich unendlich verändernden Naturphänomen und im weiteren Sinne das Prinzip, das das menschliche Schicksal entscheidend bewirkt, dar.

Die Lehre von den 5 Elementen war eine ursprünglich unabhängige naturphilosophische Spekulation, die im 4. Jahrhundert v. Chr. systematisiert wurde. Die 5 Elemente wurden als die Urelemente angesehen, aus denen alle Dinge entstanden waren. Diese Lehre wurde als eine der fundamentalen wissenschaftlichen Ideen ausgehend von China her im ostasiatischen Raum (insbesondere Korea und Japan) von der allgemeinen Philosophie aufgegriffen und beeinflußte so über Jahrhunderte das Denken aller Richtungen.

Die fünf Elemente sind Metall, Holz, Wasser, Feuer und Erde. Sie werden in mehreren Ordnungen zusammengestellt, um die Phänomen des Kosmos zu erklären. Da gibt es die kosmische Ordnung, in der die Entstehung der Elemente an sich gedacht wurde in der Reihenfolge Wasser, Feuer, Holz, Metall und Erde. Dann gibt es die Ordnung, in der die Elemente auseinander entstehen können. Sie beginnt mit dem Holz, aus dem Feuer entsteht, das wiederum Erde erzeugt. Die Erde gibt das Metall und letzteres Wasser. Gleichzeitig spiegelt diese Reihenfolge auch die Wechsel der Jahreszeiten mit dem Holz für den Frühling und dem Wasser für den Winter, wobei die Erde einem Monat zwischen dem Sommer und dem Herbst entspricht. Eine weitere wichtige Ordnungsreihe ist die der Eroberung der Elemente. So erobert und zerstört das Holz die Erde, z. B. durch hölzerne Pflüge oder Werkzeuge, während das Holz wiederum durch Metall zerstört werden kann. Das Metall wird wiederum durch das Feuer erobert, das es schmelzen oder zerstören kann, und das Feuer wird dann durch das Wasser gebändigt oder gelöscht. Der Kreis schließt sich dann mit der Erde, die das Wasser aufnehmen oder eindämmen kann.

Später wurden die 5 Elemente in alle Dinge und Ereignisse des Leben hineingedeutet und jedem dieser wurde eines der 5 Elemente zugeordnet. Weiterhin wurden die Elemente mit allen möglichen Kategorien, welche durch die Zahl 5 teilbar waren, in Verbindung gebracht, um so eine umfassendere Deutungsmöglichkeit der Welt zu gewinnen. 
In späterer Zeit wurden die Lehre von Yin und Yang und den 5 Elementen zu einer Theorie (Geomantik) vereinigt, wobei an den Beginn das Tao gesetzt wurde, das in sich bereits die Zweiteilung enthält, die dann durch die Kräfte Yin und Yang dargestellt wurde. Im Austausch und Umwandlungsprozeß dieser beiden entstehen die 5 Elemente, die wiederum aus sich heraus die Vielfalt der Dinge erzeugen.

Die Geomantik beruht auf der Kenntnis der richtigen Verteilung der Doppelpotenz des Universums, Yin und Yang; sie ist die Lehre von den atmosphärischen und tellurischen Einflüssen auf den Menschen während seines Lebens und nach seinem Tode. Sozialer Status, Glück und Unglück des Menschen werden bestimmt durch die Qualität der „Be-lebung“ (animation) durch Yin und Yang - eine "Belebung", die natürlich durch das wechselseitige Verhältnis von Yin und Yang bedingt ist. Das Wirken dieser Doppelpotenz herrscht in der Erde vor und wird Sallyong (Bergseele, Bergenergie) genannt: diese Energie emaniert als eine Art Fludium, das sich in alle Richtungen ergießen kann. Wenn man also z.B. Erfolg im Leben anstrebt, muß man einen Ort zur Wohnung wählen, der durch diese Wirkung begünstigt wird. Orte, an denen die Erdwirkung akkumuliert ist, werden von Bergen und Flüssen begrenzt; sie halten den Wind auf und blicken auf das Wasser. Das Fludium verbreitet sich nämlich, wenn es vom Wind getragen wird, so daß sein quantitatives und qualitatives Vorhandensein durch die Bedingungen vom Wasser und Wind bestimmt wird. Daher kommt der Namen dieser Lehre: P'ungsu (Wind-Wasser). ${ }^{11}$

Die wichtigere Frage für die Arbeit ist, was diese Lehre ökologisch bedeutet? Die heutige ökologische Krise ist im allgemeinen sowohl auf das Mißverständnis der Natur und des Menschen als auch auf das Mißverständnis des Verhältnisses des Menschen zur Natur zurückzuführen. Unsere wissenschaftliche, technische Zivilisation sieht die Natur nur als einen Gegenstand der Ausbeutung, des menschlichen Nutzens und der Herrschaft an. Im allgemeinen beruht dies auf dem Mißverständnis der Natur als unserer Umwelt, das von dem wissenschaftlich-technischen Mechanismus verursacht worden ist. Er geht davon aus, daß die Natur ein vollendetes Werk der mechanischen Kräfte nach dem eindimensionalen Kausalgesetz sei, das ihre Wirkungen kontrolliert und daß alles in der Welt als ein geschlossenes System gestaltet und darum einzeln und getrennt behandelt werden könne. ${ }^{12}$ Aber angesichts der ökologischen Krise darf man die Natur nicht mehr als ein geschlossenes System, als etwas statisches und ein isoliertes und atomisches Teil

\footnotetext{
${ }^{11}$ Es gibt zwei Hauptmethoden in dieser Lehre, um Orte mit einer günstigen Erdwirkung zu finden, nämlich das „Eumtaek-Beop“ und das „Yanggi-Beop“. Das Eumtaek-Beop bezieht sich auf das Streben nach einer guten Karriere und Lebensglück aufgrund der Beerdigung der Ahnen in einem Eumtaek, d.h. einem nach der P`ungsu-Lehre gut gelegenen Grab, in dem der Verstorbene Ruhe findet. Das Yanggi-Beop ist die Methode, einen günstigen Ort auszuwählen, dort ein Haus, ein Palast usw. zu bauen und auf diese Weise von einer segensreichen Erdwirkung zu profitieren.

${ }^{12}$ Vgl. Cheng Chung Ying (1986), S. 354.
} 
verstehen, sondern als dynamische, organische Totalität und Beziehung. Eben eine solche ökologische Naturanschauung vertritt die Lehre der Geomantik, wie dies im Taoismus der Fall ist.

Der Taoismus als ethische Grundlagen der Umweltsicht: Der Taoismus ist eine der wichtigsten naturphilosophischen Richtungen, sie fand ihre Ursprung im alten China und hat die Naturanschauung in allen ostasiatischen Raum stark geprägt bzw. prägt sie bis heute.

Wenn man das taoistische Verständnis von Natur und Mensch übersieht, läßt man einen wichtigen Teil des Taoismus und dabei auch der Naturanschauung der koreanischen Gesellschaft unberücksichtigt. Daher soll im folgenden das Naturverständnis im Taoismus als ethische Grundlage der Umweltsicht in Südkorea untersucht werden.

Der Taoismus formierte sich als Philosophie im 4. Jahrhundert v. Chr. Sein Grundmotiv ist die Ablehnung anerkannter Werte, um zum ursprünglichen Zustand einer friedlichen Anarchie zurückzukehren. Damit ist eine Ablehnung all dessen, was Kultur, d.h. was von Menschen geschaffen ist, verbunden. Zurück zur Natur, zu Einfachheit und ursprünglicher Harmonie und das Lob der Schwäche, der Sanftheit und der Weichheit sind die Grundprinzipien der taoistischen, praktischen Gedanken. Was sie betonen, ist nicht eine harte Technologie sondern eine sanfte Technologie, nicht „Krieg aller gegen alle“, sondern Frieden und symbiotisches Leben zwischen allen. ${ }^{13}$

Die Zeit, in der Laotse und Chuangtse ${ }^{14}$ lebten, war eine Periode sozialer Unordnung, die mit der heutigen Situation verglichen werden kann. Durch zahlreiche Schlachten und wirtschaftlichen

\footnotetext{
${ }^{13}$ Laotse sagt: „Der Mensch, wenn er ins Leben tritt, ist weich und schwach, und wenn er stirbt, so ist er hart und stark. Die Pflanzen, wenn sie ins Leben treten, sind weich und zart, und wenn sie sterben, sind sie dürr und starr. Darum sind die Harten und Starken Gesellen des Todes, die Weichen und Schwachen Gesellen des Lebens. Darum: Sind die Waffen stark, so siegen sie nicht. Sind die Bäume stark, so werden sie gefällt. Das Starke und Große ist unten. Das Weiche und Schwache ist oben.“ Tao Te King, K. 76 (Wilhelrn, 119). „Auf der ganzen Welt gibt es nichts Weicheres und Schwächeres als das Wasser. Und doch in der Art, wie es dem Harten zusetzt, kommt nichts ihm gleich. Es kann durch nichts verändert werden. Das Schwaches das Starke besiegt und Weiches das Harte besiegt, weiß jedermann auf Erden, aber niemand vermag danach zu handeln. Also auch hat ein Berufener gesagt: 'Wer den Schmutz des Reiches auf sich nimmt, der ist der Herr bei Erdopfern. Wer das Unglück des Reiches auf sich nimmt, der ist der König der Weit.' Wahre Worte sind wie umgekehrt.“ Tao Te King, K. 78 (Wilhelrn, 121).

${ }^{14}$ Der philosophische Taoismus ist von zwei wichtigen Persönlichkeit (Laotse und Chuangtse) vertreten worden. Laotse, den man für den Verfasser von „Tao Te King“ hält, und Chuangtse, den man als Verfasser von „Chuangtse“ nennt, sind mit dem Taoismus im allgemeinen gleichzusetzen. Darum nennt man den Taoismus auch Lao-ChunangPhilosophie. Wenn man Laotse und Chuangtse zum Vergleich zusammenstellt, kann man sich leicht davon überzeugen, daß es keine wesentlichen Unterschiede zwischen den beiden gibt, und daß die Verwirrungen in der Lehre von Laotse durch Chuangtse aufgeklärt werden können. Beide sprechen von Tao und Te, Sein und Nichtsein, Tun und Nichttun im gleichen Sinne. Sie bieten die gleichen Antworten auf die Frage: Woher kommen alle Dinge? Wie muß man in der Welt leben? Was ist das der Natur entsprechende Leben? Wohin kehren alle Dinge schließlich zurück? Ihre Philosophie ist eine Philosophie der Wesenseinheit der Welt, der Polarität (Yin-Yang) und des ewigen Kreislaufs, des Ausgleichs aller Verschiedenheiten, der Realität aller menschlichen Maßstäbe, der Rückkehr aller Dinge zum Ursprünglich-Einen, der Quelle aller Dinge. Man kann sagen all diese zusammengenommen, daß Chuangtse
} 
Aufschwung wurden die Sozialsysteme, Moralnormen und Werte zerstört. Die Taoisten meinten, daß die grundlegende Ursache dafür in der menschlichen Begierde nach Wissen und Haben lag. Ihrer Ansicht nach verursachte diese Begierde das chaotische Durcheinander und schadete der eigentlichen, menschlichen Natur. Darüber hinaus erkannten sie, daß die durch die Begierde und das Wissen entwickelte Technologie und Zivilisation die Natur als Heimat und Umwelt des Menschen zerstörten. Angesichts dieser Umstände versuchten Taoisten, die Lösung in der Natur, in der Wirkung der Natur zu finden, ${ }^{15}$ aber nicht in der menschlichen Moral, weil sie die von den Menschen und durch die menschlichen, künstlichen Handlungen verursachten Schäden sehr genau kannten. Für sie hatte die Natur harmonische und organische Charakterzüge. Sie empfanden die Wirkungsweise der Natur als Vorbild des Handelns des Menschen. Nach ihnen sollte die gsellschaftliche Ordnung durch Nachahmung der Grundzüge der Natur wiederhergestellt werden. Wichtiger jedoch ist, daß sie nach dem Ursprung der Natur, ihrer Harmonie, ihrer Einheit und hrer Spontaneität fragten. Sie beobachteten, daß das höchste Wesen, das alle Dinge erzeugte, erhielt und ernährte, und zu dem alle Dinge zurückkehrten, in der Natur manifest geworden ist. Sie nannten es Tao.

Der Grundbegriff dieser Schule ist also das „Tao“, ein Konzept, das nur schwer faßbar und erklärbar ist. Der Begriff „Tao“ ist nicht nur einer der häufigsten und wichtigsten Begriffe, sondern die ganze taoistische Philosophie wie Metaphysik, Individualethik, politische Ethik und Naturanschauung stehen im tiefen Zusammenhang mit der Interpretation des Tao. ${ }^{16}$ Daher ist es notwendig, den Begriff „Tao“ zu erläutern.

Ursprünglich ist das Wort „Tao“ den Taoisten nicht eigentümlich, sondern allgemein im alten China gebraucht worden und hatte die Bedeutung von Weg, Methode, Wahrheit oder der richtigen Lebensführung, wie es z.B. im Konfuzianismus der Fall ist. Bis heute wird der Taobegriff im Westen verschieden übersetzt und interpretiert: als Sinn, Ordnung der Natur, das dynamische harmonische Eine, Gott im jüdisch-christlichen Sinne, Weg, Begriff oder Prinzip, allerletzte Realität, Logos, das allumfassende erste Prinzip und Vernunft.

Das chinesische Zeichen meinte am Anfang eigentlich nur „Weg“. Doch wandelte sich das Verständnis bald in „Wege des Menschen“, womit sein moralische Verhalten gemeint war. Es bezog sich in diesem Verständnis rein auf die menschlichen Dinge. Mit Laotse hat dieses Konzept dann

die Gedanken von Laotse übernahm und sie etwas umfangreicher weiter entwickelte. Vgl. Fung Yu Lan (1952), insb. S. 174f.

${ }^{15}$ Vgl. Needham, J. (1969), S. 33.

${ }^{16}$ Vgl. Choi, Insik (1991), S. 128ff. 
metaphysische Tiefe bekommen. Das Tao ist zum allumfassenden ersten Prinzip geworden. Als solches ist es formlos, namenlos und unerklärbar und gleichzeitig doch der Urgrund aller Dinge, aus dem das Universum entstanden ist. Das Geschaffene ist nicht absichtlich hervorgebracht, sondern es entsteht aus Spontaneität des Tao. Da aus ihm alles kommt, kann es nicht so sein wie alles andere, das durch es entsteht und benennbar und verstehbar ist. Das Tao ist dabei weder Sein noch Nicht-Sein, beide sind nur Aspekte des Tao, denn das Tao, das man beschreiben könnte, wäre schon nicht mehr das Tao.

Wichtig für die vorliegende Arbeit ist die Frage, ob und inwiefern der Begriff Tao im Taoismus ökologisch orientiert ist. Die heutige ökologische Krise ist im allgemeinen auf das Mißverhältnisses des Menschen zur Natur zurückzuführen. Unsere Zivilisation sieht die Natur nur als einen Gegenstand der Ausbeutung, des menschlichen Nutzens und der Herrschaft an. Im allgemeinen beruht dies auf dem Mißverständnis der Natur als unserer Umwelt, das vom wissenschaftlich-technischen Mechanismus verursacht worden ist. Dieser geht davon daraus, daß die Natur ein vollendetes Werk der mechanischen Kräfte nach dem eindimensionalen Kausalgesetz ist, das ihre Wirkungen kontrolliert, und daß alles in der Welt als ein geschlossenes System gestaltet und darum einzeln und getrennt behandelt werden kann. Aber angesichts der ökologischen Krise darf man die Natur nicht mehr als geschlossenes System, als statisches und isoliertes und atomisches Teil verstehen, sondern als dynamische, organische Totalität und Beziehung. Eben eine solche ökologische Naturanschauung vertritt der Taoismus. Wichtig ist, daß die Dynamik und Spontaneität der Natur beim Taoismus gerade auf der des Tao basieren. ${ }^{17}$

Nun stellt sich die Frage, was man unter dem Tao verstehen kann bzw. soll. Um darauf antworten zu können, müssen kurz die Eigenschaften des Tao weiter behandelt werden.

„Tao, kann es ausgesprochen werden, ist nicht das ewige Tao. ${ }^{\text {“1 }}$ Hier sind zwei Aspekte des Tao erwähnt worden: Unaussprechlichkeit und Ewigkeit. Nach Chuangtse kann Tao mit Worten nicht

\footnotetext{
${ }^{17}$ Cheng nennt die Spontaneität der Natur auch das ökologische Prinzip der Natur und stellt den Zusammenhang zwischen dem Verständnis des Tao und der Natur etwas ausführlicher dar: „Ecology originally meant the economy of nature: when nature acts, it acts ecologically. The production of life and all things in nature can be said to come from the ecological movement of nature. In understanding the ecology of nature, one would naturally understand the Tao; but only when one independently sees the universality, unity, and life-creativity of the Tao, will one truly understand the ecology of nature. Hence, the Tao can be said to be the metaphysical foundation of the ecology of nature, whereas the ecology of nature is one principle of movement manifesting the Tao, corresponding to its spontaneity.“ Cheng Chung Ying (1986), S. 357. Zit. nach Po-Keung Ip (1983), S. 337.

${ }^{18}$ Tao Te King, K. 1.
} 
beschrieben werden, ${ }^{19}$ denn Tao ist kein Ding. „Worüber man daher reden kann, das ist die feinen Dinge. ${ }^{20}$ „Was sich mit Worten erschöpfend beschreiben läßt, was dem Wissen zugänglich ist, das reicht eben nur bis zur Welt der Dinge. ${ }^{21}$ Nach Chuangtse lassen sich sowohl ein Ding selbst als auch die Erscheinungen der Dingwelt, das Naturgesetz und sogar Gefühle des Menschen wie Neigung und Abneigung, Friede und Gefahr, Glück und Unglück, Hast und Zögern begrifflich verfolgen und verstandesgemäß erkennen. ${ }^{22}$ All das gehört zum Bereich des Ding. Aber man kann Tao dem Wesen nach mit der menschlichen, sinnlichen Sprache nicht völlig bestimmen, denn Tao ist kein Ding. ${ }^{23}$ Tao ist Urgrund und Mutter aller Dinge. ${ }^{24}$ Chuangtse nimmt die Priorität des Tao vor allen Dingen an und sagt, daß etwas, was der Entstehung von Himmel und Erde vorausgeht und den Dingen ihre Dinglichkeit gibt, nicht selbst ein Ding ist. ${ }^{25}$ Tao kann kein Ding sein, das von einer äußeren, anderen Kraft verursacht und bewegt wird, sondern erzeugt sich selbst und ist seine eigene Wurzel. Vielmehr hängen alle Dinge von Tao ab und alle Umwandlungen werden von ihm verursacht. ${ }^{26}$

Die Ewigkeit ist als eine der vorzüglichsten Eigenschaften des Tao in taoistischen Texten erwähnt. Mit dem Tao verbunden, bedeutet es nicht nur „ewig“, sondern auch „unveränderlich“ und „,beständig“. Wie wird die Ewigkeit des Tao in den taoistischen Texten näher bestimmt? Im letzten Kapitel seines Werkes sagt Chuangtse, daß Laotses philosophisches System auf ewigem Nichtsein und ewigem Sein beruhe. Im ersten Kapitel spricht Laotse selbst von ewigem Nichtsein und ewigem Sein. Laotse sagt, daß Nichtsein und Sein dem Ursprung nach eins und nur durch ihre Namen unterschieden seien. Dieses Nichtsein und Sein sind zwei wesentliche Aspekte des Tao. Nichtsein bedeutet nicht, daß es nichts gibt, sondern ,really real reality“, 27 während Sein nicht ein Ding selbst meint bzw. eine allgemeine Bezeichnung aller Dinge ist, weil beide

\footnotetext{
${ }^{19}$ Im Buch des Chuangtse finden sich an mehreren Stellen solche Einschränkungen: „Denn der Sinn (Tao) ist tief und schwer mit Worten zu erreichen.“ Chuangtse, K. 22 (Wilhelm, 228). „Der Sinn, von dem man reden kann, ist nicht der Sinn." Chuangtse, K. 22 (Wilhelm, 232).

${ }^{20}$ Chuangtse, K. 17 (Wilhelm, 182).

${ }^{21}$ Chuangtse, K. 25 (Wilhelm, 272).

${ }^{22}$ Vgl. Chuangtse, K. 25 (Wilhelm, 272).

${ }^{23}$ Im K. 19 beschreibt Chuangtse ein Ding auch als „alles, was Gestalt, Klang und Farbe hat.“ Im K. 25 sagt er, daß Himmel und Erde die größten aller Dinge sind, die Gestalt haben. Das bedeutet, daß alle Dinge einschließlich des Himmels und der Erde, dem Bereich der sinnlich wahrnehmbaren Realität angehören. In demselben Kapitel spricht er davon, daß der Naturverlauf, oder das Gesetz der Natur dem Ding so inhärent ist, daß es sich mit Worten beschreiben läßt und dem Wissen zugänglich ist. „Kann man nun dies als Tao bezeichnen?“ Darauf antwortet Chuangtse klar mit „Nein“ (Vgl. Wilhelm, 270-274). Also darf man Tao nicht als Ordnung der Natur bzw. Gesetz der Natur im Sinne der reinen physischen Wirkungsweise der Natur verstehen. (vgl. dazu Cho Kah-Kyung (1977), S. 240) Das Wort wu oder Ding hat eine sehr umfangreiche Bedeutung. Die Frage, die wir oben gestellt haben, ob man Tao mit Dingen gleichsetzen kann, ist mit der Frage identisch, ob man Tao mit dem Naturgesetz, den natürlichen und menschlichen Phänomenen, der sinnlich wahrnehmbaren Realität, oder der Totalität der Natur, wie sie ist, gleichsetzen kann.

${ }^{24} \mathrm{Vgl}$. Tao Te King, K. 1.

${ }^{25}$ Vgl. Chuangtse, K. 22 (Wilhelm, 231, 233).

${ }^{26}$ Vgl. Chuangtse, K. 6 (Wilhelm, 87).
} 
beide desselben Ausgangs sind und als „des Geheimnisses noch tieferes Geheimnis“, als „das Tor, durch das alle Wunder hervortreten, ${ }^{20}$ dargestellt sind. Also sind ewiges Nichtsein und ewiges Sein die wesentlichen, bipolaren Aspekte des Tao. Darum zeigen diese Ausdrücke, daß Tao ewig ist.

Nach den Taoisten ist Tao sowohl die schöpferische Kraft als auch die Erhaltungskraft, die in dlen Dingen allgegenwärtig wirkt. Das bedeutet, daß das Tao alle Dinge erhält, nährt und ihnen das Leben gibt. Aber der taoistische Gedanke der Erhaltung aller Dinge bezieht sich nicht auf die Erhaltung eines unveränderlichen, stationären und in sich geschlossenen Systems, weil alle Dinge in unaufhörlicher Bewegung und Wandlung sind, mit anderen Worten, in dauerndem Auftreten, Wachsen und Vergehen. Der dauernde Vorgang und die Wandlung aller Dinge sind auf das Wirken des Tao zurückzuführen und bedeuten sie die bleibende Immanenz in der Welt und die Manifestation des unendlichen schöpferischen Wirkens des Tao. ${ }^{29}$ Darum kann Tao nicht nur ,als Anfangsprinzip herausgestellt werden, das gleichsam nur den ersten Anstoß zur Weltentstehung gibt, sondern zugleich als die vermittelnde Potenz, die alle Stufen des Wachstums und Vergehens der Einzelwesen begleitet und sie als natürliches Geschehen erhält. ${ }^{30}$

Zusammenhängend mit dem Begriff des Tao muß dabei kurz das Konzept des „Te“ erwähnt werden, was man mit „Kraft“ oder „Wirkung“ übersetzen könnte. Sie ist jedem geschaffenen Dinge inhärent und gibt ihm die Qualität zu sein, wie es ist. Ist das Tao das, wodurch die Dinge entstehen, so ist Te das, wodurch sie sind, was sie sind.

Te ist „tief“, ,geheimnisvoll ${ }^{\star 31}$ und „ewig ${ }^{‘ 32}$. Laotse beschreibt Tao und Te mit ähnlichen Metaphern. ${ }^{33}$ Er spricht vom „Te des Nichtstreitens“ ${ }^{34}$ Diese Eigenschaft gibt er auch Tao, indem er sagt, daß Tao nicht streitet. ${ }^{35}$ Somit ist deutlich, daß Tao und Te untrennbar verbunden sind und die Frage kann gestellt werden, ob sie beide identisch sind und sich überhaupt nicht voneinander unterscheiden. Laotse betrachtet Te nicht als etwas, was mit dem Tao identisch ist, obwohl er dem Te dieselben Eigenschaften wie dem Tao zuschreibt. Im Tao Te King K. 51 sagt er: „Tao erzeugt sie (die Wesen), Te nährt sie, erhält sie, zieht sie auf, vollendet sie, macht sie reif, pflegt

\footnotetext{
${ }^{27}$ Fang H. Thome (1964), S. 4.

${ }^{28}$ Tao Te King, K. 1 (Wilhelm, 41).

${ }^{29}$ Vgl. Giradot, N.J. (1983), S. 49 und 55.

${ }^{30}$ Cho Kah Kyung (1977), S. 249.

${ }^{31}$ Tao Te King, K. 10, S. 51 und 65. Zur Erwähnung dieses Wortes in bezug auf Tao vgl. K. 1 und 6.

${ }^{32}$ Tao Te King, K. 28. In bezug auf Tao vgl. K. 1, S. 32 und 37.

${ }^{33} \mathrm{Vgl}$. Tao Te King K. 41.

${ }^{34}$ Tao Te King, K. 68.

${ }^{35}$ Vgl. Tao Te King, K. 73.
} 
sie, schirmt sie.“ „Darum verehren alle Dinge Tao und schätzen Te.“ Chuangtse sagt, „was Himmel und Erde durchdringt, ist Tao; was in allen Einzelwesen wirksam ist, ist Te. ${ }^{\text {(36 }}$ Hier läßt sich sicherlich eine Unterscheidung der Funktionen von Tao und Te feststellen. „Der Unterschied ist jedoch nicht von solcher Art, daß es notwendig wäre, vom Te als von etwas Selbständigem, vom Tao Unabhängigem zu sprechen, ${ }^{\text {‘37 }}$ denn „Te folgt nur aus dem Tao. ${ }^{38}$

Te hat verschiedene Bedeutungen in den taoistischen Texten wie andere Begriffe auch. Es ist auch nicht so leicht, es mit einem Wort zu definieren. Aber sicher ist, daß Te weder bloß Tugend im Sinne einer moralischen Perfektion durch bewußte Kultivierung und Verwirklichung des Guten noch die magische Kraft des Herrschers bedeutet. ${ }^{39}$ Betrachtet man Te als die Gegenwart des Tao in der Welt und seine Manifestation in ihr, darf man Te nicht mit der alldurchdringenden, allumfassenden Gegenwart, mit anderen Worten, mit der Allgegenwart des Tao verwechseln. Te ist räumlich und zeitlich begrenzte Einwohnung. Es ist konkrete und spezielle Gegenwart. Darum sagt Chuangtse: „Das, was Himmel und Erde durchdringt, ist Tao; das, was im Einzeldinge wirksam ist, ist Te. ${ }^{\text {(40 }}$

Und man könnte sagen, daß Te dem Sein, dem Aspekt des Tao, das aus dem Nichtsein entsteht, ähnlich ist, wenn man Te als Manifestation des Tao versteht. Aber wir müssen unter dem Sein die Selbstverwirklichung des Tao oder seine Manifestation vor dem Schaffen der Dinge, d.h. den Prozeß des zum Schaffen der Dinge aus sich selbst Heraustretens verstehen, während Te Einwohnung und Wirken des Tao in den schon geschaffenen Einzeldingen besagt.

Alle Dinge bekommen die Lebenskraft des Tao und werden lebendig. Tao übt seine schöpferische Aktivität im Einzelding aus. Durch Te nehmen alle Dinge am Tao teil und umgekehrt nimmt Tao an ihnen teil. Die Aktivität der Dinge ist von Te als der dynamischen Aktivität des Tao im Einzelding abhängig.

Te läßt alle Dinge wachsen, entwickelt und erhält sie. ${ }^{41}$ Mit anderen Worten, Te ist für Wachsen, Leben und Wandlung verantwortlich. Trotzdem ist Te keine patriarchalische, monarchische Macht, sondern ,the power of the weak, and yielding, the tender and small.'42

\footnotetext{
${ }^{36}$ Chuangtse, K. 12.

${ }^{37}$ Beky, G. ( 1972), S. 97.

${ }^{38}$ Tao Te King, K. 21.

${ }^{39}$ Chen, E. M. (1973), S. 457ff.

${ }^{40}$ Chuangtse, K. 12.

41 „Tao erzeugt sie, seine Tugend nährt sie, erhält sie, zieht sie auf, vollendet sie, macht sie reif, pflegt sie, schirmt sie“" (Tao Te King, K. 51).
} 
Laotse verbindet das Wort „Ch'ang“ oder „ewig“ eng mit dem Wirken des Tao: „Tao ist ewiges Nicht-Tun und doch bleibt nichts ungetan. ${ }^{\text {(43 }}$ Nichttun heißt nicht nichts zu tun. Tao produziert alle Dinge, erhält sie, gestaltet sie, und vollendet sie. ${ }^{44}$ Tao tut alles. Was ist dann mit einem Nicht-Tun des Tao gemeint? Es meint: nicht besitzen, nicht beherrschen, obwohl es alles produziert, erhält und bewirkt. Nichttun ist das wahre Tun, nämlich nichtwollendes, nichthabendes Wirken des Tao. Daß Tao also ewiges Nichttun ist, impliziert die Ewigkeit des Wirkens des Tao.

Wu-Wei oder Nichttun ${ }^{45}$ ist der wichtigste Begriff im Taoismus. Für die Taoisten heißt Wu-Wei nicht Nichts-tun. ${ }^{46} \mathrm{Wu}$-Wei muß verstanden werden nicht im Blick darauf, ob Tao handelt oder nicht, sondern im Blick darauf, auf welche Weise Tao handelt. Tao Te King K. 51 lautet: „Es (Tao) gebiert sie und eignet sie nicht, handelt (hilft) und nimmt sie nicht in Besitz, ist überlegen und beherrscht sie nicht: Das ist die mystische Tugend.“47 „Während Tao für seine Geschöpfe alles tut, verfährt es doch dabei auf das allerselbstloseste. Für sich will es mit alledem nichts. Es setzt nichts ins Leben, schafft nicht, um dadurch etwas zu haben, es tut, wirkt und erweist nichts um seiner selbst willen, es bringt sie empor, zieht und leitet sie, ohne ihnen den Zwang der Herrschaft aufzulegen. ${ }^{48}$ Dazu kommentiert Strauss: „Laotse erkennt hier Tao ausdrücklich Liebe zu allen Geschöpfen zu, das mitleidende und sich mitfreuende, das wohltuende und sich erbarmende Lieben. Obgleich Tao alle Wesen erschafft, vollendet, liebt und versorgt, so stellt es sich doch nicht in das Verhältnis eines Herrn und Gebieters, „macht nicht den Herrn“ oder macht sich nicht zum Herrn. Seine Liebe ist selbstlos und bedürfnislos. ${ }^{\text {‘9 }}$ Das bedeutet, daß Tao weder mit Cewalt in die Natur eingreift noch willkürlich mit übernatürlicher Macht wirkt und erhält. Laotse sagt eher, Sanftheit ist die Wirkung des Tao. ${ }^{50}$ „Sanftheit überwindet Stärke. ${ }^{51}$ Darum wird Tao mit dem Wasser verglichen. Laotse sagt: „Wasser ist gut, allen Wesen zu nützen, und streitet nicht, es bewohnt, was die Menschen verabscheuen. ${ }^{62}$ „Nichts in der Welt ist weicher und

\footnotetext{
${ }^{42}$ Im Tao Te King, K. 51 heißt es: „Erzeugen und nicht besitzen, wirken und nichts darauf geben, erhalten und nicht beherrschen, das heißt tiefe Tugend.“

43 Tao Te King, K. 37 (Strauss, 104).

44 Tao Te King, K. 41, 51.

${ }^{45}$ Wu-Wei kann aus drei Aspekten aufgefaßt werden: Hinsichtlich der Gottesvorstellung, der Umweltkrise und des politischen, sozialen Hintergrundes des Zeitalters Laotses. Auf der anderen Seite kann Wu-Wei danach verstanden werden, wer Subjekt des Wu-Wei ist: Wu-Wei des Tao, der Natur und des Menschen. Das dritte läßt sich als der ethische Aspekt des Menschen besser verstehen, wenn man es in bezug auf die Naturzerstörung und den politischen, sozialen Hintergrund betrachtet, während das erstere in bezug auf die damalige Gottesvorstellung besser aufgefaßt werden kann.

${ }^{46}$ Vgl. Needham, J. (1969), S. 68.

47 Tao Te King, K. 51.

${ }^{48}$ Strauss, V. von (1959), S. 330f.

${ }^{49}$ Strauss, V. von (1959), S. 283.

${ }^{50} \mathrm{Vgl}$. Tao Te King, K. 40.

51 Tao Te King, K. 36.

52 Tao Te King, K. 8 (Strauss, 65).
} 
schwächer als Wasser, und doch nichts, was Hartes und Starkes angreift, vermag es zu übertreffen, es gibt nichts, wodurch es zu ersetzen wäre. Schwaches überwindet das Starke, Weiches überwindet das Harte. ${ }^{53}$ Kurzum: Tao erzeugt und besitzt nicht. Es wirkt und behält nicht. Es nährt und erhält und macht sich nicht zum Herrn. Tao tut nichts durch übernatürliche Macht und Beliebigkeit, sondern durch Liebe und Sanftheit. Wu-Wei ist die Weise, auf die Tao allen Dingen immanent ist und wirkt.

Hier kann auf einige wichtige Punkte hingewiesen werden. Wu-Wei bedeutet die Verneinung eines höchsten Wesens, das mit seiner die Guten belohnenden und die Bösen bestrafenden Patriarchalmacht einen klassischen Typus des theistischen Gottes darstellte. ${ }^{54}$ Zugleich bedeutet sie auch die Ablehnung der absoluten Herrschaft über die Welt, die den Herrschern von dem allmächtigen Gott verliehen wurde. „Tao ist ewig Nichttun, und doch bleibt nichts ungetan. Wenn Fürsten und Könige (es) zu halten vermögen, werden alle Wesen von selbst sich umwandeln. ${ }^{55}$ Nicht nur die Herrscher, sondern auch der heilige Mensch, der Tao hat, beharrt im Wirken des Nichttuns, so daß er alle Dinge nicht besitzt und mit Gewalt nicht in die Natur eingreift. ${ }^{56}$ Bei Laotse soll Wu-Wei des Tao die Handlungsweise des Menschen bestimmen. Wenn der Mensch das göttliche Wesen als dasjenige ansehen würde, das alle Dinge erzeugt und doch nicht besitzt und sie durch die Liebe erhält und nährt, würde der Mensch sich selbst nicht als Herrscher oder Besitzer der Natur betrachten.

Im folgenden soll aufbauend auf den begrifflichen Grundlagen das Verständnis von Natur und Mensch im Taoismus behandelt werden.

Angesichts der heutigen ökologischen Krise sollte man sich die folgenden Fragen stellen: ${ }^{57}$

- Was ist die Natur der Natur?

- Was ist das Verhältnis des Menschen zur Natur?

- Wie sollte sich der Mensch zur Natur in Beziehung setzen?

Die Fragen verlangen eine neue Erkenntnis der Natur als der uns umgebenden, lebendigen Umwelt. Nach der modernen abendländischen Ansicht ist die Natur objektiviert, mechanisiert und entmenschlicht und wird als ein Objekt der Erkenntnis und des menschlichen Nutzens, als bloße

\footnotetext{
${ }^{53}$ Tao Te King, K. 78 (Strauss, 162).

${ }^{54}$ Vgl. Cho Kah Kyung (1977), S. 239.

${ }^{55}$ Tao Te King, K. 37 (Strauss, 104).

${ }^{56}$ Vgl. Tao Te King, K. 2.

${ }^{57}$ Vgl. Po-Keung Ip (1983), S. 335.
} 
physische und materielle Peripherie behandelt. ${ }^{58}$ Das Charakteristika solcher Naturanschauung sind nicht Polarität und ästhetische Kosmologie, sondern ein dualistisches Denken, das Geist und Materie, Subjekt und Objekt, Übernatürliches und Natürliches sowie Natur und Mensch trennt. Die Dingwelt wird durch Trennung, Unterscheidung, Unabhängigkeit und Geschlossenheit charakterisiert. ${ }^{59} \mathrm{Im}$ Gegensatz dazu weigert sich die taoistischen Philosophie, die Natur als ein geschlossenes, vollendetes, dualistisches System zu betrachten. Für sie ist die Natur weder ein entwertetes oder ein mit negativem Wert ausgestattete System noch ein dem Bösen übergebenen Raum. ${ }^{60}$ Nun soll genauer auf das taoistische Naturverständnis eingehen.

Das philosophische Denken im Taoismus verneint ,the possibilites (1) of taking things and persons in absolutely isolated systems, (2) of reducing the plenitude of reality into an impoverished mechanichal order of merely juxtaposed constituents. ${ }^{\text {61 }}$ Alle Teile von Himmel und Erde bis zum Kleinsten, einschließlich des Menschen sind voneinander abhängig, füreinander offen, gegenseitig komplementär aufeinander einwirkend und durchdringen sich gegenseitig. Der eine existiert nicht von den andern isoliert, sondern in Relation zu den anderen. D.h. der Mensch existiert nicht von sich selbst und kann nicht getrennt von seiner Umgebung und Umwelt verstanden werden.

Alle Dinge und alle natürlichen Phänomene sind sowohl in Beziehung zueinander als auch in Gleichgewicht und Harmonie, weil das Prinzip der Harmonie von Yin-Yang konsequent über alle Dinge der Welt herrscht und Tao als das Prinzip der Einheit und Harmonie alle Dinge harmonisch und einig macht.

Es ist wichtig $\mathrm{zu}$ bemerken, daß die Vorstellungen von Wechselbeziehung, Harmonie, Gleichgewicht und Ganzheit insbesondere im taoistischen Denken durch die Ideen der Dynamik ergänzt wird, damit der Gedanke der organischen, harmonischen Einheit kein geschlossenes System impliziert. Für die Taoisten ist das Universum keine statisch, unveränderlich ewige Struktur, sondern der dynamische Prozeß von Wachstum und Transformation.

Es wird oft darauf hingewiesen. daß die Taoisten die Natur und die natïrlichen Geschehen als einen zyklischen Prozeß betrachten, in dem die ständige Wiederkehr der Jahreszeiten die Haupt-

\footnotetext{
${ }^{58}$ Vgl. Cheng Chung Ying (1986), S. 353.

${ }^{59}$ Vgl. Ames, R. T. (1986), S. $318 f f$.

${ }^{60}$ Vgl. Fang H. Thome (1980), S. 24.

${ }^{61}$ Fang H. Thome (1964), S. 101.
} 
rolle spielt. Sicher erkennen sie den zyklischen Prozeß der Natur. ${ }^{62}$ Angesichts der heutigen ökologischen Krise muß der Gedanke von Rhythmus und Zyklus der Natur wiederaufgegriffen werden, weil ein Teil unserer ökologischen Krise durch das Mißverstehen der einfachen Wahrheit von Rhythmus, Wiederkehr und Zyklus verursacht ist. ${ }^{63}$ Aber der zyklischen Prozeß der Natur ist „weder eine eiserne Notwendigkeit der ewigen, unausweichlichen Wiederkehr, noch etwa die unendliche Reihe auf einander folgender Zyklen, die nach dem Ablauf (oder nach der Vernichtung) des früheren Zyklus entstehen sollen.64 ${ }^{64}$ Mit der Dynamik der Natur ist weder eine lineare Progression noch der Zyklus als unendliche Wiederholung desselben Prozesses gemeint, sondern unablässige Wandlung und Transformation. Die Universum bedeutet also kein geschlossenes System, sondern ein dynamisches Geschehen und Geflecht von Raum und Zeit. ${ }^{65}$ Übrigens sind Raum und Zeit von den aktuellen Ereignissen der Welt nicht zu trennen.

Ein Grundzug der taoistischen Naturanschauung liegt in der Betonung der Lebendigkeit der Natur. Natur kann nicht auf bloße Materie reduziert werden, die keine Lebenskraft in sich und deshalb auch keinen wesentlichen Eigenwert hat. Die Lebenskraft des Tao ist der Natur immanent und macht alle Dinge lebendig. ${ }^{66}$ Die Taoisten fassen sie als einen lebendigen dynamischen Prozeß auf.

Man versteht die Natur also nicht als das, was dem Menschen gegenübersteht und von ihm nur als Objekt angesehen werden darf, sondern als Umwelt und Mitwelt, zu der der Mensch in enger Beziehung stehen muß, um die ökologische Krise zu überleben. Die Natur als unsere Umwelt und Mitwelt ist sowohl eine lebendiger Prozeß des Lebens als auch die Kraft des Lebens selbst. Denn alle Dinge besitzen in der Natur Lebenskraft, die aus dem Tao als dem Urquell des Lebens ausströmt.

Ein grundlegender Gesichtspunkt der taoistischen Philosophie ist die Einheit von Mensch und Natur. ${ }^{67}$ Das Verhältnis zwischen Mensch und Natur, Ich und Universum, Subjekt und Objekt und Geist und Stoff wird als ein einheitlicher, harmonischer Zustand beschrieben. Besonders Chuangtse teilt diesen Grundgedanken vom Verhältnis zwischen Mensch und Natur. Er faßt den

\footnotetext{
${ }^{62}$ Vgl. Chuangtse, K.25, S. 14, 22 und 17.

${ }^{63}$ Vgl. Goodman, R. (1980), S. 74ff.

${ }^{64}$ Beky, G. (1972), S. 122.

${ }^{65}$ Fang H. Thome (1957), S. 47. Die Taoisten sowie die anderen ostasiatische Philosophen haben keinen Begriff der absoluten Zeit und des absoluten Raums entwickelt. Sie betrachten Zeit als „, a concrete reality not to be separable from the changing, growing, and developing processes of things“. Vgl. hierzu Beky, G. (1972), S. 122.

${ }^{66}$ Vgl. Ames, R. T. (1983), S. 331.

${ }^{67}$ Vgl. Roetz, H. (1984), S. 45f. Zum Subjekt-Objekt-Gegensatz in der klassischen chinesischen Philosophie Roetz, S. (1984), S. 1-77 und 226-283.
} 
Menschen und die Welt auf als ,das All-Eine, als eine ganzheitliche Organisation. ... Von dieser Auffassung her darf der Mensch kaum von der Welt getrennt und isoliert begriffen werden. Der Mensch und die Welt sind immer in Eins untrennbar verbunden. ${ }^{68}$ Der Mensch ist für die Natur offen und umgekehrt die Natur für den Menschen.

Ein Thema, das die taoistischen Schriften durchdringt, ist die Ablehnung des Versuches, dem Menschen eine besondere Stellung zu verleihen und ihn als das Zentrum des Universums zu behandeln. Der Mensch ist der Natur ebenbürtig. Alle Dinge, einschließlich des Menschen sind Manifestationen des Tao und in unaufhörlicher Wandlung und Transformation. Nach Chuangtse ist Tao sogar der Ameise, dem Unkraut, dem tönernen Ziegel und dem Kothaufen immanent. ${ }^{69}$ Die ontologische Gleichheit aller Dinge führt zur axiologischen Gleichheit. Man kann nicht sagen, daß das Menschliche wertvoll sei und das Natürliche wertlos.

Also ist der Mensch nicht das Maß aller Dinge. Er ist nichts anderes als ein Einzelwesen in der Natur. Er ist kein Subjekt, das Macht iber die Natur zum eigenen Zweck ausüben darf, sondern ein Teil der Natur. Warum wird der Mensch nicht als die Krone der Schöpfung und als Maßstab aller Dinge angesehen? Für die Taoisten ist er ontologisch nicht nur ein winziges Teilchen zahlloser Dinge, ${ }^{70}$ sondern hat auch die raumzeitliche Relativität und Grenze der Erkenntnis und der Urteilsfähigkeit. $^{71}$

Der Taoismus findet den Grund für die Zerstörung des harmonischen Verhältnisses zwischen Natur und Mensch auch im Anthropozentrismus und in den künstlichen Handlungen des Menschen. Er fordert vom Menschen, daß der sich dem Rhythmus der Natur anpaßt und die Natürlichkeit, die natürliche Schönheit und die Ordnung der Natur als ihren Anteil an ihren eigenen Rechten anerkennt. Trotzdem greift der Mensch nach seinem eigenem Urteil in die Natur ein. Chuangtse deutet auf den Irrtum und Fehler der künstlichen Handlung, die den Originalzustand zerstört, auf allegorische Weise: „Der Herr des Südmeeres war der Schillernde (Shu); der Herr des Nordmeeres war der Zufahrende (Hu); der Herr der Mitte war der Unbewußte (Hundun). Der

\footnotetext{
${ }^{68}$ Chien Sche-Yen (1982), S. 125.

${ }^{69}$ Chuangtse, K. 22.

70 Chuangtse, K. 17. „Ich bin inmitten von Himmel und Erde nur wie ein Steinchen oder ein Bäumchen auf einem großen Berg, das in seiner Kleinheit nur eben sichtbar ist. Wie sollte ich mich da selber für groß halten? Denkst du etwa, daß die vier Meere inmitten von Himmel und Erde nicht nur einer kleinen Erhöhung oder Vertiefung in dem großen Urmeer entsprechen? Um die Zahl aler Dinge zu bezeichnen, redet man von Zehntausenden, und der Mensch ist nur eben eines davon. Von all den vielen Menschen, die die neun Erdteile bewohnen, sich von Körnerspeise nähren und zu Schiff und Wagen miteinander verkehren, ist der Einzelmensch nur Einer. Wenn man ihn also vergleicht mit den Myriaden von Wesen, ist er da nicht wie die Spitze eines Härchens am Leibe eines Pferdes?“ (Wilhelm, 180).

${ }^{71}$ Vgl. Chuangtse K. 2, S. 6 und 17; Needham, J. (1969), S. 49 und 81ff.
} 
Schillernde und der Zufahrende trafen sich häufig im Lande des Unbewußten, und der Unbewußte begegnete ihnen stets freundlich. Der Schillernde und der Zufahrende überlegten nun, wie sie des Unbewußten Güte vergelten könnten. Sie sprachen: „Die Menschen alle haben sieben Öffnungen zum Sehen, Hören, Essen und Atmen, nur er hat keine. Wir wollen versuchen, sie ihm zu bohren.“ So bohrten sie ihm jeden Tag eine Öffnung. Am siebenten Tage, das war der Unbewußte tot. ${ }^{672}$

In diesem Text kennzeichnen die anthropomorphen Figuren „Shu“ und „Hu“ ein im schlechten Sinne typisch menschliches Handeln und versinnbildlichen damit die Entstehung der Zivilisation, ${ }^{73}$ während Hundun der unangetasteten Originalzustand der Natur bedeutet. Dieser Text zeigt, daß die Natur durch das künstliche Handeln und das zweckhafte, zielgerichtete Eingreifen nach Maß menschlicher Willkür zerstört worden ist. Mit anderen Worten: „Ihr verhängnisvolles Unterfangen, Hundun ein menschliches Gesicht zu verleihen, symbolisiert den rohen Zugriff des berechnenden Menschen auf die Natur - ein abrupter Einbruch, dessen Gewalt und Schärfe im Bild des Meißelns krass zum Ausdruck kommt. Hundun, als das jedem Zweck absolut Fremde der Berechnung seiner Wohltäter hilflos ausgeliefert, stirbt einen stummen Tod. So endet der eifernde Versuch des Menschen, die ihn in Überfluß bewirtende und wie Hundun ,freundlich behandelnde“" Natur nach seinem Bilde umzugestalten, mit deren Zerstörung und dem endgültigen Verlust der All-Einheit, die ihn mit ihr verband."ㄱ

Die Natur hat ihre eigene Beschaffenheit und ihre Rechte auf Existenz, die durch die Instrumente der Zivilisation nicht zerstört werden dürfen. ${ }^{75}$

„Die Beine einer Ente sind wohl kurz; wollte man sie strecken, so täte es ihr weh. Die Beine $\dot{\mathrm{a}}$ nes Kranichs sind wohl lang; wollte man sie kürzen, so empfände er Schmerz. Darum: was von Natur lang ist, soll man nicht kürzen; was von Natur kurz ist, soll man nicht strecken.“ 76

\footnotetext{
72 Chuangtse, K. 7 (Wilhelm, S. 99-100). Zu den verschiedenen Auslegungen dieser Allegorie vgl. Roetz, H. (1984), S. 255f.; Needham, J. (1969), S. 112.

${ }^{73}$ Roetz, H. (1984), S. 255.

${ }^{74}$ Roetz, H. (1984), S. $256 f$.

${ }^{75}$ Chuangtse, K. 8, sagt: „Wer mit Haken und Richtschnur, mit Zirkel und Richtscheit die Leute recht machen will, der verkümmert ihre Natur; wer mit Stricken und Bändern, mit Leim und Kleister sie festigen will, der vergewaltigt ihr Wesen; wer Umgangsformen und Musik zurechtzimmert, um die Moral dadurch aufzuschmücken und so dem Herzen der Welt Trost zu spenden, der zerstört ihre ewigen Gesetze. Es gibt ewige Gesetze in der Welt, und was nach diesen ewigen Gesetzen krumm ist, das ist nicht durch einen Haken so geworden; was gerade ist, ist nicht durch eine Richtschnur so geworden; was rund ist, ist nicht durch einen Zirkel so geworden; was rechteckig ist, ist nicht durch das Richtscheit so geworden. Die Vereinigung des Getrennten bedarf nicht des Leims und des Kleisters und die Verbindung bedarf nicht Strick noch Schlinge.“

${ }^{76}$ Chuangtse, K. 8 (Wilhelm, 104).
} 
Die Taoisten vertreten die Meinung, daß die Natur keiner Korrekturen bedarf. Das anthropozentrische Denken, daß der menschliche Urteilsmaßstab auch auf die Natur angewendet werden kann, damit die natürlichen Dinge oder ihre Ordnung verbessert werden sollen, ruft den Tod der Natur und darum die Zerstörung der Harmonie zwischen Mensch und Natur hervor.

Wie schon erwähnt wurde, verneinen die Taoisten die Sonderstellung des Menschen als Krone der Schöpfung und halten daran fest, daß der Mensch nichts anderes ist als ein Teil der Natur. Roetz sagt, daß ,hinter allen Spekulationen des Taoismus immer auch die Frage nach dem Menschen steht. ${ }^{\text {"77 }}$ Sie verachten die persönliche, soziale und politische Frage nicht, sondern versuchen vielmehr, unermüdlich einen Weg zur Lösung dieser Fragen zu finden. Sie verneinen lediglich die Absolutierung der menschlichen Normen, Moral und Institutionen und die Anwendung der menschlichen Urteils- und Erkenntnismaßstäben auf die Natur, denn sie haben erkannt, daß die Antwort nicht in den menschlichen Normen, Moralvorstellungen und Institutionen gefunden werden kann, sondern nur im Wirkungskreis und Rhythmus der Natur. Darüber hinaus lehren sie, daß die Wiederherstellung der menschlichen Eigennatur darin besteht, daß man die wesentliche Einheit von Mensch und Natur erkennt und sich mit der Natur versöhnt.

Das taoistische Menschenbild wird in bezug auf den anderen Menschen, die Natur und Tao verstanden. Der Mensch ist in Kommunion, Einung mit Tao und erkennt Tao nicht intellektuell und analytisch, sondern intuitiv. Er führt sein Leben in tiefer Beziehung zu den anderen Geschöpfen und in der Harmonie mit der Natur, mit der Ordnung des ganzen Universums.

Nach der taoistischen Philosophie sucht der verfallene Mensch nicht nach der intuitiven, ganzheitlichen wahren Erkenntnis, sondern legt großen Wert auf die analytische, rationale und unterscheidende Erkenntnis. Also kann er Tao nicht erkennen. Und er versteht die natürliche Schönheit der Natur und das Verhältnis zwischen Tao, Mensch und Natur nicht als ganzheitlich, einheitlich und harmonisch.

Chuangtse bestimmt den Entwicklungsprozeß der Geschichte als Verfallsprozeß des Te oder der Urtugend. Diesen Verfallsprozeß des Te setzt er mit dem Entwicklungsprozeß der Technologie und Zivilisation gleich. Die Geschichte der Menschheit ist bei ihm nicht auf dem Weg zum idealen Endziel, sondern eine Verfallsgeschichte, die nur schwer zum Originalzustand und zur großen Harmonie zurückgeführt werden kann. Durch die technische Zivilisation und das sie antrei-

\footnotetext{
${ }^{77}$ Roetz, H. (1984), S. 226.
} 
bende Wissen und Begehren wird die Harmonie des Menschen mit der äußeren Natur sowie die innere Natur des Menschen zerstört.

Nach den Taoisten ist das Streben nach Mehrbesitz eine Wurzel für die Entwicklung von Technologie und Zivilisation und die durch die menschliche Begierde getriebene Technik und Zivilisation stachelt umgekehrt wieder die Begierde an. „Mit der Erfüllung der Bedürfnisse wachsen die Ansprüche. Die steigenden Ansprüche sind die Triebkraft für steigende Produktion. Doch ist dieser Wettlauf zwischen steigenden Ansprüchen und dem Zwang, sie erfüllen zu müssen, nicht zu gewinnen. Mit beschränkten Ressourcen kann man nicht unbegrenzte Fortschritte machen und mit begrenzten Möglichkeiten keine unbegrenzten Ansprüche befriedigen. Auch abgesehen davon, ob die Menschheit in Zukunft neue Energiequellen entdeckt und durch genetische Techniken neue Nahrungsmittel produziert, treibt dieser Wettlauf in die globale Krise hinein, wenn es bei der Maßlosigkeit der Ansprüche bleibt. ${ }^{\text {778 }}$

„Je mehr die Technik fortschreitet, desto häufiger sind wir in Versuchung, immer mehr besitzen zu wollen. Demzufolge leben wir ständig in Angst und Sorgen, ohne dessen vielleicht bewußt zu werden. Hier erinnert uns Laotse, daß viele Wünsche nicht zur Notwendigkeit gehören und das Glück in der Zufriedenheit mit dem Wenigen besteht, da die Begierde ja keine Grenzen kennt.“79 Darum sagt Laotse auch: „Kostbarkeiten nicht schätzen, so macht man, daß das Volk nicht stiehlt. Nichts Begehrenswertes zeigen, so macht man, des Volkes Herz nicht wirr wird. Darum regiert der Berufene also: Er leert ihre Herzen und füllt ihren Leib. Er schwächt ihren Willen und stärkt ihre Knochen und macht, daß das Volk ohne Wissen und ohne Wünsche bleibt, und sorgt dafür, daß jene Wissenden nicht zu handeln wagen. Er macht das Nichtmachen, so kommt alles in Ordnung. ${ }^{40}$ „Hat das Reich Tao, so hält man Gangpferde zur Felddüngung. Hat das Reich nicht Tao, so züchtet man Kriegsrosse an den Grenzen. 'Kein größerer Frevel, als Gelüst erlaubt zu nennen, kein größeres Unheil, als Genügen nicht zu kennen, kein größeres Laster, als nach Mehrbesitz zu brennen.' Darum: Wer sich zu genügen weiß, hat ewig genug. ${ }^{\text {(\$1 }}$ „Umfasse deine Urnatur, beherrsche deine Selbstsucht, bezähme deine Begierde. ${ }^{(\$ 2}$

Die moderne wissenschaftlich-technische Zivilisation beschleunigt die Zentralisierung von Industrien und Menschenmassen, die Mechanisierung und Automatisierung, um die Konkurrenz-

\footnotetext{
78 Moltmann, J. (1985), S. 42f.

${ }^{79}$ Hsiao, P. Y. (1956), S. 74.

${ }^{80}$ Tao Te King, K. 3 (Wilhelm, 43).

81 Tao Te King, K. 46 (Strauss, 119).

${ }^{82}$ Tao Te King, K. 19 (Lin Yu Tang, 93). In seinem Kommentar zu Tao Te King betrachtet Kim die Wu-Yü-Lehre bei Laotse als die Wirtschaft des Nichtbegehrens. Vgl. Kim, K. T. (1978), S. 376.
} 
gesellschaft zu fördern, während die Taoisten sich dieser Entwicklung verweigern und sich lieber nach dem Land sehnen, in dem es keine Kriege und Mrdwaffen gab, die Harmonie und alle originelle Natur nicht durch die menschlichen Technologie und Zivilisation zerstört worden war. ${ }^{83}$

Nun soll auch das Prinzip des Wu-Wei des Menschen im Taoismus betrachtet werden, welche Bedeutung es angesichts der heutigen ökologischen Krise hat. ${ }^{84}$ Hier handelt es sich um den ethischen Aspekt des Wu-Wei. Im Taoismus ist das Wu-Wei des Menschen, das „Wirken durch Nichthandeln, aber intensives Dasein, ${ }^{65}$ nach dem Wu-Wei, der Wirkungsweise des Tao modelliert. Mit anderen Worten: es ist die Anwendungen der Erfahrung des Wu-Wei des Tao auf das menschlichen Leben in der Welt.

Im Taoismus bedeutet das Wei oder das Handeln ,action contrary to Nature. ${ }^{\text {(86 }}$ „Human action (wei) only interferes with and stifles the natural process of things ... . „Human action (wei), imposing an order on nature, is disruptive and destructive. ${ }^{، 87}$ Wei entspricht inhaltlich dem jen oder dem Künstlichen, Menschlichen. Die Erklärung des Begriffes jen hilft uns, den Begriff Wu-Wei $\mathrm{zu}$ verstehen. Auf die Frage: ,was heißt das Himmlische (T'ein) $?^{88}$ Was heißt das Menschliche (jen)? ${ }^{\star 89}$ antwortet Chuangtse: Jo vom Nordmeer sprach: „Daß Ochsen und Pferde vier Beine haben, das heißt ihre himmlische (Natur). Den Pferden die Köpfe zu zügeln und den Ochsen die Nasen zu durchbohren, das heißt menschliche (Beeinflussung). Darum heißt es: Wer nicht durch menschliche Beeinflussung die himmlische Natur zerstört, wer nicht durch bewußte Absichten sein Schicksal stört, wer nicht um des Gewinnes willen seinen Namen schädigt, wer sorgfältig sein Eigenes wahrt und nicht verliert: der kehrt zurück zu seinem wahren Wesen. ‘90

Dieser Text kontrastiert die eigentliche Natur der Natur und das menschliche Zutun, durch das mit Hilfe der Zivilisation die Ordnung und der Rhythmus der Natur belastet und zerstört wird. „So beeinträchtigen sie (die wahren Menschen) nicht durch eigene Bewußtsein den Sinn (Tao)

\footnotetext{
${ }^{83}$ Im Kapitel 80 des Tao Te King wird dies folgendermaßen ausgedrückt: Ein Land mag klein sein und seine Bewohner wenig. Geräte, die der Menschen Kraft vervielfältigen, lasse man nicht gebrauchen. Man lasse das Volk den Tod wichtig nehmen und nicht in die Ferne reisen. Ob auch Schiffe und Wagen vorhanden wären, sei niemand, der darin fahre. Ob auch Panzer und Waffen da wären, sei niemand, der sie entfalte. Man lasse das Volk wieder Stricke knoten und sie gebrauchen statt der Schrift. Mach süß seine Speise und schön seine Kleidung, friedlich seine Wohnung und fröhlich seine Sitten. Nachbarländer mögen in Sehweite liegen, daß man den Ruf der Hähne und Hunde gegenseitig hören kann: und doch sollen die Leute im höchsten Alter sterben, ohne hin und her gereist zu sein. Tao Te King, K. 80 (Wilhelm, 123).

${ }^{84} \mathrm{Zu}$ den verschiedenen Erklärungen dieses Begriffes vgl. etwa Needham, J. (1969), S. 68ff.; Cooper, J. P. (1977), S. $97 \mathrm{ff}$.

${ }^{85}$ Moltmann, J. (1989), S. 127.

${ }^{86}$ Needham, J. (1969), S. 68.

${ }^{87}$ Chen, E.M. (1989), S. 144.

${ }^{88}$ Vgl. z.B. Roetze, R. (1984), S. 249.

${ }^{89}$ Chuangtse, K. 17 (Wilhelm, 186).
} 
und suchen nicht durch ihr menschliches der Natur zu Hilfe zu kommen“"91. Wu-Wei ist darin Gelassenheit und Geschehenlassen, genauer gesagt: „letting nature take its own course. ${ }^{، 2}$ Nichteingreifen in die Natur meint ,refraining from activity contrary to Nature. ${ }^{63}$ Es ist, positiver gesagt, ein Tun, das ,im Einklang mit dem Rhythmus der Natur steht, und der Harmonie aller Dinge entspricht“ und „den Dingen ermöglicht, ihre eigene Integrität und Würde zu leben.“94

Man kann in den taoistischen Schriften eine skeptische Haltung gegenüber dem menschlichen Wissen spüren. Laotse sagt, daß man die Weisheit und das Wissen aufgeben und von Wissen frei sein sollte. ${ }^{95}$ Im Buch des Chuangtse heißt es: „Lückenbeißer fragte Keimwalter: Wißt Ihr, worin die Welt mit dem Ich übereinstimmt? Er sprach: wie sollte ich das wissen? Wißt Ihr, was Ihr nicht wißt? Er sprach: Wie sollte ich das wissen? Dann gibt es also kein Wissen der Dinge? Er sprach: Wie sollte ich das wissen? ${ }^{96}$

In diesem Text ist der Schwerpunkt nicht die ontologische Frage nach der Übereinstimmung des Menschen mit der Welt, sondern die epistemologische Frage, d.h. die Wissensfrage. Indem Chuangtse wiederholt sagt, wie ich das wissen sollte, zeigt er seinen skeptischen Standpunkt. Deshalb muß man die Frage stellen, ob die taoistische Erkenntnistheorie nach der Invalidierung und Verneinung jedweder Erkenntnis zielt und deshalb zum Agnostizismus führt. Darauf ist zu antworten, daß die Taoisten nicht jede Erkenntnismöglichkeit und jedes Erkenntnisvermögen des Menschen verneinen. Sie verneinen nur die ,kleine Erkenntnis“. Chuangtse teilt die Erkenntnis in zwei Kategorien ein: die kleine und die große ${ }^{97}$ und kritisiert und verneint nur erstere.

Die „kleine Erkenntnis“, die überwunden werden sollte, ist die analysierende, diskriminierende und dualisierende. „Nach Meinung der Taoisten führt die Analyse der Dinge nur zu einer Trennung des analysierten Objekts und des analysierenden Subjekts. Werden der Analysierende und das Analysierte als zwei gesehen, dann besteht das Ich in seiner Funktion des Unterscheidens weiter und verhindert das Hervortreten des großen Selbst. ${ }^{98}$ Nachdrücklich zeigt Chuangtse, daß das analysierende, diskriminierende Denken nicht zur wahren Natur der Dinge und zu Tao als

\footnotetext{
${ }^{90}$ Chuangtse, K. 17 (Wilhelm, 186).

${ }^{91}$ Chuangtse, K. 6 (Wilhelm, 84).

${ }^{92}$ Chan Wing Tsit (1973), S. 136.

${ }^{93}$ Needham, J. (1969), S. 68.

${ }^{94}$ Bischofberger, O. (1988), S. 49.

${ }_{95}$ Vgl. Tao Te King, K. 3, 15, 19 und Chuangtse, K. 9, 10, 11, 16.

${ }^{96}$ Chuangtse, K. 2 (Wilhelm, 48).

97 Chuangtse K. 2: „Great knowledge is leisurely and at ease, (or allembracing and extensive) wheras small knowledge is inquisitive (or partial and discriminative). “Zit. nach Chan Wing Tsit (1973), S. 180.

98 Chang Chung Yuan (1977), S. 71.
} 
der Einheit gelangen, mit anderen Worten, nicht das Ganze wissen kann, sondern nur das Partielle der Natur und des Wirkens des Tao. ${ }^{99}$

Die „kleine Erkenntnis“ verursacht die Entzweiung von Natur und Mensch und verstärkt die Herrschaft des Menschen über die Natur. Cooper kritisiert die Neigung, die Natur auf analytische Weise zu beobachten: „Der moderne Mensch neigt dazu, mehr Beobachter als Teilnehmer zu sein, er bildet sich ein, er könne neben dem Leben stehen, es von außen betrachten, es mit dem analytischen Geist anschauen oder, was ebenso falsch ist, mit dem flatterhaften Auge der Neugier. Es ist unmöglich, in Übereinstimmung mit einer Welt zu sein, die man als etwas ganz anderes betrachtet, das heißt also, eine gespaltene Persönlichkeit zu sein. ... Das Beobachten der Natur, so genau und scharf es auch sein mag, ist nicht dasselbe wie das Erkennen durch Intuition und Sein. ... Auf analytische Weise beobachten heißt, ein Ding als etwas Einzelnes zu sehen, es zu etwas anderem zu machen, als man selbst ist, mit einem gewissen Element der Herablassung. ... Sobald er von der Natur getrennt ist und die Fühlung mit allen Dingen, das Einssein, verloren hat, begibt er sich auf den Weg nach unten, der in die Zerstörung führt, nicht nur die der Natur, sondern auch seines eigenen spirituellen Lebens, da die beiden innig verbunden sind. Wenn er die Natur tötet, tötet er sich selbst. Wenn er sie mißhandelt und versklavt, so fügt er sich selbst Verletzungen zu und versklavt sich selbst. “100

Die taoistische Erkenntniskritik enthält nicht nur den Zweifel an dem menschlichen, rationalen Erkenntnisvermögen, nämlich die Reflexion über die Relativität und Beschränktheit dieser Erkenntnis, sondern auch den ,kulturkritischen Aspekt, die Bewertung der Auswirkungen des Wissens auf die ursprüngliche Harmonie des Daseins.“101 “Als Wissen und Klugheit erschienen, folgte ihnen große Heuchelei (wei) auf dem Fuße.“102 Darum sagt Laotse, daß man das Wissen wegwerfen solle. Und Chuangtse wie auch Laotse sehnen sich nach dem Zeitalter, in dem die Menschen Wissen hatten, es aber nicht zur Herrschaft über die Natur gebrauchten und deshalb in tiefer Harmonie mit der Natur standen. Der taoistische Gedanke, dieses Wissen nicht zl gebrauchen oder abzuwerfen, zielt nicht auf eine „Volksverdummungspolitik,“ sondern auf eine Reintegration mit der Ordnung der Natur. „Man sollte beachten, daß die ganze Philosophie Laotses sich gegen eine übermäßige Entwicklung von Wissen und Lehren stellte. ‘103

\footnotetext{
${ }_{99}$ Chuangtse, K. 2 (Watson, 43-44). Chuangtse, K. 12 (Wilhelm, 131) sagt auch, daß man nicht durch das rationale Denken und die „kleine Erkenntnis“ zur Wahrheit und zum wahren Wissen der Natur und des Tao gelangen kann.

${ }^{100}$ Cooper, J. C. (1977), S. 87f.

${ }^{101}$ Roetz, H. (1984), S. 264.

102 Tao Te King, K. 18 (Lin Yu Tang, 92).

${ }^{103}$ Lin Yu Tang (1986), S. 198.
} 
„Immerhin, ich will versuchen, darüber zu reden! Woher weiß ich, daß das, was ich Wissen nenne, nicht Nicht-Wissen ist? Woher weiß ich, daß das, was ich Nicht-Wissen nenne, nicht Wissen ist? Nun will ich dich einmal fragen. Wenn die Menschen an enem feuchten Ort schlafen, so bekommen sie Hüftweh, und die ganze Seite stirbt ab; geht es aber einem Aale ebenso? Wenn sie auf einem Baum weilen, so zittern sie vor Furcht und sind ängstlich besorgt; geht es aber einem Affen ebenso? Wer von diesen drei Ceschöpfen nun weiß, welches der richtige Wohnort ist? Die Menschen nähren sich von Mastvieh; die Hirsche nähren sich von Gras; der Tausendfuß liebt Würmer, und der Eule schmecken Mäuse. Welches dieser vier Geschöpfe weiß nun, was wirklich gut schmeckt? Die Paviane gesellen sich zu Äffinnen, die Hirsche zu Hindinnen, die Aale schwimmen mit den Fischen zusammen, und schöne Frauen erfreuen der Menschen Augen. Wenn die Fische sie sehen, so tauchen sie in die Tiefe; wenn die Vögel sie sehen, so fliegen sie in die Höhe; wenn die Hirsche sie sehen, so laufen sie davon. Welches von diesen Geschöpfen weiß nun, was wahre Schönheit unter dem Himmel ist?‘104

Dieser Text zeigt: Was für die Menschen gilt, gilt nicht immer auch für die anderen Geschöpfe. Der Mensch versucht, alle Dinge und die Naturordnung aus seiner anthropozentrischen Sicht zu erkennen. Er macht alles zu seinem Erkenntnisobjekt, verabsolutiert seine Vorverständnisse und Erfahrungen und versucht, sie auf die Natur anzuwenden. Er wird als eigenständiges Erkenntnissubjekt nicht durch die Erkenntnis der Dinge beeinflußt, noch ist er selbst ein Erkenntnisobjekt. Er denkt, daß der Mensch das absolute Erkenntnisvermögen hat. Aber nach Chuangtse kann der Mensch, der an die anthropozentrischen Vorurteilen gefesselt ist, nicht das wahre Wissen der Dinge erreichen. Die menschliche, kleinen Erkenntnis darf den eigenen Standpunkt nicht verabsolutieren und als allein richtig ansehen. Sie ist nichts anderes als eine relative Erkenntnis. Wenn man die „kleine Erkenntnis“ als eine ganzheitliche und absolute versteht, so ist das gerade, ,als wollte man den Himmel überschauen durch eine Röhre, oder als wollte man mit der Spitze einer Ahle die Erde bedecken. ${ }^{\star 105}$

Der Grund dafür, daß die Taoisten die „kleine Erkenntnis“ so heftig kitisieren, beruht gerade auf ihrem Seinsverständnis, ihrem Verständnis von Natur und Mensch. Nach den Taoisten gibt es nur die gegenseitig durchdringende, abhängige Beziehung zwischen Natur und Mensch. Ontologisch, epistemologisch oder axiologisch hat der Mensch keinen Vorrang über die Natur. Er ist eher ein Teil der Natur und muß deshalb ihrem Rhythmus entsprechend leben. Er weigert sich,

\footnotetext{
${ }^{104}$ Chuangtse, K. 2 (Wilhelm, 48).

105 Chuangtse, K. 17 (Wilhelm, 190). An anderer Stelle spricht er von der zeitlich-räumlichen Relativität und Beschränktheit der kleinen Erkenntnis: „Mit einem Brunnenfrosch kann man nicht über das Meer reden, er ist be-
} 
als Erkenntnissubjekt der Natur gegenüberzustehen und die Natur zum bloßen Erkenntnisobjekt zu machen. In der wahren Erkenntnis wird der Dualismus von Subjekt und Objekt aufgehoben. Sie ist die innere Erfahrung der ursprünglichen Einswerdung, der gegenseitigen Durchdringung und Vereinigung von Subjekt und Objekt, dem Einen und dem Vielen, von Mensch und Natur. Ihr Ziel ist nicht Macht, Eroberung und Herrschaft, sondern Sympathie, Teilhabe und Teilnahme. Der Mensch, der diese Erkenntnis hat, sieht die Natur nicht als Gegenstand des menschlichen Nutzens an, sondern akzeptiert die eigenen Rechte der Natur, erkennt die Natur gnzheitlich und gerade so, wie sie da ist, läßt sich mit dem Rhythmus der Natur in Einklang stehen, dringt ins Herz der Natur und nimmt ihre Freude als seine Freude wahr. Dies nennt man die ästhetische, sympathische Erfahrung und wie Hall bemerkt, ,a ... mode of participation in the processes of nature. “106

\subsection{Westlicher Einfluß auf die koreanische Gesellschaft}

Ein drastische Veränderung der koreanischen Gesellschaft ist ohne Zweifel durch den Prozeß der Modernisierung, Urbanisierung und Industrialisierung entstanden. Der soziale Wandel wird besonders von den sechziger Jahren an als eine dramatische und rapide Transformation bezeichnet. ${ }^{107}$ Diese gesellschaftliche Transformation hat eine neue industrielle Kultur hervorgebracht, die sich an der westlichen liberalen Gesellschaftsform orientiert.

Daher weist die moderne koreanische Industriegesellschaft eine in ihrer soziokulturellen Struktur veränderte neue Gesellschaftsformation auf. Es ist ein entwicklungsdynamisches und leistungsorientiertes System entstanden, dessen Wirtschaftswachstum eine große Dynamik entfaltete. Die strukturellen Veränderungen der koreanischen Gesellschaft lassen sich insbesondere im politischen, wirtschaftlichen und kulturellen System und in den persönlichen Weltanschauungen feststellen. Diese sozialen Systeme und die dazugehörigen Institutionen sind zweckmäßig und ratio-

schränkt auf sein Loch. Mit einem Sommervogel kann man nicht über das Eis reden, er ist begrenzt durch seine Zeit“" (K. 17, Wilhelm, 180).

${ }^{106}$ Hall, D. L. (1978), S. 281. Diese Erfahrung beschreibt Chuangtse im Dialog mit seinem Gesprächspartner Hui Dsi: „Dschuang Dsi ging einst mit Hui Dsi spazieren am Ufer eines Flusses. Dachuang Dsi sprach: Wie lustig die Forellen aus dem Wasser herausspringen! Das ist die Freude der Fische. Hui Dsi sprach: Ihr seid kein Fisch, wie wollt Ihr denn die Freude der Fische kennen? Dschuang Dsi sprach: Ihr seid nicht ich, wie könnt Ihr da wissen, daß ich die Freude der Fische nicht kenne? Hui Dsi sprach: Ich bin nicht Ihr, so kann ich Euch allerdings nicht erkennen. Nun seid Ihr aber sicher kein Fisch, und so ist es klar, daß Ihr nicht die Freude der Fische kennt. Dschuang Dsi sprach: Bitte laßt uns zum Ausgangspunkt zurückkehren! Ihr habt gesagt: wie könnt Ihr denn die Freude der Fische erkennen? Dabei wußtet Ihr ganz gut, daß ich sie kenne, und fragtet mich dennoch. Ich erkenne die Freude der Fische aus meiner Freude beim Wandern am Fluß!“ (Chuangtse, K. 17, Wilhelm, 192). Wilhelm, 179 nennt diese Erfahrung das sympathetische Erlebnis der Mitfreude an der Freude der Fische.

107 Vgl. Barringer, H. R. (1968), S. 203. 
nal eingerichtet. Allerdings verlangen sie im Sinne der „Anpassungsstruktur“ von jedem auch ein institutionell angepaßtes Verhalten.

Die Grundformen des Leistungsethos werden in der hohen Wertschätzung der individuellen Leistung und in der von ihr abhängigen Zuweisung eines sozialen Status verkörpert. Aus diesem soziokulturellen Orientierungssystem geht die heutige Leistungsmotivation der Koreaner hervor. Wegen des sozialen Strukturwandels hin zur leistungsorientierten, industriellen Gesellschaft befindet sich Südkorea in einem starken soziokulturellen Dualismus. Insbesondere die Wertvorstellung der Koreaner ist zwar leistungsorientiert, aber es läßt sich unschwer erkennen, daß das individuelle Leistungsverhalten weiterhin durch traditionelle und emotionsgeladene Wertvorstellungen geprägt ist. Diese Entwicklung der koreanischen Gesellschaft sieht Eliseit vor dem traditionellen Hintergrund: „Zwar befinden sich diese (traditionellen) Regeln und Normen in einem Übergang. In manchen Kreisen ist der traditionelle gesellschaftliche Kodex streng und unverändert erhalten, in anderen mit westlichen Einflüssen gemischt, teilweise aber auch bereits aufgegeben. “6108

Die asketische Lebensführung des Protestantismus war bei Weber einer der entscheidenden Faktoren für die kapitalistische Wirtschaftsentwicklung. Sie galt zugleich als eine Grundlagen für die Leistungsmotivation. Wie sieht es nun in der koreanischen Gesellschaft aus?

Nach der Tradition des konfuzianischen Denkens basieren die Einstellung und die Verhaltensweise auf einer emotionsgeladenen und autoritären Handlungsstruktur. Um die Rolle dieser Denk- bzw. Handlungsstruktur hinsichtlich der Leistungsmotivation zu erläutern, wird zuerst der Begriff der Rationalität von Weber kurz erläutert.

Weber unterscheidet zwei rationale Typen des sozialen Handelns: Zweckrationales und wertrationales Handeln. ${ }^{109}$ Zweckrational heißt, daß ein soziales Handeln ,durch Erwartungen des Verhaltens von Gegenständen der Außenwelt und von anderen Menschen und unter Benutzung dieser Erwartungen als „Bedingungen“ oder als „Mittel“ für rational, als Erfolg, erstrebte und abgewogene eigene Zwecke ${ }^{\text {“110 }}$ bestimmt ist. Wertrationales Handeln demgegenüber ist ein soziales Handeln, das sich an ethischen, religiösen oder pietätischen „Geboten“ oder „Forderungen“ ausrichtet, die der Handelnde an sich gestellt glaubt. Dieses Handeln ist von den Handlungser-

\footnotetext{
${ }^{108}$ Eliseit, H. (1978), S. 322.

${ }^{109}$ Vgl. Weber, M. (1980), S. $12 \mathrm{f}$.

${ }^{110}$ Weber, M. (1980), S. 13.
} 
gebnissen, nämlich vom Erfolg oder Mißerfolg, völlig unabhängig. ${ }^{111}$ Ein solches, rein wertrationales Handeln ist im sozialen Handlungsfeld kaum vorstellbar. Es äußert sich meist nur in religiösen Einstellungen.

Das Leistungsverhalten kann von einer Kalkulation ausgehen, die mögliche Mittel zur Verwendung heranzieht, um das subjektiv vorgelegte Ziel zu erreichen. In der koreanischen Gesellschaft vollzieht sich die Zielverfolgung nicht immer gemäß den sozialen Normen und der sozialen Ordnung. Alles, womit die Koreaner sich beschäftigen, ist nach Lee, ihr Ziel ohne Zweck-MittelÜberlegungen zu erreichen. Diese Einstellung, die durch die konfuzianische Denktradition geprägt ist, will er als eine Folge einer zweckrationalen Verhaltensorientierung verstanden wissen. ${ }^{112}$ Eine solche Verhaltensweise kann jedoch aufgrund der Weber'schen Rationalitätsbegriffe nicht als eine Folge der zweckrationalen Handlung erklärt werden. Sie ist eine Verhaltensweise, die im strengen Sinne zu keiner der weber'schen rationalen Handlungen zählt.

Zunächst soll die Wirkung des kulturellen Konflikts für die Verhaltensänderung eines Individuums hinsichtlich der Leistungsorientierung ausgeführt werden. Der kulturelle Konflikt zwischen der traditionellen koreanischen und westlichen Kultur motiviert eine Interessenänderung: ${ }^{113}$ Der geschichtliche Entwicklungsprozeß ist von großer Bedeutung. In den 60er und 70er Jahren mobilisierte die Regierung Südkoreas alle Kräfte für die gesellschaftliche Industrialisierung und Modernisierung, welche in diesem Land binnen kürzester Zeit zur absoluten Maßgabe avancierte. Der Umweltschutz blieb dabei völlig unberücksichtigt. Die koreanische Regierung glaubte fest an ihr Programm und propagierte, daß nur dieser Weg zur wirtschaftlichen Entwicklung führen könne. Die daraus folgende Wertorientierung der Koreaner umfaßt hauptsächlich die wirtschaftlichen Aspekte der Entwicklung. Es versteht sich von selbst, daß eine psychologisch so fixierte Vorstellung viele daraus resultierende Nebenwirkungen, wie beispielsweise Umweltzerstörung, außer acht läßt.

In folgenden soll der westliche Einfluß auf die koreanische Gesellschaft insbesondere in bezug auf das Naturverständnis untersucht werden. Dabei zu bemerken ist, daß die heutige Weltanschauung und das Wertsystem in Südkorea, welche die Grundlagen der Kultur bilden und die sorgfältig neuformuliert werden müssen, stark an die westlichen orientiert sind.

\footnotetext{
${ }^{111}$ Vgl. Weber, M. (1980), S. 12.

112 Vgl. Lee, M.-T. (1974), S. 190.

${ }^{113}$ Vgl. Lee, M.-T. (1974), S. 185.
} 
Zwischen den 15. und 17. Jahrhundert veränderte sich auf bemerkenswerte Weise sowohl die Art, wie die Menschen die Welt beschrieben, als auch ihre gesamte Denkweise in der abendländischen Zivilisation. Sie wurden zur Grundlagen des Paradigmas in der abendländischen Zivilisation, aber auch in anderen Regionen der Welt, das die Kultur während der letzten drei Jahrhunderte beherrscht hat und vor allem aufgrund der ökologischen Krise sich allmählich zu ändern anschickt.

Die Vorstellung von der Natur als ein lebendiger Organismus blieb vor den 15. Jahrhundert im abendländischen Denksystem vorherrschend. ${ }^{114}$ Das organische Denken setzte die Natur, zumal die Erde, mit einer nahrungsspendenden Mutter gleich. ${ }^{115}$ Sie war ein freundlich-wohltätiges weibliches Wesen, das für die Bedürfnisse der Menschheit sorgt. Die Menschen lebten in Harmonie mit der Natur, mit dem Zyklus und mit dem Rhythmus der Natur. Für sie war die Erde von einer Kraft erfüllt, die den auf ihr weilenden Lebewesen Leben verlieh. Die Menschen sahen sich als ein Teil der Natur, die Natur wurde als etwas Heiliges verehrt. „Das Bild von der Erde als einem lebendigen Organismus und einer nahrungspendenden Mutter hatte als kulturelle Handlungshemmung gewirkt, die dem Tätigkeitsdrang des Menschen in Schranken hielt. Man schlachtet nicht mir nichts dir nichts seine Mutter, wühlt in ihren Eingeweiden nach Gold oder verstïmmelt ihren Leib; genau das war es aber, was der kommerzielle Bergbau schon bald fordern sollte. Solange die Erde als belebt und fühlend gedacht wurde, konnte es als Verstoß gegen die menschliche Ethik gelten, zerstörend in sie einzugreifen. ${ }^{\text {‘1 } 16}$

Diese organisch ausgerichtete Mentalität änderte sich im 16. und 17. Jahrhundert radikal und wurde durch eine mechanisch orientierte Mentalität ersetzt. Statt des organischen Naturverständnisses trat nun die Maschine als Metapher für Naturerfahrung auf. ${ }^{117}$ Denn die organischen Metaphern waren mit den neuen technischen und wirtschaftlichen Veränderungen und Umständen unvereinbar. „Die Gesellschaft bedurfte dieser neuen Bilder in dem Maße, wie sie jenen Prozeß der Kommerzialisierung und Industrialisierung vorantrieb, der vom unmittelbaren Eingreifen in die Erde - durch Bergbau, Entwässerung, Entwaldung und Rodung - abhängig war. Bei diesen neuen Aktivitäten setzte man in großartiger Vielfalt und Kombination neue Techniken ein.“118 „Die Verschiebung der leitenden Metaphorik hing direkt mit der Veränderung menschlicher Einstellung und Verhaltensweisen gegenüber der Erde zusammen. Während man das Bild von der

\footnotetext{
${ }^{114}$ Vgl. Capra. F. (1991), S. 51.

115 Der wissenschaftliche Rahmen dieser organischen Weltsicht wurde von zwei Autoritäten geschaffen (von Aris toteles und der Kirche). Vgl. hierzu Capra. F. (1991), S. 51.

${ }^{116}$ Merchant, C. (1987), S. 20.

117 Vgl. zum mechanischen Weltbild und seiner Entwicklung z.B. Merchant, C. (1987); Capra, F. (1991); Crombie, A. C. (1977); Dijksterhuis, E. J. (1956); Freudenthal, G. (1982).
} 
nahrungspendenden Erde als kulturelle Handlungshemmung ansehen kann, die die Formen des gesellschaftlich und moralisch zulässigen menschlichen Einwirkens auf die Erde einschränkt, wirkten die neuen Metaphern der Beherrschung und Bemächtigung als kultureller Freibrief für den die Natur entblößenden Zugriff des Menschen. “119 So geriet die weibliche Erde unter die Erpressung der Maschine und ist der wissenschaftlichen Revolution und dem Aufstieg einer marktorientierten Kultur zum Opfer gefallen.

„Wenn wir den Wurzeln des gegenwärtigen Umweltdilemmas und seinen wissenschaftlichen, technischen und wirtschaftlichen Hintergründen nachgehen, müssen wir die Herausbildung einer Weltanschauung und Wissenschaft prüfen, die die Wirklichkeit nicht mehr als lebendigen Organismus, sondern als Maschine auffaßte und dadurch die Herrschaft über die Natur wie über die Frauen legitimierte. ${ }^{\text {،120 }}$ Das mechanische Weltbild, das mit Kopernicus begann, der das geozentrische Weltbild von Ptolemäus zu Fall brachte, wurde von Bacon, Descartes und Newton durchgesetzt, und die „Weltmaschine“ wurde zur beherrschenden Metapher der modernen Ära. ${ }^{121}$ Erst im 20. Jahrhundert entwickelte die neue Physik eine neue Sicht der Wirklichkeit. ${ }^{122}$ Aber noch üben die mechanische kartesianische Weltanschauung und die Prinzipien der Newtonschen Physik ihren starken Einfluß auf das abendländische wissenschaftliche Denken aus. ${ }^{123}$

Descartes war der Meinung, daß es der Philosophie nicht gelang, einen Satz zu finden, ,über den man nicht streitet und der infolgedessen nicht zweifelhaft ist ${ }^{\star 124}$ und versuchte „eine vollständig neue Wissenschaft,“ ... „,die im allgemeinen alle Fragen der Quantität löst, der kontinuierlichen wie der diskontinuierlichen. “25 Decartes hatte den festen Glauben an die Gewißheit wissenschaftlicher Erkenntnis, und seine Gewißheit war im wesentlichen mathematisch. Für ihn konnte die Beziehung zwischen Quantitäten mit Hilfe der Mathematik beschrieben werden und damit den Status wahrer physikalischer Gesetze. ${ }^{126}$

\footnotetext{
118 Merchant, C. (1987), S. 18.

${ }^{119}$ Merchant, C. (1987), S. 18.

${ }^{120}$ Merchant, C. (1987), S. 13.

${ }^{121}$ Vgl. Capra, F. (1991), S. 51-76.

122 Vgl. Capra, F. (1991), S. 77-103 und 293-474.

${ }^{123}$ Vgl. Capra, F. (1991), S. 107-289.

${ }^{124}$ Merchant, C. (1987), S. 205.

125 Capra, F. (1991), S. 55.

${ }^{126}$ Descartes sagte: „Ich lasse keine von ihnen als wahr gelten, die nicht mit der Klarheit mathematischer Beweisführung aus allgemeinen Vorstellungen abgeleitet ist, deren Wahrheit nicht angezweifelt werden kann. Da alle Naturerscheinungen auf diese Weise erklärt werden könnten, bin ich der Ansicht, daß keine sonstigen Grundsätze der Physik zugelassen werden müssen oder auch nur wünschenswert sind. Meine gesamte Physik ist nichts weiter als Geometrie.“ Zit. nach Capra, F. (1991), S. 57.
} 
„Descartes rationalistische Antwort auf das Problem der Gewißheit führt zu einer Wissenschaft der Mechanik auf der Grundlage quantitativer Eigenschaften (oder primärer Qualitäten) wie etwa der Menge der Materie in einem Körper und dessen Bewegung. Die Quantität der Bewegung dnes Körpers kann ganz oder teilweise in einen anderen Körper überführt werden, wobei die Größe dieser Quantität jeweils durch eine Reihe von abgeleiteten Regeln bestimmt ist. Der Mechanismus als Wissenschaft von der bewegten Materie kann dazu dienen, das gesamte Weltall zu beschreiben - den menschlichen Körper, seine physikalische Umgebung und den größeren Kosmos.“127 In seinem Buch „Principia philosophiae“ rekonstruiert Descartes den Kosmos als Mechanismus. Der Grundzug des Kosmos ist für ihn „die Bewegung träger stofflicher Teilchen, die die Bewegung durch bewirkende Verursachung konsekutiv von Teil zu Teil weitergeben. Die Kraft, die die Bewegung hervorbringt, ist nicht etwas Vitales, Beseeltes, den Körpern selbst Innewohnendes, sondern ergibt sich nach Maßgabe der Quantität ihrer Materie und Geschwindigkeit ihrer Bewegung. Bewegung ist etwas der Materie Äußerliches und dem Weltall vom Augenblick der Schöpfung an mitgeben.“' ${ }^{\text {128 }}$ Natur wird im Grunde als Masse-Kraft-Beziehung, die kausal determiniert ist, und als der Inbegriff regelmäßiger Gesetzmäßigkeiten in einem System unabhängiger substantieller Einzelelemente beschrieben. Mit anderen Worten gesagt ist die Natur als res extensa für ihn nichts anderes als eine Maschine, die nach regelmäßigen Gesetzen funktioniert und in Begriffen der Anordnung und der Bewegung seiner Teile erklärt werden kann. Etwas Vitales, Beseeltes und Geistiges ist aus der Natur verbannt.

In seinen „Principia philosophiae“ führt Descartes aus: „man wird sich hiernach leicht davon überzeugen, daß es in den Steinen und Pflanzen keine so verborgenen Kräfte, keine so staunenswerten Wunder der Sympathie oder Antipathie und nichts endlich in der ganzen Natur gibt, wenigstens von dem, was man auf rein körperliche Ursachen, d.h. solche, die des Geistes und Bewußtseins entbehren, beziehen muß, dessen Grund nicht aus denselben Prinzipien abgeleitet werden könnte, so daß es keiner Zuhilfenahme anderer weiter bedarf. “ ${ }^{129}$ Er dehnte seine mechanistische Anschauung auf lebende Organismen aus und sah auch Pflanzen und Tiere als Maschine an. Der Körper war für ihn auch nur eine Maschine. ${ }^{130}$

\footnotetext{
${ }^{127}$ Merchant, C. (1987), S. 206.

${ }_{128}$ Merchant, C. (1987), S.206f.

129 Descartes, R. (zit. nach Merchant, C. (1987), S. 207).

${ }^{130}$ Er sagte: „Wir sehen Uhren, künstliche Brunnen, Mühlen und ähnliche Maschinen, die, obwohl nur von Menschenhand gemacht, doch fähig sind, sich von selbst auf verschiedene Weise zu bewegen.(...) Ich sehe keinerlei Unterschied zwischen Maschinen, die von Handwerkern hergestellt wurden, und den Körpern, die allein die Natur zusammengesetzt hat. (...) Für mich ist der menschliche Körper eine Maschine. In Gedanken vergleiche ich einen kranken Menschen und eine schlecht gemachte Uhr mit meiner Idee von einem gesunden Menschen und einer gut gemachten Uhr.“Zit. nach Capra, F. (1991), S. 61.
} 
Newton hielt an einem kennzeichnenden Merkmal des mechanistischen Denkens und entwickelte eine vollständige mathematische Ausformulierung der mechanistischen Naturauffassung. ${ }^{131}$ Die Physik Newtons lieferte eine geschlossene mathematische Theorie der Welt. Er behielt die Grundannahme von Deseartes bei, daß Materie ein passives Prinzip sei und die Ursache für Bewegung der Dinge in äußerlichen Kräften, nicht in einer inneren Wirkkraft liege. Der Legende nach kam Newton die entscheidende Einsicht durch einen Gedankenblitz, als er einen Apfel vom Baum fallen sah. Er erkannte, daß der Apfel von derselben Kraft zur Erde gezogen wurde, die auch die Planeten zur Sonne zieht. Und erfand auf dieser Weise den Schlüssel zu seiner großen Synthese. Er nutzte dann seine neue mathematische Methode, um die exakten Bewegungsgesetze für alle Körper unter dem Einfluß der Schwerkraft zu formulieren.

Das Newtonsche Universum war wirklich ein gewaltiges mechanisches System, das nach exakten mathematischen Gesetzen funktionierte. Newton stellte seine Welttheorie in allen Einzelheiten in seinem Buch „Mathematische Grundlagen der Naturwissenschaft“ vor, das ein umfassendes System von Definitionen, Thesen und Beweisen hielt und von den Wissenschaftlern über zweihundert Jahre lang als genaue Beschreibung der Natur angesehen wurde. Sie beinhaltet auch eine ins einzelne gehende Diskussion der experimentellen Methode Newtons, die er selbst als ein systematisches Verfahren betrachtete, bei dem die mathematische Beschreibung Schritt für Schritt auf der kritischen Bewertung der experimentellen Ergebnisse beruht. So fordert Newton: „Alles, was nicht aus Naturerscheinungen abgeleitet werden kann, seien sie metaphysischer oder physikalischer, okkulter oder mechanischer Art, haben in der experimentellen Philosophie keinen Platz. In dieser Philosophie werden einzelne Thesen aus den Phänomenen abgeleitet und aschließend durch Induktion allgemeingültig gemacht. “ ${ }^{\text {،132 }}$

Alle physikalische Erscheinungen werden in der Newtonischen Mechanik auf die Bewegung von materiellen Teilchen im Raum reduziert, die durch ihre gegenseitige Anziehung, d.h. durch die Schwerkraft verursacht wird. Die Wirkung dieser Kraft auf einen Partikel oder auf irgendein anderes materielles Objekt wird mathematisch durch Newtons Bewegungsgleichung beschrieben, welche die Grundlage der klassischen Mechanik bildet. Sie wird als festes Gesetze betrachtet, nach welchem materielle Objekte sich bewegen, und man glaubte mit ihnen alle in der physikalischen Welt beobachteten Veränderungen erklären zu können. ${ }^{133}$

\footnotetext{
${ }^{131}$ Vgl. zum newtonischen mechanistischen Weltbild Capra, F. (1991), S. 62ff.; Merchant, C. (1987), S. $263 \mathrm{ff}$.

132 Zit. nach Capra, F. (1991), S. 64.

${ }^{133}$ Vgl. Capra, F. (1991), S. 65.
} 
Newton entwickelte den Begriff von dem absoluten Raum und der absoluten Zeit. Er sagte: „Der absolute Raum ist seinem Wesen nach so beschaffen, daß er ohne Rücksicht auf etwas außerhalb Liegendes immer gleich und unbeweglich bleibt.“ „Die absolute, wahre und mathematische Zeit fließt von sich aus und gemäß ihrem Wesen gleichförmig und ohne Rücksicht auf irgendwelche äußeren Dinge. “134 Die Elemente, welche sich im absoluten Raum und der absoluten Zeit bewegen, seien Masseteilchen, kleine, feste und unersetzliche Objekte, aus denen alle Materie zusammengesetzt sei. Er glaubte, daß Gott sie so geschaffen habe. In Opticks sagte er: „Ich halte es für wahrscheinlich, daß Gott am Anfang die Materie als feste, harte, massive, undurchdringliche, bewegliche Partikeln schuf, in der Größe und Gestalt und mit solchen Eigenschaften und in solchem Verhältnis zum Raum, wie sie dem Zweck am dienlichsten waren, für den er sie erschaffen hatte, und daß diese einfachen Partikeln als Festkörper unvergleichlich härter sind als irgendwelche porösen Körper, die aus ersteren aufgebaut sind; sogar so hart, daß sie nie verschleißen oder zerbrechen. Keine gewöhnliche Kraft vermag zu trennen, was Gott selbst am ersten Schöpfungstag erschuf “135

„Aus Newtons Sicht hat Gott am Anfang die Masseteilchen, die Kraft zwischen ihnen und die Grundgesetze der Bewegung geschaffen. Auf diese Art wurde das gesamte Universum in Bewegung gesetzt und läuft seitdem wie eine Maschine, gelenkt von unabänderlichen Gesetzen. Die mechanistische Weltanschauung ist somit eng verbunden mit einem strengen Determinismus, mit der Auffassung einer kausalen und völlig determinierten kosmischen Maschine. Alles, was geschieht, hat nach dieser Auffassung eine definitive Ursache und eine definitive Wirkung, und die Zukunft eines jeden Teils des Systems könnte im Prinzip mit absoluter Sicherheit vorausgesagt werden, wenn sein Zustand zu irgendeiner Zeit in allen Einzelheiten bekannt wäre. ‘136

Dieses Bild einer vollkommenen Weltmaschine erforderte einen außerhalb stehenden Schöpfer, einen monarchischen Gott, der die Welt von oben regiert, indem er ihr seine göttlichen Gesetze auferlegt. Die physikalischen Vorgänge selbst galten nicht als göttlich, und als die Wissenschaft es zunehmend schwieriger machte, an einen solchen Gott zu glauben, verschwand das Göttliche vollkommen aus der wissenschaftlichen Weltanschauung und ließ jenes spirituelle Vakuum zurück, das so charakteristisch für den Hauptstrom unserer Kultur geworden ist. Philosophische Grundlage dieser Säkularisierung der Natur war die kartesianische Spaltung von Geist und Materie. Als Folge dieser Spaltung hielt man die Welt für ein mechanisches System, das objektiv be-

\footnotetext{
134 Zit. nach Capra, F. (1991), S. 65.

135 Zit. nach Capra, F. (1991), S. $65 f$.

${ }^{136}$ Capra, F. (1991), S. 66.
} 
schrieben werden konnte, ohne daß der menschliche Beobachter je erwähnt wurde. Eine derart objektive Beschreibung der Natur wurde zum Ideal der gesamten Naturwissenschaft. ${ }^{137}$

Seit Bacon und Descartes das Verhältnis von Mensch und Natur als Subjekt-Objekt-Verhältnis, als Herrscher-Sklave-Verhältnis darstellten, begann der Siegeszug der klassischen Naturwissenschaft und der modernen Technologie. ${ }^{138}$ Indem Bacon in seinem Buch „Neues Organon“ drei Stufen menschlichen Macht- und Gewaltstrebens unterscheidet, betrachtet er die Macht und Herrschaft des menschlichen Geschlechtes über die Gesamtnatur als das höchste und vornehmste Machtstreben. ${ }^{139}$ Diese menschliche Machtergreifung über die Natur ist das Ziel der wissenschaftlichen Erkenntnis. Bacon erklärt, daß Wissen Macht sei. Nach ihm wurzelt die Macht des Menschen im angemessenen Wissen von den Naturprozessen, von den Ursachen der Natur: „Menschliches Wissen und menschliche Macht sind eins; denn wo die Ursache nicht bekannt ist, kann die Wirkung nicht hervorgerufen werden. ${ }^{\text {،140 }}$ Im Erkennen geht es um den Bau eines wahren Modells der Welt. Dies kann man nicht erhalten ohne sorgfältige Zerlegung und Präparierung der Welt. Das Wissen, das zugleich Macht ist, kann nur durch Eingriffe in Naturprozesse erworben werden. Schäfer weist darauf hin, daß das Eingreifen in die Natur das Erkenntnisziel und Erkenntnismittel ist. ${ }^{141}$ Auch Descartes sagt, daß das Ziel der Naturwissenschaft darin liegt, die Menschen zu „Herren und Besitzern der Natur“ zu machen. ${ }^{142}$ Für ihn ist der Mensch ein erkennendes Subjekt, während die Natur ein Erkenntnisobjekt ist. Bei Descartes steht der Mensch als res cogitans der Natur als res extensa gegenüber. Für ihn sind die Tiere nichts anders als mechanische Automaten. So wird das Natürliche nicht mehr menschlich und das Menschliche nicht mehr natürlich erfahren. ${ }^{143}$

Bislang wurde den geistigen Hintergrund der heutigen Umweltkrise betrachtet. Daraus läßt sich feststellen, daß das Verhalten des Menschen gegenüber der Natur in engem Zusammenhang mit seinem Verständnis von Mensch und Natur steht. Ganzheitliches Denken, die Vorstellung von

\footnotetext{
${ }^{137}$ Vgl. Capra, F. (1991), S. 66.

138 Vgl. Moltmann, J. (1985), S. 41.

${ }^{139}$ Vgl. Krohn, W. (1990), S. 129 und 271: „Es gehört zur Sache, drei Arten oder Grade des Ehrgeizes bei den Menschen zu unterscheiden. Bei der ersten ist man darauf aus, die eigene Macht in seinem Vaterlande zu vermehren, dies ist die gewöhnliche und teilweise unedle Art; bei der zweiten strebt man dahin, des Vaterlandes Macht und Herrschaft über das menschliche Geschlecht zu erweitern; diese Art is t gewiß würdiger, reizt aber zu stärkerer Begierde; erstrebt nun jemand, die Macht und die Herrschaft des Menschengeschlechtes selbst über die Gesamtheit der Natur zu erneuern und zu erweitern, so ist zweifellos diese Art von Ehrgeiz, wenn man ihn so nennen kann, gesünder und edler als die übrigen Arten. Der Menschen Herrschaft aber über die Dinge beruht allein auf den Künsten und Wissenschaften. Die Natur nämlich läßt sich nur durch Gehorsam besiegen.“ Zur Kritik an Bacon aus ökologischer Sicht: Vgl. Jonas, H. (1979), 251ff.; Schäfer, L. (1993); Liedke, G. (1972), 36-65. bes. 39-51.

${ }^{140}$ Bacon, F. (1990): Novum Organum I. Buch, Aph. 3.

${ }^{141}$ Vgl. Schäfer, L. (1993), S. 102ff.

142 Vgl. Liedke, G. (1972), S. 51f.

${ }^{143}$ Vgl. Meyer-Abich, K. M. (1984), S. 205.
} 
der notwendigen Balance der Gegensätze, die Unterordnung des Menschen in die Harmonie der Natur und die daraus gesetzten Grenzen wurden als Grundlagen traditioneller Denkweise Südkoreas betrachtet. Damit wird unterstellt, daß der harmonische Umgang der Menschen mit ihrer ratürlichen Umwelt mit der traditionellen Weltanschauung Südkoreas im Gegensatz zu der konventionellen technozentrischen Weltanschauung des Westens möglich wäre.

Trotz dieses geistigen Hintergrundes genießt der Umweltschutz in Südkorea seit der Wiederaufbauphase bis heute nicht die ihm gebührende Beachtung. Umweltpolitik und ihre Instrumente werden hinsichtlich der rechtlichen Grundlagen und der darauf beruhenden Praxis weitgehend nach dem Muster der westlichen Industriestaaten konzipiert und vollzogen. Primäres Ziel des Umweltschutzes ist es, zu verhindern, daß Umweltprobleme mit der raschen Zunahme der Bevölkerung und der Entwicklung der Industrialisierung überhandnehmen. Das heißt, die koreanische Weltanschauung ist stark durch westliche Einflüsse überlagert worden und in der bisherigen praktischen Umweltpolitik nicht zum tragen gekommen.

In dieser Krisensituation muß man ernsthaft die Frage stellen: Wie sollen Natur und Mensch verstanden werden.? Wie soll das Verhältnis des Menschen zu der Natur bestimmt werden? Der Taoismus, der versuchte, die ökologische Krise im alten China zu überwinden, stößt auf die eine neue Herausforderung, weil seine wichtigen, ökologischen Gedanken vergessen und verachtet worden sind. Literatur bzw. Diskussionen, die die taoistischen Texte und Begriffe aus ökologischer Sicht erläutern und diskutieren, sind in Südkorea selten zu finden. Das bedeutet entweder, daß Südkorea vom Fortschrittsglauben besessen ist, absichtlich seine Tradition verachtet oder sich der katastrophalen Folgen der Umweltzerstörung noch nicht bewußt ist. Deshalb ist es Zeit zu betrachten, welche Antwort man in der taoistischen Tradition angesichts dieser Krise finden kann.

\subsection{Wertewandel in bezug auf der Umweltfrage in der koreanischen Gesellschaft}

Eines der größten Probleme der heutigen (Industrie-) Gesellschaft ist sicherlich das Umweltproblem und die dadurch ausgelösten Phänomene sind vielfältig. ${ }^{144}$ Sie finden in einem wachsenden Vertrauensverlust in Staat, Wirtschaft und deren Institutionen, sowie in Zukunftspessimismus und einer Sinn- und Orientierungskrise ihren Niederschlag und können den gesellschaftlichen Wertewandel auslösen.

${ }^{144}$ Vgl. Kap. 2.1 dieser Arbeit. 
Die Umweltkrise mit ihren einzelnen Symptomen stellt dabei einen wesentlichen Faktor für den gesellschaftlichen Wertewandel dar. Ökologische Auswirkungen wie befürchtete oder bereits eingetretene Gesundheitsschäden, das Aussterben von Tieren und Pflanzen, verschmutzte Gewässer und sichtbar werdendes Waldsterben haben in der Gesellschaft ein starkes Bewußtsein für Umweltgefahren geschaffen.

Mit dem Begriff „Umweltbewußtsein“ lassen sich eine Vielzahl von Verhaltensweisen, Einstellungen, Wertmaßstäbe und Auffassungen verbinden, die Individuen, Gesellschaften, Staatswesen, Unternehmen, Verbände und andere Gruppierungen in Zusammenhang mit umweltrelevanten Themen aufweisen. Sagt jemand von sich, er sei „umweltbewußt“, so wird darunter allgemein verstanden, daß sich diese Person oder Institution zumindest weniger umweltschädlich verhält als der Durchschnitt des vergleichbaren Personen-, Gesellschafts- oder sonstigen Körperschaftskreises. $^{145}$

Bei Individuen als kleinste Einheiten der Gesellschaft ist die Bedürfnisbefriedigung (Bedürfnis nach Sicherheit und Gesundheit, aber auch nach Selbstverwirklichung und sozialen Kontakten) an erster Stelle bei der Motivation zu umweltbewußtem Verhalten zu nennen. Dies äußert sich in den bevorzugten Betätigungsfeldern im Umweltschutz Man kann an Umweltschutzkampagnen teilnehmen und/oder seine Verhaltensweise in puncto Umweltschutz ändern, wie z.B. Abfälle getrennt sammeln. Dabei wird in vielen Fällen keine direkte finanzielle Einbuße für den Einzelnen spürbar werden, wodurch die eigene Verhaltensänderung mangels meßbarer, quantifizierbarer Vergleichsmöglichkeiten subjektiv aufgewertet wird und damit eine innere Befriedigung erzielt werden kann. Das gesellschaftliche Interesse am Umweltschutz als kumuliertes individuelles Interesse liegt ergo in der Motivation zur Erhaltung der eigenen Umwelt.

„Was soll der Staat besser für den Umweltschutz tun bzw. unternehmen?“

\begin{tabular}{|c|c|c|c|}
\hline $\begin{array}{l}\text { Förderung des } \\
\text { Umweltbewußtseins }\end{array}$ & $\begin{array}{l}\text { Effektivisierung der } \\
\text { Umweltpolitik }\end{array}$ & $\begin{array}{l}\text { Vergrößerung des } \\
\text { Umweltetats }\end{array}$ & $\begin{array}{l}\text { Verstärken der } \\
\text { Umweltgesetzgebung }\end{array}$ \\
\hline $56,30 \%$ & $17,30 \%$ & $8,70 \%$ & $17,30 \%$ \\
\hline
\end{tabular}

Abb. 5.1: Staatliche Aufgaben für den Umweltschutz

(Quelle: KEI (1997), S. 50)

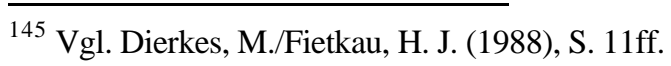


Mit der Steigerung der Umweltprobleme seit Anfang der 70er Jahre in Südkorea sind die ökologischen Aspekte immer stärker in das Bewußtsein einer breiten Öffentlichkeit getreten. Um diesen Problemen zu begegnen, werden stärkere staatliche Aktivitäten gefordert (vgl. Abb. 5.1) und der Ruf wird laut, daß die einzelnen Bürger sich umweltfreundlich verhalten sollten.

Das Umweltbewußtsein kann durch Öffentlichkeitsarbeit gefördert werden. ${ }^{146}$ Diese kann durch Ein-Weg-Kommunikation mit Anzeigen oder Informationsblättern erfolgen. Aber auch dialogorientierte Aktivitäten wie Informationskampagnen in Betrieben, Schulen, öffentliche Anhörungen oder Workshops können durchaus Erfolg haben. Das Angebot von umweltfreundlichen Produkten allein reicht nicht aus, vielmehr muß auch über sie informiert werden, wenn sich eine Nachfrage nach diesen Produkten einstellen soll. Ohne die entsprechende Nachfrage kann sich kein Produkt auf Dauer im Markt halten.

„Die Sorge der Nation“ (in \%)

\begin{tabular}{|l|c|c|c|c|}
\hline & $\mathbf{1 9 8 2}$ & $\mathbf{1 9 8 7}$ & $\mathbf{1 9 9 2}$ & $\mathbf{1 9 9 7}$ \\
\hline Umweltschutz & 5,70 & 17,10 & 10,20 & 27,70 \\
\hline Friedenssicherung & 13,50 & - & - & 17,50 \\
\hline Innere Sicherheit & - & - & 15,03 & 10,70 \\
\hline Erziehung & 17,00 & 13,90 & - & 14,90 \\
\hline Arbeitslosigkeit & 9,50 & 5,60 & - & - \\
\hline Wirtschaftsstabiliät & 10,60 & - & 10,30 & 13,50 \\
und -wachstum & & & & \\
\hline
\end{tabular}

Abb. 5.2: Die relative Wichtigkeit der Umweltprobleme in Südkorea

(Quelle: KEI (1997) und Ku, D.-H. (1996))

Das Interesse an einer intakten, sauberen Umwelt, an einem bedachteren Umgang mit ökologisch knappen Ressourcen sowie einem Erhalt der natürlichen Lebensgrundlagen und - daraus abgeleitet - die Herausbildung eines ausgeprägten Umweltbewußtseins i.S. eines sehr stabilen Wertekomplexes kann in Südkorea nachgewiesen werden. Nach der repräsentativen Umfrage, die Einstellungen der koreanischen Bevölkerung bzw. Unternehmen in Bezug auf Umweltschutz untersucht hat, haben 94,2 \% der Befragten Umweltprobleme mehr als besorgniserregend bezeichnet. 
Dies zeigt sich daran, daß im Jahr 1997 die schlechte Einschätzung der Umweltprobleme bzw. die persönliche Betroffenheit durch Umweltverschmutzung gegenüber Anfang der 80er bzw. 90er Jahre deutlich zugenommen hat. Das Umweltthema hat im Jahre 1982 eine untergeordnete Rolle gespielt (mit 5,7\% an letzter Stelle), ist aber im Jahre 1997 mit 27,7\% an die 1. Stelle grückt. ${ }^{147}$ Ein Ergebnis dieser Untersuchungen ist die Erkenntnis, daß die Bevölkerung für die Umweltproblematik in hohem Maße sensibilisiert ist. In Abb. 5.2 ist die zeitliche Entwicklung des Umweltbewußtseins in Südkorea dargestellt.

Wie groß dabei die persönliche Betroffenheit und Angst von der Umweltverschmutzung (vgl. Abb. 5.3), aber auch wie tief die Unzufriedenheit der Bevölkerung mit dem Verhalten der Institutionen von Staat und Wirtschaft (Unternehmen) sind, offenbaren nicht nur diese Befragungen zum Umweltbewußtsein, sondern auch das Phänomen der Bürgerinitiativen und der Umweltbewegung. ${ }^{148}$

„,ühlt mich persönlich bedroht von Umweltverschmutzung“ (in \%)

\begin{tabular}{|c|c|c|}
\hline & bedroht & nicht bedroht \\
\hline $\mathbf{1 9 8 2}$ & 71,40 & 28,60 \\
\hline $\mathbf{1 9 9 1}$ & 89,60 & 10,40 \\
\hline 1997 & 94,20 & 5,80 \\
\hline
\end{tabular}

Abb. 5.3: Die persönliche Betroffenheit von Umweltverschmutzung (Quelle: KEI (1997), Ku, D.-H. (1996))

Vor dem Hintergrund eines weitgehend gesicherten materiellen Wohlstandsniveaus und eines durchschnittlich höheren Bildungsstands der Bevölkerung vollzog sich in der koreanischen Gesellschaft ein Bewußtseinwandel, der den an Quantitäten ausgerichteten „Materialismus“ der heutigen Generation anzweifelt und immaterielle Aspekte des Lebens in den Vordergrund stellt. Nicht allein materielle und physische Sicherheitsziele, wie ein möglichst hohes Einkommen und

\footnotetext{
${ }^{146} \mathrm{Zu}$ den Ansatzpunkte, das Umweltbewußtsein zu steigern vgl. Wicke, L. (1993), S. 282ff.

${ }^{147}$ Im Jahr 1992 ist der Stellenwert des Umweltschutzes gegenüber dem Jahr 1987 zurückgegangen. Diese dürfte auf die schlechte innenpolitische und wirtschaftliche Lage in diesem Zeitraum zurückzuführen sein.

${ }^{148}$ Hier sind die Bürgerinitiative und ihre Umweltbewegung in Südkorea weiter unberücksichtigt. Zu verweisen ist auf Ku, D.-H. (1996).
} 
das Streben nach Konsumgütern sind entscheidend, sondern darüber hinausgehende Bedürfnisse und Ziele - was immer diese auch sein mögen - erhalten eine höhere Bewertung. ${ }^{149}$

Ökonomisches Denken, das beinahe alle gesellschaftlichen Lebensbereiche weitgehend kommerzialisiert hat, wird im Zuge der postmaterialistischen Orientierung zunehmend kritisiert. Dagegen gewinnen vor allem individuelle bzw. kollektive Ethik- und Moralvorstellungen an Bedeutung. ${ }^{150}$ Im Zuge dieser gesellschaftlichen Strömungen gelangen neben den sozialen und ökonomischen Wachstumsgrenzen vor allem ökologische Grenzen einer Wirtschaft in das Bewußtsein, die die natürliche Umwelt zerstört und die Reproduktionsgrundlagen gefährdet. Im Zentrum dieser Kritik stehen dabei die Unternehmen bzw. die Industrie, die eine Schlüsselrolle im fortschreitenden Prozeß der ökologischen Zerstörung einnehmen. In diesem Sinne schätzt die koreanische Bevölkerung die Anstrengungen zum Umweltschutz der Unternehmen äußert schlecht ein und hält sie für die Hauptverursacher der Umweltprobleme. So hat die Bevölkerung nach einer im Jahr 1997 durchgeführten Befragung über das Umweltbewußtsein zu mehr als $70 \%$ die Unternehmen als Hauptverursacher für die Umweltprobleme verantwortlich gehalten (vgl. Abb. 5.4). ${ }^{151}$

„Wie schätzen Koreaner die Umweltschutzanstrengungen der Unternehmen ein“

\begin{tabular}{|c|c|c|c|}
\hline sehr gut & gut & nicht gut & mangelhaft \\
\hline $4,3 \%$ & $25,5 \%$ & $57,1 \%$ & $13,1 \%$ \\
\hline
\end{tabular}

Abb. 5.4: Die Anstrengungen der Unternehmen für Umweltschutz in der Bewertung durch die koreanischen Bevölkerung (Quelle: KEI (1997), S. 67)

Diese schlechte Einschätzung hat natürlich Auswirkungen für die Unternehmensfuihrung: Einerseits Umsatzeinbußen durch Boykott der Produkte und andererseits Imageverlust für die betreffenden Unternehmen. Als grundlegendes Werteziel ökologisch verpflichteter Unternehmensführung resultiert hieraus die Forderung: Das Unternehmen soll einen Beitrag zum Erhalt und zur Förderung einer intakten Umwelt leisten.

\footnotetext{
149 Bei einer im Jahr 1997 durchgeführten Befragung hat etwa 54,9\% der koreanischen Bevölkerung geantwortet, daß man die Bedürfnisse nach der Sicherung der tatsächlichen Lebensqualität gegenüber dem materiellen Wohlstand in den Vordergrund stellt. Vgl. KEI (1997), S. 10. In diesem Sinne hat die koreanische Regierung in ihrer langfristigen Gesamtplanung zum Umweltschutz (sog. Umweltvision 21) als eines der Hauptziele der (Umwelt) Politik die Erreichung hoher Lebensqualität angesetzt. Vgl. Umweltministerium Südkorea (1996), S. $12 \mathrm{ff}$.

${ }^{150}$ Vgl. Inglehart, R. (1981), S. $279 \mathrm{ff}$.
} 
Die Antwort auf die Frage, was dieser gesellschaftliche Wertewandel für die Unternehmensführung bedeutet, ist darin zu sehen, daß veränderte Konsumeinstellungen und ein erhöhter ökologischer Wissensstand auf der Verbraucherseite zu einem differenzierteren und durchaus kritischeren Verbraucherverhalten führen. Auch von Mitarbeiterseite her und insbesondere von Führungsnachwuchskräften werden in verstärktem Maße ökologische Erwartungen an das Unternehmen gerichtet. Die somit umrissenen ökologiebezogenen Push-Faktoren (z.B. Mitarbeiter, Konkurrenten) sowie die ökologiebezogenen Pull-Faktoren (z.B. Verbraucher, Handel) wirken damit in hohem Maße erfolgs-, überlebens- und entwicklungskritisch auf das Unternehmen ein. $^{152}$

\footnotetext{
${ }^{151}$ Dieses Ergebnis stammt aus einer Untersuchung, die über das Umweltbewußtsein von Bevölkerung und Unternehmen im Jahr 1997 durchgeführt wurde. Vgl. KEI (1997).

${ }^{152} \mathrm{Vgl}$. zu den durch die ökologische Probleme induzierten Anforderungen und Auswirkung auf die Unternehmen Kap. 2.2 dieser Arbeit.
} 


\section{Politisch-rechtliche Rahmenbedingungen}

\subsection{Umweltpolitik und Umweltgesetzgebung in Südkorea}

Der Staat setzt die Rahmenbedingungen für das wirtschaftliche bzw. unternehmerische Handeln. Darüber hinaus übt er bei der nationalen Wirtschaft und Unternehmensführung die Aufgabe der Regulierung und Koordinierung aus. Im Zuge jeden Wertewandels, der vor allem hier durch die Ökologieproblematik ausgelöst wird, gerät auch der Staat in Zugzwang, die Rahmenbedingungen zu setzen. Dabei handelt es sich bei der ökologisch verpflichteten Unternehmensführung besonders um die staatliche Umweltpolitik und Umweltgesetzgebung.

Das ökologieorientierte Handeln gesellschaftlicher Akteure formt insgesamt die Umweltpolitik. Umweltpolitik kann demzufolge definiert werden als die ,...Gesamtheit der Ziele und Maßnahmen gesellschaftlicher Akteure, die den Umgang der Gesellschaft mit der Umwelt als natürlichem System regeln; sie hat Sanierungs-, Erhaltungs- und Gestaltungsaspekte. Da die Gesellschaft in ihrer Existenz letztlich von der natïrlichen Umwelt und ihren Ressourcen abhängt, deckt Umweltpolitik prinzipiell alle Regeln ab, die den Umgang des Menschen mit der Natur zum Inhalt haben. “'

Umweltpolitische Einflüsse des Staats auf die Gesellschaft zeichnen sich dadurch aus, daß sie auf staatlichen Hoheitsrecht bzw. der souveränen Staatsgewalt basieren. Darunter versteht man das Recht des Staats ,zur Ausübung der höchsten, völkerrechtsunmittelbaren ... Gewalt über Menschen und Sachen. ${ }^{2}$ Die staatliche Umweltpolitik kann somit innerhalb der jeweiligen Staatsgrenzen durch Zwangsmaßnahmen umgesetzt werden. Das bedeutet, daß bei Zuwiderhandlung gegen staatliche Auflagen eine strafrechtliche Verfolgung der Verantwortlichen bzw. eine Schließung der Betriebsanlagen erfolgen kann. Die umweltpolitischen Einflüsse des Staates können somit das Entscheidungsfeld von Unternehmen einengen und deren Verhalten in eine bestimmte Richtung lenken. Die staatliche Umweltpolitik stellt somit wesentliche Rahmenbedingungen für eine ökologisch verpflichtete Unternehmensführung dar. Ein wesentliches Element der staatlichen Umweltpolitik stellt das rechtliche System dar. Dabei handelt es sich um Gesetze, Vorschriften und Handlungsergebnisse oder konkreter, allgemeinverbindliche Willensbekundungen des politischen Systems eines Staates. ${ }^{3}$ Die umweltrelevanten Gesetze können nach der Art der Zielverwirklichung in präventive, sanierende, sanktionierende sowie vollziehende Normen

\footnotetext{
${ }^{1}$ International Institut für Umwelt und Gesellschaft (zitiert nach Simonis, U. E. (1988), S. 113).

${ }^{2}$ Seidl-Hohenveldern, I. (1991), S. 139.
} 
unterschieden werden. ${ }^{4}$ Präventive Regelungen sollen einer Gefährdung der Umwelt vorbeugen bzw. das Auftreten von Schäden verhindern. Für Unternehmen besonders relevante präventive Regelungen betreffen etwa die Vorschriften bei der Betriebsansiedlung sowie die Umweltverträglichkeitsprüfung. Sanierende Regelungen bezwecken die Wiederherstellung des umweltverträglichen Zustandes, nachdem eine Schädigung bereits eingetreten ist. Darunter fallen etwa Abmahnungen zur Beseitigung einer Störungsquelle oder - im Extremfall - Verfügung zur Schließung der Gewerbebetrieben. Sanktionierende Regelungen beziehen sich auf die Bestrafung nach einem erfolgten Verstoß gegen ein gesetzliches oder administratives Verhaltensgebot. Solche Regelungen betreffen insbesondere den Bereich des Strafgesetzes. Überwachende (vollziehende) Regelungen schließlich normieren die Kontrolle der Erhaltung der umweltrelevanten Gesetze.

Aus volkswirtschaftlicher Sicht wäre eine ökologische Vorsorge (präventive Umweltpolitik) durch eine umweltfreundliche und resourcenschonende Lenkung von Investitionsentscheidungen wünschenswert. Dadurch können Rohstoff- und Umweltschutzkosten sowie Umweltschäden minimiert, Innovationen und die wirtschaftliche Produktivität erhöht und mögliche Problemursachen beseitigt oder vermieden werden. Demgegenüber werden bei einer reaktiven Umweltschutzpolitik, der sog. ökologische Nachsorge, Umweltschädigungen nicht vermieden, sondern bereits entstandene Umweltbeeinträchtigungen nachträglich saniert. Es handelt sich bei dieser Art von Politik um eine ,verhältnismäßig ineffektive, kostenträchtige, volkswirtschaftlich eher unproduktive und ewig innovative Strategie, die die Problemursachen nicht ändert “. 5

Zur Durchsetzung der angestrebten staatlichen Umweltpolitik und Umweltschutzziele stehen eine Anzahl umweltpolitischer Instrumente zur Verfügung. Die zur Anwendung kommenden Instrumente können in ordnungsrechtliche Instrumente (Vorschreibungen, Verbot), ökonomische Anreizinstrumente (Erhebung von Lenkungsabgaben auf Emissionen, Umweltzertifikate, Kompensationsregelungen) und sonstige Instrumente (Steuervergünstigungen, Subventionen, Haftungsrecht) unterteilt werden. ${ }^{6}$

Das am meisten angewandten Instrumente im Umweltbereich in Südkorea sind die ordnungspolitischen Regelungen. Sie können als Kombination von „generally applicable rules“ und „placebased approach“ charakterisiert werden. Wichtige ordnungsrechtliche Instrumente in Südkorea

\footnotetext{
${ }^{3}$ Vgl. Macharzina, K. (1993), S. 24.

${ }^{4}$ Vgl. Mayntz, R./Hucke, J. (1978), $220 \mathrm{ff}$.

${ }^{5}$ Jänicke, M. (1988), S. 13.

${ }^{6}$ Vgl. Meffert, H./Kirchgeorg, M. (1998), S 105.
} 
sind u.a. „environmental Standards“, „emission/discharge limits“ und „designation of special zones“. 7 Aber dabei weisen diese Instrumente allerdings Schwachpunkte auf. ${ }^{8}$ So orientieren sie sich am Einsatz nachgeschalteter Reinigungseinrichtungen (End-of-Pipe-Technologien) statt an der Entwicklung integrierter Umweltschutztechnologien. ${ }^{9}$ Additiver Umweltschutz, bei dem Filter- und Reinigungstechnologien an die existierenden Produktionsapparate gleichsam angehängt werden, hat zwar gegenüber Vermeidungstechnologien zwei vordergründige ökonomische Vorteile: Es handelt sich um zusätzliche Geschäftsfelder, Verdienste und Arbeitsplätze; Unternehmen und Politik können auf strukturpolitische Eingriffe verzichten, die weh tun können und komplizierter erscheinen. Integrierter und vorbeugender Umweltschutz wird dadurch aber eher behindert. Für ihn käme es darauf an, Sanierungs- und Reparaturtechnologien immer überflüssiger zu machen und eine ökologische Innovationsstrategie zu befördern, bei der die Vermeidung ökologischer Schäden und Zerstörungen im Zentrum steht. Solche Überlegungen verweisen auf das ökologische Handeln an der Quelle ökonomischer Aktivitäten. Damit sind die (produzierenden bzw. dienstleistenden) Unternehmen und die Verbraucher/innen angesprochen, wobei letztere hier aus der weiteren Betrachtung ausgeklammert bleiben sollen. So veranlassen z.B. Unternehmen unter dem Gesichtspunkt der kurzfristigen Kostenoptimierung bei einer Entscheidung über Investitionsalternativen nachgeschaltete Reinigungstechniken, solange es keine ökonomischen Anreize gibt, die gesetzlichen Mindeststandards zu übertreffen. Diese Instrumente fördern somit eher reaktive als proaktive Umweltschutzstrategien von Unternehmen.

Wegen dieser Schwachpunkte der ordnungsrechtlichen Instrumente sollten zur Verwirklichung einer präventiven Umweltpolitik ergänzend der Einsatz marktwirtschaftlicher (ökonomischer) Instrumente gefördert werden. Die ökonomischen Instrumente gehören zur indirekten Steuerung durch den Staat, welche auf eine imperative, strikte Determination des Verhaltens der Normadressaten verzichtet und sich statt dessen bemüht, motivierend auf deren Entscheidungen einzuwirken. Im Unterschied zu ordnungsrechtlichen Instrumenten, bei denen dem Verursacher von Umweltbeeinträchtigungen meist im Detail vorgeschrieben wird, welche Anforderungen mit welchen Mitteln zu erfüllen sind, verbleibt bei ökonomischen Instrumenten ein gewisser Entscheidungsspielraum, ob und in welchem Ausmaß ein vom Staat gewünschtes Verhalten erfüllt wird bzw. auf welche Weise eine staatliche Zielvorgabe erreicht wird. Im Vergleich zu den ordnungsrechtlichen Instrumenten ist der Vorteil der ökonomischen Instrumente darin zu erkenne,

\footnotetext{
${ }^{7}$ Vgl. OECD (1997), S. 129f.

${ }^{8}$ Nach Wicke werden folgende Punkte kritisiert: Es werden keine Anreize für Unternehmen geschaffen, nach neuen technischen Lösungen zu suchen. Mit ordnungspolitischen Instrumenten können nicht alle Umweltbelastungen erfaßt werden und sie stellen meistens den teuersten Weg dar, die Umwelt zu schützen. Vgl. Wicke, L. et al. (1992), S. 589.

${ }^{9}$ Vgl. Fügraff, G. (1991), S. 32.
} 
daß sowohl bei den Unternehmen als auch bei den Verbrauchern ein ökonomisches Interesse an umweltverträglichem Verhalten geschaffen und somit ein eigenverantwortliches Vermeiden von Umweltbelastungen gefördert wird. Der Nachteil ökonomischer Instrumente liegt u.a. in deren Langwierigkeit, Wirkungsunsicherheit und -unvollständigkeit. Sie sind deshalb insbesondere für solche Probleme ungeeignet, in denen eine schnelle, sichere und ausnahmslose Abhilfe zwingend geboten ist. ${ }^{10}$ Die ökonomische Instrumente in Südkorea, die bisher zum Einsatz gekommen sind, werden mit anderen Instrumenten z.B. mit „command-and-control type regulations“ kombiniert eingesetzt. Als wichtige ökonomische Instrumente der Umweltpolitik in Südkorea sind zu nennen: „Environmental (Improvement) Charge“, „Deposit-refund system“, „Waste disposal charge“, „Congestion charge“, „Financial assitance“ und „Liability and insurance“. ${ }^{11}$

Zusammenfassend läßt sich festhalten, daß Unternehmen vielfältigen ökologieintendierten Lenkungseinflüssen durch ihre Umwelt ausgesetzt sind, wobei zwingenden Beschränkungen durch das umweltpolitische und umweltrechtliche Instrumentarium wie z.B. Strafrecht, Auflagen etc. bedeutsam werden. Damit kann die staatliche Umweltpolitik als eine der wichtigen Rahmenbedingungen für die ökologisch verpflichtete Unternehmensführung bezeichnet werden.

Nach der allgemeinen Darstellung der staatlichen Umweltpolitik soll im folgenden ein Überblick der Entwicklung der Umweltpolitik und der Umweltgesetzgebung Südkoreas gegeben werden. Zuvor sollen aber kurz die Grundprinzipien der staatlicher Umweltpolitik in Südkorea behandelt werden. Bei der staatlichen Umweltpolitik haben sich vor allem drei Grundprinzipien als Handlungsmaximen durchgesetzt: das Verursacherprinzip, das Gemeinlastprinzip und das Kooperationsprinzip.

Das Verursacherprinzip bedeutet, daß derjenige für eine Umweltbelastung zur Verantwortung gezogen wird, dem ursächlich die Schäden zugerechnet werden können. Der Grundgedanken des Verursacherprinzips ist die Theorie der externen Effekte. Ziel des Prinzips ist es, Kosten von Umweltverschmutzungen $\mathrm{zu}$ einem großen Anteil nicht $\mathrm{zu}$ sozialisieren, sondern dem Verursacher zuzurechnen. Im Rahmen des Verursacherprinzips kommen als wichtige Instrumente kommen Produkt- und Verfahrensnormen, Abgaberegelungen sowie ordnungsrechtliche Maßnahmen (z.B. Gebot und Verbot) zur Anwendung. Dabei steht mehr die Kostenzurechnung im Vordergrund, auch wenn diese auf der Verantwortungszurechnung aufbaut. Mit Hilfe des Verursacherprinzips soll also erreicht werden, ,daß die umweltverbessernden Aktivitäten der Wirtschaftssub-

\footnotetext{
${ }^{10}$ Vgl. Kloepfer, M. (1990), S. 243.

${ }^{11}$ Vgl. OECD (1997), S. 131ff.
} 
jekte soweit gesteigert werden, bis der zusätzliche Nutzen einer weiteren Umweltverbesserung genau den zusätzlichen Kosten für diese Umweltverbesserung entspricht. “12 Die mit der verursachergerechten Kostenzurechnung verknüpften ökonomischen Anreize für einzelwirtschaftliche Entscheidungen empfehlen das Verursacherprinzip als generelle Handlungsorientierung der Umweltpolitik. Der praktischen Umsetzung des Verursacherprinzips stehen eine Reihe sehr erheblicher Probleme entgegen. ${ }^{13}$ Anwendbarkeitsvorbehalte ergeben sich vor allem bei der Identifikation individueller Verursacher. Wird der Standard der angestrebten Umweltqualität politisch erhöht, so stellt sich die Frage nach dem Verursacher der mit den durchzuführenden Maßnahmen verbundenen Kosten. Es können sowohl die Emittenten als auch die Nachfrager nach besserer Umweltqualität als Verursacher der Kosten verstanden werden. Wenn das Verursacherprinzip in der Realität aus verschiedenen Gründen nicht möglich oder nicht angeraten ist, treten Maßnahmen nach dem sog. Gemeinlastprinzip in den Vordergrund. ${ }^{14}$ An Stelle des Verursachers übernimmt die staatliche Gemeinschaft die Kosten zur Bewältigung der Umweltschäden.

Das Vorsorgeprinzip der Umweltpolitik bedeutet, „daß umweltpolitische und sonstige staatliche Maßnahmen so getroffen werden sollen, daß von vorherein möglichst sämtliche Umweltgefahren vermieden und damit (für die Existenz der Menschen vorsorgend) die Naturgrundlagen geschützt

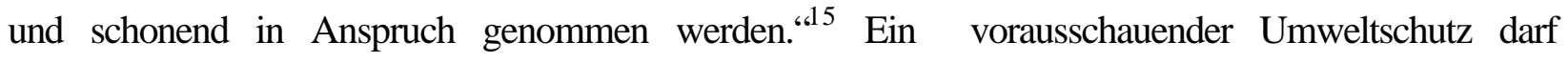
sich nicht auf die Abwehr von Gefahren beschränken, sondern muß bereits im Vorfeld der Gefahren handeln. Produktions- bzw. Wirtschaftsprozesse müssen im Sinne eines integrierten Umweltschutzes bereits an der Inputseite umweltschonend bzw. emissionsarm verändert werden, anstatt eingetretene Schäden im nachhinein zu beseitigen, also umweltschützende Maßnahmen erst an der Outputseite der Produktions- und Konsumtionsprozesse (End-of-the-pipe-Maßnahmen) durchzuführen.

Das Maßnahmenspektrum des Vorsorgeprinzips wird ohne Kooperation der beteiligten Akteure kaum durchsetzbar sein. Umweltschutz ist also nicht nur die Aufgabe des Staates, sondern jeder einzelne trägt Verantwortung für die Erhaltung der natürlichen Umwelt. Das Kooperationsprinzip soll daher eine möglichst weitgehende Mitverantwortlichkeit, Beteiligung und Mitwirkung aller gesellschaftlichen Gruppen bzw. Betroffenen von umweltbeeinträchtigenden wirtschaftlichen und sonstigen Aktivitäten bei der Konzeption und der Durchsetzung umweltpolitischer

\footnotetext{
${ }^{12}$ Wicke, L. (1993), S. 152.

${ }^{13}$ Vgl. Wicke, L. (1991), S. $130 \mathrm{ff}$.

${ }^{14}$ Vgl. Wicke, L. (1991), S. $135 \mathrm{ff}$.

${ }^{15}$ Vgl. Wicke, L. (1991), S. 139f.
} 
Zielsetzungen und Maßnahmen sichern. ${ }^{16}$ Dieses Prinzip bei der Festlegung und Durchsetzung der umweltpolitischen Ziele und Maßnahmen basiert somit auf dem Einfordern der Umweltverantwortung nicht nur der Mitglieder der Verwaltungen, sondern auch der Wissenschaftler und sonstiger Fachleute, der Bürgerinitiativen und Umweltorganisationen, und vor allem der Wirtschaft (Unternehmensvertreter und Verbände). Und dieses Prinzip dient somit zum einem dem Zweck, den politischen Entscheidungsträgern durch die Einbeziehung externen Sachverstandes eine verbesserte Entscheidungsgrundlage zu bieten, zum anderen soll über die Mitwirkung auch ein verbesserter Informationsstand und Aufklärungsgrad der beteiligten Bürger und Gruppen erreicht werden und das Umweltbewußtsein ein höheres Niveau erzielen.

Die staatliche Umweltpolitik in Südkorea seit der Industrialisierung der 60er Jahre kann in vier Phasen eingeteilt werden:

1. Phase (1963-1970): Identifizierung der Umweltbelastung

2. Phase (1971-1977): widersprüchliche Umweltpolitik

3. Phase (1978-1989): Konstituierung der Umweltpolitik

4. Phase (1990-bis heute): Instrumentierung der verbesserten Umweltpolitik

Durch die Einteilung in vier Phasen soll der Frage nachgegangen werden, wie das politische System auf die mit der Industrialisierung eng verbundenen Umweltprobleme reagiert, welche Problemlösungen seitens der Zentralregierung getroffen wurden und welche Erfolge die angestrebten Lösungen zu verzeichnen hatten. ${ }^{17}$

Bevor diese Phasen genauer betrachtet werden sollen, lohnt sich ein Blick auf die wichtige Umweltgesetze, die Südkorea seit Beginn der 60er Jahre eingeführt wurden (vgl. Abb. 6.1).

\begin{tabular}{|l|l|l|}
\hline 1961 & Water Supply Act (1993) & $\begin{array}{l}\text { Establishes a comprehensive plan for tap water; requires the Minister of } \\
\text { Construction and city/county chief to establish a basic plan for tap water } \\
\text { every ten years. }\end{array}$ \\
\hline 1963 & Public Nuisance Act (1991) & $\begin{array}{l}\text { Deals, for the first time in Korean law, with public nuisance matters; water } \\
\text { pollution, noise, etc. (replaced by the 1997 Environmental Conservation } \\
\text { Act). }\end{array}$ \\
\hline 1966 & Sewer System Act (1994) & Designates standards for installation and maintenance of sewer systems; \\
\hline
\end{tabular}

${ }^{16}$ Vgl. Wicke, L. (1991), S. 144.

${ }^{17}$ Diese Einteilung in vier Phasen wurde nach dem Erlassen der Gesetzgebung verfolgt, z.B. Gesetz zum Schutz vor Luftverunreinigungen von November 1963 als erste Phase und Gründung des Umweltministeriums im Jahr 1990 als vierte Phase der staatlichen Umweltpolitik. 


\begin{tabular}{|c|c|c|}
\hline & & $\begin{array}{l}\text { requires municipal or county chiefs to establish a comprehensive plan for } \\
\text { sewer system installation and maintenance in their jurisdiction. }\end{array}$ \\
\hline 1977 & $\begin{array}{l}\text { Environmental Conservation } \\
\text { Act (1986) }\end{array}$ & $\begin{array}{l}\text { Introduces environmental impact assessment procedures and ambient envi- } \\
\text { ronmental standards for water and air pollution, noise, industrial solid, etc. }\end{array}$ \\
\hline 1983 & $\begin{array}{l}\text { Environmental Management } \\
\text { Corporation Act (1993) }\end{array}$ & $\begin{array}{l}\text { Establishes the Environmental Management Corporation for the efficient } \\
\text { and effective management of projects intended to control pollution. }\end{array}$ \\
\hline 1990 & $\begin{array}{l}\text { Basic Environmental Policy } \\
\text { Act }\end{array}$ & $\begin{array}{l}\text { Aims to prevent danger or injury resulting from pollution, and to manage } \\
\text { and preserve property and the natural living environment; defines the rights } \\
\text { and duties of citizens as well sa the obligations of the Government for envi- } \\
\text { ronmental preservation. }\end{array}$ \\
\hline 1990 & $\begin{array}{l}\text { Toxic Chemicals Control Act } \\
\text { (1991) }\end{array}$ & $\begin{array}{l}\text { Establishes a comprehensive management system and strengthens safety } \\
\text { inspection of chemical products. }\end{array}$ \\
\hline 1990 & $\begin{array}{l}\text { Environmental Dispute } \\
\text { Settlement Act }\end{array}$ & $\begin{array}{l}\text { Allows fair compensation for damage to health and property caused by pol- } \\
\text { lution; provides procedures for mediation, reconciliation, awarding of da- } \\
\text { mages and adjustment of disputes caused by pollution. }\end{array}$ \\
\hline 1990 & $\begin{array}{l}\text { Air Quality Preservation Act } \\
\text { (1993) }\end{array}$ & $\begin{array}{l}\text { Aims to prevent damage to health and the environment by air pollution; } \\
\text { establishes an air quality monitoring network and sets emission control } \\
\text { standards. }\end{array}$ \\
\hline 1990 & $\begin{array}{l}\text { Water Quality Preservation } \\
\text { Act (1993) }\end{array}$ & $\begin{array}{l}\text { Seeks to prevent water pollution and requires proper management and pre- } \\
\text { servation of the quality of public water resources such as rivers, lakes and } \\
\text { marshes; sets discharge standards for pollutants from waste water discharge } \\
\text { facilities and industries. }\end{array}$ \\
\hline 1990 & $\begin{array}{l}\text { Noise and Vibration Control } \\
\text { Act (1993) }\end{array}$ & $\begin{array}{l}\text { Intends to control excessive noise and vibration from fatories, construction } \\
\text { sites, roads, etc. }\end{array}$ \\
\hline 1991 & $\begin{array}{l}\text { Act Relating to Punishment } \\
\text { for Environmental Crimes }\end{array}$ & $\begin{array}{l}\text { Establishes sanctions on persons whose actions detrimentally affect public } \\
\text { health and the environment. }\end{array}$ \\
\hline 1991 & $\begin{array}{l}\text { Act Relating to Environmen- } \\
\text { tal Improvement Charges }\end{array}$ & $\begin{array}{l}\text { Implements environmental improvement measures and secures resources } \\
\text { for necessary investment; requires the Minister of Environment to establish } \\
\text { and implement a Medium-term Plan for Environmental Improvement every } \\
\text { five years; imposes Environmental Improvement Charges on owners of } \\
\text { commercial facilities with floor space in excess of } 160 \text { square metres and } \\
\text { of diesel-powered vehicles. }\end{array}$ \\
\hline 1991 & $\begin{array}{l}\text { Act Relating to the Treatment } \\
\text { of Sewage, Night-soil and Li- } \\
\text { vestock Waste Water (1993) }\end{array}$ & $\begin{array}{l}\text { Intends to improve management of sewerage, night-soil and livestock wa- } \\
\text { ste water. }\end{array}$ \\
\hline 1991 & $\begin{array}{l}\text { Natural Environment Conser- } \\
\text { vation Act (1994) }\end{array}$ & $\begin{array}{l}\text { Aims to preserve the natural Environment so that people can enjoy a heal- } \\
\text { thy and comfortable life; calls for protection of the natural environment } \\
\text { from damage and prevention of extinction of endangered species, and for } \\
\text { maintenance of biodiversity; provides regulations concerning preservation } \\
\text { of the natural environment. }\end{array}$ \\
\hline 1991 & Marine Pollution and & the marine environment through the regulation of oil, \\
\hline
\end{tabular}




\begin{tabular}{|c|c|c|}
\hline & Preservation Act (1993) & $\begin{array}{l}\text { hazardous liquid substances, ships discharging waste into marine waters, } \\
\text { and marine facilities. }\end{array}$ \\
\hline 1991 & $\begin{array}{l}\text { Waste Management Act } \\
\text { (1993) }\end{array}$ & $\begin{array}{l}\text { Provides the general framework for waste management; requires the Minis- } \\
\text { ter of Environment to make a National Comprehensive Plan for Waste Ma- } \\
\text { nagenemt with mayors and governors responsible for establishing the mas- } \\
\text { ter plan for general waste management every ten years. }\end{array}$ \\
\hline 1992 & $\begin{array}{l}\text { Act Relating to Promotion of } \\
\text { Resource Saving and Reutili- } \\
\text { sation }\end{array}$ & $\begin{array}{l}\text { Aims to reduce volumes of waste, promote waste recycling and utilisation } \\
\text { programmes and enhance resource saving and environmental conservation } \\
\text { activities. }\end{array}$ \\
\hline 1992 & $\begin{array}{l}\text { Act Relating to Transbounda- } \\
\text { ry Movement of Wastes and } \\
\text { their Disposal }\end{array}$ & $\begin{array}{l}\text { Incorporates into national law the Basel Convention on Control of Trans- } \\
\text { boundary Movements of Hazardous Wastes and their Disposal. }\end{array}$ \\
\hline 1993 & $\begin{array}{l}\text { Environmental Impact As- } \\
\text { sessment Act }\end{array}$ & $\begin{array}{l}\text { Disignates the scope of EIA coverage, items and standards for assessment; } \\
\text { calls for convening public hearings in which environment related experts } \\
\text { and residents can participate. }\end{array}$ \\
\hline 1993 & $\begin{array}{l}\text { Korean Resource Recovery } \\
\text { and Reutilisation Corporation } \\
\text { Act }\end{array}$ & $\begin{array}{l}\text { Promotes the efficient management of projects to curb waste generation } \\
\text { and encourage recycling of resources. }\end{array}$ \\
\hline 1994 & Groundwater Act & $\begin{array}{l}\text { Regulates use of groundwater and aims to prevent contamination of aqui- } \\
\text { fers by waste. }\end{array}$ \\
\hline 1994 & $\begin{array}{l}\text { Special Account for Envi- } \\
\text { ronmental Improvement Act }\end{array}$ & $\begin{array}{l}\text { Establishes a special Environmental Improvement Account to make neces- } \\
\text { sary finances available for investment in environmental improvement pro- } \\
\text { jects and their efficient management. }\end{array}$ \\
\hline 1994 & $\begin{array}{l}\text { Act Relating to support and } \\
\text { Development of Environmen- } \\
\text { tal Technologies }\end{array}$ & $\begin{array}{l}\text { Aims to develop domestic environmental technologies and promote the de- } \\
\text { velopment of low-pollution technologies. }\end{array}$ \\
\hline 1995 & $\begin{array}{l}\text { Drinking Water Management } \\
\text { Act }\end{array}$ & $\begin{array}{l}\text { Controls hazards to human health from polluted drinking water; establishes } \\
\text { drinking water quality standards and sets guidelines for inspection and ma- } \\
\text { nagement. }\end{array}$ \\
\hline 1995 & $\begin{array}{l}\text { Soil Environment Preservati- } \\
\text { on Act }\end{array}$ & $\begin{array}{l}\text { Intends to prevent damage to human health and the environment from soil } \\
\text { contamination (except via radioactive substances) and to preserve soil. }\end{array}$ \\
\hline 1995 & $\begin{array}{l}\text { Act for Promotion of Waste } \\
\text { Treatment Facilities and Sup- } \\
\text { por for Local Communities }\end{array}$ & $\begin{array}{l}\text { Intends to promote waste treatment facilities and establishes site selection } \\
\text { committees for decisions on waste treatment facilities. }\end{array}$ \\
\hline
\end{tabular}

\section{(...): Das Jahr, in dem das Gesetz novelliert wurde.}

Abb. 6.1: Wichtige Umweltgesetze in Südkorea (Quelle: OECD (1997), S. 40-42)

Bei der Identifizierung konkreter Umweltbelastungen begann man mit den industriellen Emissionsarten in den großen Städten, vornehmlich in Seoul und Busan u.a. Ein erster Anstoß für ein 
gesteigertes Umweltbewußtsein der Öffentlichkeit erfolgte durch einen spektakulären Fall von Luftverpestung aus einem Kohlekraftwerk, der ein Viertel Mio. Menschen Elektrizitätswerk des Stadtteils der größten Hafenstadt Busan betraf. ${ }^{18}$ Bald darauf häuften sich Pressemeldungen z.B. über Fischsterben, aber auch über landwirtschaftliche Schäden im Umkreis von Fabriken. Umweltprobleme, die sich zunächst auf lokaler Ebene bemerkbar machten, wurden allmählich flächendeckend. Die Bevölkerung in den städtischen-industriellen Räumen spürte hautnah, was Umweltverschmutzung bedeutete. Wissenschaftler wurden umweltbewußter und leiteten Untersuchungen über die Umweltqualität ein, hauptsächlich bezogen auf die Umweltmedien wie Wasser und Luft. Die Tagespresse veröffentlichte mit großer Aufmachung z.B. ,rettet den HanFluß“.

Eine Verordnung zur Durchführung des „Gesetzes zum Schutz vor Umweltverschmutzung“ wurde im Jahr 1963 erlassen, dadurch sollten die Umweltschutzgesetze in Anwendung gebracht werden. Parallel hierzu wurde die zuständige Verwaltung des Gesundheitsministeriums ausgebaut. So entwickelten sich langsam administrative Handlungsmöglichkeiten in Bezug auf die sichtbar gewordenen Umweltbelastungen. Die Regelungen anderer Industrieländer bildeten dafür das Muster. Allerdings hatten die gesetzlichen Regelungen und einige nachfolgende Umweltschutz-Gesetze auf die Entwicklung der Umweltqualität nur geringe Auswirkungen, denn wirtschaftliches Wachstum hatte gemessen an Indikator Bruttosozialprodukt absolute Priorität.

Die zweite Phase der Umweltpolitik war durch höchst widersprüchliche Umweltschutzmaßnahmen gekennzeichnet. Zum einen versuchte der Staat die Industrialisierung zu forcieren, in dem eine Küstenindustriezone für Schwer- und Chemieindustrie und eine Industriezone für kleine und mittlere Industrie im Binnenland errichtet wurden. Zum anderen bemühte man sich, mit Hilfe gesetzlicher (Novellierung des Gesetzes zur Umweltverschmutzung, 1971), planerischer (erster 10 jähriger Raumentwicklungsplan, 1971) und populistischer (sog. neue Dorfbewegung) Maßnahmen einer weiteren Umweltbelastungen Einhalt zu gebieten.

Aufgrund des dritten Fünfjahresplanes wurden Industriekomplexe (Changwon, Yochon, Pohang, Gumi usw.), spezielle Industrien (Banwol, Wolsong usw.) sowie lokale Industrien (Chunchon, Wonju usw.) errichtet. Die dadurch erfolgte Ansiedlung der besonders umweltschädlichen Schwer- und Chemieindustrie in den Küsteregionen war eine Fortsetzung der flächendeckenden Umweltzerstörung des Landes, da bei dieser Standortwahl die Umweltaspekte unberücksichtigt blieben. Weitgehend herrschte vor allem im Regierungskreis die Meinungen, daß die Industriali-

\footnotetext{
${ }^{18}$ Vgl. Yu, I.-H. (1973).
} 
sierung nicht durch frühzeitiges Einbeziehen eitler Umweltschutzmaßnahmen gestört werden sollte. Begleitet wurde sie daher mit öffentlichen Bekenntnissen der Regierung, daß der Umweltschutz vorerst ein Luxus der Industrieländer sei und ökologische Maßnahmen erst nach einer Anhebung des ökonomischen Entwicklungsniveaus in Angriff genommen werden könnte.

Andererseits sah die Regierung dennoch die Notwendigkeit, sich Gedanken über den Umweltschutz zu machen, da die Umweltqualität sich ständig verschlechterte. Der wichtigste Schritt in diese Richtung war die Verabschiedung des novellierten Gesetzes zum „Schutz vor Umweltverschmutzung“ von 1963 im Jahr 1971. Die Bedeutung des Gesetzes ist darin zu sehen, daß man seitdem ein Recht auf Entschädigung besitzt. Allerdings wurde die für den Vollzug erforderliche Administration nicht in gleichem Maße ausgebaut wie die gesetzlichen Bedingungen. Die Abteilung „Umweltverschmutzung“ im Gesundheitsministerium war völlig unterbesetzt und in den mit Umweltschutz beauftragten Abteilungen der verschiedenen Ministerien waren die Kompetenzen zersplittert. Die schwache Stellung des Umweltschutzes machte sich auch bei den Staatsausgaben für Umweltschutzmaßnahmen bemerkbar: Sie betrugen $0,01 \%$ des gesamten Staatsbudgets. $^{19}$

Die Umweltbelange fanden auch in der Raumplanung Beachtung. Die Bedeutung des Umweltschutzes im ersten 10-Jahres-Raumentwicklungsplan (1972-1981) bestand darin, daß man einen räumlichen Ausgleich durch Dezentralisierung erreichen wollte. Neben raumstruktuellem Vorgehen faßte der Plan auch spezielle „Pollution Controll Measure“ ins Auge mit den Ziel, eine menschengerechte Wohnumwelt zu gestalten. ${ }^{20}$ Hierzu gehörte die Ausweisung des „Green belt“ nach englischem Modell, um die Ausweitung urbaner Zonen zu kontrollieren und Landschaftsgebiete in Umkreis der städtischen Zonen zu konservieren. ${ }^{21}$

Auf der internationalen Ebene bekundete die Regierung ihr Interesse am Umweltschutz. So nahmen z.B. Vertreter des Gesundheitsministeriums an der internationalen Umweltkonferenz in Stockholm 1972 teil. Allerdings wurde erst 1975 erstmals eine nationale Umweltkonferenz einberufen. Die Teilnehmer mußten konstatieren, daß das Niveau der Umweltqualität auf ein alarmierendes Ausmaß gesunken war. $^{22}$ Die offizielle Feststellung, daß 1976 erstmals umweltgeschädigter Fische gefunden wurde, untermauert lediglich den bereits festgestellten Umweltzu-

\footnotetext{
${ }^{19}$ Vgl. Kim, C.-D. (1973), S. 74.

${ }^{20}$ Vgl. National Land Use Development Plan (1971), S. 133.

${ }^{21}$ Die gesamte Fläche der ausgewiesenen „Green belt“-Gebiete betrug rd. $5500 \mathrm{Km}^{2}$, was etwa $6 \%$ der Gesamtlandesfläche ausmacht. Vg. Park, S.-Y. (o.J.), S. 34.

${ }^{22}$ Vgl. Kim, K.-C./Rho, C.-S. (1976).
} 
stand. Die Folgen der industriellen Umweltbelastung zeigen sich in deutlichem Maße in der $\mathrm{Zu}-$ nahme der Entschädigungssummen für geschädigte landwirtschaftliche Produkte. ${ }^{23}$

In den 70er Jahren entstand allmählich ein Bewußtsein für Umweltbelastungen vor allem in den Agglomerationsräumen. Die Umweltbelastungssituation hatte als Folge von Verstädterung und Industrialisierung seit den 60er Jahren die Grenzen der staatlichen Handlungsmöglichkeiten mit dem vorhandenen Instrumentarium überschritten. Deswegen wurde zunächst überwiegend im wissenschaftlichen und danach auch im politisch-administrativen Bereich über die Notwendigkeit eines umfassenden Umweltschutzgesetzes diskutiert. Diese Diskussion führte im Jahre 1977 zur Verkündung eines allgemeinen Umweltschutzgesetzes ${ }^{24}$ und zur Einführung des Vorsorgeprinzips in seiner Zweckbestimmung. Dieses Gesetz hatte eine Verbesserung der Umweltsituation in Südkorea zur Folge, konnte allerdings nicht verhindern, daß sich in der Zeit der Ausführung des dritten Fünfjahresplans für die wirtschaftliche Entwicklung zwischen den Jahre 1972 und 1976 die Umweltprobleme in Südkorea weiter verschärften und die Umweltbelastungen erhöhten. Sie wurden durch verstärkte Emissionen, insbesondere infolge der drastischen Zunahme der Industrie und des Verkehrs, verursacht.

Seit 1977 läßt sich als dritte Phase „eine Konstituierung der staatlichen Umweltpolitik“ beobachten, wobei der Umweltschutz als neues Leitbild und als Integrationsbegriff in die Politik eingeführt wurde. Im vierten Fünfjahresplan entwickelte sich der Sozialsektor einschließlich der Umweltfrage erstmals zu einem gewichtigen Faktor. Die stärkere Berücksichtigung der Umweltfrage war vor allem auf die geschilderte Verschlechterung der Umweltsituation zurückzuführen, die selbst von Wirtschaftsexperten für die weitere Industrialisierung als hemmend betrachtet wurde. ${ }^{25}$ Dies war der erste Versuch, das Begriffspaar „,wirtschaftliche Entwicklung“ und „Umweltschutz" auf einer Nenner zu bringen. Die beide Begriffe sind keine Kontrahenten, sondern sie können sich ergänzen. Fehlende wirtschaftliche Entwicklung verursacht Umweltprobleme durch Armut (und unzureichende sanitäre Situation) und durch Übernutzung der natürlichen Ressourcenbasis (Verwüstung u.a.). Die allein auf ökonomische Maximierung orientierte kurzfristige Entwicklung bedeutet eine kurzfristige Ausbeutung der natürlichen Ressourcen und kann ungleichmäßige Einkommensverteilung hervorbringen. Bei einer ökologisch-ökonomischen Ent-

\footnotetext{
23 1974: 9,6 Mio. Won, 1975: 74,1 Mio. Won, 1976: 81,2 Mio. Won, 1977: 151,4 Mio. Won. Vgl. Hashimoto, M. (o.J.), Anhang IX, S. 5.

${ }^{24}$ Umweltschutzgesetz vom Dezember 1977.

${ }^{25}$ Chungang (1976/8), S. 294.
} 
wicklung verbindet sich die soziale Frage mit sinnvoller Ressourcennutzung. Außerdem werden gleichmäßige Einkommensverteilung und nachhaltige Ressourcennutzung gesichert. ${ }^{26}$

Die wachsende umweltpolitische Aktivität in der dritten Phase fand in der verstärkten Bereitstellung von Finanzmitteln zur Umweltschutzkontrolle ihren Niederschlag. ${ }^{27}$ So verfügte die Seouler Umweltverwaltung 1979 erstmals seit ihrer Errichtung (1972) über eine nennenswerte Geldsumme, so daß sie zunächst die erforderlichen Meßeinrichtungen beschaffen konnte. ${ }^{28}$

Die Gesetzgebung verbesserte sich: „Das Umweltschutzgesetz“ wurde im Jahre 1977 verabschiedet. Es hatte zum Ziel, die gesunde Natur zum Schutz der menschlichen Gesundheit und des Naturraumes zu erhalten und vor weiteren Belastungen zu schützen. Dieses Gesetz (USG) ist der programmatische Rahmen des gesamten Umweltrechts; die Regelung im einzelnen bleibt besonderen Gesetzen vorbehalten. Ebenfalls im selben Jahr wurde das „Gesetz zum Schutz vor Umweltverschmutzung der Küstengewässer“"verabschiedet.

Eine ,Zentralorganisation für die Umweltfrage“" wurde 1980 errichtet. Dieses Umweltamt soll seither die bis dahin auf 10 Fachressorts verteilten unkoordinierten Umweltbelange wahrnehmen und dadurch versuchen, das an Umfang und Stärke zunehmende Fortschreiten der Umweltzerstörung in den Griff zu bekommen. Das Umweltamt ist dem Ministerium für Gesundheit und Soziales unterstellt. ${ }^{29}$

Zwei negative Folgerungen ergeben sich aus dem administrativen Standort des Umweltamtes innerhalb des oben genannten Ministeriums: Das Ministerium für Gesundheit und Soziales beschäftigt sich traditionell mit Gesundheit, Wohlfahrt und Arbeit. Da aber die modernen Umweltprobleme aus dem Bereich von Energie, Ressourcen und industrieller Produktion stammen, ist die fachliche Kompetenz des Gesundheitsministeriums als Aufsichtsbehörde infrage zu stellen. Das Umweltamt verfügt außerdem über zu wenig Machtbefugnis, dringende Umweltschutzmaßnahmen besser gegenüber konkurrierenden Interessen vertreten zu können.

\footnotetext{
${ }^{26}$ Das Beziehungsgefüge zwischen Entwicklung und Umwelt in der Grundform vgl. United Nations Economic and Social Commission for Asia and the Pacific (ESCAP) (1982), S. 4.

27 1974; 0,36 Md. \$, 1975; 2,2 Md. \$, 1976; 2,5 Md. \$, 1977; 4,5 Md. \$, 1978; 5,0 Md. \$, 1979; 10,0 Md. \$. Vgl. Ministry of Health and Welfare (1980).

${ }^{28}$ Vgl. Dongailbo (Tageszeitung), 26. 12. 1979.

${ }^{29}$ Maßnahmen, die zu einer Verbesserung der Verwaltung im Umweltbereich führen würden, etwa die Einrichtung von Umweltabteilungen in den wichtigen Ministerien sowie die Bildung eines eigenen Umweltministeriums mit ausreichender finanzieller Ressourcenausstattung sowie gesetzlichem und politischem Rückhalt, sind in Südkorea noch nicht umgesetzt.
} 
Die Rechtsgrundlage für die Praktizierung des Vorsorgeprinzips ist in $\$ 4$ der Verordnung des Umweltschutzgesetzes (1978) formuliert: „Bei einem mit Umweltauswirkung zu rechnenden Vorhaben ist die Prüfung der Umweltverträglichkeit vorzunehmen und eine Konsultation beim Umweltamt erforderlich. Die zwingende Notwendigkeit der Durchführung ist nicht gegeben, vielmehr kann eine Umweltverträglichkeitsprüfung bei Bedarf vorgeschrieben werden, z.B. bei großen Industrieprojekten. Die Notwendigkeit der Prüfung der Umweltverträglichkeit als geeignete Vorsorgemaßnahme wird von koreanischen Experten erkannt, und es wird daher gefordert, sie vor allem bei Umweltchemikalien anzuwenden. ${ }^{\text {30 }}$

Es liegt in der Natur der Sache, das Vorsorgeprinzip bei Neuplanung im Bereich der Industrie und Infrastruktur anzuwenden, während das Verursacherprinzip eher bei vorhandenen Umweltsünden greift. Jeder, der die Umwelt belastet oder sie schädigt, soll für die Kosten dieser Belastung oder Schädigung aufkommen. ${ }^{31}$

Die geringe Tauglichkeit des Verursacherprinzips für den effektiven Umweltschutz ist in Deutschland nicht unumstritten, im Fall Südkorea wird diese Einschätzung nicht anders ausfallen, da für das Jahr 1982 nur die Hälfte der eigentlich geforderten Entschädigungssume (634 Mio. Won - umgerechnet ca. 2 Md. DM) gezahlt wurde. ${ }^{32}$

Eine Besonderheit der koreanischen Umweltpolitik sind Aufrufe zu Massenaktionen wie „NichtWeg-Werfen“ und „Reduzierung der häuslichen Abfälle“ sowie eine Naturschutzbewegung, die mit der Einführung der Charta des Naturschutzes entstand. All diese Arten der von der Zentralorganisation initiierten Aktionen haben eine gemeinsame Aussage, nämlich daß Umweltschutz eine Frage des kollektiven Handelns sei. So gewinnt man den Eindruck, als ob Umweltschutz davon abhängig sei, wie das einzelne Individuum seine Umgebung sauber hält.

Alle landesweit angelegten Kampagnen wurden belanglos, als die 1978 bekannt gewordene „Minamata“-Krankheit - durch Quecksilber kontaminierter Reis - der Familie Go die Öffentlichkeit erregte. Die Betroffenheit war sehr groß. Dieses Ereignis hatte zwei Folgen: Zum einen wuchs das Umweltbewußtsein, so daß zum Beispiel die Nachfrage nach ökologisch angebauten Nahrungsmittel drastisch stieg. Zum anderen versuchte die Bevölkerung selbst, aus der ökologi-

\footnotetext{
${ }^{30}$ Vgl. Kwon, S.-P. (1983).

31 Das Verursacherprinzip funktioniert u.a. unter folgenden Voraussetzungen: Die Schuld muß individuell nachweisbar sein, d.h. man muß die Taten konkret und vor Ort überprüfen können. Der Staat muß für Umweltzerstörung so hohe Strafen durchsetzen wollen und können, daß es für den Verursacher billiger oder angenehmer ist, Umweltschäden zu vermeiden. Vgl. Bechmann, A. (1984), S. 114.

${ }^{32}$ Vgl. Maeil Kyongje (Wirtschaftstageszeitung), 10.06.1983.
} 
schen Sackgasse, nämlich aus der allein auf Agrochemie gestützten Landwirtschaft, herauszukommen. Ein Beispiel hierzu ist das von einem Bauern verfaßte Buch ,lebendige Landwirtschaft“, das für eine ökologisch orientierte, aber nicht ganz auf agrochemische Hilfsmittel verzichtende nachhaltige Landbewirtschaftung plädiert.

Südkorea war damals durch zwei Entwicklungen geprägt: Die umweltbewußten Initiativen aus breiten Bevölkerungsschichten bildeten sich aus, die im koreanischen Sprachgebrauch „AntiUmweltverschmutzung-Bewegung“ heißt. Kennzeichnend ist dabei ihre Motivation. Die Betroffenen fanden sich $\mathrm{zu}$ dieser Bewegung, weil ihre existentiellen Grundlagen (Wasser, Landwirtschaftsfläche) gefährdet oder kurz von ihrer Zerstörung waren. So verhinderte die aus allen Bevölkerungsschichten zusammengesetzte „Bewegung der Anti-Umweltverschmutzung“ in der Hafenstadt Mokpo die Ansiedlung einer gewässerverschmutzenden Brauerei, die erheblich größere Schwierigkeiten der ohnehin ungesicherten Versorgung mit Trinkwasser verursacht hätten. Die andere ist die Umsiedlungsmaßnahme. Seit einigen Jahren wird die Bevölkerung aus nicht mehr bewohnbaren Wohngebieten evakuiert. Begonnen hatten die ersten großen Umsiedlungsmaßnahmen 1981 bei den Einwohnern der Mokpo-Gemeinde in unmittelbarer Nähe des Chemie- und Schwerindustrie-Komplexes Yochon. Mit einem Kostenaufwand von 2,8 Md. Won (rd. 900 Mio. DM) wurden 178 Haushalte (1089 Personen) umgesiedelt. ${ }^{33}$

Seitdem in Südkorea erkannt worden ist, daß der hemmungslose Umgang mit den knappen natürlichen Ressourcen zu ökonomischen und auch sozialen Problemen führt - ist auch staatlicherseits verstärktes Gewicht auf den Umweltschutz gelegt worden. Die aufgezeigten Entwicklungen verdeutlichen jedoch, daß die verstärkten Bemühungen seit Ende der 70er Jahre in bezug auf den Umweltschutz in Südkorea zwar erkennbar sind, aber trotzdem noch als unzureichend angesehen werden müssen.

Infolgedessen werden seit den 80er Jahren die Bemühungen um eine effektive Umweltvorsorgepolitik in Südkorea intensiviert. § 35 der Verfassung in Südkorea enthält ein Umweltgrundrecht und bestimmt, daß alle Bürger das Recht auf Leben in einer sauberen Umwelt haben. ${ }^{34}$ Das seit 1980 geltende Umweltgrundrecht wird vor allem vom koreanischen Umweltamt so interpretiert, daß die Einbeziehung des Umweltschutzes unter den Schutz der Verfassung eine Dokumentation des Willens des Staates sei, durch Reduzierung der Umweltbelastungen für die Bevölkerung eine bessere Umwelt und damit eine verbesserte Lebensqualität zu sichern.

\footnotetext{
${ }^{33}$ Vgl. Cho, H.-S. (1983).

${ }^{34}$ Gesetz zur Änderung der Verfassung von Oktober 1980.
} 
Seit 1990 läßt sich als vierte Phase „eine Instrumentierung der verbesserten Umweltpolitik“ bezeichnen, wobei das im Jahr 1990 gegründete Umweltministerium Südkoreas in einer programmatischen Erklärung verlautbarte, daß es im Interesse einer verstärkten Umweltvorsorgepolitik eine systematische Umweltpolitik anstrebe. Als vordringliche Aufgaben werden die Verbesserung der Trinkwasserqualität, der Abfallwirtschaft und des Umweltmanagements, die Anhebung des allgemeinen Umweltbewußtseins und schließlich die Förderung der Umwelttechnik und industrie in den Vordergrund gestellt. ${ }^{35}$

Die Leitlinien für die Umweltpolitik der 90er Jahre werden aus dem ökonomischen und sozialen Kontext der Umweltpolitik und demzufolge aus den Rahmenbedingungen des Umweltschutzes entwickelt. Die Kernaussage der Leitlinien sind die Instrumentierung einer verbesserten Umweltpolitik nicht nur aus ökologischen Gründen, sondern gleichzeitig auch zum Zwecke einer Erhöhung des ökonomischen Wachstums. ${ }^{36}$ Abb. 6.2 veranschaulicht die Ziele der koreanischen Umweltpolitik.



Abb. 6.2: Übersicht über die Ziele der Umweltpolitik in Südkorea

(Quelle: Umweltministerium Südkorea (1991), S. 29)

\footnotetext{
${ }^{35}$ Vgl. Umweltministerium Südkorea (1991).

${ }^{36}$ Vgl. Umweltministerium Südkorea (1991).
} 
Das für die Entwicklung der koreanischen Umweltpolitik entscheidende politische Ergebnis ist die umweltpolitische Deklaration des Staatspräsident vom Juli 1992. In der Präambel zu dieser Deklaration wird auf die Notwendigkeit eines verstärkten Umweltschutzes im Interesse des Gemeinwohls vor dem Hintergrund der globalen Umweltveränderungen, der Zerstörung der Ozonschicht, der Klimaänderungen und der drastischen Verschlechterung der Qualität der Umweltmedien hingewiesen. Als Leitziele werden in der Deklaration ein umfassender Ausbau der Umweltverträglichkeitsprüfung und ihre Durchführung im Rahmen aller staatlichen Politiken und Maßnahmen dargestellt. Weitere Ziele sind die Verstärkung der Umweltschutzforschung, die Verbesserung der Umweltschutztechnologien und der Risikomanagementsysteme.

Der Umweltschutz stellt eine relativ neue Aufgabe für das politische System von Staaten dar. Dieser Sachverhalt sowie die enge Verknüpfung des Umweltbereiches mit anderen Bereichen hat zur Folge, daß umweltrelevante Aufgaben von einer Vielzahl staatlicher Stellen wahrgenommen werden. Aus der Sicht von Staat ergibt sich die Erfordernis, die umweltrelevanten Aktivitäten der einzelnen Behörden in sinnvoller Weise zu konzentrieren bzw. zu koordinieren.

In diesem Sinne weisen die institutionelle Strukturen d.h. die konkrete Gestaltung des institutionellen Rahmen sowohl auf gesamtstaatlicher als auch auf regionaler Ebene in Südkorea noch Schwächen auf. ${ }^{37}$ Abb. 6.3 zeigt die institutionelle Organisation des Umweltschutzes in Südkorea.

Zusammenfassend ist festzuhalten, daß die Umweltpolitik und die Umweltschutzgesetzgebung (insbesondere im Immissionsschutz-, Abfall- und Wasserschutzgesetz) ${ }^{38}$ in Südkorea verschärfend die Rahmenbedingungen für die Unternehmensführung darstellen. Diese Sachverhalte bewirken einen starken Internalisierungsdruck im unternehmenspolitischen Handlungsfeld: Es gilt, Gefahrenpotentiale und eventuelle Risiken frühzeitig und aktiv aufzudecken und zu bewältigen. Als grundlegendes Risiken- und Haftungsziel ökologisch verpflichteten Unternehmensverhaltens resultiert hieraus die Forderung: Potentielle Gefahren vermindern; Störfälle verhindern bzw. in ihren Auswirkungen begrenzen. ${ }^{39}$

\footnotetext{
37 Die Situation der staatlichen Verwaltung im Umweltschutzbereich in Südkorea ist generell durch die vorherrschende schwierige ökonomische Situation gekennzeichnet. Weiter treten Mangel an qualifiziertem Personal, Aufgabenüberlastung, Ineffizienz, Überlappung von Kompetenzen, Schwerfälligkeit, Koordinations- und Informationsprobleme sowie mangelnde Durchschaubarkeit der Entscheidungsprozesse auf.

${ }^{38}$ Darüber hinaus haben auch das Umwelthaftungsrecht sowie das Umweltstrafrecht an Bedeutung gewonnen. Im Mittelpunkt des Umwelthaftungsrechts steht die Verpflichtung für den Schädiger, den ursprünglichen Zustand wiederherzustellen, im Mittelpunkt des Umweltstrafrechts die verschärfte Bekämpfung umweltschädigender Handlungen.
} 


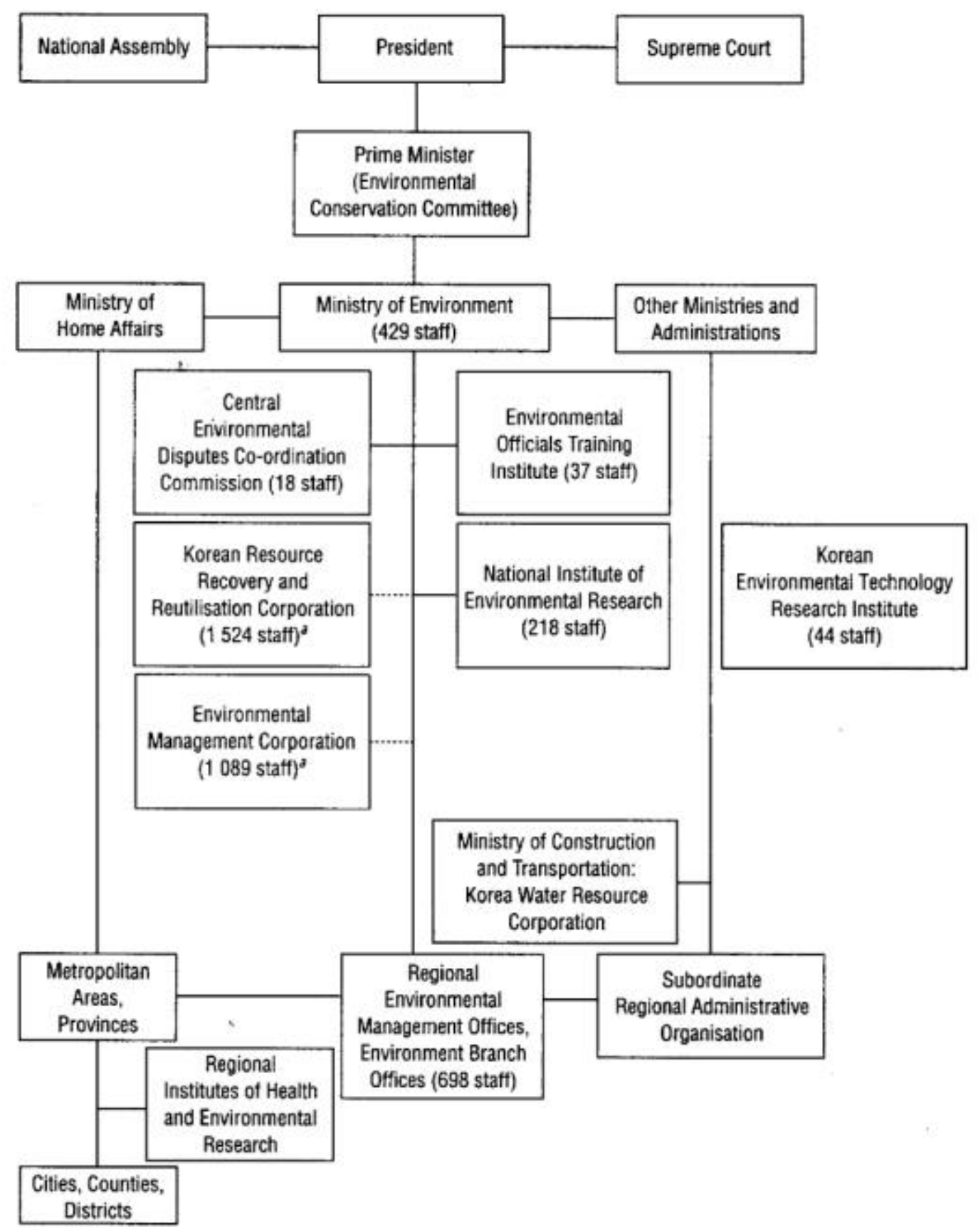

Abb. 6.3: Institutionelle Organisation des Umweltschutzes in Südkorea

(Quelle: Umweltministerium Südkorea, 1999)

\subsection{Internationale Umweltpolitik}

Ein Charakteristikum vieler Umweltprobleme (z.B. Treibhauseffekt, Schädigung der Ozonschicht, Waldvernichtung etc.) ist, daß sie sich nicht auf bestimmte Regionen oder Länder beschränken, sondern mehrere oder alle Länder umfassen. ${ }^{40}$ Nachdem diese länderübergreifende Ausdehnung vieler Umweltprobleme, die in manchen Bereichen das Ausmaß weltweiter ökolo- 
gischer Krisen angenommen hat, in der internationalen Politik lange Zeit überhaupt nicht thematisiert wurde, ${ }^{41}$ verdeutlicht die zunehmende Anzahl internationaler Erklärungen und Abkommen über den Schutz der Umwelt den zunehmenden Trend zu einer Globalisierung der Umweltpolitik. $^{42}$ Umweltpolitische Anliegen gewinnen damit sowohl innen- als auch außenpolitisch zunehmend an Bedeutung. Dieser seit Beginn der 80er Jahre zu beobachtende Prozeß wurde beschleunigt durch sich verschärfende globale Umweltprobleme: Ozonloch, Klimaveränderung und Deforesation offenbaren die ökologische Interdependenz der Staatengemeinschaft.

Von besonderer Bedeutung für die Internationalisierung der Umweltpolitik war jedoch die Umweltkonferenz der Vereinten Nationen 1972 in Stockholm. Zu den Initiativen, die in letzter Zeit in Hinblick auf eine globale Umweltpolitik unternommen wurden, zählen etwa der „Brundtlandbericht“ der Weltkommission für Umwelt und Entwicklung 1987, die Erklärung der Internationalen Umweltkonferenz in Den Haag 1989, die Beschlüsse der Zweiten Vertragsstaatenkonferenz zum Montrealer Protokoll vom Juni 1990 in London oder die Schlußerklärung der Zweiten Weltklimakonferenz in Genf im November $1990 .^{43}$ Einen letzten Höhepunkt erreichten diese Bemühungen mit der Konferenz der Vereinten Nationen über Umwelt und Entwicklung im Juni 1992 in Rio de Janeiro (UNCED). Obwohl die internationale Umweltpolitik noch von vielen Konflikten geprägt ist, kommt in diesen Bestrebungen doch die zunehmende Bedeutsamkeit zum Ausdruck, die der Umweltproblematik von vielen Staaten beigemessen wird.

International tätige Unternehmen sehen sich vielfach unterschiedlichen sozio-kulturellen, politisch-rechtlichen und ökonomischen Umfeldeinflüssen in einzelnen Ländern ausgesetzt und verursachen durch ihre Unternehmenstätigkeit grenzüberschreitende Einwirkungen auf die natürliche Umwelt. Somit kommt den Unternehmen möglicherweise in verschiedenen Ländern eine Rolle als Mitverursacher von ökologischen Problemen zu, und sie sehen sich länderspezifischen Umweltschutzanforderungen ggf. in unterschiedlichem Umfang ausgesetzt. Damit erlangen insbesondere international divergierende Umweltschutzansprüche und Standortbedingungen bei der strategischen Ausrichtung der ökologisch verpflichteten Unternehmensführung ein besondere Relevanz. Wenn Unternehmen Produkte in verschiedene Länder exportieren, stellt sich im Rahmen der Internationalisierungsstrategie z.B. die Frage, inwieweit Konsumenten in allen Ländern die gleiche oder eine unterschiedliche Bereitschaft zeigen, umweltverträgliche Produktvarianten zu einem höheren Preis zu kaufen. Sehen sich Unternehmen auf internationalen Märkten einem

\footnotetext{
${ }^{40}$ Vgl. Weder, R. (1993), S. 159.

${ }^{41}$ Vgl. Wöhlcke, M. (1993), S. 7.

${ }^{42}$ Vgl. Rohe, E.-H. (1990), S. 24f.

${ }^{43}$ Vgl. Höll, O. (1991), S. 137.
} 
unterschiedlichen Umweltbewußtsein der Konsumenten gegenüber, sind in der ökologisch verpflichteten Unternehmensführung Entscheidungen über eine internationale Differenzierung oder Standardisierung z.B. der umweltorientierten Beschaffungs-, Produktions- oder Marketingpolitik von besonderer Bedeutung, wobei ökonomische wie auch ökologische Zielwirkungen bei der Entscheidungsfindung zu berücksichtigen sind.

Grundsätzlich können umweltrelevante Einflüsse der grenzüberschreitenden Unternehmensaktivitäten und des zunehmenden globalen Welthandels durch Produkt-, Wachstums- und Struktureffekte begründet werden: ${ }^{44}$

- Produkteffekte entstehen durch den grenzüberschreitenden Austausch von natürlichen Ressourcen, Produktionsanlagen, Produkten und Dienstleistungen mit den damit einhergehenden negativen wie auch positiven Einflüssen auf die natürliche Umwelt. So führt der grenzüberschreitende Handel mit umweltproblematischen Produkten zu einer internationalen oder sogar weltweiten Verbreitung von Schadstoffen (z.B. FCKW-Problematik). Der weltweite Güteraustausch erschwert die Analyse und Kontrolle der Entstehung und des Lebenszyklusses von Produkten. Damit wird auch die geforderte Umsetzung des Kreislaufprinzips und die Wahrnehmung einer erweiterten Produktverantwortung der Hersteller erschwert. Darüber hinaus ist der internationale Handel mit einer erheblichen Zunahme an Transportprozessen verbunden, durch deren Emissionen in hohem Maße Umweltbelastungen entstehen. Positive Einwirkungen des internationalen Handels auf die natürliche Umwelt sind dann zu erwarten, wenn Umweltschutztechnologien in Länder exportiert oder über Direktinvestitionen dort etabliert werden, die bisher nicht über entsprechendes technologisches Wissen verfügten und in denen eine Verbesserung der Umweltqualität durch den Einsatz moderner Umweltschutztechnologien erzielt werden kann.

- Die Ursachen für die Wachstumseffekte liegen darin, daß durch grenzüberschreitende Unternehmensaktivitäten nationale Wachstumsgrenzen, die aufgrund der begrenzten Ressourcenund Nachfragepotentiale eines Landes gegeben sind, überwunden werden können.

- Weiter werden aus einer gesamtwirtschaftlichen Perspektive Struktureffekte des internationalen Handels angeführt, durch die ein relevanter Einfluß auf die ökologische Umwelt entstehen kann. Struktureffekte beziehen sich auf die Ausnutzung von komparativen Vorteilen (Arbitrage-Effekte) durch internationale Arbeitsteilung und einen damit einhergehenden grenzüberschreitenden Handel. Werden umweltbelastende und energieintensive Produktionsprozesse ins Ausland verlagert (Industrieflucht) und die Produkte wieder in das Ursprungs-

\footnotetext{
$\overline{{ }^{44} \text { Vgl. Althammer, W. (1997), S. 50ff. }}$
} 
land importiert, so führen diese Produktverlagerungen $\mathrm{zu}$ einer Verbesserung der Umweltqualität in dem Ursprungsland und zu einer erhöhten Belastung in jenen Ländern, in denen eine entsprechende Produktion verstärkt stattfindet. Den durch den Export von diesen Ländern erzielten Einkommenssteigerungen stehen zunehmende externe Effekte durch produktionsbedingte Umweltbelastungen gegenüber. In diesem Zusammenhang besteht die Gefahr, daß insbesondere Länder mit geringem Einkommensniveau bewußt eine Ansiedlung umweltbelastender Industrien befürworten, ohne die externen Kosten über umweltpolitische Maßnahmen den Unternehmen wieder zurechnen. Die aus diesen Ländern exportierten Produkte können damit zu sog. „ökologischen Dumping-Preisen“ am Weltmarkt abgesetzt werden. Wenngleich die internationale Arbeitsteilung aufgrund von komparativen Kostenvorteilen ihre Berechtigung findet, stehen internationale tätige Unternehmen gemäß der Agenda 21 in der Verantwortung, die i.d.R. in den Industrieländern etablierten Umweltstandards gleichermaßen auch in einkommenschwachen Ländern umzusetzen.

Diese sog. ökologieorientierte Globalisierungsfalle zeigt insgesamt, daß Unternehmen sowohl bei nationaler und insbesondere internationaler Geschäftstätigkeit Einfluß auf die Träger-, Versorgungs- und Regenerationsfunktion der natïrlichen Umwelt auch außerhalb des Heimatlandes nehmen. Würde durch nationale sowie internationale Bemühungen der Umweltpolitik sichergestellt werden, daß eine vollständige Internalisierung sämtlicher Umweltkosten der Unternehmenstätigkeiten erfolgt, dann würde aus gesamtwirtschaftlicher Sicht die zunehmende Internalisierung der Wirtschaft einen wohlfahrtssteigernden Effekte bewirken. Da eine vollständige Internalisierung der externen Kosten auch in Zukunft nicht zu erreichen ist, stehen international tätige Unternehmen in der Verantwortung, durch eine internationale ökologisch verpflichtete Unternehmensführung unter Berücksichtigung der länderspezifischen Gegebenheiten die grenzüberschreitenden und länderbezogenen Umwelteinwirkungen zu verringern. Im Mittelpunkt steht dabei das Problem, inwieweit angesicht unterschiedlicher Kontextbedingungen in einzelnen Ländern die ökologisch verpflichtete Unternehmensführung international standardisiert oder differenziert ausgestaltet werden muß.

Die Unternehmensaktivitäten in Südkorea, die sich insbesondere auf dem Außenhandel stïtzen und/oder international tätig sind, können auf zwei Arten durch die internationale Umweltpolitik beeinflußt sein. ${ }^{45}$ Zum einen gibt es Bestrebungen, insbesondere große (multinationale) Unternehmen als eigenständige Völkerrechtssubjekte mit entsprechenden Rechten und Pflichten zu be- 
trachten und einen eigenen, auf multinationale Unternehmen bezogenen internationalen Rechtsrahmen zu schaffen. ${ }^{46}$ Das würde bedeuten, daß (multinationale) Unternehmen nicht mehr nur dem nationalen Recht der jeweiligen Staaten unterstellt sind, in denen sie operieren, sondern direkt internationalem Recht (Völkerrecht) und somit auch den entsprechenden umweltrelevanten Regelungen. Die zweite Wirkung ergibt sich aus der Beeinflussung der nationalen Umweltpolitik in den anderen Staaten. Für Südkorea haben internationale Tendenzen eine besondere Bedeutung, da es traditionell einem großen internationalen Einfluß, insbesondere von seiten der Industrieländer, unterliegt: „Aufgrund der begrenzten Macht der Entwicklungsländer, ihrer kolonialen Vergangenheit sowie der politischen und wirtschaftlichen Interessen der Industrieländer können diese einen erheblichen Einfluß auf die Politik bestimmter Entwicklungsländer ausüben. ${ }^{\star 47}$

Die internationale Politik kann die politischen und wirtschaftlichen Rahmenbedingungen in Südkorea somit wesentlich beeinflussen. Ein Beispiel dafür ist das „Structural Adjustment Programm“ des IMF, welches auf Maßnahmen der Geld-, Fiskal- und Wechselkurspolitik sowie auf eine Verbesserung landwirtschaftlicher Anbaumethoden und auf die Privatisierung verstaatlichter Betriebe abzielt, das zu einer drastischen Änderung der wirtschaftlichen Systeme in den jeweiligen Ländern geführt hat, in denen es zur Anwendung kam (z.B. Nigeria, Mexiko, Venezuela). ${ }^{48}$ Ein zunehmender Einfluß der Industrieländer erfolgt auch über die Bereiche Entwicklungshilfe und Kreditvergabe, die vermehrt mit Auflagen im Umweltbereich verbunden werden. Als weiteres Instrument kommen in letzter Zeit zunehmend Debt-Nature-Swaps zum Einsatz. ${ }^{49}$ Grundgedanke dieser Instrumente ist es, Schulden eines Entwicklungslandes gegen Verfügungsrechte über Naturvermögen einzutauschen. ${ }^{50}$

Gerade in Südkorea verläuft der Prozeß der umweltpolitischen Willensbildung daher nicht in nationaler Isolation: „Ökologische Erkenntnisse und Forderungen, die Bewertung von Umweltproblemen und das Aufzeigen von Lösungsansätzen werden international gehandelt. ${ }^{51}$ Die internationale Politik stellt daher einen wichtigen externen Einflußfaktor der nationalen Umwelt-

\footnotetext{
45 Seit der Industrialisierung hat sich Südkorea seien wirtschaftspolitischen Schwerpunkt stark an Export orientiert (der Anteil des Exports am BSP: 1,8\% (1961), 14,0\% (1970), 36,7\% (1987), 27,0\% (1996)). Südkorea gilt zurzeit als zwölfgrößte Expotnation weltweit. Vgl. o. V. (1994), S. 27.

${ }^{46}$ Vgl. Fatouros, A. A. (1994), S. 1ff.

${ }^{47}$ Austin, J. E. (1991), S. 82.

${ }^{48}$ Vgl. Austin, J. E. (1991), S. 109.

${ }^{49}$ Vgl. Krieg, H.-H. (1992), S. 358ff.

${ }^{50}$ Die meisten bisher realisierten Debt-Nature-Swaps wurden in Zusammenarbeit privater Organisationen, v. a. dem WWF, mit den jeweiligen Regierungen der Entwicklungsländer vollzogen. Vgl. Krieg, H.-H. (1992), S. $359 f f$.

${ }^{51}$ Simonis, U. E. (1988), S. $102 f$.
} 
politik in Südkorea dar, der zu einer wesentlichen Dynamisierung dieses Politikbereiches beitragen kann.

Die zentralen Akteure der internationalen Umweltpolitik stellen die Nationalstaaten dar. Das Zusammentreffen der jeweiligen nationalen (Außen)Politiken formt im wesentlichen das internationale System und die internationale Politik. ${ }^{52}$ Die internationale Umweltschutzpolitik kann dabei als dynamischer Prozeß der Bildung von Umweltschutz-Regimes aufgefaßt werden. ${ }^{53}$ Solche Umweltschutz-Regimes „... wachsen allmählich aus kleinen Kerngruppen von Staaten, die sich auf mehr oder weniger klare Regelungen geeinigt haben, und binden langsam einen großen Randbereich von zögernden oder ablehnenden Staaten in das Regime ein, dessen Ziele allmählich höher gesteckt werden“. ${ }^{54}$ Demnach stellen Staaten, die selbst eine fortschrittliche nationale Umweltpolitik verfolgen wie z.B. die Bundesrepublik Deutschland, die treibende Kraft im Prozeß der internationalen Umweltpolitik dar. Eine entscheidende Determinante ist dabei der innenpolitische Druck einer zunehmend umweltbewußter werdenden Bevölkerung in den Industrieländern. ${ }^{55}$

Außer den nationalen Regierungen, welche die wesentlichen Handlungsträger darstellen, üben auch nationale und internationale nichtstaatliche Organisationen (nongovernmental organizations, NGOs), die Medien sowie Unternehmen selbst einen Einfluß auf die internationale Umweltpolitik aus. ${ }^{56}$ Die Aktivitäten dieser Akteure bzw. Interessengruppen - welche von deren oft konfligierenden Interessen bestimmt werden - sind mitentscheidend für die Ergebnisse des internationalen politischen Systems bzw. der internationalen Politik. ${ }^{57}$

Die einzelnen Akteure verfügen dabei über eine Reihe unterschiedlicher Mittel zur Durchsetzung ihrer Ziele, die im wesentlichen ihre Einflußmöglichkeiten bzw. Macht in diesem politischen Prozeß bestimmen. Abb. 6.4 zeigt eine Zusammenstellung der wichtigsten Akteure der internationalen Umweltpolitik. Auch Unternehmen bzw. Unternehmerorganisationen können in diesem internationalen politischen Prozeß als Akteure eine Rolle spielen. ${ }^{58}$

\footnotetext{
${ }^{52}$ Vgl. Fischer, W. (1992), S. 24.

${ }^{53}$ Vgl. Fischer, W. (1992), S. 55.

${ }^{54}$ Fischer, W. (1992), S. 55.

${ }^{55}$ Vgl. Mayer-Tasch, P. C./Merk, K. P. (1988), S. $266 f$.

${ }^{56}$ Vgl. Meyers, R. (1993), S. 543ff.

${ }^{57}$ Vgl. Fischer, W. (1992), S. 24.

${ }^{58}$ In diesem Zusammenhang ist insbesondere die Rolle des BCSD - einer Gruppe von ca. 50 Unternehmern und Leitern großer nationaler und multinationaler Unternehmen - im Rahmen der UNCED zu erwähnen. Vgl. Schmidheiny, St./Business Council for Sustainable Development (1992), S. $21 \mathrm{ff}$.
} 


\begin{tabular}{|c|c|}
\hline Akteurstypus & Beispiele \\
\hline \multicolumn{2}{|l|}{ Politische Institutionen } \\
\hline International & UNO, EU, UNEP, Weltbank, GATT, WTO, ISO \\
\hline National & Umweltministerien \\
\hline \multicolumn{2}{|c|}{ Geberorganisationen von Entwicklunshilfe } \\
\hline International & Weltbank \\
\hline National & GTZ \\
\hline \multicolumn{2}{|l|}{ Nichtstaatliche Organisationen } \\
\hline International & „Greenpeace“, WWF \\
\hline \multirow[t]{2}{*}{ National } & Umweltorganisationen in Industrie- und \\
\hline & Entwicklungsländern \\
\hline Netzwerke & PAN, ILEIA, IFOAM \\
\hline \multicolumn{2}{|l|}{ Forschungsorganisationen } \\
\hline International & IDRC (Ottawa), WIR \\
\hline National & Universitäten \\
\hline \multicolumn{2}{|l|}{ Parteien und Bewegungen } \\
\hline International & „Friends of the Earth International“" \\
\hline \multirow[t]{2}{*}{ National } & Parteien und Umweltbewegungen in \\
\hline & Industrie- und Entwicklungsländern \\
\hline
\end{tabular}

Abb. 6.4: Akteure der globalen Umweltpolitik (Quelle: Bruckmeier, K. (1994), S. 205)

Die Tendenz zur Globalisierung der Umweltpolitik führte auf institutioneller Ebene zur Bildung internationaler Organisationen, welche mit umweltschutzrelevanten Aufgabenstellung befaßt wurden. Viele dieser Organisationen stellen Unterorganisationen der Vereinten Nationen dar. Zu nennen ist hier etwa das United Nations Environmental Program (UNEP), dessen Hauptaufgabe in der ökologierelevanten Informations- und Datenerfassung auf globaler Ebene sowie in der finanziellen Unterstuitzung staatlicher und nichtstaatlicher Umweltorganisationen liegt. ${ }^{59}$ Ein Ziel ist die Erstellung einer integrierten ökologischen und ökonomischen Gesamtrechnung (SEEA), ${ }^{60}$ das die nationalen volkswirtschaftlichen Gesamtrechnungen um die Umweltberichterstattung erweitern soll, um als konsistente Datenbasis für eine Politik der nachhaltigen Entwicklung dienen zu können. ${ }^{61}$ Daneben beschäftigen sich auch andere Unterorganisationen der Vereinten Nationen, z.B. die Weltgesundheitsorganisation (WHO), die Organisation der Vereinten Nationen für Erziehung, Wissenschaft und Kultur (UNESCO), die Organisation für Ernährung und Land-

\footnotetext{
${ }^{59}$ Höll, O. (1991), S. 147f.

${ }^{60}$ SEEA = System of Integrated Environmental and Economic Accounting.

${ }^{61}$ Vgl. Sprenger, R.-U./Wacherbauer, J./Adler, U./Poskny, E. (1992), S. 24.
} 
wirtschaft (FAO), sowie die Organisation der Vereinten Nationen für Industrielle Entwicklung (UNIDO) mit ökologischen Problemstellungen auf internationaler Ebene. ${ }^{62}$

Weiters gibt es eine große Anzahl nichtstaatlicher Organisationen im Bereich des internationale Umweltschutzes, wobei der World Wildlife Fund (WWF) sowie die Internationale Vereinigung zur Erhaltung der Natur (IUCN) die Institutionen mit dem größten Einfluß darstellen. ${ }^{63}$

Einen besonders großen Einfluß auf Entwicklungsländer im Ökologiebereich dürfte die Weltbank ausüben. Die Umweltpolitik stellt dabei innerhalb der Weltbank in den letzten Jahren einen bedeutenden innovativen Bereich dar. ${ }^{64}$ So werden bei der Kreditvergabe von Entwicklungsprojekten durch die Durchführung von Umweltverträglichkeitsprüfungen in zunehmendem Maße ökologische Erfordernisse berücksichtigt. Weitere Anstrengungen werden darüber hinaus bei der Erstellung von Umweltaktionsplänen in Zusammenarbeit mit nationalen Regierungen unternommen. ${ }^{65}$

Im Rahmen des Allgemeinen Zoll- und Handelsabkommens (GATT) spielte der Umweltschutz bisher nur eine kleine Rolle. Die Bestimmungen bezüglich der Meistbegünstigungsklausel (Art. I) sowie der Gleichbehandlung inländischer und ausländischer Ware (Art. III) schließen beispielsweise eine ungleiche Behandlung von Produkten entsprechend ihrer Umweltverträglichkeit aus. ${ }^{66}$ Das Allgemeine Zoll- und Handelsabkommen bietet den Vertragsparteien einen beträchtlichen Spielraum, umweltpolitischen Ziele auch unter Verletzung von GATT-Vorschriften (z.B. der Nichtdiskriminierungsverpflichtungen der Artikel I und III) zu verwirklichen. Die zentrale Grundlage eines solchen Vorgehens ist Artikel XX des GATT-Vertrags. Artikel XX steht im Zlsammenhang mit Exportbeschränkungen: Zum Schutz heimlicher natürlicher und erschöpfbarer Ressourcen kann eine GATT-Vertragspartei Exportrestriktionen einführen und gegen Artikel XI GATT-Vertrag (Verbot mengenmäßiger Maßnahmen) verstoßen. Im Zusammenhang mit Artikel XX besteht ein fundamentales Problem, das bisher noch nicht gelöst werden konnte und die umweltpolitische Tauglichkeit des GATT-Vertrages erheblich beeinträchtigt. Der GATT-Vertrag beruht auf dem Konzept des ,like product“, demzufolge Importgüter, die heimlichen Produkten gleichartig sind, nicht diskriminiert werden dürfen. Dieses Nichtdiskriminierungsgebot gilt selbst

\footnotetext{
${ }^{62}$ Vgl. Kilian, M. (1991), S. 871ff.; Hein, W. (1994), S. 547ff.

${ }^{63}$ Vgl. Höll, O. (1991), S. 147f.

${ }^{64}$ Vgl. Weitzeneger, K. (1992), S. 73.

${ }^{65}$ Vgl. Warford, J./Partow, Z. (1989), S. 6ff.; Weitzeneger, K. (1992), S. 41.

${ }^{66}$ Vgl. Altemöller, F. (1998), S. 47ff.
} 
dann, wenn gleichartige Importprodukte mit extrem umweltbelastenden Produktionsverfahren hergestellt werden. ${ }^{67}$

Neben diesen Bestimmungen, die dem Umweltschutz eher abträglich sind, finden sich im GATT keine Regelungen zugunsten des Umweltschutzes. ${ }^{68}$ Jedoch gibt es in letzter Zeit auch für diese Institution von seiten einiger Staaten Bestrebungen, verstärkt Umweltschutzaspekte im Rahmen des GATT zu berücksichtigen. ${ }^{69}$ Dabei wird eine massive Ausdehnung der im GATT verankerten nationalen Souveränitätsrechte gefördert, um die Handelspolitik stärker in den Dienst regionaler und globaler Umweltpolitik zu stellen. ${ }^{70}$ Es geht vor allem darum, die sich auf die souveräne Festsetzung von Produktvorschriften beschränkenden GATT-Vorschriften um klare Regeln für die extraterritoriale Anwendung von Verfahrensvorschriften zu erweitern. ${ }^{71}$

Ergebnis der Uruguay-Runde ist das „Marrakesh Agreement Establishing the World Trade Organization“. ${ }^{72}$ Es ist das Gründungsstatus der World Trade Organization (WTO) und enthält in verschiedenen Anhängen deren Vertragstexte. Art. II bestimmt, daß die WTO ,... shall provide the common institutional framework for the conduct of trade relations among ist Members in matters related to the agreements and associated legal instruments included in the Annexes to this Agreement“.

Nach Art. III Abs. 1 des „Marrakesh Agreement Establishing the World Trade Organization“ soll die WTO ,... facilitate the implementation, administration and operation, and further the objectives, of this Agreement and of the Multilateral Trade Agreements, and shall also provide the framework for the implementation, administration and operation of the Plurilateral Trade Agreements“. Weiterhin soll die WTO ein Verhandlungsforum für ihre Mitglieder zur Verfügung stellen (Art. III Abs. 2), Streitschlichtungsverfahren (Art. III Abs. 3) und einen „Policy Review Mechanism“ (Art. III Abs. 4) durchführen.

\footnotetext{
${ }^{67}$ Vgl. Hauser, H./Schanz, K.-U. (1995), S. 259ff.

${ }^{68}$ Vgl. Palme, C. E. (1992), S. 176ff.

${ }^{69}$ Vgl. Uimonen, P. (1992), S. $26 f$.

${ }^{70}$ Vgl. Esty, D. G. (1994), S. 59ff.

${ }^{71}$ Die extraterritoriale Anwendung von Verfahrensbestimmungen (z.B. das Verbot von FCKW) auf Importgüter ist bislang im GATT noch nicht geregelt. Dieses Regelungsdefizit ist in Anbetracht der zunehmenden Zahl grenzüberschreitender und weltweiter Umweltproblem äußerst schwierwiegend. Allerdings steht hierbei das multilaterale Handelssystem vor der großen Herausforderung, eine Brücke zu schlagen zwischen dem Anliegen der Handelsliberalisierung einerseits und dem wirksameren Schutz der Umwelt andererseits, ohne neue protektionistische Schlupflöcher zu schaffen. Vgl. Sorsa, P. (1992).

${ }^{72} \mathrm{Vgl}$. Zu den Übereinkommen in allgemeinen und zu den folgenden Ausführung: Hauser, H./Schanz, K.-U. (1995); Gemperle, R./Teller, W./Wartenweiler, R. (1994). Die Ergebnisse der Uruguay-Runde, vom GATT zur WTO und
} 
Die WTO-Vertragstexte umfassen folgende Bereiche:

- Verschiedene multilaterale Übereinkommen über den Handel mit Gütern,

- General Agreement on Trade in Services,

- Agreement on Trade-Related Aspects of Intellectual Property Rights,

- Understanding on Rules and Procedures Governing the Settlement of Disputes,

- Trade Policy Review Mechanism und

- Plurilateral Trade Agreements. $^{73}$

$\mathrm{Zu}$ den multilateralen Übereinkommen über den Handel mit Gütern gehört wesentlich das am 30. Oktober 1947 verabschiedete GATT (GATT 1947). Es ist nunmehr integraler Bestandteil der WTO-Vertragstexte geworden (GATT 1994). Nach Art. II Abs. 4 des Marrakesh Agreement Establishing the World Trade Organisation ist das GATT 1994 ,legality distinct“ gegenüber dem GATT 1947 und erhält somit einen eigenen Rechtsstatus. Das GATT 1994 wird durch verschiedene Interpretationsnoten (Understandings) ergänzt. Zudem bilden weitere multilaterale Übereinkommen die Grundlage über den Handel mit Gütern der WTO-Vertragstexte. Sie regeln jeweils bestimmte Spezialbereiche. Es handelt sich um das:

- Agreement on Agricukture,

- Agreement on Application of Sanitary and Phytosanitary Measures,

- Agreement on Textiles and Clothing,

- Agreement on Technical Barriers to Trade,

- Agreement on Trade Related Investment Measures,

- Agreement on Implementation of Article VI of the General Agreement on Tariffs and Trade 1994,

- Agreement on Implementation of Article VII of the General Agreement on Tariffs and Trade 1994 ,

- Agreement on Preshipment Inspection,

- Agreement on Rules of Origin,

- Agreement on Import Liscensing Procedures,

- Agreement on Subsidies and Countervailing Measures

- Agreement on Safeguards.

speziell zum Bereich internationaler Handel und Umwelt vgl. Hauser H./Schanz, K.-U. (1995), S. 258-270 und KIET (1995).

${ }^{73}$ Dabei handelt es sich um das Agreement on Trade in Civil Aircraft, Agreement on Government Procurement, International Dairy Agreement sowie International Bovine Meat Agreement. 
Diese Übereinkommen stellen z.T inzwischen revidierte Kodizes der Tokyo-Runde dar. Im Hinblick auf den Umweltschutz modifizieren das Agreement on Technical Barriers to Trade sowie das Agreement on the Application of Sanitary and Phytosanitary Measures die Rechtslage nach dem GATT. Das GATT 1994 kann daher bei der Beurteilung der Rechtmäßigkeit von Umweltschutzmaßnahmen, die diese Bereiche betreffen, nicht mehr isoliert von diesen Übereinkommen gesehen werden. Weiterhin enthält der WTO-Vertragstext ein Understanding on Commitments in Financial Services.

Schließlich werden die WTO-Vertragstexte ergänzt durch eine Reihe von Ministererklärungen. Es handelt sich um die ,Ministerial Decisions and Declarations adopted by the Trade Negotiations Commitee on 15 December“ sowie die „Ministerial Decisions adopted by the Ministers at the Meeting of the Trade Negotiations Committee in Marrakesh on 14 April 1994“. Zu diesen Minister-Erklärungen gehört auch die „Decision on Trade and Environment“. Sie formuliert das zukünftige Arbeitsprogramm der internationalen Staatengemeinschaft für den Bereich Handel und Umwelt. ${ }^{74}$

Umweltrelevante Vorschriften in den Vertragstexten der WTO sind dabei: ${ }^{75}$

- Die Präambel des Marrakesh Agreement Establishing the World Trade Organization,

- Das General Agreement on Tariffs and Trade (GATT),

- Das Agreement on Technical Barriers to Trade (TBT),

- Das Agreement on Application of Sanitary and Phytosanitary Measures(SPS),

- Das Agreement on Agriculture,

- Das Agreement on Subsidies and Countervailing Measures,

- Das Agreement on Trade-Related Intellectual Property Rights (TRIPS) und

- Das Agreement on Trade in Services (GATS).

In der gegenwärtigen Diskussion wird die Forderung nach einer stärkeren Berücksichtigung des Umweltschutzes im internationalen Handel mit unterschiedlicher Ausrichtung und Intensität formuliert und im wesentlichen von zwei Argumentationslinien geprägt. ${ }^{76}$ Sie unterscheiden sich

\footnotetext{
${ }^{74}$ Vgl. Altemöller, F. (1998), S. 33 und 39ff.

${ }^{75}$ Vgl. Altemöller, F. (1998), S. $34 \mathrm{ff}$.

${ }^{76}$ Auf der einen Seite wird behauptet, daß Umweltschutz und Handel nicht im Widerspruch stünden und die Regeln des GATT Umweltschutzmaßnahmen nicht behindern. Besondere Bedeutung sehen die Vertreter dieser Richtung in der optimalen Ausnutzung der durch Freihandel erzielbaren Wachstumseffekte. Erst Wachstum ermögliche den Regierungen, Steuern zu erheben und Mittel für den Umweltschutz bereitzustellen. Die Nachfrage nach sauberer Umwelt werde durch Wachstum verstärkt. Auf der anderen Seite wird demgegenüber im Handel einen Katalysator für Umweltschädigungen gesehen und deshalb Handelsbeschränkungen bis hin zum Handelsverbot bestimmter Güter
} 
grundlegend darin, ob ein Zielkonflikt zwischen einem auf Wachstum ausgerichteten freien Handel und dem Umweltschutz besteht. Im Kern geht es um die Frage, ob der internationale Handel aus Umweltschutzgründen einzuschränken sei. Die WTO-Vertragstexte GATT begünstigen durch die Förderung des Freihandels umweltschädlichen Konsum und Produktion sowie das Umweltdumping. $^{77}$ Die Befürworter ökonomischer Freizügigkeit streben nach Maximierung von Gewinnen und Produktion, ohne die verborgenen sozialen und ökonomischen Kosten in Betracht zu ziehen. Das ökonomische Wachstum drohe die Umweltkosten schneller zu erhöhen als die Produktionsgewinne, so daß man letztlich ärmer statt reicher werden. Die letzten Jahrzehnte hätten gezeigt, daß Wachstum größere Umweltprobleme hevorgebracht, als gelöst habe. Es wäre damit durchaus vorstellbar, daß die Lösung zur Reduzierung umweltschädigenden Handels durch eine Dezentralisierung der Wirtschaft, die Hinwendung zu einer Lebensweise in lokalen Gemeinschaften und eine neue Umweltethik viel besser erreicht werden könne.

Diese Richtung fordert, handelspolitische Maßnahmen aktiv als Instrument zur Realisierung umweltpolitischer Ziele oder als Korrektiv für fehlgeleitete Politiken einzusetzen. Eine konstruktive Umweltpolitik der Industrieländer werde ausgehöhlt, wenn importierte umweltschädliche Produkte oder Produkte aus umweltschädlicher Produktion im Ursprungsland diesen Belastungen nicht ausgesetzt seien und somit Kosten umgehen könnten. Diese führt zu einer Privilegierung importierter bzw. Schlechtherstellung heimischer Güter, die durch entsprechende Belastungen auszugleichen sei.

Diese Konfliktlinien verlaufen zum einen durch die Industriestaaten selbst. Die Interessen der vom Freihandel profitierenden Wirtschaftszweige konkurrieren mit den Anliegen von Befürwortern einer stärker an Umweltbelastungen ausgerichteten Wirtschaft. Zum anderen verläuft die Konfliklinie aber auch zwischen Nord und Süd (d.h. zwischen Industrieländern und Entwicklungsländern). Die Forderer nach Berücksichtigung von Handelsbeschränkungen zum Umweltschutz sehen sich erheblicher Kritik von den Entwicklungs- und Schwellenländern ausgesetzt. Diese machen geltend, die Industriestaaten hätten jahrzehntelang auf Kosten der Umwelt be-

gefordert. Einige ihrer Vertreter fordern zwar primär eine Internalisierung der externen Kosten durch entsprechende wirtschaftspolitische Maßnahmen und zum Ausgleich von hierdurch entstehenden Wettbewerbsnachteilen entsprechende Schutzmaßnahmen. Jedoch beurteilen sie die Durchsetzungschance wirtschaftspolitischer Instrumente zur Kosteninternalisierung eher pessimistisch. Deshalb sei auf die Anwendung dieser Instrumente nicht länger zu warten, sondern Umweltprobleme durch die Einschränkung umweltschädlichen Handels anzugehen. Vgl. Altemöller, F. (1998), S. 6ff.

${ }^{77}$ Vgl. Weizäcker, E.-U. v. (1990), S. 64 und 120f.; Kulessa, M. E. (1992), S. 299ff. 
trächtliche Wohlfahrtssteigerungen erlebt, die sie nun den Entwicklungs- und Schwellenländern verweigern. $^{78}$

Die Entwicklungs- und Schwellenländer heben hervor, die Forderungen nach Handelsmaßnahmen zum Umweltschutz behinderten ihre wirtschaftliche und soziale Entwicklung. Bei größerem Wachstum in einer zunächst umweltintensiveren Wirtschaft könnten sie später mehr für den Umweltschutz tun. Sie werfen den Industriestaaten vor, das Souveränitätsprinzip zu verletzen, wenn sie versuchen, Einfluß auf die Politik der weniger entwickelten Länder zu nehmen, um dabei einseitig ihre eigenen Vorstellungen über Umweltpolitik durchzusetzen (sog. „ÖkoImperialismus").

Es ist schließlich hervorzuheben, daß die WTO- und GATT-Verträge für Südkorea sowie die meisten Entwicklungsländer, die bisher noch nicht die internationalen Standards an Umweltschutzforderungen erreicht haben sollen, eine große Herausforderung für die nationale Wirtschaft darstellen. In der Realität dominieren und bestimmen die Industrieländer die Weltwirtschaft, die nach ihren Standards und Interessen beurteilt werden. Sie wirken damit auch als Handelsbeschränkung für die Entwicklungsländer, denn die meisten Entwicklungsländer sind am Export relativ billigerer Waren orientiert, besitzen jedoch weder eine technische noch eine finazielle Basis, um solche Umweltschutzforderungen zu erfüllen.

Auch internationale Umweltschutzabkommen enthalten wichtige Handelsbestimmungen. Die für den Handel wohl wichtigsten Umweltschutzabkommen sind das Washingtoner Abkommen von 1973 über den internationalen Handel mit gefährdeten Arten freilebender Tiere und Pflanzen, das Wiener Abkommen von 1985 zum Schutz der Ozonschicht und das Basler Übereinkommen von 1989 über die Kontrolle des Handels mit gefährlichen Abfällen.

Daneben beschäftigen sich zunehmend regionale interstaatliche Organisationen mit ökologischen Problemstellungen. So übernimmt die Europäische Gemeinschaft seit Mitte der 80er Jahre, bedingt durch die zunehmende Integrationsdynamik (Einheitliche Europäische Akte, Vertrag über die Europäische Union), explizit Kompetenzen in der Umweltpolitik. ${ }^{79}$ Auch die OECD hat ebenso wie die Association of South-East Asian Nations (ASEAN) mit der Einrichtung eines

\footnotetext{
${ }_{78}$ In diesem Sinne betont der indische Umweltminister Kamal Nath beispielsweise so: „Die Umweltzerstörung ist das Resultat des extravaganten Konsums, den die Industrieländer seit Jahtzehnten betrieben haben. Warum sollen wir unseren wachsenden und immer noch bescheidenen Lebensstandard auf dem Altar des verschwenderischen Lebensstils der reichen Länder opfern?“ In: Neue Zürcher Zeitung Nr. 271 vom 21.11.1995, S. 15, zit. nach Altemö ller, F. (1998), S. 10.

${ }^{79}$ Vgl. Fischer, W. (1992), S. 89; Sondermann, W. D. (1992), S. 29 f.
} 
Umweltausschusses sowie einer Reihe internationaler Tagungen die Umweltpolitik in ihre Agenda aufgenommen. ${ }^{80}$

Im Rahmen der NAFTA spielt der Umweltschutz ebenfalls eine Rolle. Die Zielsetzungen im Umweltschutz wurden dabei in einem stark von der UNCED beeinflußten Zusatzabkommen, dem „North American Agreement on Environmental Cooperation“ vom September 1993, festgehalten. Wesentliches Ziel ist es, die jeweils strengsten Umweltgesetze eines Mitgliedslandes auf sämtliche Mitgliedsländer zu übertragen und eine nachhaltige Entwicklung zu ermöglichen. Auf institutioneller Ebene ist die Bildung der „North American Commission on the Environment (NACE)“ sowie der „Commission for Environmental Cooperation (CEC)“ erfolgt. Die Hauptaufgabe dieser Kommissionen liegt in der Harmonisierung der Umweltpolitiken und Programme der Mitgliedsländer. ${ }^{81}$

Im Rahmen der internationalen Umweltpolitik nimmt die EU eine Sonderstellung ein, da die jeweils festgesetzten Regeln für die Mitglieder verbindlich sind. ${ }^{82}$ Die EU hat auch eine gewisse Vorbildwirkung für andere regionale Organisationen. Innerhalb der EU gilt der „Grundsatz des bestmöglichen Umweltschutzes“ sowie die Forderung nach einem „hohen Schutzniveau“ im Umweltbereich. ${ }^{83}$ Im Art. 130 EWG-Vertrag von 1989 werden folgende gemeinschaftlichen umweltpolitischen Ziele gesetzt: Umwelterhaltung, Umweltschutz, Verbesserung der Umweltqualität, Beitrag zum Gesundheitsschutz und schonende Ressourcenbewirtschaftung. Ein weiteres Ziel ist die Beteiligung der Gemeinschaft an den internationalen Maßnahmen zur Abwendung der Gefahren für das ökologische Gleichgewicht der Erde. Als Handlungsgrundsätze dienen dabei das Vorbeugungsprinzip, das Ursprungsprinzip sowie das Verursacherprinzip.

Eine wichtige Bedeutung in der heutigen Diskussion über die internationale Umweltpolitik nimmt insbesondere die EMAS-Verordnung 1836/93 (EG-Öko-Audit-Verordnung) ${ }^{84}$ und die Zertifizierung im Rahmen der Internationalen Norm zum Umweltmanagement (ISO 14001 ff.) ${ }^{85}$ ein.

\footnotetext{
${ }^{80}$ Vgl. Klenk, J. (1993), S. 359; Hein, W. (1993), S. 549.

${ }^{81}$ Vgl. Esty, D. C. (1994), S. 59ff.

${ }^{82}$ Vgl. Hein, W. (1993), S. 549.

${ }^{83}$ Vgl. Hoffmann-Riem, V. (1991), S. $19 f f$.

84 Environmental Management- and Eco-Audit-System (EMAS), auch Community Environmental Managementand Eco-Audit-System (CEMAS). Vgl. EG (1993) und Dyllick, T. (1994).

85 Die Internationale Organisation für Standardisierungen (ISO) bezweckt die Normenstandardisierung im Industrieund Dienstleistungebereich. In ihr sind über 130 Länder organisiert, wobei jedes Mitgliedland nur mit einem nationalen Komitee vertreten sein darf. Vgl. ISO (1994).
} 
Im Februar 1993 wurde vom Rat der EG und dem Rat der vereinten Vertretern der Regierung der Mitgliedstaaten das EG-Programm „Für eine dauerhafte und umweltgerechte Entwicklung“ vorgelegt. Dieses Aktionsprogramm der EG kann als Wendepunkt der europäischen Umweltpolitik bezeichnet werden. Der Industrie wird als Verursacher von Umweltproblemen eine eigenverantwortlichen Rolle $\mathrm{zu}$ deren Lösung übertragen. Eine der wesentlichen Aussagen des EGProgramms zum „sustainable development“ ist, daß ,die Industrie im Umweltbereich nicht nur einen Teil des Problems darstellen darf, sondern auch ein Teil der Lösung dieses Problems sein muß.“86 Im ökonomischen Konzept dieses EG-Programms wird neben Abgaben und Gebühren, steuerliche Anreizen und staatlicher Beihilfe die umweltorientierte Bilanzprüfung, das sog. ÖkoAuditing als eigenständiger Maßnahmenbereich genannt.

Einer der Gründe für dese große Beachtung der Verabschiedung der EMAS-Verordnung der EU in Managementkreisen mag im völlig neuen Ansatz der Verordnung liegen. Das EMAS repräsentiert hierzu eine neue, vierte politische Strategie der Regulierung von Managementmethoden. ${ }^{87}$ Dabei schafft der Staat für Unternehmen Anreize (d.h. die Verleihung offizieller Bestätigungen guten Umweltmanagements sowie deren Publikation im europäischen Amtsblatt), bestimmte methodische Anforderungen des Umweltmanagements freiwillig $\mathrm{zu}$ erfüllen (Beeinflussung von Methoden des Umweltmanagements).

Die Durchsetzung dieser Politik bleibt in erster Linie dem Markt, d.h. der Nachfrage nach EMAS-Zertifikaten, überlassen. Für die Berücksichtigung könnte die erfolgte, breite und schnelle marktmäßige Durchsetzung der im Grundsatz ähnlich strukturierten ISO 9000-Qualitätsnormen sprechen; dagegen die vielerorts erfahrenen administrativen Probleme einer Qualitätszertifizierung. Zertifikate dürften auch von Firmen nachgefragt werden, die lediglich beabsichtigen, eine im Fall eines Nichterwerbs zu erwartende Negativprofilierung zu verhindern.

Folgende Grundsätze kennzeichnen die wesentliche Ziele der Verordnung: ${ }^{88}$

- Die Industrie trägt Eigenverantwortung für die Bewältigung der Umweltfolgen ihrer Tätigkeit und sollte daher in diesem Bereich zu einem aktiven Konzept kommen.

\footnotetext{
${ }^{86}$ Bundesumweltministerium/Umweltbundesamt (1995), S. 562.

87 Bisherige staatliche Regulierungen im Umweltbereich basierten auf einer der folgenden drei politischen Strategien: (vgl. Schalteger, S./Sturm, A. (1995), S. 3f.)

- Technische oder verhaltensorientierte Vorschriften (Auflagen, Verbote, Gebote),

- Beeinflussung von Preisen (z.B. Tarife, Lenkungsabgaben),

- Beeinflussung von Mengen (z.B. Emissionshandel, Kontingentierungen).

${ }^{88} \mathrm{Vgl}$. Bundesumweltministerium /Umweltbundesamt (1995), S. 562f.
} 
Ziel des Systems ist die Förderung der kontinuierlichen Verbesserung des betrieblichen Umweltschutzes im Rahmen der gewerblichen Tätigkeiten durch: Festlegung und Umsetzung standortbezogener Umweltpolitik, -programme und -managementsysteme durch die Unternehmen; systematische, objektive und regelmäßige Bewertung der Leistung dieser Instrumente; Bereitstellung von Informationen über den betrieblichen Umweltschutz für die Öffentlichkeit.

An dem System können sich alle Unternehmen beteiligen, die eine betriebliche Umweltpolitik festlegen, die nicht nur die Einhaltung aller einschlägigen Umweltvorschriften vorsieht, sondern auch Verpflichtungen zur angemessenen kontinuierlichen Verbesserung des betrieblichen Umweltschutzes umfaßt. Diese Verpflichtungen müssen darauf abzielen, die Umweltwirkungen in einem solchen Umfang zu verringern, wie es sich mit einer wirtschaftlich vertretbaren Anwendung der besten verfügbaren Technik erreichen läßt.

Die nationalen Gesetze bleiben unabhängig von der Verordnung bestehen. Die Teilnahme am Öko-Audit-System ist für Unternehmen freiwillig. Wer jedoch teilnimmt, muß sich an die „Spielregeln“ (Art. 3 Abs. 1) halten. Die für die Teilnahme vorgesehene Standortprüfung eines Unternehmens kann ein Öko-Audit eigenverantwortlich oder von Dritten durchführen lassen. Das Prüfungsergebnis muß dann von einem zugelassenen Umweltgutachter für gültig erklärt (validiert) werden. Auf dieser Basis erteilt die Behörde das „Bestanden“ oder „Nicht Bestanden“ für den jeweiligen Standort. Das Bestehen des Audits kann vom Unternehmen für Marketingzwecke verwendet, darf jedoch nicht in der direkten Produktwerbung eingesetzt werden.

Die Anforderungen und Module des EMAS betreffen entscheidungsorientierte Methoden und Organisationsformen, mit denen: ${ }^{89}$

- Ökologische Schwachstellen analysiert und operationale Ziele festgelegt (Unternehmenspolitik, Leitbilder, Ziele),

- Daten gemanagt (Datenmanagement),

- Pläne erstellt (Umsetzungsprogramme),

- Aktivitäten gesteuert und kontrolliert (Organisation) sowie

- Zustände und Entwicklungen kommuniziert (Umwelterklärung, Jahresbericht) werden können.

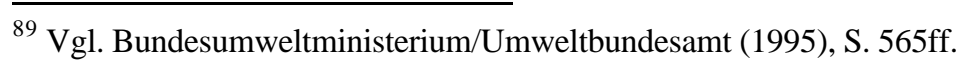


Die EMAS-Verordnung sieht vor, daß das betriebliche Umweltmanagement einer externen, formalen Betriebsprüfung (Audit) aufgrund der Existenz und Wirksamkeit von Unternehmensleitbild, Umweltschutzzielen, Umsetzungsprogrammen, Organisation und Umwelterklärung unterzogen wird. Entspricht das Umweltmanagement diesen Anforderungen, so kann eine standortbezogene Teilnahmebestätigung (Zertifikat) am EU-Umweltmanagement-System und Öko-Audit-System erworben werden. Die Namen der Firmen mit den zertifizierten Standorten werden im EU-Journal veröffentlicht.

\begin{tabular}{|c|c|c|}
\hline EU-Audit-Verordnung & BS 7750 & ISO 14001 \\
\hline & $\begin{array}{l}\text { Environmental management } \\
\text { System }\end{array}$ & \\
\hline Umweltpolitik & Environmental policy & Umweltpolitik \\
\hline $\begin{array}{l}\text { Organisation und } \\
\text { Personal }\end{array}$ & Organisation and personnel & $\begin{array}{l}\text { Organisationsstruktur und } \\
\text { Verantwotung/Schulung, Bewußtseinbil- } \\
\text { dung, Kompetenz }\end{array}$ \\
\hline $\begin{array}{l}\text { Auswirkungen } \\
\text { auf die Umwelt }\end{array}$ & Environmental effects & Umweltspezifische Aspekte \\
\hline Umweltziele & Environmental objectives and targets & Zielsetzungen und Ziele \\
\hline Umweltprogramme & Environmental management programme & Umweltmanagementprogramm \\
\hline $\begin{array}{l}\text { Umweltmanagement- } \\
\text { Dokumentation }\end{array}$ & $\begin{array}{l}\text { Environmental management manual } \\
\text { and documentation }\end{array}$ & Dokumentation und Handhabung \\
\hline \multirow[t]{3}{*}{$\begin{array}{l}\text { Aufbau- und } \\
\text { Ablaufkontrolle }\end{array}$} & Operational control & $\begin{array}{l}\text { Ablaufkontrolle/Überwachung und } \\
\text { Korrekturmaßnahmen/Überwachung } \\
\text { und Messung }\end{array}$ \\
\hline & & Notfallvorsorge und Maßnahmenplanung \\
\hline & Environmental management records & Aufzeichnungen und Protokolle \\
\hline \multirow[t]{2}{*}{ Umweltbetriebsprüfung } & Environmental management audits & Umweltmanagementsystem-Audit \\
\hline & Environmental management reviews & Überprüfung durch die oberste Leitung \\
\hline Umwelterklärung & & Kommunikation \\
\hline
\end{tabular}

Abb. 6.5: Elemente von Umweltmanagementsystemen

(Quelle: Schitag Ernst \& Young (1995), S. 13)

Die Befürchtungen verschiedener Nicht-EU-Mitgliedstaaten - insbesondere der USA, Japan und der Schweiz - von der EU Umweltnormen aufoktroyiert zu bekommen bzw. mit neuen nicht-tarifären Handelshemmnissen konfrontiert zu werden, hat dazu geführt, daß von der International Organization for Standardization (ISO) parallel zum EMAS die Entwicklung einer neuen Umweltmanagement-Normenreihe, die ISO 14000, vorangetrieben wird. Die nationalen und 
internationalen Normenorganisationen schlagen mit dem Angebot, öffentliche Normen zu zertifizieren, seit jeher denselben Weg ein wie das EMAS - allerdings auf privatwirtschaftlicher Basis. Auch arbeiten die Normenorganisationen eng mit der Privatwirtschaft zusammen. Besonders erwähnenswert sind hierbei die vom British Standards Institute (BSI) 1992, also vor der EMAS-Verordnung veröffentlichte Norm BS 7750 und die Norm ISO 14001 der International Organization for Standardization (ISO). Die International Organization for Standardization hat den Auftrag zur Ausarbeitung ihrer Norm an das British Standards Institute vergeben. Die Systemstrukturen und -inhalte der EU-, BS- und ISO-Normen präsentieren sich bisher ähnlich (vgl. Abb. 6.5). Es wird deshalb hier nur kurz auf den Inhalt von ISO 14001 und die Unterschiede zum EMAS eingegangen.

Die ISO-Norm unterscheidet fünf Phasen eines kontinuierlichen Verbesserungsprozesses: ${ }^{90}$

- Erstellung einer betrieblichen Umweltpolitik

- Planung

- Umsetzung

- Kontrolle und Korrekturmaßnahmen

- Revision des Umweltmanagementsystems

Die ISO-Norm unterscheidet sich von der EMAS-Verordnung in folgenden wesentlichen Punkten: ${ }^{91}$

Außer, daß die Umweltpolitik der Öffentlichkeit zugänglich gemacht werden muß, besteht keine Veröffentlichungspflicht. Es wird lediglich empfohlen, Wege der externen Kommunikation zu bedenken.

- ISO 14001 ist nicht auf die Zertifizierung von Standorten beschränkt, sondern kann auch Produkte einbeziehen. Da eine reine Standortbetrachtung im bisherigen Entwurf nicht ausgeschlossen ist, wird ISO $14001 \mathrm{zu}$ einer ,Sowohl-als-auch“-Norm. Die EU hat hingegen eine eigene Verordnung zum Öko-Label für Produkte verabschiedet (EG 1992).

- Die Normensetzung erfolgt durch eine privatwirtschaftliche Organisation anstelle einer supranationalen oder nationalen Behörde.

- EMAS verlangt eine Anwendung der besten verfügbaren Technologie und gute Managementpraktiken, womit sie der Wirtschaft Anreize zur Einfrierung von Innovationen für den

${ }^{90} \mathrm{Vgl}$. ISO (1994). 
Umweltschutz liefert. ISO plädiert nur zu einer Berücksichtigung ökonomisch sinnvoller Umweltschutztechnologien, fordert hingegen eine Einhaltung der relevanten Umweltgesetze und -regulierungen sowie ein „Bekenntnis zur kontinuierlichen Verbesserung“.

\begin{tabular}{|c|c|c|}
\hline $\begin{array}{l}\text { Unterscheidungs- } \\
\text { merkmal }\end{array}$ & Öko-Audit-Verordnung & ISO 14001 \\
\hline Gültigkeit & 13. Juli 1993/April 1995 & Oktober 1996 \\
\hline $\begin{array}{l}\text { Räumlicher } \\
\text { Geltungsbereich }\end{array}$ & Europäische Union & Weltweit \\
\hline Branchen & Gewerbliche Unternehmen & Keine Beschränkung \\
\hline $\begin{array}{l}\text { Untersuchungs- } \\
\text { gegenstand }\end{array}$ & $\begin{array}{l}\text { Der jeweilige Standort des } \\
\text { Unternehmens wird einzeln geprüft }\end{array}$ & $\begin{array}{l}\text { Das Unternehmen und seine } \\
\text { Organisation wird geprüft }\end{array}$ \\
\hline Publikationspflicht & $\begin{array}{l}\text { Umwelterklärung muß veröffentlicht } \\
\text { werden }\end{array}$ & $\begin{array}{l}\text { Nur die Umweltpolitik muß } \\
\text { veröffentlicht werden }\end{array}$ \\
\hline Rechtsstatus & $\begin{array}{l}\text { Gesetzliche Regelung, in Deutschland } \\
\text { durch das Umweltauditgesetz (UAG) } \\
\text { und drei Ausführungsverordnungen } \\
\text { geregelt (UAG-Zulassungsverordnung } \\
\text { (UAGZVV), UAG } \\
\text { Beleihungsverordnung (UAGBV), } \\
\text { UAG-Gebührenordnung (UAGGebV) }\end{array}$ & Privatwirtschaftliche Norm \\
\hline $\begin{array}{l}\text { Stand des Systems } \\
\text { bei der ersten } \\
\text { Validierung/ } \\
\text { Zertifizierung }\end{array}$ & $\begin{array}{l}\text { Das Managementsystem muß auf- } \\
\text { gebaut sein. Eine Überprüfung der } \\
\text { Funktionsweise muß jedoch noch nicht } \\
\text { stattgefunden haben. } \\
\text { Für die Valdierung reicht die erste } \\
\text { Umweltprüfung aus; eine erneute Um- } \\
\text { weltbetriebsprüfung muß noch nicht } \\
\text { stattgefunden haben }\end{array}$ & $\begin{array}{l}\text { Das Managementsystem muß } \\
\text { komplett umgesetzt sein. Eine Über- } \\
\text { prüfung der Funktionsweise muß } \\
\text { stattgefunden haben. } \\
\text { Die Umweltbetriebsprüfung und das } \\
\text { Management-Review müssen bereits } \\
\text { durchgeführt worden sein. }\end{array}$ \\
\hline $\begin{array}{l}\text { Ergebnis der } \\
\text { erfolgreichen } \\
\text { Anwendung }\end{array}$ & $\begin{array}{l}\text { Valdierung durch zugelassenen } \\
\text { Umweltgutachter (überwacht durch die } \\
\text { DAUmbH; Deutsche Akkreditierungs- } \\
\text { und Zulassungsgesellschaft für } \\
\text { Umweltgutachter) }\end{array}$ & Zertifizierung \\
\hline
\end{tabular}

Abb. 6.6: Unterschiede zwischen Öko-Audit-Verordnung und ISO 14001

(Quelle: Schulz, W. (1997), S. 14) 
In dem durch diese Normen und Regulierungen sowie durch den Wandel von Werthaltungen bewirkten Prozeß der Veränderung ist es von größter Wichtigkeit, daß seitens der Unternehmen dort angesetzt wird, wo ökologische und ökonomische Ziele kompatibel sind oder sich gar ergänzen. Nur so können effizient Wettbewerbsvorteile geschaffen bzw. das Auftreten von Wettbewerbsnachteilen verhindert werden. Hierzu werden praktikable, an die bekannten Managementinstrumente angelehnte, betriebliche Umweltmanagementsysteme benötigt.

Ein Umweltmanagementsystem kann hierbei als ein Teil des gesamten Managementsystems aufgefaßt werden: „Es stellt die organisatorische Struktur, Verantwortlichkeiten, Abläufe, Prozesse und Voraussetzungen für die Durchführung einer betrieblichen Umweltpolitik dar. ${ }^{\text {92 }}$

Zur Unterstïtzung eines betrieblichen Umweltmanagementsystems wurden in den letzten Jahren eine Reihe von Konzepten entwickelt. Die verschiedenen Umweltmanagement-Ansätze (Ökobilanzierung, Total Quality Environmental Management (TOEM), ökologisches Rechnungswesen, Umwelt-Audit, Umweltberichterstattung, Öko-Controlling etc.) erfüllen eine oder mehrere Funktionen des Umweltmanagements (Zielsetzung, Informationsmanagement, Entscheidungsunterstützung, Steuerung und Kommunikation). Die Herausforderung des Managements besteht damit nun darin, in diesem Umfeld konkrete, ökonomische Wege zu finden, um der Idealvorstellung einer nachhaltigen öko-effizienten Wirtschaftsweise näherzukommen. ${ }^{93}$

Die erfolgreiche Beteiligung und damit auch die Zertifizierung eröffnen dem Unternehmen folgende Vorteile: ${ }^{94}$

- Die Dokumentation der eigenen Umweltverträglichkeit in der Öffentlichkeit

- Kostenvorteile auch Einsparung von Energie, Ressourcen und Gebühren

- Bessere Kontakte zu den Umweltbehörden und Gewerbeaufsichtämtern

- Sicherheit bei Investitionsentscheidungen.

\footnotetext{
${ }^{92}$ Clausen, J. (1993), S. 25.

93 Öko-Effizienz kann grob auf drei Arten interpretiert werden: Bei der ökonomischen Kosteneffizienz geht es um die kostengünstigste Erstellung einer bestimmten Leistung. Voraussetzung für eine kosteneffiziente Wirtschaftsweise ist, daß Ressourcen dort eingesetzt werden, wo sie den größten zusätzlichen Nutzen stiften (allokative Effizienz). Die ökologische Effizienz ist die Maßgröße für die verursachte Umweltbelastung pro erstellte Leistung. Die ökonomisch-ökologische Effizienz mißt die verursachte Umweltbelastung pro erwirtschaftete Geldeinheit. Umweltschutz wird nur dann langfris tig erfolgreich betrieben, wenn er als ökonomisch tragbar erachtet wird. Öko-Effizienz als Maßgröße für nachhaltiges Wirtschaften wird im Rahmen vorliegender Arbeit deshalb als ökonomisch-ökologische Effizienz verstanden und behandelt. Für eine detailliertere Diskussion des Konzepts der Öko-Effizienz vgl. Schalteger, S./Sturm, A. (1994).

${ }_{94}$ Vgl. Stark, R./Reichenbach, D./Kreipe, E. (1998), S. 244.
} 
Ein wesentliches Element der internationalen Umweltpolitik stellt das Völkerrecht ${ }^{95}$ dar. Dieses hat neben seiner klassischen Aufgabe, nämlich der Vermeidung von Konflikten zwischen den Staaten (Kriegs- und Humanitätsrecht), in letzter Zeit zunehmend die Aufgabe der Bewahrung des Ökosystems der Erde übernommen. Multinationale Unternehmen können auf zwei Arten durch das Völkerrecht beeinflußt werden. Das Völkerrecht enthält erstens Normen, die unmittelbar an multinationale Unternehmen gerichtet sind und für diese bestimmte Rechte und Pflichten festlegen. Zweitens folgen aus völkerrechtlichen Regelungen Bestimmungen für die einzelnen Nationalstaaten, welche eine bindende, die staatliche Souveränität in gewissen Bereichen einschränkende Wirkung haben, und auf dem Umweg der innerstaatlichen Implementierung solcher Normen auf multinationale Unternehmen in ihrer Gesamtheit bzw. auf die einzelnen Konzernfilialen zurückwirken. Multinationale Unternehmen unterliegen neben einer Kontrolle durch ihre Heimat- und Gastgeberstaaten aufgrund ihrer internationalen Ausdehnung und politischen Einflußmöglichkeit auch Regelungen durch völkerrechtliche Verträge und internationale Organisationen; sie befinden sich in einer „Grauzone“ partieller Völkerrechtssubjektivität, d.h. sie sind Träger bestimmter Rechte und/oder Pflichten. ${ }^{96}$

Für die Tätigkeit multinationaler Unternehmen ist das internationale Wirtschaftsrecht von besonderer Bedeutung. Dieses wird definiert als ,... das Recht der internationalen Wirtschaftsbeziehungen und daher die Summe aller Normen, die das Verhalten der am grenzüberschreitenden Wirtschaftsverkehr beteiligten Rechtssubjekte regeln“. 97

Das internationale Wirtschaftsrecht setzt sich aus dem Völkerrecht sowie aus dem innerstaatlichem Recht zusammen. Das innerstaatliche Recht ist dabei in jenen Fällen relevant, wo ihm vom Gesetzgeber exterritoriale Wirkungen verliehen wurden. Dieser Einfluß kann dann von besonderer Bedeutung sein, wenn das Freihandels- oder Wirtschaftslenkungsrecht eines Industriestaates das Verhalten der Muttergesellschaft im Ausland oder ihrer Tochtergesellschaften zu kontrollieren versucht.

Das Wirtschaftsvölkerrecht als internationales Wirtschaftsrecht im engeren Sinne umfaßt vor allem völkerrechtliche Verträge, z.B. Handels-, Schiffahrts-, Niederlassungs-, Konsularverträge, sowie bindende Beschlüsse der internationalen Wirtschaftsorganisationen, wie GATT, Weltbank, IMF, EU oder OECD etc. Die wesentlichen Regelungsbereiche stellen das internationale Recht

\footnotetext{
${ }^{95}$ Als Völkerrecht läßt sich die Summe der rechtlichen Normen definieren, die das Verhalten der Völkerrechtssubjekte regeln und nicht dem inneren Recht eines dieser Subjekte angehören. Völkerrechtssubjekte als Träger von Rechten und Pflichten sind dabei neben Staaten auch internationale Organisationen. Vgl. Neuhold, H. (1991), S. 2.

${ }^{96}$ Vgl. Dahm, G./Delbrück, J./Wolfrum, R. (1989), S. 26.
} 
des Warenaustausches und der wirtschaftlichen Integration, das internationale Rohstoffrecht, das internationale Finanz- und Währungsrecht, das internationale Recht der Wettbewerbsbeschränkungen sowie das internationale Steuer-, Gesellschafts-, Investitions- und Konzessionsrecht dar. ${ }^{98}$ Im Umweltbereich stellen multilaterale völkerrechtliche Verträge sowie rechtsverbindliche Beschlüsse und Empfehlungen von internationalen Organisationen die wichtigsten internationalen Rechtsquellen dar. ${ }^{99}$

Eine wesentliche Bestimmung im internationalen Umweltrecht stellt die Deklaration 21 der Stockholmer Umweltkonferenz der Vereinten Nationen dar. Darin heißt es: „Die Staaten haben nach Maßgabe der Charta der Vereinten Nationen und der Grundsätze des Völkerrechts, das souveräne Recht zur Ausbeutung ihrer eigenen Hilfsquellen nach Maßgabe ihrer eigenen Umweltpolitik, sowie die Pflicht, dafür zu sorgen, daß durch Tätigkeiten innerhalb ihres Hoheitsund Kontrollbereiches der Umwelt in anderen Staaten oder Gebieten außerhalb ihres internationalen Hoheitsbereiches kein Schaden zugefügt wird. ${ }^{\text {(100 }}$ Von Bedeutung ist in diesem Zusammenhang, daß diese Deklaration, die ein inzwischen geltendes Völkergewohnheitsrecht widerspiegelt, eine Beschränkung der territorialen staatlichen Souveränität für die nationale Umweltpolitik impliziert. ${ }^{101}$

Insgesamt läßt sich festhalten, daß im Bereich des internationalen Umweltschutzes, aufgrund der Komplexität bei der Entstehung völkerrechtlicher Normen, im einzelnen noch vieles umstritten ist. Gemeinhin anerkannt ist allerdings, ,... daß kein Staat befugt ist, sein Territorium auf beliebige Weise zu nutzen“. ${ }^{102}$

Im Rahmen des internationalen Umweltrechts nehmen die umweltrelevanten Bestimmungen der EU eine Sonderstellung ein, denn sie sind für die einzelnen Mitgliedsstaaten verbindlich. Eine Angleichung der nationalen Umweltgesetze soll dabei durch sog. Richtlinien erreicht werden. ${ }^{103}$ Diese Richtlinien stellen Mindestanforderungen dar, wobei den Mitgliedsstaaten jedoch das Recht auf strengere Umweltgesetze verbleibt. ${ }^{104}$ Die Implementierung dieser Richtlinien in nationales Recht kann durch Direktklagen oder durch Vorlagen der nationalen Gerichte eingeklagt

\footnotetext{
${ }^{97}$ Fischer, P. (1991), S. 385.

${ }^{98}$ Vgl. Fischer, P. (1991), S. 392ff.

${ }^{99}$ Vgl. Zehetner, F. (1991), S. 377.

${ }^{100}$ Mayer-Tasch, P. C./Merk, K. P. (1988), S. 263.

${ }^{101}$ Vgl. Mayer-Tasch, P. C./Merk, K. P. (1988), S. 264.

102 Martin, J. (1989), S. 215.

103 Vgl. Glaeser, B. (1989), S. 91.

${ }^{104}$ Vgl. Hoffmann-Riem, W. (1991), S. 21f.
} 
werden. ${ }^{105}$ Generell ergibt sich für die einzelnen Staaten innerhalb der EU aufgrund der unterschiedlichen Rechtssysteme die Schwierigkeit, die Richtlinien sowohl juristisch umzusetzen als auch praktisch zu vollziehen. ${ }^{106}$

In jüngster Zeit wurden im Rahmen der internationalen Umweltpolitik verstärkt Bestrebungen unternommen, die Tätigkeit multinationaler Unternehmen durch internationale Verhaltenskodizes zu regulieren. Verhaltenskodizes enthalten zunächst rechtlich unverbindliche Richtlinien. Werden sie jedoch in der Folge von den völkerrechtlichen Akteuren in der Praxis befolgt, so können sie dadurch normative Bedeutung gewinnen, indem sie zu Völkergewohnheitsrecht werden bzw. sich zu vertraglichem Völkerrecht verdichten. ${ }^{107}$ Einige dieser Verhaltenskodizes enthalten auch explizit Urnweitschutzbestimmungen. ${ }^{108}$ Ein Verhaltenskodex, der sich explizit auf den Umweltschutz bezieht, ist die „Charter für eine langfristig tragfähige Entwicklung: Grundsätze des Umweltmanagements“ der Internationalen Handelskammer (ICC). ${ }^{109}$

\footnotetext{
${ }^{105}$ Vgl. Everling, U. (1991), S. 29ff.

${ }^{106}$ Vgl. Glaeser, B. (1989), S. 91.

${ }^{107}$ Vgl. Fischer, P. (1991), S. 388.

${ }^{108}$ Vgl. Fischer, P. (1991), S. 389.

${ }^{109}$ Vgl. ICC (1991); Meffert, H./Kirchgeorg, M. (1998), S. 184f.
} 


\section{Wirtschaftliche Rahmenbedingungen}

In diesem Abschnitt werden die wirtschaftlichen Rahmenbedingungen für die ökologisch verpflichtete Unternehmensführung in Südkorea insbesondere unter drei Aspekten, und zwar der Wirtschaftsordnung, der Entwicklungsstrategie und der wirtschaftspolitischen Maßnahmen betrachtet. Im Mittelpunkt stehen dabei die Fragen, wie die Umweltprobleme auf den Wirtschaftsentwicklungsprozeß in Südkorea Einfluß haben und welche Faktoren für die Entstehung von Umweltproblemen verantwortlich sind und schließlich, welche Rolle die heutige Marktsituation und die wirtschaftspolitischen Rahmenbedingungen für den Umweltschutz bei der Unternehmensführung spielen (Märkte und wirtschaftspolitische Maßnahmen zur Beförderung des Umweltschutzes und Wettbewerbsfähigkeit insbesondere auf den Märkten des Umweltschutzes).

\subsection{Dynamik der wirtschaftlichen Entwicklung und Umweltprobleme}

Spricht man von Südkorea, assoziert man gewöhnlich hohes Wirtschaftswachstum. Die starken Umweltprobleme als Folge der raschen, auf Umweltschutz nicht rücksichtsnehmenden Industrialisierung werden aber dabei entweder bagatellisiert oder übersehen.

Die Geschichte der Konfrontation mit Umweltschäden ist in Südkorea fast genauso lang wie die Geschichte der Industrialisierung. Seit dem Beginn der Industrialisierung in den 60er Jahren mit dem Ziel der „Schaffung eines industrialisierten modernen Staates“ werden die sensiblen Naturbedingungen, die ja eine menschliche Lebensgrundlage bilden, in wachsendem Maße in Mitleidenschaft gezogen. Die Belastung vor allem der natürlichen Umwelt nimmt dabei an Umfang und Tiefe zu.

Nach dem Ende der japanischen Kolonialzeit (1910-1945) und des Koreakrieges (1950-1953) gehörte Südkorea zu einem der ärmsten Länder der Welt. ${ }^{1}$ Bis zum Ende der 50er Jahre wurde in Südkorea typischerweise eine binnenorientierte Entwicklungsstrategie mit vielen ungenutzten potentiellen Arbeitskräften im landwirtschaftlichen Bereich betrieben. Daraus resultierte eine hohe Inflation, Arbeitslosigkeit und Staatsverschuldung, die wiederum einen Importsubstitutionseffekt auslösten. Dazu kam die äußerst schlechte natürliche Ressourcenausstattung. Bei einer Fläche von 96,929 $\mathrm{Km}^{2}$ und einer Bevölkerung von knapp 21,546 Mio. Einwohnern im Jahr 1955 betrug die Bevölkerungsdichte rund 222 Einwohner pro Quadratkilometer. ${ }^{2}$ Diese kann für

\footnotetext{
${ }^{1}$ Das GDP pro Kopf betrug 86\$ im Jahr 1961.

2 1995: 44,90 Mio. Einwohner und rund 452 Einwohner pro Quadratkilometer.
} 
einen Flächenstaat als sehr hoch eingestuft werden. Erschwerend kommt hierzu, daß etwa drei Viertel der Landoberfläche gebirgig und damit kaum bewohnbar sind und nur ca. $20 \%$ der Fläche landwirtschaftlich nutzbar ist. Diese Fläche reichte trotz der traditionell intensiven Bewirtschaftung nicht aus, um die Bevölkerung zu ernähren.

Trotz der schlechten Rohstoffausstattung und industriellen Basis, die insbesondere auf die Ausbeutung der Bodenschätze in der japanischen Kolonialzeit und auf die völlige Zerstörung der wenigen erhalten gebliebenen Industrieanlagen während des Koreakriegs zurückzuführen sind, ${ }^{3}$ verfügte Südkorea in den 50er Jahren über günstige Voraussetzungen für Industrialisierung, die für ein Entwicklungsland nicht selbstverständlich sind.

Dazu zählen folgende Faktoren: ${ }^{4}$

- Der relative hohe Bildungsstand der Bevölkerung: Im Jahr 1960 betrug die Alphabetenquote für Erwachsene bereits $71 \%$.

- Die vergleichsweise egalitäre Einkommens- und Vermögensverteilung: Sie ist durch die in der zweiten Hälfte der 40er Jahre durchgeführte Landreform zustandegekommen, die die Einführung neuer landwirtschaftlicher Technologien erleichterte und Investitionen förderte.

- Die relativ gute administrative Infrastruktur: Das bereits in der Yi-Dynastie (1392-1910) existierende Verwaltungssystem wurde während der japanischen Kolonialzeit zum Zweck der politischen und sozialen Kontrolle weiter ausgebaut.

- Außerdem hat die kulturelle und ethische Homogenität des Volkes zur Sicherung der sozialen Stabilität beigetragen.

Um die wirtschaftliche Entwicklung voranzubringen, oder um zumindest der Armut zu entkommen, legten Wirtschaftswissenschaftler der koreanischen Regierung die Erkenntnisse der Wirtschaftstheorie und der Wirtschaftsplanungstheorie nahe, eine gemischte Wirtschaftsordnung in Form einer Marktwirtschaft mit vielen staatlichen Eingriffen in Südkorea einzuführen. Das Ergebnis war eine Marktwirtschaft mit planwirtschaftlichen Komponenten auf Regierungs- und Wissenschaftsebene.

\footnotetext{
${ }^{3}$ Außerdem waren die Ausgangslagen zu Beginn der Industrialisierung auch sehr ungünstig. Der Großteil der während der japanischen Kolonialzeit aufgebauten Industrien befand sich nach der Teilung des Landes im Norden, ebenso die Zentren des Bergbau und Energiewirtschaft (z.B. 90\% der Elektrizität, 80\% der mineralischen Rohstoffe und $80-90 \%$ der chemischen und Metallerzeugnisse wurden im Norden des Landes produziert). Vgl. Balassa, B. (1985), S. 142; Jones, L. P./Sagong, I. (1980), S. 27.

${ }^{4}$ Vgl. Ahn, S. K. (1988), S. 35.
} 
Südkorea hat sich im Vergleich $\mathrm{zu}$ den meisten Entwicklungsländern weitaus schneller entwickelt. $^{5}$ Die Weltbank beschreibt die Ursachen des wirtschaftliche Erfolg Südkoreas in ihrer Zusammenfassung des Berichts „The East Asian Miracle“:

„While there is no recipe for success, there are some positive lessons: keep the macroeconomy stable; focus on early education; do not neglect agriculture; use bank to build a sound financial system; be open to foreign ideas and technology; and let relative prices reflect economic scarcities; And there are some negative ones: promoting specific industries or attempting to leap stages of technologycal development will generally fail; strongly negative real interest rates and large subsidies to borrowers debilitate the financial system; and directing credit without adequate monitoring and selection of borrowers distorts allocation. Finally, we found that a successful export push, whether it results from an open economy and strong economic fundamentals, or from a combination of strong fundamentals and prudently chosen interventions, offers high economic gains. Of all the interventions we surveyed those to promote exports were the most readily compartible with a wide diversity of economic circumstances. “ 6

Es ist festzustellen, daß den wirtschaftspolitischen Entscheidungen zentrale Bedeutung für den Erfolg oder Mißerfolg der Entwicklungsanstrengungen eines Landes zukommen können. Nicht unberücksichtigt bleiben sollte freilich auch das Umfeld, d.h. die politisch-rechtlichen und gesellschaftlichen Rahmenbedingungen, unter denen die wirtschaftspolitischen Weichenstellungen erfolgen, wirken fördernd oder hemmend auf die wirtschaftliche Entwicklung. ${ }^{7}$ Der wirtschaftliche Erfolg der Entwicklungspolitik Südkoreas ist verständlicherweise nicht das Ergebnis eines einzelnen Wachstumsfaktors oder eines besonderen politischen und gesellschaftlichen Charakteristikums. Vielmehr haben die Kombination binnen- und außenwirtschaftlicher Faktoren sowie eine entwicklungsorientierte Wirtschaftspolitik usw. zu dem Erfolg geführt.

\footnotetext{
${ }^{5}$ In Südkorea ist es gelungen, den Übergang von einer ländlichen und niedrig entwickelten Nation zu einer modernen Wirtschaft innerhalb einer Generation zu schaffen. Das reale Bruttosozialprodukt hat sich seit 1963 mehr als verzwölffacht. Eine Export orientierte Wirtschaftspolitik, die in den frühen 1960er Jahren adoptiert wird, und die Förderung schwerer und chemischer Industrien durch die Regierung in den 1970er Jahren hat zu einer langen Periode anhaltenden Wachstums geführt. Seit Ende 1996 ist Südkorea Mitglied des OECD. Seine Wirtschaft ist zunehmend offen gegenüber internationalem Wettbewerb. Durch die Ausbreitung von sowohl Exporten als auch Investition in Anlagen (Südkorea hat den höchsten massigen festen Anlage-Anteil von GDP unter den OECD Ländern) in den 1990er Jahren hat sich der hohe Zuwachs bei der koreanischen Wirtschaft fortgesetzt (das jährliche Wachstum der Wirtschaft lag im Zeitraum 1990-95 durchschnittlich 7,8\%). Das GDP stieg in 1995 auf 455, 6 Mrd. \$. Damit ist Südkorea die neunt größte Industrienation der OECD Länder. Das GDP pro Kopf beträgt 10.076 \$, d.h. ungefähr $50 \%$ des OECD Durchschnitts. Exporte konstituieren mehr als ein Drittel des GDP, davon wiederum sind drei Viertel hergestellte Güter. Vgl. OECD (1997)

${ }^{6}$ Weltbank (1993), S. 367.

${ }^{7}$ Vgl. Serfas, A. (1987), S. 223.
} 
$\mathrm{Zu}$ den wichtigen Faktoren für das schnelle Wirtschaftswachstum bzw. die wirtschaftliche Entwicklung Südkoreas zählt die exportorientierte Wirtschaftentwicklungsstrategie. Je höher der effektive Schutz des Inlandsabsatzes und je gravierender die Überbewertung der Inlandswährung, desto ausgeprägter ist die Neigung zur Importsubstitution. ${ }^{8}$ Die exportorientierte (Wirtschafts-) Entwicklungsstrategie nutzt die komparativen Vorteile eines Landes. Damit ist vor allem eine neutrale Politik gemeint, die keinerlei Verzerrung zugunsten der Export- oder der Inlandsproduktion anstrebt. ${ }^{9}$

Im folgenden soll der Einfluß der Wirtschaftentwicklungspläne Südkoreas auf die heutigen Umweltprobleme untersucht werden. Dabei wird die Frage diskutiert, ob die wirtschaftlichen Entwicklungspläne Südkoreas seit den frühen 60er Jahren als wichtige Ursache der Umweltprobleme gesehen werden können und welche Rolle sie gespielt haben.

Das Verhältnis von Staat und Wirtschaft sowie Umfang und Art der staatlichen Eingriffe in den Wirtschaftsablauf beeinflussen in erheblichem Maße Geschwindigkeit und Charakter der wirtschaftlichen Entwicklung eines Landes. Die Frage nach einer angemessenen Wirtschaftsordnung stellt sich um so mehr, wenn sich eine Volkswirtschaft im Aufbau befindet und noch nicht über verfestigte Strukturen in diesem Bereich verfügt.

Das koreanische Wirtschaftswachstumsmodell der vergangenen 30 Jahre kann so charakterisiert werden, daß der Staat im Zentrum des dynamischen Prozesses der raschen Industrialisierung stand. Dar Staat übernahm bei der Entwicklung der nationalen Wirtschaft die Funktion der Regulierung und Koordinierung, sowie die Kontrolle bei der Einführung und Durchführung der Wirtschaftspläne. ${ }^{10}$

Auf dieser Basis läßt sich die rapide wirtschaftliche Entwicklung Südkoreas hinsichtlich der Wirtschaftspolitik und der makroökonomischen Strukturveränderungen im wesentlichen in sieben Aufbauphasen aufteilen, die mit den Fänfjahrespläne sehr eng verbunden sind. ${ }^{11}$ Dabei ist zu berïcksichtigen bzw. betrachten, wie mit der Wirtschaftsentwicklung in Südkorea die Umweltprobleme entstanden sind und wie die staatliche Umweltpolitik bzw. Umweltrechte darauf reagiert haben sollte (vgl. Abb. 7.1).

\footnotetext{
${ }^{8}$ Vgl. Weltbank (1987), S. 94.

${ }^{9}$ Vgl. Balassa, B. (1978), S. 181.

${ }^{10}$ Vgl. Sagong, I. (1993), S. 42f.

${ }^{11}$ Vgl. Byun, H.-Y. (1996), S. 109ff.
} 


\begin{tabular}{|c|c|c|c|}
\hline & 1. FJP (1962-66) & 2. FJP (1967-71) & 3. FJP (1972-76) \\
\hline $\begin{array}{l}\text { Übergeordnete } \\
\text { Ziele }\end{array}$ & 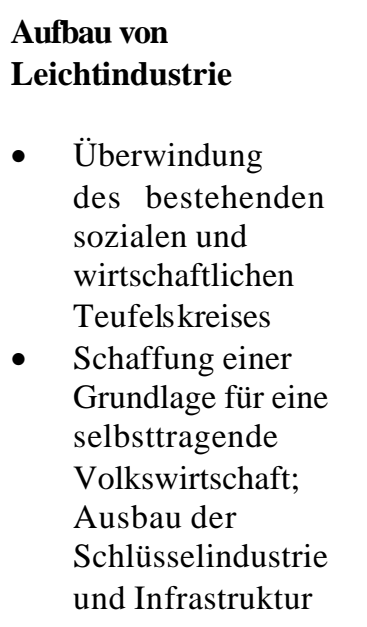 & $\begin{array}{l}\text { Aufbau von } \\
\text { Leichtindustrie } \\
\text { - } \quad \text { Verbesserung der } \\
\text { Industriestruktur } \\
\text { - } \quad \text { Aufbau einer } \\
\text { selbständigen } \\
\text { Volkswirtschaft }\end{array}$ & $\begin{array}{l}\text { Aufbau von Schwer- und } \\
\text { Chemieindustrie } \\
\text { - } \quad \text { Koordinierung } \\
\text { von Wachstum, } \\
\text { Stabilisierung und Ve r- } \\
\text { teilung } \\
\text { - Umfassende } \\
\text { nationale } \\
\text { Entwicklung und } \\
\text { Ausgewogenheit } \\
\text { der regionalen } \\
\text { Entwicklung }\end{array}$ \\
\hline $\begin{array}{l}\text { Industrialisierungs- } \\
\text { strategie }\end{array}$ & $\begin{array}{ll}\text { - } & \text { Importsubstitution } \\
\text { der Konsumgüter } \\
\text { - } & \text { Ausbau der } \\
\text { Schlüsselindustrie } \\
\text { und Infrastruktur } \\
\text { - } \quad \text { Verbesserung der } \\
\text { Handelsbilanz }\end{array}$ & $\begin{array}{l}\text { Importsubstitution } \\
\text { der Zwischen- und } \\
\text { Investitionsgüter } \\
\text { - } \quad \text { Förderung der } \\
\text { arbeitsintensiven } \\
\text { Exportindustrie } \\
\text { - } \\
\text { Ausbau der } \\
\text { Infrastruktur }\end{array}$ & $\begin{array}{ll}\text { - } & \text { Förderung der } \\
\text { Schwer- und } \\
\text { Chemieindustrie } \\
\text { - Verbesserung der } \\
\text { Industriestruktur }\end{array}$ \\
\hline Gefördert Industrie & $\begin{array}{ll}\text { - } & \text { Elektrizität } \\
\text { - } & \text { Kunstdüngemittel } \\
\text { - } & \text { Textil } \\
\text { - } & \text { Zement }\end{array}$ & $\begin{array}{l}\text { - Synthetische Fasern } \\
\text { - Chemie und } \\
\text { Petrochemie } \\
\text { - Elektrische } \\
\text { Haushaltswaren }\end{array}$ & $\begin{array}{ll}\text { - } & \text { Stahl } \\
\text { - } & \text { Elektrische } \\
\text { - } & \text { Saushaltswaren } \\
\text { - Schiffbau }\end{array}$ \\
\hline Umweltprobleme & $\begin{array}{l}\text { Keine konkreten } \\
\text { Daten für Umwelt- } \\
\text { probleme }\end{array}$ & $\begin{array}{l}\text { Keine konkreten Da- } \\
\text { ten für } \mathrm{Um} \text { - } \\
\text { weltprobleme }\end{array}$ & $\begin{array}{l}\text { Starke Zunahme der } \\
\text { industriellen Abfälle } \\
\text { und der Abfallprobleme } \\
\text { in den großen Städten }\end{array}$ \\
\hline Umweltpolitik & $\begin{array}{ll}\text { - } & \text { Identifizierung } \\
\text { konkreter Umweltbe- } \\
\text { lastungen } \\
\text { - Gesetz zum Schutz } \\
\text { vor Umweltver- } \\
\text { schmutzung (1963) }\end{array}$ & $\begin{array}{l}\text { - Identifizierung } \\
\text { konkreter } \\
\text { Umweltbelastungen } \\
\text { - Gesetz zum Schutz vor } \\
\text { Umweltverschmutzung } \\
\text { (1963) }\end{array}$ & $\begin{array}{l}\text { - Verkündung des allg. } \\
\text { Umweltschutzgesetzes } \\
\text { (1977) } \\
\text { 10-Jahres- } \\
\text { Raumentwicklungsplan } \\
\text { (1972-81) } \\
\text { - Umweltgrundrecht } \\
\text { (1980) } \\
\text { Zentralorganisation für } \\
\text { die Umweltfrage (Um- } \\
\text { weltamt, 1980) }\end{array}$ \\
\hline
\end{tabular}




\begin{tabular}{|c|c|c|c|}
\hline 4. FJP (1977-81) & 5. FJP (1982-86) & 6. FJP (1987-91) & 7. FJP (1992-96) \\
\hline $\begin{array}{l}\text { Aufbau von Schwer- } \\
\text { und Chemieindustrie } \\
\text { - Selbsttragendes } \\
\text { Wachstum } \\
\text { - Verbesserung der sozi- } \\
\text { alen Sicherung } \\
\text { - Technologieförderung } \\
\text { und Verbesserung der } \\
\text { Effizienz }\end{array}$ & $\begin{array}{l}\text { Lieberalisierung und } \\
\text { Internationalisierung } \\
\text { - Schaffung einer } \\
\text { Grundlage für Preis- } \\
\text { stabilisierung und } \\
\text { selbsttragende } \\
\text { Volkswirtschaft } \\
\text { - Sozialer Fortschritt } \\
\text { - Überwindung der } \\
\text { Strukturschwäche }\end{array}$ & $\begin{array}{l}\text { Lieberalisierung und } \\
\text { Internationalisierung } \\
\text { - Internationalisierung und } \\
\text { Liberalisierung der } \\
\text { Wirtschaft } \\
\text { - Industrierestrukturierung } \\
\text { und Technologieverbes- } \\
\text { serung }\end{array}$ & $\begin{array}{l}\text { Nachhaltige } \\
\text { Entwicklung der } \\
\text { Wirtschaft und Umwelt } \\
\text { - Verbesserung der } \\
\quad \text { wirtschaftlichen } \\
\text { Effektivität } \\
\text { - Verbesserung der } \\
\text { - Lebensqualität } \\
\text { - Umweltschutz }\end{array}$ \\
\hline $\begin{array}{l}\text { - Förderung der Techno- } \\
\text { logie und arbeitsinten- } \\
\text { siven Industrie } \\
\text { - Verbesserung der } \\
\text { Wettbewerbsfähigkeit } \\
\text { durch Forcierung von } \\
\text { F\&E }\end{array}$ & $\begin{array}{ll}\text { - } & \text { Modernisierung der } \\
\text { Industriestruktur } \\
\text { - Förderung von Bil- } \\
\text { dung, Wissenschaft } \\
\text { und Technik }\end{array}$ & $\begin{array}{l}\text { - Handelsliberalisierung } \\
\text { - } \quad \text { Förderung der kleinen } \\
\text { und mittleren Betriebe } \\
\text { Realisierung des Han- } \\
\text { delsüberschüsses und } \\
\text { Reduzierung der Aus- } \\
\text { landsverschuldung }\end{array}$ & $\begin{array}{l}\text { - Verbesserung der } \\
\text { internationalen } \\
\text { Wettbewerbsfähigkeit } \\
\text { durch Innovation }\end{array}$ \\
\hline $\begin{array}{l}\text { - Stahl } \\
\text { - Elektroindustrie } \\
\text { - Maschinenbau } \\
\text { - Schiffbau }\end{array}$ & $\begin{array}{l}\text { - Elektroindustrie } \\
\text { - Maschinenbau } \\
\text { - Informations- und } \\
\text { Nachrichtentechnik }\end{array}$ & $\begin{array}{ll}\text { - } & \text { Maschinenbau } \\
\text { - } & \text { Automobilindustrie } \\
\text { - } & \text { Elektroindustrie } \\
\text { - } & \text { Schiffbau }\end{array}$ & $\begin{array}{ll}\text { - } & \text { Automobilindustrie } \\
\text { - } & \text { Schiffsbau } \\
\text { - } & \text { Automationstechnik } \\
\text { - } & \text { Umweltschutztechnik } \\
\text { - } & \text { Halbleiterindustrie } \\
\text { - } & \text { Elektroindustrie } \\
\text { - } & \text { Maschinen- und } \\
& \text { Anlagenbau } \\
\end{array}$ \\
\hline $\begin{array}{l}\text { Starke Zunahme } \\
\text { der industriellen } \\
\text { Abfälle und der } \\
\text { Abfallprobleme in } \\
\text { den großen Städten }\end{array}$ & $\begin{array}{l}\text { - Starke Zunahme der } \\
\text { industriellen sowie } \\
\text { häuslichen Abfälle } \\
\text { - Verschlechterung der } \\
\text { Umweltzustände } \\
\text { insb. Umweltmedien } \\
\text { (Wasser, Luft und } \\
\text { Boden) }\end{array}$ & $\begin{array}{l}\text { - Starke Zunahme der } \\
\text { industriellen sowie } \\
\text { häuslichen Abfälle } \\
\text { Verschlechterung der } \\
\text { Umweltzustände } \\
\text { insb. Umweltmedien } \\
\text { (Wasser, Luft und } \\
\text { Boden) }\end{array}$ & $\begin{array}{ll}\text { - } & \text { Globalisierung der } \\
\text { Umweltfrage } \\
\text { - } \quad \text { Zunahme des } \\
\text { Umweltbewußtseins }\end{array}$ \\
\hline $\begin{array}{l}\text { Verkündung des allg. } \\
\text { Umweltschutzgeset- } \\
\text { zes (1977) } \\
\text { 10-Jahres- } \\
\text { Raumentwicklungs- } \\
\text { plan (1972-81) } \\
\text { - Umweltgrundrecht } \\
\text { (1980) } \\
\text { - Zentralorganisation } \\
\text { für die Umweltfrage } \\
\text { (Umweltamt, 1980) }\end{array}$ & $\begin{array}{l}\text { - Konstituierung der } \\
\text { Umweltpolitik } \\
\text { Umweltpolitik in ö- } \\
\text { konomischem, so- } \\
\text { zialem und ökologi- } \\
\text { schem Kontext }\end{array}$ & $\begin{array}{l}\text { Konstituierung der } \\
\text { Umweltpolitik } \\
\text { Umweltpolitik } \\
\text { in ökonomischem, } \\
\text { sozialem und ö- } \\
\text { kologischem } \\
\text { Kontext }\end{array}$ & $\begin{array}{l}\text { - Umweltpolitische } \\
\text { Deklaration des } \\
\text { Staatspräsidenten } \\
\text { (1992) } \\
\text { - Umweltministerium } \\
\text { (1994) } \\
\text { Gesetz zur Umweltver- } \\
\text { träglichkeitsprüfung } \\
\text { (1993) }\end{array}$ \\
\hline
\end{tabular}

Abb. 7.1: Inhalte der Fünfjahrespläne (FJP) der Wirtschaftsentwicklung und Umweltprobleme in Südkorea (Quelle: Eigene Darstellung) 
Die erste Aufbauphase umfaßte den ersten und zweiten FP. In dieser Periode konzentrierte sich die Wirtschaftspolitik der Regierung auf den Aufbau der Infrastruktur (Elektrizität, Verkehrswesen) und auf die Unterstïtzung der Schlüsselindustrien vor allem Textilindustrie, Zement und Kunstdünger, später auch synthetische Fasern und petrochemische Industrie, die gleichzeitig zum großen Teil als arbeitsintensive Exportindustrien gefördert wurden. Der erste Wirtschaftsplan (1962-66) konzentrierte sich vornehmlich auf den sekundären Sektor, vor allem umweltrelevante Faktoren wie z.B. Primärenergie, Rohstahl und Zement. Dessen Wachstumsrate war in diesem Zeitraum sehr hoch $(7,8 \%) .{ }^{12}$ Mit dem wachstumsorientierten Wandel der koreanischen Wirtschafts- bzw. Industriestruktur gingen allerdings unerwünschte Umwelteffekte einher. ${ }^{13}$

Als Resultat der erfolgreichen Ergebnisse des ersten FJP konnte der zweite FJP (1967-71) auf die Modernisierung der Industriekultur und eine intensive Förderung der eigenständigen Wirtschaft abzielen. So förderte die Regierung vorrangig die arbeitsintensiven Branchen, weil Südkorea ein rohstoffarmes Land mit relativ gut ausgebildeten Arbeitskräften war. Aufgrund der äuBerst niedrigen Löhne wurde Südkorea sehr schnell zu einem der führenden Exporteure für elektronische Waren und Textilien, die ohne hohen Kapitalaufwand hergestellt werden konnten. Hierdurch wurden die gesteckten Planziele wiederum übertroffen. Die Wachstumsrate des BSP betrug in diesem Zeitraum durchschnittlich 9,6\% pro Jahr. ${ }^{14}$ Die wesentlichen Erfolgsfaktoren des Wirtschaftsaufschwungs (bzw. -erfolges) von dieser Aufbauphase waren an die Anstrengungen zur Exportförderung, die Festlegung konkreter Exportziele sowie steuerliche und finanzielle Anreize für Exportindustrien in Verbindung mit komparativen Vorteilen bei lohn- und arbeitsintensiven Sektoren, in denen billige und relativ gut ausgebildete Arbeitskräfte vorhanden waren, die damals komparative Kostenvorteile einbrachten.

Es ist besonders schwierig, eine genauen zahlenmäßigen Zusammenhang zwischen Wirtschaftsentwicklung und Umweltbelastungen (z.B. Emissionsentwicklung) herzustellen, denn nur wenige haben sich in diesem Zeitraum mit den Umweltproblemen beschäftigt und daher existieren auch nur wenige Daten darüber, (besser gesagt, man hat erst in diesem Zeitraum mit der Identifizierung der Umweltbelastung angefangen). Jedoch kann der Zusammenhang zwischen industrieller Produktion und Umweltbelastungen anhand globaler Daten (Rohstahl, Zement, Primärenergie und BSP) abgeschätzt werden. So werden die Wissenschaftsbereiche in dieser Zeit allmählich umweltbewußter und es werden Untersuchungen über die Umweltqualität eingeleitet, die sich hauptsächlich auf die Umweltmedien Wasser und Luft bezogen.

\footnotetext{
${ }^{12}$ Vgl. Lee, K.-S. (1969), S. 62.

${ }^{13}$ Vgl. Lee, K.-S. (1969), S. $62 \mathrm{ff}$.
} 
Der dritte FJP (1972-76), der unter dem Motto „Harmonisierung des Wachstums, Stabilisierung und Gleichgewicht" stand, sollte vor allem die Zahlungsbilanz verbessern, die Landwirtschaft stark entwickeln und die Schwer- und Chemieindustrie fördern. Angesichts der sich verschärfenden internationalen Wettbewerbsbedingungen durch die Öffnung anderer Niedriglohnländer, insbesondere im Textilbereich und in der Elektroindustrie, mußte Südkorea die einseitige Ausrichtung auf Leichtindustrie und arbeitsintensive Fertigung überwinden, um die Wettbewerbsfähigkeit weiter beizubehalten. Die Regierung hatte daher im Jahr 1973 das Gesetz zur Förderung der Schwer- und Chemieindustrie erlassen und ihre strategischen Schwerpunkte bewußt auf die petrochemische Industrie, die Stahlindustrie und den Schiffbau gelegt.

Die exzessive, schwerindustrielle Förderung verbunden mit einer einseitigen Bevorzugung der Großunternehmen führte einerseits zu einem deutlichen Anstieg besonders kapital- und technologieintensiver Exporte, führte aber am Ende der 70er Jahre zu Überkapazität in den Schwerund Petrochemieindustrie. Dies wurde in den Jahren 1980 und 1981 noch deutlicher. Die unausgelastete Überkapazitäten können als negatives Erscheinungsbild einer massiven Fehlallokation von Ressourcen interpretiert werden. ${ }^{15}$

Wichtige Ziele des vierten FJP (1977-81), der unter das Motto „Wachstum, Gleichgewicht und Effektivität“ gestellt wurde, waren die Verwirklichung der eigenständigen Wachstumsstruktur, die Förderung der Sozialentwicklung und die Erhöhung der Effektivität durch technische Innovation. ${ }^{16}$ In dieser Planungsphase unternahm die Regierung, systematisch allgemeine Industriekomplexe (Changwon, Yochon, Pohang, Gumi usw.), spezielle Industriekomplexe (Banwol, Wolsong usw.) sowie lokale Industriekomplexe (Chunchon, Wonju usw.) zu errichten. Andererseits bemühte sich die Regierung, mit Hilfe planerischer Maßnahmen einer weiteren Umweltbelastungen Einhalt $\mathrm{zu}$ gebieten. Aber diese höchst widersprüchlichen Umweltschutzmaßnahmen waren erfolglos. Vielmehr wurde die flächendeckende Umweltzerstörung durch Ansiedlung der besonders umweltschädlichen Chemie- und Schwerindustrie in den Küstengebieten fortgesetzt. Man hatte die Ansicht, insbesondere von der Seite des Staates, daß die Industrialisierung nicht durch frühzeitige Einbeziehung von Umweltschutzmaßnahmen gestört werden sollte und daß der Umweltschutz vorerst ein Luxus der Industrieländer sei und ökologische Maßnahmen erst nach einer Anhebung des ökonomischen Entwicklungsniveaus in Angriff genommen werden könnte.

\footnotetext{
${ }^{14}$ Vgl. Brown, G. T. (1973), S. 46.

${ }^{15}$ Vgl. Wade, L. E./Kim, B. S. (1978), S. 191ff.

${ }^{16}$ Vgl. Sagong, I. (1993), S. 50.
} 
Aufgrund der oben geschilderten Verschlechterung des Umweltzustandes im Ende der 70er Jahre verbreitete sich allmählich ein umweltbewußtes Denken vor allem in den großen Städte einschließlich der Industriekomplexe. Demzufolge entwickelte sich die Umweltfrage erstmals zu einem wichtigen Faktor und es wurde versucht, über die wirtschaftliche Entwicklung im Einklang mit dem Umweltschutz nachzudenken.

In der drittem Aufbauphase der Wirtschaftsentwicklung, in den 80er Jahren (fünfter und sechster FJP), begann die koreanische Regierung zunächst mit einer Stabilisierungspolitik und liberalisierte die Wirtschaft durch den Abbau von Preiskontrolle, Importrestriktionen und Finanzmarktinterventionen. Die intensive Liberalisierung von Importen mit Ausnahme von landwirtschaftlichen Gütern bzw. der Reform der Zollpolitik, sollten Monopolstellungen verhindern und die Wettbewerbsfähigkeit der inländischen Industrie erhöhen. In dieser Periode stand die Aufbauförderung kapitalintensiver High-Tech-Industrien im Zentrum der Wirtschaftsstrukturpolitik. Während der 90er Jahre bestanden die strategischen Schwerpunkte im massiven Aufbau mittelständischer Unternehmen, einer noch intensiveren Diversifikation der Wirtschaftsstruktur und der Export- und Importmärkte. ${ }^{17}$

Die Kurskorrektur der staatlichen Politik hat auch Auswirkung auf die staatliche Planung. Die Harmonisierung von ökonomischem Wachstum und Umweltschutz wurde als Ziel in den fünften wirtschaftlichen Entwicklungsplan (1982-1986) aufgenommen. Außerdem wurde ein langfristiger Gesamtplan für den Umweltschutz bis zum Jahr 2001 als Rahmenplan erarbeitet. Sein Hauptziel war die Erhöhung der Lebensqualität der Bevölkerung mit Hilfe verschiedener abgestufter Maßnahmen zur Erreichung der Ziele des Umweltschutzes.

Seit den frühen 60er Jahren hat der FJP die Richtung der koreanischen Wirtschaftspolitik aufgezeigt. Von 1992-96 galt der siebte FJP (der sog. neue Wirtschaftentwicklungsplan) und es wurde versucht, umweltfreundliche, bzw. ökologieorientierte Wirtschaftsentwicklung zu fördern. In dieser Periode wurden unter dem Gesichtspunkt der Globalisierung nicht nur die Wirtschaft, sondern verstärkt auch die Umweltprobleme in die Planung der Entwicklungspolitik einbezogen. ${ }^{18}$ In dieser Periode setzte der Staat seine Wirtschaftspolitik mit Liberalisierungs- und Internationalisierungskurs durch Beseitigung von Handelsbarrieren und vereinfachten Regelungen bzw. Kontrollen fort. Damit sollte vor allem die Effektivität der Wirtschaft verbessert werden.

\footnotetext{
${ }^{17}$ Vgl. Song, B.-N. (1990), S. 138ff.; Weltbank (1982).

18 In diesem Zeitraum war die Globalisierung viel im Rede, z.B. Eintritt der Luftverschmutzung aus China durch Luftströmung und Barriere der Außenhandel durch internationale Handels - und Umweltpolitik.
} 
$\mathrm{Zu}$ bemerken ist dabei, daß die Politik einen Schwerpunkt auf die Verbesserung der Lebensqualität der Bevölkerung und die Förderung des Umweltschutzes legte.

Der Umweltschutz und die Verbesserung der Umweltqualität, die auf die starke Forderung der Bevölkerung nach einer intakten, sauberen Umwelt, nach einem rücksichtsvollen Umgang mit ökologisch knappen Ressourcen sowie dem Erhalt der natürlichen Lebensgrundlagen und - daraus abgeleitet - die auf die Herausbildung eines ausgeprägten Umweltbewußtseins zurückzuführen sind, wurden dringende Aufgaben der Regierung. Das „Presidental Vision for Environmental Welfare“ im Jahr 1996 war einer wichtige Anlaß für die Umsetzung der Umweltpolitik. Umweltstandards und -gesetze wurde strenger und mit der Erhöhung der Investitionen zur effektiven Reduzierung und Kontrolle verbesserte sich die Integration der ökologischen Dimensionen in der sektoralen Wirtschaftspolitik. Dieses Prozeß war durch die Überlegung von Kosten-Effektivität wiederum ein wichtiger Schritt für den Umweltschutz.

Der siebte FJP umfaßte außerdem die Elemente für die Integration von environmental considerations in die sektoralen Wirtschaftpolitik; z.B. energy conservation and efficiency measures and aims to encourage long-term energy supply and demand development consistent with the sustainable use of energy and protection of the environment.

Die Harmonisierung von ökonomischem Wachstum und Umweltschutz wurde als eine der Hauptaufgabe in den siebten Entwicklungsplan der Wirtschaft (1992-1996) aufgenommen. 1994 wurde das Umweltministerium eingerichtet. Außerdem wurde ein mittelfristiger Gesamtplan für Umweltverbesserung, der nötige Investitionen zum Umweltschutz mit dem siebten FJP verbinden sollte, „Master Plan for the Preservation of the Natural Environment“" (1994-2003), der zwischen der (wirtschaftlichen) Entwicklung und dem Schutz der natürlichen Umwelt balancieren sollte, als Rahmenplan erarbeitet. „Die sog. Umwelt-Vision 21“ im Jahr 1995 dokumentierte auch die Ziele der koreanischen Umweltpolitik (1996-2005). ${ }^{19}$

Zusammenfassend ist festzuhalten, $\mathrm{da}$ es in Südkorea gelungen ist, innerhalb einer Generation den Übergang von einer ländlichen und niedrig entwickelten Nation zu einer modernen Wirtschaft zu schaffen. Die reale Bruttosozialprodukte hat sich seit 1963 um mehr als das Zwölffache vermehrt. Eine exportorientierte Wirtschaftspolitik, die in den frühen 1960er Jahren adoptiert wurde, und die Förderung schwerer und chemischer Industrien durch die Regierung in den 1970er Jahren hat zu einer langen Periode anhaltenden Wachstums geführt. Aber dabei sollte

\footnotetext{
${ }^{19} \mathrm{Zu}$ den Einzelheiten der sog. „Umweltvision 21“ vgl. Umweltministerium Südkorea (1995).
} 
nicht unberücksichtigt bleiben, daß diese wirtschaftlichen Entwicklungen erhebliche Umweltprobleme mit sich gebraucht haben, besser gesagt, daß der Prozeß des quantitativen Wirtschaftswachstums vor allem auf Kosten der natürlichen Umwelt abgelaufen ist.

Schließlich sollte in Südkorea folgende Richtungen weiter verfolgt werden, um weitere schwer zu lösende Umweltprobleme besser in den Griff zu bekommen:

- ,implement environmental policies with determination and along the lines already defined;

- $\quad$ pursue current efforts to bring the environmental infrastructure to the desires level;

continue gradually tightening environmental standards and discharge/emission limits;

continue improving the effectiveness of economic instruments, including raising the rates at which they are applied;

strengthen the capacity of local government to carry out its new environmental functions;

strengthen the role of industry associations in raising environmental awareness, expertise and management standards among small and mediumsizes firms;

give the public access to environmental information to encourage wellinformed debate on environmental issues, exceptions to this general principle being limited to defined circumstances; educate consumers regarding the health and environmental effects of current production and consumption practices. ${ }^{\text {20 }}$

\subsection{Wirtschaftspolitische Maßnahmen zur Förderung des betrieblichen Umweltschutzes}

In diesem Abschnitt sollen die wesentlichen Programme wirtschaftspolitischer Maßnahmen zur Förderung von Umweltschutzvorhaben bzw. Umweltschutztechnologie in Südkorea behandelt werden. Dabei handelt es sich vor allem um marktorientierte Umweltpolitik.

Das wesentliche Charakteristikum einer marktorientierten Umweltpolitik besteht darin, daß für diejenigen, die sich umweltfreundlicher verhalten sollen, ohne direkten staatlichen Eingriff ein monetärer oder sonstiger Anreiz entsteht. Unternehmer, Privathaushalte und andere umweltbeeinflussende Subjekte sollen dabei die Möglichkeit erhalten, in den umweltpolitisch notwendigen Grenzen flexible $\mathrm{zu}$ agieren und sich möglichst kostengünstig auf diese Umweltschutzerfordernisse einzustellen. Der Eigennutz, d.h. das Streben nach möglichst hohem Gewinn oder Kosumentennutzen von Arbeitnehmern, Konsumenten und Unternehmen soll für den Umweltschutz mobilisiert werden.

${ }^{20}$ Vgl. OECD (1997), S. 19f. 
Mit der Verwirklichung einer solchen Politik soll die soziale Marktwirtschaft neben dem vorhandenen sozialen Rahmen einen ökologischen Rahmen erhalten und materielle und nichtmaterielle Vorteile bei umweltfreundlichem bzw. relativ umweltfreundlichem Verhalten (z.B. Benutzung eines Katalysatorautos oder des öffentlichen Personenverkehrs) gewährt werden. Durch diese Anreize innerhalb der durch den ökologischen Rahmen gesteckten Grenzen können und sollen sich die einzelnen Wirtschafts- und Umweltsubjekte flexibel entsprechend ihren eigenen Zielsetzungen umweltfreundlicher verhalten.

Marktorientierte Lösungen des Umweltschutzes, die im Bereich einer besseren Umweltpolitik für unumgänglich gehalten werden, können auf folgende Weise erreicht werden: ${ }^{21}$

Der Umweltschutz soll durch das freiwillige Verhalten aller Marktteilnehmer, das durch verbesserte Informationen und Anreize unterstuitzt werden soll, erhöht werden:

- Steigerung des Umweltbewußtseins und - verhaltens der Verbraucher,

- Umweltbewußte Unternehmensführung durch ein gewinnorientiertes offensives Umweltschutzmanagement,

- Umweltfreundliche staatliche Beschaffung,

- Schaffung von Benutzervorteilen für umweltfreundliche Produkte.

Der Umweltschutz soll durch Umweltvereinbarungen verbessert werden: Vereinbarungen zwischen Wirtschaft und lokal von Schadstoffbelastungen und Betroffenen (z.B. auf Basis verbesserter Information über die Umweltbelastungen, d.h. verbesserte Umweltberichterstattung) und Branchenabkommen oder -vereinbarungen, in denen sich bestimmte Wirtschaftszweige dem Staat gegenüber zu einem festgelegten umweltfreundlichen Verhalten verpflichten.

Der Umweltschutz soll durch das Wecken von Gewinninteressen der Unternehmen für ein ökologisch orientiertes Verhalten erreicht werden:

- Umweltabgaben in Abhängigkeit von dem jeweiligen Schadstoffausstoß oder der Umweltschädlichkeit der Produkte,

- Umweltschutzlizenzen, mit denen der Schadstoffausstoß insgesamt auf ein bestimmtes Niveau begrenzt wird und ein Anreiz entsteht, durch Schadstoffreduzierungen Lizenzen gewinnbringend verkaufen zu können,

${ }^{21}$ Vgl. Hopfenbeck, W. (1991), S. 32. 
Flexible nachträgliche Anordnungen, bei denen diejenigen, die freiwillig mehr Schadstoffe reduzieren als angeordnet, diese Zusatzminderungen gewinnbringend einsetzen können.

Schließlich soll eine verschärfte Umwelthaftung das wirtschaftliche Risiko bei umweltbelastender Produktion deutlich steigern.

Eingriffsarten der Umweltpolitik, die von staatlicher Seite innerhalb des marktwirtschaftlichen Rahmens möglich sind, lassen sich nach Uhlig wie folgt in 5 Strategien unterscheiden: ${ }^{22}$

Bei der Auflagenstrategie soll durch direkte Eingriffe des Staates auf das einzelwirtschaftliche Verhalten eingewirkt werden (z.B. Verbote, Gebote).

- Bei der Marktstrategie soll die autonome Marktregelung, unter gezielter Vorgabe von Rahmenbedingungen wirtschaftlichen Handelns, aufrechterhalten bleiben (z.B. Umweltzertifikate, ökologische Buchführung).

- Bei der Anreizstrategie sollen durch verschiedene Anreize individuelle Entscheidungen beeinflußt werden (z.B. Emissions-, Produkt- und Ressourcensteuer, Subventionen).

- Bei der Substitutionsstrategie sollen mittels marktsubstituierender Handlungen das Entstehen aktivitätsinduzierter Störgrößen bzw. realer Schadenspositionen vermieden werden (z.B. Gebühren).

- Bei der Kompensationsstrategie wird die Beseitigung entstandener realer Schadenspositionen angestrebt (z.B. Einbau von Sauerstoffbelüftungsanlagen in stark verschmutzte Gewässern).

Dabei geht es für die Unternehmen nicht nur darum, daß sie und ihre Aktivitäten vielfältigen ökologieintendierten Lenkungseinflüssen durch ihre Umwelt ausgesetzt sein können, wobei zwingende Beschränkungen durch das umweltpolitische und umweltrechtliche Instrumentarium wie z.B. Strafrecht, Auflagen etc. bedeutsam werden, sondern auch daß diese für die Unternehmen neue Marktchancen und Expansionsmöglichkeiten in Märkte des Umweltschutzes und Umweltschutztechnologien bieten können. Damit kann die staatliche Umweltpolitik (hier insbesondere die Programme der wirtschaftspolitischen Maßnahmen zur Förderung von Umweltschutzvorhaben und der Wettbewerbsfähigkeit von Umweltschutztechnologie) als eine der wichtigen Rahmenbedingungen für die ökologisch verpflichtete Unternehmensführung bezeichnet werden.

In Südkorea wird Umweltpolitik auf der Grundlage von drei Prinzipien praktiziert: Verursacherprinzip, Kooperationsprinzip und Vorsorgeprinzip. ${ }^{23}$ Zur Durchsetzung der angestrebten staatli-

${ }^{22}$ Vgl. Uhlig, C. A. (1978). Zitiert nach Hopfenbeck, W. (1991), S. 32. 
chen Umweltpolitik und Umweltschutzziele stehen eine Anzahl politischer Instrumente zur Verfügung. Die zur Anwendung kommenden Instrumente können in ordnungsrechtliche Instrumente (Vorschreibungen, Auflagen in Form von Geboten oder Verboten), ökonomische Anreizinstrumente (Erhebung von Lenkungsabgaben auf Emissionen, Umweltzertifikate, Kompensationsregelungen) und sonstige Instrumente (Steuervergünstigungen, Haftungsrecht) unterteilt werden. Dabei sollen ordnungsrechtliche Regelungen immer dort Vorrang haben, wo Schutzansprüche der Bürger und ökologische Erfordernisse einen bestimmten Umweltschutzstandard verlangen. Gleichzeitig müssen marktwirtschaftliche Anreize dort verstärkt genutzt werden, wo die Suche nach integrierten Vermeidungstechniken vorangebraucht werden soll. Neben dieser ordnungspolitischen und marktwirtschaftlichen Steuerung kann eine weitere, bisher weitgehend außer Betracht gebliebene Handlungsmöglichkeit, der freiwillige Verzicht zum Einsatz kommen.

Was für die ökologisch verpflichtete Unternehmensführung wichtig ist und in diesem Abschnitt besonderes behandelt werden soll, sind die ökonomischen Instrumente staatlicher Umweltpolitik.

Die ökonomischen Instrumente gehören zur indirekten Steuerung durch den Staat, welche auf $\dot{a}-$ ne imperative, strikte Determination des Verhaltens der Normadressten verzichtet und sich statt dessen bemüht, motivierend auf deren Entscheidungen einzuwirken. Im Unterschied zu den ordnungsrechtlichen Instrumenten, bei denen dem Verursacher von Umweltbeeinträchtigungen meist im Detail vorgeschrieben wird, welche Anforderungen mit welchen Mitteln zu erfüllen sind, verbleibt bei ökonomischen Instrumenten ein gewisser Entscheidungsspielraum, ob und in welchem Ausmaß ein vom Staat gewünschtes Verhalten erfüllt wird bzw. auf welche Weise eine staatliche Zielvorgabe erreicht wird. Im Vergleich $\mathrm{zu}$ den ordnungsrechtlichen Instrumenten ist der Vorteil der ökonomischen Instrumente darin zu erkenne, daß sowohl bei den Unternehmen als auch bei den Verbrauchern ein ökonomisches Interesse an umweltverträglichem Verhalten geschaffen und somit ein eigenverantwortliches Vermeiden von Umweltbelastungen gefördert wird. Der Nachteil ökonomischer Instrumente liegt u.a. in deren Langwierigkeit, Wirkungsunsicherheit und -unvollständigkeit. Sie sind deshalb insbesondere für solche Probleme ungeeignet, in denen eine schnelle, sichere und ausnahmslose Abhilfe zwingend geboten ist. ${ }^{24}$

Die ökonomischen Instrumente, die in Südkorea bisher zum Einsatz gekommen sind, werden mit anderen Instrumenten z.B. mit „command-and-control type regulations“ kombiniert durchge-

\footnotetext{
${ }^{23}$ Die Grundprinzipien der Umweltpolitik in Südkorea sind nicht anders als in Deutschland. Sie orientieren sich an westlichen Vorbildem der Umweltpolitik. Vgl. zu den Grundprinzipien der Umweltpolitik in Südkorea Kap. 4.1 dieser Arbeit.

${ }^{24}$ Vgl. Kloepfer, M. (1990), S. 243.
} 
führt. Die wichtigen ökonomischen Instrumente der Umweltpolitik in Südkorea sind u.a. „Environmental (Improvement) Charge“, „Defosit-refund system“, „Waste disposal charge“, „Congestion charge“, ,Financial assitance“ und „Liability and insurance“. 25

Für den betrieblichen Umweltschutz ist den Unternehmen ein umfangreicher und unüberschaubarer Vorschriftenrahmen vorgegeben, der die unternehmerischen Aktivitäten stark beschränken kann. Neben bestimmten ordnungspolitischen Maßnahmen oder der Veränderung von Entscheidungsparametern ist hier vor allem an die klassischen direkten Eingriffe z.B. Auflagen in Form von Geboten oder Verboten zu denken.

Auflagen in Form von Geboten oder Verboten schreiben ein bestimmtes Verhalten vor, z.B. die Einhaltung bestimmter Emissionsgrenzwerte. Als wesentliche Nachteil dieses allerdings unerläßlichen Instrumentariums der Umweltpolitik ist ihre wirtschaftliche Ineffizienz zu sehen. Denn bei Festlegung etwa eines bestimmten Emissionsstandards ist - unabhängig von den beim einzelnen Unternehmen gegebenen Kosten - jeder zur Erhaltung dieser Norm verpflichtet. Damit wird die Verbesserung volkswirtschaftlich nicht mit geringstmöglichem Kostenaufwand erreicht, und sie ist bei veränderten Rahmenbedingungen wenig flexibel. Zudem fehlt bei der Orientierung der Umweltpolitik am sog. Stand der Technik der Anreiz, über die Auflagenerfüllung hinaus weitere innovative Anstrengungen zu unternehmen (das berüchtigte „Schweigekartell“ der Anbieter). Der gegenwärtige technische Stand wird damit festgeschrieben und die Entwicklung neuer Technologien gebremst. Wegen dieser Schwachpunkte der ordnungsrechtlichen Instrumente sollen zur Verwirklichung einer präventiven Umweltpolitik bzw. zur Gestaltung eines offensiven Umweltmanagements ergänzend der Einsatz marktwirtschaftlicher (ökonomischer) Instrumente gefördert werden. In dem sie die Nutzung von Umweltgütern mit Kosten belegen, bieten Abgaben ökonomisch-finanzielle Anreize und geben, aus dem Eigeninteresse der Unternehmen heraus, Anregungen zu Vermeidungsmaßnahmen. Über den Regelungsmechanismus des Preises der Umweltgüter sollten also innovative Marktprozesse ausgelöst werden. Eine solche gewinnorientierte betriebliche Umweltpolitik müßte ,durch positive oder negative Anreize (z.B. Verkauf von überobligationsmäßigen Emissionsminderungen bzw. Erhebung von Umweltabgaben) oder Erhöhung der Haftungsrisiken dafür sorgen, daß es für den Betrieb wirtschaftlicher und damit zugleich rational ist, sich umweltfreundlich zu verhalten“ ${ }^{26}$

Umweltschutz sollte sich u.a bezahlt machen, wenn ein Unternehmen durch den Verkauf von freiwilligen und zusätzlichen Emissionsminderungen Erlöse erzielen, durch Umweltschutzmaß-

\footnotetext{
${ }^{25} \mathrm{Vgl}$. OECD (1997), S. 131ff.

${ }^{26}$ Vgl. Wicke, L. (1988). Zit. nach Hopfenbeck, W. (1991), S. 36.
} 
nahmen Umweltabgaben sparen, bessere Verkaufserfolge erreichen oder wirtschaftliche Risiken infolge denkbarer Schadenersatzleistungen vermeiden kann.

Umweltschutz wird dann auch für die Konsumenten erstrebenswert sein, wenn sie bei umweltfreundlichem Verhalten Kosten sparen oder Nachteile vermeiden können. Wenn dem so ist, dann wird das Gewinn- und Eigennutzenstreben von Unternehmen und Konsumenten für den Umweltschutz wirken. Dann wird die Unternehmensleitung alles daran setzen, daß nach kostengünstigen Umweltschutzlösungen gesucht wird, weil eine effiziente Umweltschutzmaßnahmen dem Unternehmen höhere Erträge (gesparte Abgabe oder Einnahmen) bringt als Kosten. Auf diese Weise wird die Umweltbelastung zu einem Kosten- und Ertragsfaktor in der betrieblichen Kalkulation. Die Forderung nach mehr marktorientiertem Umweltschutz ist gleichzusetzen mit der Zielsetzung der Verwirklichung von mehr Umweltschutz, der seinerseits wegen der sehr positiven Nutzen-Kosten-Verhältnisse sinnvoller Umweltschutzmaßnahmen und der hohen Kosten der Umweltbelastungen auch aus ökonomischen Gründen erforderlich wird.

Nun sollen im folgenden die ökonomischen Programme zur Förderung des betrieblichen Umweltschutzes in Südkorea behandelt werden. Hierbei handelt es sich vor allem um Abgaben und Subventionen. Auch andere umweltschutzfördernde Maßnahmen wie z.B. „Umweltzeichen“, „Auszeichnung der umweltbewußten bzw. freundlichen Unternehmen“ und Maßnahmen zur Förderung der Umweltschutztechnologien sollen in Betracht gezogen werden. Doch zunächst sollen noch ein Paar theoretische Anmerkung zu den Maßnahmen eingeführt werden.

Umweltabgaben sind Preislösungen: Der Preis einer Umweltressource wird fixiert, während die Menge der durch umweltbelastende Verhaltensweise entstehenden Schäden variabel bleibt. Umweltabgaben werden in instrumenteller Sichtweise u.a. definiert als „Geldleistungen, die von einem öffentlich-rechtlichen Gemeinwesen kraft seines Hoheitsrechts erhoben werden, um umweltpolitische Ziele zu verfolgen“. 27

Abgaben werden in der Umweltpolitik in Abhängigkeit von ihrer Zielsetzung in Umweltabgaben im weiteren Sinne als Finanzierungsabgaben und in Umweltabgaben im engeren Sinne als Lenkungsabgaben unterschieden. ${ }^{28}$ Bei ersten steht der fiskalische Zweck der Einnahmenerzielung im Vordergrund, dagegen dominiert bei Umweltabgaben i.e.S. die Anreizwirkung, durch welche die betroffenen Wirtschaftssubjekte (hier vor allem die Unternehmen) zu der ökologisch ge-

\footnotetext{
${ }^{27}$ Ewringmann, D./Schafhausen, F. (1985), S. 18.

${ }^{28}$ Vgl. Wicke, L. (1993), S. 395.
} 
wünschten Verhaltensweise veranlaßt werden sollen. Gegenstand der weiteren Untersuchung soll die Umweltabgaben i.e.S. sein, d.h. die Lenkungsabgabe. Denkbar sind Schadstoffabgaben (z.B. auf Abgase), Lärmschutzabgaben (z.B. für Lastwagen) oder gezielte Abgaben auf einzelne Stoffe oder Produkte (z.B. Einwegflaschen).

Die Abgabesätze sind vielfach auf einem so geringen Niveau festgelegt, daß sie ihre Lenkungsfunktion nur unzureichend entfalten können. Infolge der geringen Abgabenbelastung pro Emissions- oder Verschmutzungseinheit ist es für die einzelnen Umweltverschmutzer rational, die $\mathrm{Ab}$ gabe $\mathrm{zu}$ bezahlen und keine Anpassung vorzunehmen. Somit wird die fiskalische Funktion der staatlichen Einnahmenerzielung trotz oder gerade wegen der niedrigen Umweltabgabensätze erfuillt.

Der entscheidende Vorteil der Abgaben gegenüber den beschriebenen Auflagen liegt darin, daß das einzelne Unternehmen als Umweltnutzer sich individuell an das gesetzte Preissignal anpassen kann. Es ist in diesem Fall für das Unternehmen rational, seine Schadstoffe auch unterhalb der Grenzwerte bis zu dem Punkt zu verringern, an dem die Vermeidung der nächsten Schadstoffeinheit teuer wird als die Zahlung der Abgabe. Das Umweltziel wird zudem volkswirtschaftlich billiger erreicht, da je nach den gegebenen Vermeidungskosten des Umweltschutzes im Fall niedriger Kosten verstärkt, im anderen Fall schwächere Maßnahmen veranlaßt werden. In Südkorea kommen zur Zeit folgende Abgabearten zum Einsatz: ${ }^{29}$ Emissionsabgabe auf Luft (Abgas), Wasser (Abwasser), Abgabe für die Umweltverbesserung, Abgabe für die Verbesserung der Wasserqualität, Abfallabgabe und Depositabgabe für Abfälle

Mit Abgaben sollen zum einem gemäß des Verursacherprinzips die bisher nicht erfaßten externen Kosten innerhalb der volkswirtschaftlich entstehenden Gesamtkosten erhoben werden, zum anderen über die bewußte Verteuerung der umweltbelastenden Produkte eine Verbrauchsdrosselung und eine Lenkung der individuellen Kaufentscheidung hin $\mathrm{zu}$ den (dann relativ billigeren) umweltfreundlichen Produkten erreicht werden. ${ }^{30}$

Es existieren zahlreiche, im Umfang sich unterscheidende Überlegungen zu den ökonomischen Instrumenten der Umweltpolitik: Rohstoff- und Energiesteuern, Verpackungssteuern vor allem

\footnotetext{
${ }^{29}$ Die einzelnen Abgabenarten und deren Erläuterungen bzw. Ausführung im Detail, die in Südkorea zum Einsatz kommen, soll im Rahmen dieser Arbeit nicht weiter behandelt werden. Statt dessen wird auf das Umweltministerium Südkorea (1998), S. 92-144 verwiesen.

30 Auf die zahlreichen Probleme beim Einsatz solcher Verbrauchersteuern wie z.B. Bemessung der Höhe, voraussichtlicher Einfluß auf den Verbrauch, Verwendung der einhergehenden Mittel, ihre Sozialverträglichkeit bei privaten Haushalten mit geringem Einkommen usw. kann im Rahmen dieser Arbeit nur hingewiesen werden.
} 
für bestimmte Getränkepackungen und viel mehr. Weitere ökonomische Anreize bestehen etwa in einem Entsorgungszuschlag auf den Kaufpreis von Produkten (z.B. für Autos) und in einer erweiterten Rücknahmepflicht für den Hersteller bestimmter Produkte (z.B. für Altöl), womit bereits bei der Produktplanung in Zukunft eine Vermeidung angestrebt werden muß.

Subventionen $^{31}$ werden in Südkorea - ungeachtet der regelmäßig vorgetragenen Kritik ${ }^{32}$ - zur Verfolgung der unterschiedlichsten politischen Ziele eingesetzt. Der Begriff Förderung wird in der Finanzwirtschaft wie folgt definiert: Subventionen sind Geldzahlungen oder geldwerte Leistungen, die ,die öffentliche Hand (Transfergeber) ohne marktliche Gegenleistung privaten Wirtschaftssubjekten (Transferempfänger), die die als Voraussetzung festgelegten Merkmale aufweisen, finanzielle Zuwendungen oder geldwerte Vorteile gewähren. Als Gegenleistung wird von den Transferempfängern eine bestimmte realisierte (Empfangauflage) bzw. noch zu realisierende (Verwendungsauflage), vom Förderungsgeber erwünschte Verhaltensweise gefordert bzw. zumindest erwartet“ ${ }^{33}$ Nach ihrer Form unterscheidet man Geldzahlungen oder geldwerte Leistungen wie Zuschüsse, verbilligte Kredite, Übernahme von Zins- und Tilgungsleistungen, Bürgschaften und Garantien Verzicht auf öffentlich-rechtliche Forderungen gegenüber dem Förderungsempfänger. Zur letztgenannten Kategorie zählen Steuervorteile oder der Erlaß bzw. die Aussetzung von Abgaben.

Seit dem Beginn einer systematischen Umweltpolitik in Südkorea wurden auf den verschiedenen staatlichen Ebenen zahlreiche Programme zur Förderung umweltpolitischer Vorhaben entwickelt, die sich in Zielsetzung, Ausprägung der Förderungstatbestände und des Adressantenkreises kaum auf einen gemeinsamen Nenner bringen lassen. Dazu sind die vorhandenen Programme, die unmittelbar bzw. mittelbar dem (betrieblichen) Umweltschutz, dem schonenden Umgang mit den knappen Ressourcen und der Förderung der Forschung und Entwicklung von Umweltschutztechnologien u.a. dienen, zu vielzählig und darüber hinaus ständigen Änderungen unter-

\footnotetext{
${ }^{31}$ Der Subventionsbegriff wird aufgrund des unterschiedlichen Erkenntnisinteresses, das die Rechtswissenschaft, die Wirtschaftswissenschaft, Finanzwissenschaft, die Wettbewerbstheorie und -politik, die Statistik sowie die Politik haben, sehr unterschiedlich verwendet und es wird häufig von Förderung, Zuwendung, Prämien, Finanzhilfen, Unterstützungen, Transfers oder Beihilfen gesprochen, um den negativ besetzten Begriff der „Subvention“ zu vermeiden. In den folgenden Ausführungen soll der Begriff „Subvention“ mit staatlicher Förderung Sy nonym verstanden.

${ }^{32}$ Der wichtigste Kritikpunkt der Subventionen sei vor allem u.a. darin zu sehen, daß die Subventionszahlungen zu problematischen Wettbewerbsverzehrungen führen. Vgl. Cansier, D. (1993), S. 140ff.

${ }^{33}$ Kötzle, A. (1980), S. 105. Diese Definition weist gegenüber der in der wirtschaftswissenschaftlichen Literatur ansonsten üblichen, nur die Förderung an Unternehmen einschließenden Abgrenzung, den Vorteil auf, daß sie bereits Leistungen der öffentlichen Hand an private Haushalte einschließt. Zur problembezogenen Abgrenzung ist diese Definition um die zwischen den verschiedenen öffentlichen Haushalte fließenden Finanz- und Leistungsströme zu ergänzen, so daß Förderung neben der Transferleistungen an Unternehmen und an private Haushalte auch finanzausgleichähnliche Leistungen zwischen inländischen öffentlichen Körperschaften erfaßt. Dabei beschränkt sich die „Umweltschutz-Förderung“ nicht nur auf Maßnahmen mit originär umweltpolitischer Zielsetzung, sondern schließt
} 
worfen. Aus diesem Grunde beschränkt sich die folgende Ausführung darauf, die derzeit zentralen Förderungsmöglichkeiten aufzuweisen. ${ }^{34} \mathrm{Zu}$ unterscheiden sind im wesentlichen: Steuervergünstigungen, konditionsverbesserte Kreditprogramme, Investitionszuschüsse sowie Bürgschaftsprogramme.

Allerdings ist stellvertretend der Umweltforschungsplan zur Entwicklung der Umweltschutztechnologien der koreanischen Regierung zu nennen. Dieses Förderungsprogramm, das vor allem die Umweltschutztechnologien und umweltschutzorientierte Industrien fördern soll, wird seit 1992 durchgeführt. ${ }^{35}$ Die innerhalb dessen bereitgestellten Haushaltmittel betrugen im Jahr 1997 88.455 Md. Won (umgerechnet ca. 1.5 Md. DM) Dies entsprach 0,021\% der GNP und kann so als sehr gering eingeschätzt werden.

Mit dieser umweltbedeutsamen staatlichen Forschungs- und Entwicklungsförderung soll erreicht werden, daß der umwelttechnische Fortschritt sich beschleunigt und dadurch die Bedingungen für einen wirksamen und kostengünstigen technischen Umweltschutz verbessert werden. Der Schwerpunkt der Maßnahmen hat sich von der direkten institutionellen Forschungsförderung auf indirekte Maßnahmen zur Förderung von Forschung und Entwicklung in Unternehmen verlagert. Dadurch soll der Wettbewerb gestärkt und das Innovationstempo der Wirtschaft beschleunigt werden und insbesondere ein verbesserter Technologietransfer durch sog. Verbundvorhaben (intensive Kooperation zwischen Staat, Unternehmen und Forschungseinrichtungen) gewährleistet werden.

Ziel und Maßnahmen der Forschungspolitik der koreanischen Regierung werden in Forschungsund Entwicklungsprogrammen zusammengefaßt. Im Fachprogramm „Entwicklung und Forschung zur Förderung von Umwelschutztechnologien“ (sog. G-7 Projekt) sollen neben der reinen umweltbezogenen Forschung als Voraussetzung für einen wirksamen Umweltschutz (Grundlagenforschung: Informationen über die Wirkung von Schadstoffen auf Menschen und Ökosystem) Technologien zur Vermeidung bzw. Reduzierung von Umweltbelastungen und zur Sanierung von eingetretenen Umweltschäden gefördert werden. Dazu zählt neben der Initiierung, Planung und fachlichen Begleitung der Vorhaben auch deren verwaltungstechnische und finanzielle $\mathrm{Ab}$ wicklung.

auch die Integration umweltpolitischer Anliegen in Förderungsansätze anderer Politikbereiche ein. Vgl. hierzu Kötzle, A. (1983), S. 7; Schneider, W. (1977), S. 266.

${ }^{34}$ Hier sind zu verweisen auf Umweltministerium (1998). 
Ein wichtiger Beitrag zur Information der Öffentlichkeit über umweltfreundliche Eigenschaften von Produkten und damit zur Mobilisierung des Umweltbewußtseins der Käufer zu realem umweltfreundlichem Kaufverhalten ist das sog. „Umweltzeichen“. Der Begriff „Umweltzeichen“ stellt die Kurzform für „ökologiebezogene Auszeichnung“ dar. Hierunter soll im folgenden der Prozeß der Beurteilung, der Informationsverdichtung und Kennzeichnung eines Meinungsgegenstandes in ökologischer Dimension zwecks Information der Marktteilnehmer verstanden werden.

Für eine Vergabe des Umweltzeichens kommen solche Produkte in Betracht, die im Vergleich zu anderen, dem selben Gebrauchszweck dienenden Produkte, bei einer ganzheitlichen Betrachtung, unter Beachtung aller möglichen Gesichtspunkte des Umweltschutzes (einschließlich eines sparsamen Rohstoffeinsatzes) sich insgesamt durch besondere Umweltfreundlichkeit auszeichnen, ohne daß sich dadurch ihre Gebrauchstauglichkeit wesentlich verschlechtert oder ihre Sicherheit beeinträchtigt wird. ${ }^{36}$

Das „Umweltzeichen“ ist mit dem Erlaß der „Verordnung über Ecomark“ im April 1992 in Südkorea eingeführt worden. Danach ist im Dezember 1994 mit dem Erlaß vom „Gesetz für die Entwicklung und Unterstützung der Umweltschutztechnologie“ die rechtliche Grundlagen für das „Ecomark“ geschaffen worden. Damit soll zunächst verbindet werden, die Produkte mit Umweltzeichen vor allem durch die öffentliche Institutionen einzukaufen, d.h. umweltfreundliche staatliche Beschaffung. ${ }^{37}$ Mit diesem Umweltzeichen will man Verbraucher und Handel eine Hilfestellung beim Einkauf geben und der Hersteller soll motiviert werden, umweltfreundliche Produkte anzubieten. Den mit dem Umweltzeichen ausgezeichneten Waren schenken die Konsumenten besondere Aufmerksamkeit. Nach einer Untersuchung im Jahr 1997 ziehen rd. 82\% der Befragten meistens, den Kauf eines umweltfreundlichen Produktes vor. ${ }^{38}$ Da objektive Kriterien fehlen, ist für den Käufer schwer nachprüfbar, welche Produkte tatsächlich weniger umweltbelastend sind. Wie Untersuchungen zeigen, weist das Öko-Label bei der Bevölkerung inzwischen einen sehr hohen Bekanntheitsgrad auf. Im Jahr 1997 sind bereits 231 Waren und Ceräte von rund 143 Herstellern mit dem Umweltzeichen ausgezeichnet worden. ${ }^{39}$

\footnotetext{
35 Zu den Einzelheiten der Programme der umweltbedeutsamen Forschungs- und Entwicklungsförderung in Südkorea vgl. Umweltministerium Südkorea $(1992,1998)$.

${ }^{36}$ Vgl. Wicke, L. (1991), S. 253.

${ }^{37}$ Vgl. Umweltministerium Südkorea (1998), S. 138ff.

${ }^{38}$ Vgl. KEI (1997).

${ }^{39}$ Vgl. Umweltministerium Südkorea (1998), S. 42.
} 
Zur Erlangung des Zeichens muß der Hersteller in einem Prüfungsverfahren nachweisen, daß das Produkt im Vergleich zu anderen Produkten mit demselben Gebrauchswert - also relativ gesehen - umweltfreundlicher ist (z.B. besonders lärm- oder emissionsarm, Abfall vermindert, Abwasser entlastet, schädliche Inhaltstoffe reduziert oder ganz vermeidet, das Recycling fördert usw.). Die Prüfung geschieht an Hand von Anforderungen, die als Vergabegrundlagen für jede Produktgruppe festgelegt sind. Da diese entsprechend der technischen Entwicklung verändert werden, wirken sie innovativ. ${ }^{40}$ Für eine adäquate Wirksamkeit sind bestimmte Anforderungen an ein sinnvolles Öko-Labeling zu stellen. Aus umwelt- und verbraucherpolitischer Perspektive ist dabei in erster Linie auf Glaubwürdigkeit und Kompetenz des Labeling sowie auf informationelle Entlastung der Konsumenten $\mathrm{zu}$ achten. Für Unternehmen muß ein Umweltzeichen mit möglichst geringeren Kosten eine zusätzliche Positionierungschance am Markt bieten. Dies ist am ehesten bei einer interessenungebundenen Vergabestelle der Fall, die alle beteiligten Interessengruppen in den Labeling-Prozeß mit einbezieht.

Zur Förderung bzw. Induktion der freiwilligen Umweltschutzanstrengung des Unternehmens ist die „Auszeichnung für umweltbewußte bzw. freundliche Unternehmen“ 1995 in Südkorea eingeführt worden.

Den als umweltfreundliche Unternehmen ausgezeichnete Unternehmen werden umfangreiche Unterstützungsprograme gewährleistet z.B. Zuschüsse, verbilligte Kredite, Übernahme von Zinsund Tilgungsleistungen, Bürgschaften, Verzicht auf öffentlich-rechtliche Forderungen sowie Steuervorteile oder der Erlaß bzw. die Aussetzung von Abgaben. ${ }^{41}$ Bewerber müssen Kriterien des Bewertungskatalogs erfüllen, die alle Phasen von der Erstellung, über den Verkauf, den Geund Verbrauch und die Entsorgung umfassen. Darüber hinaus müssen die sich bewerbenden Uhternehmen einen Gesamtplan Umweltschutzmaßnahmen (sog. Umweltverträglichkeitsprüfung und Umweltverbesserungsplan) vorlegen. ${ }^{42}$ Im Jahr 1997 sind bereits 112 Unternehmen als umweltfreundliche Unternehmen ausgezeichnet worden.

Als neue ökonomische Instrumente, die im Rahmen der wirtschaftspolitischen Maßnahmen zur Förderung des betrieblichen Umweltschutzes zum Einsatz kommen können, u.a. sind die folgenden denkbar: ${ }^{43}$

\footnotetext{
${ }^{40}$ Vgl. Umweltministerium Südkorea (1998), S. 138ff.

${ }^{41}$ Vgl. KETRI (1997), S. 85ff.

${ }^{42} \mathrm{Zu}$ den Einzelheiten vgl. KETRI (1997), S. 85ff.
} 
- Branchenabkommen oder freiwillige Kooperationsabkommen. Sie setzen allerdings voraus, daß sich die Konkurrenten auch an die Vereinbarungen halten.

- Aufrufe an die Konsumenten zum freiwilligen Verzicht.

- Ausweitung der Umwelthaftung auf alle Schäden durch Produkte (verschuldensunabhängige Produzentenhaftung im Verbraucherschutz und durch Produktion bzw. Betriebsunfälle). Über das Streben nach Reduzierung der die Umweltrisiken abdeckenden Versicherungsprämien will man eine Aktivierung des Eigeninteresses der Industrie erreichen.

- Einführung eines „Umwelt-TÜV“ mit besseren automatisierten Meß- und Kontrollverfahren, da die Gewerbeaufsichtsämter eine wirksame Kontrolle moderner Produktionsmethoden nicht gewährleisten können.

- ,Arbeitsverweigerungsrecht“ bei Verstößen gegen Umweltvorschriften.

- Einsetzen eines Vorstandsmitgliedes für Umweltschutzaufgaben und Arbeitsicherheit.

- Steuerliche Förderung umweltfreundlicher Produkte und Herstellungsverfahren.

- Abkehr des auf Individualinteressen fixierten Rechtschutzes und Schaffung der Verbandsklagemöglichkeit in Umweltangelegenheiten.

- Restemissionsabgaben für genehmigte, aber unerwünschte Emissionen.

- Bekanntgabe der genehmigten Emissionswerte.

- Ausgleichs- oder Offset-Politik (Genehmigung einer Anlage trotz Überschreitens der Emissionswerte bei Überkompensation durch Minderung einer anderen Anlage).

- Flexible Emissionslizenzen/Umweltzertifikate.

- Vetorecht des Umweltministers gegen naturzerstörende Gesetze und Vorhaben.

- Verbot bestimmter Verpackungsarten mit Hilfe des Abfallgesetzes bzw. ministerielle Zielvorgaben etwa für flächendeckende Erfassung und Verwertung.

Zusammenfassend ist festzuhalten, daß wirtschaftspolitische Maßnahmen zum Umweltschutz (sog. Economie instruments) einmal in konventionellen Auflagen (wie z.B. Ge- oder Verbote, Produkt- oder Produktionsstandards), zum anderen aber auch eine Kosteninternalisierung bezwecken können (wie z.B. durch Umweltsteuern oder handelbare Zertifikate). Neben diesen belastenden Instrumenten sind auch Umwelt-Subventionen als begünstigende Maßnahmen denkbar. Belastende und begünstigende Maßnahmen sind kombinierbar, so daß eine einheitliche Steuer auf umweltfreundliche und umweltschädliche Produkte erhoben werden kann, wobei das hierdurch erzielte Steueraufkommen zur Subventionierung der umweltfreundlichen Produkte verwendet werden kann. Die Umweltökonomie empfiehlt, wirtschaftspolitische Maßnahmen so

\footnotetext{
${ }^{43}$ Vgl. Hopfenbeck, W. (1991), S. 36f. Diese Instrumente finden sich nicht alle in der aktuellen Diskussion in Süd-
} korea. Aber sie können Denk-Anstöße für Alternativen zum ökonomischen Instrument der Umweltpolitik sein. 
einzusetzen, daß durch eine Verteuerung umweltschädlicher Produkte und Produktion die Nachfrage auf umweltfreundliches Verhalten gelenkt wird.

Neben der oben dargestellten wirtschaftspolitischen Maßnahmen können handelspolitische Maßnahmen als Strategien zur Verfolgung von Umweltschutzzielen dienen. Instrumente der Handelspolitik (sog. Trade related environmental measures, TREMs) sind umweltpolitisch motivierte Ein- und Ausfuhrverbote, Mengenbeschränkungen und Einfuhrabgaben. ${ }^{44}$

Handelsmaßnahmen zum Umweltschutz sind erstens denkbar zur Unterstützung wirtschaftspolitischer Maßnahmen. Die wohl häufigste Funktion handelspolitischer Maßnahmen dieser Gruppe ist die Begleitung einer Auflagenpolitik. Handelspolitische Maßnahmen können in dieser Hinsicht als Weiterführung wirtschaftspolitischer Maßnahmen auf internationaler Ebene angesehen werden (z.B. kann ein wirtschaftspolitisches Verbot auf nationaler Ebene durch ein Einfuhrverbot auf internationaler Ebene abgesichert werden). Handelspolitische Maßnahmen können aber auch eine Kosteninternalisierung begleiten. Dabei haben sie die Funktion, durch die Kosteninternalisierung bedingte Wettbewerbsnachteile auszugleichen.

Handelspolitische Maßnahmen sind aber auch denkbar zur Reduktion umweltschädigenden Handels, ohne wirtschaftspolitische Maßnahmen zu begleiten. Als solche sind sie denkbar: zum Schutz eines Landes vor grenzüberschreitender Verschmutzung sowie zum Schutz internationaler öffentlicher Güter.

In Südkorea können sich dem Unternehmen aufgrund der Verschärfung staatlicher Umweltschutzanforderungen rapide wachsende Marktchancen auf Umweltschutzmärkten ergeben, wobei die Regierung selbst zunehmend als Nachfrager nach Umweltschutztechnologien auftritt. Die Geschäftsfelder in Südkorea, die größte Marktchancen im Umweltbereich aufzeigen, sind, vor allem in Einrichtungen der Emissionskontrolle, Aufbereitung und Entsorgung gefährlicher Abfälle, Entsorgung industrieller und kommunaler Abfälle bzw. Abwässer, Ersatzstoffen für FCKW und Entsorgung von FCKW, umweltfreundlichen Konsumgütern, Recycling usw. zu sehen. Um diese Marktchancen von der Seite des Unternehmens auszunutzen, bieten die oben dargestellten marktorientierte Maßnahmen zur Förderung des betrieblichen Umweltschutzes dem Unternehmen viele Möglichkeiten. Zum einem ist das Unternehmen selbst gefordert, diese Marktchancen durch die rechtzeitige Adaption der ökologisch verpflichteten Unternehmensführung auszunutzen. Auf der anderen Seite steht auch der Staat zur Förderung des betrieblichen Umweltschutzes

${ }^{44}$ Vgl. Subramanian, A. (1992), S. 135ff.; Mathis, J. H. (1991), S. 37ff. 
einerseits durch als externe Zwänge (z.B. durch Setzung von politisch-rechtlichen Rahmenbedingungen) andererseits als auch Anreiz-Stifter (Förderer), der z.B. durch wirtschaftspolitische Maßnahmen (Subventionen oder Steuervergünstigung usw.) den betrieblichen Umweltschutz fördert, zur Verfügung. Das Unternehmen soll die stark wachsenden Zukunftsmärkte für Umweltschutztechnologien und die vom Staat geförderten Maßnahmen seinerseits aufnehmen und ausnutzen. 


\section{Schlußbetrachtung: Möglichkeiten und Grenzen für die Implementierung einer ökologisch verpflichteten Unternehmensführung in Südkorea}

Seit der Industrialisierung in den frühen 60er Jahren hat die Wirtschaft viel zur Wohlstandsmehrung und Güterproduktion in Südkorea beigetragen. In diesem Sinne haben die Unternehmen in Südkorea als Orte der Wertschöpfung und damit Träger des Wohlstands die Aufgabe nach ihrer Bestimmung in der herkömmlichen Vorstellung von einer Industriegesellschaft hervorragend erfuillt. Gleichzeitig hat das Wirtschaftswachstum eine Zunahme der Umweltbelastung und damit Umweltprobleme mit sich gebracht. Der Prozeß des quantitativen Wirtschaftswachstums ist also auch auf Kosten der natïrlichen Umwelt abgelaufen. Trotzdem bestimmt die Ideologie des quantitativen Wachstums die Gesellschaft in Südkorea.

Angesichts der Konsequenzen der Umweltprobleme, die unternehmerische Tätigkeiten zunehmend in ihrer ökologischen, gesellschaftlichen und wettbewerbsstrategischen Dimension beeinflussen, ist die Notwendigkeit der Berücksichtigung von Umweltschutzforderungen bei unternehmerischen Entscheidungen kaum mehr in Frage zu stellen. Trotz der Notwendigkeiten einer ökologisch verpflichteten Unternehmensführung gibt es Grenzen und Hemmnisse, welche die Berücksichtigung ökologischer Aspekte von Seiten der Unternehmen in Südkorea verhindern.

In diesem Kapitel als Schlußbetrachtung werden Problemfelder für die Gestaltung und Umsetzung einer ökologisch verpflichteten Unternehmensführung in Südkorea betrachtet. Im Mittelpunkt steht dabei die Frage, welche Faktoren für die Zurückhaltung oder Forderung nach ökologisch verpflichteter Unternehmensführung in Südkorea bestimmend sind. Schließlich wird damit auch versucht, möglichst grundlegende Denkansätze für die Implementierung einer ökologisch verpflichteten Unternehmensführung in Südkorea herauszuarbeiten.

\subsection{Problemfelder für die Implementierung einer ökologisch verpflichteten Unternehmensführung in Südkorea}

Grundsätzlich ist festzustellen, daß sich eine Vielzahl von Hindernissen und Grenzen, die zu Problemfeldern werden, im Bereich der ökologisch verpflichteten Unternehmenspolitik, der Managementprozesse und im Rahmen der funktionsbereichsbezogenen Aspekte zeigt, wenn es um die Gestaltung oder Umsetzung ökologisch verantwortlichen Handelns in der Unternehmensführung geht. 
Die Grenzen und Hemmnisse einer ökologisch verpflichteten Unternehmensführung sind ökonomischer, ökologischer, individueller, kollektiver und struktueller Art, wobei häufiger das eine aus dem anderen folgt oder/und eine wechselseitige Beeinflussung stattfindet. Eine eindeutige Zuordnung ist deshalb nur teilweise möglich. Im folgenden wird versucht, Gestaltungs- oder Umsetzungsprobleme einer ökologisch verpflichteten Unternehmensführung und daraus folgende Umsetzungsmöglichkeiten für Südkorea darzustellen.

\begin{tabular}{|l|}
\hline \multicolumn{1}{|c|}{ Unternehmensexterne Problemfelder } \\
\hline - Hohe Preiselastizität der Nachfrage \\
- Unklare Umweltgesetzgebung und fehlende Anreizwirkung der staatlichen Umweltpolitik \\
- Traditionelle Präferenzen von Banken, Lieferanten, Handel etc. \\
- Fehlendes oder niedriges Umweltbewußtsein und ambivalentes Kaufverhalten der Konsumenten \\
- Nichtverfügbarkeit von Technologien
\end{tabular}

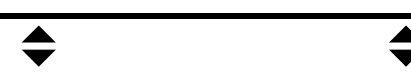

\begin{tabular}{|c|c|}
\hline Übergreifendes Problemfeldeiner ökologisch verpflichteten Unternehmensführung \\
\hline \multirow{2}{*}{ Gefährdung der Wettbewerbsfähigkeit } \\
\hline
\end{tabular}

\section{Unternehmensinterne Problemfelder}

- Mangelhaft ausgeprägte Umweltverantwortung, mangelnde Durchschaubarkeit der Entscheidungsprozesse und damit Umweltschutzinsellösung im Management

- Fehlende Kenntnis der eigenen Situation und mangelnde Beobachtung des Umfeldes von Unternehmen

- Defizite in der internen und externen Kommunikation

- Schlechte finanzielle Ausgangslage und Kostendruck durch Umweltschutzmaßnahmen und -investitionen

- Defizite in der Organisation des betrieblichen Umweltschutzes und organisatorische Abstimmu ngsprobleme

- Mangel an qualifiziertem Personal, Aufgabenüberlastung, Ineffizienz, Überlappung von Kompetenzen, Schwerfälligkeit, Koordinationsprobleme, Informationsprobleme

- Informations- und Methodendefizit und fehlendes Know-how zur Entwicklung einer ökologisch verpflichteten Unternehmensführung

Abb. 8.1: Gestaltungs- und Umsetzungsprobleme einer ökologisch verpflichteten Unternehmensführung in Südkorea (Quelle: eigene Darstellung)

Als unternehmensexterne Problemfelder sind eine relativ hohe Preiselastizität der Nachfrage sowie eine fehlende Anreizwirkung der staatlichen, eher „kurativen“ Umweltpolitik zu beobachten. Eine wenig stringente Umweltgesetzgebung, andersgelagerte Präferenzen von Banken, Lieferanten und Handel, fehlendes oder niedriges Umweltbewußtsein, ambivalentes Kaufverhalten und die Nichtverfügbarkeit von Technologien erzeugen weitere Problemfelder. 
Das Umweltbewußtsein der Bürger als externer Zwang d.h. als aktives Kritik- und Forderungspotential in bezug auf einen wirksamen Umweltschutz beeinflußt Unternehmen einerseits direkt auf den Märkten durch ein geänderten Konsumentenverhalten, was eine ökologisch orientierte Produktpolitik erforderlich macht. Andererseits ergeben sich nichtmarktliche Wirkungen durch die öffentliche Meinung, welche es ratsam erscheinen lassen, ein ökologisches Firmenimage aufzubauen und das Vertrauen in die Problemlösungskraft von Unternehmen wieder herzustellen.

Trotz steigender Tendenz läßt sich feststellen, daß das Umweltbewußtsein der Bevölkerung in Südkorea immer noch relativ niedrig ist und daß darüber hinaus zwischen dem Umweltbewußtsein und den tatsächlichen Umweltverhalten eine große Divergenz besteht. Wenngleich sich Unternehmen heute umweltsensibilisierten Kundengruppen gegenübersehen, bestehen erhebliche Probleme, mit umweltverträglicheren Problemlösungen auch Profilierungs- und Wettbewerbsvorteile zu erschließen. Dies liegt nicht zuletzt darin, daß sich das Umweltbewußtsein der Konsumenten und daraus resultierende umweltorientierte Forderungen gegenüber Industrie und Handel im konkreten Kaufverhalten nicht hinreichend niederschlagen. Vielmehr ist eine erhebliche Divergenz zwischen Umweltbewußtsein und Umweltverhalten festzustellen, welche die Akzeptanz und Diffusion von umweltgerechteren Produktvarianten erschwert. Aufgabe für das Unternehmen ist es deshalb primär, bekannte Kaufbarrieren (z.B. den Preis oder eine empfundene gringere Produktqualität) zu vermeiden oder durch eine gezielte Informationspolitik zu überwinden.

Insofern erfordert die Analyse der Kunden- und wettbewerbsbezogenen Profilierungsmöglichkeiten im Umweltschutz die Beantwortung der Schlüsselfrage, wieweit Umweltvorteile eines Produktes oder einer Dienstleistung den Anforderungen von Wettbewerbsvorteilen gerecht werden können. Da sich Wettbewerbsvorteile letztlich nur im Verhalten der Konsumenten manifestieren können, ist die Frage nach der Schnittmenge zwischen Umwelt- und Wettbewerbsvorteilen unweigerlich mit einer Analyse des Ausmaßes des Umweltbewußtseins und Umweltverhaltens von Konsumenten verknüpft.

Die von Umweltschutzauflagen und -normen betroffenen Unternehmen stehen aufgrund der durchzuführenden Umweltschutzinvestitionen einer veränderten Kosten- und Liquiditätssituation und damit neuen preispolitischen Determinaten gegenüber. Die Herstellung umweltgerechter Produkte verursacht in der Regel höhere Herstellungskosten. Das beruht einerseits auf den meist komplizierten und kostenintensiveren Herstellungsverfahren und andererseits auf der Schwierigkeit, schnell Absatzzahlen zu erreichen, die das Unternehmen im Sinne von ,economies of scale“ 
bringen kann. Diese bei der Mehrzahl des Unternehmens anfallenden Kostensteigerungen durch Umweltschutzmaßnahmen müssen ganz oder teilweise auf den Nachfrager überwälzt werden. Die Auswirkungen der erhöhten Preisforderung auf die abgesetzte Menge und die Gewinnsituation hängen von der Preiselastizität der Nachfrage nach dem umweltverträglichen Produkt ab. In der Regel ist damit zu rechnen, daß die Reaktion auf Preiserhöhungen bei der Einführung umweltfreundlicher Produktvarianten relativ elastisch erfolgt, d.h. ein entsprechender Nachfragerückgang eintritt.

Die relative Veränderung des Absatzes im Vergleich zur relativen Veränderung des Preises wird Preiselastizität genannt. Die Preiselastizität drückt aus, um wieviel Prozent sich der Absatz verändert, wenn der Preis um ein Prozent verändert wird. Hohe Preiselastizität der Nachfrage der ökologisch hergestellten Produkte kann so gekennzeichnet werden: Je höher der Preis der umweltgerechten Produkte ist, desto geringer ist die Nachfrage. Ökologisch hergestellte Produkte werden von Konsumenten nach wie vor für teuer gehalten. Dadurch entsteht auch die oben erwähnte Diskrepanz zwischen dem Umweltbewußtsein und dem tatsächlichen Umweltverhalten.

Die Unternehmen sind also gefordert, diese Diskrepanz zu überwinden und durch gezielte ökologisch verpflichtete Unternehmensführung die beim Unternehmen anfallenden Kostensteigerung durch Umweltschutzmaßnahmen möglichst niedrig zu halten. Eine Möglichkeit bietet sich z.B. im Rahmen des Öko-Marketings insbesondere in der Preispolitik durch ökologieorientierte Mischkalkulation innerhalb der gesamten Produktpalette eines Unternehmens zugunsten der umweltverträglichen Produkte an. ${ }^{1}$ Das Grundprinzip der Mischkalkulation liegt darin, daß einzelne Produktgruppen, Produkte oder Artikel über die jeweils zurechenbaren Einzelkosten hinaus mit unterschiedlich hohen Kalkulationsaufschlägen oder -abschlägen belegt werden. Kalkulationsobjekte mit überdurchschnittlichem Aufschlag nennt man Ausgleichgeber, solche mit unterdurchschnittlichem Aufschlag Ausgleichnehmer. Die Höhe der jeweiligen Auf- oder Abschläge bestimmt sich nach den Prinzipien der retrograden Kalkulation. ${ }^{2}$ Entscheidend ist, daß insgesamt ein kalkulatorischer Ausgleich zustande kommt, der die periodenbezogenen Gewinnziele des Unternehmens befriedigt. ${ }^{3}$

\footnotetext{
${ }^{1}$ Vgl. Meffert, H./Kirchgeorg, M. (1998), S. 339ff.

${ }^{2}$ Grundprinzip der marktorientierten Preisstellungsverfahren ist es, nicht wie bei den kostenorientierten Verfahren die Kosten, sondern aus dem Marktgeschehen ableitbare Preise als kalkulatorischen Ausgangspunkt zu wählen und diese in einer Rückrechnung auf ihre Erfolgswirkungen hin zu überprüfen. Man spricht deshalb auch von retrograder Kalkulation. Vgl. zur retrograden Kalkulation Diller, H. (1991), S. 163ff.

${ }^{3}$ Vgl. Diller, H. (1991), S. $206 f f$.
} 
Es ist auch eine Preisdifferenzierung denkbar, bei der vom umweltbewußt denkenden und handelnden Konsumentensegment ein höherer Preis gefordert wird als in den anderen Marktsegmenten. Aber der wesentliche Bestimmungsgrund für eine solche Kostenüberwälzung ist die Preisbereitschaft bei den umweltbewußten Konsumenten, die im Umweltbewußtsein der Bürger ihren Niederschlag findet. Deshalb müssen die Unternehmen neben ihren umweltverträglichen Aktivitäten das Umweltbewußtsein fördern, d.h. sich nicht im Sinne von Hauptverursachern der ökologischen Probleme, sondern als ökologische Akteure profilieren. Es ist auch denkbar, daß umweltfreundliche Produkte im Vergleich zu herkömmlichen Produkten für den Konsumenten wegen sonstiger ökonomischer Vorteile (Material-, Energie-, Wasser/Abwasser-, und Ersatzteilkostenreduzierungen etc.) auch rein wirtschaftlich attraktiver zu machen z.B. Mehrwegflaschen, Recyclingpapier.

Umweltgesetzgebung und Umweltpolitik (vor allem die ordnungspolitischen Instrumente), die bisher in Südkorea in Kraft getreten sind, wirken beschränkend auf die unternehmerische Handlungs- und Haftungssituation. Hierbei fehlt vor allem die Anreizwirkung der staatlichen Umweltpolitik. In diesem Sinne wird auch der Staat gefordert, neben den ordnungpolitischen Instrumenten (z.B. Gebot und Verbot) Anreizwirkungen zum betrieblichen Umweltschutz durch zusätzliche ökonomische Instrumente (z.B. durch das Wecken des Gewinninteresses der Unternehmen zur Anregung für ein ökologisch orientiertes Verhalten, Steigerung des Umweltbewußtseins und -verhaltens der Verbraucher, Förderung der ökologisch verpflichteten Unternehmensführung durch ein gewinnorientiertes offensives Umweltschutzmanagement, umweltfreundliche staatliche Beschaffung, Schaffung von Benutzervorteilen für umweltfreundliche Produkte usw.) zu schaffen. Sinnvoll für die Zukunft scheint also, von politischer Seite eine Rahmensetzung zu verfolgen, die den Unternehmen Handlungsspielräume gewährt, auf deren Basis zu Eigenaktivität und selbständiger Suche nach den Möglichkeiten einer ökologisch verpflichteten Unternehmensführung motiviert wird. Nach Möglichkeiten sollten dafür Anreize, z.B. in Form von Steuervorteilen, geliefert werden.

Weitere unternehmensexterne Problemfelder zur Gestaltung und Umsetzung einer ökologisch verpflichteten Unternehmensführung in Südkorea sind in der Nichtverfügbarkeit von Umweltschutz-Technologien zu beobachten. Obwohl die Umweltschutz-Technologie große Marktchancen sowohl auf den inländischen als auch den internationalen Märkten aufzeigt, fehlt in Südkorea das Interesse daran. Dies zeigt sich besonders am niedrigen Investitionsniveau für Forschung und Entwicklung von Umweltschutz-Technologien sowohl von der Seite des Staates als auch von Unternehmen in Südkorea. Allerdings werden Anstrengungen zur Förderung von Umwelt- 
schutz-Technologien erst von der Seite der Staat unternommen. Hier ist stellvertretend der Umweltforschungsplan der koreanischen Regierung zur Entwicklung von Umweltschutztechnologien zu nennen. Dieses Förderungsprogramm, das vor allem die Umweltschutztechnologien und umweltschutzorientierte Industrien fördern soll, wird seit 1992 durchgeführt. ${ }^{4}$ Den Unternehmen werden verschiedene Möglichkeiten angeboten, die staatlichen Förderungsprogramme auszunutzen. Darüber hinaus sollten die Unternehmen ihrerseits weitere Anstrengungen unternehmen, um die daraus entstehenden Marktchancen auszuschöpfen und damit die Unternehmensexistenz weiter zu sichern.

Unternehmensinterne Problemfelder bestehen in Informations- und Methodendefiziten, in Umweltschutzinsellösungen und organisatorischen Abstimmungsproblemen, in mangelhaft ausgeprägter Umweltverantwortung beim Management, Defiziten in der externen Kommunikation, einer schlechten finanziellen Ausgangslage oder einem Kostendruck durch Umweltschutzmaßnahmen.

Die Unternehmen (vor allem die kleinen und mittleren Unternehmen) in Südkorea betrachten Umweltschutz immer noch einseitig als Kostenfaktor. Viele sind froh, wenn sie den gesetzlichen Anforderungen überhaupt ohne allzu große betriebswirtschaftliche Einbußen nachkommen können. Wo die Wettbewerbssituation hart und die Rendite schmal ist, wird es häufig als zu teuer angesehen, mehr für den Umweltschutz zu leisten als vorgeschrieben. Darüber hinaus stellt die mangelhaft ausgeprägte Umweltverantwortung beim Management bzw. Unternehmen ein großes Hindernis für die Gestaltung und Umsetzung einer ökologisch verpflichteten Unternehmensführung in Südkorea dar. Wenn die Wahrnehmung ökologischer Handlungs- und Entscheidungsfreiräume von Unternehmen als eine zwangsläufig recht subjektive Angelegenheit betrachtet wird, dann folgt daraus, daß eine Sichtweise, die die ökologisch verpflichtete Unternehmensführung auf „Gewinn durch Umweltschutz“ reduziert, eine unangemessene Einengung ökologischen Engagements unternehmenpolitischer Entscheidungsträger darstellt. Damit werden die Unternehmen bzw. Management und Manager auf eine Rolle der bloßen Vollstrecker ökonomischer Sachzwänge reduziert. ${ }^{5}$

Die ökonomischen Zielsetzungen (Gewinn, Wachstum, Marktanteil etc.) bestimmen jedoch die Philosophie des Unternehmens in Südkorea. In diesem Sinne wird dem Unternehmen gefordert, die umweltbezogene Unternehmensphilosophie im Sinne der sozialen Verantwortung herauszu-

\footnotetext{
${ }^{4}$ Vgl. Kap. 7.2 dieser Arbeit.

${ }^{5}$ Vgl. Pfriem, R. (1995), S. 91ff.
} 
bilden. Hieraus erwächst der Unternehmensführung die Aufgabe, ihre Aktivitäten auf langfristige außerökonomische Wirkungen hin zu überprüfen und damit auch die soziale Verantwortung für die Erhaltung der Grundlagen der jetzigen und zukünftigen Gesellschaft im Sinne von „Sustainable Development“ wahrzunehmen. Erst recht ist eine dauerhafte Entwicklung ökologisch verpflichteter Unternehmensführung nicht möglich, wenn es einzelnen Promotoren innerhalb des Managements nicht gelingt, ökologisches Engagement nicht nur in Worten, sondern auch in Taten zur Sache der ganzen Gruppe zu machen.

Die Frage, welche Rolle die ökologische Dimension gegenwärtig für unternehmenspolitische Innovationsprozesse in Südkorea spielt, läßt sich nach gegebenem Forschungsstand kaum präzise beantworten. Die Bedeutung, die spezifischen Aspekten weiterer gesellschaftlicher Entwicklung beigemessen wird, ist sicherlich abhängig von der (relativ geringen) Bedeutung, die andere Gesichtspunkte haben. In diesem Sinne kann man zwar einerseits von einer zumindest rhetorischen Durchsetzung des Umweltschutzes als allgemein verbindlichem Ziel sprechen. Auf der anderen Seite hat es in den letzten Jahren Entwicklungen gegeben, die vom ständigen Bedeutungsanstieg der ökologischen Frage abgelenkt haben. Gerade Unternehmen, die aufgrund ihrer technischen und organisatorischen Struktur seit langem zu bestimmten Minimalaktivitäten verpflichtet sind, neigen offensichtlich dazu, darüberhinausgehenden Anforderungen mit Skepsis und Mißtrauen zu begegnen.

Betrieblicher Umweltschutz ist nicht nur eine Frage des Wollens, sondern auch eine des Könnens. Gerade kleine und mittelständische Unternehmen verfügen oft nicht über das nötige Knowhow zur Entwicklung einer ökologischen Unternehmenspolitik, zumindest nicht in allen dafür relevanten Bereichen. Hervorzuheben ist dabei, daß es nicht nur auf Wissensbestände hinsichtlich des Standes und der auf dem Markt verfügbaren Umwelttechniken etc. ankommt, sondern ebenso auf Kenntnisse hinsichtlich der ökologischen Problemzusammenhänge, in die die spezifische Unternehmenstätigkeit einzuordnen ist. Solche Kenntnisse sind häufig am ausgeprägtesten dort vorhanden, wo Unternehmensführungen nach wie vor gesellschaftliche Gegnerschaft wittern und von daher vermeidbare Berührungsängste haben. Hier sind Unternehmen gefordert, Managementverantwortung gegenüber der Gesellschaft und vor allem der ökologischen Umwelt zu übernehmen.

Die Berücksichtigung des Umweltschutzes im Zielsystem des Unternehmens, seine Einbeziehung in die strategische Ausrichtung und die operative Umsetzung des Umweltschutzes in den funktionalen Bereichen ist eine (zwingend) notwendige, aber noch längst keine hinreichende 
Voraussetzung, um der ökologischen Herausforderung gewachsen $\mathrm{zu}$ sein. Vielmehr muß auch darüber nachgedacht werden, mit welchen Maßnahmen die Umsetzung in praktisches Handeln $\mathrm{zu}$ erreichen ist. Wenn dabei strukturelle Regelungen ins Spiel kommen, zeigt dies Defizite an Umweltschutzorganisation des Unternehmens in Südkorea auf, weil derartige Arrangements Mittel der Verhaltenssteuerung darstellen.

Für die organisatorische Auslegung des Umweltschutzes im Betrieb existieren minimale gesetzliche Standards. So sind Unternehmen unter bestimmten Voraussetzungen verpflichtet, Betriebsbeauftragte für Immissionsschutz, für Gewässerschutz oder für Abfall einzusetzen. ${ }^{6}$ Reichweite und Grenzen der Effizienz dieses Instruments sind aber sehr beschränkt, da die Betriebsbeauftragten nur eine recht bescheidene Rolle bei der ökologischen Organisationsentwicklung übernehmen dürfen. Dazu kommen für die Umweltschutzorganisation im Unternehmen Mangel an qualifiziertem Personal, Aufgabenüberlastung, Ineffizienz, Überlappung von Kompetenzen, Schwerfälligkeit, Koordinationsprobleme, Informationsprobleme etc..

Das auf Minimierung des Inputs bei definiertem Output oder auf Maximierung des Outputs bei gegebenem Input festgelegte ökonomische Prinzip der Allgemeinen Betriebswirtschaftslehre ${ }^{7}$ ist zur Praxis hin keineswegs offen: noch geht der Zugriff von vielen (vor allem kleineren) Unternehmen eher zum ersten Pfad, den auszuloten in vieler Hinsicht auch einfacher erscheinen mag. Es braucht mehr Phantasie, strategische Erfolgspotentiale ausfindig zu machen, auf die das Unternehmen bisher noch nicht gekommen ist; gerade hier liegt aber die ökologische (und auch ökonomische) Zukunft.

Das in den Unternehmen Südkoreas vorherrschende Erfolgsdenken ist nach wie vor vielfach zu kurzfristig angelegt. Der Vormarsch strategischer Planung hat hier zwar Besserung geschaffen; jedoch drohen neuere Formen des internen Wettbewerbs, die aus Gründen weiterer Effizienzsteigerung implementiert werden (Profitcenter, Championship, Erfolgskontrollfristen etc.), die Vorteile langfristiger Erfolgsorientierung wieder zunichte zu machen.

Traditionell ist die Unternehmensführung darauf orientiert, als sicherste und zuverlässigste Daten jene der Finanzbuchhaltung und des kaufmännischen Rechnungswesens anzusehen. Im ökologischen Handlungsfeld ist verstärkter Umgang mit weichen Daten erforderlich. So lassen sich etwa das langfristige Verbraucherverhalten, die Entwicklung der staatlichen Rahmenbedingungen so-

\footnotetext{
${ }^{6}$ Vgl. Umweltministerium Südkorea (1997).

${ }^{7}$ Vgl. z.B. Wöhe, G. (1991), S. 1ff.
} 
wie die Auswirkungen ökologischen Engagements auf die Leistungsbereitschaft der Führungskräfte wie der übrigen Beschäftigten nicht exakt messen, schon gar nicht sinnvoll monetarisieren. Je mehr Unternehmensmanager am herkömmlichen Geschäftsverhalten kleben, desto weniger werden sie gerade im ökologischen Handlungsfeld zukunftsorientierte und innovationsfähige Entscheidungen treffen können. Als Kurzsichtigkeit scheint hier insbesondere ein starres Festhalten an der gegebenen Produktpalette von Belang zu sein, denn es steht dem Denken in Alternativen und neuen Problemlösungen im Wege.

Interne und externe Umsetzungshindernisse können sich im übergreifenden Problemfeld „Gefährdung der Wettbewerbsfähigkeit“" kondensieren. Grundsätzlich läßt sich zum Umweltschutzverhalten von Unternehmen aufzeigen, daß Unternehmen in Abhängigkeit von der Wettbewerbssituation ihr Verhalten an ökologischen Erfordernissen ausrichten. Nach Porter werden die Determinanten der Wettbewerbsintensität auf die folgenden zentralen Schlüsselfaktoren verdichtet: ${ }^{8}$

- Gefahr des Markteintritts neuer Konkurrenten,

- Bedrohung durch Ersatzprodukte,

- Verhandlungsstärke der Lieferanten,

- Verhandlungsstärke der Abnehmer,

- Rivalität der Unternehmen innerhalb der Branchen.

Dabei kann man aber die Frage stellen, ob der Umweltschutz über die oben beschriebenen Faktoren Eingang in den Wettbewerbsprozeß findet. Grundsätzlich scheint es möglich zu sein, daß der Umweltschutz über jede Wettbewerbsdeterminante auf den Branchenwettbewerb einwirken kann. Die Gefahr des Markteintritts neuer Konkurrenten, die umweltgerechtere Problemlösungen oder Ersatzprodukte anbieten, ist bereits in vielen Branchen in Südkorea feststellbar, wobei der Eintritt der neuer Konkurrenten vielfach als Reaktion auf ein verändertes Nachfrageverhalten der Konsumenten zurückzuführen ist. Insbesondere ökologische Nischenanbieter können zu verstärkten umweltorientierten Anpassungsmaßnahmen bei traditionellen Anbietern anregen. Staatliche Einflüsse sowie das Lieferanten- und Abnehmerverhalten lassen wiederum Rückschlüsse zu, die auf dem Einfluß von Anspruchsgruppen im Hinblick auf die Berücksichtigung von Umweltschutzerfordernissen auf Anbieterseite beruhen.

Allerdings läßt die verfügbare Datenbasis keine allgemeingültigen Aussagen darüber zu, ob und unter welchen Bedingungen auf welchen Märkten bestimmte umweltschutzbezogene Verhaltens-

${ }^{8}$ Vgl. Porter, M. (1999); Porter, M./van der Linde, C. (1995), S. $120 f f$. 
anpassungen eintreten. ${ }^{9}$ Letztlich kann nur eine entsprechende Strategiebildung mit aktiver Orientierung (auch) an ökologischen Stärken und Potentialen einen anfänglichen, kostenbezogenen Wettbewerbsnachteil in eine langfristige Erlössteigerung und einen entwicklungsorientierten Vorteil umkehren.

Ökologisch verpflichtete Unternehmensführung kann in dem Maße gelingen, wie sich Unternehmen als strukturpolitische Akteure begreifen lernen - ein Lemprozeß, der den meisten Unternehmen wohl noch bevorsteht. Es steht zu vermuten, daß diejenigen Unternehmen Wettbewerbsvorteile im ökologischen Handlungsfeld aufbauen werden, die reflektierter mit den folgenden Fallstricken ökologisch verpflichteter Unternehmensführung umgehen: ${ }^{10}$

- Fehlende Kenntnis der eigenen Situation

- Mangelnde Beobachtung des Umfeldes

- Unklare Zielstrukturierung

- Konfliktverdrängung

- Konzentration auf kurzfristige Probleme

- Beschränkung auf harte Daten

- Behandlung von Gestaltungsfeldern als Sachzwänge

- Defizite in der Organisation des betrieblichen Umweltschutzes.

Insgesamt ist festzustellen, daß die Situation im Umweltschutzbereich in Südkorea sowohl in der staatlichen Verwaltung als auch in der Unternehmensführung generell durch die vorherrschende schwierige ökonomische Situation gekennzeichnet ist. Des weiteren treten Mängel an qualifiziertem Personal, Aufgabenüberlastung, Ineffizienz, Überlappung von Kompetenzen, Schwerfälligkeit, Koordinationsprobleme, Informationsprobleme und mangelnde Durchschaubarkeit der Entscheidungsprozesse auf.

Konzepte einer ökologisch verpflichteten Unternehmensführung haben sich meistens nur marginal mit der Umsetzungs- und Implementationsproblematik beschäftigt. Trotzdem gibt es Motive für die Umstellung auf eine ökologisch verpflichtete Unternehmensführung.

Die Motivation $\mathrm{zu}$ umweltgerechterem Verhalten fordert von allen Beteiligten und Interessengruppen einen grundlegenden Wandel im Denken, Handeln und Verhalten. Hierzu kommen

\footnotetext{
${ }^{9}$ In diesem Sinne ist festzustellen, daß es sowohl an den theoretischen Überlegungen als auch den empirischen Analysen und Untersuchungen zum Umweltschutzverhalten von Unternehmen in Südkorea fehlt.
} 
insbesondere drei Instrumentbereiche in Frage: eine Veränderung des betrieblichen Anreizsystems in Richtung einer umweltorientierten Anreizgestaltung, Unterstuitzung der Ökologieorientierung bzw. -verpflichtung durch ein adäquates Führungsmodell sowie durch ein Controlling-System, das durch die Mitberücksichtigung ökologischer Kennziffern die Entscheidungsvorbereitung und den Strategieentwurf umweltbezogen prägt. Für den eigentlichen Implementationsprozeß könnte eine Prozeßfolge gewählt werden, die sich stufenweise verfeinert.

Im folgenden soll auf verschiedene Motive, die die Umsetzung ökologisch verpflichteten Handelns bestimmen und fordern können, näher eingegangen werden. ${ }^{11}$

Die naheliegendsten Schnittmengen von ökologischen und einzelwirtschaftlich-ökonomischen Zielen ergeben sich dort, wo Reduzierungen des Inputs in beiderlei Hinsicht zu Vorteilen führen (z.B. Einsparungen an Rohstoffen und Energieverbrauch, Schließung materialwirtschaftlicher Kreisläufe, innerbetriebliches Recycling). (Investitions-)Kosten werden ferner dann gesenkt, wenn Produktionsumstellungen bezüglich ihres Zeitpunktes vom Unternehmen selbst bestimmt werden, statt daß hier die umweltrechtlichen Vorgaben terminierend wirken und das Unternehmen in eine betriebswirtschaftlich auf jeden Fall ungünstigere Reaktions- und Anpassungssituation zwingen.

Weit mehr als ein Kostenkalkül ist das Ziel der langfristigen Unternehmensstabilisierung. Grundsätzlich können Unternehmen, die sich der ökologischen Herausforderung verweigern, in eine existentielle Krise geraten, weil notwendig gewordene ökologische Anpassungen betriebswirtschaftlich möglicherweise nicht mehr verkraftet werden können. Unternehmen schaden sich selbst, wenn sie sich in die Abhängigkeit einer auf längere Sicht nicht haltbaren Technologie oder Produktstrategie begeben.

Ökologie ist zu einem strategischen Erfolgspotential im Wettbewerb geworden, auch in der internationalen Dimension. Daraus resultiert die Möglichkeit früher Gewinne und spezifischer Marktführerschaften. Neue, ökologisch relevante Produkte bzw. Technologien können gewichti-

\footnotetext{
${ }^{10} \mathrm{Vgl}$. Bundesumweltministerium/Umweltbundesamt (1995), S. 18ff.

11 Eine theoretische Erörterung von Motiven und Hemmnissen für ökologisch verpflichtete Unternehmensführung läßt sich nicht aus einer allgemeinen Theorie deduzieren. Auf dem Wege zu einer kritischen und empirisch gehaltvollen Theorie des Unternehmens im ökologischen Handlungsfeld müssen erst einmal die praktischen Erfahrungen verarbeitet werden, die über die ersten Ansätze zu ökologischer Unternehmenspolitik in den vergangenen Jahren gemacht werden konnten. In diesem Sinne muß festgestellt werden, daß es sowohl theoretisch als auch praktisch an fundierten Untersuchungen und Materialien über die ökologisch verpflichtete Unternehmensführung in Südkorea fehlt. Daher können die Ausführungen vorliegender Arbeit nur als ein Versuch verstanden werden, die Erkenntnisse aus den kritischen und logischen Betrachtungen darzustellen.
} 
ge ökonomische Vorsprünge schaffen. Wenn bei staatlichen Aufträgen ökologische Anforderungen stärker berücksichtigt werden, kommen eher Unternehmen zum Zuge, die diesen Anforderungen gerecht werden. Die Fähigkeit hierfür muß antizipiert werden, etwa im Rahmen von Angeboten auf öffentliche Ausschreibungen.

Die Ansprüche der Konsumenten an die Unternehmen sind deutlich gestiegen. Qualitätskontrolle hat einen gewichtigen ökologischen Gehalt bekommen. Unternehmen, die weiterhin einseitig auf Verbrauchervorstellungen setzen, in denen Ökologie keine Rolle spielt, können Schiffbruch erleiden. Aufklärungsarbeit der öffentlichen Institutionen, der Informationsmedien und spezifischen Einrichtungen, wie Verbraucherinitiativen etc., unterstützen ökologisch bewußte Konsumentscheidungen. Unternehmen, die die ökologische Problemstellung aktiv aufgreifen, zeichnen sich allgemein durch ein hohes $\mathrm{Maß}$ an Flexibilität und Zukunftsorientierung aus, d.h. sie sind offensichtlich generell die wettbewerbsstärksten.

Schließlich ist in ertragsorientierter Perspektive Ökologie von Gewicht für die Bildung des Unternehmensprofils in der Öffentlichkeit. Angesichts der Schlüsselrolle, die der Zerstörung der natürlichen Umwelt mittlerweile zukommt, sind Unternehmen in zunehmendem Maße bemüht, darauf zu reagieren. Durch Überschreiten der gesetzlichen Mindestanforderungen beweisen Unternehmen ihre besondere gesellschaftliche Verantwortung.

Trotz der weiter im Steigen begriffenen Bedeutung normativen Managements für den Unternehmenserfolg läßt sich in der Praxis feststellen, daß technische und unmittelbar ökonomische Aspekte im Vordergrund betrieblichen Umweltschutzes stehen. Welche Bedeutung die umweltbewußten Einstellungen des Managements selber haben, wird dabei oft unterschätzt. Diese Aspekte bilden dabei eigenständige strategische Motive für die ökologisch verpflichtete Unternehmensführung.

Für die Beschäftigten beginnt die Möglichkeit der ökologischen Identifikation mit ihrem Betrieb eine zunehmende Rolle zu spielen. Die Unternehmensführung führt dadurch zur Steigerung des innerbetrieblichen Leistungs- und Innovationspotentials. Diese ökologische Identifikation betrifft nicht allein das Mehr oder Weniger an ökologischem Profil des Unternehmens. Auch Probleme des Arbeitsschutzes sind oft eng mit solchen des Umweltschutzes verknüpft. Daher ergeben sich Ansatzpunkte, im Rahmen arbeitnehmerorientierter Strategien umweltschutzbezogene Lösungen zu thematisieren. 
Die vorgenannten strategischen Gründe für ökologisch verpflichtete Unternehmensführung lassen sich auch als ökologische Nutzenpotentiale beschreiben: ${ }^{12}$

\begin{tabular}{|l|l|}
\hline \multicolumn{2}{|c|}{ Erfolgreiche Umsetzung einer ökologisch verpflichteten Unternehmensführung } \\
\hline \multicolumn{1}{|c|}{ Externe Nutzenpotentiale } & \multicolumn{1}{c|}{$\underline{\text { Interne Nutzenpotentiale }}$} \\
Beschaffung, Marktstellung, Fachkräfte, Finanzierung, & Informationssysteme, Investitionsvorsprünge, Clean- \\
Konsumenten, Image, Kommunikation, strategische & Management, Know-how, Wertsteigerung, Standort- \\
Allianzen, Politikmitgestaltung. & sicherung, Leistungsklima, Unternehmensführung. \\
\hline
\end{tabular}

Abb. 8.2: Ökologische Nutzenpotentiale

(Quelle: Bundesumweltministerium/Umweltbundesamt (1995), S. 11)

Externe ökologische Nutzenpotentiale:

- Beschaffung: Nutzung von Kostensenkungseffekten durch eine sorgfältige Auswahl der Materialien und der Lieferanten.

- Konsumenten: Auch in Zeiten, in denen manchem betrieblicher Umweltschutz als Modeartikel erscheint, zeigt die zunehmende Umweltorientierung der Kunden ihre Auswirkungen. Unternehmen sollten die bestehende Nachfrage nach umweltverträglichen Produkten befriedigen können.

- Marktposition und Marktstellung: Das Vorhandensein umweltverträglicher Produkte in der Angebotspalette ist eine Voraussetzung, um überhaupt am „Umweltmarkt“ teilhaben zu können. Unternehmen sollten diesen Markt nicht der Konkurrenz überlassen und sich um eine Ausweitung desselben bemühen. Sozial- und Umweltverträglichkeit sind außerdem wichtige Kriterien, die immer öfter den Ausschlag bei der Auftragsvergabe geben - insbesondere bei öffentlichen Auftraggebern.

- Finanzierung: In vielen Bereichen bestehen Umweltförderungsprogramme und -finanzierungshilfen, in denen z.B. der Staat Mittel für eine umweltverträgliche Wirtschaftsweise bereitstellt.

- Fachkräfte, qualifiziertes Personal: Qualifizierte Fachkräfte sind häufig engagiert in Frage des Umweltschutzes. Aktives ökologisches Engagement des Unternehmens ist ein positiver Wettbewerbsfaktor bei der Rekrutierung von Fachpersonal.

- Image: Angesichts der zunehmend kritischer werdenden Öffentlichkeit ist eine ökologisch verpflichtete Unternehmensführung ein wesentlicher Faktor für die gesellschaftliche Akzeptanz.

\footnotetext{
${ }^{12}$ Vgl. Bundesumweltministerium/Umweltbundesamt (1995), S. 10ff.; Fischer, G. (1996), S. 14ff.
} 
- Kommunikation: Eine offensive, umweltorientierte Kommunikationspolitik gegenüber allen gesellschaftlichen Anspruchsgruppen ist eine wichtige Voraussetzung für den Erfolg des Unternehmens.

- Strategische Allianzen: Die Kooperation mit Lieferanten, Kunden und Marktpartnern verschafft dem Unternehmen Handlungsspielräume im Marktgeschehen. Kooperationen mit Konkurrenten auf bestimmten Gebieten ermöglichen Projekte, die sich einer allein nicht leisten könnte, und helfen, das Investitionsrisiko zu senken.

- Politikmitgestaltung: Mit einer offensiven Umweltpolitik und mit gesellschaftspolitischem Engagement kann das Unternehmen in Zusammenarbeit mit anderen an der Gestaltung der Rahmenbedingungen zukünftiger Entwicklung aktiv mitwirken.

Interne ökologische Nutzenpotentiale:

- Kostensenkung: Durch eine Schwachstellenanalyse im Betrieb, die Einsparmöglichkeiten (z.B. in den Bereichen Energie, Material usw.) verdeutlicht, durch eine optimale Ressourcenausnutzung und durch eine Schließung der Materialkreisläufe lassen sich bedeutsame Kostensenkungspotentiale erschließen. Integrierte Materialwirtschaft ist hier das Schlüsselwort.

- Investitionsvorsprünge: Neuste Technologien ermöglichen effizientes und umweltverträgliches Arbeiten. Die meisten Unternehmen warten jedoch erst auf gesetzliche Auflage.

- Clean Management: Nutzung der Vorteile des vorsorgenden Umweltschutzes im Unternehmen.

- Informationssysteme: Mit der Einrichtung eines Umweltinformationssystems geht meist eine Verbesserung der betrieblichen Informationssysteme einher. Dies hat positive Auswirkungen auf innerbetriebliche Entscheidungsprozesse. So führt z.B. eine Stoff- und Energiebilanz zu einer hohen Aufmerksamkeit für Ressourcenverbräuche und damit zur Erschließung von ökologischen wie technischen und ökonomischen Effizienzreserven und Innovationen.

- Wertsteigerung: Die Vermeidung von Altlasten und baubiologische Aktivitäten erhöhen den Unternehmenswert.

- Standortsicherung: Wer den gestiegenen Anforderungen von Öffentlichkeit und Gesetzgeber entspricht, leistet wichtige Beiträge zur Unternehmenssicherung.

- Leistungsklima: Die aktive Mitwirkung der Mitarbeitern ist eine zentrale Voraussetzung für den Unternehmenserfolg. Dies gilt auch für den Bereich des Umweltschutzes. Arbeitssicherheit und Gesundheitsschutz sind weitere wichtige Kriterien für das Engagement der Beschäftigten. 
- Ökologische Schlüsselqualifikation: Eine erweiterte Qualifikation der Beschäftigten im Umweltschutzbereich, insbesondere bezogen auf ihre jeweiligen Tätigkeiten, sind ein wichtiges Erfolgskriterium für das Unternehmen. Hierzu gehört auch die Aufgeschlossenheit der Beschäftigten für ökologische Probleme und für die Notwendigkeit ihrer Beseitigung.

- Unternehmensführung: Betrieblicher Umweltschutz ist eine Querschnittsaufgabe. Er verlangt klare, aufeinander abgestimmte Zielsetzungen (ökonomische, soziale und ökologische Zielsetzungen) und ständige Integrationsleistungen auf allen Hierarchieebenen des Unternehmens. Aufgabenverteilung und Verantwortlichkeiten müssen für die Beschäftigten aller Ebenen transparent sein.

Aus diesen strategischen Motiven ergeben sich die oben dargestellten Schnittmengen im einzelwirtschaftlichen Spannungsfeld zwischen Ökonomie und Ökologie. Die Schnittmengen drücken zugleich die Verschränkung zwischen den einzelwirtschaftlichen Entscheidungsspielräumen und den übergeordneten Rahmenbedingungen aus; bei mehreren der strategischen Motive für die ökologisch verpflichtete Unternehmensführung wird der natürlich nicht aufhebbare Bezug zu den zunächst von außen kommenden Anreizen deutlich: ${ }^{13}$

- Je stärker z.B. die energiewirtschaftliche Struktur eines Landes auf Verschwendung ausgelegt ist, desto weniger Kostenanreize für Energieeinsparungen sind gegeben.

- Je ökologisch unsensibler die Verbraucher bleiben, desto weniger werden ökologische Qualitätskriterien nachfragerelevant.

- Je weniger effizient eine staatliche Umweltpolitik ist, desto weniger sehen sich Unternehmen gefordert, in absehbaren Einzelschritten vorauszueilen. usw.

Ökologische Entwicklungen bedürfen also einer entsprechenden Koevolution von Staat und Gesellschaft d.h. möglichst viele der Elemente, aus denen die Gesellschaft besteht. Weder lassen sich die Elemente der Gesellschaft hinreichend allein durch externe Vorgaben des Staates in Bewegung setzen, noch können die Unternehmen voluntaristisch handeln unter Absehung von den staatlicherseits gesetzten Rahmenbedingungen.

So verstanden und eingeführt könnte die ökologisch verpflichtete Unternehmensführung durchaus zu einem strategischen Erfolgsfaktor werden. Sie ist dann insbesondere Ausdruck einer akti-

${ }^{13}$ Vgl. Pfriem, R. (1995), S. 102. 
ven und selbstbewußten Unternehmenspolitik und -kultur, die sich zukünftigen Anforderungen unternehmerischer Anspruchs- und Interessengruppen eben nicht verschließt. ${ }^{14}$

Der Zielkonflikt zwischen ökologischen Forderungen und ökonomischen Zielsetzungen stellt hohe Anforderungen an eine ökologisch verpflichtete Unternehmensführung, Lösungen für die Berücksichtigung der ökologischen Umwelt im Rahmen der Unternehmensaktivitäten zu entwickeln. Angesicht der sich verschärfenden Umweltprobleme und des wachsenden Drucks der Öffentlichkeit ergibt sich für das Unternehmen die Notwendigkeit, den zukünftigen Handlungsund Entscheidungsspielraum zu sichern oder auszuweiten. Auf diese Weise können aus der ökologischen Entwicklung resultierende strategischen Erfolgspotentiale aktiv genutzt werden.

Voraussetzung dafür ist die Bereitschaft der Unternehmen, die Ökologie bzw. den Umweltschutz nicht als Restriktion der Unternehmenspolitik zu begreifen, sondern als wichtigen Wettbewerbsund Erfolgsfaktor wahrzunehmen und in die Unternehmensführung $\mathrm{zu}$ integrieren. Die aufgezeigten Probleme in Südkorea machen aber deutlich, daß es noch erheblicher Anstrengungen der Praxis und der Wissenschaft bedarf. Ein harter Wettbewerb und die Notwendigkeit zur Erzielung ausreichender Gewinne erschweren das ökologisch verantwortungsbewußte Handeln. Dem einzelnen Unternehmen sind zur Lösung umweltbezogener Aufgaben oft enge Grenzen gesetzt. Die Sicherung der ökologischen Lebensgrundlagen ist letztlich eine gesamtgesellschaftliche Aufgabe (Staat, Gesellschaft sowie Unternehmen), zu deren Bewältigung ein breites Spektrum von Maßnahmen eingesetzt werden muß. Sie reichen von der Anpassung an gesetzliche Vorschriften über freiwillige Beschränkungen bis hin zu verhaltensbeeinflussenden Aktivitäten.

\subsection{Möglichkeiten für die Implementierung einer ökologisch verpflichteten Unternehmensführung in Südkorea}

Die wettbewerbsstrategische Relevanz der Ökologie wird in Südkorea vielfach unterschätzt oder verkannt. Die Gründe dafür sind sowohl in der Praxis als auch in der Theorie zu suchen. Aus der Sicht der Praxis wird der Umweltschutz häufig als reiner Kostenfaktor und als operatives Problem betrachtet, nicht aber als Wettbewerbsfaktor und als strategische Herausforderung. Aus der Sicht der Theorie mangelt es bisher an geeigneten Konzepten und Instrumenten, um der wettbewerbsstrategischen Relevanz der Ökologie gerecht zu werden. Herkömmliche Konzepte und Instrumente der strategischen Unternehmensplanung und der Allgemeinen Managementlehre sind im ökologischen Kontext nur bedingt einsetzbar. Möchte man der ökologischen Herausforderung

${ }^{14}$ Vgl. Stitzel, M. (1994). S. 95ff. 
gerecht werden, dann müssen vorhandene Management- oder Wettbewerbskonzepte und strategien neu überdacht werden. Eines der wichtigen Problemfelder für die Implementierung einer ökologisch verpflichteten Unternehmensführung in Südkorea besteht im Informations- und Methodendefizit und fehlenden Know-how zur Entwicklung oder Durchführung einer ökologisch verpflichteten Unternehmensführung. Im Rahmen der vorliegenden Arbeit wurde daher der Versuch unternommen bzw. das Ziel gesetzt, viele Bausteine für die ökologisch verpflichtete Unternehmensführung in Südkorea bereitzustellen, um möglichst umfangreiche Denkmuster zu erzeugen, die helfen, die konzeptionelle Gesamtsicht einer Ökologieverpflichtung etwas problemadäquater $\mathrm{zu}$ formulieren und $\mathrm{zu}$ gestalten. Abschließend wird auf die folgenden konzeptionellen Vorgehensweisen hingewiesen: ${ }^{15}$

Zur erfolgreichen Bewältigung der Komplexität, die mit den Anforderungen des Umweltschutzes an die Unternehmen verbunden ist, stellt sich die ganzheitlich-integrative Ausrichtung einer ökologisch verpflichteten Unternehmensführung als zwingende Notwendigkeit dar. Diese erhält ihren Rückhalt auf der Ebene der Unternehmenspolitik durch die Verankerung umweltschutzbezogener Werte. Zentrale Bedingungsfaktoren sind dabei eine Vision/Philosophie, die der ökologiebezogenen Entwicklung des Unternehmens die Richtung vorgibt, die Unternehmensethik, welche als „situatives Korrektiv“ die Unternehmenspolitik in ökologiebezogener Hinsicht beeinflußt, und schließlich die Unternehmenskultur, in der zum Ausdruck kommt, inwieweit und welche ökologiebezogene(n) Werte im Handeln des Unternehmens zum Tragen kommen.

Die Unternehmenspolitik konkretisiert, unter Berücksichtigung der Interessen der Anspruchsgruppen des Unternehmens, deren ökologische Ausrichtung. Ihre Umsetzung erfährt sie durch das Leitbild, welches vor allem den Mitarbeitern die notwendige Transparenz bezüglich des erwarteten ökologiebezogenen Handelns bietet. Zur Erzielung der entsprechenden Glaubwürdigkeit ist eine entscheidende Voraussetzung für die Formulierung des Leitbildes die Beteiligung der Mitarbeiter. Die Unternehmen, die die ökologische Herausforderung glaubwürdig anzunehmen bereit sind, werden ihr auf umfassende und grundlegende Weise Rechnung tragen müssen. Dabei ist auch an eine konsequente Berücksichtigung im System der Unternehmensziele zu denken. Zur Konkretisierung der Unternehmenskultur in Form wünschenswerter Zustände dienen damit die Unternehmensziele.

Das Konzept des „sustainable Development“ kann als Leitbild für eine ökologisch verpflichtete Unternehmensführung dienen. Im ökologisch verpflichteten Unternehmensleidbild wird eine O-

\footnotetext{
${ }^{15}$ Vgl. ausführlich die Ausführung im Kap. 4 dieser Arbeit.
} 
rientierung für unternehmerisches Handeln vorgegeben und kann als Führungsphilosophie in Form globaler Prinzipien eine reale Utopie vermitteln, die zukunftsgerichtet, realisierbar und symbolhaft kommunizierbar ist. Die Gestaltung und Umsetzung einer ökologisch verpflichteten Unternehmensführung insbesondere auf der normative Ebene in Südkorea kann durch die Verankerung traditioneller umweltschutzbezogener Werte z.B. der taoistischen Naturanschauung berücksichtigt und erleichtert werden. Das Unternehmen kann dabei zwischen der grundsätzlichen Umweltphilosophie (vgl. Abb. 8.3) und einer detaillierten Umweltpolitik unterscheiden.

\section{Unsere}

\section{ökologisch verpflichtete Unternehmensphilosophie}

Zurück zur Natur, Einfachheit und ursprünglichen Harmonie und zum Lob der Schwäche, der Sanftheit und der Weichheit.......

In Sinne der Grundprinzipien der taoistischen praktischen Gedanken wollen wir unseren Beitrag leisten, die ökologische Umwelt als Lebensgrundlage aller Lebewesen einschließlich der Menschen zu schützen bzw. den nachfolgenden Generationen eine lebens- und liebenswerte Umwelt zu erhalten.

Hieraus leiten wir unsere Umweltgrundsätze ab:

1. Jeder einzelne von uns ist mitverantwortlich.

2. Wir wollen die Ressourcen der Natur schonen.

3. Unser wirtschaftliches Tun soll dem Menschen und der Umwelt dienen.

Es ist unser erklärter Wille, daß diese Philosophie und die daraus folgende Umweltpolitik in allen Unternehmensbereichen und auf allen Ebenen gelebt und realisiert wird.

Abb. 8.3: Mögliches Beispiel zur Formulierung einer ökologisch verpflichteten Unternehmensphilosophie für ein Unternehmen in Südkorea (Quelle: Eigene Darstellung)

Die betriebliche Umweltpolitik eines Unternehmens könnte wie folgt formuliert werden: ${ }^{16}$

- Wir ordnen den Umweltschutz den vorrangigen Unternehmenszielen zu und nehmen ihn in unsere Unternehmensleitsätze auf.

\footnotetext{
${ }^{16}$ Vgl. Winter, G. (1998); Bundesumweltministerium/Umweltbundesamt (1995).
} 
Wir betrachten den Umweltschutz als wichtige Führungsaufgabe und stellen sicher, daß er in allen betrieblichen Funktionen auf allen Ebenen in konkrete Ziele und Verhaltensregeln umgesetzt wird.

- Mittels einer etablierten Umweltschutzorganisation z.B. von Umweltschutzbeauftragten ausgestattet mit Fachkompetenz, stellen wir sicher, daß Maßnahmen zur Vorbeugung von betrieblichen Störfällen ergriffen werden.

- Wir geben uns periodisch detaillierte Rechenschaft über den Stand des Umweltschutzes in unserem Unternehmen, um Schwachstellen zu erkennen, die notwendigen Maßnahmen zu veranlassen und erreichte Fortschritte zu dokumentieren.

Wir informieren unsere Mitarbeiter ausführlich über Umweltaspekte und motivieren sie zu umweltbewußtem Verhalten.

- Bei der Entwicklung unserer Produkte und Verfahren bemühen wir uns um eine ständige Verbesserung der Umweltverträglichkeit. Wir setzen dabei Rohstoffe, Energie, Wasser und sonstige Güter so sparsam wie möglich ein und berïcksichtigen die gesamte Lebenszeit unserer Produkte einschließlich ihrer Entsorgung.

- Wir beziehen alle Geschäftspartner in unsere Bemühungen um verbesserten Umweltschutz ein. Unsere Kunden klären wir über unsere umweltschonenden Maßnahmen auf.

- Wir sind zum offenen Dialog mit allen gesellschaftlichen Gruppen bereit, stellen den Medien umweltrelevante Informationen über unser Unternehmen zur Verfügung und arbeiten mit Behörden, Verbänden und anderen Institutionen im Umweltschutz zusammen.

- Wir kontrollieren und beachten das Abfallmanagement, berücksichtigen seine ökologischen und ökonomischen Aspekte und machen den Umgang mit Abfall transparent.

- Wir prüfen alle Emissionen im bestimmungsgemäßen Betrieb, auch solche, die von nicht genehmigungspflichtigen Anlagen ausgehen.

- Wir verstehen die gesetzlichen Bestimmungen als Mindestanforderungen und streben im gesamten Unternehmen ein höheres Maß an Umweltschutz an.

- Wir stellen die Mittel zur Erreichung der Umweltschutzziele zur Verfügung.

Aufbauend auf der grundlegenden ökologisch verpflichteten Unternehmenspolitik kann das Unternehmen das Umweltprogramm entwickeln. Dabei sind die folgenden Punkte zu berücksichtigen: ${ }^{17}$

Auswertung der ökologischen Bestandsaufnahme.

Ableitung konkreter Ziele je Bereich.

${ }^{17}$ Vgl. Winter, G. (1998); Bundesumweltministerium/Umweltbundesamt (1995). 
- Festlegung der Verantwortlichen für die Schwerpunktthemen.

- Erarbeitung konkreter Umsetzungsvorhaben.

- Festlegung der bereitzustellenden Mittel.

- Bestimmung von Verantwortlichen.

- Schriftliche Fixierung des Umweltprogramms.

Es ist festzustellen, daß die Unternehmensführung Südkoreas sowohl in der theoretischen Forschung als auch im Praxis nicht anders als die Deutschlands ist. Daher wird für die Konzeption einer ökologisch verpflichteten Unternehmensführung auf weiteren Managementebenen in Südkorea davon ausgegangen, daß eine zunehmende Homogenisierung der internationalen Produktanforderung sowie des Marketings aufgrund einer weltweiten Angleichung der Käuferwünsche im Sinne der Globalisierung des Marktes besteht. Eine solche Angleichung der Anforderungen der Konsumenten an die ökologiebezogenen Produkteigenschaften würde ceteris paribus auch zu einer Angleichung der betrieblichen Problemlösungen in den verschiedenen Ländern, einschließlich Südkorea, führen. Die konzeptionelle Ausführung, die in den deutschsprachigen Publikationen dargestellt wird, soll deswegen als Referenz dienen. Dabei sind folgende grundsätzliche Ansatzpunkte zu beachten und eventuell unternehmensspezifisch zu ergänzen. ${ }^{18}$

Zur Bewältigung der Umweltprobleme in ihren ökologischen, gesellschaftlichen und wettbewerbsstrategischen Dimensionen stellt die Integration von Umweltschutzzielen in das Zielsystem des Unternehmens die notwendige Voraussetzung dar, um die Unternehmensaktivitäten den veränderten Rahmenbedingungen anzupassen und um bei der Planung, Durchführung und Kontrolle ökonomischer Tätigkeiten eine Vermeidung oder Verminderung von Umweltbelastungen sicherzustellen. Damit bringt das Ziel der ökologisch verpflichteten Unternehmensführung zum Ausdruck, daß es neben den ergriffenen Einzelmaßnahmen aufbauend auf einer Analyse der unternehmensexternen und -internen Rahmenbedingungen $\mathrm{zu}$ einem systematisch geplanten, ökologisch intendierten und kontrollierten Umweltschutzverhalten kommt. Dies dokumentiert die Relevanz und den Stellenwert der Thematik für das gesamte Unternehmen und gereicht so für alle Mitarbeiter zur Handlungsmaxime. Dementsprechend sind umweltschutzbezogene Aufgaben, Kompetenzen und Verantwortungen im Unternehmen $\mathrm{zu}$ formulieren, aufzubauen und zu verteilen.

\footnotetext{
${ }^{18}$ Die einzelnen unternehmensspezifischen Gegebenheiten bzw. Rahmenbedingungen für die ökologisch verpflichtete Unternehmensführung in Südkorea blieben in vorliegender Arbeit unberücksichtigt, da sie individueller, kollektiver und struktueller Art sind, wobei häufiger das eine aus dem anderen folgt oder/und eine wechselseitige Beeinflussung stattfindet. Eine eindeutige Zuordnung ist deshalb nur teilweise möglich.
} 
Die Grundstrategie gibt den ökologischen Handlungsspielraum vor, und die auf dieser strategischen Ebene aufbauende Planung führt die normativen Leitvorstellungen zur Ökologieverpflichtung des Unternehmens in konkrete Handlungsoptionen über. Dabei sollte die ökologiebezogene Orientierung der Basisstrategie und der strategische Planung auch als „Handschrift“ in der operativen Durchführungsplanung erkennbar sein, d.h. operationalisierte Vorgaben für die einzelnen Bereiche machen. Dazu sind die einzelnen Phasen des Planungsprozesses und die parallel laufende strategische Kontrolle konsequent auf die ökologische Zielsetzung hin abzustimmen.

Bei der organisatorischen Umsetzung des Umweltschutzes ist zur Durchdringung des gesamten Unternehmens eine Dezentralisierung von Umweltschutzaufgaben und somit die Integration entsprechender Aufgaben in das Aufgabenfeld aller Mitarbeiter vorzunehmen. Im Sinne eines Organisationsmix $^{19}$ gilt es zudem, in funktional-additiven Organisationseinheiten umweltschutzbezogenes Expertenwissen aufzubauen. Die Durchsetzung und Unterstützung der organisatorischen Lösungen ist als Aufgabe der Unternehmensleitung zu sehen, was die Bedeutung des Umweltschutzes als „Chefsache“ unterstreicht. Ferner ist von den gesetzlich betroffenen Unternehmen die Institution des „Betriebsbeauftragten für Umweltschutz“ einzurichten. Dem Personalmanagement kommt auch die wesentliche Aufgabe zu, die Mitarbeiter als entscheidendes Potential in die ökologisch verpflichtete Unternehmensführung einzubinden. Zentrale Ansatzpunkte sind die Dimensionen der Leistungsbereitschaft (,Wollen“) und Leistungsfähigkeit (,Können“).

Der Managementprozeß ist darauf ausgerichtet, das Mitarbeiterverhalten auf die ökologiebezogenen Unternehmensziele abzustimmen. Grundlegende Bedeutung dafür hat das Führungskonzept des sog. „Management by Objectives“, ${ }^{20}$ welches die Operationalisierung der Unternehmensziele in Zielvereinbarungsprozessen zwischen Führungskräften und Mitarbeitern verfolgt.

\footnotetext{
${ }^{19} \mathrm{Da}$ sich die funktional-additive und integrative organisatorische Lösungenen gegenseitig nicht ausschließen und folglich kombiniert werden können, wird an dieser Stelle nach Antes zur optimalen Bewältigung der Umweltschutzaufg aben für einen „Organisationsmix“ plädiert. Vgl. Antes, R. (1994), S. 28.

${ }^{20}$ Die Integration der Mitarbeiter in die Umweltschutzanstrengungen des Unternehmens und auch ihre diesbezügliche Weiterentwicklung ist insbesondere durch eine indirekte, Freiräume zur Selbstorganisation zulassende Führung möglich. Ein zur Realisierung dieser Anforderungen im Umweltschutzkontext häufig herangezogenes Führungskonzept ist das sog. „Management by Objectives“. Durch seinen interaktiven kaskadenhaften Zielaushandlungsprozeß ermöglicht dieses Modell das „Hineintragen“ des Umweltschutzgedankens in die einzelnen Unternehmensebenen. Auf diese Weise kann die notwendige Operationalisierung der in der Unternehmenspolitik definierten Ziele (auch im Bereich Umweltschutz) geleistet werden. Dieses Modell bietet in seiner partizipativen Ausprägung die Möglichkeit, dem Mitarbeiter bei seiner Aufgabenwahrnehmung die notwendigen Freiräume zu gewähren, dabei aber auch die gesamtunternehmensbezogene Steuerungsnotwendigkeit über die Ziele zu gewährleisten. Die Partizipation der Mitarbeiter an Zielbildung und -anpassung ermöglicht eine nachhaltige Identifikation mit den Zielen und auch mit dem Unternehmen. Motivationale Effekte ergeben sich ebenso aus dem den Mitarbeitern zur Verfügung stehenden Handlungsspielraum bei der Verfolgung der gemeinsam mit den Führungskräften definierten Ziele. Zwischen dem Handlungsspielraum und der Motivation wird dabei eine wechselseitige, positiv korrelierte Beziehung vermutet. Vgl. hierzu z.B. Macharzina, K. (1995), S. 451ff.; Steinle, C. (1992), S. 551; Ahlers, F. (1996), S. 73; Albach, H. (1994), S. 1574.
} 
Für den Prozeß von Änderung und Wandel im Sinne der Organisationsentwicklung ${ }^{21}$ ist das Vorbildverhalten der Führungskräfte von herausragender Bedeutung. Es gilt, Sinn und Zweck des Wandels zu vermitteln, was durch die Partizipation der Mitarbeiter an den Veränderungsprozessen wesentlich unterstuitzt wird. Der schrittweise Übergang von einer rein ökonomischen Rationalität hin zur verstärkten Berücksichtigung ökologischer Aspekte kann sich ebenfalls reibungsloser vollziehen.

Das Umweltinformationssystem und Öko-Controlling als Querschnittfunktion einer ökologisch verpflichteten Unternehmensführung ist durch einen strategischen Schwerpunkt gekennzeichnet und dabei auf die Identifizierung von Chancen und Risiken, aber auch von umweltschutzbezogenen Stärken und Schwächen des Unternehmens ausgerichtet. Hauptaufgabe ist die Unterstützung der Unternehmensleitung bei der Sicherung der auf Umweltschutzaspekte bezogenen Koordinationsfähigkeit.

Konkrete Umsetzung erfährt die ökologisch verpflichtete Unternehmensführung auf der operativen Ebene in den Funktionsbereichen Forschung und Entwicklung, Produktion, Marketing sowie Recycling/Entsorgung. Durchweg bestehen Notwendigkeiten oder Ansatzpunkte, ökologische Aspekte verstärkt in den Mittelpunkt zu stellen. Es gilt dabei zu beachten, daß in den einzelnen Bereichen nicht isoliert vorgegangen wird, sondern daß die jeweiligen Interdependenzen mit den anderen Bereichen Berïcksichtigung finden.

${ }^{21}$ Vgl. z.B. Steinle, C./Lawa, D./Schollenberg, A. (1994), S. 429f. 


\section{LITERATURVERZEICHNIS}

Achleitner, P. (1985): Sozio-politische Strategien multinationaler Unternehmungen, Bern et al., 1985.

Adams, H. W./Maier, B. (1993): Die Organisation des Umweltschutzes, in: zfo, Jg. 62 (1993), Nr. 2, S. 74-84.

Adelt, P./Müller, H./Zitzmann, A. (1991): Umweltbewußtsein und Konsumentenverhalten - Befunde und Zukunftsperspektiven, in: Szallies, R./Wiswede, G. (Hrsg.): Wertewandel und Konsum, Landsberg/Lech, 1991, S. 155-184.

Ahlers, F. (1996): Zukunftorientierte Personalführung - Sinnstiftung und -vermittlung als Führungsaufgabe, in: Bruch, H./Eickhoff, M./Thiem, H. (Hrsg.): Zukunftorientiertes Management - Handlungshinweise für die Praxis, Frankfurt a.M., 1996, S. 71-82.

Ahn, K.-H. (1987): Analyse des Umweltbewußtseins im Zusammenhang mit politischen Entwicklungsprozessen, in: Environmental Law Review, Vol. IX, 1987.

Ahn, S.-K. (1988): Die wirtschaftliche Entwicklung Südkoreas, in: Aus Politik und Zeitgeschichte, H. 36 (1988), S. 33-41.

Albach, H. (1994): Umweltmanagement als Führungsaufgabe, in: ZfB, 64. Jg. (1994), Nr. 12, S. 1567-1579.

Altemöller, F. (1998): Handel und Umwelt im Recht der Welthandelsorganisation WTO - Umweltrelevante Streitfälle in der Spruchpraxis zu Artikel III und XX GATT, Frankfurt a.M. et al., 1998.

Althammer, W. (1997): Umweltpolitik, internationaler Handel und Wettbewerbsfähigkeit, in: Meffert, H./Gisholt, O. (Hrsg.): Managementsperspektiven und Managementausbildung, Leipzig, 1997.

Altvater, E. (1987): Sachzwang Weltmarkt - Verschuldungskrise, blockierte Industrialisierung, ökologische Gefährdung - der Fall Brasilien, Hamburg, 1987. 
Ames, R. T. (1986): Taoism and the Nature of Nature, in: Environmental Ethics 8 (1986), S. 317-350.

Antes, R. (1992): Die Organisation des betrieblichen Umweltschutzes, in: Steger, U. (Hrsg.): Handbuch des Umweltmanagements, München, 1992, S. 487-509.

Antes, R. (1994): Organisation des Umweltschutzes im Unternehmen, in: UWF, 2. Jg. (1994), H. 6, S. 25-31.

Antes, R. (1996): Präventiver Umweltschutz und seine Organisation im Unternehmen, Wiesbaden, 1996.

Austin, J. E. (1991): Management in Entwicklungsländern - Ein Handbuch, Frankfurt a.M. et al., 1991.

Balassa, B. (1985): The Role of Foreign Trade in the Economic Development of Korea, in: Calenson, W. (Hrsg.): Foreign Trade and Directinvestment, The University of Wisconsin Press, 1985, S. 141-175.

Barmann, J. P. (1992): Ökologie, eine unternehmerische Herausforderung - Gesellschaftliche Akzeptanz als Voraussetzung für wirtschaftlichen Erfolg, in: Die Unternehmung, Jg. 46 (1992), Nr. 6, S. 415-428.

Barringer, H. R. (1968): Social Change and Social Differentiation in Korea, in: Kim, C. I. E./Chee, E. (Hrsg.), Detroit, S. 203-227.

Bartscher, T. R./Fleischer, H. (1991): Perspektiven einer ökologisch orientierten Unternehmensführung - Ansatzpunkte für eine adäquate Personalpolitik, in: zfo, Jg. 62 (1991), Nr. 6, S. 440-444.

Bateson, G. (1985): Ökologie des Geistes, Frankfurt a.M., 1985.

BDI (Hrsg.) (1992): Umweltpolitik International - Perspektiven 2000, Drucksache Nr. 250, Köln, 1992. 
Beck, U. (1986): Risikogesellschaft - Auf dem Weg in eine andere Moderne, Frankfurt a.M., 1986.

Becker, C.(1998): Wertorientiertes Umwelt-Management, Bamberg, 1998.

Bechmann, A. (1984): Leben wollen, neue Anleitung für eine Umweltpolitik, Köln, 1984.

Beky, G. (1972): Die Welt des Tao, Freibug et al., 1972.

Berg, C. C. (1979): Recycling in betriebswirtschaftlicher Sicht, in: WiSt, 8. Jg. (1979), S. 201205.

Bertalanffy, L. v./Beier, W./Laue, R. (1977): Biophysik des Fließgleichgewichts, 2. Aufl., Braunschweig, 1977.

Bick, H./Hansmeyer, K. H./Olschowy, G./Schmoock, P. (Hrsg.) (1984): Angewandte Ökologie Mensch und Umwelt, Bd. I: Einführung, räumliche Strukturen, Wasser, Lärm, Luft, Abfall, Bd. II: Landbau, Energie, Naturschutz und Landschaftspflege, Umwelt und Gesellschaft, Stuttgart, 1984.

Bischofberger, O. (1988): Mensch und Natur. Die Sicht der Religion des Ostens, in: Bischofberger, O. et al. (Hrsg.): Umweltverantwortung - aus religiöser Sicht, Freiburg et al., 1988.

Bleicher, K. (1979): Unternehmungsentwicklung und organisatorische Gestaltung, Stuttgart et al., 1979 .

Bleicher, K. (1992): Leitbilder, Stuttgart, 1992.

Bleicher, K. (1996): Das Konzept integriertes Management, 4. Aufl., Frankfurt a.M. et al., 1996.

Blofeld, J. (1986): Der Taoismus und die Suche nach Unsterblichkeit, Köln, 1986.

Borsdorf, A. (1989): Kurswissen Dritten Welt und Weltwirtschaft, 2. Aufl., Stuttgart, 1989. 
Braunschweig, A./Müller-Wenk, R. (1993): Ökobilanzen für Unternehmungen - Eine Wegleitung für die Praxis, Bern et al., 1993.

Brenken, D. (1987): Strategische Unternehmensführung und Ökologie - Rekonstruktion eines ausgewählten Denkmodells und die Analyse seiner Anwendung am Beispiel ökonomischökologischer Problemkomplexe, Köln, 1987.

Brockhaus, M. (1996): Gesellschaftsorientierte Kooperationen - Möglichkeiten und Grenzen der Zusammenarbeit von Unternehmungen und gesellschaftlichen Anspruchsgruppen im ökologischen Kontext, Wiesbaden, 1996.

Brodel, D. (1996): Internationale Umweltmanagement - Gestaltungsfelder, Determinanten, Ausprägungen., Wiesbaden, 1996.

Brown, G. T. (1973): Korean Pricing Policies and Economic Development in the 1960s, Baltimore et al., 1973.

Bruckmeier, K. (1994): Strategien globaler Umweltpolitik - Umwelt und Entwicklung in den Nord-Süd-Beziehungen, Münster, 1994.

Bundesumweltministerium/Umweltbundesamt (Hrsg.) (1995): Handbuch Umweltcontrolling, München, 1995.

Bungard, W. (1995): Förderung ökologisch orientierten Mitarbeiterverhaltens, in: Eichhorn, P. (Hrsg.): Ökosoziale Marktwirtschaft - Ziele und Wege, Wiesbaden, 1995, S. 45-73.

Burschel, C./Claes, T./Hallay, H./Pfriem, R. (1999): Umweltpolitik in kleinen und mittelständischen Unternehmen - EG-Öko-Audit, DIN ISO 14001 ff., München et al., 1999.

Byun, H.-Y/Kim, S. (1996): Wirtschaftsentwicklungspläne in Südkorea, in: Byun, H.-Y. (Hrsg.): Wirtschaftsentwicklung Südkoreas, 3. Aufl., Seoul, 1996, S. 109-174. (auf koreanisch)

Cansier, D. (1993): Umweltökonomie, Stuttgart, 1993. 
Capra, F. (1984): Das Tao der Physik - Die Konvergenz von westlicher Wissenschaft und östlicher Philosophie, Berlin et al., 1984.

Capra, F. (1991): Wendezeit - Bausteine für ein neues Weltbild, München, 1991.

Chang, K.-K./Lee, S.-H. (1993): Laotse und Chuangtse, Seoul, 1993. (chinesisch/koreanisch)

Chang, G. C. C. (1989): Die buddhistische Lehre von der Ganzheit des Sein - Das holistische Weltbild der buddhistischen Philosophie, Wien, 1989.

Chen, E. M. (1973): The Meaning of Te in Tao Te Ching - An Examination of the Concept of Nature in Chinese Taoism, in: Philosophy East and West 23 (1973), S. 457-470.

Cheng Chung Ying (1986): On the Environmental Ethics of the Tao and the Ch'i, in: Environmental Ethics 8 (1986), S. 351-370.

Chien Sche-Yen (1982): Das Verhältnis von Mensch und Weltalls - Grundproblem der Bildungstheorie von Humboldt, Fink und Chuang Tzu. Ein kulturkritischer Vergleich, Frankfurt a.M., 1982.

Cho, H.-S. (1983): Bewegung der Anti-Umweltverschmutzung, in: Institut für Umweltforschung (Hrsg.), Seoul, 1983, H. 6. (auf koreanisch)

Cho Kah Kyung (1977): Das Absolute in der taoistischen Philosophie, in: Papenfuss, D./Sörig, J. (Hrsg.): Transzendenz und Immanenz. Philosophie und Theologie in der veränderten Welt, Stuttgart, 1977, S. 239-255.

Cho, S. (1994): The Dynamics of Korean Economic Development, Washington D.C., 1994.

Cho, B.-S. (1993): Umweltstrafrecht in Südkorea und Japan, Seoul, 1993. (auf koreanisch)

Choi, I.-S. (1991): Die taologische Frage nach Gott - Paul Tillichs philosophischer Gottesbegriff des „Seins-selbst“ und sprachliche Verantwortung des Glaubens in Begegnung mit dem Taogedanken Laotzus, Frankfurt a.M., 1991, S. 128-142. 
Choi, J.-S. (1998): Abfallpolitik in Südkorea - Theoretische Grundlagen und umweltpolitische Realisierungsprobleme, Frankfurt a.M., 1998.

Choi, C.-J. (1984): Feng Shui-Theorie in Korea, Seoul, 1984. (auf koreanisch)

Chung, H.-S. (1994): Studie für die Abfallwirtschaftspolitik in der industrialisierten Ländern, Seoul, 1994. (auf koreanisch)

Clausen, J. (1993): „Begriffliche Definitionen rund um die ,Öko-Audit““, in: UWF, 1. Jg. (1993), H. 3, S. 25-27.

Coenenberg, A. G./Baum, H.-G./Günther, E./Wittmann, R. (1994): Unternehmenspolitik und Umweltschutz, in: ZfbF, 46. Jg. (1994), S. 81-100.

Cooper, J. C. (1977): Der Weg des Tao - Eine Einfuihrung in die älteste chinesische Weisheitslehre, Bern et al., 1977.

Corsten, H./Reiß, M. (Hrsg.) (1995): Handbuch Unternehmungsführung - Konzepte, Instrumente, Schnittstellen., Wiesbaden, 1995.

Dahm, G./Delbrück, J./Wolfrum, R. (1989): Völkerrecht, Bd. I/1 - Die Grundlagen: Die Völkerrechtssubjekte, Berlin, et al., 1989.

Dichtl, E. (1991): Ökorationalität - Gebot der Vernunft oder Geschäft der Stunde?, in: WiSt, 20. Jg. (1991), H. 6, S. 269.

Dierkes, M. (1974): Die Sozialbilanz - ein gesellschaftsbezogenes Informations- und Rechnungssystem, Frankfurt a.M., 1974.

Dierkes, M. (1984): Gesellschaftsbezogene Berichterstattung, in: ZfB, 54. Jg. (1984), S. 12101235.

Diller, H. (1991): Preispolitik, 2. Aufl., Stuttgart, 1991. 
Dinkelbach, W. (1996): Ökologische Aspekte in der Produktionstheorie. In: Kein, W. (Hrsg.): Handwörterbuch der Produktionswirtschaft, 2. Aufl., Stuttgart, 1996, Sp. 1338 - 1346.

Dyckhoff, H. (1991): Berücksichtigung des Umweltschutzes in der betriebswirtschaftlichen Produktionstheorie. In: Ordelheide, D./Rudolph, B./Büsselmann, E. (Hrsg.): Betriebswirtschaftslehre und ökonomische Theorie, Stuttgart, 1991, S. 275 - 309.

Dyckhoff, H./Soukal, R. (1996): Kombinierte Mengen- und Tourenplanung als Beitrag zur umweltverträglichen Logistikorganisation, in: UWF, 4. Jg. (1996), H. 1, S. 43 - 47.

Dyllick, T. (1986): Die Beziehungen zwischen Unternehmung und gesellschaftlicher Umwelt, in: DBW, Jg. 46 (1986), Nr. 3, S. 373-392.

Dyllick, T. (1989): Management der Umweltbeziehungen - Öffentliche Auseinandersetzung als Herausforderung, Wiesbaden, 1989.

Dyllick, T. (1990): Ökologisch bewußtes Management. Die Orientierung Nr. 96, Schweizerische Volksbank, Bern, 1990.

Dyllick, T. (1992): Ökologisch bewusste Unternehmungsfuihrung - Bausteine einer Konzeption, in: Die Unternehmung, Jg. 46 (1992), Nr. 6, S. 391-413.

Dyllick, T. (1994): Die EU-Verordnung zum Umweltmanagement und zur Umweltbetriebsprüfung (EMAS-Verordnung) - Darstellung, Beurteilung und Vergleich mit der geplanten ISO 14001 Norm, IWÖ-Diskussionsbeitrag Nr. 20, St. Gallen, 1994.

Dyllick, T. (1995): Forschungsprogramm Ökologie und Wettbewerbsfähigkeit von Unternehmen und Branchen, in: Freimann, J./Hildebrandt, E. (Hrsg.): Praxis der betrieblichen Umweltpolitik, Wiesbaden, 1995, S. 75-90.

Dyllick, T./Hummel, J. (1995): EMAS und/oder ISO 14001? - Wider das strategische Defizit in den Umweltmanagementsystemnormen, in: UWF, 3. Jg. (1995), H. 3, S. 24-29.

Dyllick, T./Hummel. J. (1996): Integriertes Umweltmanagement - Ein Ansatz im Rahmen des St. Galler Management-Konzepts, IWÖ-Diskussionsbeitrag Nr. 35, St. Gallen, 1996. 
EG (Rat der Europäischen Gemeinschaften) (1993): „Verordnung (EWG) Nr. 1836/93 des Rates vom 29. Juni 1993 über die freiwillige Beteiligung gewerblicher Unternehmen an einem Gemeinschaftssystem für das Umweltmanagement und die Umweltbetriebsprüfung“, in: Amtsblatt der Europäischen Gemeinschaften, Nr. L. 168/1-168/18.

Eliseit, H. (1978): Korea, das zerrissene Lächeln, Berlin, 1978.

Engelhardt, A. (1990): Öko-Management ist mehr als ein Modetrend, in: Die Mitbestimmung, 36. Jg. (1990), S. 682-686.

Esty, D. C. (1994): Making Trade and Environmental Policies Work Together - Lessons from NAFTA; Außenwirtschaft, in: Schweizerischen Zeitschrift für internationale Wirtschaftsbeziehungen, 49. Jg. (1994), H. 1, S. 59-79.

Eulgem, S. (1993): Die Beziehungen zwischen Unternehmung und Umwelt - Theoretische Grundlagen und praktische Implikationen eines Umweltmanagementskonzepts, Stuttgart, 1993.

Everling, U. (1991): Umweltschutz durch Gemeinschaftsrecht in der Rechtsprechung des EuGH, in: Behrens, P./Koch, H.-J. (Hrsg.): Umweltschutz in der Europäischen Gemeinschaft Spannungsfelder zwischen nationalem Recht und europäischem Gemeinschaftsrecht, Baden-Baden, 1991, S. 29-45.

Ewringmann, D./Schafhausen, F. (1985): Abgaben als ökonomischer Hebel in der Umweltpolitik, UBA-Bericht 5/85, Berlin, 1985.

Eyerer, P. (Hrsg.) (1996): Ganzheitliche Bilanzierung - Werkzeug zum Planen und Wirtschaften in Kreisläufen, Berlin et al., 1996.

Faber, M./Jöst, F./Manstetten, R. (1997): Was ist und wie erreichen wir eine nachhaltige Entwicklung?, in: in: Steger, U. (Hrsg.): Handbuch des integrierten Umweltmanagements, München et al., 1997, S. 51-67.

Fang H. Thome (1964): The World and the Individual in Chinese Philosophy, in: Philosophy East and West 14 (1964), S. 101-129. 
Farmer, K.(1991): Wirtschaft und Umwelt aus ökonomisch-biblischer Sicht, Graz et al., 1991.

Fatouros, A. A. (1994): Looking for an International Legal Framework for Transnational Corporations; in: Fatouros, A. A. (Hrsg.): Transnational Corporations - The International Legal Framework, Unites Nations Library on Transnational Corporations, Vol. 20, London et al., 1994, S. 1-40.

Fees, E./Hohmann, H. (1994): Aktuelle Tendenzen im Umweltrecht und ihre Auswirkungen auf Unternehmen, in: Kreikebaum, H/Seidel, E./Zabel, H.-U. (Hrsg.): Unternehmenserfolg durch Umweltschutz, Wiesbaden, 1994, S. 83-102.

Feess-Dörr, E./Steger, U./Weihrauch, P. (1993): „Sustainable Development“, Nachhaltige und dauerhafte Entwicklung - Ein ökologisch relevantes und wirksames Leitbild ökonomischer Entscheidungen?, in: Steger, U./Timmermann, M. (Hrsg.): Mehr Ökologie durch Ökonomie?, Berlin et al., 1993, S. 93-120.

Feess, F. (1997): Sustainable Development und Rahmenbedingungen, in: Steger, U. (Hrsg.): Handbuch des integrierten Umweltmanagements, München et al., 1997, S. 31-49.

Fellenberg, G. (1985): Umweltforschung - Einführung in die Probleme der Umweltverschmutzung, Berlin et al., 1985.

Fietkau, H.-J. (1991): Umweltbewußtsein (1987), in : Seidel, E./Strebel, H. (Hrsg.): Umwelt und Ökonomie, Wiesbaden, 1991, S. 144-150.

Fischer, H./Kriese, R. (1991): Gedanken und Handlungsalternativen zum Gestalten einer ganzheitlichen Arbeits- und Lebenswelt, in: Schanz, G. (Hrsg.): Handbuch Anreizsysteme, Stuttgart, 1991, S. 903-932.

Fischer, G. (1996): Ökologie und Management - Eine Einführung für Praxis und Studium, Zürich, 1996.

Fischer, P. (1991): Internationales Wirtschaftsrecht und Internationale Wirtschaftsorganisationen, in: Neuhold, H./Hummer, W./Schreuer, C. (Hrsg.): Österreichisches Handbuch des Völkerrechte, Bd. I, Textteil, 2. Aufl., Wien, 1991, S.384-407. 
Fischer, U./Weigand, S. (1990): Ökologisch orientierte Unternehmensführung - Herausforderung für die Zukunft, in: Czap, H. (Hrsg.): Unternehmensstrategien im sozio-ökonomischen Wandel, Berlin, 1990, S. 91-107.

Fischer, W. (1992): Klimaschutz und internationale Politik - Die Konferenz von Rio zwischen globaler Verantwortung und internationalen Interessen, Aachen, 1992.

Fraser-Darling, F. (1986): Die Verantwortung des Menschen für seine Umwelt, in: Birnbacher, D. (Hrsg.): Ökologie und Ethik, Stuttgart, 1986, S. 2-19.

Freemann, R. E. (1984): Strategic Management - A Stakeholder Approach, Boston et al., 1984.

Freimann, J. (1989): Instrumente sozial-ökologischer Folgenabschätzung im Betrieb, Wiesbaden, 1989.

Freimann, J. (Hrsg.) (1990): Ökologische Herausforderung der Betriebswirtschaftslehre, Wiesbaden, 1990.

Freimann, J. (1990a): Vorwort des Herausgebers, in: Freimann, J. (Hrsg.): Ökologische Herausforderung der Betriebswirtschaftslehre, Wiesbaden, 1990, S. 7-15.

Freimann, J. (1990b): Plädoyer für die Normierung von betrieblichen Öko-Bilanzen, in: Freimann, J. (Hrsg.): Ökologische Herausforderung der Betriebswirtschaftslehre, Wiesbaden, 1990, S. 177-195.

Freimann, J. (1991): Betriebliche Umweltökonomie oder ökologische Unternehmenspolitik?, in: Seidel, E./Strebel, H. (Hrsg.) (1991): Umwelt und Ökonomie - Reader zur ökologieorientierten Betriebswirtschaftslehre, Wiesbaden, 1991, S. 73-79.

Freimann, J. (1996): Betriebliche Umweltpolitik, Bern et al., 1996.

Frese, E./Kloock, J. (1989): Internes Rechnungswesen und Organisation aus der Sicht des Umweltschutzes, in: BFuP, Jg. 41 (1989), H. 1, S. 1-29. 
Frese, E. (1992): Organisation des Umweltschutzes, in: Frese, E. (Hrsg.): Handwörterbuch der Organisation, Stuttgart, 1992, Sp. 2433-2451.

Frey, B. S. (1985): Umweltökonomie, 2. Aufl., Göttingen, 1985.

Fung Yu Lan (1952): A History of Chinese Philosophie I, Princeton, 1952.

Fülgraff, G. (1991): Ökonomische Instrumente und proaktives Handeln der Unternehmer, in: Kreibich, R./Rogall, H./Boes, H. (Hrsg.): Ökologisch produzieren - Zukunft der Wirtschaft durch umweltfreundliche Produkte und Produktionsverfahren, Weinheim et al., 1991, S. 31-44.

Fussler, C. (1999): Die Öko-Innovation - wie Unternehmen profitable und umwelffreundlich sein können, Stuttgart et al., 1999.

Gälweiler, A. (1986): Unternehmensplanung. Überarbeitete Neuausgabe, Frankfurt a.M., 1986.

Gege, M. (1994): Motive einer umweltorientierten Unternehmensführung, in: Hansmann, K. W. (Hrsg.): Marktorientiertes Umweltmanagement, Schriften zur Unternehmensführung Nr. 50/51, Wiesbaden, 1994, S. 83-116.

Gege, M. (1997): Kosten senken durch Umweltmanagement, München, 1997.

Georgescu-Rogen, N. (1991): The Entropy Law and the Economic Process (1971), Cambridge, 1991.

Georgescu-Rogen, N. (1991): Was geschieht mit der Materie im Wirtschaftsprozeß? (1974), in : Seidel, E./Strebel, H. (Hrsg.): Umwelt und Ökonomie, Wiesbaden, 1991, S. 64-74.

Gladwin, T. N. (1987): Environment, Development and Multinational Enterprise, in: Pearson, C. S. (Hrsg.): Multinational Corporations, Environment and the Third World, Business Matters, Durham, 1987.

Glaeser, B. (1989): Umweltpolitik zwischen Reparatur und Vorbeugung - Eine Einführung am Beispiel der Bundesrepublik im internationalen Kontext, Opladen, 1989. 
Global 2000 (1980): Der Bericht an den Präsidenten, Hrsg.: Council on Environmental Quality und US-Außenministerium (dt. Übersetzung), Frankfurt a.M., 1980.

Götzelmann, F. (1992): Umweltschutzinduzierte Kooperation der Unternehmung - Anlässe, Typen und Gestaltungspotentiale, Frankfurt a.M. et al., 1992.

Goodman, R. (1980): Taoism and Ecology, in: Environmental Ethics 2 (1980), S. 73-80.

Grochla, E. (1970): Systemtheorie und Organisationstheorie, in: ZfB, 40. Jg. (1970), S. 1-16.

Güldenberg, S. (1997): Führungsorientiertes Öko-Controlling, in: Steger, U. (Hrsg.): Handbuch des integrierten Umweltmanagements, München et al., 1997, S. 155-177.

Günther, E./Wagner, B. (1993): Ökologieorientierung des Controlling (Öko-Controlling), in: DBW, 53. Jg. (1993), S. 143-166.

Günther, E. (1994): Ökologieorientiertes Controlling, München, 1994.

Gutenberg, E. (1983): Grundlagen der Betriebswirtschaftslehre, Bd. I: Die Produktion, 24. Aufl., Berlin et al., 1983.

Haas, J.-P. de (1989): Management-Philosophie im Spannungsfeld zwischen Ökologie und Ökonomie, Köln, 1989.

Haber, W. (1980): Fragestellung und Grundbegriffe der Ökologie, in: Buchwald, K./Engelhardt, E. (Hrsg.): Handbuch für Planung, Gestaltung und Schutz der Umwelt, Bd. I: Die Umwelt des Menschen, 1980, S. 74-79.

Haber, W.(1991): Über den Beitrag der Ökosystemforschung zur Entwicklung der menschlichen Umwelt (1980), in: Seidel, E./Strebel, H. (Hrsg.): Umwelt und Ökonomie, Wiesbaden, 1991, S. 39-63.

Habermas, J. (1983): Moralbewußtsein und kommunikatives Handeln, in: Habermas, J. (Hrsg.): Moralbewußtsein und kommunikatives Handeln, Frankfurt a.M., 1983, S. 127-206. 
Hallay, H./Pfriem, R. (1992): Öko-Controlling - Umweltschutz in mittelständischen Unternehmen, Frankfurt a.M., 1992.

Hallay, H. (1996): Ökologische Entwicklungsfähigkeit von Unternehmen, Marburg, 1996.

Hansen, U. (1992): Umweltmanagement im Handel, in: Steger, U. (Hrsg.): Handbuch des Umweltmanagements, München, 1992, S. 733-756.

Hansen, U. (Hrsg.) (1995): Verbraucher- und umweltorientiertes Marketing - Spurensuche einer ökologischen Marketingethik, Stuttgart, 1995.

Harborth, H.-J. (1991): Dauerhafte Entwicklung statt globaler Selbstzerstörung - Eine Einfuihrung in das Konzept des Sustainable Development, Berlin, 1991.

Hartje, V. J. (1982): Umwelt- und Ressourcenschutz in der Entwicklungshilfe zum Überleben?, Frankfurt a.M., 1982.

Hauff, V. (Hrsg.) (1987): Unsere gemeinsame Zukunft - Der Brundtland-Bericht der Weltkommission für Umwelt und Entwicklung, Greven, 1987.

Hauff, M. v./Schmid, U. (Hrsg.) (1992): Ökonomie und Ökologie - Ansätze zu einer ökologisch verpflichteten Marktwirtschaft, Stuttgart, 1992.

Hauser, H./Schanz, K.-U. (1995): Das neue GATT - Die Welthandelsordnung nach Abschluß der Uruguay-Runde, 2. Aufl., München, 1995.

Hein, W. (1994): Internationale Umweltpolitik, in: Nohlen, D. (Hrsg.): Lexikon der Politik, Bd. 6: Internationale Beziehungen, München, 1994, S. 547-555.

Heinen, E. (1966): Das Zielsystem der Unternehmung - Grundlagen betriebswirtschaftlicher Entscheidungen, Wiesbaden, 1966.

Heinen, E. (1985): Industriebetriebslehre als Entscheidungslehre, in: Heinen, E. (Hrsg.): Industriebetriebslehre - Entscheidungen im Industriebetrieb, 8. Aufl., Wiesbaden, 1985, S. 5-75.

Heinen, E./Dill, P. (1986): Unternehmenskultur, in: ZfB, 56. Jg. (1986), H. 3, S. 202-218. 
Herkendell, J. (1992): Entwicklungsländer und Umwelt am Beispiel der Bodenschutzproblematik, in: Dreyhaupt/Peine/Wittkämper (Hrsg.): Umwelt-Handbuch, Berlin et al., 1992.

Hickmann, E. (1959): Korea, in: Handwörterbuch der Sozialwissenschaft, Band 6, Stuttgart, 1959, S. 199-198.

Hildebrandt, E. (1995): Arbeitspolitische Aspekte unternehmerischer Ökologisierungspfade, in: Freimann, J./Hildebrandt, E. (Hrsg.): Praxis der betrieblichen Umweltpolitik, Wiesbaden, 1995, S. 139-158.

Hill, W. (1991): Basisperspektiven der Managementforschung, in: Die Unternehmung, 45. Jg. (1991), Nr. 1, S. 2-15.

Hinterhuber, H. H. (1992): Strategische Unternehmensführung, Band II: Strategisches Denken, 5. Aufl., Berlin et al., 1992.

Hinterhuber, H. H. (1996): Strategische Unternehmensführung, Band I: Vision, Unternehmenspolitik, Strategie, 6. Aufl., Berlin et al., 1996.

Hoffmann-Riem, W. (1991): Gemeinschaftspolitik zwischen Marktfreiheit und Umweltschutz, in: Behrens, P./Koch, L. (Hrsg.): Umweltschutz in der Europäischen Gemeinschaft Spannungsfelder zwischen nationalem Recht und europäischem Gemeinschaftsrecht, Baden-Baden, 1991, S. 9-28.

Höll, O. (1991): Internationale Dimensionen der Umweltpolitik, in: Glatz, H. (Hrsg.): Die ökologische Herausforderung, Wien, 1991, S. 136-157.

Hopfenbeck, W. (1990): Urnweltorientiertes Management und Marketing - Konzepte, Instrumente, Praxisbeispiele., Landsberg/Lech, 1990.

Hopfenbeck, W./Willig, M. (1995): Umweltorientiertes Personalmanagement - Umweltbildung, Motivation, Mitarbeiterkommunikation, Landsberg/Lech, 1995. 
Hopfenbeck, W. (1998): Allgemeine Betriebswirtschafts- und Managementslehre - Das Unternehmen im Spannungsfeld zwischen ökonomischen, sozialen und ökologischen Interessen, 12. Aufl., Landsberg/Lech, 1998.

Horst, P. (1991): Ökocheck für die Unternehmensstrategie, in: Gablers Magazin, 4. Jg. (1991), H. 6, S. 10-16.

Hsiao, A. (Hrsg.) (1985): Deutsche Denker über China, Frankfurt a.M., 1985.

Hübner, H./Jahnes, S. (1992): Instrumente als „Management-Technologie“ für die Technikwirkungsanalyse - Technik- und Produktfolgenabschätzung im Unternehmen als Kern eines vorsorgenden Umweltmanagements, Kassel: Universität-Gh., 1992.

Hunziker, R. (1980): Die soziale Verantwortung der Unternehmung - Auseinandersetzung mit einem Schlagwort, Bern et al., 1980.

ICC (Internationale Handelskammer) (1991): Charter für eine langfristige tragfähige Entwicklung - Grundsätze des Umweltmanagements, ICC Publ. Nr. 210/356 A, Paris, 1991.

Immler, H. (1989): Vom Wert der Natur. Zur ökologischen Reform von Wirtschaft und Gesellschaft. Natur in der ökonomischen Theorie, Teil 3, Opladen, 1989.

ISO (International Standards Organisation) (1994): Environmental Management Systems, Committee Draft 14001, United Kingdom, BSI, 1994.

ISO/DIN 14.001 (1995): Umweltmanagementsysteme. Spezifikationen und Leitfaden zur Anwendung, Entwurf, DIN, Oktober 1995.

Jänicke, M. (1988): Ökologische Modernisierung - Optionen und Restriktionen präventiver Umweltpolitik, in: Simonis, U. E. (Hrsg.): Präventive Umweltpolitik, Frankfurt a.M., 1988, S. 13-26.

Jähnike, M./Weidner, W. (1997): Zum aktuellen Stand der Umweltpolitik im internationalen Vergleich - Tendenzen zu einer globalen Konvergenz?, in: Aus Politik und Zeitgeschichte, 27. Juni 1997, Nr. B27/97, S. 15-24. 
Jahnes, S./Tammler, U. (1997): Anforderungen an Unternehmen, in: Winter, G. (Hrsg.): Ökologische Unternehmensentwicklung, Berlin et al., 1997, S. 5-24.

Janisch, M. (1993): Das strategische Anspruchsgruppenmanagement - Von Shareholder zum Stakeholder Value, Bern et al., 1993.

Jones, L. P./Sagong, I. (1980): Government, Business and Entpreneurship in Economic Development: The Korean Case, Harvard University Press, 1980.

Kaas, K. P. (1992): Marketing für umweltfreundliche Produkte, in: DBW, 52. Jg. (1992), S. 473487.

Kaltenmark, M. (1981): Lao-Tzu und der Taoismus, Frankfurt a.M., 1981.

Katz, D./Kahn, R. L. (1966): The Social Psychology of Organizations; New York et al., 1966.

Katz, D./Kahn, R. L. (1971): Open-System Theory; in: Maurer, J. G. (Ed.): Readings in Organization Theory - Open-System Approaches, New York, 1971, S. 13-30; Nachdruck aus: Katz, D./Kahn, R. L.: The Social Psychology of Organizations, New York, 1966, S. 452 455,17 - 28, 32 - 33, 59 - 62, 8182,123 - 124.

KEI (Korea Environment Institute) (1997): Befragung zum Umweltbewußtsein in Südkorea, Seoul, 1997. (auf koreanisch)

KETRI (Korea Environmental Technology Research Institute) (1997): Richtlinie für das Umweltmanagement, Forschungsbericht 97/03, Seoul, 1997. (auf koreanisch)

Kil, H.-S. (Hrsg.) (1997): Umwelt und Religion, Seoul, 1997. (auf koreanisch)

Kilian, M. (1991): Umweltschutz, in: Wolfrum, R. (Hrsg.): Handbuch Vereinte Nationen, 2. Aufl., München, 1991, S. 868-876.

Kim, C.-D. (1973): Ökonomische Betrachtung der Umweltverschmutzung, Seoul, 1973. (auf koreanisch) 
Kim, K.-C./Rho, C.-S. (1976): Korean Environment and National Development, Seoul, 1976. (auf koreanisch)

Kim, K.-T. (1978): Laotse, Seoul, 1978. (chinesisch/koreanisch)

Kim, M.-J. (1991): Östliche und westliche Wissenschaftstradition und Umweltbewegung, Seoul, 1991. (auf koreanisch)

Kippes, S. (1991): Stakeholder-Analyse, Instrument der Unternehmenspolitik - Ansprüche rechtzeitig erkennen; in: Gablers Magazin, H. 6 (1991), S. 32 - 36.

Kirchgeorg, M. (1990): Ökologieorientiertes Unternehmensverhalten - Typologien und Erklärungsansätze auf empirischer Grundlage, Wiesbaden, 1990.

Kirchgeorg, M. (1992): Sustainable Development, in: DBW, 52. Jg. (1992), Nr. 4.

Kirchgeorg, M. (1998): Unternehmensstrategische Gestaltungsprobleme von Stoffkreisläufen, Wiesbaden, 1998.

Kirsch, W. (1971): Entscheidungsprozesse, Band III: Entscheidungen in Organisationen, Wiesbaden, 1971.

Kirschten, U. (1997): Ökologische Organisationsentwicklung am Beispiel der Einführung eines Öko-Controlling - Eine konzeptionelle und empirische Untersuchung, Wiesbaden, 1997.

Kirschten, U./Stitzel, M. (1995): Umweltorientierte Unternehmensfuihrung, in: Junkerheinrich, M./Klemmer, P./Wagner, G. R. (Hrsg.): Handbuch zur Umweltökonomie, Berlin, 1995, S. 311-317.

Kistner, K.-P. (1989): Umweltschutz in der betrieblichen Produktionsplanung, in: BFuP, 41. Jg. (1989), Nr. 1, S. 30 - 50.

Kistner, K.-P./Steven, M. (1993): Lineare Aktivitätsanalyse und Umweltschutz, In: Wagner, G. R. (Hrsg.): Betriebswirtschaft und Umweltschutz, Stuttgart, 1993, S. 106-125. 
KIET (Korea Institute for industrial Economics \& Trade) (1995): Trade and Environment, Seoul, 1995. (auf koreanisch)

Klenk, J. (1993): Organisation for Economic Cooperation and Development - OECD, in: Nohlen, D. (Hrsg.): Lexikon der Politik, Bd. 6: Internationale Beziehungen, München, 1993, S.355-361

Klink, G. O. (1996): Genese einer ökologieorientierten Unternehmensführung - Ein evolutionstheoretisches Modell, Berlin, 1996.

Kloepfer, M. (1990): Rechtsstaatliche Probleme ökonomischer Instrumente im Umweltschutz, in: Wagner, G. R. (Hrsg.): Unternehmung und ökologische Umwelt, München, 1990, S. 241-261.

Kötzle, A. (1980): Die Eignung von Subventionen für die Umweltpolitik, Berlin, 1980.

Kratky, K. W. (1989): Vom linearen zum systemischen Denken, in: Kratky, K. W./Bonet, E. M. (Hrsg.): Systemtheorie und Reduktionismus, Wiener Studien zur Wissenschaftstheorie, Bd. 3, Wien, 1989, S. 11-32.

Kreikebaum, H. (Hrsg.) (1990): Integrierter Umweltschutz - Eine Herausforderung für das Innovationsmanagement, Wiesbaden, 1990.

Kreikebaum, H. (1993): Strategische Unternehmensplanung, 5. Aufl., Stuttgart et al., 1993.

Kreikebaum, H. (1994): Ökologieverträglichkeit der Produktion und deren Erfolgswirkungen, in: Kreikebaum, H./Seidel, E./Zabel, H.-U. (Hrsg.): Unternehmenserfolg durch Umweltschutz, Wiesbaden, 1994, S. 103-120.

Kreikebaum, H./Seidel, E./Zabel, H.-U. (Hrsg.): Unternehmenserfolg durch Umweltschutz, Wiesbaden, 1994.

Krieg, H.-H. (1992): Der Tausch >Schulden gegen Umwelt $<$ - Ein Beitrag zur Lösung der Schuldenkrise und Umweltkrise der Weltwirtschaft, Marburg, 1992. 
Krödgen, G. (1982): Umweltzerstörung als Entwicklungsstimulans, in: epd - Entwicklung Materialien II/1982.

Kropfberger, D. (1986): Erfolgsmanagement statt Krisenmanagement, Linz, 1986.

Krulis-Randa, J. (1990): Entwicklung einer Unternehmungspolitik und Marketingstrategie in einem ökologisch sensibilisierten Umfeld, in: Lengwiller, C. (Hrsg.): Ökologie und Umweltschutz - Unternehmen vor neuen Marktchancen, Grüsch, 1990, S. 45-67.

Krystek, U./Behrendt, J. (1991): Früherkennung ökologisch orientierter Chancen und Bedrohungen, Forschungsinformationsdienst Ökologisch orientierte Betriebswirtschaftslehre (FÖB), Nr. 12, Nov./Dez., 1991, S. 14-19.

Ku, D.-H. (1996): Soziologie der Umweltbewegung in Südkorea, Seoul, 1996. (auf koreanisch)

Kuba, R. (1986): Kultur wohin? Recycling langfristig gedacht, in: io Management Zeitschrift, 55/7-8 (1986), S. 329-332.

Kubicek, H./Thom, N. (1976): Umsystem betriebliches, in: Grochla, E./Wittmann, W. (Hrsg.): Handwörterbuch der Betriebswirtschaft, 4. Aufl., Stuttgart, 1976, Sp. 3977-4017.

Kuhn, T./Wittmann, S. (1995): Ökoeffizient durch Personalmanagement - Grundmodell und Gestaltungsperspektiven, in: UWF, 3. Jg. (1995), H. 1, S. 10-15.

Kulessa, M. E. (1992): Freihandel und Umweltschutz - ist das GATT reformbedürftig?, in: Wirtschaftsdienst, 1992, S. 299-307.

Kwon, S.-P. (1983): Maßnahmen zur Umweltverschmutzung, in: Journal of Environmental Pollution Control, Vol. 14, Nr. 2, 1983/84. (auf koreanisch)

Lange, C. (1978): Umweltschutz und Unternehmensplanung - Die betriebliche Anpassung an den Einsatz umweltpolitischer Instrumente, Wiesbaden, 1978.

Lee, J.-H. (1979): Das traditionelle Verhältnis von Politik und Religion in Korea und die christliche Missionen, Hamburg, 1979. 
Lee, M.-T. (1974): Moral und moralische Erziehung, Seoul, 1974. (auf koreanisch)

Lee, S.-N. (1995): Traditionelle Auffassungen über die Natur in Korea - Einführung in die koreanische Geschichte des Naturschutzes, Seoul, 1995. (auf koreanisch)

Lee, Y.-H./Yoon, K.-B. (1986): Lexikon der Landschaftsarchitektur, Seoul, 1986. (auf koreanisch)

Lin Yu Tang (1986): Die Weisheit des Laotse, Frankfurt a.M., 1986.

Luhmann, N. (1990): Ökologische Kommunikation, 3. Aufl., Opladen, 1990.

Luhmann, N. (1991): Zweckbegriff und Systemrationalität - über die Funktion von Zwecken in sozialen Systemen, 5. Aufl., Frankfurt a.M., 1991.

Luhmann, N. (1996): Soziale System - Grundriß einer allgemeinen Theorie, 6. Aufl., Frankfurt a.M., 1996.

Lutz, R. (Hrsg.) (1992): Innovations-Ökologie - Ein praktisches Handbuch für umweltbewußtes Industriemanagement, Stuttgart et al., 1992.

Macharzina, K. (1993): Unternehmensführung: das internationale Managementwissen - Konzepte, Methoden, Praxis, Wiesbaden, 1993.

Malik, F. (Hrsg.) (1979): Praxis des systemorientierten Managements, Bern et al., 1979.

Mann, R. (1990): Das ganzheitliche Unternehmen, Bern et al., 1990.

Martin, J. (1989): Strafbarkeit grenzüberschreitender Umweltbeeinträchtigungen - Zugleich ein Beitrag zur Gefährdungsdogmatik und zum Umweltvölkerrecht, Freiburg i. B., 1989.

Mathis, J. H. (1991): Trade Related Environmental Measures in the GATT, LIEI 1991/2, S. 3767. 
Maurer, R. (1987): Heideggers Metaphysik der Physik. Zur Hauptrichtung seines Denkwegs, in: Wisser, R. (Hrsg.): Martin Heidegger - Unterwegs im Denken, Freiburg et al., 1987, S. 131-160.

Mayer-Tasch, P. C./Merk, K. P. (1988): Präventive internationale Umweltpolitik, in: Simonis, U. E. (Hrsg.): Präventive Umweltpolitik, Frankfurt a.M., 1988, S. 259-270.

Mayntz, R./ Hucke, J. (1978): Gesetzesvollzug im Umweltschutz - Wirksamkeit und Probleme, in: Zeitschrift für Umweltpolitik 2. 1978, S. 217-244.

Meadows, D. L./Meadows, D. H./Zahn, E./Milling, P. (1972): Die Grenzen des Wachstums. Bericht des Club of Rome zur Lage der Menschheit (dt. Übers. von „The Limits of Growth“), Stuttgart, 1972.

Meadows, D. L./Meadows, D. H./Randers, J. (1992): Die neue Grenzen des Wachstums, Stuttgart, 1992.

Meffert, H./Bruhn, M./Schubert, F./Walther, T. (1986): Marketing und Ökologie - Chancen und Risiken umweltorientierter Absatzstrategien der Unternehmung, in: DBW, 46. Jg. (1986), S. 140-159.

Meffert, H./Benkenstein, M./Schubert, F. (1987): Umweltschutz und Unternehmensverhalten, in: HBM, 9. Jg. (1987), H. 2, S. 32-39.

Meffert, H./Kirchgeorg, M./Ostmeier, H. (1988): Analysekonzepte und strategische Optionen des ökologieorientierten Marketing, in: Thexis, 5. Jg. (1988), H. 3, S. 22-27.

Meffer, H. (1988): Ökologisches Marketing als Antwort der Unternehmen auf aktuelle Problemlagen der Umwelt, in: Brandt, A./Hansen, U./Schoenheit, I./Werner, K. (Hrsg.): Ökologisches Marketing, Frankfurt a.M., 1988, S. 131-158.

Meffert, H./Kirchgeorg, M. (1989): Umweltschutz als Unternehmensziel, Münster, 1989.

Meffert, H.(1991): Strategisches Ökologie-Management, in: Coenenberg, A. G. et al. (Hrsg.): Ökologie-Management als strategischer Wettbewerbsfaktor, Stuttgart, 1991, S. 7-33. 
Meffert, H. (1996): Stand und Perspektiven des Umweltmanagement in der betriebswirtschaftlichen Forschung und Lehre . Handelshochschule Leipzig - Arbeitspapier Nr. 1, 1996.

Meffert, H./Kirchgeorg, M. (1998): Marktorientiertes Umweltmanagement - Grundlagen und Fallstudien, 3. Aufl., Stuttgart, 1998.

Merchant, C. (1987): Der Tod der Natur - Ökologie, Frauen und neuzeitliche Naturwissenschaft, München, 1987.

Meuser, T. (1994): Der Umweltschutz im Zielsystem von Unternehmen, in: Zeitschrift für Planung, Jg. 5 (1994), S. 49-62.

Meyer-Abich, K. M. (1991): Im sozialen Frieden zum Frieden mit der Natur (1985), in : Seidel, E./Strebel, H. (Hrsg.): Umwelt und Ökonomie, Wiesbaden, 1991, S. 121-131.

Meyers, R. (1993): Transnationale Politik, in: Nohlen, D. (Hrsg.): Lexikon der Politik, Bd. 6: hternationale Beziehungen, München, 1993, S. 543-547.

Middelhof, H. (1994): Die Organisation des betrieblichen Umweltschutzes - Beispiel deutsche und schweizerische chemische Industrie (Teil II), in: zfo, 63. Jg. (1994), H. 6, S. 388-392.

Ministry of Agriculture, Forestry \& Fisheries (1993): Statistical Yearbook of Agriculture, Forestry \& Fisheries, Seoul, 1993. (auf koreanisch)

Ministry of Construction (Hrsg.) (1971): Land Use Development Plan (1972-1981), Seoul, 1971. (auf koreanisch)

Moltmann, J. (1985): Gott in der Schöpfung - Ökologische Schöpfungslehre, München, 1985.

Moltmann, J. (1989): Gerechtigkeit schafft Zukunft - Friedenspolitik und Schöpfungsethik in einer bedrohten Welt, München, 1989.

Müllendorff, R. (1981): Umweltbezogene Unternehmungsentscheidungen unter besonderer Berücksichtigung der Energiewirtschaft, Frankfurt a.M., 1981. 
Müller-Stewens, G./Osterloh, M. (1996): Kooperationsinvestitionen besser nutzen - Interorgationales Lernen als Know-how-Transfer oder Kontext-Transfer?, in: zfo, Jg. 65 (1996), Nr. 1, S. 18-24.

Müller-Wenk, R. (1978): Die ökologische Buchhaltung - Ein Informations- und Steuerungsinstrument für umweltkonforme Unternehmenspolitik, Frankfurt a.M. et al., 1978.

Na, S.-L. (1995): Die Möglichkeiten der Einführung einer Umweltabgabe und wirtschaftliche Effekte, in: Kwak, T.-W./Kim, H.-G. (Hrsg.): Studie für die Möglichkeiten der Einführung einer Umweltabgabe, KETRI (Korea Environmental Technology Research Institute), Dezember 1995. (auf koreanisch)

National Statistical Office Republic of Korea (1995-1999): Major Statistics of Korean Economy, Seoul. (auf koreanisch)

Needham, J. (1969): Science and Civilisation in China II, Cambridge, 1969.

Neuhold, H. (1991): Abgrenzungen, Strukturmerkmale und Besonderheiten der Völkerrechtsordnung, in: Neuhold, H./Hummer, W./Schreuer, C. (Hrsg.): Österreichisches Handbuch des Völkerrechte, Bd. I, Textteil, 2. Aufl., Wien, 1991, S. 2-12.

Neumann, M. (1994): Theoretische Volkswirtschaftslehre III - Wachstum, Wettbewerb und Verteilung, 2. Aufl., München, 1994.

Nitze, A. (1991): Die organisatorische Umsetzung einer ökologisch bewußten Unternehmungsführung - Eine empirische Erhebung mit Fallbeispielen, St. Galler Beiträge zum Integrierten Management. Bd. 2, Bern et al., 1991.

Nolte, H. (1996): Managementbildung: ein ökonomische Konstrukt, in: Wagner, D./Nolte, H. (Hrsg.): Managementbildung, München et al., 1996, S. 31-51.

Nüßgens, K. H. (1974): Umweltschutz als Führungsaufgabe im Unternehmen, in: Fortschrittliche Betriebsführung, 23. Jg. (1974), S. 111-125. 
Oberholz, A. (1990): Umweltorientierte Unternehmensführung - Notwendigkeit, Einführung, Erfolge, Frankfurt a.M., 1990.

Odum, E. P. (1980): Ökologie: Grundbegriffe, Verknüpfungen, Perspektiven, München, 1980.

Odum, E. P. (1991): Prinzipien der Ökologie: Lebensräume, Stoffkreisläufe, Wachstumsgrenzen, Heidelberg, 1991.

OECD (Organisation for Economic Co-operation and Development) (1982): Economic and Ecological Interdependence, Paris, 1982.

OECD (1997): Environmental Performance Reviews Korea, Paris, 1997

Organisationsforum Wirtschaftskongress e. V. (Hrsg.) (1991): Umweltmanagement im Spannungsfeld zwischen Ökologie uns Ökonomie, Wiesbaden, 1991.

Osche, G. (1981): Ökologie. Grundlagen, Erkenntnissen, Entwicklungen der Umweltforschung, Freiburg et al., 1981.

Ospelt, F. (1977): Unternehmungspolitik und Umweltschutz, Wien, 1977.

Osterloh, M./Tiemann, R. (1995): Konzepte der Wirtschafts- und Unternehmensethik - Das Beispiel der Bren Spar, in: Die Unternehmung, Jg. 49 (1995), Nr. 5, S. 321-338.

O. V. (1994): Niederschlag des sauren Regens in Seoul, in: Die Cho-Sun-Zeitung, 4. 3. 1994, S. 28. (auf koreanisch)

O. V. (1994): Südkorea verdrängt Taiwan in der Export-Rangliste, in: Süddeutsche Zeitung, 7. 12. 1994, S. 27.

Palme, C. E. (1992): Nationale Umweltpolitik in der EG. Zur Rolle des Art. 100a. IV im Rahmen einer Europäischen Umweltgemeinschaft, Berlin, 1992.

Park, S.-Y. (o. J.): National Land Development Planning in Korea, Paper of KRIHS (Korea Research Institute for Human Settlements), Seoul, o. J. (auf koreanisch) 
Passmore, J. (1986): Den Unrat beseitigen - Überlegungen zur ökologischen Mode, in: Birnbacher, D. (Hrsg.): Ökologie und Ethik, Stuttgart, 1986, S.207-246.

Peter, W. S. (1968): Menzius, in: Opitz, P. J. (Hrsg.): Chinesisches Altertum und konfuzianistische Klassik, München, 1968, S. 69-100.

Peter, W. S. (1972): Die konfuzianistische Literaten und die Grundwerte des Konfuzianismus, in: Wolfgang, S. (Hrsg.): Max Webers 228 Studie über Konfuzianismus und Taoismus, $\mathbf{h}-$ terpretation und Kritik, 1972.

Pfnür, A. (1995): Informationsinstrumente und -systeme im betrieblichen Umweltschutz, Heidelberg, 1995.

Pfriem, R. (Hrsg.) (1986): Ökologische Unternehmenspolitik, Frankfurt a.M. et al., 1986.

Pfriem, R. (1986): Option für das Forschungsprogramm, eine ökologisch orientierte Betriebswirtschaftslehre auszuarbeiten, in: Pfriem, R. (Hrsg.): Ökologische Unternehmenspolitik, Frankfurt a.M., 1986, S. 98-106.

Pfriem, R. (1989): Ökologische Unternehmensführung, Schriftreihe des IÖW Nr. 13/88, Berlin.

Pfriem, R. (1990): Können Unternehmen von der Natur lernen? Ein Begründungsansatz für Unternehmensethik aus der Sicht des ökologischen Diskurses, in: Freimann, J. (Hrsg.): Ökologische Herausforderung der Betriebswirtschaftslehre, Wiesbaden, 1990, S. 19-41.

Pfriem, R. (1995): Unternehmenspolitik in sozialökologischen Perspektiven, Marburg, 1995.

Po-Keung Ip (1983): Taoism and Foundations of Environmental Ethics, in: Environmental Ethic 5 (1983), S. 335-343.

Popper, K. R. (1982): Logik der Forschung, 7. Aufl., Tübingen, 1982.

Porter, M. E. (1999): Wettbewerbsstrategie (Competitive Strategy): Methoden zur Analyse von Branchen und Konkurrenten, 10. Aufl., Frankfurt a.M. et al., 1999. 
Porter, M./van der Linde, C. (1995): Green and Competitive, in: Harvard Business Riview, September-October, 1995, S. 120-134.

Porter, M. E. (1999): Wettbewerbsvorteile (Competitive Advantage): Spitzenleistungen erreichen und behaupten, 5. Aufl., Frankfurt a.M., 1999.

Postel, S. (1994): Die Grenzen der Erde und ihre Tragfähigkeit, in: Worldwatch Institute (Hrsg.): Zur Lage der Welt, Frankfurt a.M., 1994, S. 11-43.

Prange, C./Probst, G./Rüling, C.-C. (1996): Lernen zu kooperieren - Kooperieren, um zu lernen: Plädoyer für eine lernorientiertes Betrachtung von Unternehmenskooperationen, in: zfo, Jg. 65 (1996), Nr. 1, S. 10-16.

Probst, G. J. B./Siegwart, H. (Hrsg.) (1985): Integriertes Management - Bausteine des systemorientierten Managements, Bern et al., 1985.

Raffèe, H./Wiedmann, K.-P. (1985): Die Selbstzerstörung unserer Welt durch unternehmerische Marktpolitik?, in: Marketing - Zeitschrift für Forschung und Praxis, 7. Jg. (1985), Nr. 4 S. 229-239.

Raffèe, H./Wiedmann, K.-P. (1988): Der Wertewandel als Herausforderung für Marketingforschung und Marketingpraxis, in: Marketing - Zeitschrift für Forschung und Praxis, Jg. 10 (1988), Nr. 3, S. 198-210.

Rat von Sachverständigen für Umweltfragen (1987): Umweltgutachten 1987, Drucksache $11 / 1568$ von 21.12 .1987 , o. O.

Rat von Sachverständigen für Umweltfragen (1994): Umweltgutachten 1994, Drucksache 12/6995 des Deutschen Bundestages, Bonn, 1994.

Rautenstrauch, C. (1993): Betriebliches Recycling, in: ZfB-Ergänzungsheft 2 (1993), S. 87-103.

Ro, C.-H. (1996): Korea in the era of post-development and globalization, Seoul, 1996. (auf koreanisch) 
Roetz, H. (1984): Mensch und Natur im alten China. Zum Subjekt-Objekt-Gegensatz in der klassischen chinesischen Philosophie. Zugleich eine Kritik des Klischees von chinesischen Universum, Frankfurt a.M., 1984.

Rohe, E.-H. (1990): Unternehmensziel Umweltschutz vor dem Hintergrund internationaler Umweltpolitik, in: ZfB-Ergänzungsheft 2 (1990), S. 23-41.

Rückle, D./Terhart, K.(1986): Die Befolgung von Umweltschutzauflagen als betriebswirtschaftliches Entscheidungsproblem, in: ZfbF, 38. Jg. (1986), H. 5. S. 393-424.

Rückle, D.(1992): Entscheidungstheoretische Ansätze für umweltbezogene Unternehmensrisiken, in: Wagner, G. R. (Hrsg.): Ökonomische Risiken und Umweltschutz, München, 1992.

Rüdenauer, M. R. A. (1991): Ökologisch Führen - Evolutionäres Wachstum durch ganzheitliche Führung, Wiesbaden, 1991.

Rühli, E./Krulis-Randa, J. S. (Hrsg.) (1990): Gesellschaftsbewusste Unternehmungspolitik „Societal Strategy“, Bern et al., 1990.

Rühli, E. (1990): Visionen, in: Die Unternehmung, 40. Jg. (1990), Nr. 2, S. 112-119.

Sagong, I. (1993): Korea in the World Economy, Seoul, 1993. (auf koreanisch)

Sauter-Sachs, S. (1992): Die unternehmerische Umwelt - Konzept aus der Sicht des Zürcher Ansatzes zur Führungslehre, in: Die Unternehmung, Jg. 46 (1992), Nr. 6, S. 183-204.

Savage, G. T./Nix, T. W./Whitehead, C. J./Blair, J. D. (1991): Strategies for Assessing ans Managing Organizational Stakeholders, in; Academy of Management Excutive, Vol. 5 (1991), Nr.2, S. 61-75.

Schahausen, F. J. (1997): Globale Umweltpolitik nach Rio und Berlin, in: Barz, W./Brinkmann, B./Furger, F. (Hrsg.): Globale Umweltveränderung, Landsberg, 1997, S. 275-293. 
Schalteger, S./Sturm, A. (1990): Ökologische Rationalität: Ansatzpunkte zur Ausgestaltung von ökologieorientierten Managementsinstrumenten, in: Die Unternehmung, Jg. 44 (1990), Nr. 4, S. 273-290.

Schalteger, S./Sturm, A. (1992): Erfolgskriterien ökologieorientierten Managements - Interdependenzen zur staatlichen Umweltpolitik, in: Hauff, M. v./Schmid, U. (Hrsg.): Ökonomie und Ökologie - Ansätze zu einer ökologisch verpflichteten Marktwirtschaft, Stuttgart, 1992, S. 195-219.

Schalteger, S./Sturm, A. (1993): Ökologieorientiertes Management, in: Frey, R. L. et al. (Hrsg.): Mit Ökonomie zur Ökologie - Analyse und Lösungen des Umweltproblems aus ökonomischer Sicht, 2. Aufl., Basel et al., 1993, S. 179-201.

Schalteger, S./Sturm, A. (1994): Ökologieorientierte Entscheidungen in Unternehmen. Ökologisches Rechnungswesen statt Ökobilanzierung: Notwendigkeit, Kriterien, Konzepte, 2. Aufl., Bern, 1994.

Schanz, G. (1977): Grundlagen der verhaltenstheoretischen Betriebswirtschaftslehre, Tübingen, 1977.

Schanz, G.(1988): Erkennen und Gestalten: Betriebswirtschaftslehre in kritisch-rationaler Absicht, Stuttgart, 1988.

Schanz, G. (1990): Wissenschaftsprogramme der Betriebswirtschaftslehre, in: Bea, F. X./Dichtl, E./Schweitzer, M. (Hrsg.): Allgemeine Betriebswirtschaftslehre, Bd. I: Grundfragen, 5. Aufl., Stuttgart et al., 1990, S. 55-137.

Schanz, G. (1994): Organisationsgestaltung. Management von Arbeitsteilung und Koordination, 2. Aufl., München, 1994.

Schanz, G. (1999): Ökologisch verpflichtete Unternehmensführung - Unternehmensführung, Organisation, Personalwirtschaft, Veranstaltungsmaterialien Heft 4, Göttingen, 1999.

Schein, E. H. (1985): Organisational Culture and Leadership, San Francisco, 1985. 
Schitag Ernst \& Young (Hrsg.) (1995): Das Buch des Umweltmanagement, Weinheim et al., 1995.

Schmid, U. (1992): Unternehmerische Rationalität im Lichte der ökologischen Frage, in: Hauff, M. v./Schmid, U. (Hrsg.): Ökonomie und Ökologie - Ansätze zu einer ökologisch verpflichteten Marktwirtschaft, Stuttgart, 1992, S. 163-194.

Schmidheiny, S./Business Council for Sustainable Development (1992): Kurswechsel - Globale unternehmerische Perspektive für Entwicklung und Umwelt, München, 1992.

Schneider, W. (1977): Steuern und Subventionen als umweltpolitische Instrumente, Hannover, 1977.

Schneidewind, U. (1995): Ökologie und Wettbewerbsfähigkeit in der Chemiebranche, Marburg, 1995.

Schreiner, M. (1993): Umweltmanagement in 22 Lektionen - Ein ökonomischer Weg in die ökologische Wirtschaft, 3. Aufl., Wiesbaden, 1993.

Schreyögg, G. (1993): Umfeld der Unternehmung, in: Wittmann, W. et al. (Hrsg.): Handwörterbuch der Betriebswirtschaft (HWB), 5. Aufl., Stuttgart, 1993, Sp. 4231-4247.

Schulz, W. (1989): Betriebliche Umweltinformationssysteme, in: Umwelt und Energie, 1989, Nr. 6. S. 33-98.

Schulz, W./Schulz, E. (1994): Ökomanagement - So nutzen sie den Umweltschutz im Betrieb, München, 1994.

Schwaninger, M. (1989): Integrale Unternehmensplanung, Frankfurt a.M., 1989.

Schwaninger, M. (1990): Umweltverantwortung - Manager sind herausgefordert, in: io Management Zeitschrift, 59. Jg. (1990), Nr. 1, S. 89-94.

Schweitzer, M. (1990): Gegenstand der Betriebswirtschaftslehre, in: Bea, F. X./Dichtl, E./Schweitzer, M. (Hrsg.): Allgemeine Betriebswirtschaftslehre, Bd. I: Grundfragen, 5. Aufl., Stuttgart et al., 1990, S. 15-53. 
Seidel, E./Menn, H.: Ökologisch orientierte Betriebswirtschaft, Stuttgart et al., 1988.

Seidel, E.(1989): Ökologisch orientierte Unternehmensführung als betriebliche Kultur- und Strukturinnovation, in: Seidel, E./Wagner, D. (Hrsg.): Organisation - evolutionäre Interdependenzen von Kultur und Struktur der Unternehmung, Wiesbaden, 1989, S. 261-279.

Seidel, E. (1990): Zur Organisation des betrieblichen Umweltschutzes - Die kommenden Aufgaben gehen über die Einordnung der Betriebsbeauftragten weit hinaus!, in: zfo, Jg. 59 (1990), Nr. 5, S. 334-341.

Seidel, E. (1991): Anreize zu ökologisch verpflichtetem Wirtschaften, in: Schanz, G. (Hrsg.): Handbuch Anreizsysteme in Wirtschaft und Verwaltung, Stuttgart, 1991, S. 171-189.

Seidel, E./Strebel, H. (Hrsg.) (1991): Umwelt und Ökonomie - Reader zur ökologieorientierten Betriebswirtschaftslehre, Wiesbaden, 1991.

Seidl-Hohenveldern, I. (1991): Die Staaten, in: Neuhold, H./Hummer, W./Schreuer, C. (Hrsg.): Österreichisches Handbuch des Völkerrechts, Bd. I, Textteil, 2. Aufl., Wien, 1991, S. 129156.

Seifert, E./Pfriem, R. (Hrsg.): Wirtschaftsethik und ökologische Wirtschaftsforschung, Bern et al., 1989 .

Seisreiner, R. (1997): Das Corporate-Ecological-Performance-Modell zur Unterstïtzung einer umweltorientierten Unternehmensführung, Berlin, 1997.

Sellmann, J. D. (1987): Three Models of Self-Integration (tzu-te) in early China, in: Philosophy East and West 37 (1987), S. 375.

Senge, P./Scharmer, C. O. (1996): Infrastrukturen des Lernens: Über den Aufbau eines Konsortiums lernender Unternehmen am MIT, in: zfo, Jg. 65 (1996), Nr. 1, S. 32-36.

Senn, J. F. (1986): Ökologieorientierte Unternehmensführung - Theoretische Grundlagen, empirische Fallanalysen und mögliche Basisstrategien, Frankfurt a.M. et al., 1986. 
Serfas, A. (1987): An der Schwelle zum Industrieland - Die wirtschaftliche Entwicklung Südkoreas 1963-1983, Frankfurt a.M., 1987.

Servatius, H.-G. (1991): Vom strategischen Management zur evolutionären Führung - auf dem Weg zu einem ganzheitlichen Denken und Handeln, Stuttgart, 1991.

Seydel, S. (1998): Ökologieorientiertes Kommunikationsmanagement in polyzentrischer Ausrichtung - Strategische Kommunikation mit Anspruchsgruppen, Wiesbaden, 1998.

Shin, H.-G. (1994): Das Syndrom von NIMBY (Not In My Back Yard) und die Abfallentsorgung, in: Volkswirtschaft, H. 2, Seoul, 1994, S. 117. (auf koreanisch)

Siebert, H. (1976): Analyse der Instrumente der Umweltpolitik, Göttingen, 1976.

Siebert, H. (1978): Ökonomische Theorie der Umwelt, Tübingen, 1978.

Sietz, M./Sondermann, W. D. (1990): Umwelt-Audit und Umwelthaftung - Anleitung zur Risikominderung, Vorsorge und Produktqualitätssicherung in der Betriebspraxie, Taunusstein, 1990.

Sihler, H. (1987): Die Bewältigung ökologischer Herausforderungen im Rahmen der Unternehmensziele, in: Schöttle, K. M. (Hrsg.), Jahrbuch des Marketing, 4. Ausg., Essen, 1987, S. 11-17.

Sietz, M./Sondermann, W. D. (1990): Umwelt-Audit und Umwelthaftung - Anleitung zur Risikominderung, Vorsorge und Produktqualitätssicherung in der Betriebspraxis, Taunusstein, 1990.

Simonis, U. E. (1988): Ökologische Orientierung - Vorträge zur Strukturanpassung von Wirtschaft, Technik und Wissenschaft, 2. Aufl., Berlin, 1988.

Sondermann, W. D. (1992): Umweltgesetze und Umwelthaftung in der Praxis, in: Sietz, M. (Hrsg.): Umweltbewußtes Management - Umwelt-Checklisten, Umweltqualitätsziele undRisikoanalysen, Organisationsentwicklung, Umwelt-Auditing, Umweltrecht, Umwelthaftung, UVP, Abfallmanagement, Umwelt-Marketing, Taunisstein, 1992, S. $27-60$. 
Song, B.-N. (1990): The Rise of the Korean Economy, Hong Kong, 1990.

Sprenger, R.-U./Wacherbauer, J./Adler, U./Poskny, E. (1992): Möglichkeiten und Grenzen einer umweltökonomischen Berichterstattung - dargestellt am Beispiel des geplanten EGBerichtssystems SERIEE, ifo-Studie zur Umweltökonomie, München, 1992.

Staehle, W. H. (1980): Management, München, 1980.

Staehle, W. H./Nork, M. E. (1992): Umweltschutz und Theorie der Unternehmung, in: Steger, U. (Hrsg.): Handbuch des Umweltmanagements, München, 1992, S. 67-82.

Staehle, W. H. (1989): Management - Eine verhaltenswissenschaftliche Perspektive, 4. Aufl., München, 1989.

Stähler, C. (1991): Strategisches Ökologiemanagement - Praktische Ansätze und theoretische Überlegungen zu einer Ökologieorientierung der Unternehmenspolitik, Herrsching, 1991.

Stahlmann, V. (1988): Umweltorientierte Materialwirtschaft, Wiesbaden, 1988.

Stahlmann, V. (1994): Umweltverantwortliche Unternehmensführung - Aufbau und Nutzen eines Öko-Controlling, München, 1994.

Stahlmann, V. (1998): Ökobilanzen, in: Winter, G. (Hrsg.): Das umweltbewußte Unternehmen, 6. Aufl., München, 1998, S. 759-784.

Stark, R./Reichenbach, D./Kreipe, E. (1998): Das umweltorientierte Managementkonzept der Continental AG, in: Winter, G. (Hrsg.): Das umweltbewusste Unternehmen - Die Zukunft beginnt heute, 6. Aufl., München, 1998, S. 233-254.

Steger, U. (1990): Unternehmensführung und ökologische Herausforderung, in: Wagner, G. R. (Hrsg.): Unternehmung und ökologische Umwelt, München, 1990, S. 48-57.

Steger, U. (Hrsg.) (1992): Handbuch des Umweltmanagements, München, 1992. 
Steger, U. (1993): Umweltmanagement - Erfahrungen und Instrumente einer umweltorientierten Unternehmensstrategie, 2. Aufl., Wiesbaden, 1993.

Steger, U./Antes, R. (1991): Unternehmensstrategie und Risiko-Management, in: Steger, U. (Hrsg.): Umwelt-Auditing, Frankfurt a.M., 1991, S. 13-44.

Steger, U./Winter, M. (1996): Strategische Früherkennung zur Antizipation ökologisch motivierter Marktveränderungen, in: DBW, Jg. 56 (1996), S. 607-629.

Steger, U. (Hrsg.) (1997): Handbuch des integrierten Umweltmanagements, München, 1997.

Steinle, C. (1992): Managementprinzipien, in: Corsten, H. (Hrsg.): Lexikon der Betriebswirtschaftslehre, München, 1992, S. 547-552.

Steinle, C. (1994): Betriebswirtschaftslehre als Führungslehre? - Mehrebenenanalytische Skizze zur führungszentrierten Betriebswirtschaftslehre, in: Wunderer, R. (Hrsg.): Betriebswirtschaftslehre als Management- und Führungslehre, 3. Aufl., Stuttgart, 1994, S. 285-307.

Steinle, C. (1995): Ökologieorientierte Unternehmungsführung, in: Corsten, H./Reiß, M. (Hrsg.): Handbuch Unternehmungsfuihrung - Konzepte, Instrumente, Schnittstellen, Wiesbaden, 1995, S. 913-939.

Steinle, C./Lawa, D./Schollenberg, A. (1994): Ökologieorientierte Unternehmungsfuihrung - Ansätze, Integrationskonzept und Entwicklungsperspektiven, in: Zeitschrift für Umweltpolitik und Umweltrecht, Jg. 17 (1994), Nr. 4, S. 409-444.

Steinle, C./Lawa, D./Jordan, W. (1995): Elemente und Instrumente eines ökologiebezogenen Controlling - Überblick und Implementationshinweise, in: BFuP, 47. Jg. (1995), S. 99-117.

Steinmann, H./Oppenrieder, B. (1985): Brauchen wir eine Unternehmensethik: ein thesenartiger Aufriß einzulösender Argumentationspflichten, in: DBW, Jg. 45 (1985), Nr. 2, S. 170-183.

Steinmann, H./Löhr, A.(1989): Einleitung: Grundfragen und Problembestände einer Unternehmensethik, in: Steinmann, H./Löhr, A.(Hrsg.): Unternehmensethik, Stuttgart, 1989, S. 321. 
Steinmann, H./Löhr, A.(1992): Grundlagen der Unternehmensethik, Stuttgart, 1992.

Stephan, G./Ahlheim, M. (1996): Ökonomische Ökologie, Berlin et al., 1996.

Steven, M. (1991): Umwelt als Produktionsfaktor, in: ZfB. 61. Jg. (1991), H. 4, S. 509-523.

Stier, P. (1988): Umweltproblematik und Entwicklungsländer, in: Handbuch Entwicklungsländer - Sozioökonomische Prozesse, Fakten und Strategien, Wien, 1988, S. 79-81.

Stitzel, M. (1976): Das Verhalten der Unternehmung gegenüber gesellschaftspolitischem Wandel, München, 1976.

Stitzel, M.(1987): Ökologisch orientierte Unternehmensführung - Hemmung oder Förderung der Wettbewerbsfähigkeit der Unternehmung? in: Dichtl, E. et al. (Hrsg.): Innovation und Wettbewerbsfähigkeit, Wiesbaden, 1987, S. 377-397.

Stitzel, M./Simonis, U. E. (1988): „Ökologisches Management“ oder Ist eine umweltverträgliche Unternehmenspolitik realisierbar?, Berlin, 1988.

Stitzel, M./Wank, L. (1990): Was kann die Lehre vom strategischen Management zur Entwicklung einer ökologischen Unternehmensführung beitragen, in: Freimann, J. (Hrsg.): Ökologische Herausforderung der Betriebswirtschaftslehre, Wiesbaden, 1990, S. 105-132.

Stitzel, M.(1991): Ökologische Ethik und wirtschaftliches Handeln, in: Schauenberg, B. (Hrsg.): Wirtschaftsethik, Wiesbaden, 1991, 101-116.

Stitzel, M. (1994): Arglos in Utopia? - Die Literatur zum Umweltmanagement bzw. zur ökologisch orientierten Betriebswirtschaftslehre, in: DBW, 54. Jg. (1994), S. 95-116.

Stöckl, W. (1996): Ökologieorientierte Führung multinationaler Unternehmen in Entwicklungsländern, Wiesbaden, 1996.

Stölzle, W. (1993): Umweltschutz und Entsorgungslogistik, Berlin, 1993. 
Strebel, H. (1980): Die natürliche Umwelt als Gegenstand der Unternehmenspolitik, Berlin, 1980.

Strebel, H. (1988): Rückstand und Rückstandsverwertung in der unternehmerischen Forschung und Entwicklung, in: DBW, 48. Jg. (1988), S. 97-107.

Stumm, W./Davis, J. (1991): Kann Recycling die Umweltbeeinträchtigung vermindern ? (1984), in: Seidel, E./Strebel, H. (Hrsg.): Umwelt und Ökonomie, Wiesbaden, 1991, S. 75-87.

Subramanian, A. (1992): Trade Measures for Environment - A Nearly Empty Box?, in: The World Economy, 1992, S. 135-141.

Südkommission (1991): Der Bericht der Südkommission - Über die Eigenverantwortung der Dritten Welt für dauerhafte Entwicklung. Stiftung Entwicklung und Frieden (SEF) (Hrsg.), Bonn - Bad Godesberg, 1991.

Suzuki, D. T. (1971): Der westliche und östliche Weg, Essays über christliche und buddhistische Mystik, Frankfurt a.M., 1971.

Suzuki, D. T. (1982): Die Quintessenz des Buddhismus, Wien, 1982.

Terhart, K. (1986): Die Befolgung von Umweltschutzauflagen als betriebswirtschaftliches Entscheidungsproblem, Berlin, 1986.

Thielemann, U. (1990): Die Unternehmung als ökologischer Akteur?, in: Freimann, J. (Hrsg.): Ökologische Herausforderung der Betriebswirtschaftslehre, Wiesbaden, 1990, S. 43-72.

Timmermann, M. (1993): Das ökologische System im gesamtgesellschaftlichen Prozeß, in: Steger, U./Timmermann, M. (Hrsg.): Mehr Ökologie durch Ökonomie, Berlin et al., 1993, S. 3-18.

Töpfer, K. (1991): Umweltpolitische Grundsätze, in: Organisationsforum Wirtschaftskongress e. V. (Hrsg.) (1991): Umweltmanagement im Spannungsfeld zwischen Ökologie uns Ökonomie, Wiesbaden, 1991, S. 29-38.. 
Trepl, L. (1987): Geschichte der Ökologie - Vom 17. Jahrhundert bis zur Gegenwart, Frankfurt a.M., 1987.

Trepl, L. (Hrsg.) (988): Beiträge zum ökologischen Diskurs, Schriftreihe des IÖW 15/88, Berlin, 1988.

Uimonen, P. (1992): Handelspolitik und Umwelt - Welche Wirkungen haben die bestehende Handelsregeln auf die Umweltpolitik?, in: Finanzierung und Entwicklung, Juni 1992, S. 539-543.

Ulrich, H./Krieg, W. (1974): Das St. Galler Management Konzept, Bern et al., 1974.

Ulrich, H. (1970): Die Unternehmung als produktives soziales System, 2. Aufl., 1970 (1968).

Ulrich, H. (1981): Die Bedeutung der Management-Philosophie für die Unternehmungsführung, in: Ulrich, H.(Hrsg.): Management-Philosophie für die Zukunft - Gesellschaftlicher Wertewandel als Herausforderung an das Management, Bern et al., 1981, S. 11-23.

Ulrich, H. (1987): Unternehmungspolitik, 2. Aufl., Bern et al., 1987 (1978).

Ulrich, H./Probst, G. J. B. (1991): Anleitung zum ganzheitlichen Denken und Handeln, 3. Aufl., Bern et al., 1991.

Ulrich, P. (1977): Die Großunternehmung als quasi-öffentliche Institution, Stuttgart, 1977.

Ulrich, P. (1986): Transformation der ökonomischen Vernunft - Fortschrittsperspektiven der modernen Industriegesellschaft, Bern et al., 1986.

Ulrich, P. (1991): Ökologische Unternehmenspolitik im Spannungsfeld von Ethik und Erfolg, Beiträge und Berichte des Institut für Wirtschaftsethik Nr. 47, St. Gallen, 1991.

Ulrich, P./Fluri, E. (1992): Management: Eine konzentrierte Einführung, 6. Aufl., Bern et al., 1992. 
Ulrich, P. (1996): Brent Spar und der „,moral point of view“ (Replik), in: Die Unternehmung, Jg. 50 (1996), Nr. 1, S. 27-46.

Umweltbundesamt (1995): Umweltschutz - Ein Wirtschaftsfaktor; Sieben Argumente gegen eine Vorreiterrolle im Umweltschutz, Berlin, 1995.

Umweltministerium Südkorea (1991): Mittelfristiger Gesamtplan für den Umweltschutz 19911995 (Kurzfassung), Seoul, 1991. (auf koreanisch)

Umweltministerium Südkorea (1991): Forschungsbericht über Maßnahmen zur Förderung der Umweltverbesserung, Seoul, 1991. (auf koreanisch)

Umweltministerium Südkorea (1996): Umweltvision 21 - Langfristiger Masterplan zum Umweltschutz (1996-2005), Seoul, 1996. (auf koreanisch)

Umweltministerium Südkorea (1990-1998): Koreanisches Umweltjahrbuch, Seoul. (auf koreanisch)

United Nations Economic and Social Commission for Asia and the Pacific (ESCAP) (1982): Review and Appraisal of Environmental Situation in the ESCAP Region, Bangkok, 1982.

UNCTC (1986): Environmental Aspects of the Activities of Transnational Corporations - A Survey, New York, 1986.

Vester, F. (1984): Ökologie, in: Kerber, H./Schmieder, A. (Hrsg.): Handbuch der Soziologie, Osnabrück, 1984, S. 415-419.

Vester, F. (1988): Neuland des Denkens. Vom technokratischen zum kybernetischen Zeitalter, 5. Aufl., Stuttgart, 1988.

Vester, F. (1989): Was wir als Fortschritt bezeichnen, ist ein Rückschritt in der Evolution, in: Die Mitbestimmung, 35. Jg. (1989), S. 606-610.

Vos, F. (1977): Die Religion Koreas, Stuttgart, 1977. 
Wade, L. E./Kim, B.-S. (1978): Economic Development of South Korea - The Political Economy of Success, New York, 1978.

Wagner, D. (1994): Personalfunktion in der Unternehmensleitung - Grundlagen, empirische Analyse, Perspektiven, Wiesbaden, 1994.

Wagner, G. R. (1990): Unternehmung und ökologische Umwelt - Konflikt oder Konsens?, in: Wagner, G. R. (Hrsg.): Unternehmung und ökologische Umwelt, München, 1990, S. 1-28.

Wagner, G. R. (1997): Betriebswirtschaftliche Umweltökonomie, Stuttgart, 1997.

Wagner, G. R. (1999): Umweltmanagement, in: Bitz, M. et al. (Hrsg.): Vahlens Kompendium der Betriebswirtschaftslehre, Bd. 2, 4. Aufl., München, 1999.

Walletschek, H./Graw, J.: Ökologie und Umwelt, in: Walletschek, H./Graw, J.: Öko-Lexikon, Stichworte und Zusammenhänge, 3. Aufl., München, 1991, S. 33-56.

Warford, J.Partow, Z. (1989): Die Umweltpolitik der Weltbank, in: Finanzierung und Entwicklung, Dez. 1989, S. 5-8.

Weber, M. (1980): Wirtschaft und Gesellschaft, 5. Aufl., Tübingen, 1980 (1920).

Weder, R. (1993): Globale Umwelt und Entwicklung, in: Frey, R. L. et al. (Hrsg.): Mit Ökonomie zur Ökologie: Analysen und Lösungen des Umweltproblems aus ökonomischer Sicht. 2. Aufl., Basel et al., 1993, S. 157-178.

Weimann, J. (1991): Umweltökonomik - Eine theorieorientierte Einführung, 2. Aufl., Berlin et al., 1991.

Weizäcker, E.-U. v. (1990): Erdpolitik - Ökologische Realpolitik an der Schwelle zum Jahrhundert der Umwelt, Darmstadt, 1990.

Weizenegger, K. (1992): Die Umweltpolitik der Weltbank - Reform oder Rhetorik einer internationalen Organisation, Münster et al., 1992. 
Weltbank (Internationale Bank für Wiederaufbau und Entwicklung) (1987): Korea, A World Bank Country Study, Managing the Industrial Transition, Vol. 1, Washington D.C., 1987.

Weltbank (Internationale Bank für Wiederaufbau und Entwicklung) (1989): Weltentwicklungsbericht 1989 - Finanzsysteme und Entwicklung. Kennzahlen der Weltentwicklung, Washington, D. C., 1989.

Weltbank (Internationale Bank für Wiederaufbau und Entwicklung) (1992): Weltentwicklungsbericht 1992 - Entwicklung und Umwelt. Kennzahlen der Weltentwicklung, Washington, D. C., 1992.

Weltbank (Internationale Bank für Wiederaufbau und Entwicklung) (1993): Weltentwicklungsbericht 1993 - Investition in die Gesundheit. Kennzahlen der Weltentwicklung, Washington, D. C., 1993.

Weltbank (Internationale Bank für Wiederaufbau und Entwicklung) (1993): The East Asian Miracle. Economc Growth and Public Policy, New York, 1993.

Wicke, L. (1988): Chancen durch ein offensives, gewinnorientiertes Umweltmanagement der Betriebe - Plädoyer für ein offensives Umweltmanagement, in: Pieroth, E./Wicke, L. (Hrsg.): Chancen der Betriebe durch Umweltschutz, Plädoyer für ein offensives gewinnorientiertes Umweltmanagement, Freiburg, 1988, S. 11-33.

Wicke, L. (1991): Umweltökonomie, 3. Aufl., München, 1991.

Wicke, L./Haasis, H.-D./Schafhausen, F./Schulz, W. (1992): Betriebliche Umweltökonomie Eine praxisorientierte Einführung, München, 1992.

Wiedmann, K.-P. (1989): Gesellschaft und Marketing - Neuorientierung der Marketingkonzeption im Zeichen des gesellschaftlichen Wertewandels, in: Specht, G./Silberer, G./Engelhardt, H. (Hrsg.): Marketing-Schnittstellen, Stuttgart, 1989, S. 227-246.

Wiesenthal, H. (1990): Ökologischer Konsum - ein Allgemeininteresse ohne Mobilisierungskraft? Eine Bestandsaufnahme im Lichte der Rational-Choice-Theorie, in: Hildebrandt, E. (Hrsg.): Schriftreihe des IÖW 25/89, S. 21-32. 
Wiesner, J.(1991): Ein „Öko-Soziales Interdependenz-Modell“. Entwurf zu einer politischen Theorie der Umweltbeziehungen (1983), in: Seidel, E./Strebel, H. (Hrsg.): Umwelt und Ökonomie, Wiesbaden, 1991, S. 88-120.

Wildemann, H. (1996): Entwicklungstendenzen in der Entsorgungslogistik, in: UWF, 4. Jg. (1996), H. 1, S. 58-64.

Wilhelm, R. (1972): Dschuang Dsi - Das wahre Buch vom südlichen Blütenland, Düsseldorf et al., 1972.

Wilhelm, R. (1978): Laotse. Tao Te King - Das Buch vom Sinn und Leben, Düsseldorf et al., 1978.

Wilhelm, S. (1994): Umweltpolitik - Bilanz, Probleme, Zukunft, Opladen, 1994.

Willke, H. (1996): Systemtheorie - Eine Einführung in die Grundprobleme der Theorie sozialer Systeme, Stuttgart, 1996.

Winter, G. (1990): Das umweltbewußte Unternehmen - Ein Handbuch der Betriebsökologie mit 22 Check-Listen für die Praxis, 4. Aufl., München, 1990.

Winter, G. (Hrsg.) (1998): Das umweltbewusste Unternehmen - Die Zukunft beginnt heute, 6. Aufl., München, 1998.

Wöhe, G. (1991): Einführung in die Allgemeine Betriebswirtschaftslehre, 17. Aufl., München, 1991.

Wöhlcke, M. (1993): Der ökologische Nord-Süd-Konflikt, München, 1993.

Woo, B. M. (1982): Soil erosion control in South Korea, Seoul, 1982. (auf koreanisch)

Wunderer, R. (Hrsg.): Betriebswirtschaftslehre als Management- und Führungslehre, 2. Aufl., Stuttgart, 1988.

Yu, I.-H. (1973): Wirtschaftswachstum und Umweltzerstörung, Seoul, 1973. (auf koreanisch) 
Zabel, H.-U. (1994): Ökologiegerechte strategische Unternehmensfuihrung - Grundlagen, Instrumente und Ablauffolge, in: Zeitschrift für Planung, 5. Jg. (1994), Nr. 5, S. 63-80.

Zahn, E./Gassert, H. (Hrsg.)(1992): Umweltorientiertes Management, Stuttgart, 1992.

Zahn, E./Schmid, U. (1992): Wettbewerbsvorteile durch umweltschutzorientiertes Management, in: Zahn, E./Gassert, H. (Hrsg.): Umweltorientiertes Management, Stuttgart, 1992, S. 3994.

Zahn, E./Steinle, V. (1993): Umweltinformationssysteme und umweltbezogene Strategieunterstützungssysteme, in: Wagner, G. R. (Hrsg.): Betriebswirtschaft und Umweltschutz, Stuttgart, 1993, S. 225-249.

Zahn, E./Dogan, D. (1996): Umweltschutz im Wertschöpfungssystem, in: Eyerer, P. (Hrsg.): Ganzheitliche Bilanzierung - Werkzeug zum Planen und Wirtschaften in Kreisläufen, Berlin et al., 1996, S.48-65.

Zahn, E./Schmid, U./Seebach, A. (1996): Zusammenspiel von Ökonomie und Ökologie, in: Eyerer, P. (Hrsg.): Ganzheitliche Bilanzierung - Werkzeug zum Planen und Wirtschaften in Kreisläufen, Berlin et al., 1996, S. 65-90.

Zehetner, F. (1991): Das internationale Umweltschutzrecht, in: Neuhold, H./Hummer, W./Schreuer, C. (Hrsg.): Österreichisches Handbuch des Völkerrechte, Bd. I, Textteil, 2. Aufl., Wien, 1991, S. 375-382. 